NIST Special Publication 1620

\title{
Summary of NIST/GSA \\ Cooperative Research on the Use of Elevators During Fire Emergencies
}

National Institute of Standards and Technology • U.S. Department of Commerce 



\section{NIST Special Publication 1620}

\section{Summary of NIST/GSA \\ Cooperative Research on the Use of Elevators During Fire Emergencies}

Richard D. Peacock, Editor Building and Fire Research Laboratory

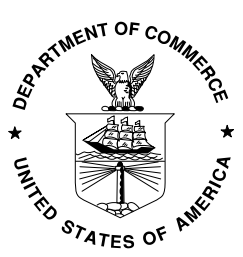

U.S. Department of Commerce Carlos M. Gutierrez, Secretary 
Certain commercial entities, equipment, or materials may be identified in this document in order to describe an experimental procedure or concept adequately. Such identification is not intended to imply recommendation or endorsement by the National Institute of Standards and Technology, nor is it intended to imply that the entities, materials, or equipment are necessarily the best available for the purpose.

National Institute of Standards and Technology Special Publication 1620

Natl. Inst. Stand. Technol. Spec. Publ. 1620, 349 pages (January 2009) CODEN: NSPUE2 


\section{Table of Contents}

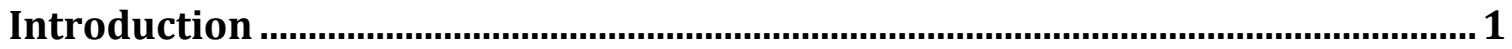

R. W. Bukowski, Protected Elevators for Egress and Access During Fires in Tall

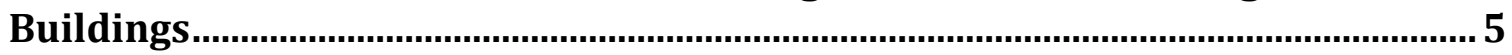

J. H. Klote, An Overview of Elevator Use for Emergency Evacuation..................... 6

E. D. Kuligowski, Elevators for Occupant Evacuation and Fire Department

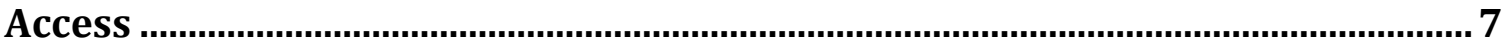

E. D. Kuligowski and R. W. Bukowski, Design of Occupant Egress Systems for Tall Buildings ............................................................................................................... 8

J. H. Klote, Hazards Due To Smoke Migration Through Elevator Shafts -Volume I: Analysis And Discussion ...................................................................................9

J. W. Klote, Hazards Due to Smoke Migration Through Elevator Shafts. Volume

2. Results of Tenability Calculations ................................................................. 10

R. W. Bukowski and E. D. Kuligowski, The Basis for Egress Provisions in U.S. Building Codes .................................................................................................... 11

R. W. Bukowski, Is There a Need to Enclose Elevator Lobbies in Tall Buildings? R. W. Bukowski, Is There a Need to Enclose Elevator Lobbies in Tall Buildings?

R. W. Bukowski, Protected Elevators and the Disabled........................................... 13

R. W. Bukowski, et. al., Elevator Controls ............................................................. 14

R. W. Bukowski, Emergency Egress Strategies for Buildings............................... 15

R. W. Bukowski, Emergency Egress from Buildings, Part 1: History and Current Regulations for Egress Systems Design................................................................ 16 


\section{Introduction}

Historically, building egress systems have evolved in response to specific large loss incidents. Currently, systems are designed around an antiquated concept of providing stair capacity for the largest occupant load floor in the building with little or no consideration of occupant behavior, needs of emergency responders, or evolving technologies. Aggressive building designs, changing occupant demographics, and consumer demand for more efficient systems have forced egress designs beyond the traditional stairwell-based approaches, with little technical foundation for performance and economic trade-offs.

Underlying any building system designed to provide occupant protection in the event of a fire emergency is the need to provide a sufficiently safe environment for a period of time long enough to allow the occupants to take appropriate protective action. Passive and active fire protection systems in buildings such as compartmentation, structural integrity design, sprinklers, or construction and furnishing materials controls limit the extent of fire growth and spread to provide greater times for occupant actions (typically referred to as the available safe egress time or ASET). Conversely, egress system capacity, the use of protected areas of refuge, occupant training, emergency planning efforts, and understand occupant behavior in the event of an emergency can all aid to a reduction in the time necessary for occupants to reach a point of safety (typically referred to as the required safe egress time or RSET). The NIST/GSA program focuses on optimizing RSET.

This report addresses one aspect that has the potential to significantly impact the RSET, the use of elevators during fire emergencies. Summaries are included of NIST research conducted as part of a cooperative effort funded in part by the U.S. General Services Administration (GSA). This research has formed the technical basis for significant revisions to building code provisions that consider the impact of all aspects building design including the use of elevators by occupants and first responders, appropriate design of stairwells, the use of refuge areas, and other active and passive fire protection measures that may be included in a building design.

The papers included in this report describe the history and scientific underpinnings of current egress requirements in model codes ${ }^{1,2}$. Provisions for egress stairways are traced from the early $20^{\text {th }}$ century where a minimum stair width of $510 \mathrm{~mm}$ was first recommended to the now more typically used $1.12 \mathrm{~m}$ width. While based largely on common practice in the 1930s, this width was also seen as appropriate to allow the entire population of a building to fit on a single flight of stairs and remain in the relative safety

\footnotetext{
${ }^{1}$ Bukowski, R.W., Emergency Egress from Buildings, Part 1: History and Current Regulations for Egress Systems Design, 7th International Conference on Performance-based Codes and Fire Safety Design Methods, Auckland, NZ, SFPE, 2008.

${ }^{2}$ Bukowski, R.W. and Kuligowski, E.D., The Basis for Egress Provisions in U.S. Building Codes, InterFlam 2004, Edinburgh, UK, July 2004.
} 
of the stairwell during a fire event ${ }^{1}$. Details of current prescriptive requirements are also described and related to estimates of building egress times for a range of specific building occupancies $^{2}$.

Like stairwell provisions, the use of elevators during fire emergencies was considered as well. As early as 1914, properly protected elevators were seen as essential in taller buildings, but automatic elevators were deemed unsuitable in a 1935 report $^{1}$.

More recently, there has been considerable attention to the use of elevators to speed up building evacuation. This included studies of the feasibility of elevator evacuation, human behavior, and the use of elevator lobbies as areas of refuge ${ }^{3}$. Protection from heat, flame, smoke, water, overheating of machinery, and loss of electrical power were seen as important to elevator design ${ }^{3}$. Using model calculations for example buildings, elevator evacuation was estimated to speed evacuation by $16 \%$ to $25 \%$ compared to evacuation by stairs alone; the taller the building the greater the impact.

Detailed studies of smoke protection for elevator hoistways ${ }^{4,5}$, the need for enclosed elevator lobbies ${ }^{6}$, use of elevators for evacuation of disabled occupants ${ }^{7}$, structural, sprinkler, and elevator control designs ${ }^{5}$, and egress procedures ${ }^{8}$ have provided the technical basis for new requirements for elevator use. Working with the American Society of Mechanical Engineers (see, for example, reference 5), the International Code Council (ICC), and the National Fire Protection Association (NFPA), and others, NIST and GSA, through this research, led a revolution in code provisions for the use of elevators by occupants and first responders during fire emergencies. The 2009 edition of the Life Safety Code and Building Construction and Safety Code ${ }^{10}$ includes adoptable (though not required) provisions for elevators for occupant evacuation prior to Phase I recall and for fire fighter emergency operations. The 2009 edition of the International

\footnotetext{
${ }^{3}$ Klote, J.H., An Overview of Elevator Use for Emergency Evacuation. CIB-CTBUH Conference on Tall Buildings. Proceedings. Task Group on Tall Buildings: CIB TG50. CIB Publication No. 290. October 20-23, 2003, Kuala Lumpur, Malaysia, Shafii, F.; Bukowski, R.; Klemencic, R., Editors, 187-192 pp., 2003.

${ }^{4}$ Klote, J. H., Hazards Due To Smoke Migration Through Elevator Shafts -Volume I: Analysis And Discussion. Final Report. National Institute of Standards and Technology, NIST GCR 04864-1, June 2004

${ }^{5}$ Bukowski, R. W.; Fleming, R. P.; Tubbs, J.; Marrion, C.; Dirksen, J.; Duke, C.; Prince, D.; Richardson, L. F.; Beste, D.; Stanlaske, D., Elevator Controls, NFPA Journal, Vol 100, No 2, $42-$ 57, March/April 2006.

${ }^{6}$ Bukowski, R.W., Is There a Need to Enclose Elevator Lobbies in Tall Buildings?, Building Safety Journal, Vol 3, No 4, 26-31, August 2005.

${ }^{7}$ Bukowski, R.W., Protected Elevators and the Disabled, J Fire Protection Engineering, 42, 4446, 48-49, Fall 2005.

${ }^{8}$ Bukowski, R.W., Emergency Egress Strategies for Buildings, Interflam 2007. (Interflam '07). International Interflam Conference, 11th Proceedings. September 3-5, 2007, London, England, 159-168 pp, 2007.

${ }^{9}$ NFPA 101, Life Safety Code, 2009 Edition, National Fire Protection Association, Quincy, MA September 2008.

${ }^{10}$ NFPA 5000, Building Construction and Safety Code, 2009 Edition, National Fire Protection Association, Quincy, MA October 2008.
} 
Building Code will also include similar requirements on elevator use for fire fighter access and occupant egress.

The following papers were published as part of this research.

- Bukowski, R.W., Protected Elevators for Egress and Access During Fires in Tall Buildings, Strategies for Performance in the Aftermath of the World Trade Center. CIB-CTBUH Conference on Tall Buildings. Proceedings. Task Group on Tall Buildings: CIB TG50. CIB Publication No. 290. October 20-23, 2003, Kuala Lumpur, Malaysia, Shafii, F.; Bukowski, R.; Klemencic, R., Editors, 187192 pp., 2003.

- Klote, J.H., An Overview of Elevator Use for Emergency Evacuation. CIBCTBUH Conference on Tall Buildings. Proceedings. Task Group on Tall Buildings: CIB TG50. CIB Publication No. 290. October 20-23, 2003, Kuala Lumpur, Malaysia, Shafii, F.; Bukowski, R.; Klemencic, R., Editors, 187-192 pp., 2003.

- Kuligowski, E. D., Elevators for Occupant Evacuation and Fire Department Access. CIB-CTBUH Conference on Tall Buildings. Proceedings. Task Group on Tall Buildings: CIB TG50. CIB Publication No. 290. October 20-23, 2003, Kuala Lumpur, Malaysia, Shafii, F.; Bukowski, R.; Klemencic, R., Editors, 193200 pp, 2003.

- Kuligowski, E.D., and Bukowski, R.W., Design of Occupant Egress Systems for Tall Buildings, Use of Elevators in Fires and Other Emergencies Workshop. Proceedings. Co-Sponsored by American Society of Mechanical Engineers (ASME International); National Institute of Standards and Technology (NIST); International Code Council (ICC); National Fire Protection Association (NFPA); U.S. Access Board and International Association of Fire Fighters (IAFF). March 2-4, 2004, Atlanta, GA, 1-12 pp, 2004.

- Klote, J. H., Hazards Due To Smoke Migration Through Elevator Shafts -Volume I: Analysis And Discussion. Final Report. National Institute of Standards and Technology, NIST GCR 04-864-1, June 2004

- Klote, J. H. Hazards Due to Smoke Migration Through Elevator Shafts. Volume 2. Results of Tenability Calculations. Final Report. National Institute of Standards and Technology, NIST GCR 04-864-2, June 2004

- Bukowski, R.W. and Kuligowski, E.D., The Basis for Egress Provisions in U.S. Building Codes, InterFlam 2004, Edinburgh, UK, July 2004.

- Bukowski, R.W., Is There a Need to Enclose Elevator Lobbies in Tall Buildings?, Building Safety Journal, Vol 3, No 4, 26-31, August 2005. 
- Bukowski, R.W., Protected Elevators and the Disabled, J Fire Protection Engineering, 42, 44-46, 48-49, Fall 2005.

- Bukowski, R. W.; Fleming, R. P.; Tubbs, J.; Marrion, C.; Dirksen, J.; Duke, C.; Prince, D.; Richardson, L. F.; Beste, D.; Stanlaske, D., Elevator Controls, NFPA Journal, Vol 100, No 2, 42-57, March/April 2006.

- Bukowski, R.W., Emergency Egress Strategies for Buildings, Interflam 2007. (Interflam '07). International Interflam Conference, 11th Proceedings. September 3-5, 2007, London, England, 159-168 pp, 2007.

- Bukowski, R.W., Emergency Egress from Buildings, Part 1: History and Current Regulations for Egress Systems Design, $7^{\text {th }}$ International Conference on Performance-based Codes and Fire Safety Design Methods, Auckland, NZ, SFPE, 2008.

A summary of each of the NIST papers that support these outcomes is included below. The complete text of each of the papers is included as appendices to this report. 


\title{
R. W. Bukowski, Protected Elevators for Egress and Access During Fires in Tall Buildings
}

\author{
Included as Appendix A
}

\begin{abstract}
Bukowski, R.W., Protected Elevators for Egress and Access During Fires in Tall Buildings, Strategies for Performance in the Aftermath of the World Trade Center. CIB-CTBUH Conference on Tall Buildings. Proceedings. Task Group on Tall Buildings: CIB TG50. CIB Publication No. 290. October 20-23, 2003, Kuala Lumpur, Malaysia, Shafii, F.; Bukowski, R.; Klemencic, R., Editors, 187-192 pp., 2003.

Bukowski, R.W., Protected Elevators for Egress and Access During Fires in Tall Buildings, Workshop on Building Occupant Movement During Fire Emergencies. Proceedings. Session 2.4. June 10-11, 2004, Gaithersburg, MD, Peacock, R. D.; Kuligowski, E. D., Editors, 14-21 pp, NIST SP1032, January 2005.
\end{abstract}

The events of September 11 have generated renewed interest in the use of protected elevators for egress and access. U.S. building codes contain requirements for accessible elevators for assisted evacuation of people with disabilities. Firefighter lifts, required in tall buildings in some countries, are being discussed to improve both the safety and efficiency of firefighting operations. The desire for increased egress capacity of tall buildings to facilitate simultaneous evacuation has rekindled interest in elevators as a secondary means of egress for all occupants. Elevators used for each of these purposes share many of the same design characteristics and the need for an extraordinary level of safety and reliability. This paper will review the technology, safety, and reliability issues associated with the use of elevators during fire emergencies for all three of these purposes and the solutions being considered to address them. Operational procedures and arrangements that influence system design considerations will be suggested. An innovative system for operating the elevators under the remote, manual control of the fire service will be described. Important human factors issues including communication, signage, and training will be identified. Initial plans for a demonstration project in a U.S. government building, as a proof-of-concept will be presented. 


\title{
J. H. Klote, An Overview of Elevator Use for Emergency Evacuation
}

\author{
Included as Appendix B
}

\begin{abstract}
Klote, J.H., An Overview of Elevator Use for Emergency Evacuation. CIB-CTBUH Conference on Tall Buildings. Proceedings. Task Group on Tall Buildings: CIB TG50. CIB Publication No. 290. October 20-23, 2003, Kuala Lumpur, Malaysia, Shafii, F.; Bukowski, R.; Klemencic, R., Editors, 187-192 pp., 2003.
\end{abstract}

Throughout most of the world, warning signs next to elevators indicate that they should not be used in fire situations. However, the idea of using elevators for fire evacuation has gained considerable attention. This paper is an overview of what has been learned from a number of research projects conducted at the U.S. National Institute of Standards and Technology (NIST) in the 1980s and 1990s concerning the use of elevators during building fires. An elevator system intended for evacuation needs to have protection from heat, flame, smoke, water, overheating of elevator machine room equipment, and loss of electrical power. In addition, such an elevator system needs to have a control approach to assure protection of people traveling in the elevator. In areas of high seismic activity, attention needs to be paid to earthquake design. Smoke protection technology for elevator evacuation systems has been developed. Water exposure due to sprinklers and fire hoses is a concern because of the effect that water can have on electrical and electronic elevator components, and tests have been conducted to determine water leakage rates and observe water leakage patterns. Further, the development of an elevator evacuation system needs to take into account human behavior so that building occupants will be willing and capable to use the system in an emergency. The computer program for elevator evacuation (ELVAC) was developed to estimate time for elevator evacuation, and ELVAC has been used to demonstrate the extent to which elevators can speed up emergency evacuation. 


\title{
E. D. Kuligowski, Elevators for Occupant Evacuation and Fire Department Access
}

\author{
Included as Appendix C
}

\author{
Kuligowski, E. D., Elevators for Occupant Evacuation and Fire \\ Department Access. CIB-CTBUH Conference on Tall Buildings. \\ Proceedings. Task Group on Tall Buildings: CIB TG50. CIB Publication \\ No. 290. October 20-23, 2003, Kuala Lumpur, Malaysia, Shafii, F.; \\ Bukowski, R.; Klemencic, R., Editors, 193-200 pp, 2003.
}

This paper will present a study of the potential for elevators to reduce occupant egress time and fire department access time for fires in tall buildings. Potential reductions in egress and access times will be compared for some specific cases where times for current procedures are available. The paper will review past research in elevator usage and the structure of existing models for elevator evacuation. From this review, the assumptions and limitations of the current elevator and egress models will be discussed, and future plans for improvement of the existing egress prediction techniques will be presented. 


\title{
E. D. Kuligowski and R. W. Bukowski, Design of Occupant Egress Systems for Tall Buildings
}

\author{
Included as Appendix D
}

\begin{abstract}
Kuligowski, E.D., and Bukowski, R.W., Design of Occupant Egress Systems for Tall Buildings, Use of Elevators in Fires and Other Emergencies Workshop. Proceedings. Co-Sponsored by American Society of Mechanical Engineers (ASME International); National Institute of Standards and Technology (NIST); International Code Council (ICC); National Fire Protection Association (NFPA); U.S. Access Board and International Association of Fire Fighters (IAFF). March 2-4, 2004, Atlanta, GA, 1-12 pp, 2004.
\end{abstract}

This paper presents a discussion of the features of protected elevator systems that can provide safe and reliable operation both for fire service access and for occupant egress during fires. These features include water tolerant components, fail-safe power, lobbies on each floor designed as areas of refuge, smoke protection, occupant communications, and real time monitoring of the elevator position and operating conditions from the fire command center. Egress simulations are used to quantify the improvements in efficiency that can be realized by incorporating elevators into the access and egress procedures for tall buildings. Finally, operational procedures will be discussed for the most appropriate use of vertically zoned elevator systems that are found in most tall buildings. These procedures would form the basis for the elevator control software that needs to be developed for such systems. 


\title{
J. H. Klote, Hazards Due To Smoke Migration Through Elevator Shafts -Volume I: Analysis And Discussion
}

\author{
Included as Appendix E
}

Klote, J. H., Hazards Due To Smoke Migration Through Elevator Shafts Volume I: Analysis And Discussion. Final Report. National Institute of Standards and Technology, NIST GCR 04-864-1, June 2004

During building fires, smoke often migrates through elevator hoistways to locations remote from the fire. One of the reasons for concern is that a closed elevator door has a leakage area of approximately 0.056 square meters ( 0.6 square feet $)$. This is a report of a project to study the hazards due to smoke flow through elevator hoistways. Smoke flow and the resulting hazard to life are analyzed for 27 scenarios in 5 buildings ranging from 6 to 58 stories. A fire scenario is the outline of events and conditions that are critical to determining the outcome of alternate situations and designs. In addition to the fire location and heat release rate, the fire scenario includes the status of the doors and other building systems. Other factors addressed are outside temperature, wind, height of elevator hoistway, height of building, leakage paths in the building, leakage of elevator doors, and other shafts. Stairwells are also included. Both sprinklered and nonsprinklered fires are included. Smoke transport throughout the buildings was simulated by a combination of zone fire modeling and network modeling. Options considered for mitigating hazards due to smoke flow through hoistways include (1) the use of enclosed elevator lobbies with automatic closing doors, (2) temporary barriers and (3) judicious positioning of cars within the hoistway. The results of the calculations showed that the use of enclosed elevator lobbies increased the time to reach hazard criteria significantly as compared the results without such lobbies. The use of automatic roll down barriers tended to increase the time to reach hazard criteria to some extent. The use of judicious positioning of elevator cars had no effect on the time to reach hazard criteria. 


\title{
J. W. Klote, Hazards Due to Smoke Migration Through Elevator Shafts. Volume 2. Results of Tenability Calculations
}

\author{
Included as Appendix F
}

Klote, J. H. Hazards Due to Smoke Migration Through Elevator Shafts.

Volume 2. Results of Tenability Calculations. Final Report. National

Institute of Standards and Technology, NIST GCR 04-864-2, June 2004

This project looks at the hazard to life due to smoke migration through elevator hoistways and the effectiveness of methods to reduce that hazard. This report of this project is in two volumes. The first volume presents the analysis and discusses the results of that analysis. The second volume consists of the complete results of the tenability calculations. 


\title{
R. W. Bukowski and E. D. Kuligowski, The Basis for Egress Provisions in U.S. Building Codes
}

\author{
Included as Appendix G
}

Bukowski, R.W. and Kuligowski, E.D., The Basis for Egress Provisions in U.S. Building Codes, InterFlam 2004, Edinburgh, UK, July 2004

Some of the earliest public safety-from-fire regulations in the US are requirements for egress stairs -adopted by New York City in 1860. One of the first model regulations promulgated by the National Fire Protection Association (NFPA) was the 1927 Building Exits Code, predecessor of the Life Safety Code. Thus the need to move occupants out of harms' way in building fires has long been central to fire safety regulations. The need to move occupants to a safe place was underscored in numerous historical fire disasters. Locked exits contributed to the high number of fatalities (150) in the 1911 Triangle Shirtwaist Factory fire and exit doors that opened inwards blocked by crowds was cited in the 492 fatalities of the Cocoanut Grove fire (1942). Incidents like these resulted in public outcry for stronger code provisions but even today egress problems leading to high numbers of deaths persist. The 100 fatalities at the Station Club in Rhode Island in 2003 provide the most recent example. Since the Rhode Island fire, NFPA and other code authorities are reviewing current requirements for level of safety, especially for assembly spaces. These current prescriptive codes used for building design contain a list of egress specifications depending upon certain aspects of the building, such as the type of occupancy, the configuration of the space, the presence of sprinklers, and the type of construction of the building. These code specifications aid the designer in providing a certain level of life safety for their building, but little effort has been put into quantifying this level of life safety in terms of egress times. This paper attempts to describe the prescriptive design process for specific types of buildings. Secondly, by applying some assumptions to the egress specifications listed in the codes, an estimate of resulting egress times for maximum occupant loads were performed for specific occupancies. The egress times were obtained using multiple calculation methods and include estimates of premovement time, time to exit the occupied room, and time spent to travel one flight of stairs. Lastly, additional egress issues, such as merging flows and the use of elevators for occupant egress, are discussed. 


\title{
R. W. Bukowski, Is There a Need to Enclose Elevator Lobbies in Tall Buildings?
}

\author{
Included as Appendix $\mathrm{H}$
}

Bukowski, R.W., Is There a Need to Enclose Elevator Lobbies in Tall

Buildings?, Building Safety Journal, Vol 3, No 4, 26-31, August 2005.

Several proposals have been submitted in recent years to model building code organizations to require enclosure of elevator lobbies in order to restrict the movement of smoke to other parts of buildings via hoistways. A significant development in this area occurred recently when the National Institute of Standards and Technology (NIST) which was already involved with a consortium of industry representatives, codes and standards developers, and other interested parties in a study of the protection of elevators for occupant evacuation and fire service access - was asked by the U.S. General Services Administration (GSA) to research the conditions under which enclosed elevator lobbies were called for. This article will provide an overview of the progress made to date on this line of research. 


\title{
R. W. Bukowski, Protected Elevators and the Disabled
}

\author{
Included as Appendix I
}

Bukowski, R.W., Protected Elevators and the Disabled, J Fire Protection

Engineering, 42, 44-46, 48-49, Fall 2005.

The Americans With Disabilities Act (ADA) was passed in 1990 to provide equal access to public buildings for all Americans. An objective of the ADA regulations was to permit people with disabilities access to the places where they live, work, and play with little thought of how they would get out in case of emergency. Fifteen years later, the fire protection engineering community is still addressing this important issue. The purpose of this article is to present the issues that need to be addressed in the development of elevators that can be used in fires to safely evacuate occupants, particularly those with limited mobility that affects their ability to use stairs. The ADA accessibility requirements are intended to result in public buildings that can be accessed and used by people with a range of limitations including vision, hearing, and mobility. The guidelines provide for signs that include Braille markings, strobe lights and other visible warnings, and doors with powered openers that are wide enough for wheelchairs. Smaller changes in elevation require ramps or platform lifts that eliminate barriers to wheelchair users. 


\title{
R. W. Bukowski, et. al., Elevator Controls
}

\author{
Included as Appendix $\mathbf{J}$
}

Bukowski, R. W.; Fleming, R. P.; Tubbs, J.; Marrion, C.; Dirksen, J.;

Duke, C.; Prince, D.; Richardson, L. F.; Beste, D.; Stanlaske, D., Elevator

Controls, NFPA Journal, Vol 100, No 2, 42-57, March/April 2006.

It is important that all parties, from rescue personnel to building designers understand the intent of the fire service operation provisions of ASME A17.1, Safety Code for Elevators and Escalators. The development of the passenger elevator is tied directly to the emergence of tall buildings. While various types of freight lifts were found in warehouses and factories before the advent of the high-rise, these were considered too dangerous to move people. In 1854, however, Elisha Graves Otis demonstrated an automatic safety brake that changed the landscape. Within a few years, his steam elevators had eliminated one of the major limits to building height. But, while elevators proved to be one of the safest forms of transportation, there were instances where people were killed while using elevators during building fires. Heat sometimes activated call buttons bringing cars to the fire floor where smoke prevented the doors from closing (light beams are in modern day elevators to detect people in the doorway) and water in the shaft sometimes shorted out electrical safety devices or may have caused failure of braking systems. Thus, the use of elevators for occupant egress or fire department access was discouraged. In 1973, the elevator industry developed a system that recalls elevators and takes them out of service if smoke is detected in the lobbies, machine room, or hoistway. Mandated in the American Society of Mechanical Engineers (ASME) A17.1, Safety Code for Elevators and Escalators, 1 for all automatic passenger elevators, this system involves two distinct phases of emergency operation. 


\title{
R. W. Bukowski, Emergency Egress Strategies for Buildings
}

\author{
Included in Appendix K
}

Bukowski, R.W., Emergency Egress Strategies for Buildings, Interflam 2007. (Interflam '07). International Interflam Conference, 11 th

Proceedings. September 3-5, 2007, London, England, 159-168 pp, 2007.

The primary strategy for the safety of building occupants in emergencies (especially fires) is by facilitating their relocation to a safe place. In other than a few institutional occupancies (health care and detention facilities), this generally involves the use of stairs as part of a protected means of egress (MOE) for vertical evacuation. For tall buildings with large populations, providing sufficient stair capacity for simultaneous egress has been considered practical by code making organizations, so the strategy of phased evacuation has been employed. To this point in time, little attention has been paid to the special needs of people with disabilities and other (permanent or temporary) physical limitations in moving on stairs. The aftermath of September 11,2001 new attention is being paid to many issues, especially emergency egress from tall buildings. A number of experts have called for a fundamental linking of egress strategies including all of the possible components that might be employed. In September 2006 a workshop was organized in Atlanta by CIB W14:Fire and T50:Tall Buildings, with one of the discussion topics devoted to this issue. This paper is ended to continue that discussion. 


\title{
R. W. Bukowski, Emergency Egress from Buildings, Part 1: History and Current Regulations for Egress Systems Design
}

\author{
Included as Appendix L
}

\begin{abstract}
Bukowski, R.W., Emergency Egress from Buildings, Part 1: History and Current Regulations for Egress Systems Design, $7^{\text {th }}$ International Conference on Performance-based Codes and Fire Safety Design Methods, Auckland, NZ, SFPE, 2008.

Bukowski, R.W., Emergency Egress from Ultra-Tall Buildings, Tall \& Green, Typology for a Sustainable Urban Future, CTBUH, Dubai UAE, March 2008.
\end{abstract}

The increasing height of buildings coupled with changing demographics and public concerns about the safety of tall buildings have led to a call for a fundamental rethinking of egress systems. This paper provides a review of the approaches currently found in building regulations internationally, and attempts to identify the origins of these specifications including the extent to which they may be based on scientific data or consensus opinion. The case for moving to a performance metric of time is presented and a set of criteria for evaluating egress systems against safe egress time is suggested. Performance criteria based on practical objectives are suggested but these and suggested regulatory thresholds need to be vetted through the existing consensus process of model code development and regulatory adoption followed in the adopting jurisdiction. The result should be a design approach that addresses the needs of occupants and buildings of all heights with criteria based on sound engineering principles. 
Appendix A

Protected Elevators for Egress and Access During Fires in Tall Buildings 


\title{
PROTECTED ELEVATORS FOR EGRESS AND ACCESS DURING FIRES IN TALL BUILDINGS
}

\author{
Richard W. Bukowski, P.E., FSFPE \\ NIST Building and Fire Research Laboratory \\ 100 Bureau Drive MS8664 \\ Gaithersburg, Maryland 20899 USA \\ $+13019756853$ \\ Richard.Bukowski@nist.gov
}

The events of September 11, 2001 have generated renewed interest in the use of protected elevators for egress and access. U.S. building codes contain requirements for accessible elevators for assisted evacuation of people with disabilities. Firefighter lifts, required in tall buildings in some countries, are being discussed to improve both the safety and efficiency of firefighting operations. The desire for increased egress capacity of tall buildings to facilitate simultaneous evacuation has rekindled interest in elevators as a secondary means of egress for all occupants. Elevators used for each of these purposes share many of the same design characteristics and the need for an extraordinary level of safety and reliability.

\section{HISTORY}

The development of the passenger elevator is tied directly to the emergence of tall buildings. While various types of freight lifts were found in warehouses and factories these were considered too dangerous to move people. In 1854 Elisha Graves Otis demonstrated an automatic safety brake that changed the landscape. Within a few years his steam elevators had eliminated one of the major limits to building height. But while elevators proved to provide one of the safest forms of transportation there were instances where people were killed while using elevators during building fires. Heat sometimes activated call buttons bringing cars to the fire floor where smoke prevented the doors from closing (light beams are used to detect people in the doorway) and water in the shaft sometimes shorted out safety devices. Thus the use of elevators for occupant egress or fire department access was discouraged.

In the 1973 the elevator industry developed a system that recalls the elevators and takes them out of service if smoke is detected in the lobbies, machine room, or hoistway. Mandated in the Safety Code for Elevators and Escalators ${ }^{1}$ (ASME A17.1) for all (automatic) passenger elevators this system involves two, distinct phases of emergency operation. In Phase 1, the detection of smoke or heat in specific locations results in the elevators being immediately recalled to the ground floor (unless this is where smoke was detected), the doors open, and the elevators are locked out of service. The responding fire department can then choose to use the elevators under manual control of a firefighter in the car by use of a special firefighter key, in what is called Phase 2 operation. While Phase 2 is sometimes used to evacuate people with disabilities, some fire department "standard operating procedures" for high-rise firefighting depend on the stairs for access, staging, and operations. ASME publishes a Guide for Emergency

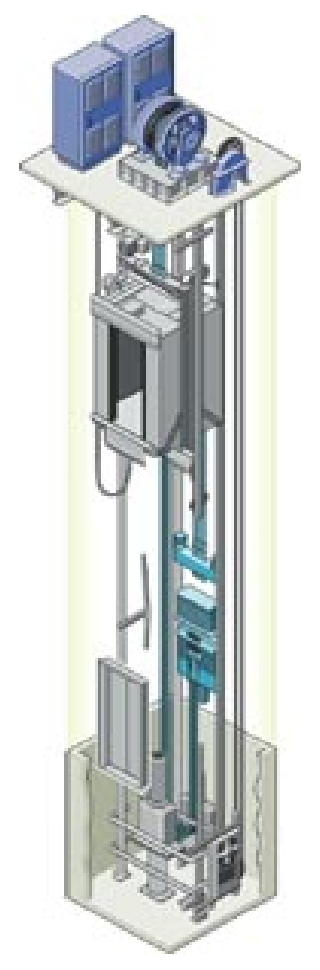

Figure 1 - Typical electric elevator Personnel ${ }^{2}$ (A17.4) that includes detailed instructions for firefighters' service operation.

\section{CURRENT REQUIREMENTS FOR EMERGENCY USE ELEVATORS}

All U.S. building codes contain a requirement for accessible elevators as a part of the accessible means of egress in any building with an accessible floor above the third floor. These requirements are all identical, being extracted from the ADA Accessibility Guidelines (ADAAG) and mandated under the Americans with Disabilities Act (ADA).

A recent survey ${ }^{3}$ by the International Organization for Standardization (ISO) TC178 Committee identified at least twelve countries that require firefighter lifts in tall buildings 
(generally those exceeding $30 \mathrm{~m}$ in height) to provide for fire department access and to support operations as well as to evacuate people with disabilities. England has such a requirement supported by a British Standard (BS 5588 Part 5$)^{4}$ requiring firefighter lifts in buildings exceeding $18 \mathrm{~m}(60 \mathrm{ft})$ in height. Firefighter lifts are also provided in the Petronas Towers, the world's tallest buildings in Kuala Lumpur, Malaysia.

The NFPA's Life Safety Code (NFPA 101) includes provisions for egress elevators to be provided as a secondary means of egress for air traffic control towers where the small footprint prohibits two, "remote" stairs. These are secure facilities not open to the public and with limited numbers of occupants.

While the above requirements exist for elevators for emergency use by firefighters and people with disabilities, there are currently no codes or standards in the world for egress elevators for use by building occupants. There is, however, an example of a structure that uses elevators as the primary means of egress and fire service access. This is the Stratosphere Tower in Las Vegas, Nevada (Fig 2). Essentially an eleven-story building sited atop an 250 $\mathrm{m}$ (800-foot) tower, it has a single emergency stair that is considered impractical. Thus the four, double deck elevators are designed for emergency use. One is reserved for use by the fire department with the remaining three used under manual control to evacuate all occupants from the two lower floors that are designed as areas of refuge. Occupancy of the tower is limited to the number of people that can be evacuated by the elevators in one hour ${ }^{6}$.

\section{COMMON CHARACTERISTICS}

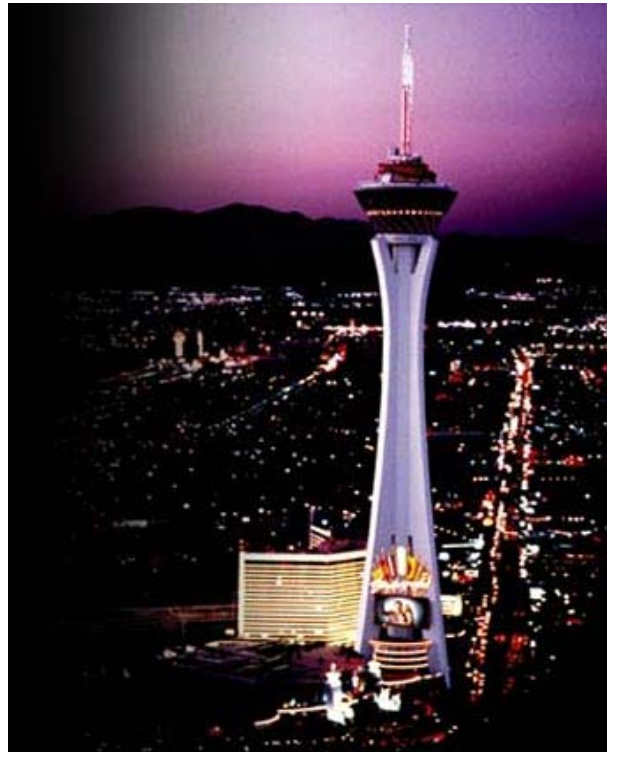

Figure 2 - Stratosphere Tower in Las Vegas

Whether for access by the fire service or for egress, elevators provided for use in fire emergencies share several characteristics intended to assure safety and reliability. They are required to be installed in a smokeproof hoistway constructed to a 2-hr fire resistance and pressurized against smoke infiltration. Enclosed lobbies are required on every floor, which are also 2-hr (1-hr in fully sprinklered buildings) and pressurized. In fact, the lobby is crucial to safe operation since elevator doors are particularly susceptible to jamming under even mild pressure differences. Thus, the smoke control system should pressurize the shaft and lobby together so that there is a minimal pressure difference across the door.

The lobbies are provided with a 2-way communication system to the building fire command center so that people in the lobby can be informed of the status of any impending rescue. Emergency power to operate the elevator in the case of main power failure is also specified. Water intrusion into the hoistway can short out safety components such as switches that prevent the doors from opening unless there is a car present, and even the safety brake; so water protection or waterproof components are needed.

Within the United States, any use of the elevator for fire service access or for rescue of people with disabilities is done under manual control of a firefighter in each car under Phase 2 recall. The elevator industry cannot guarantee that its automatic controls will react appropriately to all hazards that might occur and cannot assure safe operation. Thus, the trained operator must be able to recognize hazardous conditions and cease operations. This represents a resource allocation problem for most fire departments that simply cannot assign a firefighter to every car. Further, the susceptibility of safety controls to failure from water results in a requirement for an automatic shutdown of elevator power before activation of fire sprinklers in the machine room or hoistway. This would result in any operating elevator cars to suddenly come to a halt. 


\section{SOLUTIONS FOR RELIABLE EMERGENCY ELEVATORS}

The first solution is to eliminate the susceptibility to water by using waterproof components and eliminating the requirement to shut down power. Next is to eliminate the need for firefighters to operate each car.

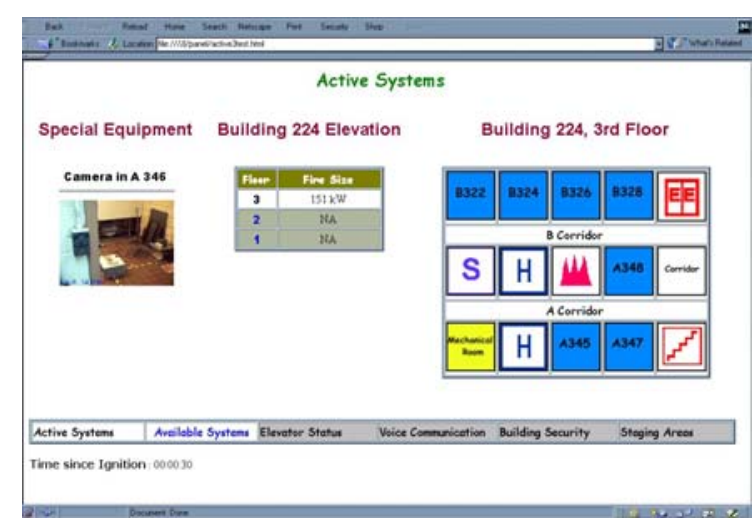

Figure 3 - NIST prototype fire service interface
Here we propose operating the elevators under remote manual control. The elevator industry would identify every parameter critical to the safe operation of the elevator and these would be monitored and displayed in real time on the standard fire service interface ${ }^{7}$ recently implemented in the National Fire Alarm Code $^{8}$ (NFPA 72). This interface was developed as a tool for incident management that can collect information from its own sensors and other building

systems (through a common communication protocol such as BACnet) and display the information in a format common to all manufacturers' systems. The interface

further supports specific control functions so that the operator could manually initiate recall if any monitored parameters exceed the allowable operating envelope (Fig 3 ).

Because continuous monitoring of the system is crucial to safe and reliable operation, we propose incorporating a triple redundant communication pathway. The fire alarm system is currently required to incorporate two redundant communication trunks usually run up the two stairways. Either trunk is sufficient for the full system operation and two-way communication to the entire building. While these trunks are "remote" it is possible that a single event could sever both trunks, rendering the portion of the system above the breaks inoperable. We propose providing a wireless link between the bottom (generally the fire command center) and the top of the system as a third, independent pathway. This would maintain full operation of the system should both trunks fail. This would add little cost, ensure high reliability, and can be done with current technology.

One outstanding reliability question involves the provision of emergency power to the elevators. Most tall buildings have triple redundant power systems with generators on site. The problem is that the power is generated at the base of the building and the hoisting and controllers are at the top. How do we provide a reliable transmission path between the two? It may be possible to use a battery/inverter system in the machine room with sufficient capacity to move the cars safely to the bottom. Similar systems powered from small batteries are used in seismic areas to move cars a single floor.

\section{DEVELOPMENT OF OPERATING PROCEDURES}

Prior research and recent advances can address all of the technology issues identified as critical to the safe and reliable operation of elevators during fires. The remaining piece is the development of operating procedures for access, egress, and rescue of the disabled that are sensitive to the human factors issues and to the need for these activities to occur simultaneously in tall buildings. Thus the systems must be designed and used such that they do not interfere with all these uses.

\section{Firefighter Lifts}

Many US fire departments have adopted operating procedures for fires in tall buildings that incorporate elevator access that are similar to those described in a draft CEN/ISO standard ${ }^{9}$ for firefighter lifts. The primary differences relate to the fact that most firefighter lifts are 
dedicated to this use and thus are immediately available to the fire service on their arrival. In the US firefighters use the passenger elevators that are either still operating or are waiting at the ground floor in Phase 1 recall.

The procedure is for the firefighters to use the lift to transport people and equipment to the protected lobby 2-3 floors below the fire floor where they stage for their suppression operations. The firefighters then move up the stairway to the fire floor with a standard length of hose $(30 \mathrm{~m}$ is common in the US and 60 $\mathrm{m}$ in Europe), which is connected to the standpipe located in the stairs. This is important because once

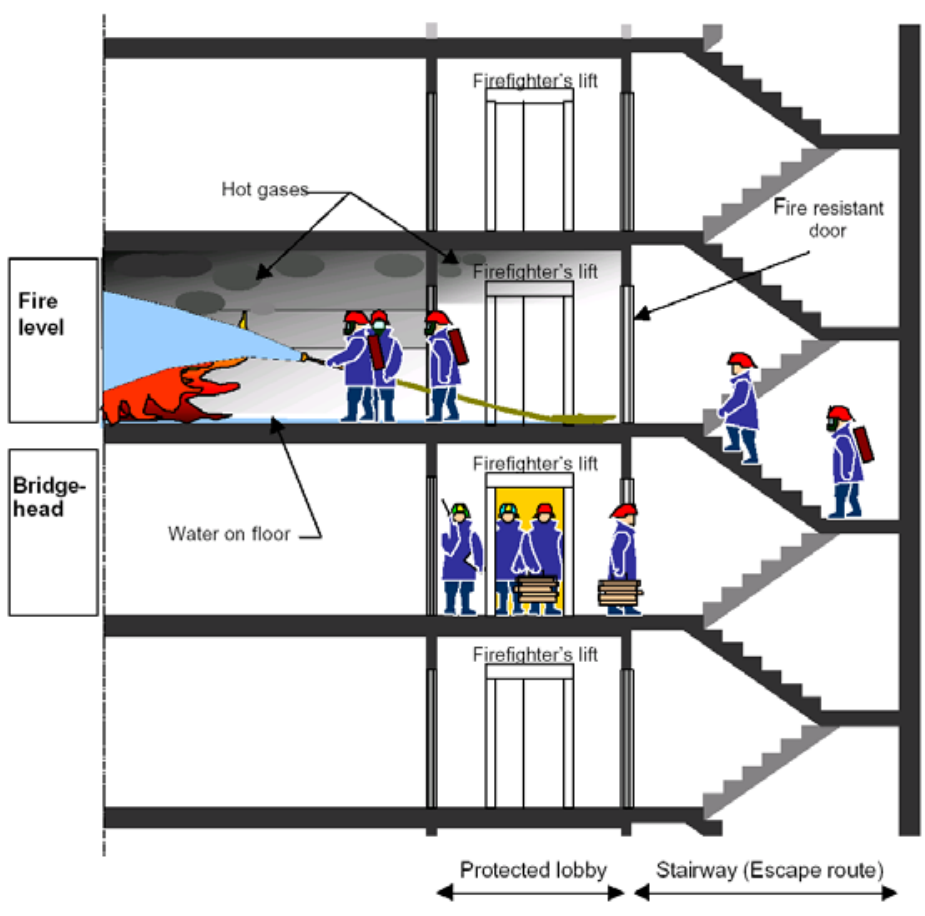

Figure 4 - firefighter lifts carry people and equipment to the floor below the fire with attack staged from the stairs 9 charged with water the hose becomes very stiff. The hose is usually looped down the stairs and back up so that it can be advanced onto the fire floor more easily. Working from the stairway also provides a protected area to which the firefighters can retreat in case the fire threatens them. The common hose lengths dictate the distribution of firefighter lifts within a building in the same way as the distribution of standpipes. For example, the New York City building regulations require standpipes located so that one is within $40 \mathrm{~m}(125$ feet $)-30 \mathrm{~m}$ (100 feet) of hose plus $10 \mathrm{~m}$ ( $25 \mathrm{feet}$ ) of water throw from the nozzle of any point on a floor. Figure 4 is an illustration of firefighting procedures utilizing a firefighter lift, taken from the CEN/ISO draft.

This operating procedure highlights the importance and interrelationship of the firefighter lift, protected lobbies, associated stairway and standpipe. These components form a system described in BS5588 as a firefighting shaft. The need for an associated stairway impacts on the arrangement of the components and on the designation of multiple cars of an elevator group as firefighter lifts. It also raises issues of the firefighting lift and stair used for occupant egress.

\section{Egress Assistance for People with Disabilities}

Standards for firefighter lifts all include their use by firefighters to provide evacuation assistance for people with disabilities. Even in the US where there are no firefighter lift standards the building codes require accessible elevators (part of an accessible means of egress) that are used by the fire service to evacuate people with disabilities. The procedures generally are that such occupants proceed to the protected lobby (sometimes called an area of refuge) and request evacuation assistance through a two-way communication system (to the fire command center) provided.

Not covered is any procedure for coordinating the use of the lift for evacuation assistance with that of firefighting. First priority will be given to moving firefighters and equipment to the staging floor to allow the start of suppression operations. Then a firefighter would presumably be assigned to begin to collect waiting occupants in the lift under manual control. Command staff in the fire command center could inform the operator on which floors there are occupants waiting and these could be gathered in some logical order and taken to the 
ground floor. If there are more occupants than can be assisted in a single trip there is a question about the order in which they are removed. Presumably, this would be done for the floors nearest the fire first, then above the fire and finally below the fire. Because these people are required to wait it is especially important to provide this two-way communication system to the lobby (Fig 5) so that they can be reassured that assistance is coming. The real-time monitoring system described earlier would assure that conditions in the occupied lobbies remain tenable.

\section{Occupant Egress Elevators}

As mentioned earlier, with only rare exceptions for special

cases, elevators are taken out of service in fires and people are advised never to use elevators during fires. This policy does not represent a severe hardship for most buildings and occupants, but poses problems for people with (mobility) disabilities and for tall buildings where stairway egress times

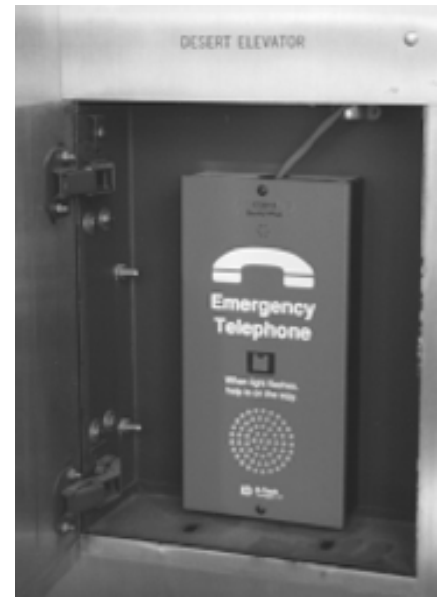

Figure 5 - Maintaining communication with waiting occupants is crucial can be measured in hours.

Operational procedures for occupant egress elevators raise some interesting issues. First, how can overcrowding be avoided? Elevators have weight switches that disable an elevator that is overcrowded. Without a floor warden or firefighter controlling the loading it is likely that occupants may attempt to overcrowd an elevator during emergency evacuation. Similarly, the elevators are unlikely to be capable of handling a large fraction of the floor load - the system specified for air traffic control towers is designed for elevator evacuation of not more than half the occupants. How will at least half the occupants be encouraged to take the stairs? One possibility is to limit the capacity of the lobbies so the excess is forced into the stairways. Another is the phased direction of the elevators to evacuate floors near the fire first. If occupants have the choice of waiting in the lobby or beginning to move to safety down stairs, what choice will they make?

Egress elevators are most likely to be utilized in tall buildings and here the elevator systems are vertically zoned in 30- to 40 -floor sections. How would elevator evacuation be operated with vertically zoned elevators? One example where this is being done is for an 88-story building currently under construction in Melbourne, Australia. In the Eureka Place Tower, elevators in the third of the building containing the fire are taken out of service and occupants all use the stairways to the next (lower) transfer floor where they board express elevators to grade. People with disabilities are assisted by firefighters in their dedicated lifts within the zone of origin. This strategy is similar to the Petronas Towers where occupants above the sky bridge level use stairs to that level, move across to the other tower, and use the elevators to grade.

\section{Coordination of emergency elevator uses}

Finally, the complete integration of the elevators into the emergency operational plans in tall buildings presents some coordination issues that will need to be addressed. One example is whether firefighter lifts and egress elevators can share common lobbies (Fig 6). Occupants awaiting egress may interfere with staging of suppression operations. Another is access to stairs and the use of the stairs for mounting the fire attack as discussed previously. A third is the sequence of egress operations. First priority would be given to egress of occupants from a few floors around the fire floor. Next a group of

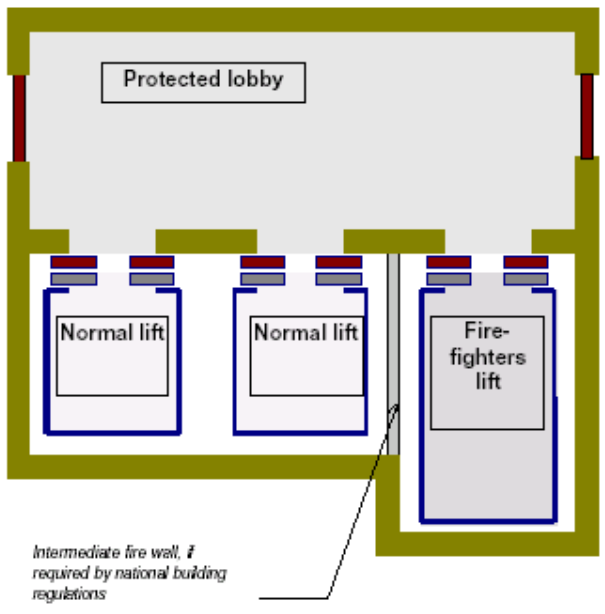

Figure 6 - Will shared lobbies lead to interference between operations and egress? 
floors above the first group should be evacuated but if a disabled person enters a lobby on another floor at what point should that person be extracted? These sequencing delays would likely cause people on other floors to use the stairs rather than awaiting the elevators.

Should people above the fire take the stairs to a point and then transfer to the elevators while people below the fire should take the stairs all the way? NIST plans to incorporate elevators into evacuation models so that a series of simulations can be conducted to identify the most effective operational procedures. NIST is also working with the US elevator industry to develop control software that can adapt to changing conditions and maintain safe and reliable operation of the elevator system.

\section{Concluding remarks}

Operational procedures and sequencing will have an effect on the design and arrangement of the entire egress system and need careful thought. The operational procedures selected must take into account complex human behavioral issues to be successful and also have significant impacts on the design and arrangement of the systems. Thus these issues should be discussed and resolved as a system so that appropriate requirements can be developed for standardization. Finally, there are significant advantages in developing common approaches globally. With the degree to which people travel internationally it is highly advantageous to have consistent emergency procedures so that people know how to react and do not depend on instructions that may not be understood clearly due to language difficulties.

\section{REFERENCES}

\footnotetext{
${ }^{1}$ Safety Code for Elevators and Escalators, ASME A17.1-2000, American Society of Mechanical Engineers, NY, 2000

${ }^{2}$ Guide for Emergency Personnel, ASME A17.4-1999, ibid

${ }^{3}$ Comparison of worldwide lift (elevator) safety standards - Firefighters lifts (elevators), ISO/TR 16765:2002(E), International Organization for Standardization, Geneva, Switzerland, 2002

${ }^{4}$ Fire Precautions in the Design, Construction, and Use of Buildings, BS 5588 Part 5 1991, Code of Practice for Firefighting Lifts and Stairs, British Standards Institution, London

${ }^{5}$ Life Safety Code (NFPA 101 2000, National Fire Protection Association, Quincy, MA 02269

${ }^{6}$ Quiter, J. R. Application of Performance Based Concepts at the Stratosphere Tower, Las Vegas, Nevada. Rolf Jensen and Associates, Inc., Deerfield, IL. Fire Risk and Hazard Assessment Symposium. Research and Practice: Bridging the Gap. Proceedings. National Fire Protection Research Foundation. June 26-28, 1996, San Francisco,CA, 118-126 pp, 1996.

${ }^{7}$ Bukowski, R. W. Development of a Standardized Fire Service Interface for Fire Alarm Systems.

National Institute of Standards and Technology, Gaithersburg, MD Fire Protection Engineering, 4,6-8, SFPE Bethesda, MD, Spring 2000.

${ }^{8}$ National Fire Alarm Code NFPA 72 (2002 ed.) Nat Fire Prot. Assn., Quincy, MA 02269, 2002.

${ }^{9}$ Safety rules for the construction and installation of lifts - Part 72:Firefighter lifts, CEN TC10,

Committee for European Standardization, Brussels, BE.
} 
Appendix B

An Overview of Elevator Use for Emergency Evacuation 


\title{
AN OVERVIEW OF ELEVATOR USE FOR EMERGENCY EVACUATION
}

\author{
John H. Klote \\ John H. Klote, Inc. - Fire and Smoke Consulting \\ Leesburg, VA, USA
}

\begin{abstract}
Throughout most of the world, warning signs next to elevators indicate that they should not be used in fire situations. However, the idea of using elevators for fire evacuation has gained considerable attention. This paper is an overview of what has been learned from a number of research projects conducted at the U.S. National Institute of Standards and Technology (NIST) in the 1980 s and 1990s concerning the use of elevators during building fires. An elevator system intended for evacuation needs to have protection from heat, flame, smoke, water, overheating of elevator machine room equipment, and loss of electrical power. In addition, such an elevator system needs to have a control approach to assure protection of people traveling in the elevator. In areas of high seismic activity, attention needs to be paid to earthquake design. Smoke protection technology for elevator evacuation systems has been developed. Water exposure due to sprinklers and fire hoses is a concern because of the effect that water can have on electrical and electronic elevator components, and tests have been conducted to determine water leakage rates and observe water leakage patterns. Further, the development of an elevator evacuation system needs to take into account human behavior so that building occupants will be willing and capable to use the system in an emergency. The computer program for elevator evacuation (ELVAC) was developed to estimate time for elevator evacuation, and ELVAC has been used to demonstrate the extent to which elevators can speed up emergency evacuation.
\end{abstract}

Keywords: Elevators, Evacuation, Fire, Human behavior, Piston effect, Smoke Control, Smoke.

\section{Introduction}

Throughout most of the world, warning signs next to elevators indicate they should not be used in fire situations. These elevators are not intended as means of fire egress, and they should not be used for fire evacuation (Sumka 1987). Frequently, the fire service uses elevators during fires for mobilization and rescue. The idea of using elevators to speed up emergency evacuation has gained considerable attention. Elevator evacuation has also gained interest as a means of emergency egress for people with mobility limitations.

Bazjanac $(1974,1977)$ examined the effect of using elevators to speed up building evacuation. In the 1980s and 1990s, the U.S. National Institute of Standards and Technology (NIST) conducted a number of research projects that examined the use of elevators during building fires. This paper is an overview of what has been learned from this research. For NIST work concerning elevator smoke control, readers are referred to Klote (1980, 1983, 1984, 1988, 1995). A joint U.S. and Canadian project also studied elevator smoke control (Klote and Tamura 1986a, 1986b, 1987, 1991a, 1991b; Tamura and Klote 1988, 1989a, 1989b, 1990).

NIST projects examined the feasibility of using elevators for emergency evacuation (Klote 1993a, Klote et al. 1992a, 1993, Klote and Braun 1996, Klote, Levin and Groner 1994, 1995). NIST sponsored studies of human considerations regarding elevator evacuation (Groner and Levin 1992, 1995; Levin and Groner 1992, 1994a, 1994b, 1995). Because elevator lobbies can be used for staging areas or areas of refuge, NIST research concerning these areas is also of interest (Klote 1993b, Klote et al. 1992b). 


\section{Concern With Elevator Evacuation}

The 1976 edition of the Life Safety Code (NFPA 101 1976) listed the following "problems" involved with the use of elevators as fire exits ${ }^{1}$ :

- Persons seeking to escape from a fire by means of an elevator may have to wait at the elevator door for some time, during which they may be exposed to fire, smoke or developing panic.

- Automatic elevators respond to the pressing of buttons in such a way that it would be quite possible for an elevator descending from floors above a fire to stop automatically at the floor involved in the fire and open automatically, exposing occupants to fire and smoke.

- Modern elevators cannot start until doors are fully closed. A large number of people seeking to crowd into an elevator in case of emergency might make it impossible to start.

- Any power failure, such as the burning out of electric supply cables during a fire, may render the elevators inoperative or might result in trapping persons in elevators stopped between floors. Under fire conditions there might not be time to permit rescue of trapped occupants through emergency escape hatches or doors.

In addition, there are other concerns. Fire or smoke might damage elevator equipment. Water from sprinklers or fire hoses could short out or cause other problems with electrical power and control wiring for the elevator. Overheating of elevator equipment could result in malfunction of elevators. Pressurization for smoke control could result in elevator doors jamming open, limiting movement of the car. Piston effect due to elevator car motion could pull smoke into the elevator lobby or the hoistway (elevator shaft). However, it is possible to design an emergency elevator evacuation systems (EEES) with a high level of protection relative to these concerns.

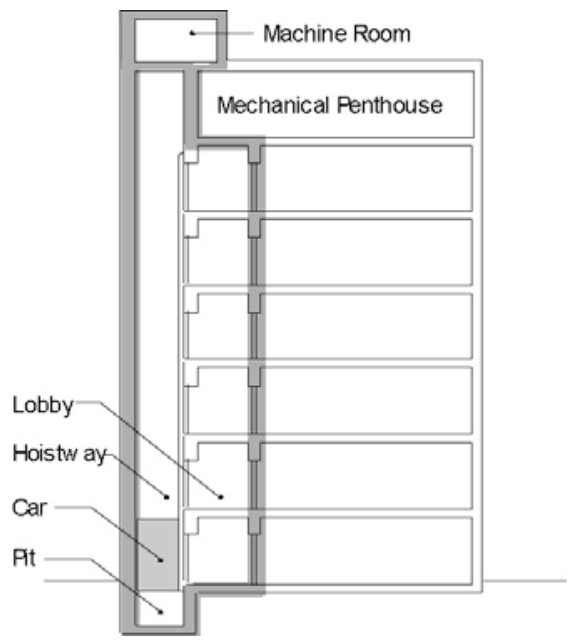

Fig. 1 Elevator system including elevator equipment, machine room, hoistway and elevator lobby

\section{EEES Concept}

An EEES includes the elevator equipment, hoistway, machine room, and other equipment and controls needed for safe operation of the elevator during the evacuation process. Because people must be protected from fire and smoke while they wait for an elevator, the system must include protected elevator lobbies (Figure 1). Such protected elevator lobbies also help to prevent the fire from activating elevator buttons so that elevator cars are prevented from being called by the fire to the fire floor ${ }^{2}$.

\footnotetext{
${ }^{1}$ This edition of the Life Safety Code was the last edition to list these "problems".

${ }^{2}$ Even buttons that are not heat sensitive can short out when subjected to the elevated temperatures of a fire.
} 
An EEES must have protection from heat, flame, smoke, water, overheating of elevator machine room equipment, and loss of electrical power. In addition, an EEES must have a control approach that assures protection of the people traveling in the elevator. In areas of high seismic activity, attention must be paid to earthquake design. Further, the development of an EEES needs to take into account human behavior so that building occupants will be willing and capable to operate the system in an emergency. The following sections address these issues.

The concern about people crowding into an elevator and doors not closing is significant only when there are enough people to form a crowd. Some EEESs might only be intended for use by a small number of people. Examples of such low use EEESs are (1) a system intended only for use by a few persons with mobility limitations, and (2) a system at an air traffic control tower (ATCT). For the purposes of this paper, a small number of people is taken to be a number that will not result in crowding that could force elevator doors to remain open and prevent motion of the car. For other applications, the conventional methods of people

movement (Pauls 2002, Nelson and Mowrer 2002, Klote and Milke 2002) can be used to evaluate the potential for crowding.

\section{EEES Protection}

\subsection{Heat and Flame}

Compartmentation is one of the oldest methods of fire protection and has been extensively used to limit the spread of fire. Compartmentation is also one approach to smoke protection, and this is addressed in the next section. As a convenience to the reader the concepts of compartmentation are briefly described here, and for further information readers are referred to Barnett (1992), Boring, Spence and Wells (1981), Bushev et al. (1978) and Campbell (1991).

Buildings are divided into compartments formed by fire barriers. These barriers are walls, partitions and floorceiling assemblies that have a level of fire resistance. The traditional approach to evaluate fire resistance is to subject a section of a barrier to a standard fire in a standard furnace. Each building fire is unique in duration and temperature, and it is not surprising that the performance of barriers in building fires differs to some extent from the performance in standard tests. Historically, the goal of fire resistant construction was property protection, but the goals of current codes include life safety. The building codes require specific levels of fire resistance for specific applications with the goal of protecting life.

\subsection{Smoke}

The mechanisms that can be used to provide smoke protection are air flow, buoyancy, compartmentation, dilution and pressurization. Detailed information about these mechanisms is presented by Klote and Milke (1992, 2002). Because of the concern about supplying oxygen to the fire as discussed by Klote and Milke, air flow is not recommended for smoke protection of EEESs. Buoyancy is primarily used to manage smoke in large spaces such as atria and shopping malls. Systems that rely on buoyancy are inappropriate for smoke protection of EEESs.

Pressurization Systems: Systems relying on compartmentation with pressurization are designed on the basis of no smoke leakage into protected spaces. Accordingly, analysis of such pressurization systems is less complex than that of systems using compartmentation alone or compartmentation with dilution. Acceptance testing and routine testing of pressurization systems is done by measurement of the pressure difference produced when the system is operating. Such testing provides a level of assurance about system performance during a fire. For systems that have windows breaking, windows opening, or doors opening to the outside; smoke control systems by pressurization as discussed later can maintain pressurization during such pressure fluctuations. Considering the potential for windows to break during unsprinklered fires, pressurization systems are recommended for smoke protection of EEESs in unsprinklered buildings.

Piston Effect: Elevator car motion results in increased air pressure in the direction of motion. There is a concern that this piston effect could reduce the effectiveness of an elevator smoke control system. An analysis of elevator piston effect was developed and experimentally verified (Klote 1988; Klote and Tamura 
1986a). Based on this analysis, Klote and Milke $(1992,2002)$ provide a simple method for design evaluation of elevator piston effect.

Elevator Doors Jamming: Elevator doors jam open when the force of the door mechanism is insufficient to overcome the force of friction. The friction force increases with the pressure difference from the hoistway to the lobby. In tall buildings, elevator doors frequently jam open during extremely cold weather. This is caused by stack effect induced pressure differences. Elevator mechanics commonly adjust the door closing forces to prevent door jamming. During elevator smoke control operation, the possibility of door jamming may decrease or increase. If the leakage area of the elevator lobby doors is less than that of the elevator doors, the pressure difference across the elevator doors can be less than that normally occurring. In field tests conducted by Klote (1984), no door jamming was encountered at pressure differences as high as $75 \mathrm{~Pa}(0.3$ in $\mathrm{H}_{2} \mathrm{O}$ ). When door jamming was encountered in an elevator without smoke control, it was found that only a small additional force applied by the palms of the hands was sufficient to overcome jamming. Fire fighters can be taught to overcome door jamming this way, and elevator doors could be fitted with grips or handles to aid in this effort.

\subsection{Water}

During a building fire water from sprinklers and fire hoses can damage electronic, electrical, and mechanical components of an EEES. The water exposure of some suppression and firefighting devices are listed in Table 1. For fires in the hoistway, elevator lobbies or machine room, the most appropriate action seems to be to take the elevators out of service. Fires in the hoistway or elevator lobbies can easily result in untenable conditions within the EEES. Further, an elevator cannot be expected to operate when there is a fire in the machine room, because of elevator equipment exposure to elevated temperatures. If there is a fire in the hoistway, elevator lobbies or machine room; the EEES should be shut down. Because of the limited fuel load, relatively small compartment size and the fire resistive construction, fires in the hoistway, elevator lobbies or machine room are not believed to have as high a potential for hazard as fires in many other building spaces. If evacuation is needed, other vertical paths (other elevators and stairs) can be used.

Table 1.Water flows of some suppression and firefighting devices

\begin{tabular}{|l|cc|}
\hline Device & L/min & gpm \\
\hline $12.7 \mathrm{~mm}(0.50$ in) Sprinkler Head & $67-200$ & $17.7-53$ \\
$29 \mathrm{~mm}(1.125$ in) Solid-Stream Hose Nozzle & 950 & 250 \\
Manually Held Hose with Spray Nozzle & $40-1150$ & $11-300$ \\
Master Flow Devices & $1900-7500$ & $500-2000$ \\
\hline
\end{tabular}

Water Leakage of Elevator Doors: Klote and Braun (1996) conduced experiments of the water flow around elevator doors and into the hoistway in a specially built facility at NIST (Figure 2). The elevator doors were supplied by an elevator manufacturer. The tests consisted of a water exposure in the elevator lobby, and water leakage of the elevator doors was determined by collecting water in the tank shown in Figure 2 . The water exposure was a ceiling sprinkler, sidewall sprinkler, standing water set up, or a fire hose. The positions of the sprinklers is shown in Figure 2. Figure 3 shows the set up for the standing water test. The set up for the fire hose test is shown in Figure 4. The results of their study are summarized in Table 2. 

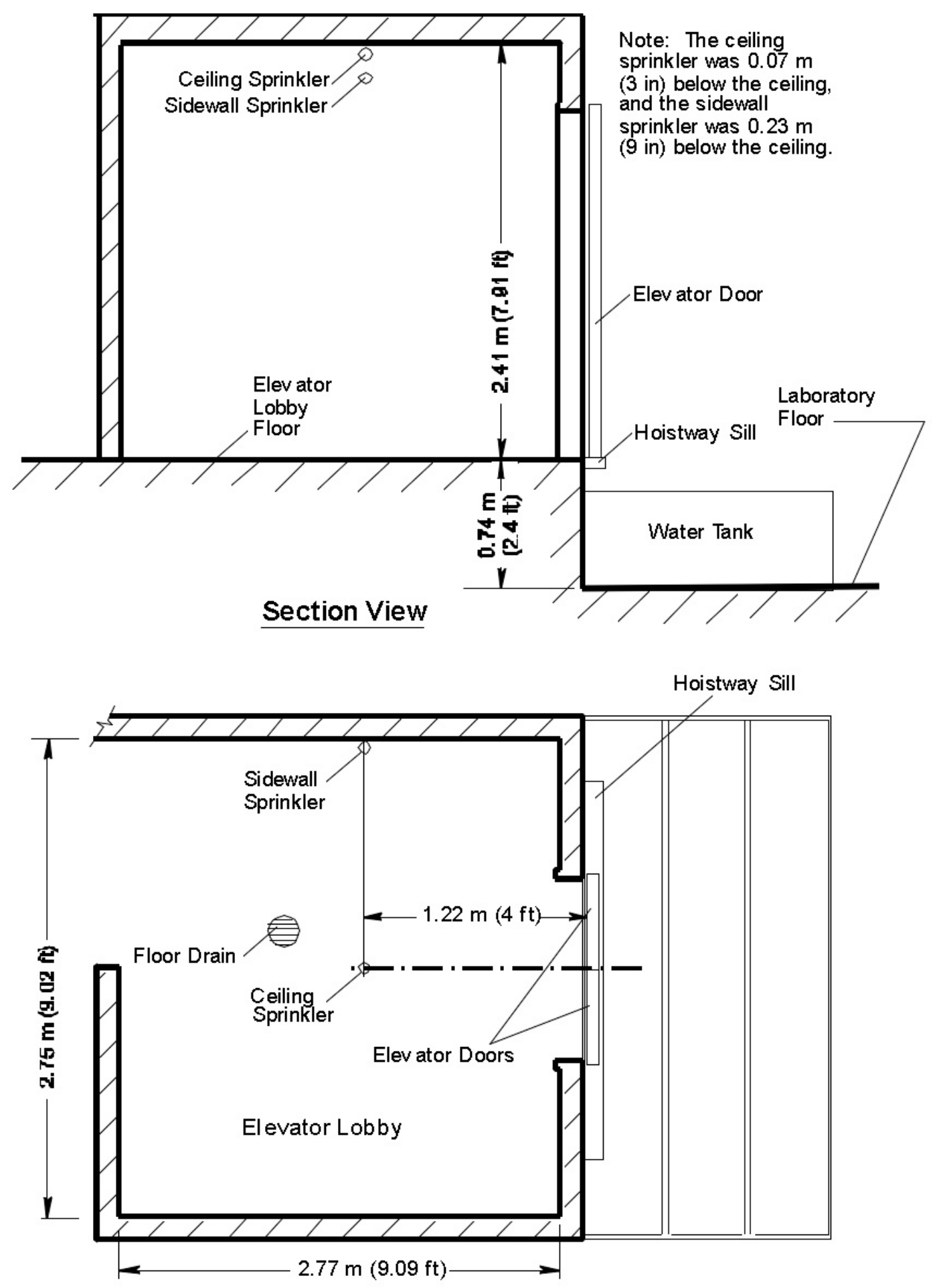

$\underline{\text { Plan View }}$

Fig. 2 Laboratory facility for testing water leakage of elevator doors 


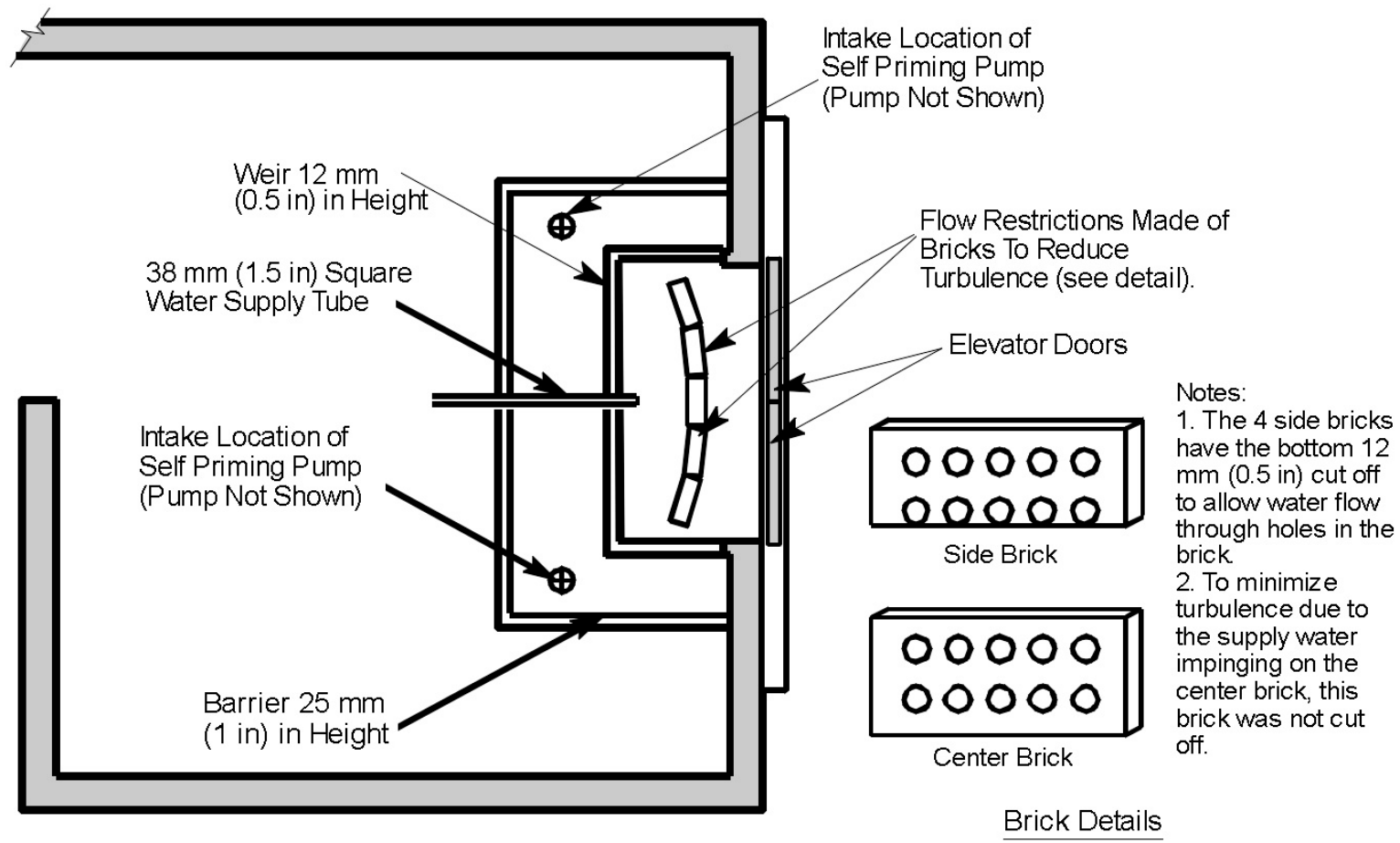

Fig. 3 Set up standing water tests

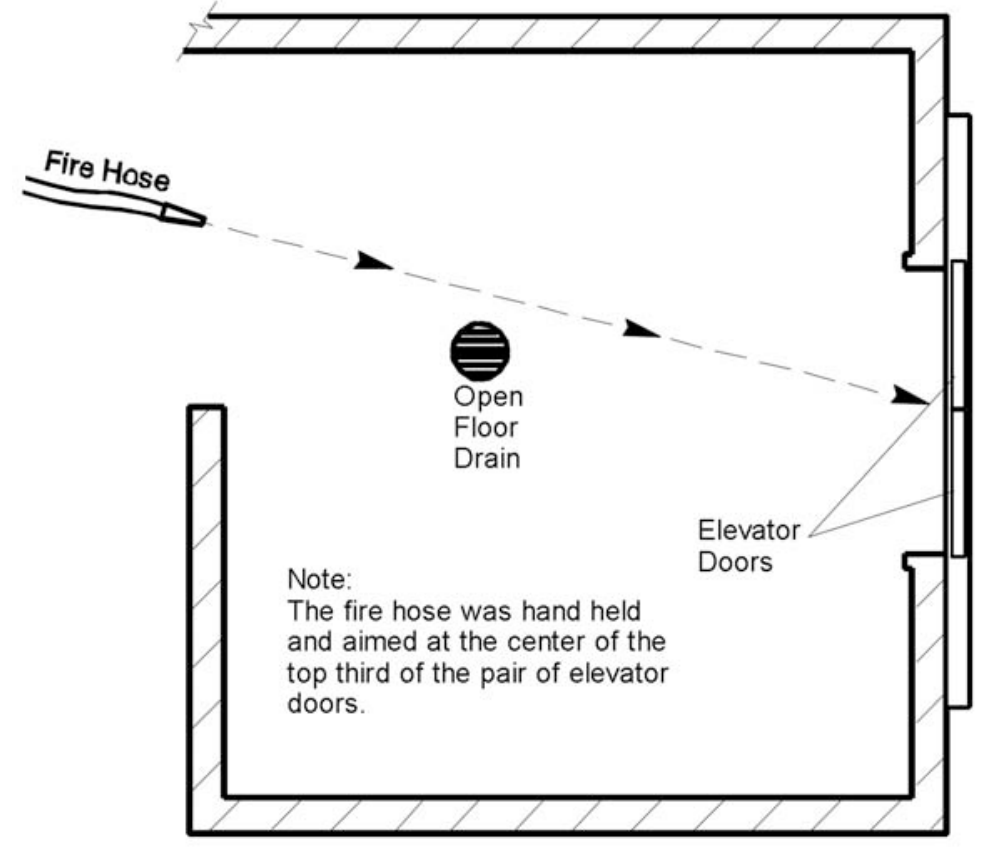

Fig. 4 Set up for fire hose tests 
Table 2. Results of elevator door ${ }^{1}$ water leakage tests (Klote and Braun 1996)

\begin{tabular}{|l|cc|cc|}
\hline & \multicolumn{2}{|c|}{} & \multicolumn{2}{|c|}{ Measured Water Leakage } \\
Type of Water Exposure & \multicolumn{2}{|c|}{ Water Exposure } & L/s & gpm \\
\hline Ceiling Mounted Sprinkler $^{2}$ & $29 \mathrm{~L} / \mathrm{s}$ & $46 \mathrm{gpm}$ & 0.22 & 3.3 \\
Sidewall Sprinkler $^{2}$ & $2.8 \mathrm{~L} / \mathrm{s}$ & $44 \mathrm{gpm}$ & 0.13 & 2.1 \\
Standing Water & $12 \mathrm{~mm}$ & $0.5 \mathrm{in}$. & 0.84 & 13 \\
Fire Hose & $28 \mathrm{~L} / \mathrm{s}$ & $440 \mathrm{gpm}$ & 13.5 & 210 \\
\hline
\end{tabular}

${ }^{1}$ The results above are for standard gibs and brackets around elevator doors.

${ }^{2}$ Test conducted with open floor drain in elevator lobby. The depth of water (standing water) at the bottom of the elevator doors was not measured, but it appeared to be on the order of 2.5 $\mathrm{mm}(0.1$ in.).

Approaches to Minimize Water Damage: For fires outside the EEES, the two major locations of concern about water damage are the machine room and the hoistway. Two potential approaches to minimize water damage are:

1. use of elevator components that can function in a wet environment, and

2. prevention of water from entering the hoistway or machine room.

Some methods that might be used to minimize or prevent water from entering the hoistway (elevator shaft) are use of sloping floors, floor drains and doors with seals. Other methods might include exterior elevators or elevators located in their own towers and are separated from the building by a section of exterior walkway or an exterior elevator lobby.

Currently no elevators have been developed with water resistant components for operation during fire evacuations. However, many elevators operate outdoors on exterior walls of buildings with many of the system components exposed to rain, wind and extremes of temperature. These outdoor conditions are believed to be much more severe than those associated with water flow inside a hoistway due to a building fire. Without routine testing for water resistance, components that degraded from years of use or were accidentally damaged would go undetected and unrepaired.

Further research and development are needed to find reliable methods of protection the EEES from water damage.

\subsection{Overheating Of Elevator Machine Room Equipment}

Loss of cooling can result in loss of elevator service due to overheating of elevator equipment, and precautions need to be taken to minimize the likelihood of such overheating. The maximum operating temperatures of most elevator equipment are in the range of 30 to $35 \mathrm{C}$ ( 86 to $95 \mathrm{~F}$ ). There are several approaches to providing the necessary machine room cooling, but dedicated air conditioning equipment has significant advantages. Dedicated equipment located in the machine room or outside the building eliminates the possibility of damage to this equipment from fire outside the machine room to the extent that the fire resistive construction withstands the fire. Further, dedicated equipment uses less electrical power than non-dedicated equipment with resulting advantages conceming reliability of electrical power.

\subsection{Electrical Power}

Reliability of electric power consists of assuring a source of power and assuring continued distribution of power to where it is used. Some components that can be used to ensure reliability of power are fire protected distribution, redundant feeds, power from multiple substations outside the building, and emergency generator sets. Because elevator evacuation can tolerate short duration power loss, uninterruptable power supplies are not necessary. Any consideration of reliability of electric power should consider potential causes of power failure and the consequences of that failure. 


\subsection{Earthquakes}

The concern with earthquakes is that the counterweight could become dislodged from its rails resulting in a collision between the elevator car and the counterweight. Such a collision could result in injury or fatality to elevator passengers. In areas of high seismic activity, some elevators have strengthened rails and a seismic switch to sense significant acceleration. The strengthened rails allow safe elevator operation up to a specific level of earthquake induced acceleration. If the seismic switch senses acceleration greater than this specific level, the elevators are put into an emergency mode to prevent collision with the counterweight and then taken out of service. Such an approach can be applied to EEESs that are in areas of high seismic activity.

\section{Availability}

When an elevator in an EEES is out of service for scheduled or unscheduled maintenance, it cannot be used for evacuation. If there are many elevators in a building, the number of elevators used for evacuation can be selected to allow for a percentage that may be out of service.

In buildings with only one elevator, the above redundancy approach to assuring availability is not possible. Two other approaches to maximize availability are off hours maintenance and short turn around repairs. Scheduled maintenance can be done during off hours when the building is shut down or in a low state of activity. Maintenance contracts can put a premium on fast repair for unscheduled maintenance. When an elevator is out of service, a sign should clearly indicate this so that valuable evacuation time is not wasted waiting for an elevator that can not come.

\section{Elevator Control}

Readers are familiar with automatic elevator controls that are common in passenger elevators in most of the world. There are two other modes of operation: elevator recall and firefighters operation. Upon alarm of a smoke detector in an elevator lobby, the elevator goes into a recall mode in which the car is moved to the exit landing and removed from service. In the event of a fire on the exit floor, the elevator goes to an alternate floor and is taken out of service. This recall is referred to as Phase $I$. The landing to which the car is moved is the exit floor or an alternate floor if smoke was detected on the exit floor. After recall, firefighters can operate the elevator, and such operation is under the control of the firefighter inside the elevator. This firefighter's operation is referred to as Phase II.

Some approaches that might be used to control elevators during an elevator emergency evacuation are:

- normal use (with less sensitive detectors),

- Phase II, and

- other mode of elevator operation.

In an EEES, the elevator (including the elevator lobbies, hoistway and machine room) is protected from the fire effects as discussed above. Thus the elevator is operating in an environment without fire. There is no physical reason why an elevator so protected cannot continue to operate normally provided that the smoke detector in the elevator lobby does not go into alarm. As stated earlier, an alarm from this smoke detector will result in Phase I elevator recall. Typical smoke detectors are very sensitive, and they can be put into alarm by a quantity of smoke so small that a person might not notice. Such small amounts of smoke may enter the lobby when lobby doors are opened for evacuation. Such low levels of smoke are not a tenability concern. To avoid unwanted elevator recall, the smoke detectors in the elevator lobbies that initiate Phase I operation can be replaced with less sensitive detectors such as heat detectors.

Using normal operation during evacuation is not appropriate for evacuation of large numbers of people, where a full elevator car might stop at every floor on its way to the exit floor. However, normal mode would be appropriate for evacuation of small numbers of people, such as a few persons with disabilities in an office building or the small number of workers in an ATCT. The computer program for elevator evacuation (ELVAC) by Klote, Alvord, Levin, and Groner (1992) can be used to estimate time for elevator evacuation. 
The fire service, using Phase II operation, could also use elevators for evacuation of small numbers of people. Further, it is possible that building personnel could operate the elevators under Phase II for evacuation before the fire service arrives. Use of Phase II by non-fire service people would require that the elevator operators be trained and that the general approach not adversely affect fire service operations. Phase II service must only be provided by people who are aware of the location and extent of the fire and of its potential for endangering people using elevators.

Approach 3 listed above is a mode of elevator operation that could be developed specifically for emergency evacuation. Features that could be considered for this emergency evacuation mode might include the ability to prioritize evacuation and the ability to cancel calls from a floor with untenable conditions in the elevator lobby. Such capabilities may be needed for evacuation of large numbers of people.

If EEESs are to be developed for evacuation of large numbers of people from buildings, further research and development are needed to find appropriate methods of elevator control.

\section{Human Considerations}

Designing and building elevators that can be safely used during a fire emergency is only half the job. The building occupants must be willing to use the EEES and be able to use it. The NIST feasibility study of elevator evacuation at ATCTs (Klote, Levin and Groner 1994; Levin and Groner 1994a) included visits to 13 control towers where interviews were conducted with air traffic controllers and other personnel.

The interviews consisted of informal discussions that lasted about 15 minutes. Considering the twenty year campaign to teach people not to use elevators during fires, it was expected that occupants would have a strong preference for using stairs during fires. It was not surprising that nearly all those interviewed expressed a strong preference for using stairs as the first choice escape route. There were considerable differences among the interviewees on how willingly they would use elevators if there was smoke in the stairs. A few would use it without hesitation, and a few indicated they would try other alternatives (wait for helicopters, escape to catwalk, or use ladders). The majority indicated that they would use elevators if it were necessary with little delay but with considerable concern.

At some ATCTs there were complaints about elevator service. It is well known in the elevator industry that buildings with only one elevator have more complaints about out-of-service elevators than buildings with multiple elevators. When there is only one elevator, occupants have to walk when elevators are not operating. In addition to complaints about out-of-service elevators, there were complaints about rough rides, and at one ATCT a cable for the counterweight had broken. While none of these occurrences were life threatening, the occupants at these towers were emphatic in expressing reluctance about elevators for fire evacuation. At ATCTs with few complaints about elevator service, occupants were more willing to accept the idea of EEES. Good maintenance of the elevator will encourage people to trust the EEES.

Communication is important to inform people waiting for elevators of the status of elevator evacuation and to inform people outside the building about the status of those waiting. The communication devices can be intercoms or telephones, but they must be capable of two way conversation. One device is needed in each elevator lobby, and another is needed at a location accessible to the emergency personnel.

In order to develop confidence in EEESs, education is needed to describe the safety features. Such education should also address general aspects of fire evacuation. This education can be by a combination of formal training classes, viewing videos, performing fire drills, reading an emergency plan and group discussions. Levin and Groner (1994) provide more information about such education.

\section{Speeding Up Evacuation}

The extent that elevators could be used to speed up evacuation in General Services Administration (GSA) office buildings was calculated by Klote et al. (1992a). For horizontal movement and movement on stairs, conventional methods of people movement were used. For movement on elevators, the computer program ELVAC (Klote 1993a) was used. ELVAC uses the generally accepted methods to calculate people movement by elevators (Strakosch 1983). 


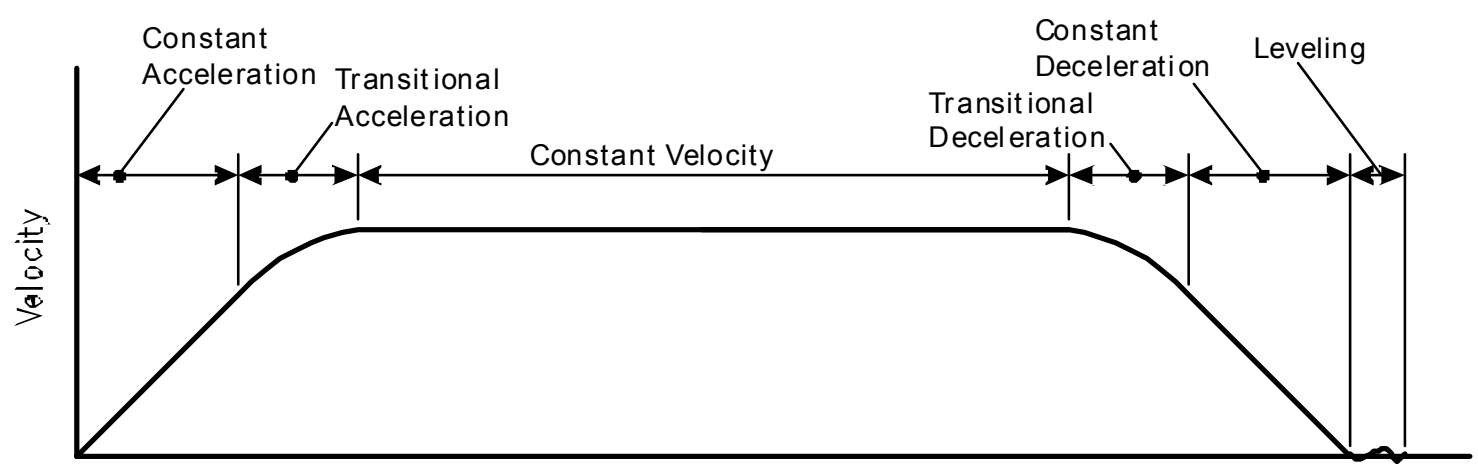

Time

Figure 5. Velocity of elevator that reaches normal operating velocity

For many trips, elevator motion is depicted in Figure 5. Motion starts with constant acceleration, followed by transitional acceleration, and constant velocity motion. Constant acceleration ends when the elevator reaches a predetermined velocity which is typically about $60 \%$ of the normal operating velocity. For office buildings, normal operating velocity generally is from 1 to $9 \mathrm{~m} / \mathrm{s}$ (200 to $1800 \mathrm{fpm}$ ), and acceleration is from 0.6 to $2.4 \mathrm{~m} / \mathrm{s}^{2}$ ( 2 to $8 \mathrm{ft} / \mathrm{s}^{2}$ ). Deceleration has the same magnitude as the acceleration, and total acceleration time equals the total deceleration time. Usually elevators do not stop exactly at the desired floor at the end of deceleration, so the elevator must be moved slowly up or down to get it nearly level with the floor. For cars not reaching normal velocity, the elevator car velocity is simpler.

In addition to elevator motion, ELVAC includes the (1) the start up time before elevator evacuation for the car to go to the discharge floor, (2) time for passengers to enter and leave the elevator on each trip, (3) the time for elevator doors to open and close on each trip. ELVAC also incorporates the following inefficiencies: (1) trip inefficiency (2) basic transfer inefficiency, (2) door inefficiency and (3) other inefficiency. Klote (1993a) discusses these inefficiencies and provides some values.

Table 3. Summary of Elevator Evacuation Calculations of the GSA Study (Klote, et al. 1992a)

\begin{tabular}{|llccc|}
\hline Building & Location & $\begin{array}{c}\text { Number } \\
\text { Of Stories }\end{array}$ & $\begin{array}{c}\text { Optimum } \\
\text { By Elevator }^{1}\end{array}$ & $\begin{array}{c}\text { Speed Up } \\
\text { Evacuation By }^{2}\end{array}$ \\
\hline General Services Building & Washington, DC & 7 & NA & NA \\
Hoffman Building II & Alexandria, VA & 13 & $33 \%$ & $25 \%$ \\
White Flint North Building & Bethesda, MD & 18 & $17 \%$ & $16 \%$ \\
Jackson Federal Building & Seattle, WA & 36 & $65 \%$ & $22 \%$ \\
\hline
\end{tabular}

${ }^{1}$ The optimum by elevators is the percent of occupants using elevators that results in the fastest building evacuation. In these calculations, the upper floors were evacuated by elevator, and the other floors were evacuated using stairs.

${ }^{2}$ This is the decrease in evacuation time using the optimum combination of elevators and stairs over evacuation by stairs only.

Table 3 is a summary of the elevator evacuation calculations of the GSA study. In these calculations, some of the elevators were considered out of service and not used for the evacuation calculations. Calculations were based on a number of upper floors being evacuated by elevators, and the rest of the occupants used stairs. For the General Services Building, there was no combination of elevators and stairs that was as fast as evacuation by stairs alone. The General Services Building is a large monumental building that takes up a city block in down town Washington, DC. One of the reason that elevators could not speed up evacuation of this building is that it has high stair capacity.

The calculations show that the elevator use has the potential to speed up evacuation significantly for the other three buildings studied. The extent to which elevators have the potential to speed up evacuation depend on many factors including the number of floors in the building, the capacity of the elevators, the capacity of the stairs, and the number of elevators in service during evacuation. However, it appears that in general to he potential benefit of using elevators is greater for taller buildings. 


\section{Conclusions}

The use of elevators to speed up emergency evacuation is feasible. An EEES must have protection from heat, flame, smoke, water, overheating of elevator machine room equipment, and loss of electrical power. In areas of high seismic activity, attention must be paid to earthquake design. Further research is needed to (1) develop reliable methods of protection the EEES from water damage, (2) develop appropriate methods of elevator control, (3) develop appropriate approaches to getting people to accept and use EEES in emergencies.

\section{Acknowledgements}

So many people have made valuable contributions to elevator research during the 1980 s and 1990 s that it is not possible the thank them all, but the following come to mind. Bernard Levin and Norm Groner provided valuable input concerning human behavior. Daniel Alvord helped with the development of ELVAC. Emile Braun contributed to the elevator water tests. Development of this overview paper is part of a research project sponsored by NIST, and Richard Bukowski is NIST's technical representative for that research project.

\section{References}

Bazjanac, V. (1974) Another Way Out? Progressive Architecture, April, pp. 88-89.

Bazjanac, V. (1977) Simulation of Elevator Performance in High-Rise Buildings Under Conditions of Emergency. Human Response to Tall Buildings, Ed by D. J. Conway. Dowden, Hutchinson \& Ross, Stroudsburg, PA, pp. 316-328.

Groner, N. E., Levin, B. M. (1995) Will Building Occupants Use Elevators for Evacuation? Factors Affecting Compliance With the Emergency Plan. Proceedings of Elevators, Fire and Accessibility, 2nd Symposium.. April 19-21, 1995, ASME, New York, NY, pp. 194-196.

Groner, N. E., Levin, B. M. (1992) Human Factors Considering in the Potential for Using Elevators in Building Emergency Evacuation Plans, NIST-GCR-92-615, NIST, Gaithersburg, MD.

Klote, J. H. (1980) Computer Program for Analysis of Pressurized Stairwells and Pressurized Elevator Shafts. NBSIR 802157. National Bureau of Standards, Gaithersburg, MD

Klote, J. H. (1983) Elevators as a Means of Fire Escape, ASHRAE Transactions, Vol. 89, Part 1B, pp. 362-378.

Klote, J. H. (1984) Smoke Control for Elevators, ASHRAE Journal, Vol. 26, No. 4, pp. 23-33.

Klote, J. H. (1988) An Analysis of the Influence of Piston Effect on Elevator Smoke Control, NBSIR 88-3751, National Bureau of Standards, Gaithersburg, MD.

Klote, J. H. (1993a) A Method for Calculation of Elevator Evacuation Time. Journal of Fire Protection Engineering, Vol. 5, No. 3, pp. 83-96.

Klote, J. H. (1993b) Design of Smoke Control Systems for Areas of Refuge. ASHRAE Transactions, Vol. 99, No. 2, pp. 793-807.

Klote, J. H. (1995) Design of Smoke Control Systems for Elevator Fire Evacuation Including Wind Effects. Proceedings of Elevators, Fire and Accessibility, 2nd Symposium. April 19-21, 1995, ASME, New York, NY, pp. 59-77.

Klote, J. H. et al. (1992a) Feasibility and Design Considerations of Emergency Evacuation by Elevators. NISTIR 4870, NIST, Gaithersburg, MD.

Klote, J. H. et al. (1992b) Staging Areas for Persons With Mobility Limitations. NISTIR 4770, NIST, Gaithersburg, MD.

Klote, J. H. et al. (1993) Workshop on Elevator Use During Fires. NISTIR 4993, NIST, Gaithersburg, MD.

Klote, J. H., Braun, E. (1996) Water Leakage of Elevator Doors With Application to Building Fire Suppression. NISTIR 5925, NIST, Gaithersburg, MD.

Klote, J. H., Levin, B. M., Groner, N. E. (1994) Feasibility of Fire Evacuation by Elevators at FAA Control Towers. NISTIR 5445, NIST, Gaithersburg, MD.

Klote, J. H., Levin, B. M., Groner, N. E. (1995) Emergency Elevator Evacuation Systems. Proceedings of Elevators, Fire and Accessibility, 2nd Symposium, April 19-21, 1995, ASME, New York, NY, pp. 131-150.

Klote, J. H., Milke, J. A. (1992) Design of Smoke Management Systems, ASHRAE, Atlanta, GA.

Klote, J. H., Milke, J. A. (2002) Principles of Smoke Management, ASHRAE, Atlanta, GA.

Klote, J. H., Tamura, G. T. (1986a) Elevator Piston Effect and the Smoke Problem, Fire Safety Journal, Vol. 11 No. 3, pp. 227-233.

Klote, J. H., Tamura, G. T. (1986b) Smoke Control and Fire Evacuation by Elevators, ASHRAE Transactions, Vol. 92, Part 1A, pp. 231-245. 
Klote, J. H., Tamura, G. T. (1987) Experiments of Piston Effect on Elevator Smoke Control, ASHRAE Transactions, Vol. 93, Part 2, pp. 2217-2228.

Klote, J. H., Tamura, G. T. (1991a) Design of Elevator Smoke Control Systems for Fire Evacuation, ASHRAE Transactions, Vol. 97, Part 2, pp. 634-642.

Klote, J. H., Tamura, G. T. (1991b) Smoke Control Systems for Elevator Fire Evacuation. Elevators and Fire. Council of American Building Officials and National Fire Protection Association. February 19-20, 1991, Baltimore, MD, pp. 83-94.

Levin, B. M., Groner, N. E. (1992) Human Behavior Aspects of Staging Areas for Fire Safety in GSA Buildings. NIST GCR 92-606, NIST, Gaithersburg, MD.

Levin, B. M., Groner, N. E. (1994a) Human Factors Considerations for the Potential Use of Elevators for Fire Evacuation of FAA Air Traffic Control Towers. NIST GCR 94-656, NIST, Gaithersburg, MD.

Levin, B. M., Groner, N. E. (1994b) Human Factors Considerations for The Potential for Using Elevators in Building Emergency Evacuation Plans, NIST-GCR-92-615, NIST, Gaithersburg, MD.

Levin, B. M., Groner, N. E. (1995) Some Control and Communication Considerations in Designing an Emergency Elevator Evacuation System. Proceedings of Elevators, Fire and Accessibility, 2nd Symposium, April 19-21, 1995, 190-193 pp, 1995, ASME, New York, NY, 2002.

Nelson, H. E. and Mowrer, F.W. (2002) Emergency Movement, SFPE Handbook of Fire Protection Engineering, Society of Fire Protection Engineers, Boston, MA.

NFPA 101 (1976) Code for Safety to Life from Fire in Buildings and Structures, National Fire Protection Association, Quincy, MA.

Strakosch, G. R. (1983) "Vertical Transportation: Elevators and Escalators", Wiley \& Sons, NY, 2nd Edition., pp. 122-127.

Sumka, E. H. (1988) Presently, Elevators Are Not Safe in Fire Emergencies, Elevator World, Vol. 36, No. 11, pp. 34-40.

Tamura, G. T., Klote, J. H. (1988) Experimental Fire Tower Studies on Adverse Pressures Caused by Stack and Wind Action: Studies on Smoke Movement and Control, ASTM International Symposium on Characterization and Toxicity of Smoke, December 5, 1988, Phoenix, AZ.

Tamura, G. T., Klote, J. H. (1989a) Experimental Fire Tower Studies of Elevator Pressurization Systems for Smoke Control. ASHRAE Transactions, Vol. 93, No. 2, 2235-2256.

Tamura, G. T., Klote, J. H. (1989b) Experimental Fire Tower Studies on Mechanical Pressurization to Control Smoke Movement Caused by Fire Pressures. Proceedings of International Association for Fire Safety Science. Fire Safety Science. 2nd International Symposium. June 13-17, 1988, Tokyo, Japan, Hemisphere Publishing Corp., New York, pp. 761-769.

Tamura, G. T., Klote, J. H. (1990) Experimental Fire Tower Studies on Controlling Smoke Movement Caused by Stack and Wind Action. Proceedings of International Association for Fire Safety Science. Fire Safety Science. 2nd International Symposium. June 13-17, 1988, Tokyo, Japan, Hemisphere Publishing Corp., New York, pp. 165-177. 
Appendix C

Elevators for Occupant Evacuation and Fire Department Access 


\title{
ELEVATORS FOR OCCUPANT EVACUATION AND FIRE DEPARTMENT ACCESS
}

\author{
E. KULIGOWSKI \\ National Institute of Standards and Technology, Gaithersburg, MD 20899, USA
}

\begin{abstract}
This paper will present a study of the potential for elevators to reduce occupant egress time and fire department access time for fires in tall buildings. Potential reductions in egress and access times will be compared for some specific cases where times for current procedures are available. The paper will review past research in elevator usage and the structure of existing models for elevator evacuation. From this review, the assumptions and limitations of the current elevator and egress models will be discussed, and future plans for improvement of the existing egress prediction techniques will be presented.
\end{abstract}

Keywords: Elevators, evacuation, firefighter lifts, elevator evacuation, evacuation models

\section{Introduction}

The recent events have caused fire safety experts to question the adequacy of phased evacuation plans for high-rise buildings. Also, the issue of lengthy travel times and physical exertion of firefighters ascending stairs of a high-rise building to reach the fire floor is a concern. Inquiries of fire departments following the incident indicates that most have adopted access by elevator policies for buildings exceeding 6 stories, but there are currently no provisions for firefighter lifts in the U.S. elevator codes. During total evacuation of a tall building, it is likely that there would be significant congestion in the stairways with a larger number of occupants, when compared with occupant numbers during phased evacuation, at the same time as firefighters traveling against the flow. Increasing the number or width of the stairwells in a building represents an extremely expensive option, especially for existing buildings. A viable option is to design elevators capable of providing a safe exit route out of the building for occupants and safe access to the fire area for firefighters. Several issues concerning elevator use in emergencies, such as human behavior, control, training, equipment reliability, and communication, should be addressed before this mode of vertical transportation can be implemented.

\subsection{Current Requirements for Firefighter Lifts}

Firefighter lifts are protected elevators provided in tall buildings for use by the fire department for moving people and equipment to the fire area and which also may be used by the fire department to provide evacuation assistance to people with disabilities. The provision of lifts dedicated to fire department use in an emergency is required in at least 12 countries around the world. As a recent survey by the ISO TC178 committee shows ${ }^{1}$ operating procedures for fire department use of elevators are similar. For example they are generally required in buildings taller than $30 \mathrm{~m}$, are provided with enclosed lobbies on each floor, and are housed in a two hour smoke protected shaft. Emergency power to the controllers and motor is required and the cars are operated under manual control by a firefighter.

British Standard 5588, Part 5 entitled Code of Practice for Firefighting Stairs and Lifts $^{2}$ describes what is referred to as a firefighting shaft. This is a dedicated, protected elevator with lobbies on every floor and an associated stairway fitted with a standpipe. The procedure is to move people and equipment to the lobby three floors below the fire. The hose team then advances up the stairs from the elevator drop-off position, connects to the standpipe, and proceeds with the attack. Enough firefighting shafts are required so that any point on a floor can be reached with $60 \mathrm{~m}$ of hose. The commentary describes several advantages to fire department dedicated lifts, such as reduction of travel time to the access floor, preservation of the building for a longer period of time, and increased safety to the occupants of the building. The standard also recognizes that firefighters who climb several flights of stairs outfitted with heavy gear and equipment may lose needed energy to fight the fire by the time they reach the fire floor. 
In the US, ASME A17.1-2000, the Safety Code for Elevators and Escalators ${ }^{3}$, does not provide for the use of elevators in emergencies either by firefighters or by occupants (except as noted below). Since 1973, A17.1 has contained emergency procedures that take the elevators out of service if smoke is detected in any lobby or in the machine room or hoistway. Under this condition the elevators are directed immediately to the ground floor where the doors open and the elevators are locked out (called Phase I recall). Subsequently, the responding fire department can reactivate individual cars under manual control using a special key (Called Phase II operation). U.S. building regulations require that buildings taller than three floors and likely to be used by people with disabilities be provided with an accessible elevator protected in a manner similar to that described for firefighter lifts. A means of summoning assistance from the fire department is required and they would use that elevator under Phase II operation to evacuate the disabled person.

The use of elevators for fire department access would enable the firefighters to ride to a specific floor, depending upon what is specified by the department's Standard Operating Procedures (SOPs) ${ }^{4}$. Examples of U.S. City Fire Department's SOPs ${ }^{5}$ state that the elevators would take firefighters from the lobby to the floor two floors below the fire floor while others, e.g. the Chicago Fire Department ${ }^{6}$, state that the elevator would stop three floors below the fire. In either case, the firefighters from an engine company, for instance, would exit the elevator on the designated floor, travel via stairs to establish a hose line one to two floors below the fire floor, and continue stair travel with the hose line to the fire floor.

\subsection{Research on Egress Elevators}

In a fire emergency, elevators are not only the focus for fire department access, but for evacuation purposes as well. Work was done in the early 1990s at the National Institute of Standards and Technology (NIST) $7,8,9,10,11$ on the use of elevators for evacuation in which pros and cons were established that still exist today. The advantages noted for elevator evacuation are the following:

- Occupants usually exit buildings the same way that they enter

- Elevator evacuation takes less physical effort

- Stair congestion is an unpleasant experience

- Overall evacuation time is decreased

- Elderly or disabled occupants may rely on elevators as their only option

On the other hand, with an elevator evacuation plan, there are many issues to consider and prepare for in an emergency. First, the 30 year campaign cautioning the public against using elevators in the event of a fire could severely lessen the occupants' confidence in the elevator system. Also, occupants could become impatient and overcrowd the elevator, which causes the car to stop functioning and remain at the floor indefinitely ${ }^{10}$. One way for these issues to be addressed is through a training program and extensive evacuation plan for the building. The evacuation plan of a single rise elevator system could involve, for example, the use of elevators by the higher floors of the buildings, stairs used by the lower floors, and fire wardens on each floor directing his/her occupants to the correct evacuation route ${ }^{8}$. Since training may not be as helpful for visitors of the high rise building, the use of fire wardens becomes even more important in elevator evacuation.

For an 88-floor residential building in Melbourne, Australia, an evacuation strategy has been used in the building design to allow for elevator use during evacuation. The Eureka Place Tower ${ }^{12}$ is separated, according to the elevator arrangement, into vertical evacuation zones. The plan states that occupants within the vertical zone that includes the fire floor would evacuate via the stairs until they reach the next transfer floor. At the transfer floors, which are located on levels 24 and 52 of the Eureka Place Tower, the occupants would then take the express elevators to the ground floor. The express elevators will be located in separate shafts in order to avoid water and smoke damage, and will be accompanied by other lifts provided for firefighter access.

Along with an evacuation plan, a reliable voice communication system can provide information on the progress of the fire and evacuation system ${ }^{8}$. Also, a decision made on the appropriate control of the elevator system (manual or automatic) in an emergency lends itself to certain advantages and disadvantages presented in the literature $\mathrm{s}^{13,14,15}$. 


\subsection{Elevator Evacuation Models}

In order to capture the differences in evacuation by stairs only, elevators only, or both, evacuation modeling and calculations can be done. $\operatorname{ELVAC}^{7}$ is the only commonly available model dedicated to the calculation of evacuation time by elevators. Other elevator models, typically used for elevator design within a building, can also be used to calculate the transit time of the last person to reach the lobby, which is ultimately the evacuation time of the building. These models have limitations when using them to simulate total evacuation of a building, as well as make assumptions, which will be addressed later in this report.

The three topics covered in this report focus on a firefighter lift case study, the U.S. General Services Administration (GSA) building evacuation case study, and a review of current elevator evacuation models. The case studies will be used to estimate the ultimate reduction in travel time by incorporating elevators into the evacuation plan for occupant evacuation and fire department access. For the firefighter lift study, firefighter travel via stairs will be compared to travel by elevator to a designated floor accompanied by continual travel via stairs to the fire floor. In the GSA evacuation study ${ }^{8}$, several ELVAC and stair evacuation calculations were made to show the reduction in travel time when both elevators and stairs are used simultaneously for evacuation, instead of stairs only. Finally, the limitations and assumptions of current elevators models will be discussed as well as future needs in the area of elevator evacuation modeling.

\section{Firefighter Lift Case Study}

For this case study, the commercial building used was designed by a Dallas architectural firm and stretches 40 stories above ground and 4 parking levels below. A typical floor of the building contains approximately $3000 \mathrm{~m}^{2}$ of floor space, with $500 \mathrm{~m}^{2}$ occupied by the core space. The core contains elevators, 2 stairwells, bathrooms, mechanical closets, etc.

The stairs are located diagonally across the core area from each other, each measuring $1.2 \mathrm{~m}$ (3.9 ft) wide with $267 / 11$ steps per flight. The 7/11 terminology refers the height of the riser followed by the depth of the tread in inches, meaning that for each step, the riser height is $17.8 \mathrm{~cm}$ (7 in) and the tread

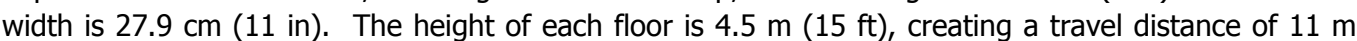
(36 ft) per flight of stairs, including the landing distance.

The elevators for a commercial building are assumed to have a speed of $5.08 \mathrm{~m} / \mathrm{s}(1000 \mathrm{fpm})$, per Table 10.7 of the Vertical Transportation Handbook ${ }^{16}$, and average acceleration of $1.5 \mathrm{~m} / \mathrm{s}^{2}\left(5 \mathrm{ft} / \mathrm{s}^{2}\right)$. For this case study, it is also assumed that a crew of 5 firefighters and their equipment will be traveling in the elevator and stairs together at one time. There are other characteristics that were assumed for the elevators that only affect the outcome of this case study in a trivial manner, such as the full car load, type of door, the door inefficiency, and door closing time.

For this case study, the fire is placed on the $35^{\text {th }}$ floor. Two groups of five firefighters are analyzed in their attempts to reach floor 35. Group 1 traverses 34 flights of stairs from the lobby to floor 35. Group 2 takes the elevators to the $33^{\text {rd }}$ floor and travels the stairs an additional 2 flights. Hand calculations were made for firefighter travel up the stairs, while hand calculations and the ELVAC model were used to calculate the one-way elevator travel time from the lobby to the $33^{\text {rd }}$ floor. ELVAC is primarily a model used to calculate gross elevator evacuation time from buildings, and the hand calculated one-way elevator travel time was used to check ELVAC results.

To obtain firefighter travel speeds on stairs and horizontal building components, adjustments were made to data already recorded from people movement studies ${ }^{17,18,19}$. Frantzich's data show a range of velocities for upstairs movement from $(0.5$ to 0.75$) \mathrm{m} / \mathrm{s}$, Fruin gives values of $(0.5$ to 0.65$) \mathrm{m} / \mathrm{s}$ and Predtechenskii and Milinskii state a range of $(0.33$ to 0.92$) \mathrm{m} / \mathrm{s}$ for low density situations. On one hand, these values may be low if studied during nonemergency situations, but alternatively, firefighters are typically equipped with heavy gear and equipment, on the order of 25 to $45 \mathrm{~kg}$ per firefighter, which should be accounted for. The primary walking speed used in this case study for firefighter travel up stairs is $0.35 \mathrm{~m} / \mathrm{s}$ (adjusted from $0.5 \mathrm{~m} / \mathrm{s}$ for heavy gear). Another velocity used came from the 
New York Fire Department's rule of thumb that states firefighters average 60 seconds per floor (unobstructed flow), which is not sustainable throughout the ascent of high-rise buildings. 60 seconds per floor will be used as the conservative ascent time and $0.35 \mathrm{~m} / \mathrm{s}$ will be used as the other extreme. For horizontal building component speed, again the standard value of $1.2 \mathrm{~m} / \mathrm{s}^{20}$ was adjusted to a conservative value of $0.8 \mathrm{~m} / \mathrm{s}$ for gear and heavy equipment.

The breakdown of the elevator calculations are as follows (multiple values indicate a range of travel speeds for that calculation):

Group 1:

$\circ \quad$ The time to traverse 34 flights of stairs $=17 \mathrm{~min}$ at $0.35 \mathrm{~m} / \mathrm{s} ; 34 \mathrm{~min}$ at 60 seconds per flight (more conservative)

Group 2:

○ The one way travel time of the elevator from the lobby to the $33^{\text {rd }}$ floor $=45 \mathrm{~s}$ with $5.08 \mathrm{~m} / \mathrm{s}$ elevator speed

- The horizontal travel time from the elevator to the stairs on the $33^{\text {rd }}$ floor $=30 \mathrm{~s}$ at $1.2 \mathrm{~m} / \mathrm{s}$; $45 \mathrm{~s}$ at $0.8 \mathrm{~m} / \mathrm{s}$ (more conservative)

- The time to traverse two flights of stairs $=60 \mathrm{~s}$ at $0.35 \mathrm{~m} / \mathrm{s} ; 120 \mathrm{~s}$ at 60 seconds per flight (more conservative)

The travel times calculated for both Groups in this case study neglect firefighter response time to the building, travel to the elevator or stairs from the building entrance, and time spent on the floor locating the point of attack, since both need to perform these activities in a fire situation.

After performing an additional calculation of adding the elevator travel, horizontal travel, and stair travel times together for Group 2, the results are as follows:

- Group 1: 17 to $34 \mathrm{~min}$

- Group 2: 2.5 to $3.5 \mathrm{~min}$

It may seem obvious that an elevator would give some advantage in speed over stair use. But, when other factors, such as heavy gear and equipment and increased elevator technology play a role, elevators substantially become a more viable and constructive option. The difference between use of stairs (Group 1) and elevators (Group 2) for firefighter ascent is approximately (15 to 30) minutes. This is a large difference in time lost due to stair use, especially when a fire can grow significantly in a matter of minutes. By using elevators as the primary means of ascent, Group 2 was able to reach the fire at least 15 min earlier in this case study. In fifteen minutes, the environment can be less toxic for the occupants, the fire smaller, and the property less damaged. Also, Group 2 would have more energy to exert on fire fighting activities on the floor, when compared to Group 1. The limitation associated with the calculation was the estimation made in the firefighter movement speed, as shown by the range of results in both Groups.

\section{Elevator Evacuation Study}

In the early 90s, four GSA buildings were analyzed as potential applications to incorporate elevator evacuation $^{8}$. The four selected were the Hoffman Building II (Virginia), White Flint North Building (Maryland), Jackson Federal Building (Seattle), and General Services Building (Washington, DC), and were chosen to gather different building heights, elevator capabilities, and architectural characteristics.

For each building, evacuation times were calculated for the following conditions: 1) Total evacuation of the building by stairs only; 2) Total evacuation of the building by elevators only; and 3) Total evacuation of the building by various distributions of occupants to stairs and elevators (the optimal time value is shown in Table 1). For the stair calculations, Klote et al. ${ }^{8}$ used the people movement methodology laid out by Nelson and MacLennan ${ }^{21}$. For these calculations, people on each floor were assumed to be waiting at the door to the stairs as soon as evacuation begins. For the elevator calculations, the ELVAC model ${ }^{7}$ was used which simulates 2-stop elevator trips until the entire building has been evacuated. Again, for these calculations, people were assumed to be waiting at the closest elevator lobbies as soon as evacuation began. Table 1 shows the characteristics of each building, 
including the number of floors, the number of stairs and elevators used, and the total population of each building. Also, the table shows the total evacuation time of the building (minutes) if only stairs were used, the total evacuation time if only the elevators were used, and the last column shows the optimal (fastest) gross evacuation time when a combination of stairs and elevators are used. Additionally, the Hoffman building and the White Flint North Building's analysis did not use the full capacity of elevators available to the building. The Hoffman building used 5 out of the 6 elevators in each group and the White Flint building used 4 out of the 6 . This was due to the fact that the existing elevator lobbies were incapable of holding as many people as would be discharged from all elevators simultaneously, and in that case, the evacuation capacity of the elevators was restricted by the size of the lobby.

\begin{tabular}{|c|c|c|c|c|c|c|}
\hline Building & Floors & $\begin{array}{c}\text { Stairs/ } \\
\text { Elevators }\end{array}$ & $\begin{array}{c}\text { Total } \\
\text { Population }\end{array}$ & $\begin{array}{c}\text { Evac. } \\
\text { Time by } \\
\text { Stairs }\end{array}$ & $\begin{array}{c}\text { Evac. } \\
\text { Time by } \\
\text { Elevators }\end{array}$ & $\begin{array}{c}\text { Optimal } \\
\text { Time by } \\
\text { Both }\end{array}$ \\
\hline Hoffman & 13 & 2/ 2 groups of 5 & 3506 & $14.9 \mathrm{~min}$ & $24.3 \mathrm{~min}$ & $11.2 \mathrm{~min}$ \\
\hline White Flint & 18 & 2/ 1 group of 4 & 1425 & 14.3 & 28.6 & 12.0 \\
\hline Jackson & 36 & 2/ 3 rises of 6 & 3021 & 23.1 & 16.5 & 12.8 \\
\hline GSA & 7 & 6/ 6 groups of 2 & 3621 & 7 & 17 & 6.3 \\
\hline
\end{tabular}

Table 1: Summary of GSA buildings and modeling results

In each of the four buildings analyzed, the optimal time was reached by designing for a combination of floors or percentage of the floor dedicated to elevator usage while the other portion of the building evacuated by stairs. The use of elevators for evacuation made the largest contribution for the tallest building, which was the Jackson Federal building equipped with low, mid, and high rise elevators. The elevator designation that provided the optimal result for this building was the following: $65 \%$ of occupants from the mid and high rise floors, all occupants from floors 11 through 14 , and only $3 \%$ on floors 1 through 13. All others in the Jackson building used the stairs. For the single rise elevator systems in the Hoffman, White Flint, and GSA buildings, the elevator designation that provided the optimal result was for total elevator evacuation from the upper floors of the building and stairs from the lower floors. Overall, it was shown that by using a combination of evacuation systems, stairs and elevators, the total evacuation time of the building can be reduced by a substantial amount, especially with taller buildings. This study is limited by the averaged movement calculations used, and the assumption that all occupants were waiting at the stair or elevator lobbies as soon as the evacuation began. Also, another limitation is that occupants were not studied using both stairs and elevators during a single evacuation route, as performed in the evacuation plan for the Eureka Place Tower.

\section{Elevator Evacuation Modeling}

While the GSA calculations were made using the ELVAC model, there are certainly limitations associated with this and other current elevator evacuation models. Due to the fact that elevators are rarely used for occupant evacuation, other than by the fire department in Phase II, few evacuation models are available that incorporate evacuation via elevators. The commercial models presently being used to simulate building evacuation in a fire situation typically model movement by stairs only, with or without the incorporation of behavior simulation. There has yet to be a commercially-available, complete simulation package to describe the entire fire scenario, including premovement and action decision making, environmental conditions inside the building, occupant behavior, and movement throughout the building via stairs, escalators, and elevators. The limitations of the current models extend beyond the obvious lack of elevator simulation. There is also a lack of data on occupant behavior during elevator use in evacuation. The uncertainties on whether or not occupants will feel comfort in using elevators arise from the lack of data on occupant overcrowding of cars on a floor, impatience due to long waits in the elevator lobby, and behavior around their particular social unit (for example, will groups remain together and let an elevator pass if there is not enough room in the car for the entire group?). Another modeling uncertainty is how the model will simulate the evacuation plan that will take place in the building. The model may need to incorporate fire wardens, manual and automatic control of the elevators, and multi-use of stairs and elevators by the same group of occupants. 
As mentioned earlier, $\mathrm{ELVAC}^{8}$ is a model dedicated to the simulation of building evacuation by elevator only. ELVAC, as will be explained, only gives the gross evacuation time of the building, and along with its assumptions, may cause the model to lose accuracy in calculation, especially when compared to a complete simulation model. The model uses the 2-stop evacuation approach, meaning that the car travels from the lobby to a specific floor and then back down to the lobby, independent of the number of tenants occupying the car. ELVAC also assumes that all occupants using the elevators for evacuation are waiting at the elevator lobbies as soon as evacuation begins. Changes could be made to ELVAC to move towards more of a simulation model, such as equipping the elevators with load sensors, which most have, that would recognize when a car has additional space and enable the car to pick up more occupants on the way down to the lobby. Also, in an actual evacuation, it is certain that people would be arriving at the elevator lobby at different times, and the load sensor device would aid in evacuation of stragglers to the lobby area after most of the occupants have been evacuated. ELVAC, by giving only the gross evacuation time, does not simulate the car movement from floor to floor and the times associated with these movements. In an actual fire evacuation, it is most likely that the cars will move to the fire floor (and floors above and below) to evacuate these occupants first. By incorporating car simulation into ELVAC, evacuation times by elevators may be more accurate, especially for worst case scenarios when the fire is on a high floor of the building. Lastly, ELVAC does not account for the actual design of the control of the elevators. This difference in control may cause delays in start-time if operated by a human, instead of computer.

ELEVATE and the Building Traffic Simulator (BTS) are both models used to design the elevators for buildings, including the number and size of the cars, for normal daily operation. ELEVATE, a commercial model, can be used to indirectly calculate total evacuation time by identifying the time that the final person has arrived at the ground floor from the elevators ${ }^{22,23}$. The user must specify a destination to the ground floor as $100 \%$ and the arrival rate (persons per 5 minutes) of the building's occupants to the elevator lobbies. As of now, evacuation modeling procedures are not specified in the users manual. $\mathrm{BTS}^{24,25}$, on the other hand, is a currently noncommercial model capable of simulating evacuation via the building's transportation devices, which includes elevators (with different control methods), escalators, and stairs. The model uses input of the building's floor shape, position of the transportation devices, passenger traffic (e.g. arrival rates to the lobbies), passenger selection of transports, and passenger walking speeds (to simulate tenants who may need to walk from one transportation device to the other during movement and/or movement on stairs) to model an evacuation. According to its developers ${ }^{24,25}$, evacuation can be modeled defining the occupant's walking speed, space requirement, and decision on which transportation mode(s) to use throughout the evacuation. Both ELEVATE and BTS provide a step toward simulation evacuation models, since these models are continually aware of occupant loads and positions (in elevator cars or stairs, depending on the model) in time throughout the evacuation. On the other hand, like ELVAC, there is no introduction of fire conditions and human behavior, as a complete simulation evacuation package could include. Also, for each of the three models, occupants are either automatically waiting at the elevator lobbies (ELVAC) or given an arrival rate (people/time period - ELEVATE, BTS) for appearing at the designated transport device, which neglects specific behavior and movement time delays occurring from their original position to the location of the transport device.

The three elevator models discussed in this report, ELVAC, ELEVATE, and BTS, all have advantages and disadvantages for using each for evacuation simulation purposes. ELVAC gives the gross evacuation time of the building by elevators only and assumes that all occupants are waiting at the elevator lobbies as soon as the evacuation begins. ELEVATE will simulate down-peak (evening rush hour for the building, for example) elevator movement with $100 \%$ probability of movement to the ground floor, and BTS will also simulate down-peak movement of the occupants using elevators, escalators, and stairs during their exit journey. The simulation models, ELEVATE and BTS, have the extra advantage of continual data on the current position of the cars and occupants, as well as an attempt to model premovement behavior through the use of occupant arrival rates to the elevator lobbies. However, none of these models incorporate specific behavior and movement time delays that occur before reaching the transport device, human behavior in relation to elevator and stair use during a fire, and the condition of the fire in the building during the evacuation. These are main reasons why a complete evacuation simulation package would be a valuable asset for evacuation design. It should be noted that relevant literature in human behavior is sparse $e^{26,27,28,29}$; because elevators are not commonly used for design of the evacuation system of a building, data on humans and elevator use is lacking for this simulation package. 


\section{Conclusions}

Elevator use in emergency situations can make a significant time saving contribution to travel towards the fire for the fire service and the evacuation of the occupants in the building. The calculations done for the firefighter case study showed that firefighters traveled to the fire floor (15 to 30) min faster via elevators when compared to stair access. The stair travel calculation, using two different estimates for the firefighter walking speeds, resulted in a range of travel time values differing by a factor of two. Research is needed in the area of firefighter movement to assess which travel times within the calculated range (17 to $34 \mathrm{~min}$ ) are more accurate.

Also, the evacuation time of occupants using a combination of stair calculations and ELVAC calculations for the elevators shows improvement over stair or elevator movement alone for the GSA examples studied. This is especially true for the taller building with multi-rise elevators. With these calculations, assumptions were made that the occupants were waiting at the elevator lobbies and staircases as soon as evacuation began. Also, the occupants were assumed to use only the stairs or the elevators during their descent, unlike the evacuation plan of the Eureka Place Tower, in which a resident could use a combination of the two during egress.

Lastly, there is a need for a complete simulation package that includes movement of the occupants on stairs, elevator movement of the cars and occupants, environmental conditions in the building due to the fire, the contribution of the building to fire and egress, and human behavior and movement during the entire evacuation. Currently, there are evacuation models that focus on all of these aspects except elevator usage, and elevator models that neglect these aspects of building evacuation except for elevator usage. Unfortunately, much data is lacking about the behavior of occupants using elevators during an emergency, which needs to be addressed.

Overall, elevators lessen the travel time of firefighters and occupants to their prospective destinations, if used properly and with an appropriate emergency plan. There are many obstacles which need to be met in order for these plans to work properly. Recently, there has been an awakening to the importance of research in these areas for eventual use in buildings all over the world.

\section{Acknowledgements}

The author recognizes the help of Mr. Richard Bukowski, of the National Institute of Standards and Technology, as an advisor of this project. The assistance in research on elevators modeling from Roger Howkins and Dr. Richard Peters (ELVATE), Dr. John Klote (ELVAC), and Dr. Marja-Liisa Siikonen (BTS) is also appreciated. Mr. Mike Scianna, Commander Bureau of Operations, Chicago Fire Department, and Mr. John O'Donoghue, Fire Officer, Massachusetts Firefighting Academy provided information about FD operations in high-rise buildings. Finally, Mr. Jason Averill provided the building used for FD access calculations ${ }^{30}$

\section{References}

${ }^{1}$ Comparison of worldwide lift (elevator) safety standards - Firefighters lifts (elevators), ISO/TR 16765:2002(E), International Organization for Standardization, Geneva, Switzerland, 2002.

${ }^{2}$ Fire Precautions in the Design, Construction, and Use of Buildings, BS 5588 Park 5 1991, Code of Practice for Firefighting Lifts and Stairs, BSI, London.

${ }^{3}$ Safety Code for Elevators and Escalators, ASME A17.1-2000, Amer Soc Mech Eng, NY, 2000.

${ }^{4}$ Klaene, B. and Sanders, R. (2001), Firefighters' Use of Elevators, Using elevators during a fire requires establishing specific SOPs, NFPA Journal, Vol. 95, No. 4, July/August 2001.

${ }^{5}$ Phoenix Fire Department Standard Operating Procedures, http://phoenix.gov/FIRE/20205.html.

${ }^{6}$ Verbal/Email Communication: Michael Scianna, Chicago Fire Department. October 2002.

${ }^{7}$ Klote, J.H. (1993), A Method of Calculation of Elevator Evacuation Time, National Institute of Standards and Technology, Gaithersburg, MD, Journal of Fire Protection Engineering, 5(3), 1993, pp. 83-95.

${ }^{8}$ Klote, J.H., Alvord, D.M., Levin, B.M., and Groner, N.E. (1992), Feasibility and Design Considerations of Emergency Evacuation by Elevators, National Institute of Standards and Technology, Gaithersburg, MD, NISTIR 4870. 
${ }^{9}$ Klote, J.H. and Alvord, D.M. (1992), Routine for Analysis of the People Movement Time for Elevator Evacuation, National Institute of Standards and Technology, Gaithersburg, MD, NISTIR 4730.

${ }^{10}$ Klote, J.H., Deal, S.P., Donoghue, E.A., Levin, B.M., and Groner, N.E. (1993), Fire Evacuation By Elevators, Elevator World, June 1993.

${ }^{11}$ Klote, J.H., Levin, B.M., and Groner, N.E. (1995), Emergency Elevator Evacuation Systems, Proceedings of the $2^{\text {nd }}$ Symposium on Elevators, Fire, and Accessibility, Baltimore, MD, April, 1995.

${ }^{12}$ Aloi, S. and Rogers, J. (2002), Reach for the Sky, Fire Prevention \& Fire Engineers Journal, Vol. 62, No. 219, FPA London, April 2002.

${ }^{13}$ Levin, B.M, and Groner, N.E. (1995), Some Control and Communication Considerations in Designing an Emergency Elevator Evacuation System, Proceedings of the $2^{\text {nd }}$ Symposium on Elevators, Fire, and Accessibility, Baltimore, MD, April, 1995.

${ }^{14}$ Groner, N.E. (1995), Selecting Strategies for Elevator Evacuations, Proceedings of the $2^{\text {nd }}$ Symposium on Elevators, Fire, and Accessibility, Baltimore, MD, April, 1995.

${ }^{15}$ Groner, N.E. and Levin, B.M. (1992), Human Factors Considerations in the Potential for Using Elevators in Building Emergency Evacuation Plans, George Mason University, Washington, DC, July 1992.

${ }^{16}$ Strakosch, G.R. (1998), The Vertical Transportation Handbook Third Edition, John Wiley \& Sons, Inc., New York, USA.

${ }^{17}$ Frantzich, H. (1996), Study of Movement on Stairs During Evacuation Using Video Analysis Techniques, Department of Fire Safety Engineering, Lund Institute of Technology, Lund University, March 1996.

${ }^{18}$ Fruin, J.J. (1987), Pedestrian Planning and Design, Revised Edition, Elevator World, Inc. Mobile, Alabama.

${ }^{19}$ Predtechenskii, V.M. and Milinskii, A.I. (1978), Planning for Foot Traffic Flow in Buildings, Amerind Publishing Co. Pvt. Ltd., New Delhi, 1978.

${ }^{20}$ Nelson, H.E. and Mowrer, F.W. (2002), Section 3, Chapter 14 Emergency Movement, The SFPE Handbook of Fire Protection Engineering, Third Edition, National Fire Protection Association, Quincy, MA.

${ }^{21}$ Nelson, H.E. and MacLennan, H.A. (1995), Section 3, Chapter 14 Emergency Movement, The SFPE Handbook of Fire Protection Engineering, Second Edition, National Fire Protection Association, Quincy, MA

${ }^{22}$ Caporale, R.S., Elevate Traffic Analysis Software (Eliminating the Guesswork), ELEVATE website: http://www.petersresearch.com/elevators/Elevate/Papers/EW\%20review/engin.pdf

${ }^{23}$ Verbal/Email communication: Roger Howkins, ELEVATE; Richard Peters, Peters Research, UK. August 2002.

${ }^{24}$ Siikonen, M.-L., Susi, T., and Hakonen, H. (2001) Passenger Traffic Flow Simulation in Tall Buildings, Elevator World, Inc. August 2001.

${ }^{25}$ Email communication: Marja-Liisa Siikonen, Kone Elevators, Finland. August, November 2002.

${ }^{26}$ Bryan, J.L. (1977), Smoke as a Determinant of Human Behavior in Fire Situations (Project People). Final Report, University of Maryland, College Park, MD, National Bureau of Standards, Gaithersburg, MD, NBS GCR 77-94; 304 p. June 30, 1977.

${ }^{27}$ Wood, P.G. (1980), Chapter 6 A Survey of Behaviour in Fires, Fires and Human Behaviour, Canter (ed.), John Wiley \& Sons, Ltd., New York.

${ }^{28}$ Quarantelli, E.L. (1975), Panic Behavior in Fire Situations: Findings and a Model From the English Language Research Literature, Proceedings from the UJNR Panel on Fire Research and Safety, 4th Joint Panel Meeting, February 5-9, 1979, Tokyo, Japan, 405-428 pp.

${ }^{29}$ Jin, T. (1997), Studies on Human Behavior and Tenability in Fire Smoke, Fire Safety Science - Proceedings of the Fifth International Symposium, International Association for Fire Safety Science, 3-21 pp.

${ }^{30}$ Averill, J.D. (1998), Performance-Based Codes: Economics, Documentation, and Design, National Institute of Standards and Technology, Gaithersburg, MD, NIST-GCR-98-752. 
Appendix D

\section{Design of Occupant Egress Systems for Tall Buildings}




\title{
Design of Occupant Egress Systems for Tall Buildings
}

CIB2004 Session Number: HTB T1 Occupant Issues

Authors:

Erica D. Kuligowski

Richard W. Bukowski, P.E., FSFPE

\begin{abstract}
:
This paper presents a discussion of the features of protected elevator systems that can provide safe and reliable operation both for fire service access and for occupant egress during fires. These features include water tolerant components, fail-safe power, lobbies on each floor designed as areas of refuge, smoke protection, occupant communications, and real time monitoring of the elevator position and operating conditions from the fire command center. Egress simulations are used to quantify the improvements in efficiency that can be realized by incorporating elevators into the access and egress procedures for tall buildings. Finally, operational procedures will be discussed for the most appropriate use of vertically zoned elevator systems that are found in most tall buildings. These procedures would form the basis for the elevator control software that needs to be developed for such systems.
\end{abstract}




\title{
Design of Occupant Egress Systems for Tall Buildings
}

\author{
Erica D. Kuligowski \& Richard W. Bukowski, P.E., FSFPE \\ National Institute of Standards and Technology
}

\begin{abstract}
This paper presents a discussion of the features of protected elevator systems that can provide safe and reliable operation both for fire service access and for occupant egress during fires. These features include water tolerant components, fail-safe power, lobbies on each floor designed as areas of refuge, smoke protection, occupant communications, and real time monitoring of the elevator position and operating conditions from the fire command center. Egress simulations are used to quantify the improvements in efficiency that can be realized by incorporating elevators into the access and egress procedures for tall buildings. Finally, operational procedures will be discussed for the most appropriate use of vertically zoned elevator systems that are found in most tall buildings. These procedures would form the basis for the elevator control software that needs to be developed for such systems.
\end{abstract}

\section{INTRODUCTION}

The unexpected collapse of the World Trade Center buildings has prompted a reexamination of the way egress systems are designed for tall buildings. Current designs specify a certain number, width, and spacing of stairs that depend upon the assumed occupant load and building use. The egress system at each floor is sized for the number of occupants on that floor, reflecting the assumption that tall buildings will be evacuated by partial or phased evacuation procedures. In the discussion of the need to design for simultaneous evacuation of tall buildings, concerns have been raised about the adequacy of relying solely on stairs to move large numbers of people from significant heights.

These discussions naturally turn to whether the elevators that normally provide vertical transportation can be designed to supplement the stairways and provide a safe exit route during fires. It is speculated that if future buildings were required to be designed for simultaneous evacuation under current egress design practices, there will be a building height beyond which the stairs would occupy such a large portion of the floor area that such buildings would be impractical. Despite a 30-year policy in the U.S. codes against the use of elevators in fires, many experts now feel that elevators can be made safe for occupant egress. Some of the relevant research was done in the 1980s by NIST in support of egress elevators in air traffic control towers $^{1,2}$ where the small footprint prohibits the provision of two, remote stairs. NIST is once again working with the U.S. codes and standards organizations and the affected industries to address any remaining technical issues and to develop performance requirements for elevator egress systems. This paper presents a discussion of the features of protected elevator systems that can provide safe and reliable operation both for fire service access and for occupant egress during fires.

\section{CURRENT REQUIREMENTS FOR EMERGENCY USE OF ELEVATORS}

All U.S. building codes contain a requirement for accessible elevators as a part of the means of egress in any building with an accessible floor above the third floor. These

\footnotetext{
*E.D. Kuligowski is a fire protection engineer and R.W. Bukowski is a senior research engineer, Building and Fire Research Laboratory, National Institute of Standards and Technology, Gaithersburg, MD.
} 
requirements are all identical, being extracted from the ADA Accessibility Guidelines (ADAAG) and mandated under the Americans with Disabilities Act (ADA).

A recent survey ${ }^{3}$ by the International Organization for Standardization (ISO) TC178 Committee identified at least twelve countries that require firefighter lifts in tall buildings (generally those exceeding $30 \mathrm{~m}$ (98 ft) in height) to provide for fire department access and to support operations as well as to evacuate people with disabilities. England has such a requirement supported by a British Standard (BS 5588 Part 5$)^{4}$ requiring firefighter lifts in buildings exceeding $18 \mathrm{~m}$ (60 ft) in height. Firefighter lifts are also provided in the Petronas Towers, the world's tallest buildings in Kuala Lumpur, Malaysia.

The NFPA's Life Safety Code (NFPA 101$)^{5}$ includes provisions for egress elevators to be provided as a secondary means of egress for air traffic control towers where the small footprint prohibits two, "remote" stairs. However, these are secure facilities not open to the public and with limited numbers of occupants.

While the above requirements exist for elevators for emergency use by firefighters and people with disabilities, there are currently no codes or standards in the world for egress elevators for use by general building occupants. Since 1973, ASME A17.1, the Safety Code for Elevators and Escalators ${ }^{6}$, has contained emergency procedures that take the elevators out of service if smoke is detected in any lobby, in the elevator machine room, or hoistway. Under this condition the elevators are directed immediately to the ground floor where the doors open and the elevators are locked out (called Phase I recall). Subsequently, the responding fire department can reactivate individual cars under manual control using a special key (called Phase II operation).

Several issues concerning elevator use in emergencies, such as equipment reliability, communication, control, human behavior, and operational procedures, need to be addressed before this mode of vertical transportation can be implemented.

\section{FEATURES OF PROTECTED ELEVATORS}

\section{Safe and Reliable Equipment ${ }^{7,8}$}

If used in an emergency, an elevator needs to be able to withstand the problems associated with heat, smoke, and water from a fire. It is important to address issues of water tolerant elevator parts, fail-safe power, enclosed lobbies on all floors, and smoke protection of the equipment, hoistway, and lobby.

Because water can come from many different sources, such as sprinkler systems and fire fighting operations, the elevator must be equipped with water tolerant components. Water can possibly enter in an elevator shaft and short out safety components such as switches that prevent the doors from opening unless there is a car present, and even compromise the safety brake. Elevators can be designed to operate on the outside of buildings, so it is clear that water-tolerant technology is available and used today.

Another reliability issue is emergency power for the elevators if the main power fails. Current codes require at least one elevator that serves every floor to be provided with emergency power. If the power and control wiring is installed within the hoistway the elevator would continue to operate as long as the hoistway was intact.

To protect occupants from the fire while awaiting the elevator and provide an area of refuge for people with disabilities, enclosed lobbies should be provided on each floor of the building. The lobby also protects the hoistway from direct exposure to the fire and smoke that 
might threaten the elevator car moving past the floor of the fire. These lobbies would require at least 1 hour fire rated, smoke tight enclosures (assuming a fully-sprinklered building).

Elevators would be installed in a smokeproof shaft constructed to a 1 hour fire resistance and pressurized against smoke infiltration. This would prevent smoke and heat from moving through the building via the shafts. The elevator lobby would be pressurized to protect it from smoke and to minimize pressure differences across the hoistway door that can jam the door mechanism.

\section{Emergency communication ${ }^{7,8}$}

Occupants and firefighters can communicate with the Fire Command Station via two systems, the emergency phone in the elevator car and a two-way voice communication system provided in the lobby. This allows the occupants in the lobby to remain informed of the status of any impending rescue. Further it allows the fire command personnel to understand the number and situation of the occupants on each floor waiting for the elevators.

\section{Control}

The firefighter manually operating the elevator (Phase II operation) knows little about the fire conditions in other parts of the building, especially the conditions in the elevator machine room to which the controller is exposed. Using the newly developed fire service interface ${ }^{9,10}$ it is possible to provide real-time monitoring of elevator system status and any conditions that may threaten its continued safe operation. This interface was developed as a tool for incident management that can collect information from its own sensors and other building systems (through a common communication protocol such as BACnet) and display the information in a format common to all manufacturers' systems. The interface further supports specific control functions so that the operator could manually initiate recall if any monitored parameters exceed the allowable operating envelope.

Because continuous monitoring of the system is crucial to safe and reliable operation it would employ a triple redundant communication pathway. The fire alarm system is currently required to incorporate two, redundant communication trunks usually run up the two stairways. Either trunk is sufficient for the full system operation and two-way communication to the entire building. While these trunks are "remote" it is possible that a single event could sever both trunks, rendering the portion of the system above the breaks inoperable. By providing a third wireless link between the bottom (generally the fire command center) and the top of the system, this should maintain full operation of the system if both trunks fail. This would add little cost, high reliability, and can be done with current technology. Emergency power could be supplied by conductors run up the hoistway, so that power is available as long as the hoistway is intact.

\section{EGRESS SIMULATIONS}

In order to quantify the increase in efficiency of fire department access and egress via elevators, two studies were performed. The first involves fire department access to a fire floor in a high-rise building. The fire department access times using elevators were compared with access times using stairs. The second case study reviews work done at NIST in the early 90 s to show the benefit of elevators for egress in four GSA buildings ${ }^{11}$.

\section{Firefighter Lift Case Study}

For this case study, the commercial building used was designed by a Dallas architectural firm and stretches 40 stories above ground with 4 parking levels below. A typical floor of the building contains approximately $3000 \mathrm{~m}^{2}\left(32,292 \mathrm{ft}^{2}\right)$ of floor space, with $500 \mathrm{~m}^{2}\left(5382 \mathrm{ft}^{2}\right)$ 
occupied by the core space. The core contains elevators, 2 stairwells, bathrooms, and mechanical closets.

The stairs are located diagonally across the core area from each other, each measuring $1.2 \mathrm{~m}$ (44 in) wide with $267 / 11$ steps per flight. The 7/11 terminology refers the height of the riser followed by the depth of the tread in inches, meaning that for each step, the riser height is $0.18 \mathrm{~m}$ (7 in) and the tread width is $0.28 \mathrm{~m}$ (11 in). The height of each floor is $4.5 \mathrm{~m}(15 \mathrm{ft})$, creating a

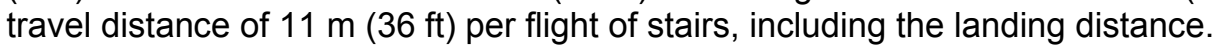

The elevators for a commercial building are assumed to have a speed of $5.08 \mathrm{~m} / \mathrm{s}(1000$ $\mathrm{ft} / \mathrm{min}$ ), per Table 10.7 of the Vertical Transportation Handbook ${ }^{12}$, and average acceleration of 1.5 $\mathrm{m} / \mathrm{s}^{2}\left(5 \mathrm{ft} / \mathrm{s}^{2}\right)$. For this case study, it is also assumed that a crew of 5 firefighters and their equipment will be traveling in the elevator and stairs together at one time. There are other characteristics that were assumed for the elevators that only affect the outcome of this case study in a trivial manner, such as the full car load, type of door, the door inefficiency, and door closing time.

For this case study, the fire originates on the 35th floor. Two groups of five firefighters are analyzed in their attempts to reach floor 35. Group 1 traverses 34 flights of stairs from street level to floor 35. Group 2 takes the elevators to the 33rd floor and travels the stairs an additional 2 flights. Hand calculations were made for firefighter travel up the stairs, while hand calculations and the ELVAC model were used to calculate the one-way elevator travel time from the lobby to the 33rd floor. ELVAC is a model used to calculate gross elevator evacuation time from buildings, and the hand calculated one-way elevator travel time was used to compare to ELVAC results.

The travel times calculated for both Groups in this case study neglect firefighter response time to the building, travel to the elevator or stairs from the building entrance, and time spent on the floor locating the point of attack, since both need to perform these activities in a fire situation.

To obtain firefighter travel speeds on stairs and horizontal building components, adjustments were made to data already recorded from people movement studies ${ }^{13,14,15}$. Frantzich's data show a range of velocities for upstairs movement from $(0.5$ to 0.75$) \mathrm{m} / \mathrm{s}$, Fruin gives values of $(0.5$ to 0.65$) \mathrm{m} / \mathrm{s}$ and Predtechenskii and Milinskii state a range of (0.33 to 0.92$)$ $\mathrm{m} / \mathrm{s}$ for low density situations. On one hand, these values may be low if studied during nonemergency situations, but alternatively, firefighters are typically equipped with heavy gear and equipment, on the order of 25 to $45 \mathrm{~kg}$ per firefighter, which should be accounted for.

The primary walking speed used in this case study for firefighter travel up stairs is 0.35 $\mathrm{m} / \mathrm{s}$ (adjusted from $0.5 \mathrm{~m} / \mathrm{s}^{13,14,15}$ for heavy gear). Another velocity used came from the New York Fire Department's rule of thumb that states firefighters average 60 seconds per floor (unobstructed flow), which is not sustainable throughout the ascent of high-rise buildings. 60 seconds per floor will be used as the conservative ascent time and $0.35 \mathrm{~m} / \mathrm{s}$ will be used as the other extreme. For horizontal building component speed, again the standard value of $1.2 \mathrm{~m} / \mathrm{s}^{16}$ was adjusted to a conservative value of $0.8 \mathrm{~m} / \mathrm{s}$ for gear and heavy equipment.

The breakdown of the elevator calculations are as follows (multiple values indicate a range of travel speeds for that calculation):

Group 1:

$\circ \quad$ The time to traverse 34 flights of stairs $=17 \mathrm{~min}$ at $0.35 \mathrm{~m} / \mathrm{s} ; 34 \mathrm{~min}$ at 60 seconds per flight (more conservative)

\section{Group 2:}

$\circ$ The one way travel time of the elevator from the lobby to the $33 \mathrm{rd}$ floor $=45 \mathrm{~s}$ with 5.08 $\mathrm{m} / \mathrm{s}$ elevator speed 
- The horizontal travel time from the elevator to the stairs on the $33 \mathrm{rd}$ floor $=30 \mathrm{~s}$ at 1.2 $\mathrm{m} / \mathrm{s} ; 45 \mathrm{~s}$ at $0.8 \mathrm{~m} / \mathrm{s}$ (more conservative)

- The time to traverse two flights of stairs $=60 \mathrm{~s}$ at $0.35 \mathrm{~m} / \mathrm{s} ; 120 \mathrm{~s}$ at 60 seconds per flight (more conservative)

After performing an additional calculation of adding the elevator travel, horizontal travel, and stair travel times together for Group 2, the results are as follows:

- Group 1: 17 to 34 min

- Group 2: 2.5 to $3.5 \mathrm{~min}$

It may seem obvious that an elevator would give some advantage in speed over stair use. But, when other factors, such as heavy gear and equipment and increased elevator technology play a role, elevators substantially become a more viable and constructive option. The difference between use of stairs (Group 1) and elevators (Group 2) for firefighter ascent ranged between (15 and 30 ) $\mathrm{min}$. This is a large difference in time lost to travel by stair, especially when a fire can grow significantly in a matter of minutes. By using elevators as the primary means of ascent, Group 2 was able to reach the fire at least 15 min earlier in this case study. In $15 \mathrm{~min}$, the environment can be less toxic for the occupants, the fire smaller, and the property less damaged. Also, Group 2 would have more energy to exert on fire fighting activities on the floor, when compared to Group 1. The limitation associated with the calculations was the estimation made in the firefighter movement speed, as shown by the range of results in both Groups.

\section{Elevator Evacuation Study}

In the early 90s, four General Services Administration (GSA) buildings were analyzed as potential applications to incorporate elevator evacuation ${ }^{11}$. The four selected were chosen to gather different building heights, elevator capabilities, and architectural characteristics.

For each building, evacuation times were calculated for the following conditions: 1) Total evacuation of the building by stairs only; 2) Total evacuation of the building by elevators only; and 3) Total evacuation of the building by various distributions of occupants to stairs and elevators (the optimal time value is shown in Table 1).

For the stair calculations, Klote et al. ${ }^{11}$ used the people movement methodology laid out by Nelson and MacLennan ${ }^{17}$. For these calculations, people on each floor were assumed to be waiting at the door to the stairs as soon as evacuation begins. For the elevator calculations, the ELVAC mode ${ }^{18}$ was used which simulates 2-stop elevator trips (movement occurs only between the specific floor and the ground floor) until the entire building has been evacuated. Again, for these calculations, people were assumed to be waiting at the closest elevator lobbies as soon as evacuation began.

Table 1 shows the characteristics of each building, including the number of floors, the number of stairs and elevators used, and the total population of each building. Also, the table shows the total evacuation time of the building (minutes) if only stairs were used, the total evacuation time if only the elevators were used, and the last column shows the optimal (fastest) gross evacuation time when a combination of stairs and elevators are used. Additionally, the Hoffman building and the White Flint North Building's analysis did not use the full capacity of elevators available to the building. The Hoffman building used 5 out of the 6 elevators in each group and the White Flint building used 4 out of the 6 . This was due to the fact that the existing elevator lobbies were incapable of holding as many people as would be discharged from all elevators simultaneously, and in that case, the evacuation capacity of the elevators is restricted by the size of the lobby. 
Table 1 Summary of GSA buildings and modeling results

\begin{tabular}{|l|l|l|l|l|l|l|}
\hline Building & Floors & $\begin{array}{l}\text { Stairs/ } \\
\text { Elevators }\end{array}$ & $\begin{array}{l}\text { Total } \\
\text { Population }\end{array}$ & $\begin{array}{l}\text { Evac. } \\
\text { Time by } \\
\text { Stairs }\end{array}$ & $\begin{array}{l}\text { Evac. } \\
\text { Time by } \\
\text { Elevators }\end{array}$ & $\begin{array}{l}\text { Optimal } \\
\text { Time by } \\
\text { Both }\end{array}$ \\
\hline Hoffman & 13 & 2/ 2 groups of 5 & 3506 & 14.9 min & $24.3 \mathrm{~min}$ & $11.2 \mathrm{~min}$ \\
\hline White Flint & 18 & 2/1 group of 4 & 1425 & 14.3 & 28.6 & 12.0 \\
\hline Jackson & 36 & 2/ 3 rises of 6 & 3021 & 23.1 & 16.5 & 12.8 \\
\hline GSA & 7 & 6/ 6 groups of 2 & 3621 & 7 & 17 & 6.3 \\
\hline
\end{tabular}

In each of the four buildings analyzed, the optimal time was reached by designing for a combination of floors or percentage of the floor dedicated to elevator usage while the other portion of the building evacuated by stairs. The use of elevators for evacuation made the largest contribution for the tallest building, which was the Jackson Federal building equipped with low, mid, and high rise elevators. The elevator designation that provided the optimal result for this building was the following: $65 \%$ of occupants from the mid and high rise floors, all occupants from floors 11 through 14 , and only $3 \%$ on floors 1 through 13 . All others in the Jackson building used the stairs. Even though the percentage distributions of occupants to stairs or elevators are quite detailed and complicated in this example, they are presented in order to show the generality that more occupants from the higher floors would use the elevator and more occupants from the lower floors would be distributed to the stairs. In an actual evacuation plan, the distribution of occupants to certain building components (stairs or elevators) should be more straightforward and easy to follow.

For the single rise elevator systems in the Hoffman, White Flint, and GSA buildings, the elevator designation that provided the optimal result was for total elevator evacuation from the upper floors of the building and stairs from the lower floors. Overall, it was shown that by using a combination of evacuation systems, stairs and elevators, the total evacuation time of the building can be reduced by a substantial amount with taller buildings. This study is limited by the averaged movement calculations used, and the assumption that all occupants were waiting at the stair or elevator lobbies as soon as the evacuation began. Also, another limitation is that occupants were not studied using both stairs and elevators during a single evacuation route.

\section{OPERATIONAL PROCEDURES}

Prior research and recent advances can address all of the technology issues identified as critical to the safe and reliable operation of elevators during fires. The remaining piece is the development of operating procedures for firefighter access, occupant egress, and rescue of the disabled that are sensitive to human factors issues and the need for these activities to occur simultaneously in tall buildings. Thus, the systems must be designed and used such that they do not interfere with all three uses.

\section{Firefighter Lifts}

Many US fire departments, Phoenix Fire Department for example ${ }^{19}$, have adopted operating procedures for fires in tall buildings that incorporate elevator access that are similar to those described in a draft CEN/ISO ${ }^{20}$ standard for firefighter lifts. The primary differences relate to the fact that most firefighter lifts are dedicated to this use and thus are immediately available to the fire service on their arrival. In the US, firefighters use passenger elevators that are either still operating or are waiting at the ground floor in Phase 1 recall.

The procedure is for the firefighters to use the lift to transport people and equipment to the protected lobby 2-3 floors below the fire floor where they stage for their suppression operations, as discussed earlier in the firefighter lift case study. The firefighters then move up the

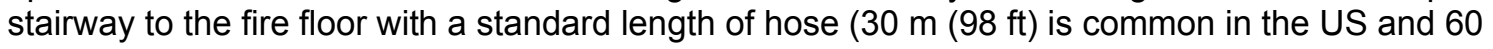


$\mathrm{m}(197 \mathrm{ft})$ in Europe), which is connected to the standpipe located in the stairs. This is important because once charged with water the hose becomes very stiff. The hose is usually looped down the stairs and back up so that it can be advanced onto the fire floor more easily. Working from the stairway also provides a protected area to which the firefighters can retreat in case the fire threatens them. The common hose lengths dictate the distribution of firefighter lifts within a building in the same way as the distribution of standpipes. For example, the New York City building regulations require standpipes located so that one is within $38 \mathrm{~m}(125 \mathrm{ft})(30.5 \mathrm{~m}(100 \mathrm{ft})$

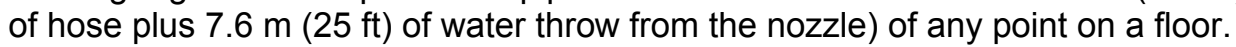

This operating procedure highlights the importance and interrelationship of the firefighter lift, protected lobbies, associated stairway and standpipe. These components form a system described in BS5588 ${ }^{2}$ as a firefighting shaft. The need for an associated stairway impacts on the arrangement of the components and on the designation of multiple cars of an elevator group as firefighter lifts.

\section{Occupant Egress Elevators}

As mentioned earlier, with only rare exceptions for special cases, elevators are taken out of service in fires and people are advised not to use elevators during fires. This policy does not represent a severe hardship for most buildings and occupants, but poses problems for people with (mobility) disabilities and for tall buildings where stairway egress times can be measured in hours. Coupled with the recent loss of public confidence in the structural stability of tall buildings caused by the collapse of the World Trade Center, there are increasing pressures to find ways in which elevator assisted egress can be provided safely.

Operational procedures for occupant egress elevators raise some interesting issues. First, the 30-year campaign cautioning the public against the use of elevators in the event of fire could severely lessen the occupants' confidence in the elevator system. Also, occupants could become impatient and overcrowd the elevator, which can cause the car to stop functioning and remain at the floor indefinitely ${ }^{21}$. Due to a fundamental lack of understanding of human use of elevators in emergencies, the time for which occupants will wait at an elevator is also unknown. Without proper preparation and training, occupants may become fearful of the dangerous conditions and decide to use the stairs. If the building is designed for a certain distribution of occupants between stairs and elevators, this could cause congestion in the stairway. It seems natural to suggest that fire wardens, who understand the capabilities of elevators in such emergencies, will lead the occupants to safety by following the planned evacuation procedure for their floor. The evacuation plan of a single rise elevator system could involve, for example, the use of elevator by the higher floors of the building, stairs by the lower floors, and the fire wardens on each floor directing his/her occupants to the correct evacuation route ${ }^{11}$. However, this implies that the fire wardens are present at the time of the emergency, have the appropriate training, and that the other occupants will follow their directions. Another concern for the evacuation procedures is whether or not the elevators attend to the disabled population first before evacuating other building occupants. This is crucial to understand because if a disabled occupant resides on a floor designated to take the stairs, the building should be aware of the occupant's needs and plan accordingly. Overall, it will be essential to understand the human behavior of the occupants during their interaction with the elevators. Work has been done in the human factors engineering and psychology fields about such a concern ${ }^{22,23,24}$, but much more work still needs to be completed to update current elevator use and concerns in light of September 11, 2001. For instance, will social groups within the building stay together throughout the duration of the evacuation, or will they allow group break-up during elevator descent? This is crucial because of the possibility of sending elevators without full capacity to the ground floor.

Egress elevators are most likely to be utilized in tall buildings, some with systems that are vertically zoned in 30- to 40 -floor sections. A concern for these tall buildings is how elevator evacuation would be operated with vertically zoned elevators. One example where this is being done is for an 88-story building currently under construction in Melbourne, Australia ${ }^{25}$. In the 
Eureka Place Tower, elevators in the vertical third of the building containing the fire are taken out of service and occupants all use the stairways to the next (lower) transfer floor where they board express elevators to grade. People with disabilities are assisted by firefighters in their dedicated lifts within the zone of origin in order to evacuate the building. This strategy is similar to the Petronas Towers where occupants above the sky bridge level use stairs to that level, move across to the other tower, and use the elevators to grade.

\section{Egress Assistance for People with Disabilities ${ }^{26}$}

Standards for firefighter lifts all include their use by firefighters to provide evacuation assistance for people with disabilities. Even in the US where there are no firefighter lift standards the building codes require accessible elevators (part of an accessible means of egress) that may be used by the fire service to evacuate people with disabilities. These elevators are normally used for travel in nonemergency situations, but may be used by the fire service for disabled occupant egress if an emergency occurs. The procedures generally are that such occupants proceed to the protected lobby (sometimes called an area of refuge) and request evacuation assistance through a two-way communication system (to the fire command center) provided. Exceptions are provided for fully sprinklered buildings.

Not covered is any procedure for coordinating the use of the lift for evacuation assistance with that of firefighting. First priority will be given to moving firefighters and equipment to the staging floor to allow the start of suppression operations. Then a firefighter would presumably be assigned to begin to collect waiting occupants in the lift under manual control. Command staff in the fire command center could inform the operator on which floors there are occupants waiting and these could be gathered in some logical order and taken to the ground floor. If there are more occupants than can be assisted in a single trip, there is a question about the order in which they are removed. Presumably, this would be done for the floors nearest the fire first, then above the fire and finally below the fire. Because these people are required to wait, it is especially important to provide this two-way communication system to the lobby so that they can be reassured that assistance is coming. The real-time monitoring system described earlier would assure that conditions in the occupied lobbies remain tenable.

\section{CONCLUSION}

Elevator use in emergency situations can provide safe and reliable operation both for fire service access and for occupant egress. A combination of reliable features, appropriate equipment, and effective operational procedures allows for successful evacuation of buildings via elevators and stairwells.

During a fire situation, the elevator needs to be able to withstand the effects of smoke, heat, and water. The current elevator technology can successfully perform this duty with the inclusion of water tolerant elevator parts, fail-safe power, lobbies of all floors, and smoke protection of the equipment, shaft, and lobby. Also, to aid in the use of elevators for fire department access and occupant egress, the use of emergency communication and remote manual control accompanied by continuous monitoring of the fire situation add another level of safety to elevator use. The Fire Command Station is continuously made aware of the increasing danger to occupants and the firefighters, and can change their evacuation, rescue, and firefighting strategies accordingly.

Elevators can make a significant time saving contribution to travel towards the fire for the fire service and the evacuation of the occupants in the building. The calculations done for the firefighter case study showed that firefighters traveled to the fire floor $15 \mathrm{~min}$ to $30 \mathrm{~min}$ faster via elevators when compared to stair access. The stair travel calculation, using two different estimates for the firefighter walking speeds, resulted in a range of travel time values differing by a factor of two. Research is needed in the area of firefighter movement to assess which travel 
times within the calculated range $17 \mathrm{~min}$ to $34 \mathrm{~min}$ are more accurate. Also, the evacuation time of occupants using a combination of stair calculations and ELVAC calculations for the elevators shows improvement over stair or elevator movement alone for the GSA examples studied. This is especially true for the taller building with multi-rise elevators.

Lastly, operational procedures are crucial in ensuring quick movement to safety for all occupants and emergency responders in the building. It is key for the occupants to recognize their main mode of travel (elevator or stairs) and understand the wait times associated. As part of this, other occupants may have priority, such as the disabled.

With all elements in place, safe and reliable features, operational procedures, and comfort in using elevators by occupants and firefighters, the use of elevators can provide a faster and safer route for evacuating a high-rise building.

\section{REFERENCES}

${ }^{1}$ Klote, J.H, Levin, B.M., and Groner, N.E., "Feasibility of Fire Evacuation by Elevators at FAA Control Towers," NISTIR 5445; 110 p. May 1994.

${ }^{2}$ Levin, B. M.; Groner, N. E., "Human Factors Considerations for the Potential Use of Elevators for Fire Evacuation of FAA Air Traffic Control Towers," NIST GCR 94-656; 23 p. August 1994.

${ }^{3}$ Comparison of worldwide lift (elevator) safety standards - Firefighters lifts (elevators), ISO/TR 16765:2002(E), International Organization for Standardization, Geneva, Switzerland, 2002

${ }^{4}$ Fire Precautions in the Design, Construction, and Use of Buildings, BS 5588 Part 5 1991, Code of Practice for Firefighting Lifts and Stairs, BSI, London

${ }^{5}$ Life Safety Code (NFPA 101) 2000, Nat Fire Prot Assn, Quincy, MA 02269

${ }^{6}$ Safety Code for Elevators and Escalators, ASME A17.1-2000, Amer Soc Mech Eng, NY, 2000

${ }^{7}$ Klote, J.H., Levin, B.M., and Groner, N.E., "Emergency Elevator Evacuation Systems," Fire and Accessibility, $2^{\text {nd }}$ Symposium, Proceedings, April 19,21, 1995, American Society of Mechanical Engineers, New York, NY, 131-150 pp., 1995.

${ }^{8}$ Chapman, E.F., "Elevator Design for the $21^{\text {st }}$ Century: Design Criteria for Elevators When Used as the Primary Means of Evacuation During Fire Emergencies. American Society of Mechanical Engineers (ASME); Elevators, Fire and Accessibility, $2^{\text {nd }}$ Symposium, Proceedings, April 19-21, 1995, New York, NY, 157-162 pp., 1995.

${ }^{9}$ Bukowski, R. W. Development of a Standardized Fire Service Interface for Fire Alarm Systems. National Institute of Standards and Technology, Gaithersburg, MD Fire Protection Engineering, 4,6-8, SFPE Bethesda, MD, Spring 2000.

${ }^{10}$ National Fire Alarm Code (NFPA 72) 2002, Nat Fire Prot Assn, Quincy, MA 02269, "Section 7.10 "Standard Fire Service Interface."

${ }^{11}$ Klote, J.H., Alvord, D.M., Levin, B.M., and Groner, N.E. (1992), Feasibility and Design Considerations of Emergency Evacuation by Elevators, National Institute of Standards and Technology, Gaithersburg, MD, NISTIR 4870. 
${ }^{12}$ Strakosch, G.R. (1998), The Vertical Transportation Handbook Third Edition, John Wiley \& Sons, Inc., New York, USA.

${ }^{13}$ Frantzich, H. (1996), Study of Movement on Stairs During Evacuation Using Video Analysis Techniques, Department of Fire Safety Engineering, Lund Institute of Technology, Lund University, March 1996.

${ }^{14}$ Fruin, J.J. (1987), Pedestrian Planning and Design, Revised Edition, Elevator World, Inc. Mobile, Alabama.

${ }^{15}$ Predtechenskii, V.M. and Milinskii, A.I. (1978), Planning for Foot Traffic Flow in Buildings, Amerind Publishing Co. Pvt. Ltd., New Delhi, 1978.

${ }^{16}$ Nelson, H.E. and Mowrer, F.W. (2002), Section 3, Chapter 14 Emergency Movement, The SFPE Handbook of Fire Protection Engineering, Third Edition, National Fire Protection

Association, Quincy, MA.

${ }^{17}$ Nelson, H.E. and MacLennan, H.A. (1995), Section 3, Chapter 14 Emergency Movement, The SFPE Handbook of Fire Protection Engineering, Second Edition, National Fire Protection Association, Quincy, MA.

${ }^{18}$ Klote, J.H. (1993), A Method of Calculation of Elevator Evacuation Time, National Institute of Standards and Technology, Gaithersburg, MD, Journal of Fire Protection Engineering, 5(3), 1993, pp. 83-95.

${ }^{19}$ Phoenix Fire Department Standard Operating Procedures, http://phoenix.gov/FIRE/20205.html.

${ }^{20}$ Safety rules for the construction and installation of lifts - Part 72:Firefighter lifts, CEN TC10, Committee for European Standardization, Brussels, BE.

${ }^{21}$ Klote, J.H., Deal, S.P., Donoghue, E.A., Levin, B.M., and Groner, N.E. (1993), Fire Evacuation By Elevators, Elevator World, June 1993.

${ }^{22}$ Levin, B.M, and Groner, N.E. (1995), Some Control and Communication Considerations in Designing an Emergency Elevator Evacuation System, Proceedings of the $2^{\text {nd }}$ Symposium on Elevators, Fire, and Accessibility, Baltimore, MD, April, 1995.

${ }^{23}$ Groner, N.E. (1995), Selecting Strategies for Elevator Evacuations, Proceedings of the $2^{\text {nd }}$ Symposium on Elevators, Fire, and Accessibility, Baltimore, MD, April, 1995.

${ }^{24}$ Groner, N.E. and Levin, B.M. (1992), Human Factors Considerations in the Potential for Using Elevators in Building Emergency Evacuation Plans, George Mason University, Washington, DC, July 1992.

${ }^{25}$ Aloi, S. and Rogers, J. (2002), Reach for the Sky, Fire Prevention \& Fire Engineers Journal, Vol. 62, No. 219, FPA London, April 2002.

${ }^{26}$ FEMA \& USFA, "Emergency Procedures for Employees with Disabilities in Office Occupancies," United States Fire Administration, Emmitsburg, Maryland, National Institute of Standards and Technology, Gaithersburg, MD, National Task Force on Life Safety and People with Disabilities, YR. 
Appendix E

Hazards Due To Smoke Migration Through Elevator Shafts -Volume I: Analysis And Discussion 
NIST GCR 04-864-I

\section{Hazards Due to Smoke Migration Through Elevator Shafts - Volume I: Analysis and Discussion. Final Report}

John H. Klote

John H. Klote, Inc.

43262 Meadowood Court

Leesburg, VA 20176 

NIST GCR 04-864-I

\section{Hazards Due to Smoke Migration Through Elevator Shafts - Volume I: Analysis and Discussion. Final Report}

Prepared for

U.S. Department of Commerce

Building and Fire Research Laboratory National Institute of Standards and Technology

Gaithersburg, MD 20899-8664

By

John H. Klote

John H. Klote, Inc. 43262 Meadowood Court

Leesburg, VA 20176

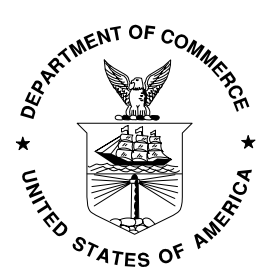

U.S. Department of Commerce

Donald L. Evans, Secretary

Technology Administration Phillip J. Bond, Under Secretary for Technology

National Institute of Standards and Technology Arden L. Bement, Jr., Director 


\section{Notice}

This report was prepared for the Building and Fire Research Laboratory of the National Institute of Standards and Technology under Contract number SB134-03-W-0477. The statement and conclusions contained in this report are those of the authors and do not necessarily reflect the views of the National Institute of Standards and Technology or the Building and Fire Research Laboratory. 



\section{Table of Contents}

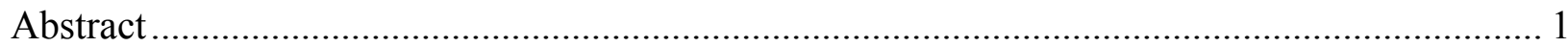

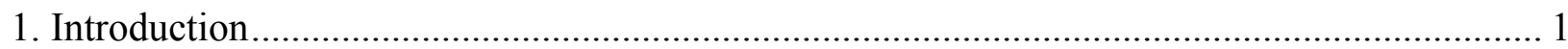

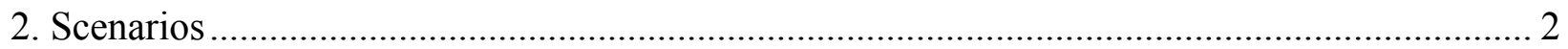

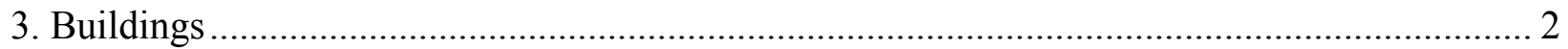

3.1 Fire Type

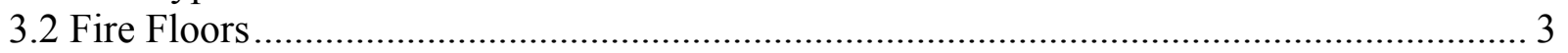

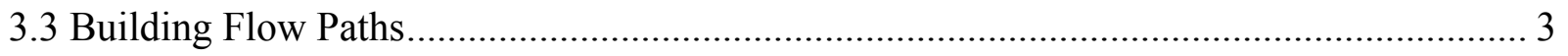

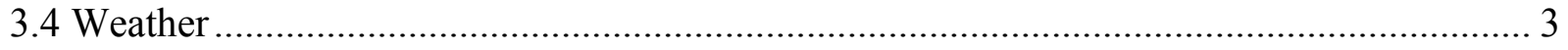

3.5 Building Temperature ................................................................................................ 3

3.6 Methods for Reduction of Hoistway Smoke Flow ……….............................................. 4

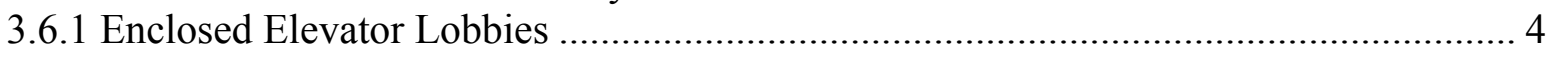

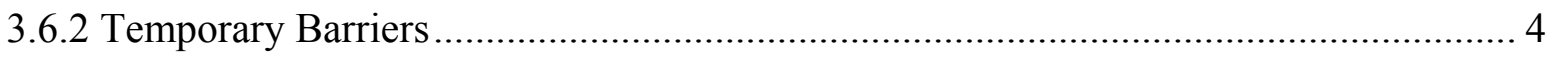

3.6.3 Positioning Of Elevator Cars ………………............................................................ 4

3.7 Arrangement of Doors ………………………….................................................. 4

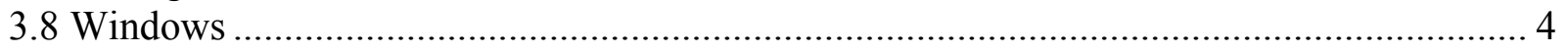

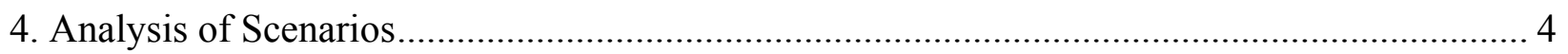

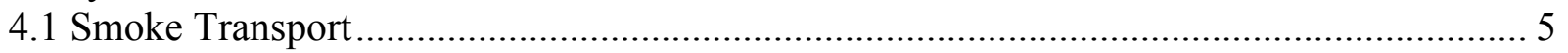

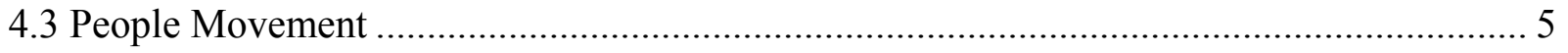

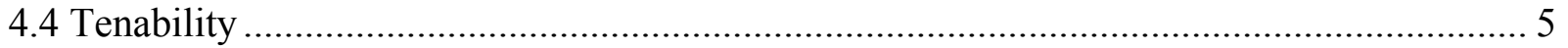

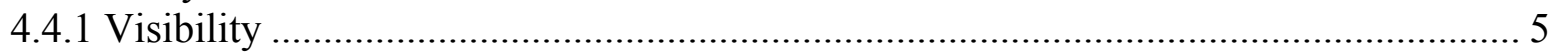

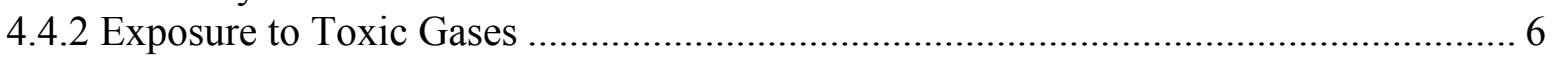

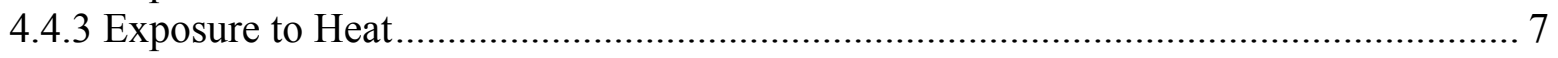

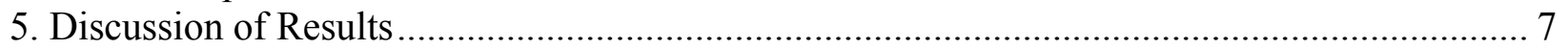

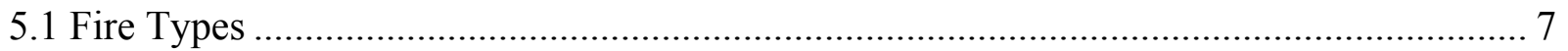

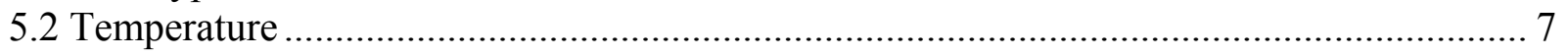

5.3 Methods of Reducing Smoke Flow through Hoistways ........................................................ 7

5.3.1 Enclosed Elevator Lobbies ................................................................................... 7

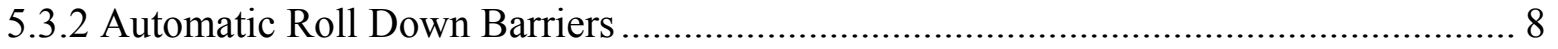

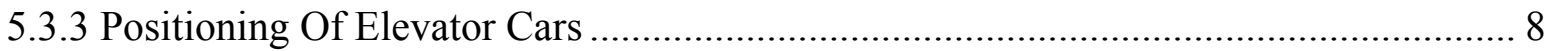

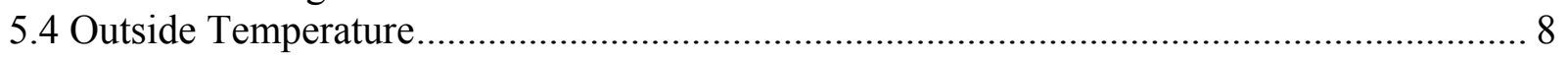

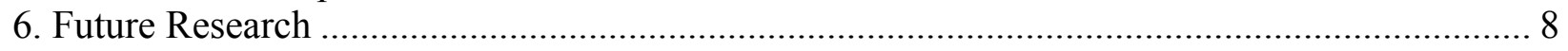

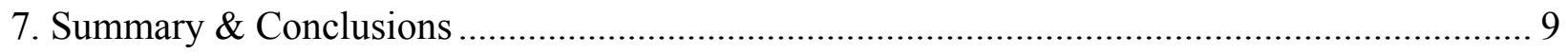

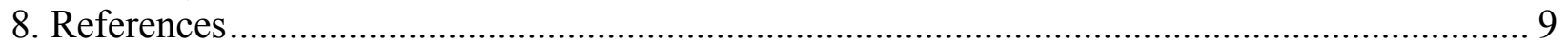

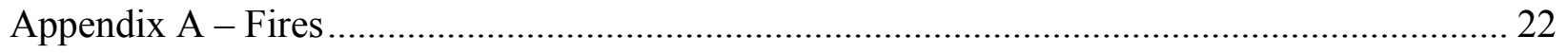

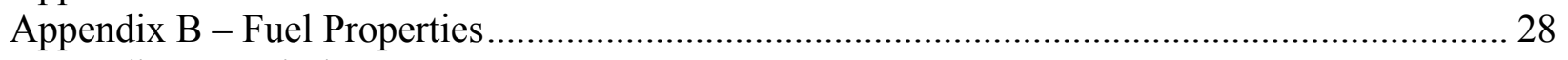

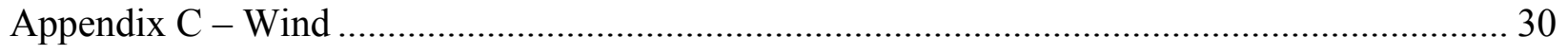




\section{List of Figures}

Figure 1. Typical Floor Plan of Building A....................................................................... 15

Figure 2. Typical Floor Plan of Buildings B and C ........................................................ 15

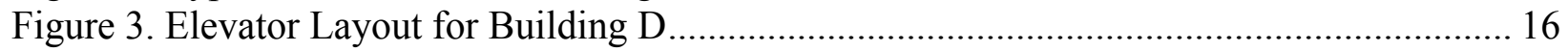

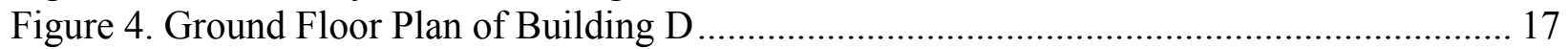

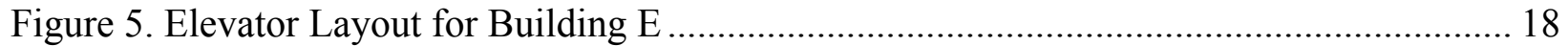

Figure 6. Ground Floor Plan of Building E ........................................................................ 19

Figure 7. HRR Curves of Fires Used in This Project ...................................................... 20

Figure 8. Thermal Tolerance of Naked Humans at Rest With Low Air Movement.................... 21

\section{List of Tables}

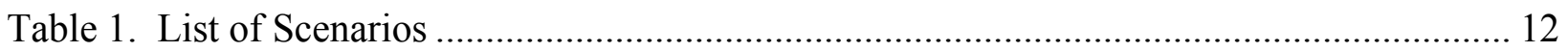

Table 2. List of Buildings ............................................................................................. 12

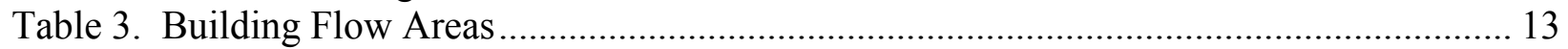

Table 4. Calculated Time (minutes) to Reach Tenability Specific Limits ................................ 14 


\title{
Hazards Due To Smoke Migration Through Elevator Shafts - Volume I: Analysis
}

\begin{abstract}
During building fires, smoke often migrates through elevator hoistways to locations remote from the fire. One of the reasons for concern is that a closed elevator door has a leakage area of approximately 0.056 square meters ( 0.6 square feet). This is a report of a project to study the hazards due to smoke flow through elevator hoistways. Smoke flow and the resulting hazard to life are analyzed for 27 scenarios in 5 buildings ranging from 6 to 58 stories. A fire scenario is the outline of events and conditions that are critical to determining the outcome of alternate situations and designs. In addition to the fire location and heat release rate, the fire scenario includes the status of the doors and other building systems. Other factors addressed are outside temperature, wind, height of elevator hoistway, height of building, leakage paths in the building, leakage of elevator doors, and other shafts. Stairwells are also included. Both sprinklered and non-sprinklered fires are included. Smoke transport throughout the buildings was simulated by a combination of zone fire modeling and network modeling. Options considered for mitigating hazards due to smoke flow through hoistways include (1) the use of enclosed elevator lobbies with automatic closing doors, (2) temporary barriers and (3) judicious positioning of cars within the hoistway. The results of the calculations showed that the use of enclosed elevator lobbies increased the time to reach hazard criteria significantly as compared the results without such lobbies. The use of automatic roll down barriers tended to increase the time to reach hazard criteria to some extent. The use of judicious positioning of elevator cars had no effect on the time to reach hazard criteria.
\end{abstract}

\section{Introduction}

During a building fire, smoke can travel through building shafts to threaten life at locations remote from the fire. The focus of this project is smoke movement through elevator shafts, and methods that might be used to reduce the resulting hazard to life.

After September 11, 2001, many people have indicated a need to reexamine basic concepts and consider major failure modes. While less extreme fires are also considered in this project, the focus is on the effects of a unsprinklered fire that involves an entire floor of a building. These large unsprinklered fires can have durations measured in hours. Because almost all modern buildings are sprinklered, this unsprinklered fire is a failure mode that could be due to a variety of causes (inadequate or no water supply, failure of a sprinkler system component, fire overpowering the sprinklers, arson, and terrorism). In the absence of comprehensive sprinkler performance data for the United States, a sprinkler failure rate between $1 \%$ and $4 \%$ may be considered ${ }^{1}$.

This project looks at the hazard to life due to smoke migration through elevator hoistways and the effectiveness of methods to reduce that hazard. These methods are: (1) enclosed elevator lobbies, (2) temporary barriers directly in front of elevator doors and (3) judicious positioning of elevator cars. Some of the parameters considered for this project are fire size, fire location, outside temperature and wind.

\footnotetext{
${ }^{1}$ Hasemi (1985) indicates sprinkler success rates in Japan of $98 \%$ for well maintained systems and $96 \%$ for poorly maintained systems. For Australia and New Zealand, Marryatt (1988) indicates a sprinkler success rate of $99 \%$ or greater for most occupancies.
} 
The time scale for large building fires often consists of a number of hours (Routley, Jennings and Chubb, 1991; Nelson, 1987, 1989; Best and Demers, 1982). Accordingly, the duration of the simulations for this project are two hours.

This report of this project is in two volumes. The first volume presents the analysis and discusses the results of that analysis. The second volume (Klote, 2003) consists of the complete results of the tenability calculations. The calculations of this project are for office buildings, but they may have application to other occupancies.

\section{Scenarios}

It is not possible to analyze all the scenarios of the relevant parameters, and a rational analysis is used for selection of scenarios. This rational approach is based on an understanding of how stack effect, buoyancy and wind effect force smoke flow in buildings.

1. When it is cold outside, stack effect (also called normal stack effect) results in upward airflow in building shafts. When a fire is below the neutral plane, normal stack effect can also drive smoke upward through shafts to floors above the neutral plane.

2. When it is hot outside, reverse stack effect results in downward airflow in shafts. For a fire above the neutral plane, reverse stack effect might result in downward smoke flow in shafts.

3. When hot smoke enters a shaft, the elevated temperature of the smoke increases the intensity of normal stack effect.

4. When hot smoke enters a shaft, the elevated temperature of the smoke decreases the intensity of reverse stack effect.

5. When all the building windows are closed, wind forces have a minimum effect on building smoke flow.

6. When the one or more fire room windows are open and the wind direction is toward the open windows, wind forces have a significant effect on building smoke flow.

The points above were kept in mind in development of the scenario list of Table 1.

\section{Buildings}

The buildings have a number of things in common. All of the buildings are office buildings. The floor to floor height is $4.0 \mathrm{~m}(13.1 \mathrm{ft})$ except for the ground floor which is $6 \mathrm{~m}(19.7 \mathrm{ft})$. The buildings have basements that house mechanical equipment. See Table 2 for a list of the buildings with information about the elevators. Figures 1 to 6 are schematics of the buildings.

\subsection{Fire Type}

This project used the following fires: (1) sprinklered fire, (2) room fire, and (3) floor fire. Details of these fires are provided in Appendix A, and the heat release rates (HRR) of these fires are shown in Figure 7. The sprinklered fire is representative of what might be expected of an office workstation fire that was successfully suppressed by a sprinkler system. The room fire can be thought of as a conference room with furniture and some storage materials in cardboard boxes. After ignition, the room fire grows until the room is fully involved in fire.

The floor fire can be thought of as starting in an open floor plan office space. Early in the fire development, windows start breaking. After this, the fire is considered to be controlled by the amount of ventilation air through the broken windows. On an occupied floor, it might be expected that the occupants 
would take action to prevent the fire from becoming so big. For any number of reasons, a floor might not be occupied during a fire, and development of such a fire becomes more likely.

\subsection{Fire Floors}

The fire locations for this project are on the second floor and the top occupied floor of the building. These fire locations were chosen to be above the neutral plane and below the neutral plane to allow for the effects of normal and reverse stack effect.

\subsection{Building Flow Paths}

Building leakage consists of: (1) construction gaps and cracks in walls, partitions and floors, (2) gaps around closed doors, and (3) large openings such as open doors and windows. The values of flow paths used for this project are listed in Table 3.

The leakage values of walls and floors are representative of values that can be expected for tight building construction as discussed by Klote and Milke (2002) and NFPA 92A (2000). It is generally recognized that the vent at the top of elevator shafts has an impact on airflow and smoke flow in buildings. Traditionally, these elevator vents have been required by codes, and the value of the vents used in this project are listed in Table 3.

The effects of door deflection due to exposure to high temperature gases are not included in the leakage values. While some data on warping of fire doors during furnace tests is provided by VanGeyn (1994), it is believed that there is insufficient information for estimation of the leakage of warped doors in this project.

Failure of compartmentation would require complex and time consuming analysis that is beyond the scope of this project. Such failure would be expected at some locations in buildings subjected to a fully developed fire that involved a large space such as one or more floors. It is anticipated that such compartmentation failure would result in increases in hazard to life. Even without compartmentation failure, the analysis of this project provides limited information about the hazard at locations remote from the fire and provides information about the relative effectiveness of various methods to reduce hazards due to smoke flow through hoistways.

\subsection{Weather}

The temperatures and wind velocities for many locations in the United States and other countries are listed in the ASHRAE Handbook of Fundamentals (ASHRAE 2001). The values of design temperature and wind speed vary over a wide range for these locations. The values of weather data chosen for this project were chosen such that they could occur at many locations in the United States. These values are:

$\begin{array}{ll}\text { Winter Outdoor Temperature } & -16^{\circ} \mathrm{C}\left(3^{\circ} \mathrm{F}\right) \\ \text { Summer Outdoor Temperature } & 35^{\circ} \mathrm{C}\left(95^{\circ} \mathrm{F}\right) \\ \text { Wind Speed } & 11 \mathrm{~m} / \mathrm{s}(25 \mathrm{mph})\end{array}$

\subsection{Building Temperature}

Generally, an HVAC system maintains the interior of a building in the range of about $21^{\circ} \mathrm{C}$ to $24^{\circ} \mathrm{C}\left(70^{\circ} \mathrm{F}\right.$ to $76^{\circ} \mathrm{F}$ ). For airflow and smoke flow in buildings, an important factor is the difference between the building temperature and that of the outdoors. For this project, the building temperature is the same as that of the shafts, and this building temperature is arbitrarily selected as $23^{\circ} \mathrm{C}\left(73^{\circ} \mathrm{F}\right)$. 


\subsection{Methods for Reduction of Hoistway Smoke Flow}

The following potential methods to reduce the smoke flow through hoistways are considered.

\subsubsection{Enclosed Elevator Lobbies}

Enclosed elevator lobbies consist of walls, doors, floors and ceilings that form a continuous barrier on all sides of an elevator lobby. It is the intent that the doors would automatically close in the event of a fire.

\subsubsection{Temporary Barriers}

Two types of temporary barriers can be considered: (1) automatic accordion barriers that form an enclosed elevator lobby and (2) automatic roll down barriers located directly in front of the elevator doors. For this project, it is considered that the accordion barriers have a fire resistance such that they would be expected to remain in place for some time when exposed to a fully developed fire. For this reason, the results of the simulations with conventional enclosed lobbies can be thought of as indicative of what would happen with enclosed lobbies formed with automatic accordion barriers.

The automatic roll down barriers would be installed above each elevator door such that they would roll down in the event of a fire. It is anticipated that such doors would be activated along with elevator recall. For this project, it is considered that the roll down barriers have a fire resistance such that they would be expected to remain in place when exposed to a fully developed fire.

The roll down doors of this project should be thought of as products that could possibly be developed and not as commercially available products. The flow area around the roll down doors (Table 3 ) used for this project was based on engineering judgment of what the leakage could be for such a door in an existing building.

\subsubsection{Positioning Of Elevator Cars}

The idea of judicious positioning of elevator cars is to locate the elevator cars in the hoistway at a floor above the fire floor to provide added resistance to smoke flow to floors above the elevator cars. This approach has the drawback that cars fixed in this position cannot be used mobilization or rescue by the fire service. However, this project addresses only the smoke restricting potential of the judicious positioning approach. When the judicious positioning approach is used, it is considered that all elevator cars will be at the floor above the fire floor. The leakage areas for judicious positioning of elevator cars (Table 3, Shafts with Cars in Place) are based on hoistway and other dimensions from NEII (1983).

\subsection{Arrangement of Doors}

For this project, it is considered that the stairwell doors and exterior building doors are closed.

\subsection{Windows}

For this project, the windows are considered closed except for fully developed floor fire where the fire breaks widows as discussed in Appendix A.

\section{Analysis of Scenarios}

The method of analysis can be considered a hazard analysis that evaluates the hazard to life for each scenario. Generally hazard analysis consists of (1) smoke transport calculations, (2) people movement (fire evacuation) calculations and (3) tenability calculations. For reasons discussed below, the analyses of this project do not include people movement calculations. 


\subsection{Smoke Transport}

The method of analysis of this project has been used for a number of applications. Ferreira $(1998,2002)$ describes use of this method for design applications, and Hadjisophocleous, Fu and Lougheed (2002) use this method as part of a study of smoke flow in a stair shaft. Klote (2002a) used the method to evaluate the hazard due to various combinations of open stairwell doors. Klote (2002b) and Klote and Milke (2002) also provide information about use of this method.

The smoke transport calculations were done by a combination of CONTAMW (Walton 1997; Dols, Denton and Walton 2000) and CFAST (Peacock, et al. 1993). The approach is to use CFAST to simulate the fire and flow of combustion products to adjacent spaces, and to use CONTAMW for unsteady flow of combustion products throughout the building. Numeric realities limit CFAST simulations to a relatively small number of rooms. However, CONTAMW can be used to simulate flows in buildings of hundreds and possibly thousands of rooms and other spaces.

CONTAMW is a network airflow program that can simulate contaminant flow. The model was developed for indoor air quality, but it has been extensively used for smoke management applications. CONTAMW solves the continuity of mass equation for a network that represents a building, and it can solve the concentration equations to calculate the concentration of one or more contaminants that flow through the network. For fire applications, the major shortcoming of CONTAMW is that it has no energy equation so it is unable to calculate the temperature of the spaces in the building. The temperature used in CONTAMW simulations are based on the results of CFAST simulations for spaces near the fire. CONTAMW Version 2 was used to allow the use of unsteady temperatures.

CFAST is a two zone fire model. In such a model, the gases in a room are represented two zones: (1) an upper layer of hot smoke and (2) a lower layer of relatively uncontaminated air. In the fire room, a smoke plume rises above the fire and flows into the upper layer. Also, smoke can flow from one room to another.

\subsection{People Movement}

The hazard of exposure to toxic gases depends on the exposure time. Fire evacuation calculations or simulations of people movement can be used to predict exposure times. A more conservative alternative is to consider the safety of people with mobility limitations who would need to stay in one place for the duration of the fire. For this project, this alternative is used with a 30 minute fire duration.

\subsection{Tenability}

The proprietary computer program, SMOKE4, was used for this project to make the fractional effective dose (FED) and visibility calculations described in this section. The FED is a used to predict the toxic effect of exposure to combustion gases. Tenability calculations consist of evaluating visibility and the effects of exposure to toxic gases and heat. While lack of visibility does not in itself result in fatality, it disorients people, and this interferes with evacuation and prolongs exposure time. Exposure to heat can either be direct exposure to hot gases or exposure to radiant flux, but exposure to hot gases is the primary form of heat exposure for the scenarios of this project.

\subsubsection{Visibility}

For any instant, the visibility can be calculated from

$$
S_{i}=\frac{K}{2.303 \delta_{m} C_{i}}
$$

where

$S_{i} \quad=$ visibility at the end of interval $i, \mathrm{~m}(\mathrm{ft}) ;$

$K=$ proportionality constant ( 8 for illuminated signs, and 2 for non-illuminated signs); 
$\delta_{m}=$ mass optical density, $\mathrm{m}^{2} / \mathrm{g}\left(\mathrm{ft}^{2} / \mathrm{lb}\right)$

$C_{i}=$ concentration of material burned in interval $i, \mathrm{~g} / \mathrm{m}^{3}\left(\mathrm{lb} / \mathrm{ft}^{3}\right)$.

The mass optical density depends on the material burned and combustion conditions (flaming or pyrolysis). Mulholland (2002) provides optical densities of a number of materials, and these values range from $0.12 \mathrm{~m}^{2} / \mathrm{g}\left(590 \mathrm{ft}^{2} / \mathrm{lb}\right)$ to $1.4 \mathrm{~m}^{2} / \mathrm{g}\left(6800 \mathrm{ft}^{2} / \mathrm{lb}\right)$. It is well known that flaming combustion of polyurethane produces a dense black smoke, and this smoke has a mass optical density of $0.33 \mathrm{~m}^{2} / \mathrm{g}(1600$ $\left.\mathrm{ft}^{2} / \mathrm{lb}\right)$. For this project, the mass optical density was chosen as $0.33 \mathrm{~m}^{2} / \mathrm{g}\left(1600 \mathrm{ft}^{2} / \mathrm{lb}\right)$.

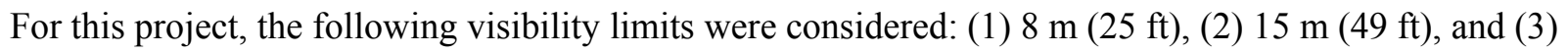
$30 \mathrm{~m}(98 \mathrm{ft})$. A visibility of $15 \mathrm{~m}(49 \mathrm{ft})$ or of $30 \mathrm{~m}(98 \mathrm{ft})$ would not be expected to interfere with people movement in the buildings of this project, but people would probably be aware that there is some smoke.

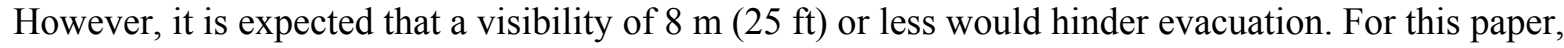
smoke with a visibility of $8 \mathrm{~m}(25 \mathrm{ft})$ or less is referred to as obscuring smoke or smoke that obscures vision.

\subsubsection{Exposure to Toxic Gases}

The methods that can be used to evaluate the effect of exposure to toxic gases are (1) the fractional incapacitating dose, (2) the N-gas model, and (3) the fractional effective dose (FED). Klote and Milke (2002) provide a detailed discussion of these methods. These methods are typically based on data from exposure times of 20 minutes, and they can be used be used to predict the toxic effects of exposures for somewhat different times. The exposure times of this project are 2 hours. The mathematical formulation of the first two methods is such that the predictions with this exposure time are of questionable value. However, the FED has a simple form that leads the author to believe that predictions using the FED for this exposure time can be applied for this project.

The mass concentration of material burned, $C_{i}$, was obtained from CONTAMW. The FED can be used to obtain an approximation of the effects of exposure to toxic gases.

$$
\mathrm{FED}=\frac{\sum_{i=1}^{n} C_{i} \Delta t}{\mathrm{LC} t_{50}}
$$

where

FED = fractional effective dose at the end of interval $i$ (dimensionless);

$C_{i} \quad=$ concentration of material burned at interval $i, \mathrm{~g} / \mathrm{m}^{3}\left(\mathrm{lb} / \mathrm{ft}^{3}\right)$;

$\Delta t \quad=$ time interval, $\min (\mathrm{min})$;

$\mathrm{LCt}_{50}=$ lethal exposure dose from test data, $\mathrm{g} \mathrm{m}^{-3} \min \left(\mathrm{lb} \mathrm{ft}^{-3} \mathrm{~min}\right)$.

This equation is written here for uniform time intervals as were produced by CONTAMW, and it evaluates the FED for the exposure time at the end of interval $i$ (exposure time is $n \Delta t$ ). An FED greater than or equal to one indicates fatality. The concentration is in mass of the material burned per unit volume. A FED of 0.5 can be considered a rough indication of incapacitation. For this project, the following terms are used as follows:
Tenable:
FED $<0.5$
FED less than 0.5.
Incapacitating: $\quad 0.5 \leq \mathrm{FED}<1$
FED equal to or greater than 0.5 and less than 1 .
Untenable:
$\mathrm{FED} \geq 1$
FED equal to or greater than 1 .

The $\mathrm{LC}_{50}$ is the concentration of airborne combustion products that is lethal to $50 \%$ of the subjects exposed for a specified time. The lethal exposure dose, $\mathrm{LC} t_{50}$, is the product of the $\mathrm{LC}_{50}$ and the exposure time. See Appendix B for the values of lethal exposure dose used in this project. 


\subsubsection{Exposure to Heat}

Generally contact with dry air of temperatures greater than $121^{\circ} \mathrm{C}\left(250^{\circ} \mathrm{F}\right)$ can be expected to result in skin burns. Also, contact with dry air at a temperature less than approximately $121^{\circ} \mathrm{C}\left(250^{\circ} \mathrm{F}\right)$ leads to hyperthermia. Figure 8 shows the data of Blockley (1973) for the thermal tolerance of naked humans at rest with low air movement. The thermal tolerance depends on moisture. For humid conditions, it can be seen that for a 15 minute exposure the tolerance is about $88^{\circ} \mathrm{C}\left(190^{\circ} \mathrm{F}\right)$, and for a 30 minute exposure the tolerance is about $60^{\circ} \mathrm{C}\left(140^{\circ} \mathrm{F}\right)$.

\section{Discussion of Results}

The results of the tenability calculations are listed in Volume II of this report, and these results are summarized in Table 4.

\subsection{Fire Types}

As expected, the sprinklered fire (scenario 1) did not result in any significant threat away from region of the fire. The fully developed room fires (scenarios 2, 18-21) were not a very significant threat at locations remote from the fire room.

The fully developed floor fires (scenarios 3-17, 22-27) resulted in significant threats at floors remote from the fire floor. For these fires, the time to reach smoke obscuration on floors remote from the fire ranged from 24 minutes to 100 minutes. While these times are long, they are representative of the times involved with some major multiple death fires.

\subsection{Temperature}

The temperatures calculated by CFAST are shown in Appendix A. At some distance from the fire, the smoke temperature drops to such an extent that it is not a concern. Because this project focuses on smoke flow through the hoistways, temperature exposure is only a minor issue. Further, the temperatures resulting from the sprinklered fire are not a concern. For the room fire, the fire room rapidly becomes untenable (Figure A1), and the open plan office space on the fire floor remains tenable for some time (Figure A2). For the floor fire, the temperature rises rapidly so that the floor quickly becomes untenable (Figure A3). However, the temperature in the enclosed elevator lobby remains tenable throughout the fire (Figure A5).

\subsection{Methods of Reducing Smoke Flow through Hoistways}

\subsubsection{Enclosed Elevator Lobbies}

Many of the scenarios included enclosed elevator lobbies (EEL on Table 1). The use of such lobbies, extends the time to obscuring smoke and untenable conditions on floors away from the fire. This can be shown in a number of scenarios. For example, scenarios 9 and 10 are the same except that scenario 9 has enclosed elevator lobbies, and scenario 10 does not (Table 4). It can be seen that with enclosed elevator lobbies, the time to obscuring smoke on the top floor increases from 31 to 66 minutes. Further, without enclosed elevator lobbies, the top floor becomes untenable in 56 minutes, and with elevator lobbies it does not become untenable during the 120 minute simulation.

For the scenarios with floor fires, the pairs of scenarios listed below are with and without enclosed elevator lobbies. It can be seen that with enclosed elevator lobbies the time to smoke obscuration increases significantly.

Increase in Time to Smoke Obscuration on Top

Scenarios $\quad$ Floor Due to Enclosed Elevator Lobbies 


$\begin{array}{lc}3,4 & 158 \% \\ 5,6 & 193 \% \\ 9,10 & 113 \% \\ 14,15 & 48 \% \\ 24,25 & 52 \%\end{array}$

\subsubsection{Automatic Roll Down Barriers}

A number of scenarios included automatic roll down barriers (TB on Table 1). For the scenarios with floor fires, the pairs of scenarios listed below are with and without automatic roll down barriers.

$\begin{array}{lc}\text { Scenarios } & \begin{array}{c}\text { Increase in Time to Smoke Obscuration on Top } \\ \text { Floor Due to Automatic Roll Down Barriers }\end{array} \\ 6,7 & 0 \% \\ 10,12 & 13 \% \\ 15,16 & 20 \% \\ 25,26 & 19 \%\end{array}$

It can be seen that with automatic roll down barriers, the time to smoke obscuration increases only slightly. The predicted performance of these roll down barriers is highly dependant on the leakage of such barriers, and roll down barriers with less leakage than used in this project would be expected to perform better.

\subsubsection{Positioning Of Elevator Cars}

A number of scenarios included positioning of elevator cars (JPC on Table 1). For the scenarios with floor fires, the pairs of scenarios listed below are with and without positioning of elevator cars.

$\begin{array}{lc}\text { Scenarios } & \begin{array}{c}\text { Increase in Time to Smoke Obscuration on Top } \\ \text { Floor Due to Automatic Roll Down Barriers }\end{array} \\ 6,8 & 0 \% \\ 10,13 & 0 \% \\ 15,17 & 0 \% \\ 25,27 & 0 \%\end{array}$

It can be seen that with positioning of elevator cars, the time to smoke obscuration remains unchanged from that without enclosed elevator lobbies.

\subsection{Outside Temperature}

All the scenarios discussed so far have been with the winter outside temperature. Scenarios 22 and 23 are with the summer outside temperature. As expected for these scenarios, the fire was on the top occupied floor, and there was little smoke flow to floors below.

\section{Future Research}

As already stated, this study did not include compartmentation failure. Future research is needed to evaluate the extent to which compartmentation failure would impact smoke flow through elevator hoistways.

The method of analysis used for this project used two computer models (CFAST and CONTAMW) as described earlier. This approach is cumbersome, time consuming, and yields questionable results for scenarios involving reverse stack effect. Research is needed to develop a fire model capable of simulating smoke flow and temperatures throughout high rise buildings. 


\section{Summary \& Conclusions}

The intent of this project is to study the hazard to life due to smoke migration through elevator hoistways and the effectiveness of various methods to reduce that hazard.

While compartmentation failure is beyond the scope of this project, such failure would be expected at some locations in buildings subjected to a fully developed fire that involved a large space such as one or more floors. It is anticipated that such compartmentation failure would result in increases in hazard to life. Even without compartmentation failure, the analysis of this project provides limited information about the hazard at locations remote from the fire and provides information about of the relative effectiveness of various methods to reduce hazards due to smoke flow through hoistways.

For the buildings and conditions analyzed, the following conclusions are made.

(1) The fully developed floor fires resulted in significant threats at floors remote from the fire floor. For these fires, the time to reach smoke obscuration on floors remote from the fire ranged from 24 minutes to 100 minutes. While these times are long, they are representative of the times involved with some major multiple death fires.

(2) Smoke from successfully sprinklered fires did not result in hazard conditions at floors away from the fire floor.

(3) The use of enclosed elevator lobbies increased the time to reach hazard criteria significantly (from $52 \%$ to $193 \%$ ) in comparison with analysis without such lobbies.

(4) The use of automatic roll down barriers tended to increase the time to reach hazard criteria (from $0 \%$ to $20 \%$ ) in comparison with analysis without such barriers. If tighter roll down barriers had been used for the analysis of this project, it is expected that they would have performed better.

(5) The use of judicious positioning of elevator cars had no effect on the time to reach hazard criteria.

\section{References}

ASHRAE 2001. Handbook of Fundamentals, American Society of Heating, Refrigerating and AirConditioning Engineers, Atlanta, GA.

Aynsley, R. M. 1989. The Estimation of Wind Pressures at Ventilation Inlets and Outlets on Buildings, ASHRAE Transactions, Vol. 95, Part 2, pp. 707-721.

Best, R. and Demers, D. P. 1982. Investigation Report on the MGM Grand Hotel Fire - Las Vegas, Nevada, November 21, 1980, National Fire Protection Association, Quincy, MA.

Blockley, W. V. 1973. Biology Data Book, Federation of American Societies for Experimental Biology, Bethesda, MD.

Dols, W. S., Denton, K. R. and Walton, G. N. 2000. CONTAMW User Manual, National Institute of Standards and Technology, Gaithersburg, MD.

Dyrbye, C. and Hansen, S. O. 1997. Wind Loads on Structures, Wiley, New York, NY.

Evans, D. D. and Stroup, D. W. 1986. Methods to Calculate the Response Time of Heat and Smoke Detectors Installed Below Large Unobstructed Ceilings, Fire Technology, Vol. 22, No. 1, pp. 54-65.

Evans, D. D., Stroup, D. W. and Martin, P. 1986. Evaluating Thermal Fire Detection Systems (SI Units), NBSSP 713, National Bureau of Standards, Gaithersburg, MD. 
Ferreira, M.J. 1998. Analysis of Smoke Control System Design Using a Computer-based Airflow Analysis, Pacific Rim Conference, Society of Fire Protection Engineers, Bethesda, MD.

Ferreira, M.J. 2002. Use of Multi-Zone Modeling for High-Rise Smoke Control Design, ASHRAE Transactions, Vol. 108, Part 2.

Hadjisophocleous, G. V., Fu, Z. and Lougheed, G. D. 2002. Computational and Experimental Study of Smoke Flow in the Stair Shaft of a 10-Story Tower, ASHRAE Transactions, Vol. 108, Part 1.

Hasemi, Y. 1985. Analysis of Failures of Automatic Sprinklers in Actual Fires, UJNR Panel on Fire Research and Safety, $8^{\text {th }}$ Joint Meeting May 13-21, 1985. Tsukuba, Japan, pp 794-807.

Heskestad, G. 1984. Engineering Relations for Fire Plumes, Fire Safety Journal, Vol. 7, No. 1, pp. 25-32.

Kandola, B. S. 1986a. Comparison of Wind Tunnel Pressure Measurements and Smoke Movement Computer Predictions Inside a Five-Story Model building, Fire Safety Journal, Vol. 10, No. 3, pp. 229238.

Kandola, B. S. 1986b. The Effects of Simulated Pressure and Outside Wind on the Internal Pressure Distribution in a Five-Story Building, Fire Safety Journal, Vol. 10, No. 3, pp. 211-227.

Kandola, B. S. 1986c. A Wind Tunnel Building Model for the Investigation of Smoke Movement Problems, Fire Safety Journal, Vol. 10, No. 3, pp. 203-209.

Klote, J. H. 1995. Design of Smoke Control Systems for Elevator Fire Evacuation Including Wind Effects, 2nd Symposium on Elevators, Fire, and Accessibility, Baltimore, MD April 19-21, 1995, ASME, New York.

Klote, J. H. 2002a. Tenability and Open Doors in Pressurized Stairwells - Final Report, ASHRAE 1203TRP, ASHRAE, Atlanta, GA.

Klote, J. H. 2002b. Smoke Management Applications of CONTAM. ASHRAE Transactions, Vol. 108, Part 2.

Klote, J. H. 2003. Hazards Due to Smoke Migration through Elevator Shafts - Vol. II: Results of Tenability Calculations, John H. Klote, Inc., Leesburg, VA.

Klote, J. H. and Milke, J. A. 2002. Principles of Smoke Management, ASHRAE, Atlanta, GA.

Liu, H. 1991. Wind Engineering - A Handbook for Structural Engineers, Prentice Hall, Englewood, NJ. MacDonald, A. J. 1975. Wind Loading on Buildings, Wiley, New York, NY.

Madrzykowski, D. 1996. Office Work Station Heat Release Rate Study: Full Scale vs. Bench Scale, $7^{\text {th }}$ International Interflam Conference, March 26-28, 1996, Cambridge, England. Proceedings. pp 47-55.

Madrzykowski, D. and Vittori, R. L. 1992. A Sprinkler Fire Suppression Algorithm, Journal of Fire Protection Engineering, Vol. 4, No. 4, pp. 151-164.

Marryatt, H. W. 1988. Fire - A Century of Automatic Sprinkler Protection in Australia and New Zealand 1986 - 1986, Australian Fire Protection Association, North Melbourne, Australia.

Mulholland, G. 2002. Smoke Production and Properties, SFPE Handbook of Fire Protection Engineering, National Fire Protection Association, Quincy, MA.

Nelson, H. E. 1987. An Engineering Analysis of the Early Stages of Fire Development - The Fire at the Dupont Plaza Hotel and Casino - December 31, 1986, National Institute of Standards and Technology, NISTIR 87-3560.

Nelson, H. E. 1989. An Engineering View of the Fire May 4, 1988 in the First Interstate Bank Building, Los Angeles, California, National Institute of Standards and Technology, NISTIR 89-4061. 
NEII, 1983. Vertical Transportation Standards: Standards for Elevators, Escalators and Dumbwaiters, National Elevator Industry, Inc., New York, NY.

NFPA 2000. Recommended Practice for Smoke Control Systems, NFPA 92A, National Fire Protection Association, Quincy, MA.

Peacock, R. D., et al., 1993. CFAST, the Consolidated Model of Fire Growth and Smoke Transport, National Institute of Standards and Technology, NIST Technical Note 1299.

Purser, D. A. 2002. Toxicity Assessment of Combustion Products, SFPE Handbook of Fire Protection Engineering, National Fire Protection Association, Quincy, MA.

Routley, G., Jennings, C. and Chubb, M. 1991. High-rise Office Building Fire - One Meridian Plaza, Technical Report, United States Fire Administration.

Shaw, C. T. and Tamura, G. T. 1977. The Calculation of Air Infiltration Rates Caused by Wind and Stack Action for Tall Buildings, ASHRAE Transactions, Vol. 83, Part 2, pp. 145-158.

Simiu, E. and Scanlan, R. H. 1996. Wind Effects on Structures: Fundamentals and Application to Design, $3^{\text {rd }}$ Ed., Wiley, New York, NY.

Tamanini, F. 1976. The Application of Water Sprays to the Extinguishment of Crib Fires, Combustion Science and Technology, Vol. 14, pp. 17-23.

VanGeyn, M. 1994. National Fire Door Fire Test Project. Positive Pressure Furnace Fire Tests. Technical Report. National Fire Protection Research Foundation, Quincy, MA, Report 6285, 201 p.

Walton, G. N. 1997. CONTAM96 User Manual, NISTIR 6056, National Institute of Standards and Technology, Gaithersburg, MD. 
Table 1. List of Scenarios

\begin{tabular}{ccccccc}
\hline \hline Scenario & Building $^{1}$ & $\begin{array}{c}\text { Fire } \\
\text { Type }^{2}\end{array}$ & $\begin{array}{c}\text { Fire } \\
\text { Floor }^{3}\end{array}$ & $\begin{array}{c}\text { Enclosed } \\
\text { Elev. Lobby }\end{array}$ & Weather $^{4}$ & $\begin{array}{c}\text { Alternative } \\
\text { Methods }^{5}\end{array}$ \\
\hline 1 & A & SP & 2 & Y & W-NW & None \\
2 & A & FDR & 2 & Y & W-NW & None \\
3 & A & FDF & 2 & Y & W-NW & None \\
4 & A & FDF & 2 & N & W-NW & None \\
\hline 5 & B & FDF & 2 & Y & W-NW & None \\
6 & B & FDF & 2 & N & W-NW & None \\
7 & B & FDF & 2 & N & W-NW & TB \\
8 & B & FDF & 2 & N & W-NW & JPC \\
\hline 9 & C & FDF & 2 & Y & W-NW & None \\
10 & C & FDF & 2 & N & W-NW & None \\
11 & C & FDF & 2 & N & W-W & None \\
12 & C & FDF & 2 & N & W-NW & TB \\
13 & C & FDF & 2 & N & W-NW & JPC \\
\hline 14 & D & FDF & 2 & Y & W-NW & None \\
15 & D & FDF & 2 & N & W-NW & None \\
16 & D & FDF & 2 & N & W-NW & TB \\
17 & D & FDF & 2 & N & W-NW & JPC \\
\hline 18 & D & FDR & 2 & Y & W-NW & None \\
19 & D & FDR & 2 & N & W-NW & None \\
20 & D & FDR & 2 & N & W-NW & TB \\
21 & D & FDR & 2 & N & W-NW & JPC \\
\hline 22 & D & FDF & 36 & Y & S-NW & None \\
23 & D & FDF & 36 & N & S-NW & None \\
\hline 24 & E & FDF & 2 & Y & W-NW & None \\
25 & E & FDF & 2 & N & W-NW & None \\
26 & E & FDF & 2 & N & W-NW & TB \\
27 & E & FDF & 2 & N & W-NW & JPC \\
\hline \hline
\end{tabular}

${ }^{1}$ See Table 2.

${ }^{2} \mathrm{SP}$ is a sprinklered fire. FDR is a fully developed room fire. FDF for fully developed floor fire.

${ }^{3} \mathrm{FDR}$ fires are located in a conference room on the floor indicated, and FDF fires are located in the open floor plan space on that floor.

${ }^{4} \mathrm{~W}-\mathrm{NW}$ for winter with no wind. S-NW for summer with no wind. W-NW winter with no wind. W-W winter with wind.

${ }^{5} \mathrm{~TB}$ for temporary barriers over elevator car doors. JPC for judicious positioning of cars within hoistways.

Table 2. List of Buildings

\begin{tabular}{cclc}
\hline \hline Building & $\begin{array}{c}\text { Number of } \\
\text { Stories }^{*}\end{array}$ & Passenger Elevators & $\begin{array}{c}\text { Service } \\
\text { Elevator }\end{array}$ \\
\hline \hline $\mathrm{A}$ & 6 & 1 Bank of 3 Elevators & None \\
$\mathrm{B}$ & 13 & 1 Bank of 6 Elevators & None \\
$\mathrm{C}$ & 16 & 1 Bank of 6 Elevators & None \\
$\mathrm{D}$ & 35 & $\begin{array}{l}\text { 3 Banks of 6 Elevators: Low, } \\
\text { Medium \& High Rise }\end{array}$ & 2 \\
$\mathrm{E}$ & 58 & $\begin{array}{l}\text { 3 Banks of 8 Elevators: Low, } \\
\text { Medium \& High Rise }\end{array}$ & 2 \\
\hline \hline
\end{tabular}

${ }^{*}$ Does not include mechanical penthouse. 
Table 3. Building Flow Areas

\begin{tabular}{|c|c|c|c|c|c|}
\hline Component & $\begin{array}{l}\text { Path } \\
\text { Type }^{1}\end{array}$ & $\begin{array}{l}\text { Path } \\
\text { Identifier }^{2}\end{array}$ & $\begin{array}{c}\text { Flow } \\
\text { Coefficient }^{3}\end{array}$ & \multicolumn{2}{|c|}{$\begin{array}{c}\text { Area } \\
\mathrm{m}^{2} / \mathrm{m}^{2}\left(\mathrm{ft}^{2} / \mathrm{ft}^{2}\right)\end{array}$} \\
\hline Exterior Wall & $\mathrm{O}$ & W-EXT & 0.65 & \multicolumn{2}{|c|}{0.00017} \\
\hline Exterior Wall Below Grade ${ }^{5}$ & $\mathrm{O}$ & W-UG & 0.65 & \multicolumn{2}{|c|}{0.000085} \\
\hline Interior Wall & $\mathrm{O}$ & W-INT & 0.65 & \multicolumn{2}{|c|}{0.00011} \\
\hline Elevator Wall & $\mathrm{O}$ & W-EL & 0.65 & \multicolumn{2}{|c|}{0.00084} \\
\hline Floor & $\mathrm{O}$ & FLOOR & 0.65 & \multicolumn{2}{|c|}{0.000052} \\
\hline Roof $^{5}$ & $\mathrm{O}$ & ROOF & 0.65 & \multicolumn{2}{|c|}{0.000026} \\
\hline Closed Doors: & & & & $\mathrm{m}^{2}$ & $\mathrm{ft}^{2}$ \\
\hline Single Door & $\mathrm{T}$ & DR-SI & 0.65 & 0.016 & 0.17 \\
\hline Double Door & $\mathrm{T}$ & DR-DO & 0.65 & 0.027 & 0.29 \\
\hline Elevator Doors ${ }^{6}$ & $\mathrm{~T}$ & DR-EL42 & 0.65 & 0.047 & 0.50 \\
\hline Large Elevator Doors ${ }^{7}$ & $\mathrm{~T}$ & DR-EL48 & 0.65 & 0.049 & 0.53 \\
\hline \multicolumn{6}{|l|}{ Open Doors: } \\
\hline Single Door & $\mathrm{T}$ & DR-SI-O & 0.35 & 1.95 & 21 \\
\hline Double Door & $\mathrm{T}$ & DR-DO-O & 0.35 & 3.90 & 42 \\
\hline \multicolumn{6}{|l|}{ Shaft Equivalent Area ${ }^{8}$ : } \\
\hline Stairwell & $\mathrm{O}$ & STAIR & 0.60 & 2.3 & 25 \\
\hline 3 Car Passenger Elevator & $\mathrm{O}$ & EL-P3 & 0.60 & 230 & 2500 \\
\hline 4 Car Passenger Elevator & $\mathrm{O}$ & EL-P4 & 0.06 & 360 & 3900 \\
\hline 2 Car Service Elevator & $\mathrm{O}$ & EL-S2 & 0.60 & 160 & 1700 \\
\hline \multicolumn{6}{|l|}{ Open Elevator Vent ${ }^{9}:$} \\
\hline 3 Car Passenger Elevator & $\mathrm{O}$ & EL-P3V & 0.32 & 0.70 & 7.5 \\
\hline 4 Car Passenger Elevator & $\mathrm{O}$ & EL-P4V & 0.32 & 1.05 & 11.3 \\
\hline 2 Car Service Elevator & $\mathrm{O}$ & EL-S2V & 0.32 & 0.52 & 5.6 \\
\hline Roll Down Barriers & $\mathrm{T}$ & ROLL & 0.65 & 0.011 & 0.12 \\
\hline \multicolumn{6}{|l|}{ Shafts with Cars in Place: } \\
\hline 3 Car Passenger Elevator & $\mathrm{O}$ & EL-P3C & 0.65 & 6.5 & 70 \\
\hline 4 Car Passenger Elevator & $\mathrm{O}$ & EL-P4C & 0.65 & 9.1 & 98 \\
\hline
\end{tabular}

\footnotetext{
${ }^{1} \mathrm{O}$ indicates an orifice path for which flow is in one direction. T indicates a two-directional flow path. The two-directional flow is used for doors, and the leakage is uniformly distributed over the height of the door.

${ }^{2}$ The path identifiers are used with CONTAMW for data input.

${ }^{3}$ The flow coefficient is defined as $m A^{-1 / 2}(2 \rho \Delta p)-1 / 2$ where $m$ is the mass flow through the path, $\rho$ is the density of gas flowing in the path, and $\Delta p$ is the pressure difference across the path.

${ }^{4}$ Areas for walls and floors are listed as area of flow path per unit of area of wall or of floor as appropriate.

${ }^{5}$ Due to lack of experimental data, the flow areas of the exterior wall below grade and the roof were estimated at half that of the exterior wall and the floor respectively.

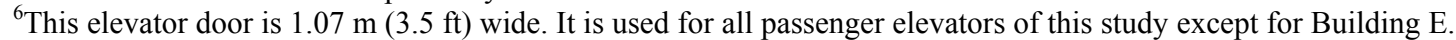

${ }^{7}$ This elevator door is $1.22 \mathrm{~m}$ (4.0 ft) wide. It is used for the passenger elevators of Building E and the service elevators.

${ }^{8}$ Shaft equivalent areas are used to calculate the pressure losses due to friction in shafts. For more information, see chapter 6 of Klote and Milke(2002).

${ }^{9}$ Vent area was calculated at $3.5 \%$ of the shaft area but not less than $0.28 \mathrm{~m}^{2}\left(3 \mathrm{ft}^{2}\right)$.
} 
Table 4. Calculated Time (minutes) to Reach Tenability Specific Limits

\begin{tabular}{|c|c|c|c|c|c|c|c|c|c|}
\hline \multirow[b]{2}{*}{ Scenario $^{1}$} & \multirow[b]{2}{*}{ Building } & \multicolumn{2}{|c|}{ Fire Floor ${ }^{2}$} & \multicolumn{2}{|c|}{$\begin{array}{l}\text { Top Floor of } \\
\text { Low Rise }\end{array}$} & \multicolumn{2}{|c|}{$\begin{array}{l}\text { Top Floor of } \\
\text { Mid Rise }^{2,4}\end{array}$} & \multicolumn{2}{|c|}{$\begin{array}{l}\text { Top Floor of } \\
\text { High Rise }^{2,5}\end{array}$} \\
\hline & & Visibility & FED & Visibility & FED & Visibility & FED & Visibility & FED \\
\hline 1 & $\overline{\mathrm{A}}$ & 5 & - & - & - & NA & NA & NA & NA \\
\hline 2 & A & - & - & - & - & NA & NA & NA & NA \\
\hline 3 & A & 1 & 6 & 62 & - & NA & NA & NA & NA \\
\hline 4 & A & 1 & 6 & 24 & 49 & NA & NA & NA & NA \\
\hline 5 & B & 1 & 6 & 88 & - & NA & NA & NA & NA \\
\hline 6 & B & 1 & 6 & 30 & 56 & NA & NA & NA & NA \\
\hline 7 & B & 1 & 6 & 30 & 55 & NA & NA & NA & NA \\
\hline 8 & B & 1 & 6 & 30 & 56 & NA & NA & NA & NA \\
\hline 9 & $\mathrm{C}$ & 1 & 6 & 66 & - & NA & NA & NA & NA \\
\hline 10 & C & 1 & 6 & 31 & 56 & NA & NA & NA & NA \\
\hline 11 & C & 1 & 6 & 40 & 79 & NA & NA & NA & NA \\
\hline 12 & C & 1 & 6 & 35 & 63 & NA & NA & NA & NA \\
\hline 13 & $\mathrm{C}$ & 1 & 6 & 31 & 56 & NA & NA & NA & NA \\
\hline 14 & D & 1 & 6 & - & - & 52 & 86 & 74 & - \\
\hline 15 & D & 1 & 6 & - & - & 48 & 82 & 50 & 89 \\
\hline 16 & D & 1 & 6 & - & - & 49 & 80 & 60 & 100 \\
\hline 17 & D & 1 & 6 & - & - & 48 & 82 & 50 & 89 \\
\hline 18 & $\mathrm{D}$ & - & - & - & - & - & - & - & - \\
\hline 19 & D & - & - & - & - & - & - & 20 & 40 \\
\hline 20 & D & - & - & - & - & - & - & 28 & 54 \\
\hline 21 & D & - & - & - & - & - & - & 20 & 40 \\
\hline 22 & $\mathrm{D}$ & 1 & 6 & 89 & - & - & - & 1 & 6 \\
\hline 23 & D & 1 & 6 & - & - & - & - & 1 & 6 \\
\hline 24 & E & 1 & 6 & - & - & 55 & 92 & 73 & - \\
\hline 25 & E & 1 & 6 & - & - & 48 & 85 & 48 & 85 \\
\hline 26 & E & 1 & 6 & - & - & 51 & 85 & 57 & 98 \\
\hline 27 & E & 1 & 6 & - & - & 48 & 85 & 48 & 85 \\
\hline
\end{tabular}

${ }^{1}$ For descriptions of the scenarios and locations of the fire floor, see Table 1.

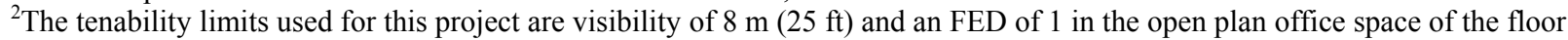
indicated.

${ }^{3}$ Buildings A, B and C have only one elevator rise, and data listed for these buildings is for the top occupied floor. For Building D, the top occupied floor of the low rise is for floor 13. For Building E, the top occupied floor of the low rise is for floor 23.

${ }^{4}$ For Building D, the top occupied floor of the mid rise is for floor 25. For Building E, the top occupied floor of the mid rise is for floor 42.

${ }^{5}$ For Building D, the top occupied floor of the high rise is for floor 35. For Building E, the top occupied floor of the high rise is for floor 58. 


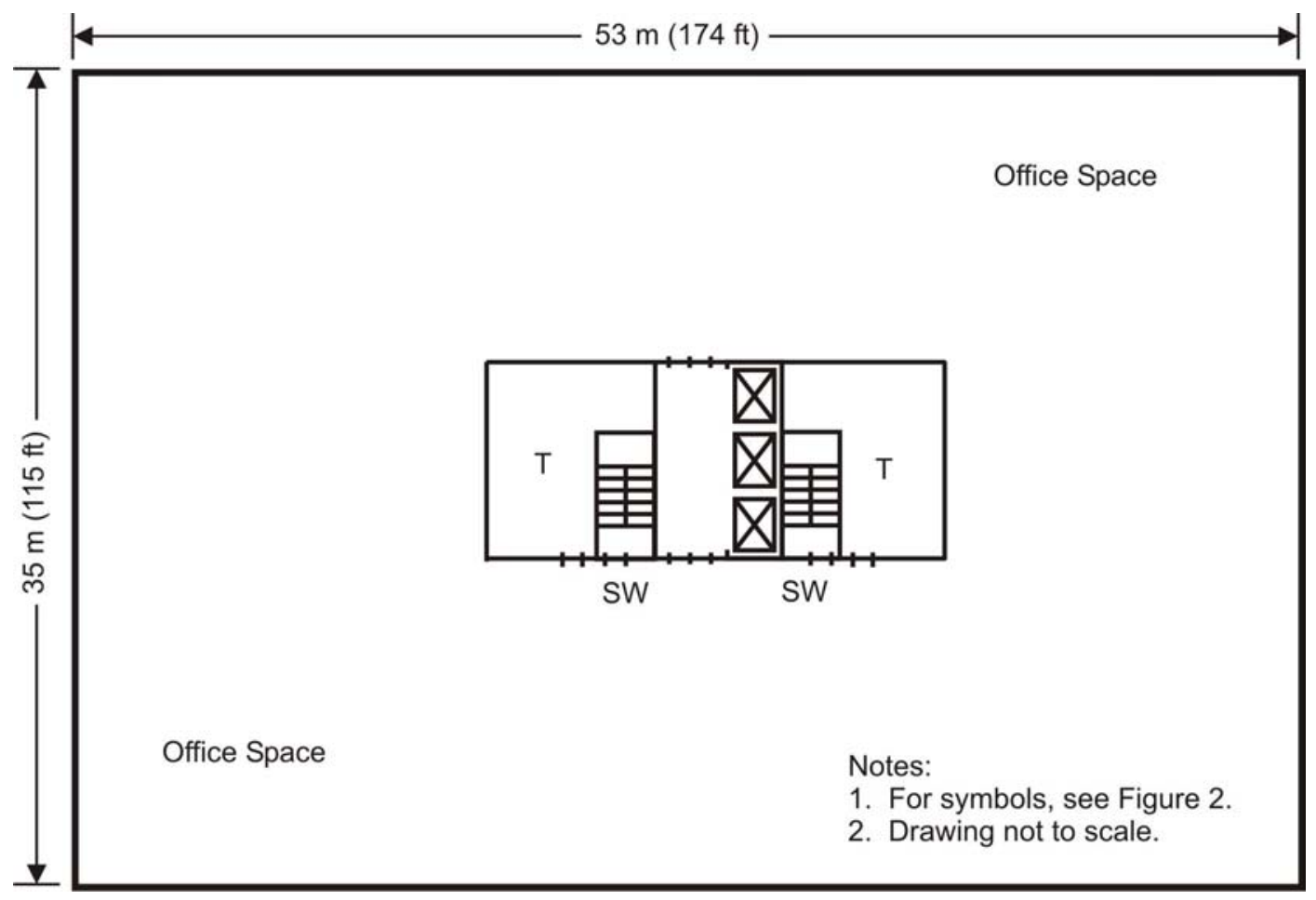

Figure 1. Typical Floor Plan of Building A

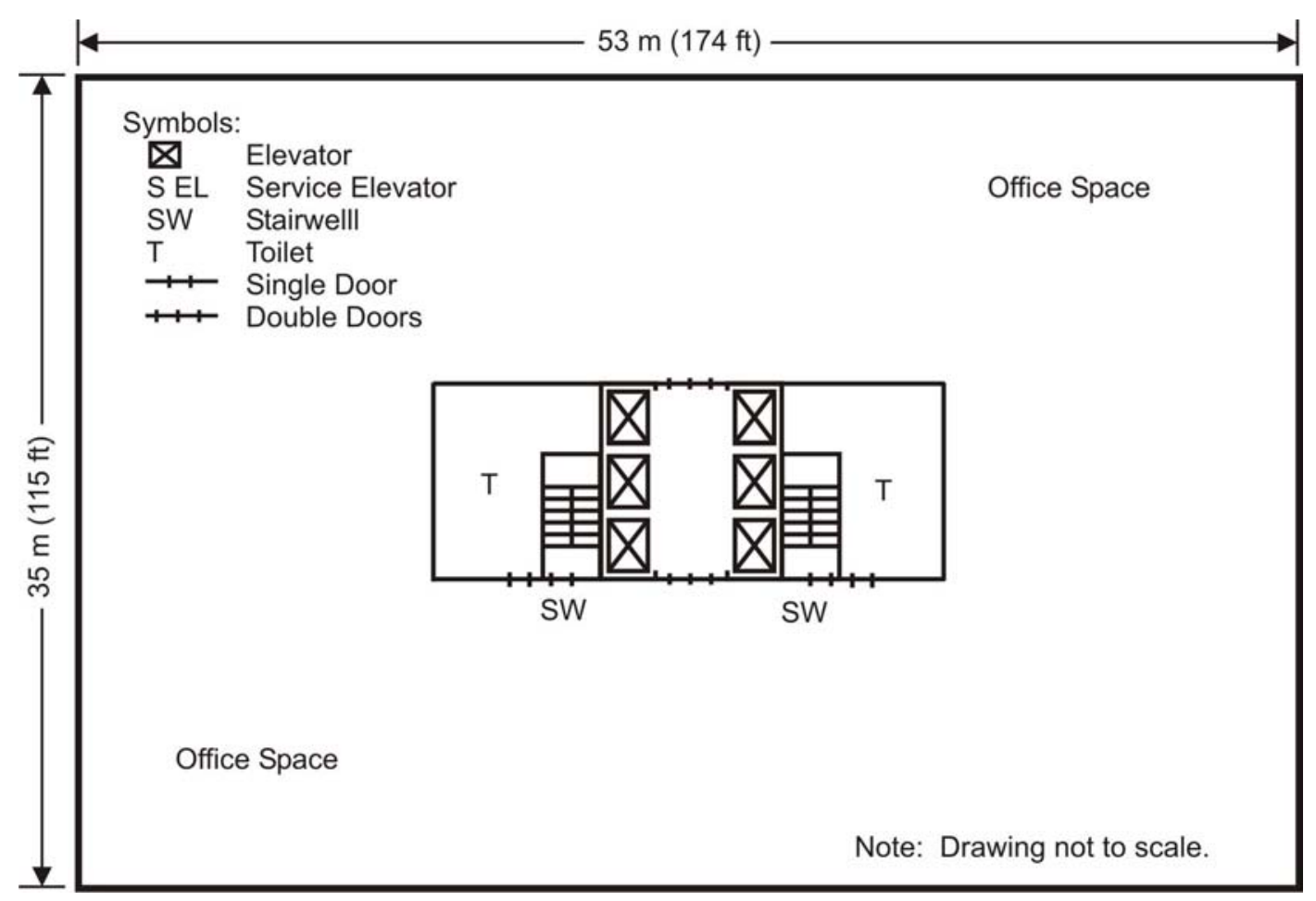

Figure 2. Typical Floor Plan of Buildings $B$ and $C$ 


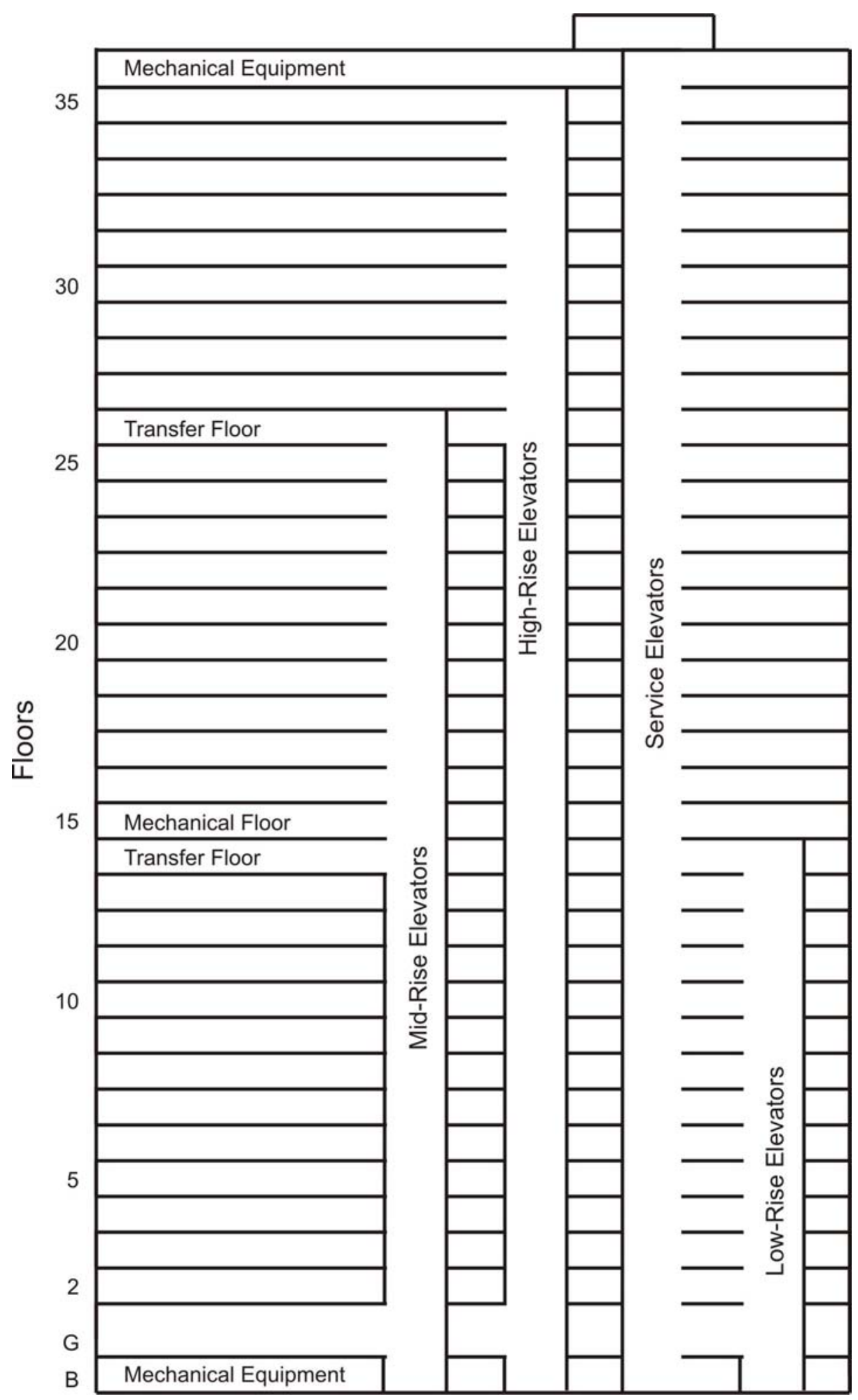

Figure 3. Elevator Layout for Building D 


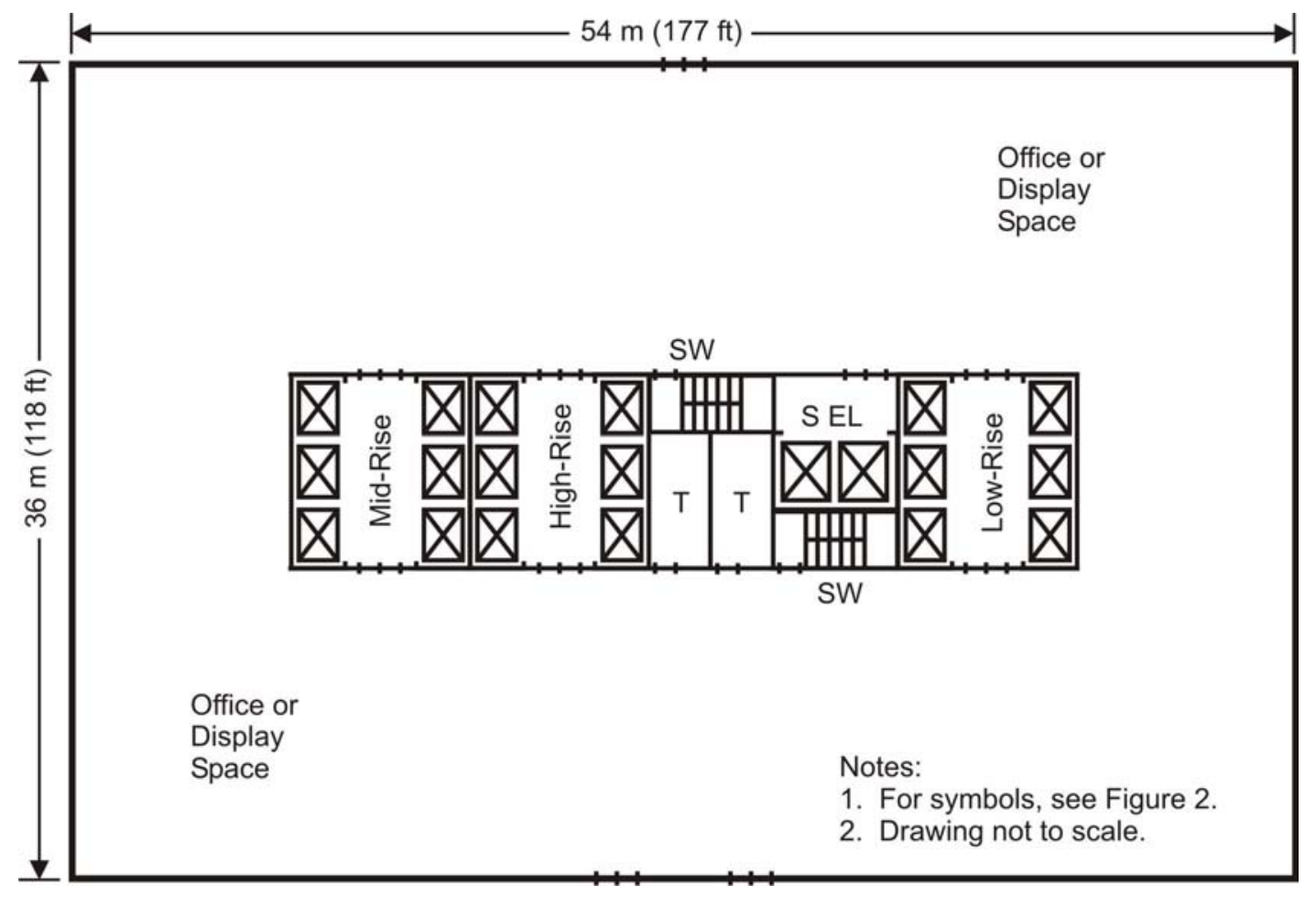

Figure 4. Ground Floor Plan of Building D 


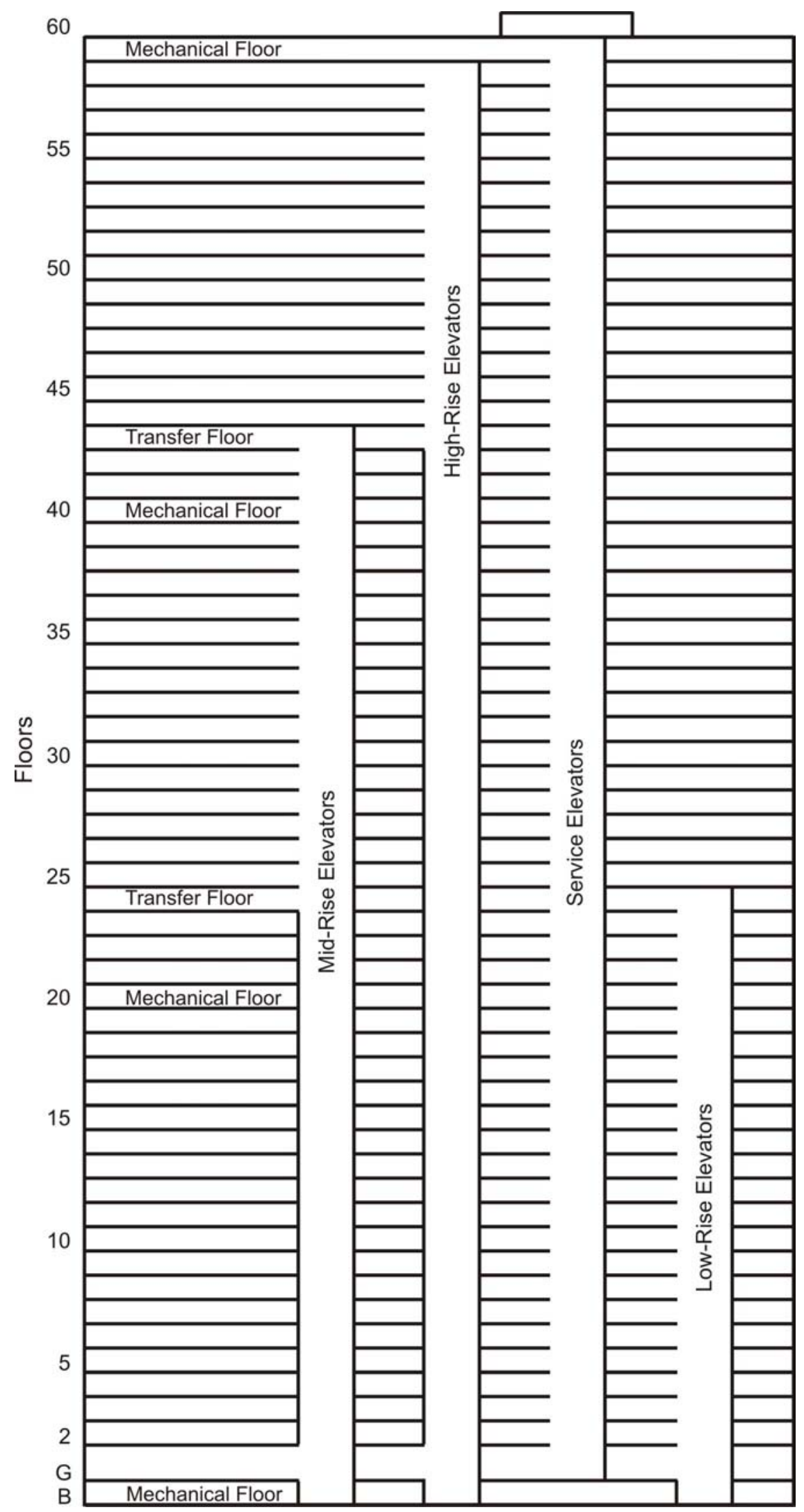

Figure 5. Elevator Layout for Building E 


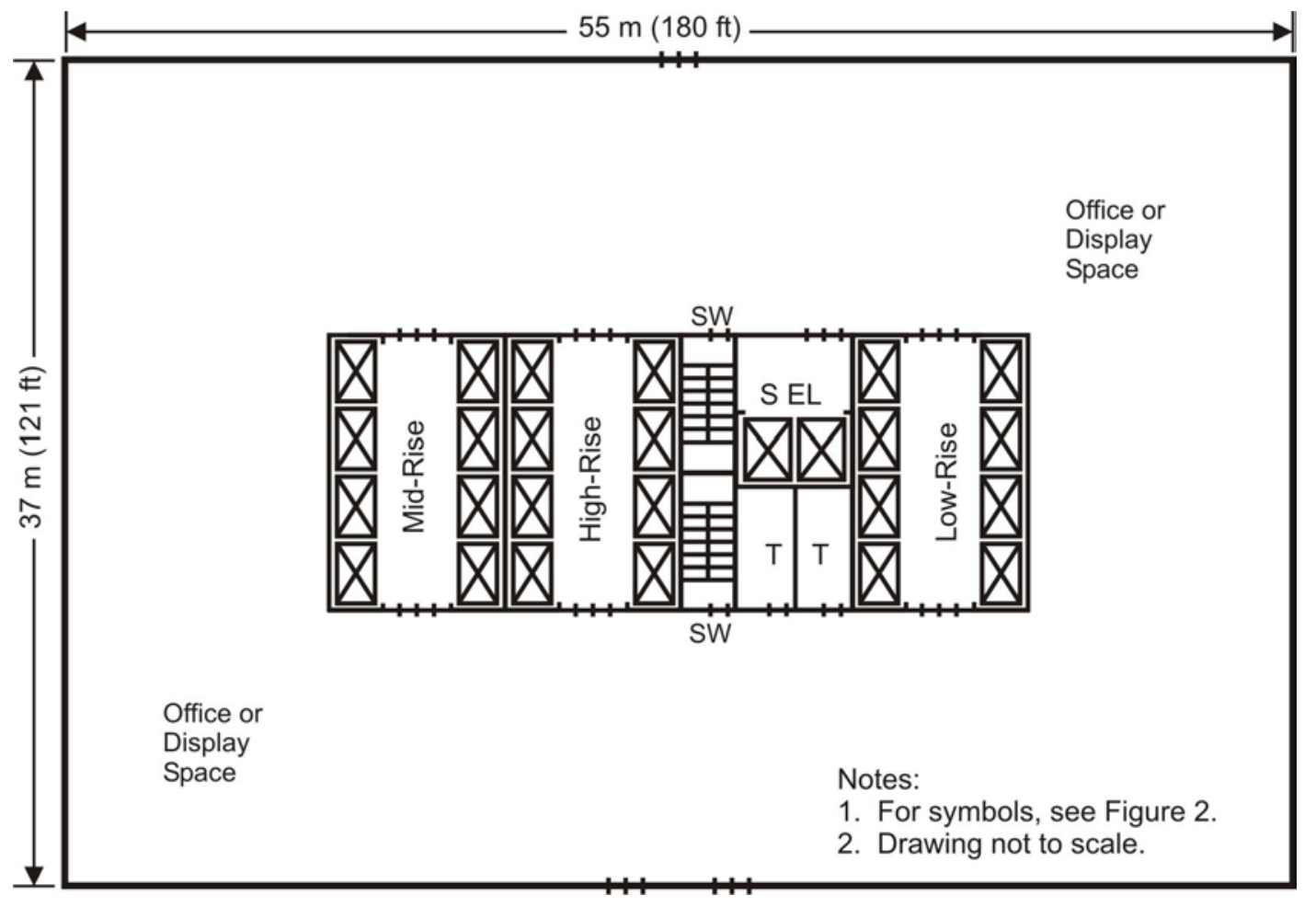

Figure 6. Ground Floor Plan of Building E 


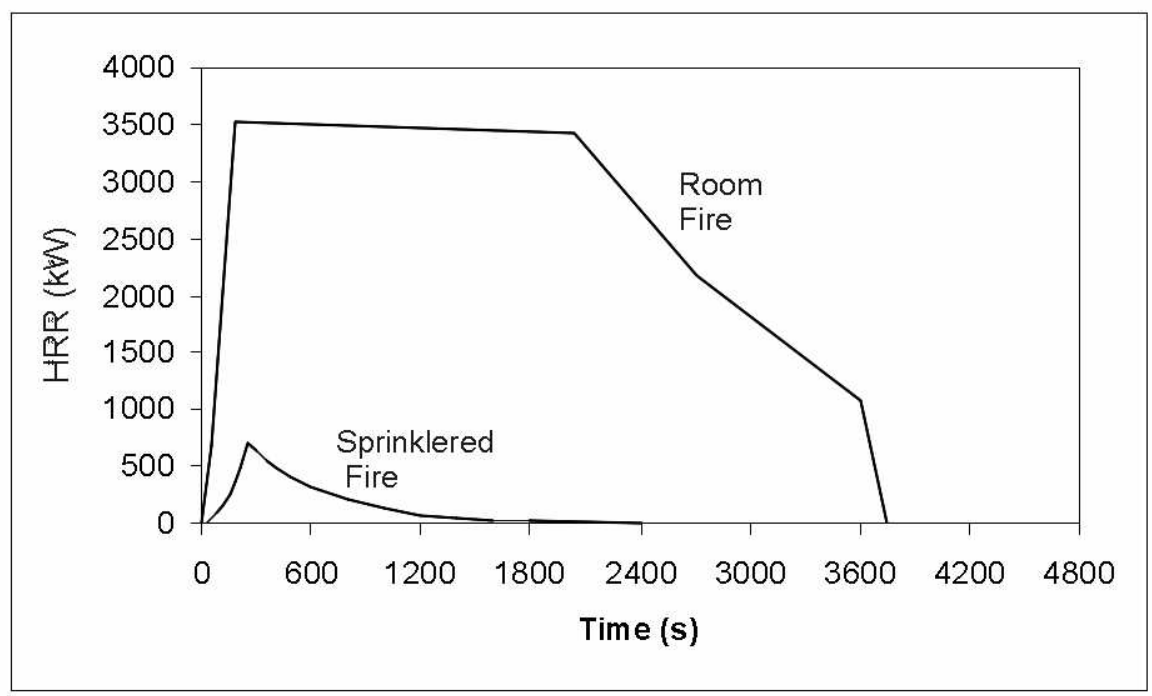

(a) HRR for sprinklered fire and room fire

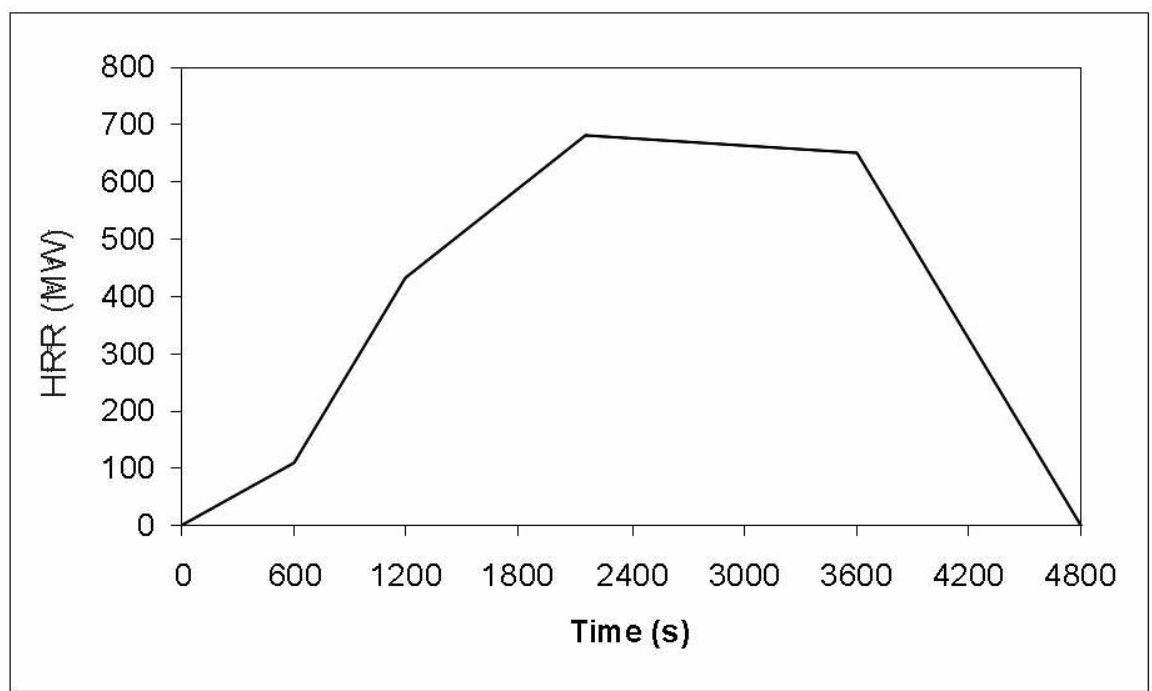

(b) HRR for floor fire

Figure 7. HRR Curves of Fires Used in This Project 


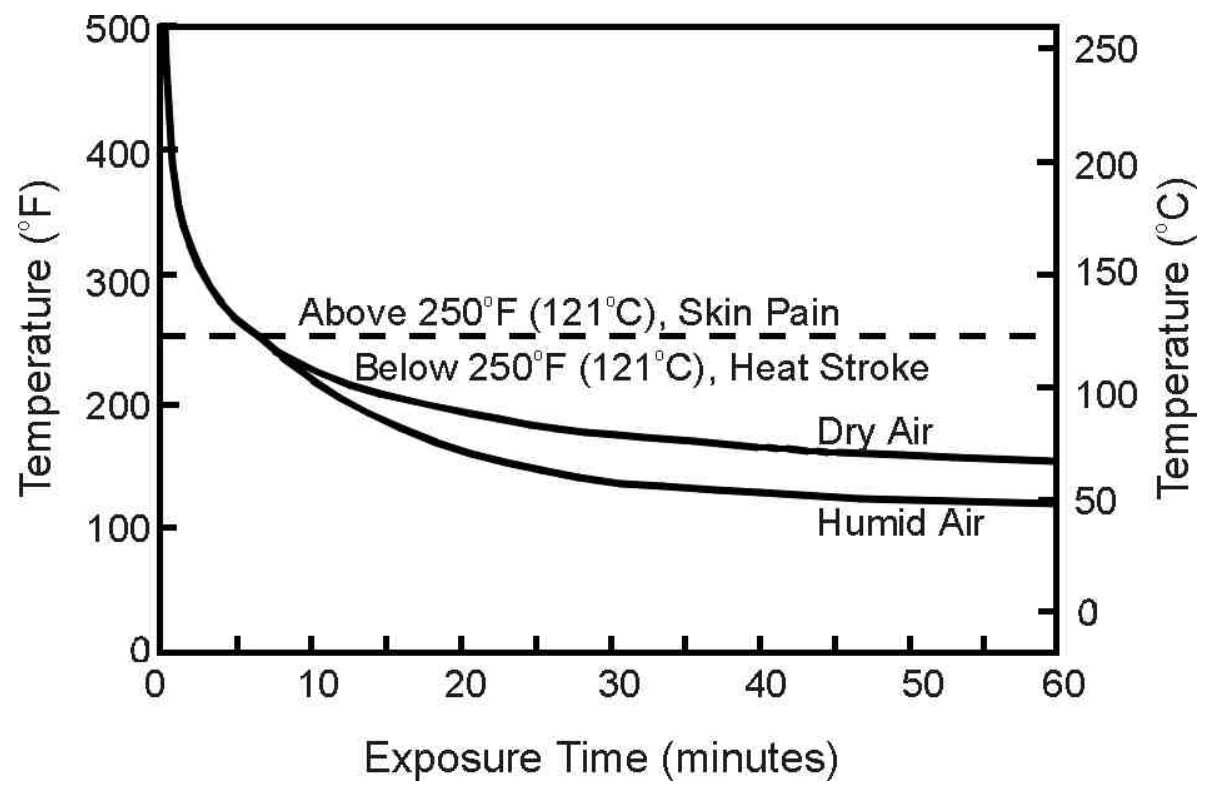

Figure 8. Thermal Tolerance of Naked Humans at Rest With Low Air Movement 


\section{Appendix A - Fires}

The fires considered for this analysis are: (1) sprinklered fire, (2) fully developed room fire, and (3) fully developed floor fire. These fires are discussed below.

\section{Sprinklered Fire}

Sprinklered fires generally proceed through an incubation period of slow and uneven growth followed by a period of established growth. Established growth is often represented by an idealized parabolic equation (Heskestad 1984).

$$
\dot{Q}=\alpha t^{2}
$$

where

$\dot{Q} \quad=$ heat release rate of fire, $\mathrm{kW}(\mathrm{Btu} / \mathrm{s}) ;$

$=$ fire growth coefficient, $\mathrm{kW} / \mathrm{s}^{2}\left(\mathrm{Btu} / \mathrm{s}^{3}\right)$;

$t \quad=$ time after ignition, $\mathrm{s}$.

Fires following this equation are called $t$-squared fires. It is generally recognized that consideration of the incubation period is not necessary for design of smoke management systems, and where $t$ is considered the time from effective ignition. In the CFAST zone fire model, the following SI version of the above equation is used to aid data input ${ }^{2}$

$$
\dot{Q}=1000\left(\frac{t}{t_{g}}\right)^{2}
$$

where

$\dot{Q} \quad=$ heat release rate of fire, $\mathrm{kW}$;

$t=$ time after effective ignition, $\mathrm{s}$;

$t_{g} \quad=$ growth time, $\mathrm{s}$.

When $t=t_{g}$, the above equation gives a value of $\dot{Q}=1000 \mathrm{~kW}$. The growth times used in CFAST are:

\begin{tabular}{lc} 
Growth Type & $t_{g}(\mathrm{~s})$ \\
\hline Slow & 600 \\
Medium & 300 \\
Fast & 150 \\
Ultra Fast & 75 \\
\hline
\end{tabular}

Madrzykowski (1996) conducted a series of fire tests of office workstations. The growth type that is closest to that of these workstation fires is medium growth with a growth time, $\operatorname{tg}$, of $300 \mathrm{~s}$. For this study, the sprinklered fire will have a growth stage of a medium t-squared fire.

For this study, the HRR is considered to decrease after sprinkler activation. This HRR decay after sprinkler actuation can be expressed as

$$
\dot{Q}=\dot{Q}_{a c t} e^{-\left(t-t_{a c t}\right) / \tau}
$$

\footnotetext{
${ }^{2}$ NFPA 92B (2000) and some other sources have a similar equation in English units: $\dot{Q}=1000\left(t / t_{g}\right)^{2}$ which gives $\dot{Q}=1000 \mathrm{Btu} / \mathrm{s}$ when $t=t_{g}$.
} 
where

$\dot{Q} \quad=$ post sprinkler actuation $\mathrm{HRR}, \mathrm{kW}(\mathrm{Btu} / \mathrm{s}) ;$

$\dot{Q}_{a c t} \quad=$ HRR at sprinkler actuation, $\mathrm{kW}(\mathrm{Btu} / \mathrm{s})$;

$t \quad=$ time from ignition, $\mathrm{s}(\mathrm{s})$;

$t_{\text {act }} \quad=$ time of sprinkler actuation, $\mathrm{s}(\mathrm{s})$;

$\tau \quad=$ time constant of fire suppression, $\mathrm{s}(\mathrm{s})$.

For a number of fuel packages likely to be found in offices, Madrzykowski and Vettori (1992) conducted sprinklered fire experiments with a spray density of $0.10 \mathrm{gpm} / \mathrm{ft}^{2}(0.07 \mathrm{~mm} / \mathrm{s})$ of water. They determined that a fire decay curve with a time constant of $435 \mathrm{~s}$ had a higher HRR than most of the sprinklered fires. Evans (1993) used this data and data for wood crib fires with sprinkler spray densities of $0.06 \mathrm{gpm} / \mathrm{ft}^{2}$ $(0.041 \mathrm{~mm} / \mathrm{s})$ and $0.097 \mathrm{gpm} / \mathrm{ft}^{2}(0.066 \mathrm{~mm} / \mathrm{s})$ from Tamanini (1976) to develop the following correlation

$$
\tau=\frac{C_{\tau}}{w^{1.85}}
$$

where

$w \quad=$ spray density, gpm $/ \mathrm{ft}^{2}(\mathrm{~mm} / \mathrm{s})$;

$C_{\tau} \quad=6.15(3.0)$.

While equation (A.4) has not been experimentally verified, it does allow us to adjust the decay time for sprinkler densities other than those of Madrzykowski and Vettori.

Sprinkler actuation depends on gas temperature and velocity near the sprinkler. In a fire a jet of hot gases flows radially from where the smoke plume intersects the ceiling. The response time index (RTI) was developed as a measure of sprinkler responsiveness that is independent of velocity. The RTI of standard sprinklers range from about 77 to $155 \mathrm{~m}^{1 / 2} \mathrm{~s}^{1 / 2}\left(140\right.$ to $\left.280 \mathrm{ft}^{1 / 2} \mathrm{~s}^{1 / 2}\right)$, and the RTI of quick-response sprinklers (QRS) range from about 28 to $55 \mathrm{~m}^{1 / 2} \mathrm{~s}^{1 / 2}\left(50\right.$ to $\left.100 \mathrm{ft}^{1 / 2} \mathrm{~s}^{1 / 2}\right)$.

Several computer programs have been developed that use correlations for such a ceiling jet and the RTI to predict actuation time. The program DETACT-QS (Evans and Stroup 1986) assumes that the thermal device is located in a relatively large area, that only the ceiling jet heats the device and there is no heating from the accumulated hot gases in the room. The required program inputs are the height of the ceiling above the fuel, the distance of the thermal device from the axis of the fire, the actuation temperature of the thermal device, the response time index (RTI) for the device, and the rate of heat release of the fire. The program outputs are the ceiling gas temperature and the device temperature both as a function of time and the time required for device actuation. DETACT-T2 (Evans, Stroup and Martin 1986) is similar to DETACT-QS except it is specifically for t-squared fires. Several zone fire models are capable of calculating ceiling jet temperatures and predicting actuation, and the CFAST model was used to calculate activation time for this project.

For estimation of activation time in this study, a sprinkler with an RTI of $155 \mathrm{~m}^{1 / 2} \mathrm{~s}^{1 / 2}\left(280 \mathrm{ft}^{1 / 2} \mathrm{~s}^{1 / 2}\right)$ was in a $10 \mathrm{~m}(33 \mathrm{ft})$ square room with a ceiling height of $2.8 \mathrm{~m}(9.2 \mathrm{ft})$. The fire growth was the medium tsquared curve mentioned above. The sprinkler was located under the ceiling and $2.1 \mathrm{~m}(7 \mathrm{ft})$ horizontally from the center line of the smoke plume. CFAST predicted an activation time of about $252 \mathrm{~s}$ at $706 \mathrm{~kW}$ $(670 \mathrm{Btu} / \mathrm{s})$. For calculation of decay after sprinkler activation, a time constant of $435 \mathrm{~s}$ was used.

\section{Conference Room Fire}

This is an unsprinklered fire that is limited to a conference room that was used for storage. The conference room includes materials in corrugated cardboard boxes and a number of pieces of upholstered furniture. Because some upholstered furniture burns like an ultra fast fire, the ultra fast growth type was used for the early stage of this fire until the room flashed over. Flashover is a transition from a locally isolated fire to a room totally involved in fire. This transition only takes a few seconds. 
After flashover the airflow through this window controls the HRR, and this HRR can be expressed as a function of the door opening to the room

$$
\dot{Q}=C_{v c} A_{w} H_{w}^{1 / 2}
$$

where

$\dot{Q} \quad=$ heat release rate of fire, $\mathrm{kW}(\mathrm{Btu} / \mathrm{s}) ;$

$A_{w} \quad=$ area of ventilation opening, $\mathrm{m}^{2}\left(\mathrm{ft}^{2}\right)$;

$H_{w} \quad=$ height of ventilation opening, $\mathrm{m}(\mathrm{ft})$;

$C_{v c} \quad=1260(61.2)$.

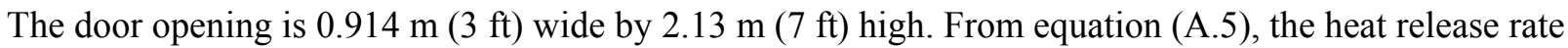
of the fully developed fire is $3590 \mathrm{~kW}(3400 \mathrm{Btu} / \mathrm{s})$.

To get temperatures to use in CONTAMW, a CFAST simulation was made of the fire in the conference room and open office space on the fire floor. The conference room is $3.2 \mathrm{~m}(10.5 \mathrm{ft})$ by $4.3 \mathrm{~m}(14.1 \mathrm{ft})$. This indicated that flashover occurred at $133 \mathrm{~s}$. The temperatures are shown in Figures A1 and A2.

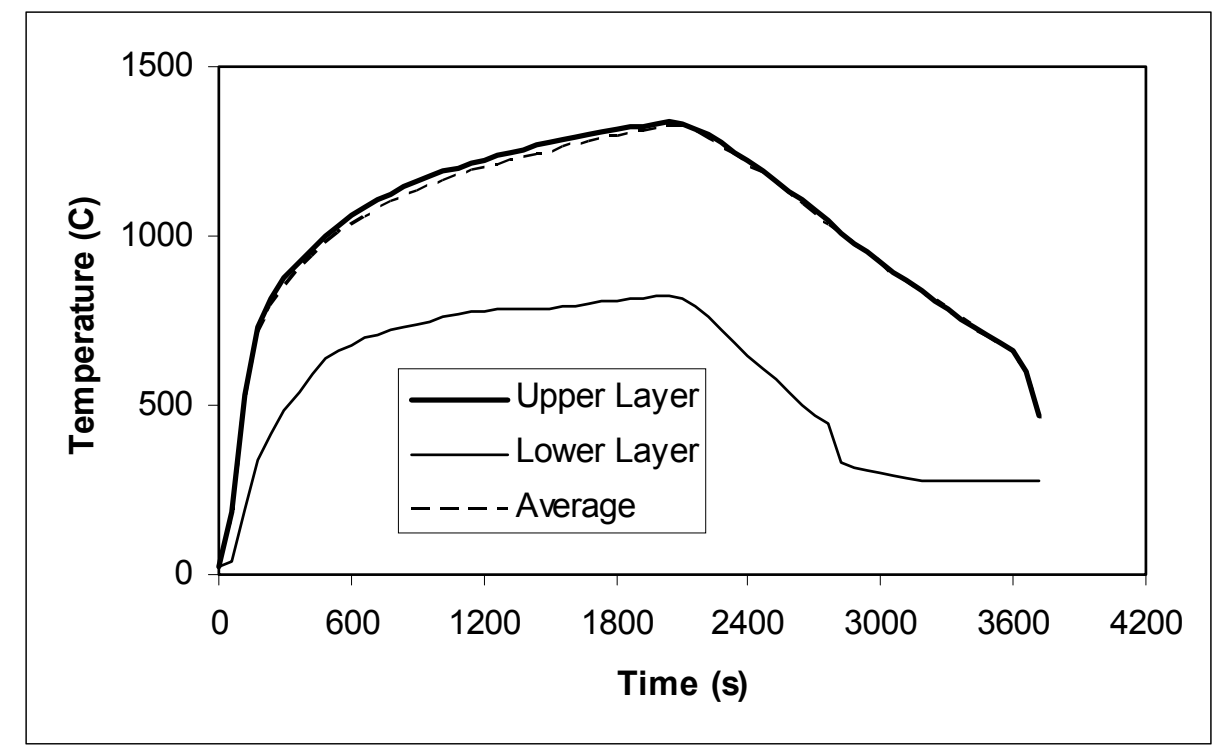

Figure A1. CFAST simulated temperatures of the conference room 


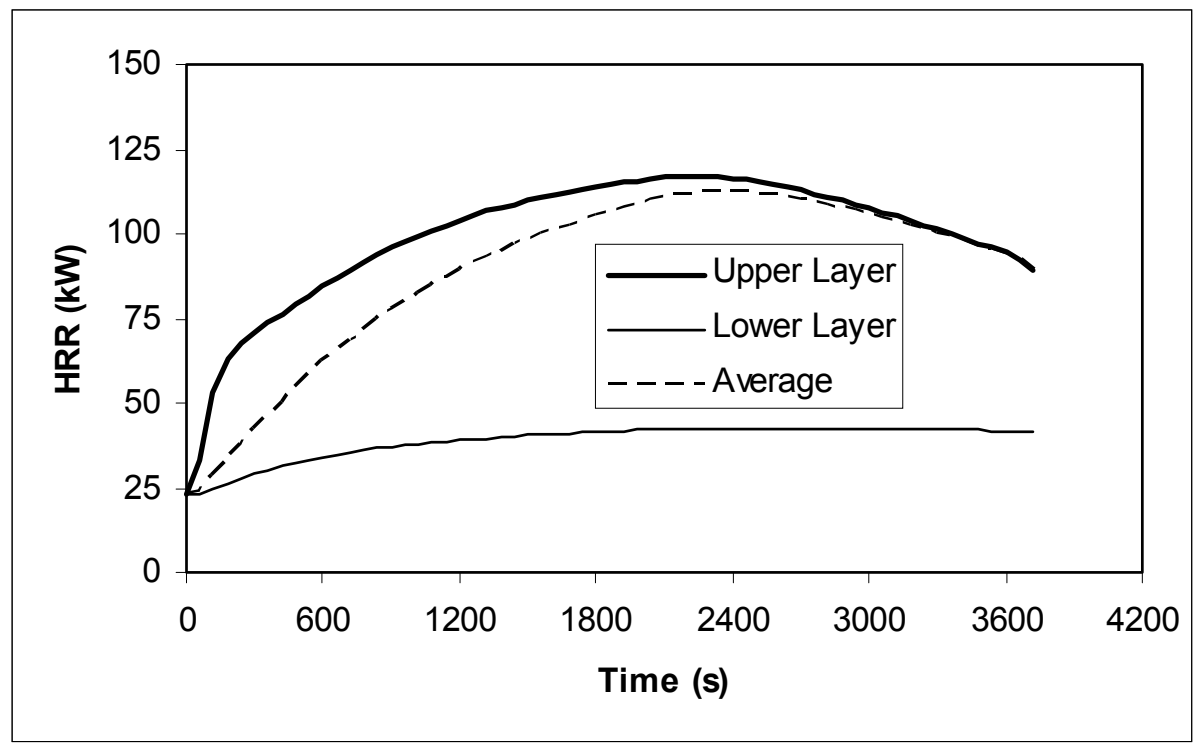

Figure A2. CFAST simulated temperatures of the open office area on the fire floor

The average temperatures shown in Figures A1 and A2 are weighted averages, and they were calculated from

$$
T_{a v}=\frac{T_{u}(H-Z)+T_{l} Z}{H}
$$

where

$T_{a v} \quad=$ weighted average temperature,

$T_{u} \quad=$ upper layer temperature,

$T_{l} \quad=$ lower layer temperature,

$H \quad=$ floor to ceiling height,

$Z \quad=$ smoke layer interface.

\section{Open Office Plan Fire}

For the buildings of this study, the gross floor area is in the range of $1900 \mathrm{~m}^{2}\left(20,400 \mathrm{ft}^{2}\right)$ to $2040 \mathrm{~m}^{2}$ $\left(22,000 \mathrm{ft}^{2}\right)$. For these calculations, the net floor area of open office space is taken as $1670 \mathrm{~m}^{2}(18,000$ $\left.\mathrm{ft}^{2}\right)$, and the area of the windows is taken as $364 \mathrm{~m}^{2}\left(3920 \mathrm{ft}^{2}\right)$. One fully developed floor fire was used for these buildings.

The HHR calculations are based on the assumption that as the fire breaks the windows open, the fire is ventilation controlled as described by equation (A.5). At $600 \mathrm{~s}$ after ignition, the fire starts breaking windows, and this continues until all the windows are broken at $1550 \mathrm{~s}$. At $600 \mathrm{~s}$, the area of broken window is $2.26 \mathrm{~m}^{2}\left(24.3 \mathrm{ft}^{2}\right)$, and at $1550 \mathrm{~s}$ all of the windows are broken with a HRR of $680,000 \mathrm{~kW}$ $(645,000 \mathrm{Btu} / \mathrm{s})$. On an area basis, the maximum HRR is $407 \mathrm{~kW} / \mathrm{m}^{2}\left(35.8 \mathrm{Btu} / \mathrm{stt}^{2}\right)$. Based on Madrzykowski's work (1996), workstation fires can support this level of fire.

The growth stage of the fire was approximated by a t-square fire that grows to $680,000 \mathrm{~kW}(645,000$ $\mathrm{Btu} / \mathrm{s})$ in $1550 \mathrm{~s}$. From equation A1, the fire growth coefficient is $0.283 \mathrm{~kW} / \mathrm{s}^{2}\left(0.268 \mathrm{Btu} / \mathrm{s}^{3}\right)$.

After the windows are broken, the fire continues to burn at this rate for 1 hour. The workstations burned by Madrzykowski do not have sufficient fuel to support this fire for such a time. However, such a fire 
could be supported by other fuel in the office space such as bookcases with books, boxes filled with paper, file cabinets filled with records and rolls of drawings. The decay phase of the fire is from $3600 \mathrm{~s}$ to $7200 \mathrm{~s}$, and a time constant of $435 \mathrm{~s}$ was used for decay.

Because of restrictions on data input, CFAST version 3.1.7 could not be used to simulate a fire with such a large HRR. For this reason, a scaled down version of the fire had to be simulated by CFAST to obtain the temperatures for use in the CONTAMW simulations. CFAST simulations were made of the floor fire with (1) an elevator shaft and no enclosed elevator lobby and (2) an enclosed elevator lobby. The temperatures from these CFAST simulations are listed in Figures A.3 to A.5. The average temperatures were calculated as before.

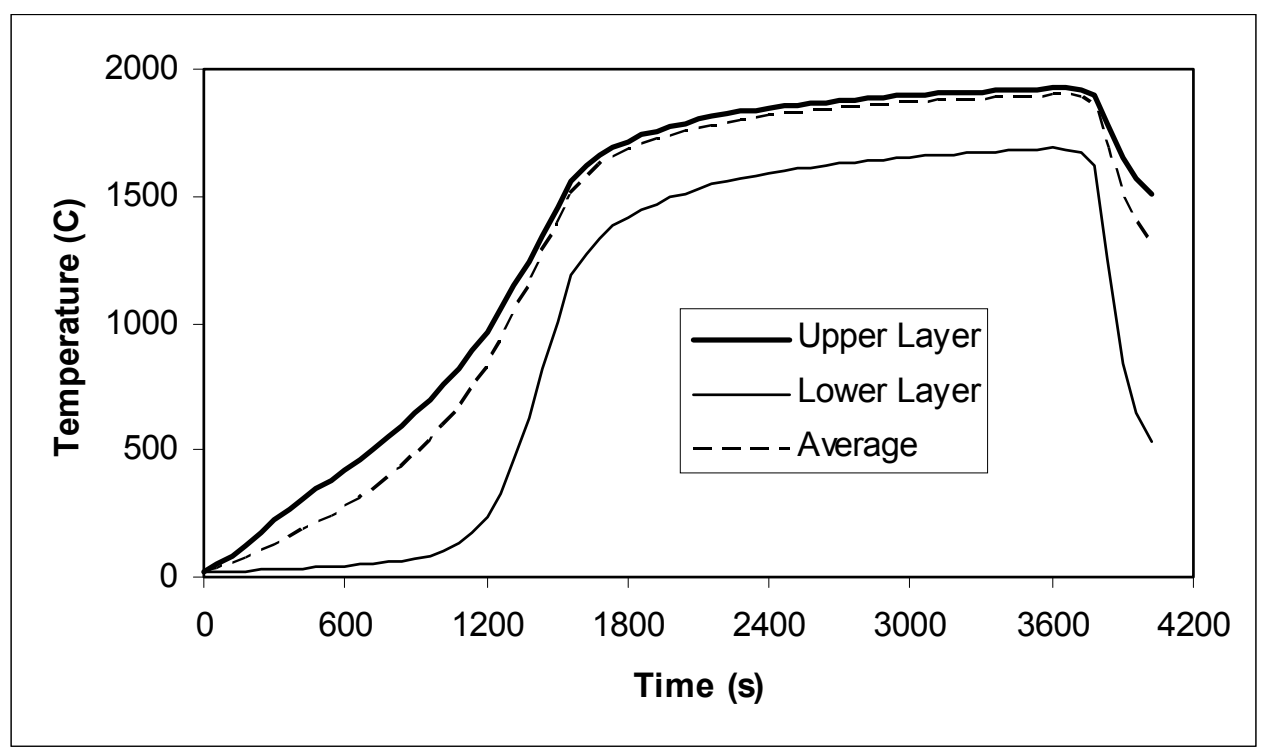

Figure A3. CFAST simulated temperatures of open office area 


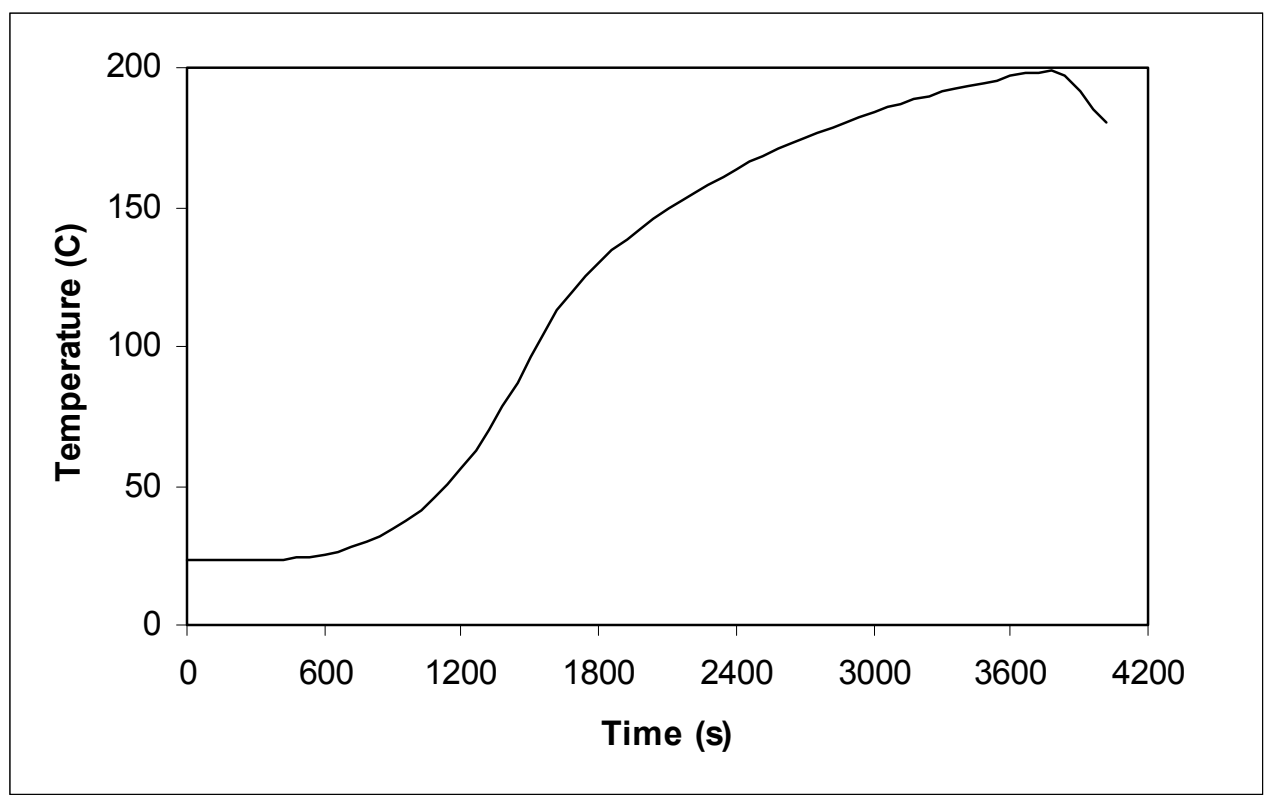

Figure A4. CFAST simulated temperature of the elevator shaft without an enclosed lobby

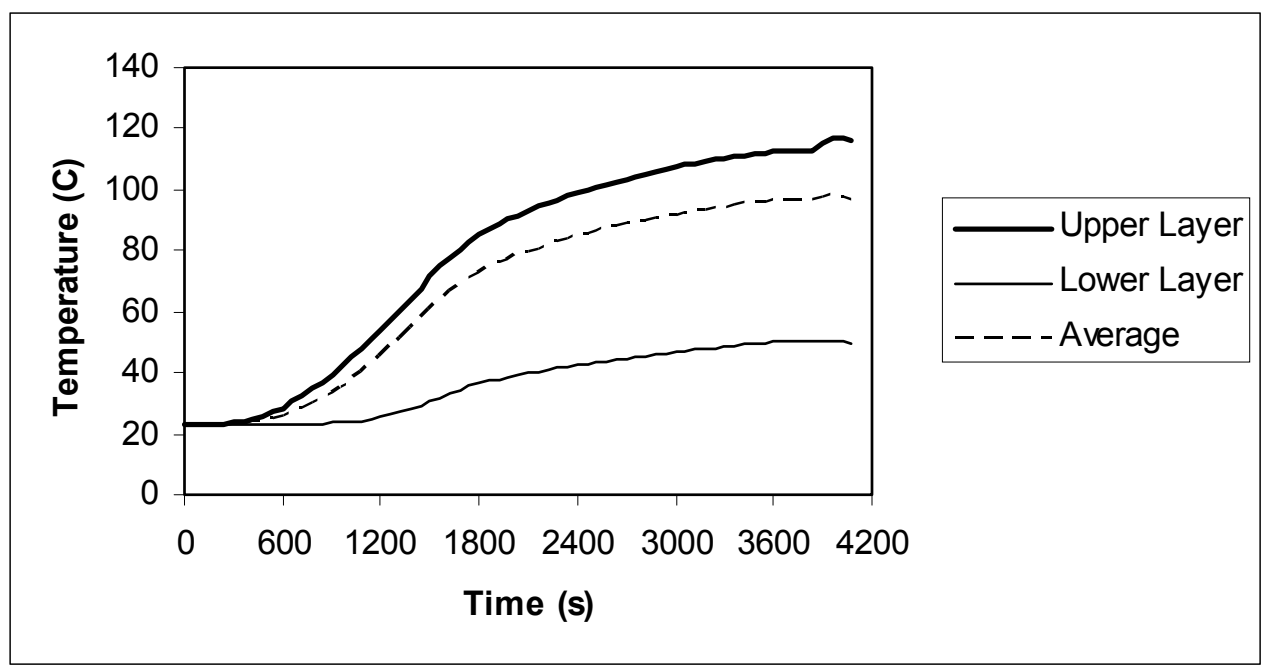

Figure A5. CFAST simulated temperatures of the enclosed elevator lobby 


\section{Appendix B - Fuel Properties}

The chemical heat of combustion of the mixture of two fuels can be calculated as

$$
\Delta H_{c h}=f_{1} \Delta H_{c h 1}+f_{2} \Delta H_{c h 2},
$$

and the mass optical density the mixture of two fuels can be calculated as

$$
\delta_{m}=f_{1} \delta_{m 1}+f_{2} \delta_{m 2}
$$

where

$\Delta H_{c h}=$ chemical heat of combustion of the mixture $(\mathrm{kJ} / \mathrm{kg})$,

$\Delta H_{c h 1}=$ chemical heat of combustion of component $1(\mathrm{~kJ} / \mathrm{kg})$,

$\Delta H_{c h 2}=$ chemical heat of combustion of component $2(\mathrm{~kJ} / \mathrm{kg})$,

$\delta_{m,} \quad=$ mass optical density of the mixture $\left(\mathrm{m}^{2} / \mathrm{g}\right)$,

$\delta_{m 1} \quad=$ mass optical density of component $1\left(\mathrm{~m}^{2} / \mathrm{g}\right)$,

$\delta_{m 2}=$ mass optical density of component $2\left(\mathrm{~m}^{2} / \mathrm{g}\right)$,

$f_{1}=$ mass fraction of component 1 (dimensionless),

$f_{2} \quad=$ mass fraction of component 2 (dimensionless).

The lethal exposure dose, $\mathrm{LC} t_{50}$, of the mixture can be expressed as

$$
\mathrm{LC} t_{50}=f_{1} \mathrm{LC} t_{50,1}+f_{2} \mathrm{LC} t_{50,2}
$$

where $\mathrm{LC} t_{50}$ is the lethal exposure dose from test data (Table A1).

Table A1. Approximate Lethal Exposure Dose, $\mathrm{LC}_{50}$, for Common Materials (adapted from Purser 2002)

\begin{tabular}{lcccccr}
\hline \hline & \multicolumn{2}{c}{ Nonflaming Fire } & \multicolumn{2}{c}{ Fuel Controlled Fire } & \multicolumn{2}{c}{ Fully Developed Fire } \\
Material & $\mathrm{lb} \mathrm{ft}^{-3} \mathrm{~min}$ & $\mathrm{~g} \mathrm{~m}^{-3} \mathrm{~min}$ & $\mathrm{lb} \mathrm{ft}^{-3} \mathrm{~min}$ & $\mathrm{~g} \mathrm{~m}^{-3} \mathrm{~min}$ & $\mathrm{lb} \mathrm{ft}^{-3} \mathrm{~min}$ & $\mathrm{~g} \mathrm{~m}^{-3} \mathrm{~min}$ \\
\hline \hline Cellulosics & 0.046 & 730 & 0.19 & 3120 & 0.047 & 750 \\
C, H, O plastics & 0.031 & 500 & 0.075 & 1200 & 0.033 & 530 \\
PVC & 0.031 & 500 & 0.019 & 300 & 0.012 & 200 \\
Wool/Nylon (low $\mathrm{N}_{2}$ ) & 0.031 & 500 & 0.057 & 920 & 0.0044 & 70 \\
Flexible Polyurethane & 0.042 & 680 & 0.087 & 1390 & 0.012 & 200 \\
Rigid Polyurethane & 0.0039 & 63 & 0.0062 & 100 & 0.0034 & 54 \\
Modacrylic/PAN $^{1}$ & 0.010 & 160 & 0.0087 & 140 & 0.0028 & 45 \\
\hline \hline
\end{tabular}

${ }^{1} \mathrm{PAN}$ is polyacrylonitrile.

Cellulosic materials (wood, paper, cardboard, etc.) are very common fuels in building fires. They often burn in combination with some amount of polymers. For these calculations the mixture used is $75 \%$ cellulosic material and $25 \%$ polyurethane foam. The properties are listed below. 


\begin{tabular}{|llll|}
\hline Component & Mass Fraction & $\begin{array}{l}\text { Chemical Heat of } \\
\text { Combustion }(\mathrm{kJ} / \mathrm{kg})\end{array}$ & $\begin{array}{l}\text { Mass Optical } \\
\text { Density }\left(\mathrm{m}^{2} / \mathrm{g}\right)\end{array}$ \\
\hline Cellulosic Material & 0.75 & 13,000 & 0.28 \\
Polyurethane Foam & 0.25 & 17,600 & 0.33 \\
\hline
\end{tabular}

Properties of the mixture are

$\Delta H_{c h}=f_{1} \Delta H_{c h 1}+f_{2} \Delta H_{c h 2}=(.75)(13,000)+(.25)(17,600)=14,150 \mathrm{~kJ} / \mathrm{kg}$

$\delta_{m}=f_{1} \delta_{m 1}+f_{2} \delta_{m 2}=(.75)(0.28)+(.25)(0.33)=0.29 \mathrm{~m}^{2} / \mathrm{g}$

For a fuel controlled fire, the lethal exposure dose of the fuel mixture is

$$
\mathrm{LC} t_{50}=f_{1} \mathrm{LC} t_{50,1}+f_{2} \mathrm{LC}_{50,2}=(.75)(3120)+(.25)(1390)=2690 \mathrm{~g} \mathrm{~m}^{-3} \mathrm{~min} .
$$

For a fully developed fire, the lethal exposure dose of the fuel mixture is

$$
\mathrm{LC} t_{50}=f_{1} \mathrm{LC}_{50,1}+f_{2} \mathrm{LC}_{50,2}=(.75)(750)+(.25)(200)=612 \mathrm{~g} \mathrm{~m}^{-3} \mathrm{~min} .
$$

\section{Mass Consumption}

The mass of fuel consumed in a fire is

$$
\dot{m}=\frac{\dot{Q}}{\Delta H_{c h}}
$$

where

$\dot{m} \quad=$ mass of fuel consumed $(\mathrm{kg} / \mathrm{s})$,

$\dot{Q} \quad=$ heat release rate $(\mathrm{kW})$.

The peak values of HRR and mass consumption are listed below for the fires of this project.

$$
\text { Peak HRR }(\mathrm{kW}) \quad \text { Peak Mass Consumption }(\mathrm{kg} / \mathrm{s})
$$

Sprinklered Fire

706

0.050

Conference Room Fire

3,590

0.254

Open Office Plan Fire

680,000

48.1 


\section{Appendix C - Wind}

For information about wind and smoke management, readers are referred to Kandola (1986a, 1986b) and Klote (1995). For additional information about wind pressures on buildings see Aynsley (1989), Shaw and Tamura (1977) and Kandola (1986c). Several civil engineering texts provide useful information about wind engineering, for example Dyrbye and Hansen (1997); Liu (1991), MacDonald (1975) and Simiu and Scanlan (1996).

The wind velocity at the top of a building wall is

$$
U_{H}=U_{m e t}\left(\frac{\delta_{m e t}}{H_{m e t}}\right)^{a_{m e t}}\left(\frac{H}{\delta}\right)^{a}
$$

where

$U_{H} \quad=$ wind velocity at the top of the wall, $\mathrm{m} / \mathrm{s}(\mathrm{fpm})$;

$U_{\text {met }} \quad=$ measured wind velocity, $\mathrm{m} / \mathrm{s}(\mathrm{fpm})$;

$H_{\text {met }} \quad=$ height of wind measurement, $\mathrm{m}(\mathrm{ft})$;

$H \quad=$ upwind height of the wall, $\mathrm{m}(\mathrm{ft})$;

$\delta_{\text {met }} \quad=$ boundary layer height in the vicinity of the wind anemometer, $\mathrm{m}(\mathrm{ft})$;

$\delta \quad=$ boundary layer height in the vicinity of the building, $\mathrm{m}(\mathrm{ft})$;

$a_{m e t} \quad=$ wind exponent in the vicinity of the wind anemometer, dimensionless;

$a \quad=$ wind exponent in the vicinity of the building, dimensionless.

General values of boundary layer height, $\delta$, are listed the ASHRAE Handbook of Fundamentals. The weather service measures wind data at airports and other locations typically at $10 \mathrm{~m}(33 \mathrm{ft})$ above the ground. For this project, the wind values are calculated as if the building was located in urban or suburban terrain with wooded areas or other similar obstructions.

The pressure that the wind exerts on a wall can be expressed as

$$
p_{w}=\frac{1}{2} K_{w} C_{h} C_{w} \rho_{o} U_{m e t}^{2}
$$

where

$$
\begin{aligned}
& C_{h}=\left(\frac{\delta_{m e t}}{H_{m e t}}\right)^{2 a_{m e t}}\left(\frac{H}{\delta}\right)^{2 a} \text { (dimensionless); } \\
& C_{w} \quad=\text { wind coefficient (dimensionless); } \\
& \rho_{o} \quad=\text { density of outside air, } \mathrm{kg} / \mathrm{m}^{3}\left(\mathrm{lb} / \mathrm{ft}^{3}\right) ; \\
& K_{w} \quad=1.00(0.0129) .
\end{aligned}
$$

For this project, the values of the above parameters are:

$$
\begin{array}{cl}
\delta_{\text {met }} & 270 \mathrm{~m}(900 \mathrm{ft}) \\
\delta & 370 \mathrm{~m}(1200 \mathrm{ft}) \\
a_{\text {met }} & 0.14 \\
a & 0.22 \\
H_{\text {met }} & 10 \mathrm{~m}(33 \mathrm{ft}) \\
H & 67 \mathrm{~m}(220 \mathrm{ft}) \text { Building C } \\
U_{m e t} & 11 \mathrm{~m} / \mathrm{s}(25 \mathrm{mph}) \\
\rho_{o} & 1.37 \mathrm{~kg} / \mathrm{m}^{3}\left(0.0855 \mathrm{lb} / \mathrm{ft}^{3}\right) \text { at }-16^{\circ} \mathrm{C}\left(3^{\circ} \mathrm{F}\right)
\end{array}
$$


From equations (C.1) and (C.3), values of $U_{H}$ and $C_{h}$ are listed below.

$\begin{array}{cccccc} & U_{\text {met }} & U_{\text {met }} & U_{H} & U_{H} & \\ \text { Building } & \mathrm{m} / \mathrm{s} & \mathrm{mph} & \mathrm{m} / \mathrm{s} & \mathrm{mph} & C_{h} \\ \mathrm{C} & 11 & 25 & 12 & 27 & 1.19\end{array}$

Average values of $C_{w}$ can be obtained from Klote and Milke (2002) depending on values of $h / w$ and $l / w$, where $h=$ height to parapit, $l=$ length, and $w=$ width. $h / w$ is 1.9 and $l / w$ is 1.5 for Building $\mathrm{C}$.

Average Values of $C_{w}$ for Building C:

$\begin{array}{ccccc}\text { Wind Angle, } \alpha & \text { A } & \text { B } & \text { C } & \text { D } \\ 0 & 0.8 & -0.25 & -0.8 & -0.8 \\ 90 & -.0 .8 & -0.8 & 0.8 & -0.25\end{array}$

The wind angle is used in Klote and Milke and is illustrated in Figure C.1.

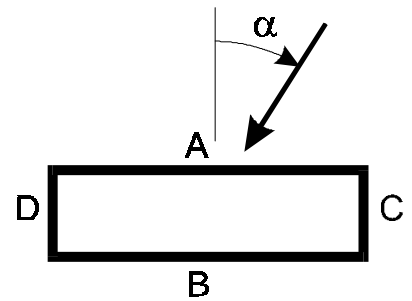

Figure C.1 Wind Angle.

For a wind angle of zero, the wind pressure is:

A

$\mathrm{Pa}$

79
in. $\mathrm{H}_{2} \mathrm{O}$
0.31

$\mathrm{Pa}$
-25

B

in. $\mathrm{H}_{2} \mathrm{O}$

$-0.10$

$\mathrm{Pa}$
-79

C

in. $\mathrm{H}_{2} \mathrm{O}$

$-0.31$

$\mathrm{Pa}$
-79

in. $\mathrm{H}_{2} \mathrm{O}$

$-0.31$ 
Appendix F

Hazards Due to Smoke Migration Through Elevator Shafts. Volume 2. Results of Tenability Calculations 
NIST GCR 04-864-II

\title{
Hazards Due to Smoke Migration Through Elevator Shafts - Volume II: Results of Tenability Calculations. Final Report
}

\author{
John H. Klote \\ John H. Klote, Inc. \\ 43262 Meadowood Court \\ Leesburg, VA 20176
}



NIST GCR 04-864-II

\section{Hazards Due to Smoke Migration Through Elevator Shafts - Volume II: Results of Tenability Calculations. Final Report}

Prepared for U.S. Department of Commerce Building and Fire Research Laboratory National Institute of Standards and Technology Gaithersburg, MD 20899-8664

John H. Klote

John H. Klote, Inc. 43262 Meadowood Court

Leesburg, VA 20176

June 2004

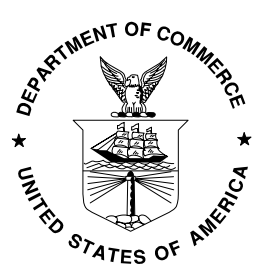

U.S. Department of Commerce

Donald L. Evans, Secretary

Technology Administration Phillip J. Bond, Under Secretary for Technology

National Institute of Standards and Technology Arden L. Bement, Jr., Director 


\section{Notice}

This report was prepared for the Building and Fire Research Laboratory of the National Institute of Standards and Technology under Contract number SB134-03-W-0477. The statements and conclusions contained in this report are those of the authors and do not necessarily reflect the views of the National Institute of Standards and Technology or the Building and Fire Research Laboratory. 


\section{Table of Contents}

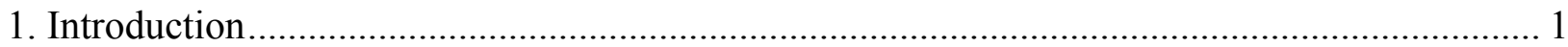

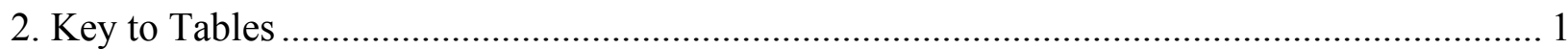

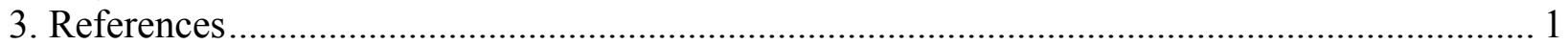

\section{List of Tables}

Table 01. Results of Tenability Analysis for Scenario 01....................................................... 2

Table 02. Results of Tenability Analysis for Scenario 02........................................................... 3

Table 03. Results of Tenability Analysis for Scenario 03........................................................... 4

Table 04. Results of Tenability Analysis for Scenario 04 ....................................................... 5

Table 05. Results of Tenability Analysis for Scenario 05............................................................... 6

Table 06. Results of Tenability Analysis for Scenario 06 ......................................................... 8

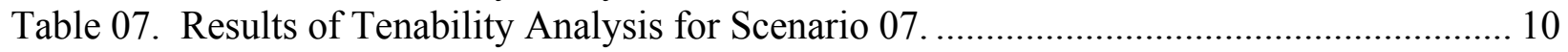

Table 08. Results of Tenability Analysis for Scenario 08 ……….............................................. 12

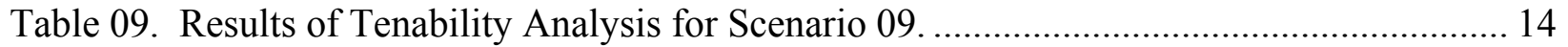

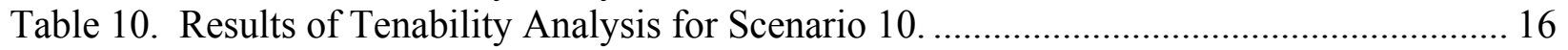

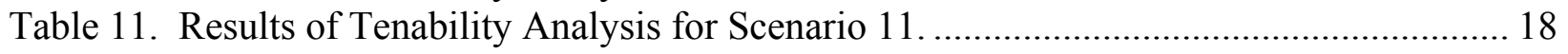

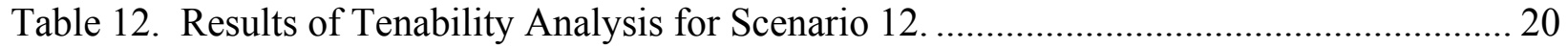

Table 13. Results of Tenability Analysis for Scenario 13 …….................................................. 23

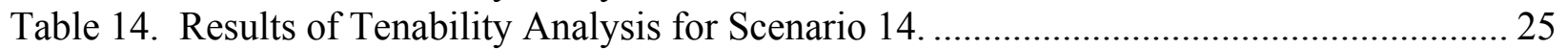

Table 15. Results of Tenability Analysis for Scenario 15.......................................................... 35

Table 16. Results of Tenability Analysis for Scenario 16 ........................................................ 45

Table 17. Results of Tenability Analysis for Scenario 17.................................................... 55

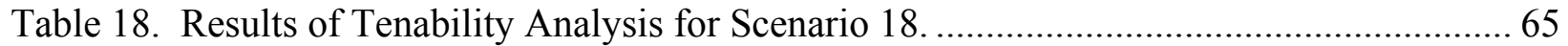

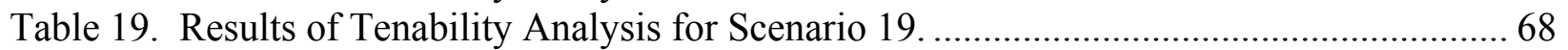

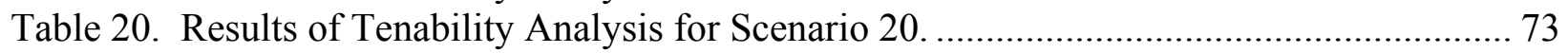

Table 21. Results of Tenability Analysis for Scenario 21........................................................ 79

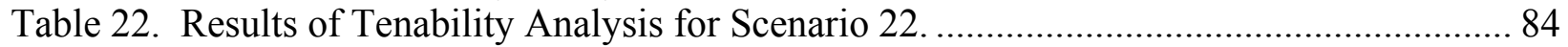

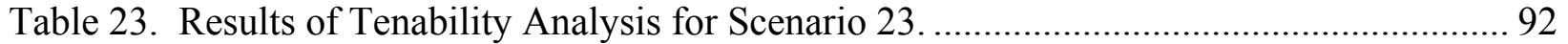

Table 24. Results of Tenability Analysis for Scenario 24....................................................... 93

Table 25. Results of Tenability Analysis for Scenario 25 ....................................................... 108

Table 26. Results of Tenability Analysis for Scenario 26 .................................................. 123

Table 27. Results of Tenability Analysis for Scenario 27..................................................... 138 


\section{Hazards Due To Smoke Migration Through Elevator Shafts - Volume II: Results of Tenability Calculations}

\section{Introduction}

This project looks at the hazard to life due to smoke migration through elevator hoistways and the effectiveness of methods to reduce that hazard. This report of this project is in two volumes. The first volume presents the analysis and discusses the results of that analysis (Klote, 2003). The second volume consists of the complete results of the tenability calculations. The results of the tenability calculations are listed in Tables 1 through 27.

\section{Key to Tables}

CONTAMW limits the length of names of zones (or rooms) to 4 characters. The following symbols are used in the zone names of this project.

$\begin{array}{ll}\text { EL } & \text { Elevator } \\ \text { ELME } & \text { Elevator Mechanical Room } \\ \text { EL-S } & \text { Service Elevator } \\ \text { LOBY } & \text { Passenger Elevator Lobby } \\ \text { L-SR } & \text { Service Elevator Lobby } \\ \text { MECH } & \text { Mechanical Space } \\ \text { OPEN } & \text { Open Plan Office Space } \\ \text { SW } & \text { Stairwell } \\ \text { T } & \text { Toilet }\end{array}$

\section{Reference}

Klote, J. H. 2003. Hazards Due to Smoke Migration through Elevator Shafts - Vol. I: Analysis and Discussion, John H. Klote, Inc., Leesburg, VA. 
Table 01. Results of Tenability Analysis for Scenario 01.

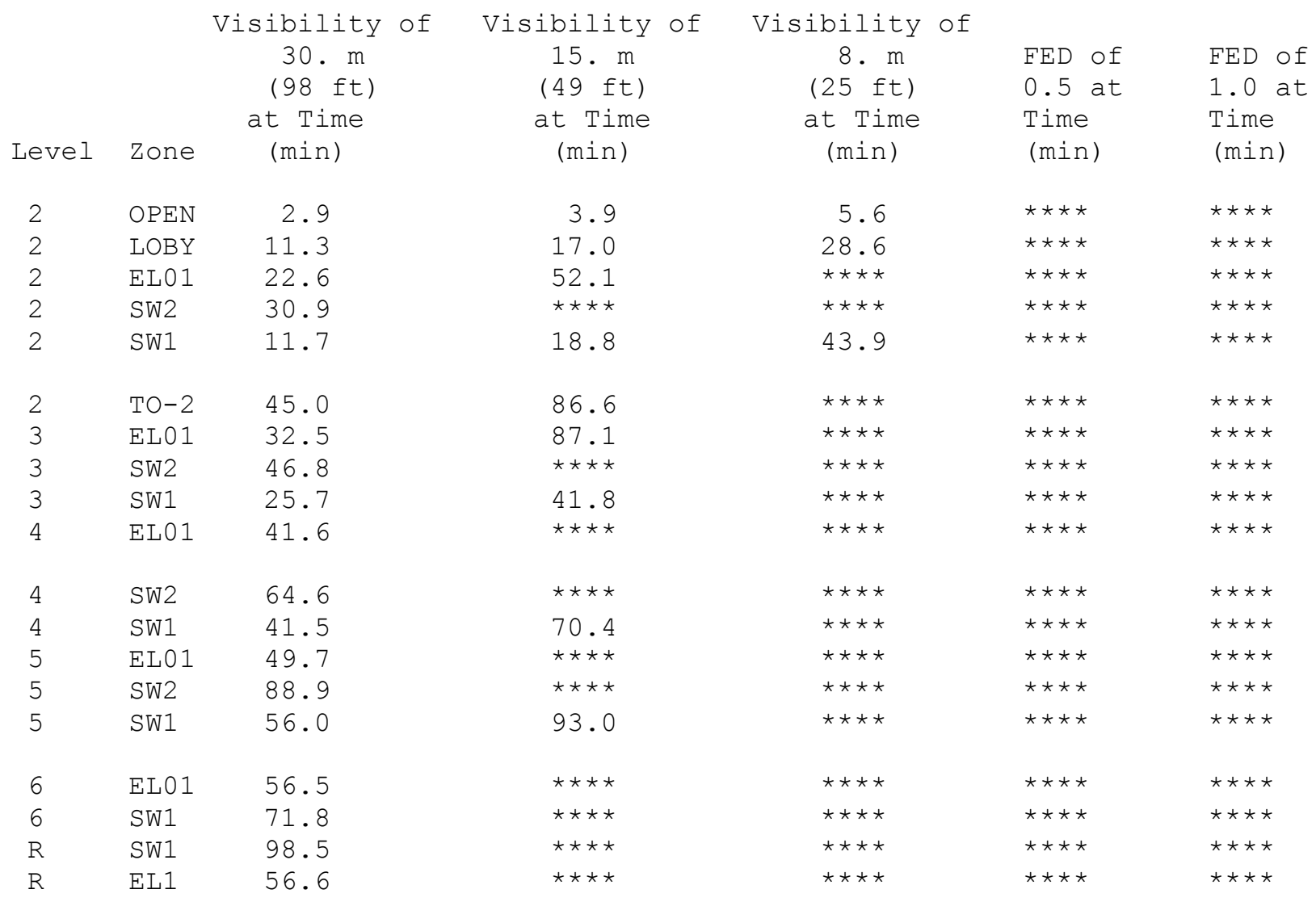


Table 02. Results of Tenability Analysis for Scenario 02.

\begin{tabular}{|c|c|c|c|c|c|c|}
\hline Level & Zone & $\begin{array}{l}\text { isibility of } \\
30 . \mathrm{m} \\
(98 \mathrm{ft}) \\
\text { at Time } \\
\text { (min) }\end{array}$ & $\begin{array}{c}\text { Visibility of } \\
15 . \mathrm{m} \\
(49 \mathrm{ft}) \\
\text { at Time } \\
\text { (min) }\end{array}$ & $\begin{array}{c}\text { Visibility of } \\
8 \cdot \mathrm{m} \\
(25 \mathrm{ft}) \\
\text { at Time } \\
\text { (min) }\end{array}$ & $\begin{array}{l}\text { FED of } \\
0.5 \text { at } \\
\text { Time } \\
\text { (min) }\end{array}$ & $\begin{array}{l}\text { FED of } \\
1.0 \text { at } \\
\text { Time } \\
\text { (min) }\end{array}$ \\
\hline 2 & LOBY & 6.3 & 8.6 & 12.0 & 47.1 & 61.4 \\
\hline 2 & EL01 & 17.8 & 24.0 & 33.0 & 97.5 & 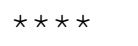 \\
\hline 2 & $\mathrm{TO}-1$ & 1.0 & 1.0 & 1.0 & 3.6 & 4.9 \\
\hline 2 & SW2 & 5.4 & 7.5 & 10.7 & 48.0 & 65.6 \\
\hline 2 & $\mathrm{C}-\mathrm{Rm}$ & 1.0 & 1.0 & 1.0 & 0.0 & 0.0 \\
\hline 3 & LOBY & 69.0 & 99.9 & $\star \star \star \star *$ & $\star \star \star \star *$ & $\star \star \star \star *$ \\
\hline 3 & EL01 & 23.3 & 30.6 & 41.2 & 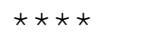 & 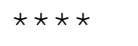 \\
\hline 3 & $\mathrm{TO}-1$ & 8.5 & 11.7 & 16.3 & 54.8 & 69.9 \\
\hline 3 & SW2 & 10.5 & 13.6 & 18.0 & 58.1 & 76.6 \\
\hline 4 & LOBY & 98.4 & $\star \star \star \star$ & $\star \star \star \star *$ & $\star \star \star \star \star$ & $\star \star \star \star *$ \\
\hline 4 & EL01 & 28.0 & 36.2 & 48.1 & 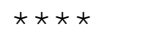 & 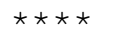 \\
\hline 4 & $\mathrm{TO}-1$ & 87.6 & 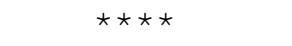 & $\star \star \star \star \star$ & 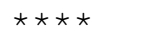 & 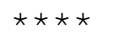 \\
\hline 4 & SW2 & 16.9 & 21.1 & 26.6 & 69.5 & 89.1 \\
\hline 5 & LOBY & 111.8 & 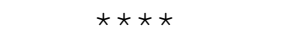 & $\star \star \star \star \star$ & 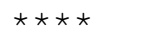 & 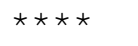 \\
\hline 5 & EL01 & 32.1 & 40.9 & 54.0 & $\star \star \star \star \star$ & $\star \star \star \star$ \\
\hline 5 & SW2 & 25.6 & 30.9 & 37.8 & 84.2 & 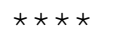 \\
\hline 6 & EL01 & 35.5 & 44.8 & 58.7 & $\star \star \star \star *$ & $\star \star \star \star *$ \\
\hline 6 & SW2 & 39.2 & 46.3 & 55.3 & $\star \star \star \star$ & $\star \star \star \star$ \\
\hline $\mathrm{R}$ & EL1 & 35.6 & 44.9 & 58.9 & 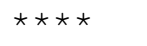 & 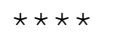 \\
\hline
\end{tabular}


Table 03. Results of Tenability Analysis for Scenario 03.

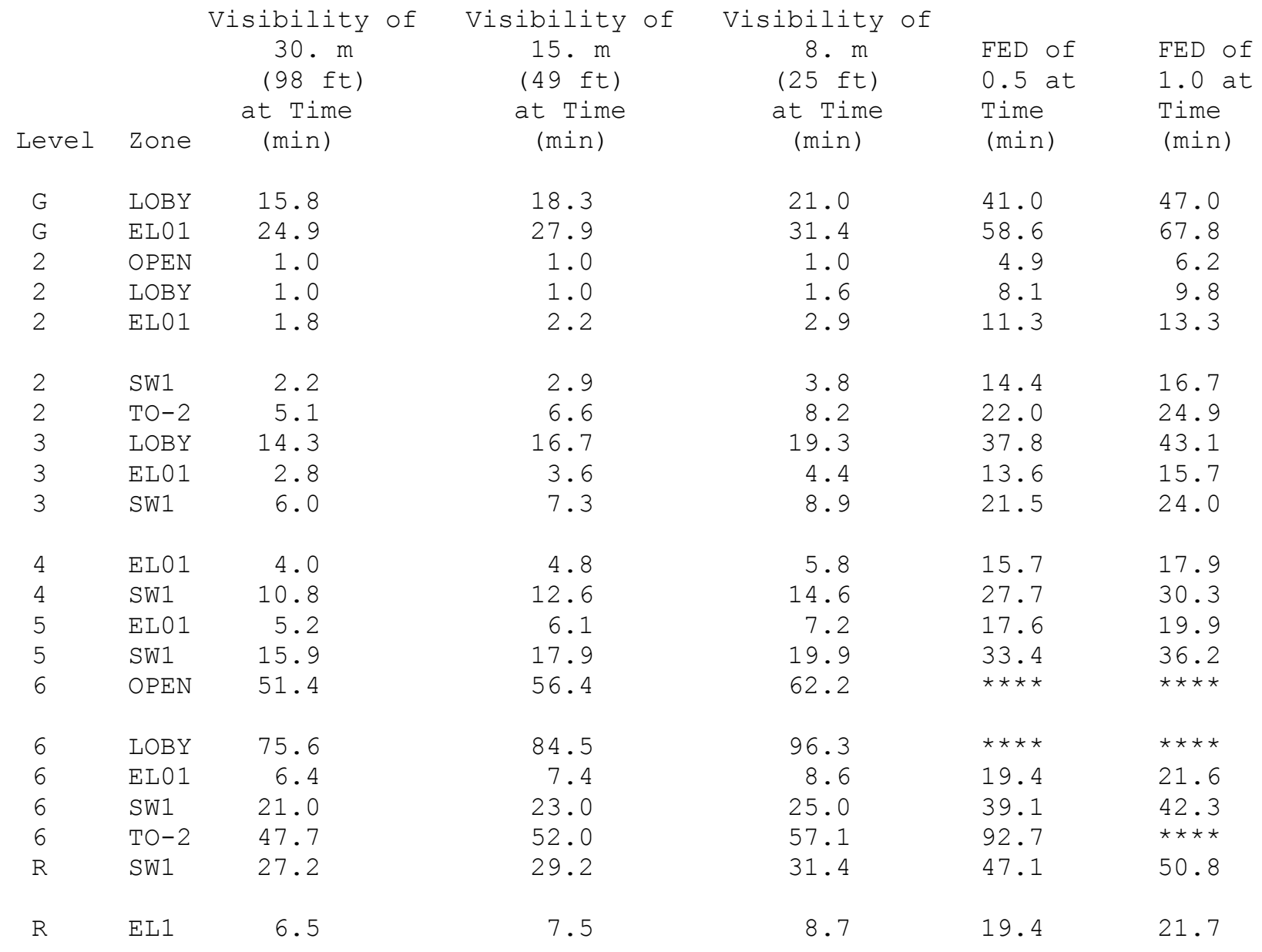


Table 04. Results of Tenability Analysis for Scenario 04.

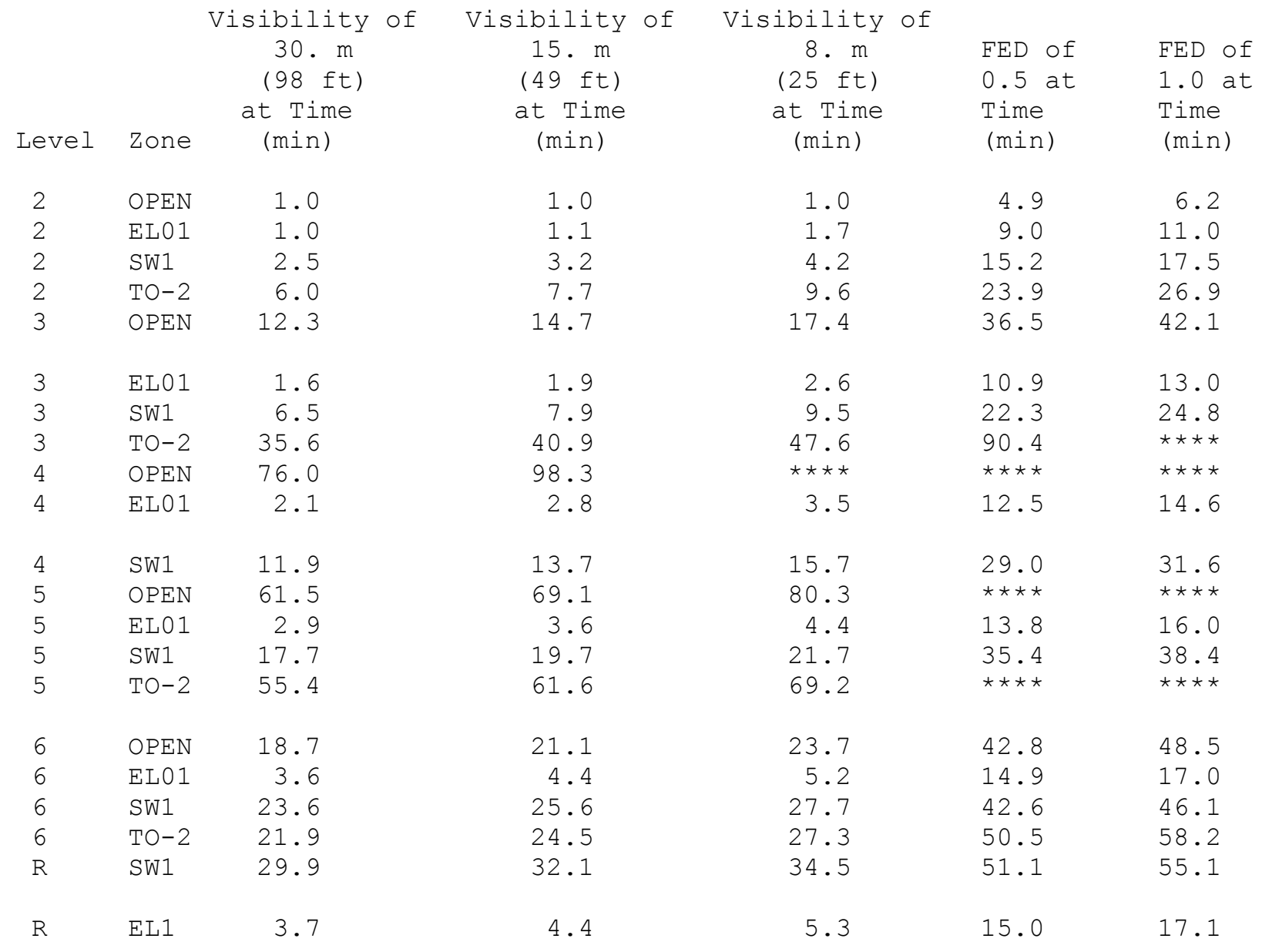


Table 05. Results of Tenability Analysis for Scenario 05.

\begin{tabular}{|c|c|c|c|c|c|c|}
\hline Level & Zone & $\begin{array}{l}\text { sibility } \\
30 . \mathrm{m} \\
(98 \mathrm{ft}) \\
\text { at Time } \\
\text { (min) }\end{array}$ & $\begin{array}{c}\text { Visibility of } \\
15 . \mathrm{m} \\
(49 \mathrm{ft}) \\
\text { at Time } \\
\text { (min) }\end{array}$ & $\begin{array}{c}\text { Visibility of } \\
8 . \mathrm{m} \\
(25 \mathrm{ft}) \\
\text { at Time } \\
\text { (min) }\end{array}$ & $\begin{array}{l}\text { FED of } \\
0.5 \text { at } \\
\text { Time } \\
\text { (min) }\end{array}$ & $\begin{array}{l}\text { FED of } \\
1.0 \text { at } \\
\text { Time } \\
\text { (min) }\end{array}$ \\
\hline G & EL01 & 26.5 & 29.8 & 33.8 & 65.3 & 77.1 \\
\hline G & LOBY & 15.9 & 18.4 & 21.2 & 42.2 & 49.0 \\
\hline G & EL02 & 28.4 & 32.0 & 36.5 & 72.8 & 88.8 \\
\hline 2 & OPEN & 1.0 & 1.0 & 1.0 & 4.9 & 6.2 \\
\hline 2 & EL01 & 1.7 & 2.0 & 2.7 & 10.8 & 12.7 \\
\hline 2 & LOBY & 1.0 & 1.0 & 1.3 & 7.4 & 9.0 \\
\hline 2 & EL02 & 1.7 & 2.0 & 2.8 & 11.0 & 13.0 \\
\hline 2 & SW1 & 1.9 & 2.5 & 3.3 & 13.1 & 15.4 \\
\hline 2 & TO-2 & 4.4 & 5.7 & 7.2 & 20.4 & 23.2 \\
\hline 3 & EL01 & 2.8 & 3.5 & 4.3 & 13.5 & 15.6 \\
\hline 3 & LOBY & 14.4 & 16.7 & 19.3 & 38.0 & 43.5 \\
\hline 3 & EL02 & 2.8 & 3.4 & 4.2 & 13.4 & 15.5 \\
\hline 3 & SW1 & 5.0 & 6.2 & 7.6 & 19.7 & 22.1 \\
\hline 4 & EL01 & 4.1 & 5.0 & 6.0 & 16.0 & 18.2 \\
\hline 4 & EL02 & 3.9 & 4.8 & 5.8 & 15.7 & 17.9 \\
\hline 4 & SW1 & 8.9 & 10.6 & 12.3 & 25.2 & 27.7 \\
\hline 5 & EL01 & 5.6 & 6.6 & 7.7 & 18.3 & 20.6 \\
\hline 5 & EL02 & 5.2 & 6.2 & 7.3 & 17.8 & 20.1 \\
\hline 5 & SW1 & 13.0 & 14.9 & 16.8 & 29.9 & 32.5 \\
\hline 6 & EL01 & 7.0 & 8.0 & 9.3 & 20.4 & 22.8 \\
\hline 6 & EL02 & 6.6 & 7.6 & 8.8 & 19.7 & 22.1 \\
\hline 6 & SW1 & 16.9 & 18.8 & 20.8 & 34.1 & 36.9 \\
\hline 7 & EL01 & 8.4 & 9.6 & 10.9 & 22.4 & 24.8 \\
\hline 7 & EL02 & 7.8 & 8.9 & 10.2 & 21.5 & 23.9 \\
\hline 7 & SW1 & 20.4 & 22.3 & 24.2 & 38.0 & 41.0 \\
\hline 8 & EL01 & 9.8 & 11.0 & 12.5 & 24.3 & 26.7 \\
\hline 8 & EL02 & 9.0 & 10.2 & 11.6 & 23.2 & 25.6 \\
\hline 8 & SW1 & 23.6 & 25.4 & 27.4 & 41.6 & 44.8 \\
\hline 9 & EL01 & 11.0 & 12.5 & 13.9 & 26.0 & 28.5 \\
\hline 9 & EL02 & 10.2 & 11.5 & 12.9 & 24.8 & 27.3 \\
\hline 9 & SW1 & 26.4 & 28.3 & 30.3 & 45.0 & 48.5 \\
\hline 10 & EL01 & 12.4 & 13.8 & 15.4 & 27.7 & 30.2 \\
\hline 10 & EL02 & 11.4 & 12.7 & 14.2 & 26.3 & 28.8 \\
\hline 10 & SW1 & 29.1 & 31.0 & 33.1 & 48.3 & 51.9 \\
\hline 11 & OPEN & 68.1 & 75.6 & 86.8 & 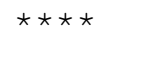 & 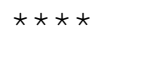 \\
\hline 11 & EL01 & 13.6 & 15.1 & 16.7 & 29.3 & 31.8 \\
\hline 11 & LOBY & 89.0 & $\star \star \star \star \star ~$ & 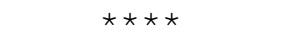 & 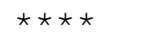 & 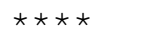 \\
\hline 11 & EL02 & 12.5 & 13.9 & 15.5 & 27.7 & 30.3 \\
\hline 11 & SW1 & 31.8 & 33.8 & 35.9 & 51.5 & 55.2 \\
\hline 11 & $\mathrm{TO}-2$ & 62.5 & 68.1 & 75.6 & 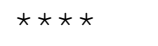 & 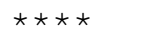 \\
\hline
\end{tabular}


Table 05. Continued.

\begin{tabular}{|c|c|c|c|c|c|c|}
\hline Level & Zone & $\begin{array}{l}\text { Libility of } \\
\text { 30. m } \\
(98 \mathrm{ft}) \\
\text { at Time } \\
\text { (min) }\end{array}$ & $\begin{array}{c}\text { Visibility of } \\
15 . \mathrm{m} \\
(49 \mathrm{ft}) \\
\text { at Time } \\
\text { (min) }\end{array}$ & $\begin{array}{c}\text { Visibility of } \\
8 . \mathrm{m} \\
(25 \mathrm{ft}) \\
\text { at Time } \\
\text { (min) }\end{array}$ & $\begin{array}{l}\text { FED of } \\
0.5 \text { at } \\
\text { Time } \\
\text { (min) }\end{array}$ & $\begin{array}{l}\text { FED of } \\
1.0 \text { at } \\
\text { Time } \\
\text { (min) }\end{array}$ \\
\hline 12 & OPEN & 67.2 & 73.6 & 82.3 & 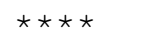 & 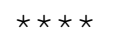 \\
\hline 12 & EL01 & 14.8 & 16.4 & 18.0 & 30.7 & 33.4 \\
\hline 12 & LOBY & 24.6 & 26.8 & 29.1 & 45.5 & 49.3 \\
\hline 12 & EL02 & 13.6 & 15.0 & 16.7 & 29.1 & 31.7 \\
\hline 12 & SW1 & 34.8 & 36.8 & 39.0 & 55.2 & 59.0 \\
\hline 12 & $\mathrm{TO}-2$ & 62.8 & 67.9 & 74.5 & 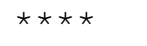 & 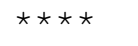 \\
\hline 13 & OPEN & 71.3 & 78.2 & 87.8 & 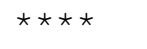 & 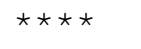 \\
\hline 13 & EL01 & 16.0 & 17.6 & 19.3 & 32.2 & 34.8 \\
\hline 13 & LOBY & 23.7 & 25.8 & 27.9 & 43.4 & 46.8 \\
\hline 13 & EL02 & 14.7 & 16.2 & 17.8 & 30.4 & 33.1 \\
\hline 13 & SW1 & 38.5 & 40.7 & 43.0 & 59.9 & 63.9 \\
\hline 13 & $\mathrm{TO}-2$ & 66.7 & 72.1 & 79.3 & $\star \star \star \star$ & $\star \star \star \star$ \\
\hline $\mathrm{R}$ & SW1 & 43.8 & 46.2 & 48.8 & 67.1 & 72.0 \\
\hline $\mathrm{R}$ & EL01 & 16.0 & 17.6 & 19.3 & 32.2 & 34.9 \\
\hline $\mathrm{R}$ & EL02 & 14.8 & 16.3 & 17.9 & 30.5 & 33.1 \\
\hline
\end{tabular}


Table 06. Results of Tenability Analysis for Scenario 06.

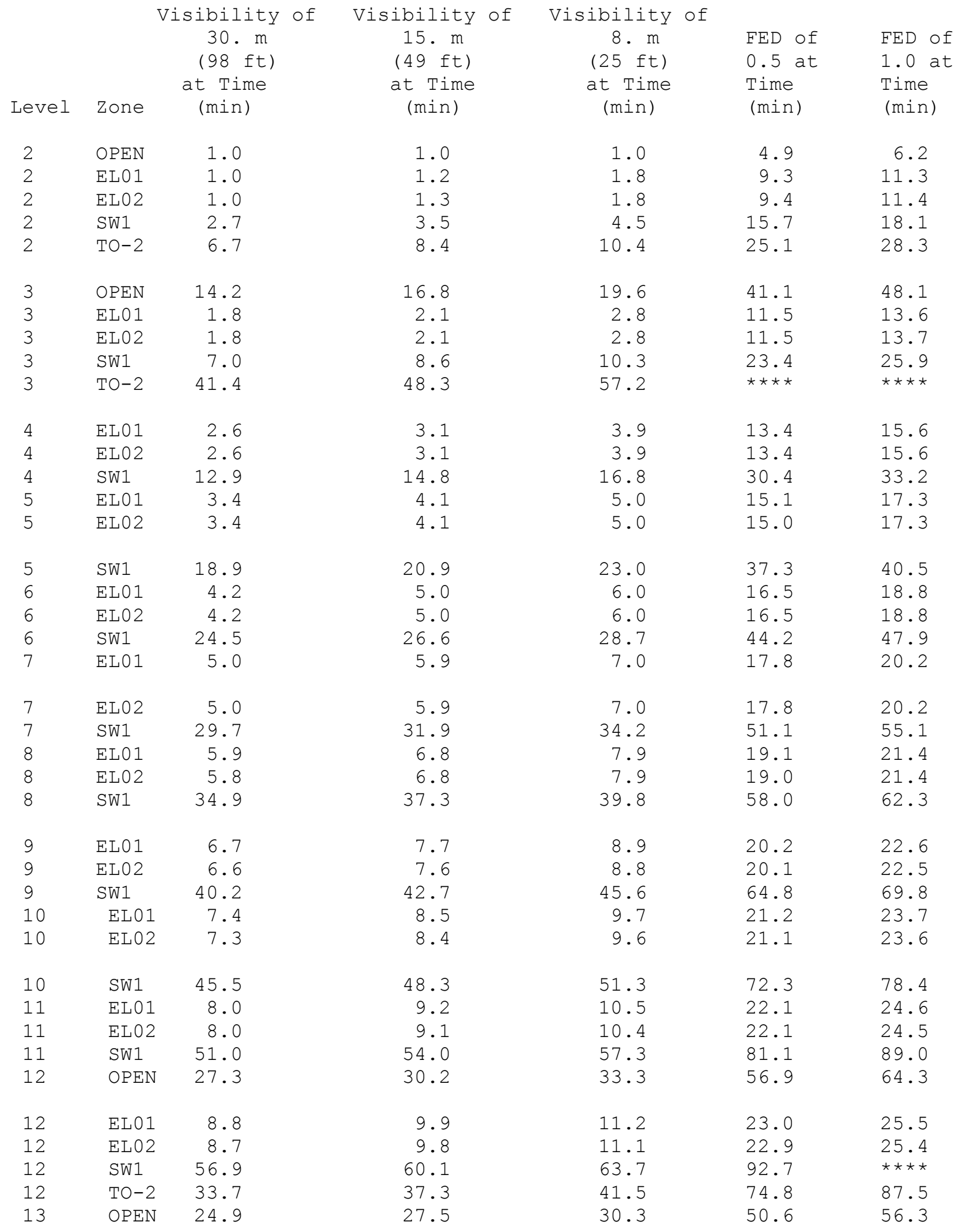


Table 06. Continued.

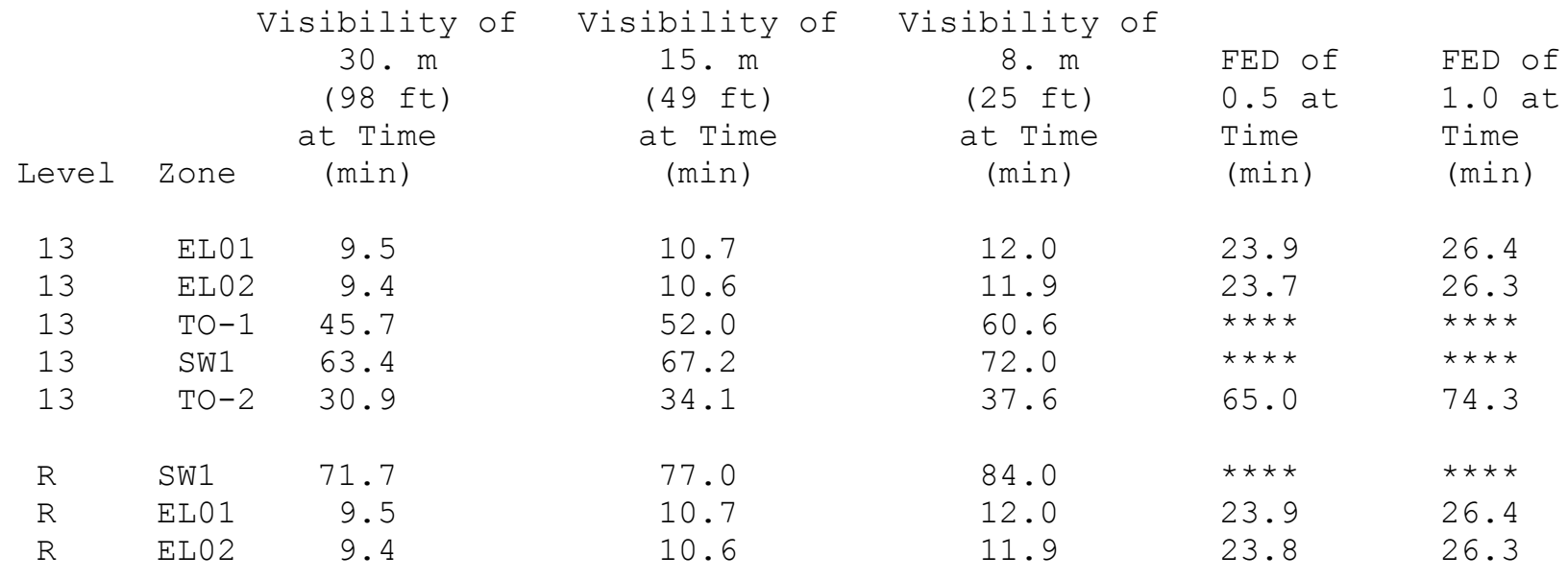


Table 07. Results of Tenability Analysis for Scenario 07.

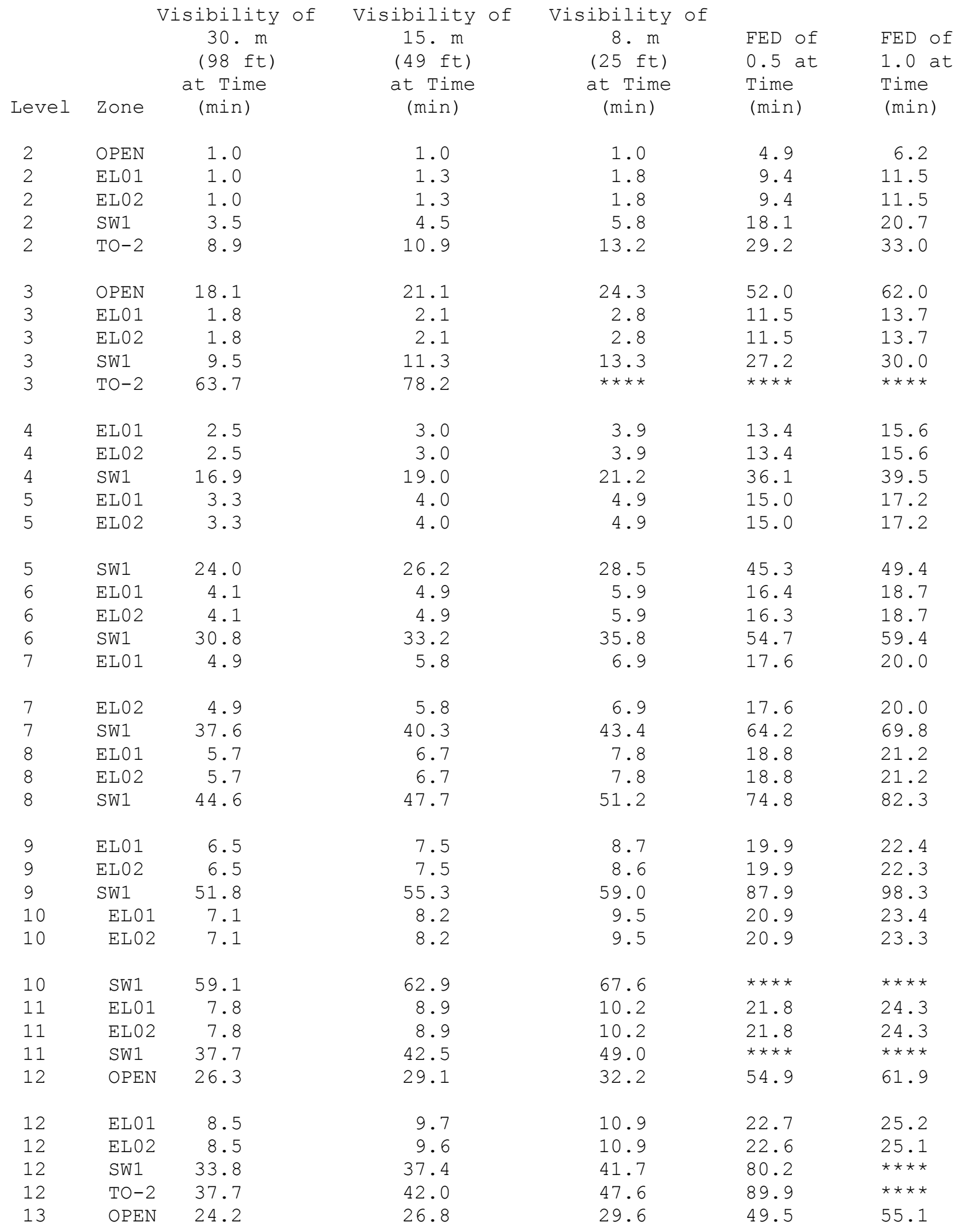


Table 07 . Continued.

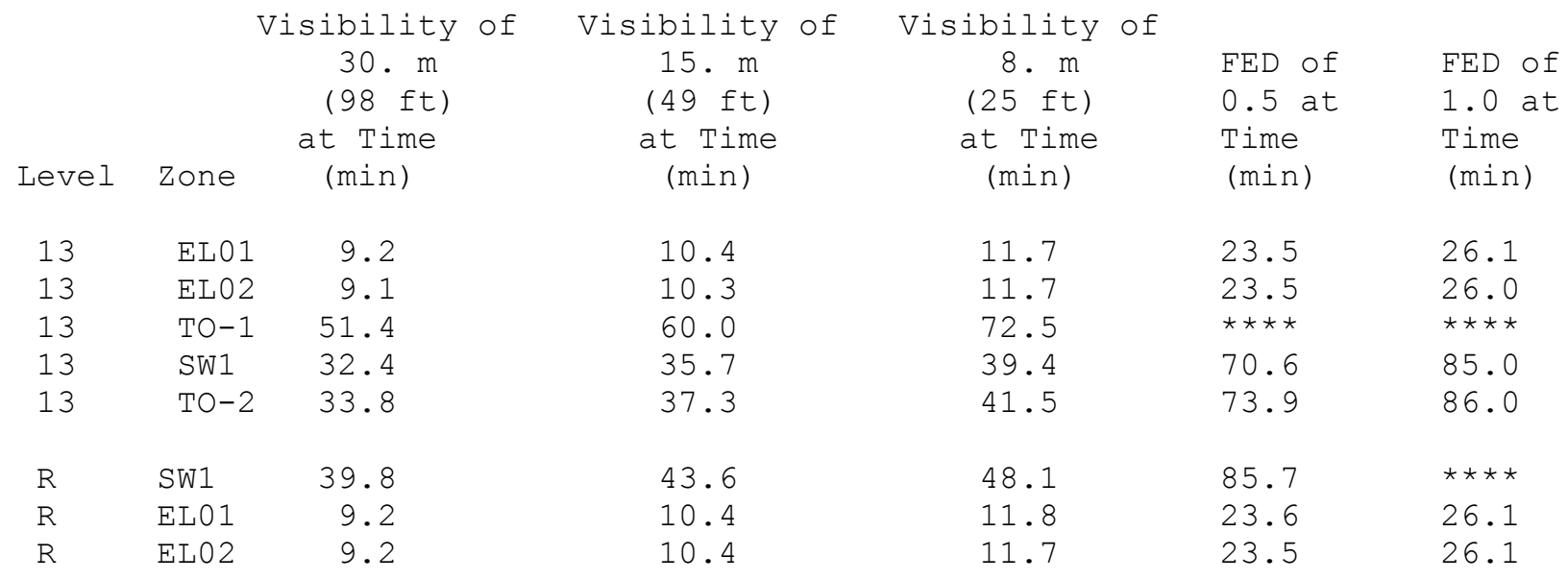


Table 08. Results of Tenability Analysis for Scenario 08.

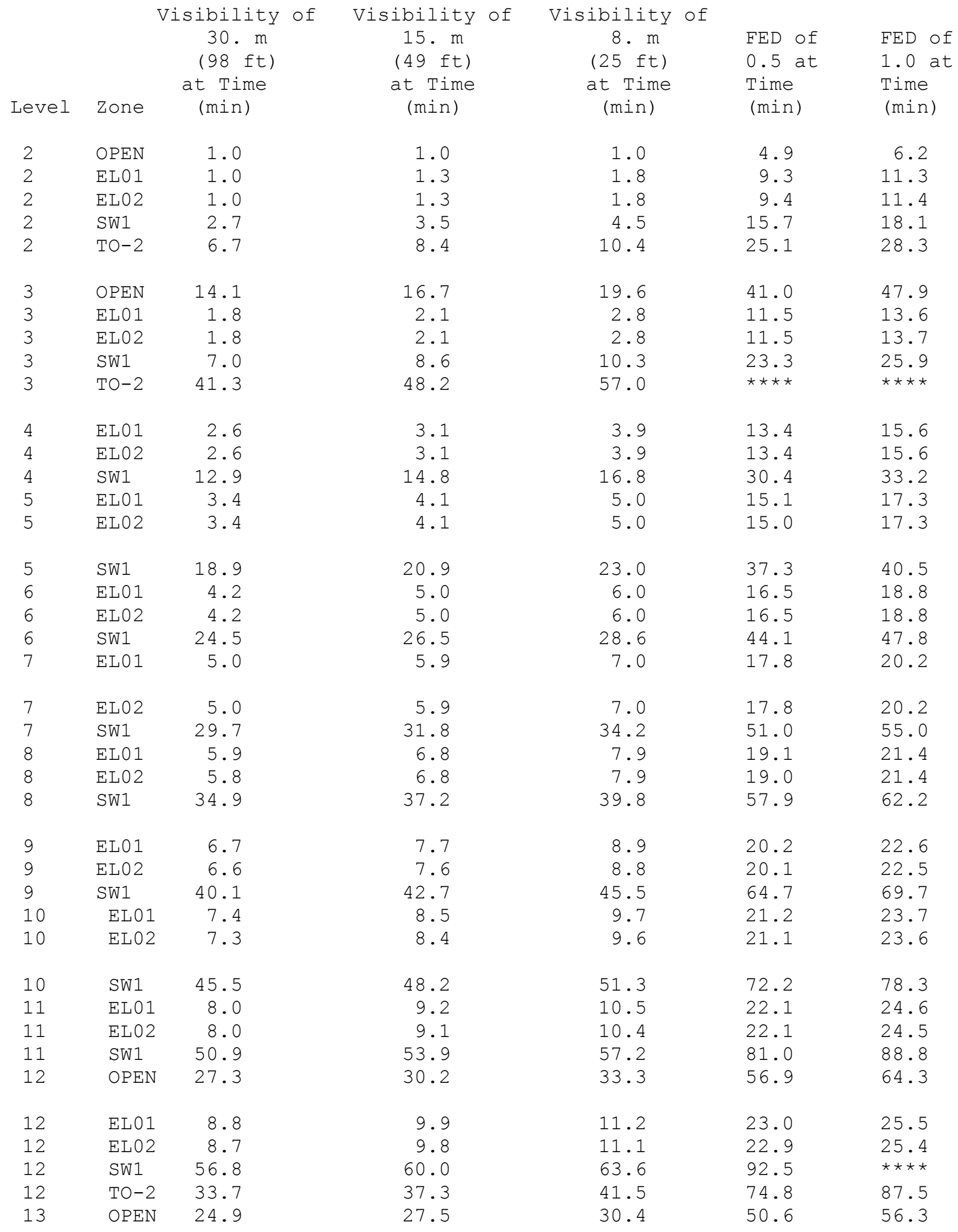


Table 08. Continued.

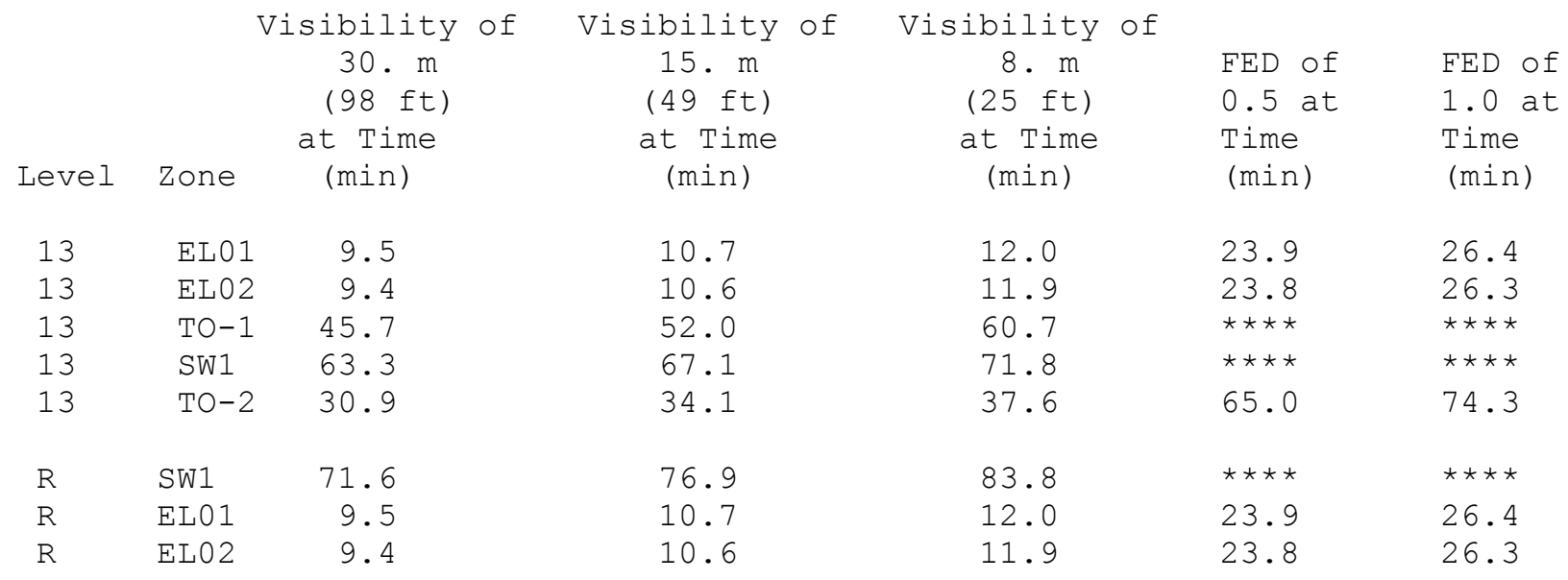


Table 09. Results of Tenability Analysis for Scenario 09.

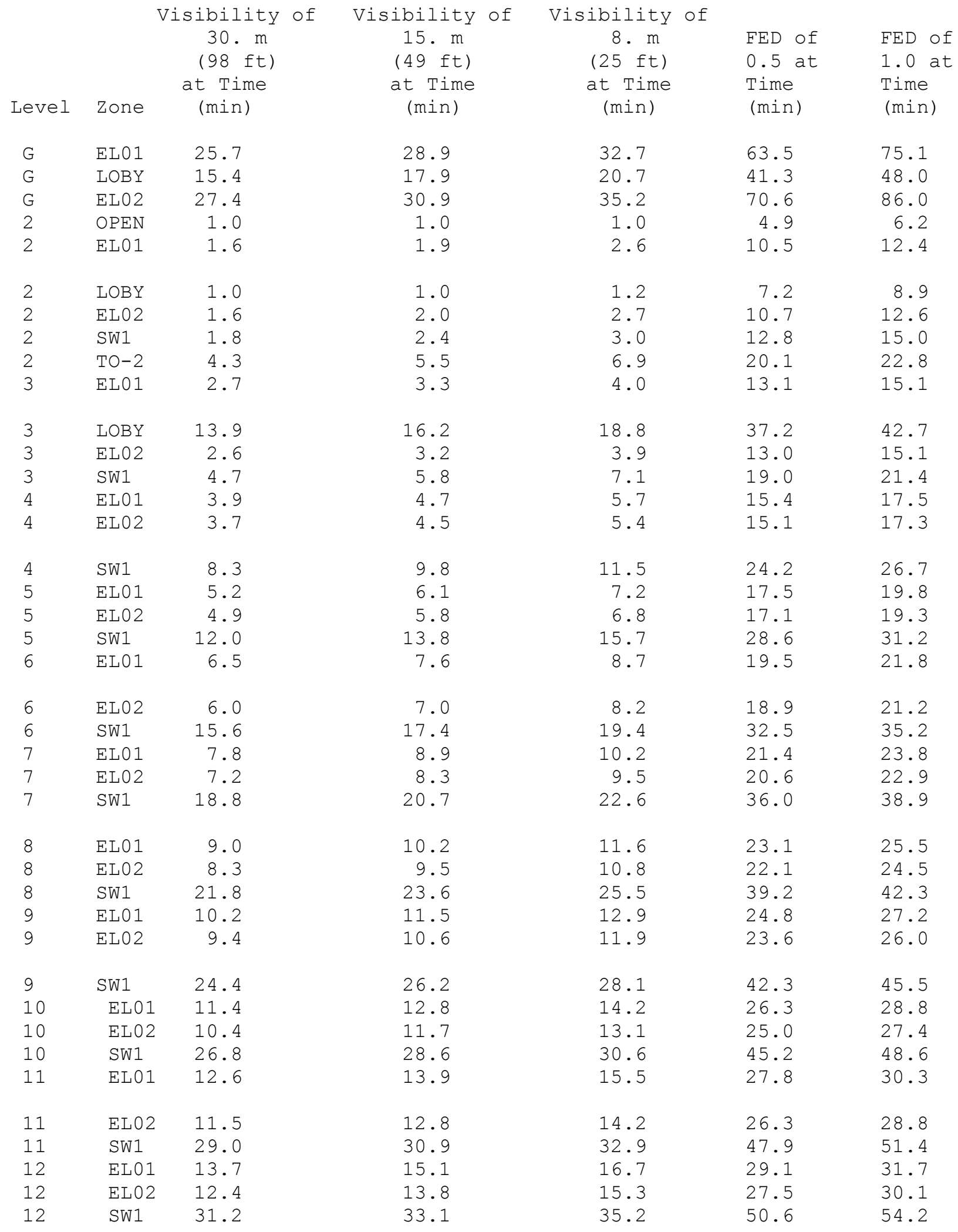


Table 09. Continued.

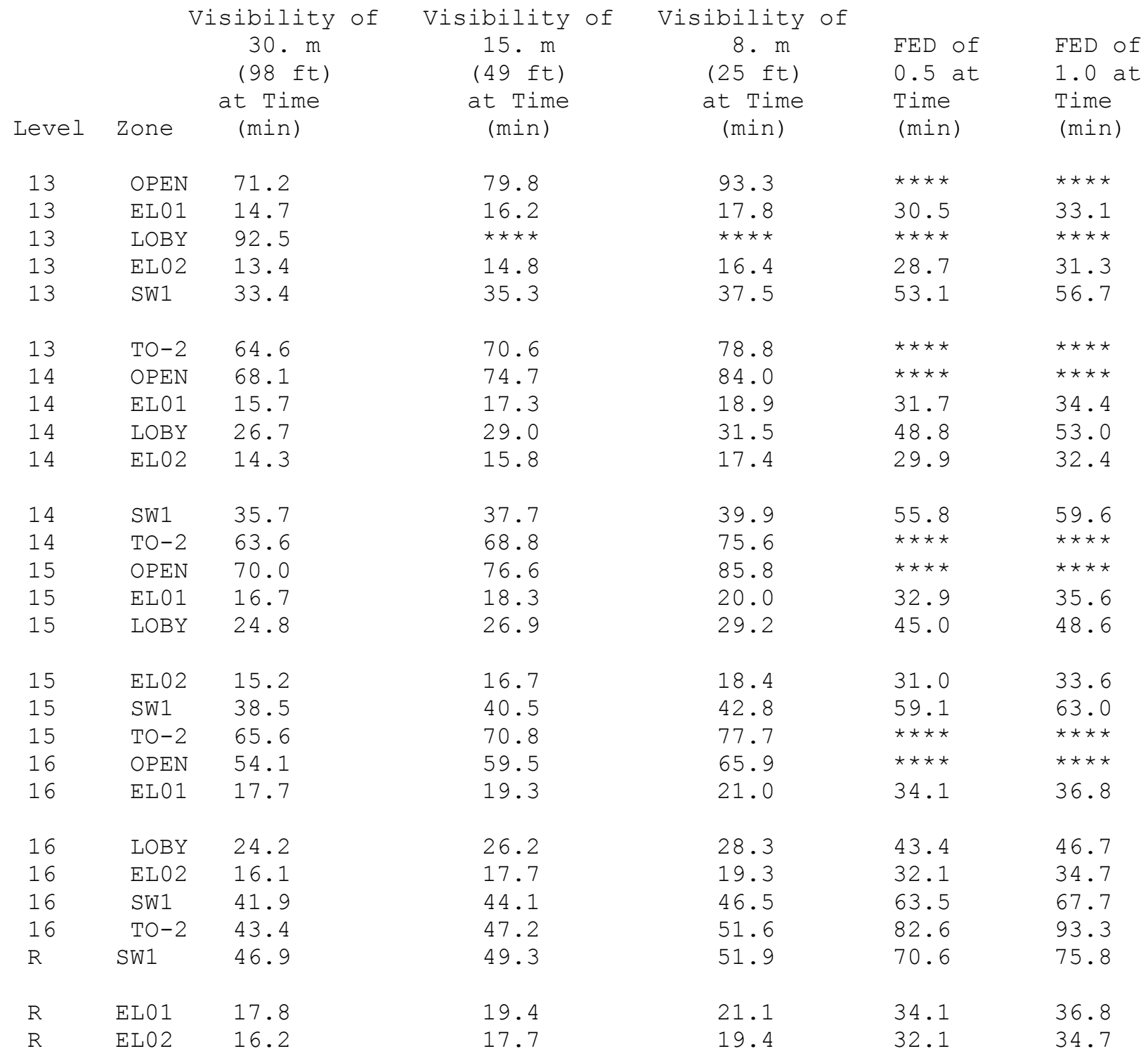


Table 10. Results of Tenability Analysis for Scenario 10.

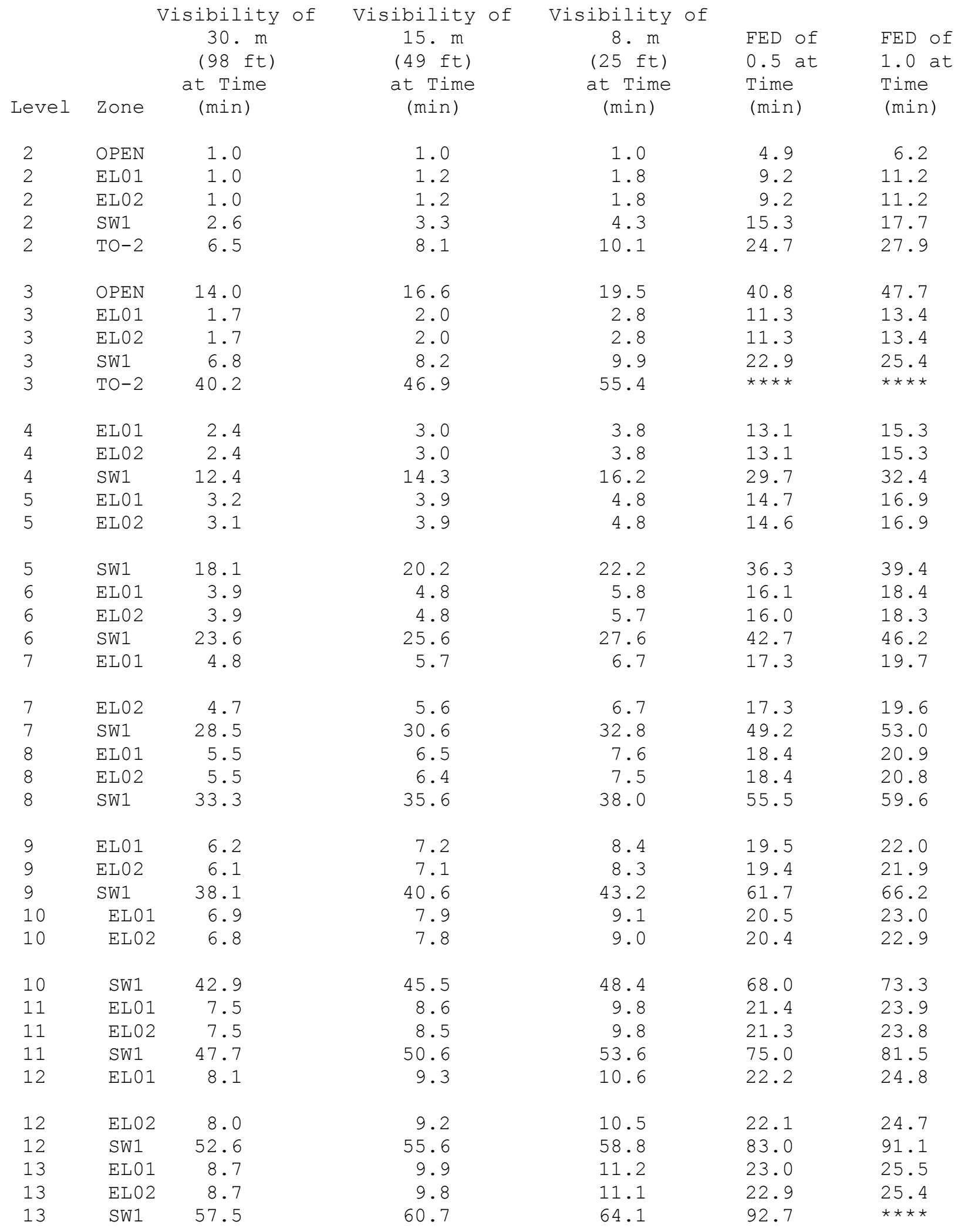


Table 10. Continued.

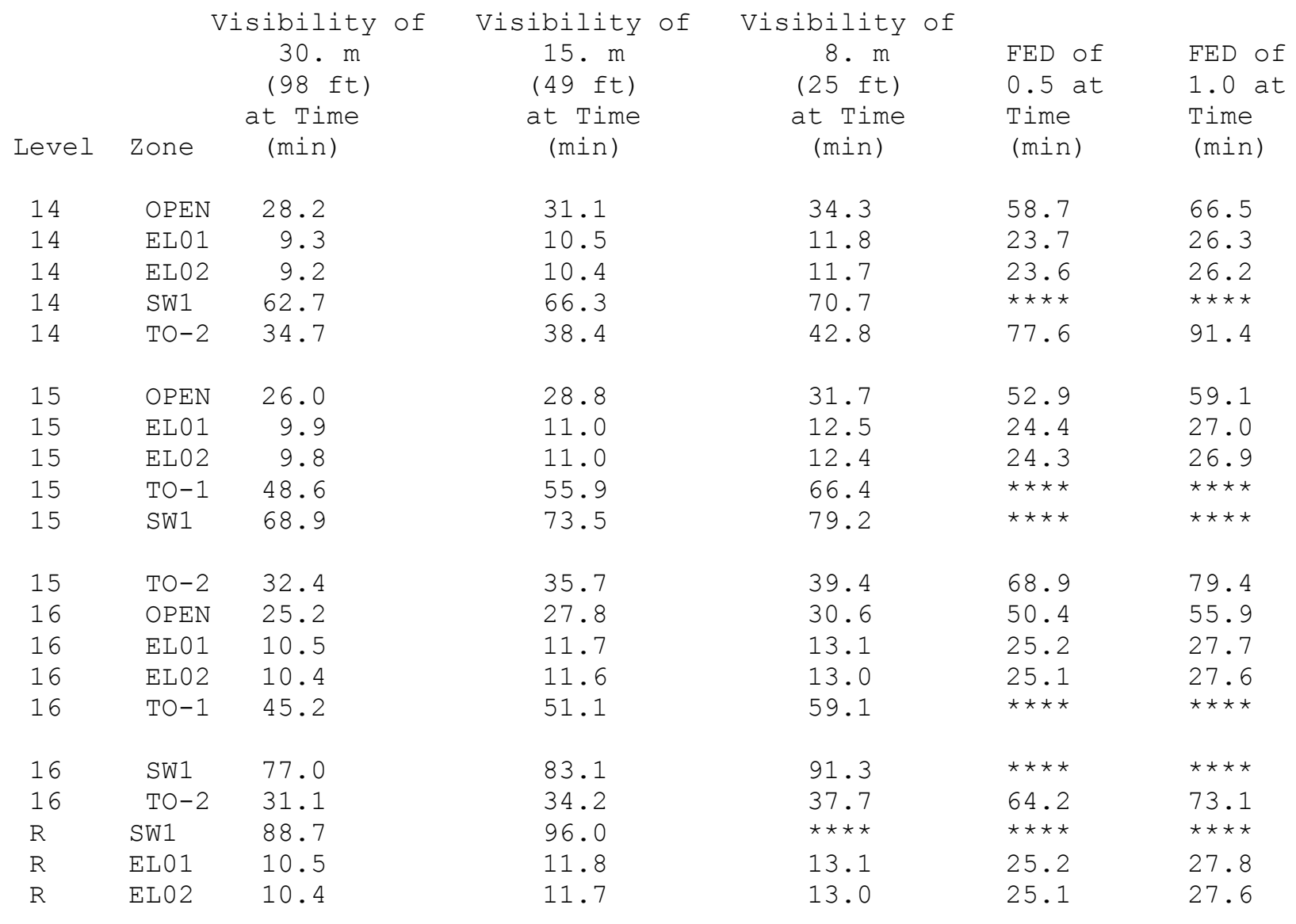


Table 11. Results of Tenability Analysis for Scenario 11.

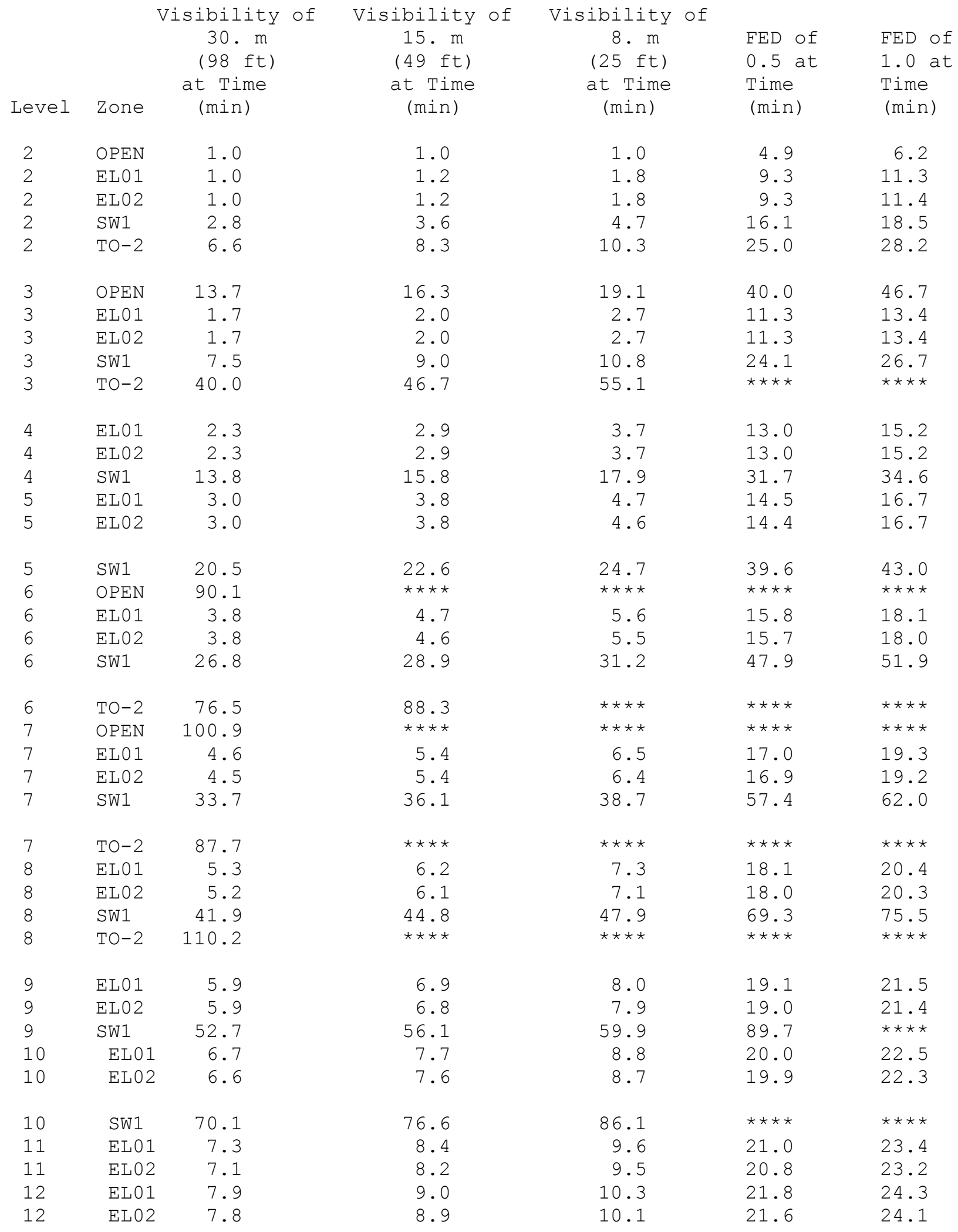


Table 11. Continued.

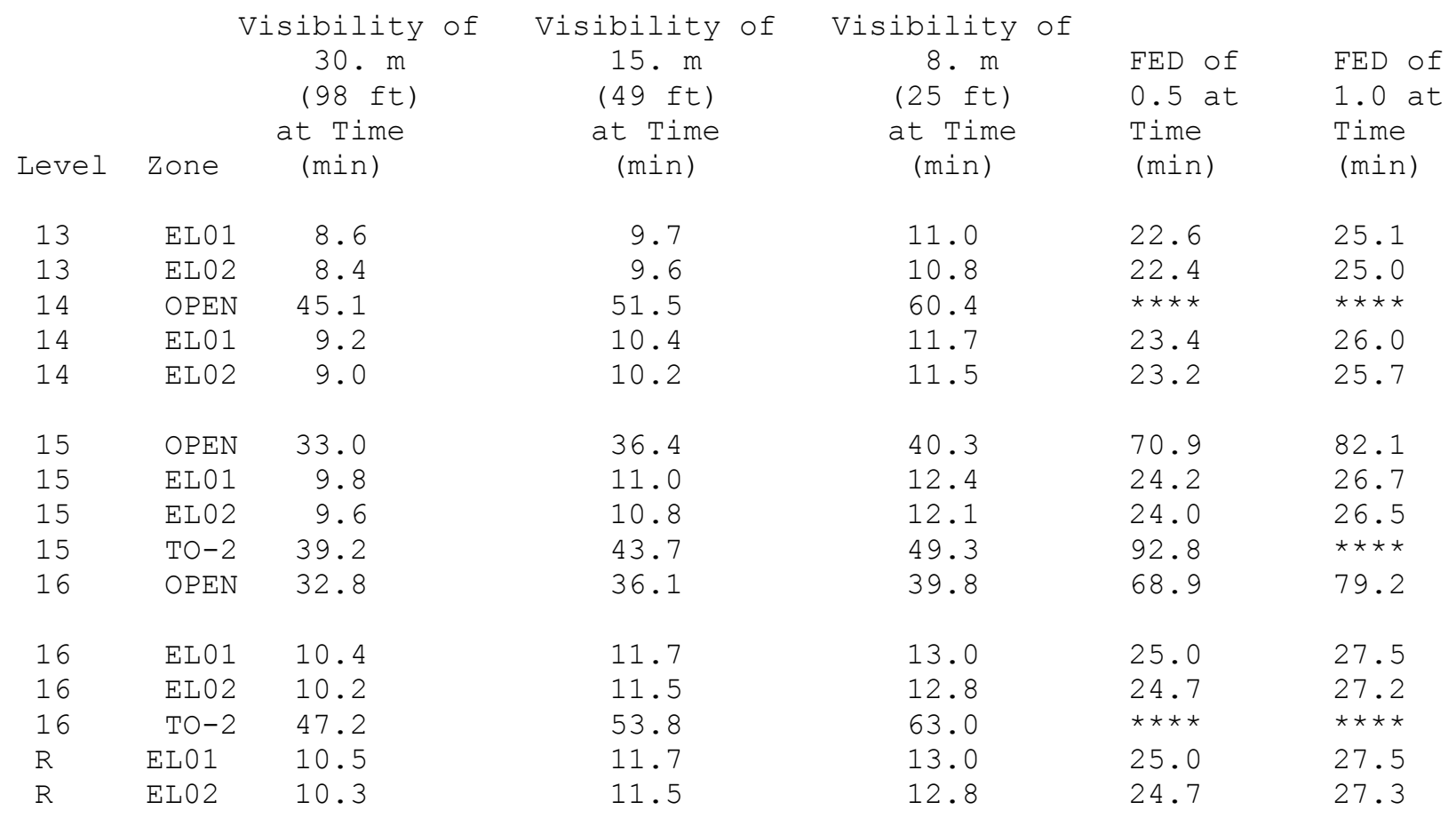


Table 12. Results of Tenability Analysis for Scenario 12.

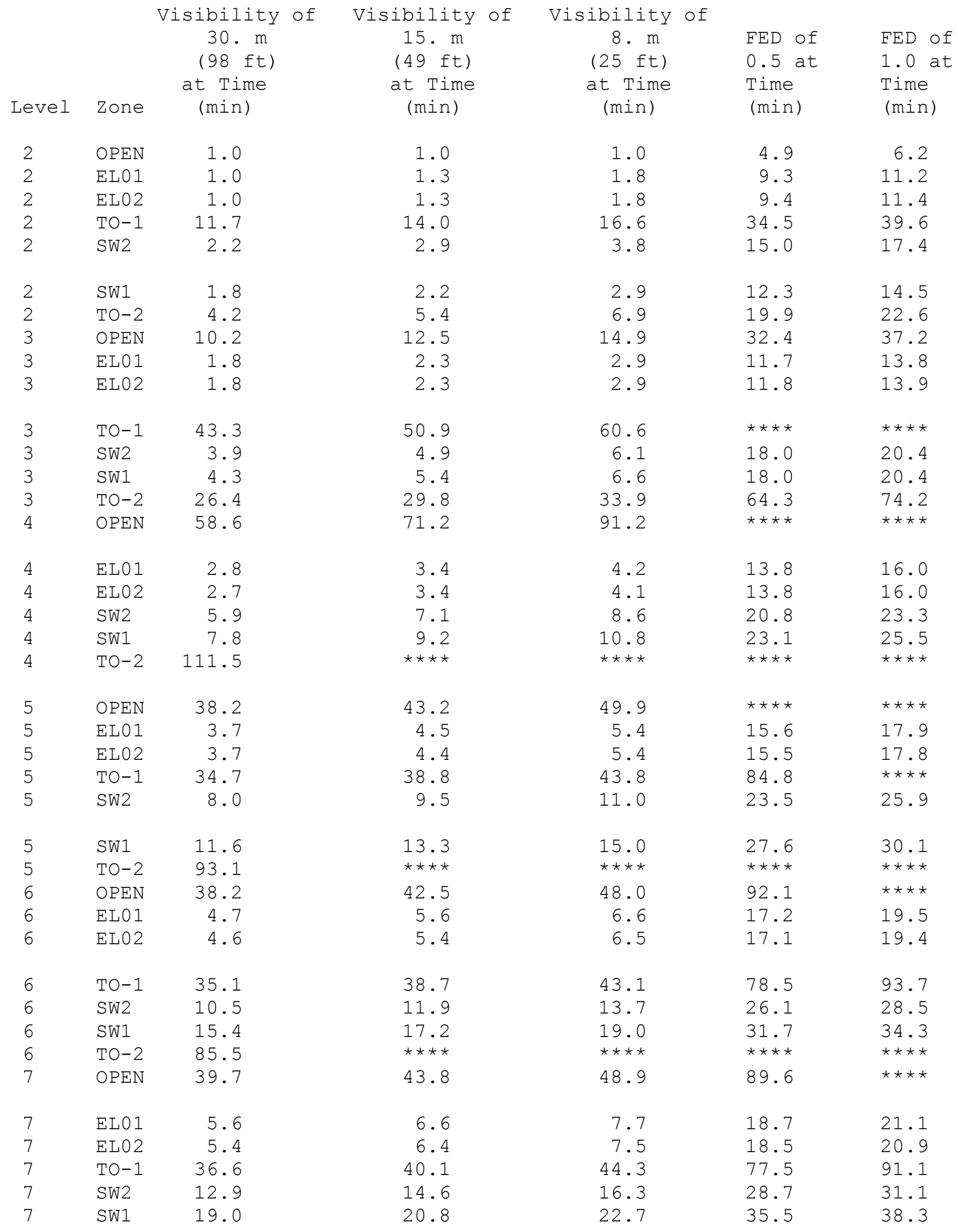


Table 12. Continued.

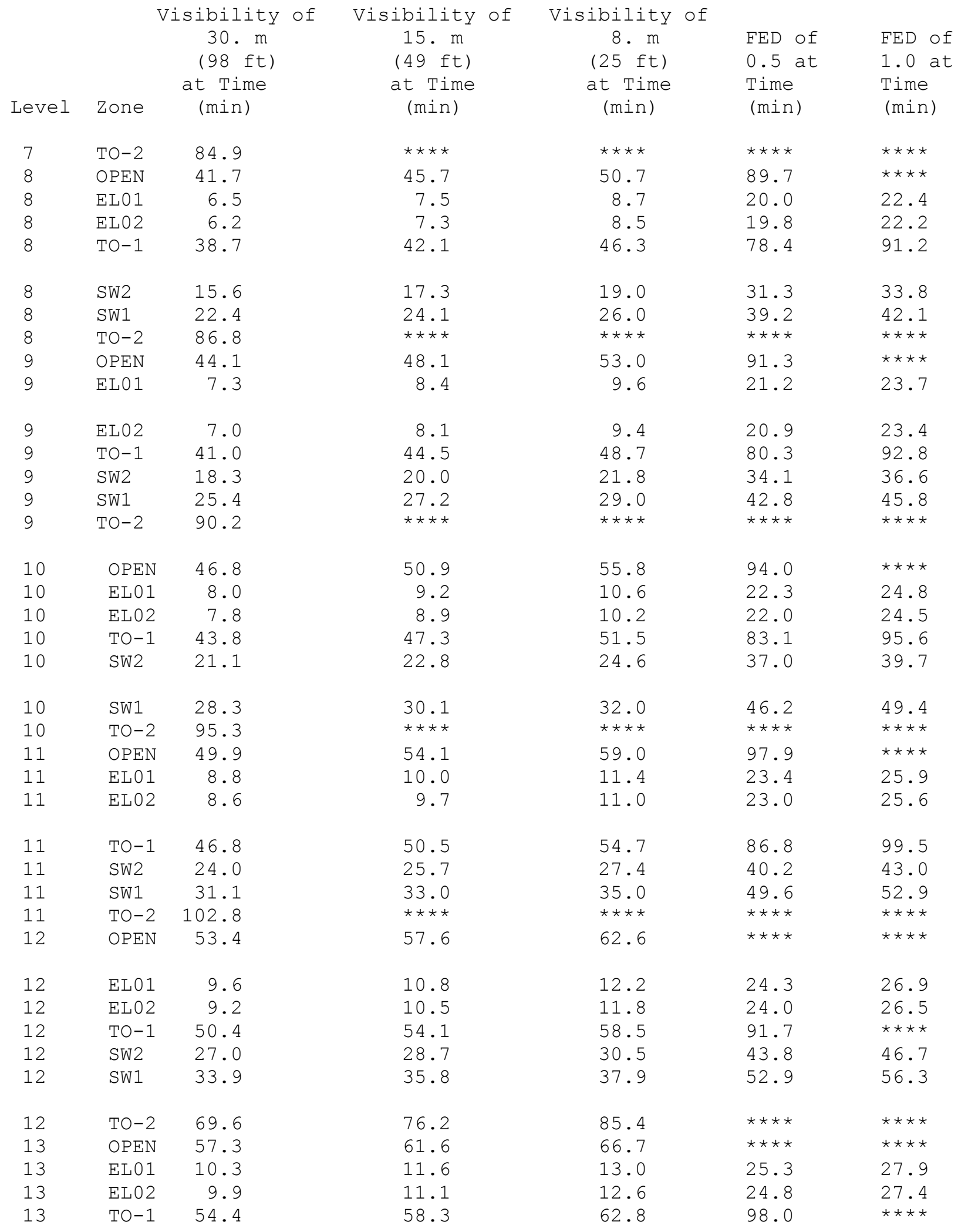


Table 12. Continued.

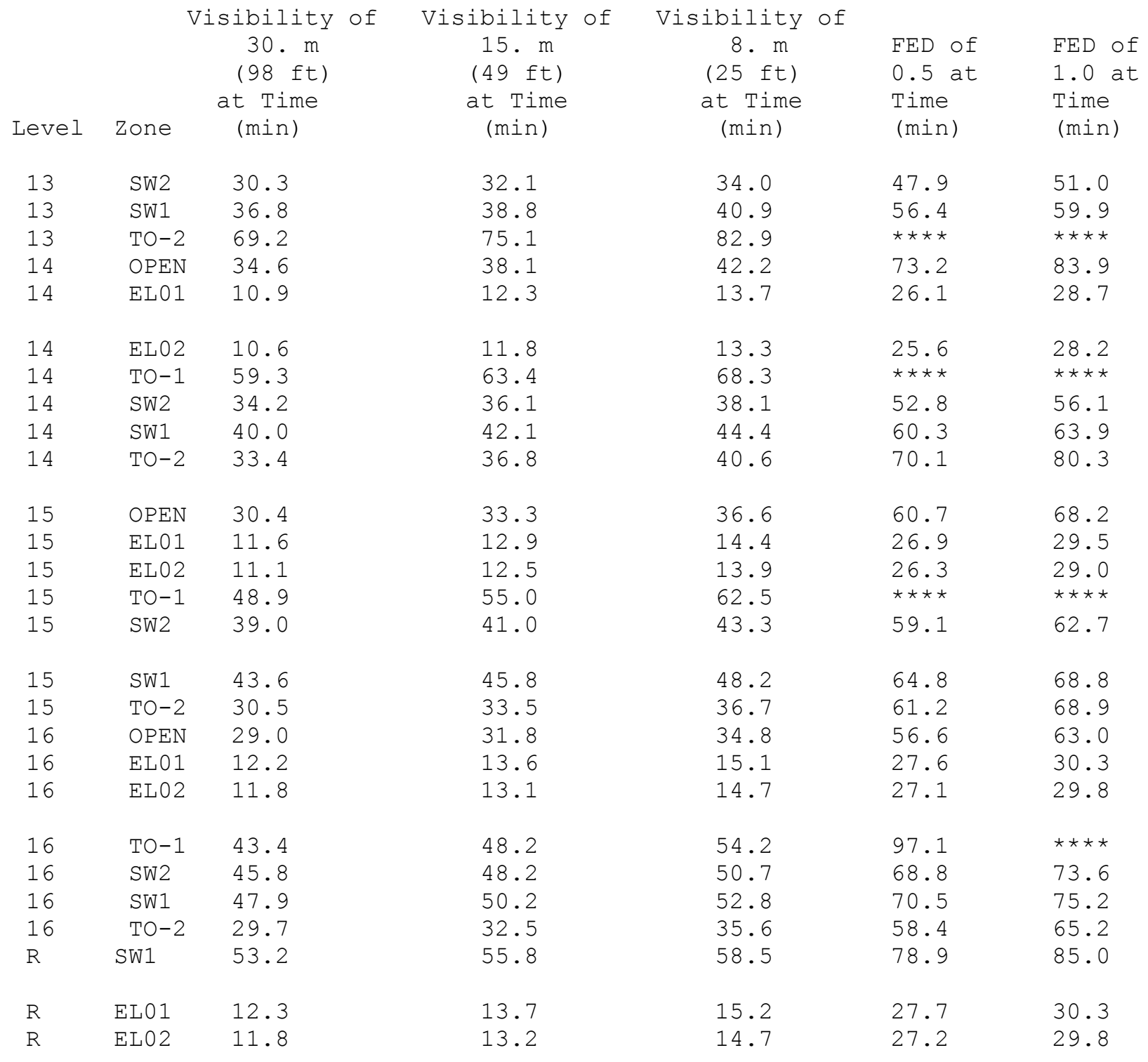


Table 13. Results of Tenability Analysis for Scenario 13.

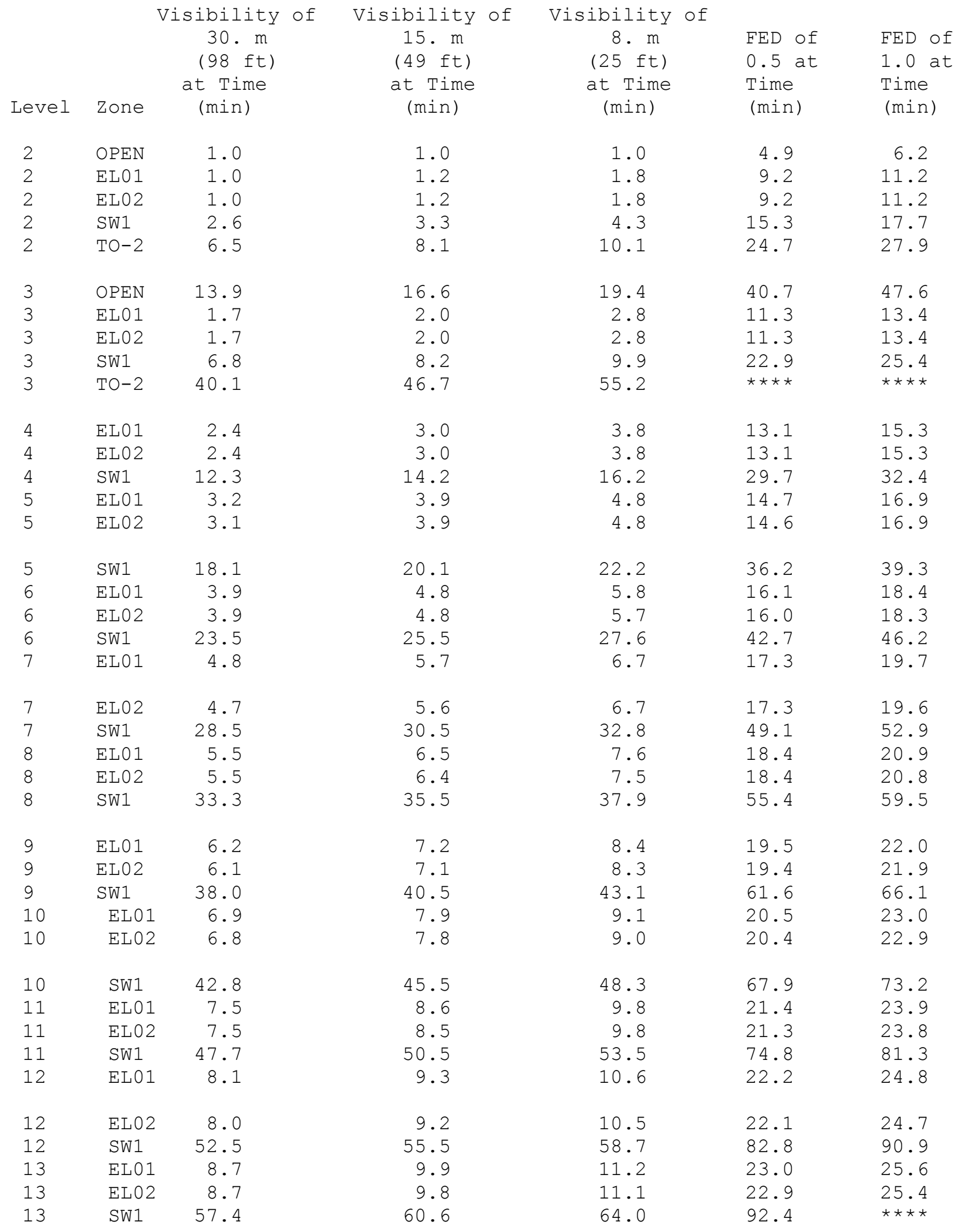


Table 13. Continued.

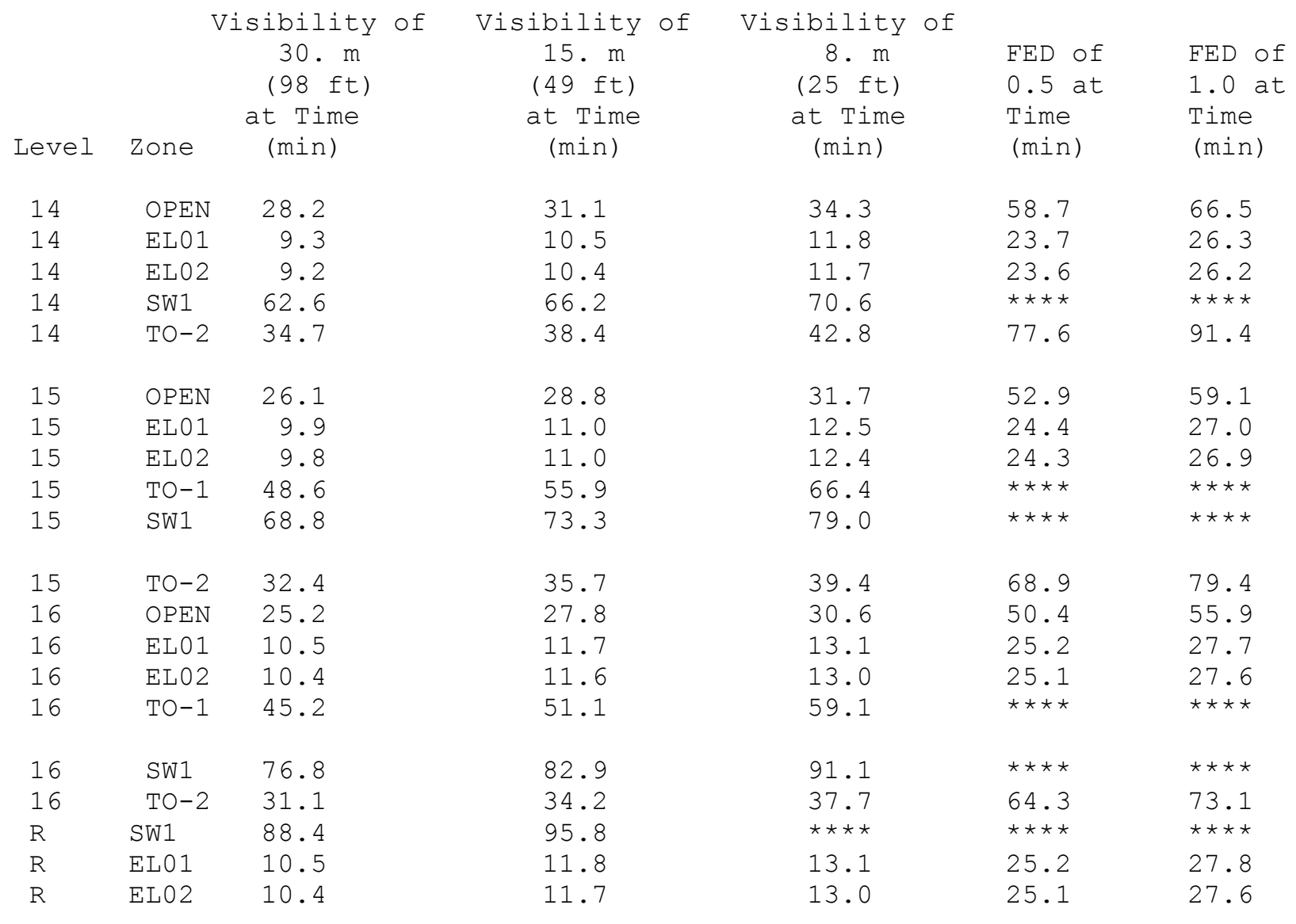


Table 14. Results of Tenability Analysis for Scenario 14.

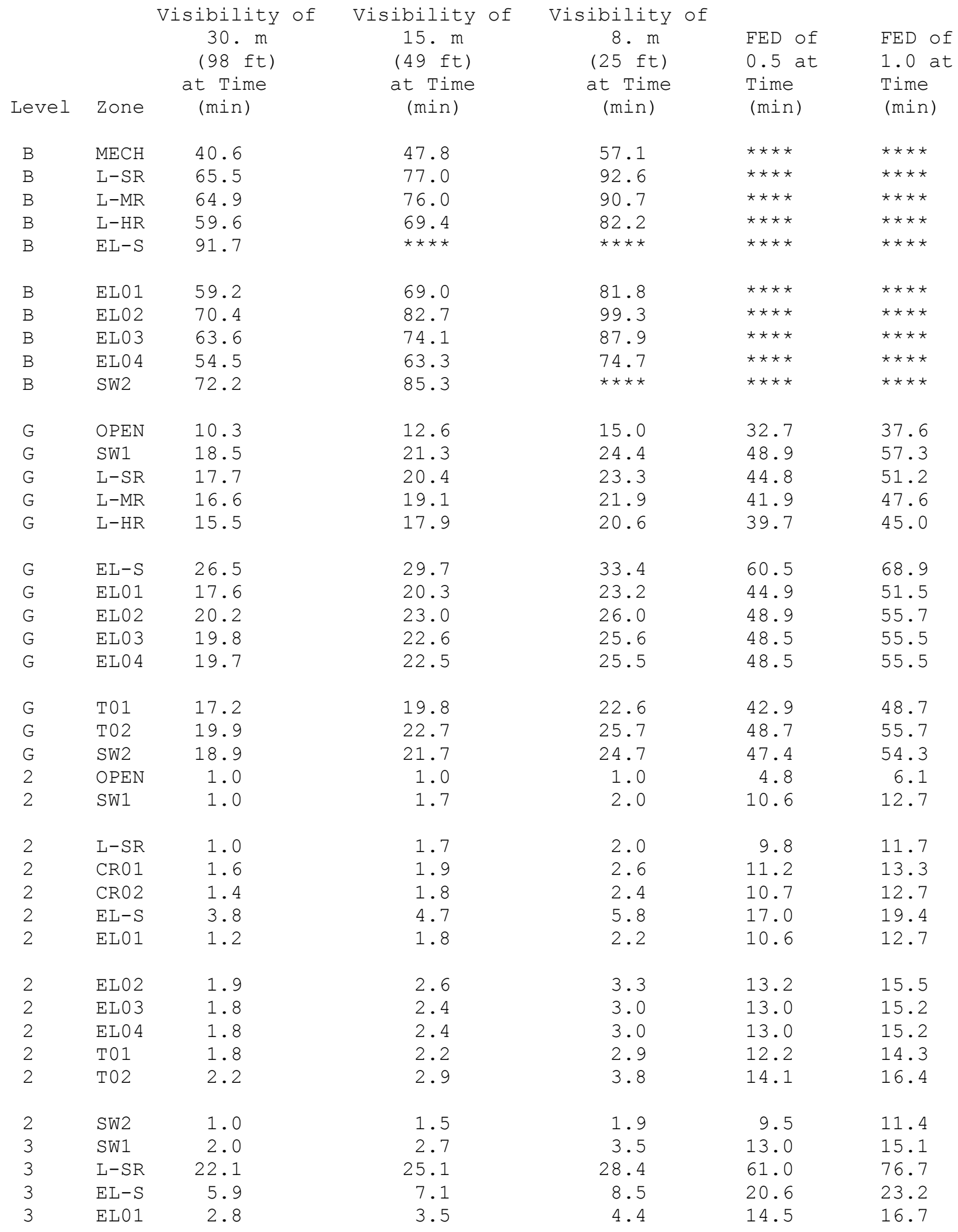


Table 14. Continued.

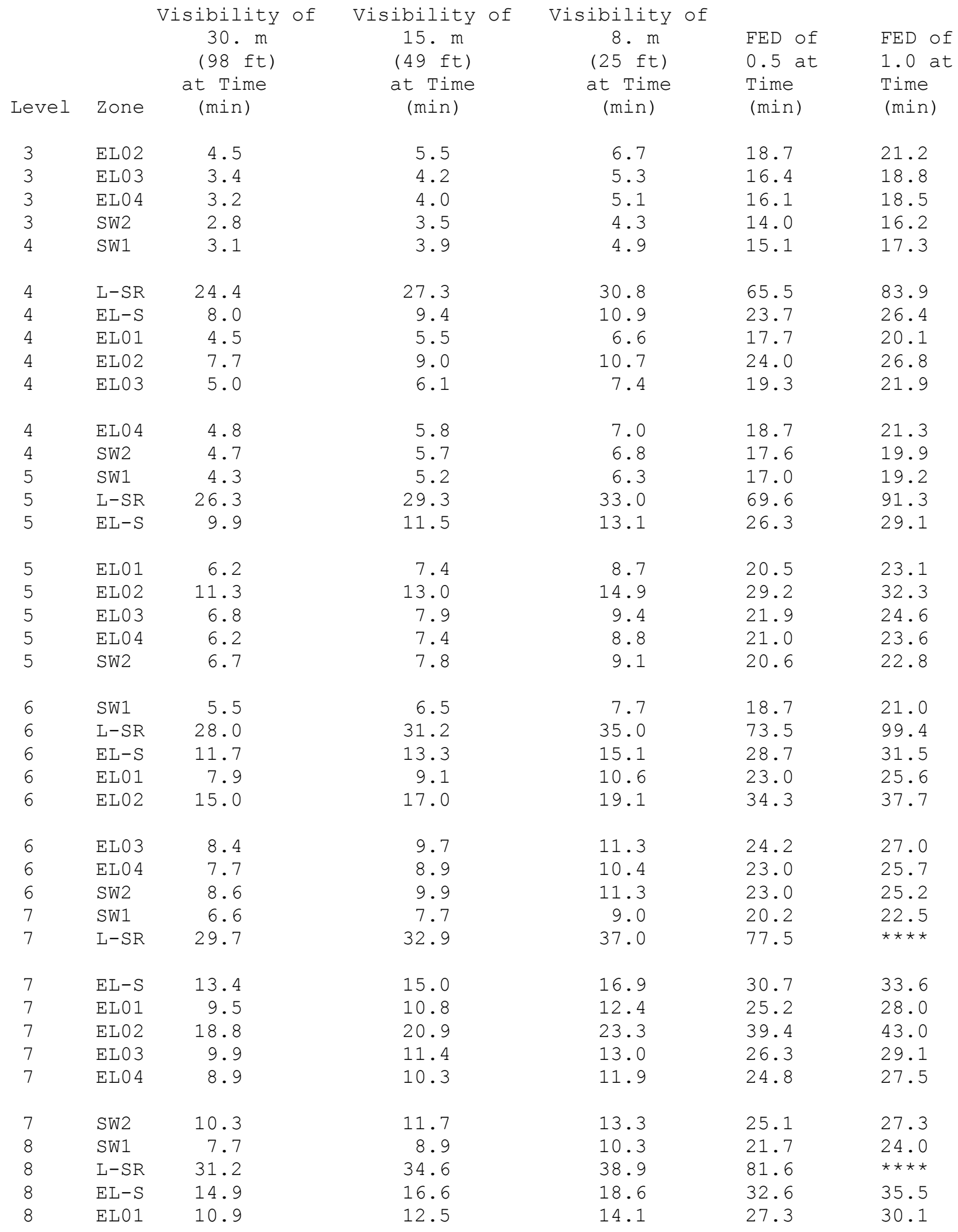


Table 14. Continued.

\begin{tabular}{|c|c|c|c|c|c|c|}
\hline Level & Zone & $\begin{array}{l}\text { sibility of } \\
30 . \mathrm{m} \\
(98 \mathrm{ft}) \\
\text { at Time } \\
\text { (min) }\end{array}$ & $\begin{array}{c}\text { Visibility of } \\
15 . \mathrm{m} \\
(49 \mathrm{ft}) \\
\text { at Time } \\
\text { (min) }\end{array}$ & $\begin{array}{c}\text { Visibility of } \\
8 . \mathrm{m} \\
(25 \mathrm{ft}) \\
\text { at Time } \\
\text { (min) }\end{array}$ & $\begin{array}{l}\text { FED of } \\
0.5 \text { at } \\
\text { Time } \\
\text { (min) }\end{array}$ & $\begin{array}{l}\text { FED of } \\
1.0 \text { at } \\
\text { Time } \\
\text { (min) }\end{array}$ \\
\hline 8 & EL02 & 22.6 & 24.9 & 27.4 & 44.3 & 48.3 \\
\hline 8 & EL03 & 11.3 & 12.9 & 14.6 & 28.2 & 31.1 \\
\hline 8 & ELO 4 & 10.1 & 11.6 & 13.3 & 26.4 & 29.1 \\
\hline 8 & SW2 & 11.9 & 13.5 & 15.1 & 26.8 & 29.1 \\
\hline 9 & SW1 & 8.8 & 10.0 & 11.5 & 23.0 & 25.2 \\
\hline 9 & $L-S R$ & 32.7 & 36.2 & 40.7 & 86.2 & 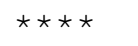 \\
\hline 9 & $E L-S$ & 16.3 & 18.1 & 20.1 & 34.3 & 37.3 \\
\hline 9 & EL01 & 12.4 & 13.9 & 15.7 & 29.1 & 32.0 \\
\hline 9 & EL02 & 26.3 & 28.8 & 31.4 & 49.2 & 53.5 \\
\hline 9 & EL03 & 12.7 & 14.3 & 16.1 & 30.0 & 32.9 \\
\hline 9 & ELO 4 & 11.3 & 12.8 & 14.5 & 27.8 & 30.6 \\
\hline 9 & sW2 & 13.5 & 15.0 & 16.7 & 28.4 & 30.7 \\
\hline 10 & SW1 & 9.9 & 11.2 & 12.7 & 24.2 & 26.4 \\
\hline 10 & $\mathrm{~L}-\mathrm{SR}$ & 34.2 & 37.9 & 42.7 & 91.6 & 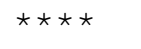 \\
\hline 10 & $E L-S$ & 17.6 & 19.5 & 21.5 & 35.9 & 39.0 \\
\hline 10 & EL01 & 13.7 & 15.3 & 17.1 & 30.8 & 33.7 \\
\hline 10 & EL02 & 30.0 & 32.6 & 35.4 & 54.1 & 58.6 \\
\hline 10 & ELO3 & 13.9 & 15.6 & 17.5 & 31.6 & 34.6 \\
\hline 10 & ELO 4 & 12.4 & 13.9 & 15.7 & 29.1 & 31.9 \\
\hline 10 & sw2 & 14.9 & 16.5 & 18.1 & 29.8 & 32.1 \\
\hline 11 & SW1 & 10.9 & 12.3 & 13.8 & 25.4 & 27.7 \\
\hline 11 & $L-S R$ & 36.1 & 40.0 & 45.1 & 98.5 & 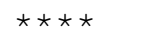 \\
\hline 11 & $E L-S$ & 18.8 & 20.7 & 22.8 & 37.3 & 40.5 \\
\hline 11 & EL01 & 14.9 & 16.6 & 18.5 & 32.4 & 35.3 \\
\hline 11 & EL02 & 33.7 & 36.4 & 39.3 & 58.8 & 63.6 \\
\hline 11 & EL03 & 15.1 & 16.8 & 18.8 & 33.1 & 36.2 \\
\hline 11 & ELO 4 & 13.4 & 15.0 & 16.8 & 30.3 & 33.2 \\
\hline 11 & SW2 & 16.2 & 17.8 & 19.6 & 31.4 & 33.8 \\
\hline 12 & SW1 & 11.9 & 13.3 & 14.9 & 26.7 & 29.0 \\
\hline 12 & $L-S R$ & 38.1 & 42.3 & 47.9 & 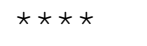 & 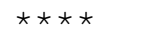 \\
\hline 12 & $E L-S$ & 20.0 & 21.9 & 24.0 & 38.7 & 41.9 \\
\hline 12 & EL01 & 16.1 & 17.9 & 19.8 & 33.9 & 36.9 \\
\hline 12 & EL02 & 37.3 & 40.1 & 43.1 & 63.5 & 68.5 \\
\hline 12 & EL03 & 16.2 & 18.0 & 20.0 & 34.5 & 37.6 \\
\hline 12 & ELO 4 & 14.4 & 16.0 & 17.8 & 31.5 & 34.4 \\
\hline 12 & SW2 & 17.5 & 19.1 & 20.9 & 32.9 & 35.3 \\
\hline 13 & SW1 & 12.9 & 14.3 & 15.9 & 27.9 & 30.2 \\
\hline 13 & $L-S R$ & 40.3 & 44.8 & 51.1 & 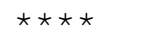 & 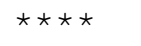 \\
\hline 13 & $E L-S$ & 21.1 & 23.1 & 25.2 & 40.0 & 43.3 \\
\hline 13 & EL01 & 17.3 & 19.0 & 21.0 & 35.3 & 38.3 \\
\hline
\end{tabular}


Table 14. Continued.

\begin{tabular}{|c|c|c|c|c|c|c|}
\hline Level & Zone & $\begin{array}{l}\text { sibility of } \\
30 . \mathrm{m} \\
(98 \mathrm{ft}) \\
\text { at Time } \\
\text { (min) }\end{array}$ & $\begin{array}{c}\text { Visibility of } \\
15 . \mathrm{m} \\
(49 \mathrm{ft}) \\
\text { at Time } \\
\text { (min) }\end{array}$ & $\begin{array}{c}\text { Visibility of } \\
8 . \mathrm{m} \\
(25 \mathrm{ft}) \\
\text { at Time } \\
\text { (min) }\end{array}$ & $\begin{array}{l}\text { FED of } \\
0.5 \text { at } \\
\text { Time } \\
\text { (min) }\end{array}$ & $\begin{array}{l}\text { FED of } \\
1.0 \text { at } \\
\text { Time } \\
\text { (min) }\end{array}$ \\
\hline 13 & ELO2 & 40.8 & 43.8 & 47.0 & 68.1 & 73.4 \\
\hline 13 & ELO3 & 17.3 & 19.1 & 21.1 & 35.8 & 39.0 \\
\hline 13 & ELO 4 & 15.3 & 16.9 & 18.8 & 32.6 & 35.5 \\
\hline 13 & SW2 & 18.7 & 20.4 & 22.1 & 34.3 & 36.8 \\
\hline 14 & SW1 & 13.8 & 15.3 & 16.9 & 29.0 & 31.3 \\
\hline 14 & $L-S R$ & 42.3 & 47.1 & 53.9 & 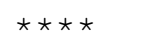 & 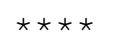 \\
\hline 14 & $\mathrm{~L}-\mathrm{MR}$ & 28.1 & 30.6 & 33.2 & 51.4 & 55.8 \\
\hline 14 & $E L-S$ & 22.1 & 24.1 & 26.3 & 41.2 & 44.5 \\
\hline 14 & EL01 & 18.3 & 20.1 & 22.1 & 36.5 & 39.6 \\
\hline 14 & ELO2 & 36.2 & 39.1 & 42.3 & 63.7 & 69.3 \\
\hline 14 & EL03 & 18.3 & 20.2 & 22.2 & 37.1 & 40.3 \\
\hline 14 & ELO 4 & 16.1 & 17.8 & 19.7 & 33.6 & 36.5 \\
\hline 14 & sw2 & 19.9 & 21.6 & 23.3 & 35.7 & 38.2 \\
\hline 15 & SW1 & 14.7 & 16.2 & 17.9 & 30.0 & 32.4 \\
\hline 15 & $L-S R$ & 42.1 & 46.5 & 52.4 & $\star \star \star \star$ & 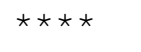 \\
\hline 15 & $\mathrm{~L}-\mathrm{MR}$ & 28.4 & 30.8 & 33.4 & 51.2 & 55.5 \\
\hline 15 & $E L-S$ & 23.1 & 25.1 & 27.3 & 42.3 & 45.6 \\
\hline 15 & EL01 & 19.3 & 21.1 & 23.2 & 37.7 & 40.9 \\
\hline 15 & EL02 & 35.5 & 38.3 & 41.3 & 62.0 & 67.4 \\
\hline 15 & EL03 & 19.3 & 21.2 & 23.3 & 38.2 & 41.5 \\
\hline 15 & ELO 4 & 16.9 & 18.7 & 20.6 & 34.6 & 37.5 \\
\hline 15 & T01 & 37.1 & 40.4 & 44.4 & 78.6 & 94.1 \\
\hline 15 & SW2 & 20.9 & 22.6 & 24.4 & 36.9 & 39.5 \\
\hline 16 & SW1 & 15.6 & 17.1 & 18.8 & 31.1 & 33.5 \\
\hline 16 & $L-S R$ & 44.5 & 49.3 & 55.8 & 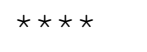 & 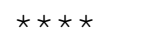 \\
\hline 16 & $\mathrm{~L}-\mathrm{MR}$ & 29.3 & 31.7 & 34.3 & 52.1 & 56.4 \\
\hline 16 & $\mathrm{EL}-\mathrm{S}$ & 24.0 & 26.0 & 28.2 & 43.4 & 46.7 \\
\hline 16 & EL01 & 20.3 & 22.2 & 24.2 & 38.9 & 42.1 \\
\hline 16 & EL02 & 35.8 & 38.5 & 41.5 & 61.7 & 67.0 \\
\hline 16 & EL03 & 20.2 & 22.1 & 24.3 & 39.3 & 42.7 \\
\hline 16 & ELO 4 & 17.8 & 19.5 & 21.5 & 35.5 & 38.5 \\
\hline 16 & SW2 & 21.9 & 23.7 & 25.5 & 38.1 & 40.7 \\
\hline 17 & SW1 & 16.5 & 18.0 & 19.7 & 32.1 & 34.5 \\
\hline 17 & $L-S R$ & 49.8 & 56.1 & 65.2 & 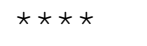 & 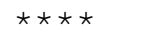 \\
\hline 17 & $\mathrm{~L}-\mathrm{MR}$ & 30.3 & 32.7 & 35.3 & 53.2 & 57.5 \\
\hline 17 & $\mathrm{EL}-\mathrm{S}$ & 24.9 & 27.0 & 29.2 & 44.4 & 47.8 \\
\hline 17 & EL01 & 21.4 & 23.2 & 25.3 & 40.1 & 43.3 \\
\hline 17 & EL02 & 36.3 & 39.0 & 42.0 & 62.1 & 67.2 \\
\hline 17 & EL03 & 21.1 & 23.0 & 25.2 & 40.4 & 43.8 \\
\hline 17 & ELO 4 & 18.5 & 20.3 & 22.2 & 36.3 & 39.4 \\
\hline
\end{tabular}


Table 14. Continued.

\begin{tabular}{|c|c|c|c|c|c|c|}
\hline Level & Zone & $\begin{array}{l}\text { sibility of } \\
30 . \mathrm{m} \\
(98 \mathrm{ft}) \\
\text { at Time } \\
\text { (min) }\end{array}$ & $\begin{array}{c}\text { Visibility of } \\
15 . \mathrm{m} \\
(49 \mathrm{ft}) \\
\text { at Time } \\
\text { (min) }\end{array}$ & $\begin{array}{c}\text { Visibility of } \\
8 . \mathrm{m} \\
(25 \mathrm{ft}) \\
\text { at Time } \\
\text { (min) }\end{array}$ & $\begin{array}{l}\text { FED of } \\
0.5 \text { at } \\
\text { Time } \\
\text { (min) }\end{array}$ & $\begin{array}{l}\text { FED of } \\
1.0 \text { at } \\
\text { Time } \\
\text { (min) }\end{array}$ \\
\hline 17 & SW2 & 22.9 & 24.7 & 26.5 & 39.2 & 41.9 \\
\hline 18 & SW1 & 17.3 & 18.9 & 20.7 & 33.1 & 35.5 \\
\hline 18 & $\mathrm{~L}-\mathrm{MR}$ & 31.3 & 33.8 & 36.4 & 54.4 & 58.7 \\
\hline 18 & $E L-S$ & 25.8 & 27.9 & 30.1 & 45.4 & 48.8 \\
\hline 18 & EL01 & 22.4 & 24.3 & 26.4 & 41.3 & 44.5 \\
\hline 18 & ELO2 & 37.0 & 39.8 & 42.7 & 62.6 & 67.7 \\
\hline 18 & ELO3 & 21.9 & 23.9 & 26.1 & 41.4 & 44.8 \\
\hline 18 & ELO 4 & 19.2 & 21.0 & 23.0 & 37.2 & 40.2 \\
\hline 18 & SW2 & 23.9 & 25.7 & 27.5 & 40.3 & 43.0 \\
\hline 19 & SW1 & 18.2 & 19.8 & 21.6 & 34.0 & 36.5 \\
\hline 19 & $\mathrm{~L}-\mathrm{MR}$ & 32.3 & 34.8 & 37.4 & 55.5 & 59.9 \\
\hline 19 & $E L-S$ & 26.7 & 28.7 & 31.0 & 46.3 & 49.8 \\
\hline 19 & EL01 & 23.4 & 25.3 & 27.5 & 42.5 & 45.8 \\
\hline 19 & ELO2 & 37.8 & 40.5 & 43.5 & 63.4 & 68.4 \\
\hline 19 & EL03 & 22.8 & 24.8 & 26.9 & 42.4 & 45.9 \\
\hline 19 & ELO 4 & 19.9 & 21.8 & 23.8 & 38.0 & 41.1 \\
\hline 19 & SW2 & 24.9 & 26.7 & 28.5 & 41.4 & 44.1 \\
\hline 20 & OPEN & 65.0 & 72.0 & 81.6 & 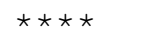 & 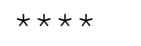 \\
\hline 20 & SW1 & 19.0 & 20.7 & 22.5 & 35.0 & 37.5 \\
\hline 20 & $L-S R$ & 41.4 & 44.3 & 47.4 & 69.0 & 74.7 \\
\hline 20 & $\mathrm{~L}-\mathrm{MR}$ & 33.4 & 35.9 & 38.5 & 56.7 & 61.1 \\
\hline 20 & CR01 & 83.2 & 93.4 & $\star \star \star \star \star$ & 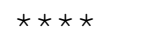 & 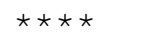 \\
\hline 20 & $E L-S$ & 27.5 & 29.6 & 31.8 & 47.3 & 50.7 \\
\hline 20 & EL01 & 24.4 & 26.4 & 28.6 & 43.7 & 47.0 \\
\hline 20 & EL02 & 38.7 & 41.4 & 44.3 & 64.2 & 69.2 \\
\hline 20 & EL03 & 23.6 & 25.6 & 27.8 & 43.4 & 46.8 \\
\hline 20 & ELO 4 & 20.6 & 22.5 & 24.5 & 38.8 & 41.9 \\
\hline 20 & T01 & 87.1 & 98.4 & 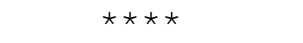 & 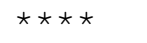 & 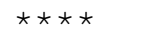 \\
\hline 20 & T02 & 49.1 & 52.8 & 56.9 & 85.4 & 94.4 \\
\hline 20 & SW2 & 25.8 & 27.6 & 29.5 & 42.5 & 45.2 \\
\hline 21 & OPEN & 47.9 & 51.9 & 56.9 & 93.5 & 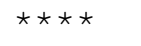 \\
\hline 21 & SW1 & 19.9 & 21.6 & 23.3 & 36.0 & 38.5 \\
\hline 21 & $L-S R$ & 40.0 & 42.7 & 45.6 & 65.6 & 70.8 \\
\hline 21 & $\mathrm{~L}-\mathrm{MR}$ & 34.4 & 36.9 & 39.6 & 57.9 & 62.3 \\
\hline 21 & CR01 & 61.3 & 67.0 & 74.1 & 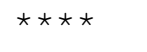 & $\star \star \star \star \star$ \\
\hline 21 & $\mathrm{EL}-\mathrm{S}$ & 28.4 & 30.5 & 32.7 & 48.2 & 51.7 \\
\hline 21 & EL01 & 25.4 & 27.5 & 29.6 & 44.9 & 48.2 \\
\hline 21 & EL02 & 39.5 & 42.2 & 45.1 & 65.0 & 70.0 \\
\hline 21 & EL03 & 24.3 & 26.4 & 28.6 & 44.3 & 47.8 \\
\hline 21 & ELO 4 & 21.3 & 23.1 & 25.2 & 39.5 & 42.7 \\
\hline
\end{tabular}


Table 14. Continued.

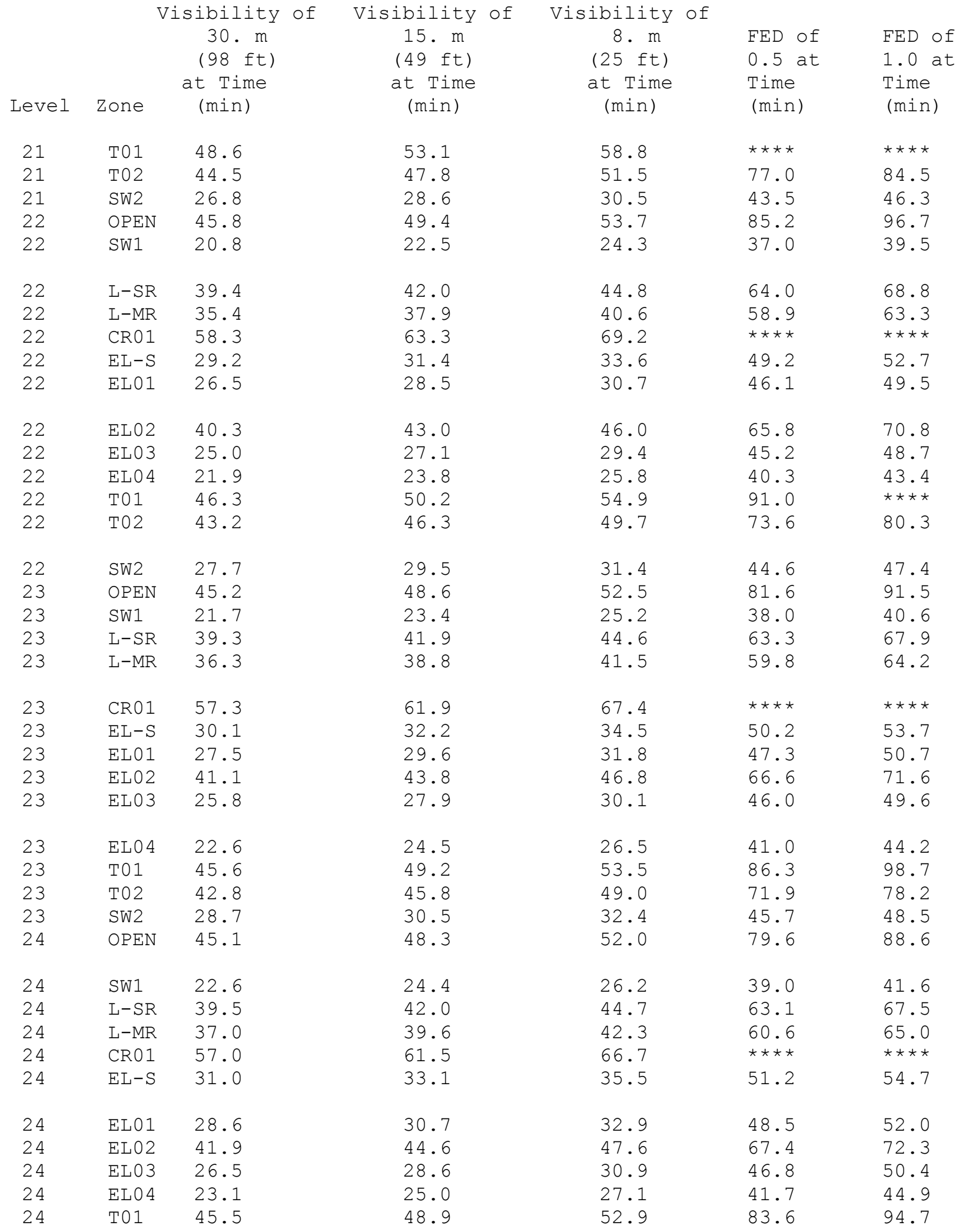


Table 14. Continued.

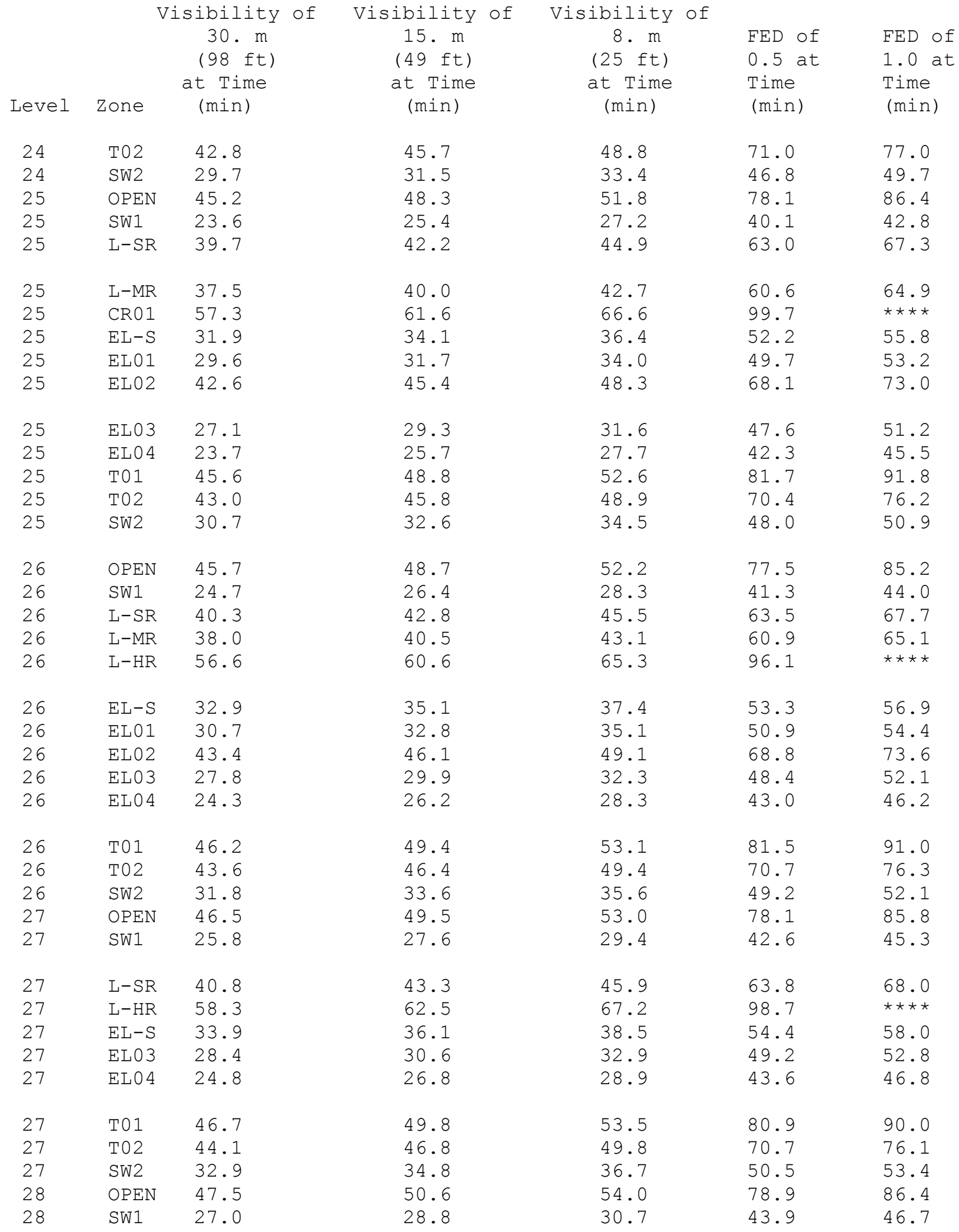


Table 14. Continued.

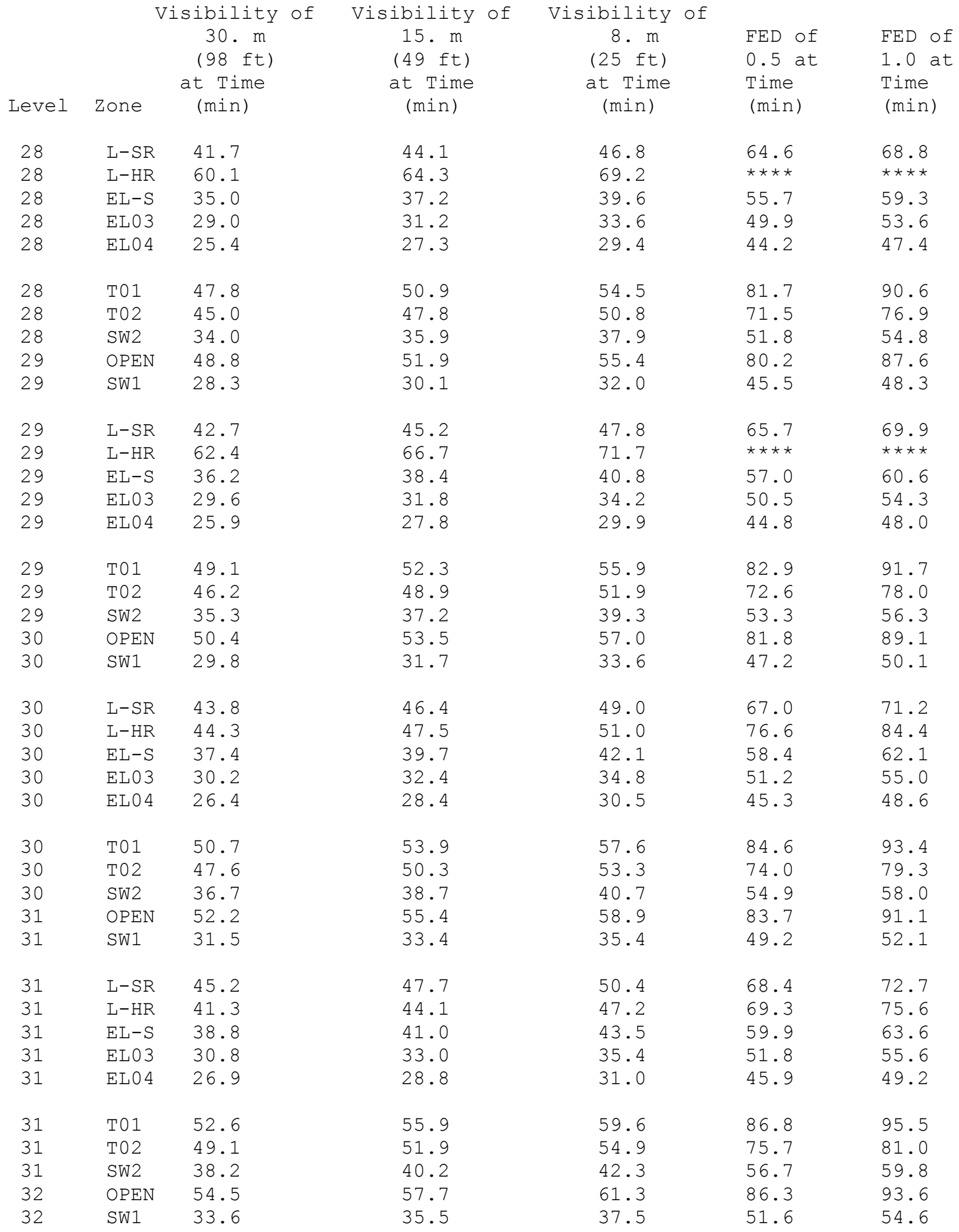


Table 14. Continued.

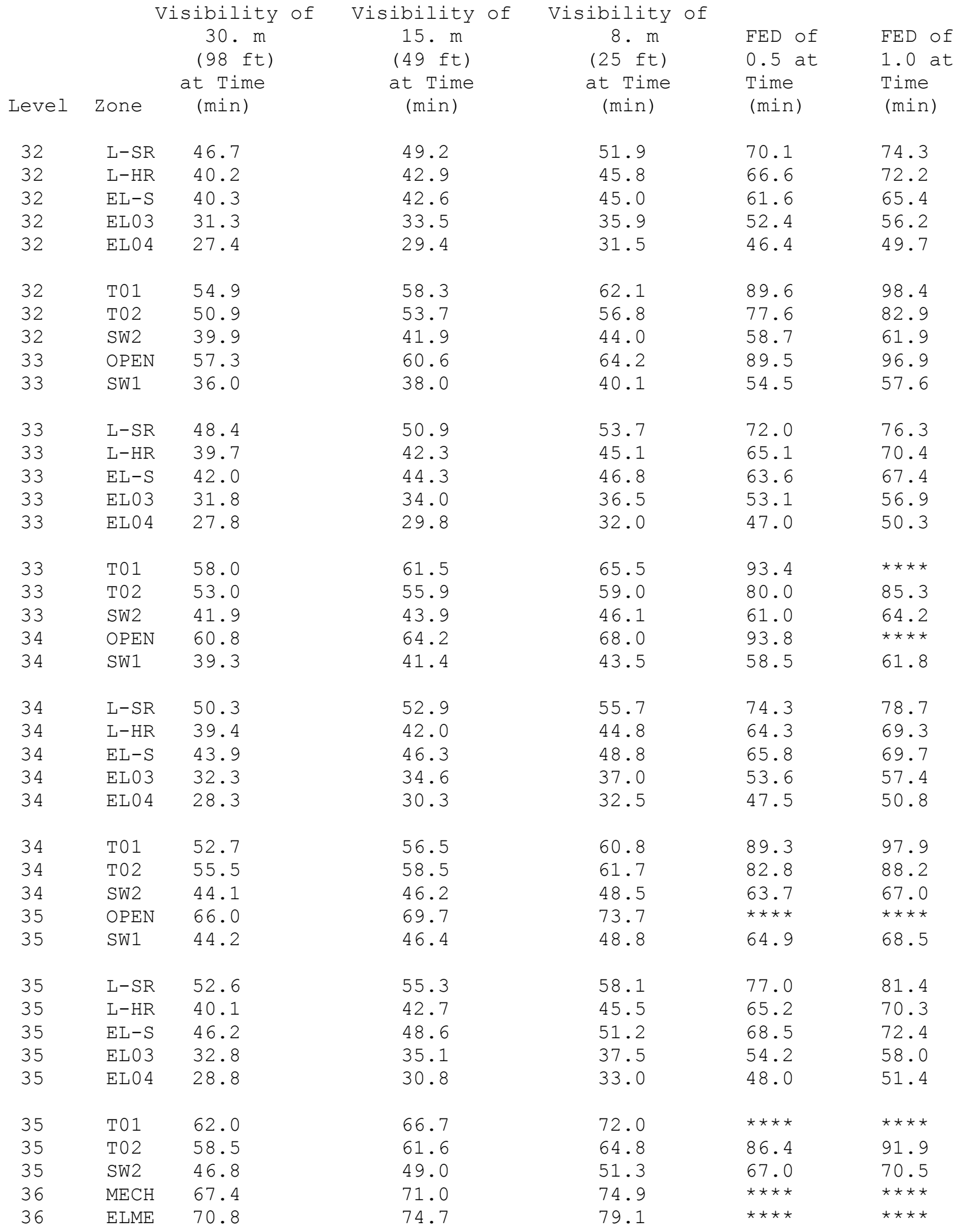


Table 14. Continued.

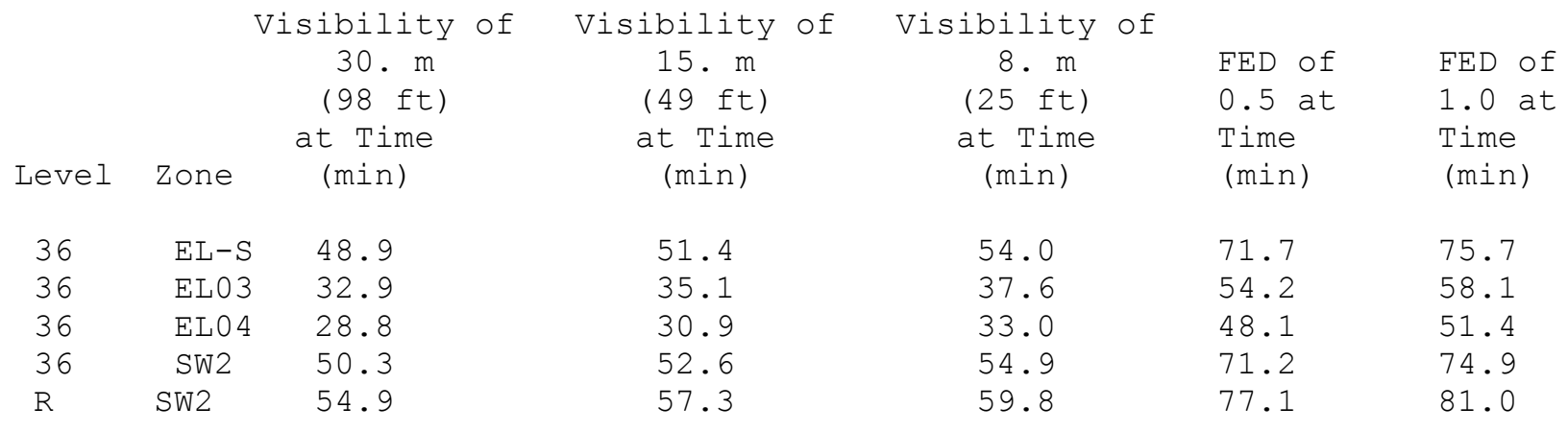


Table 15. Results of Tenability Analysis for Scenario 15.

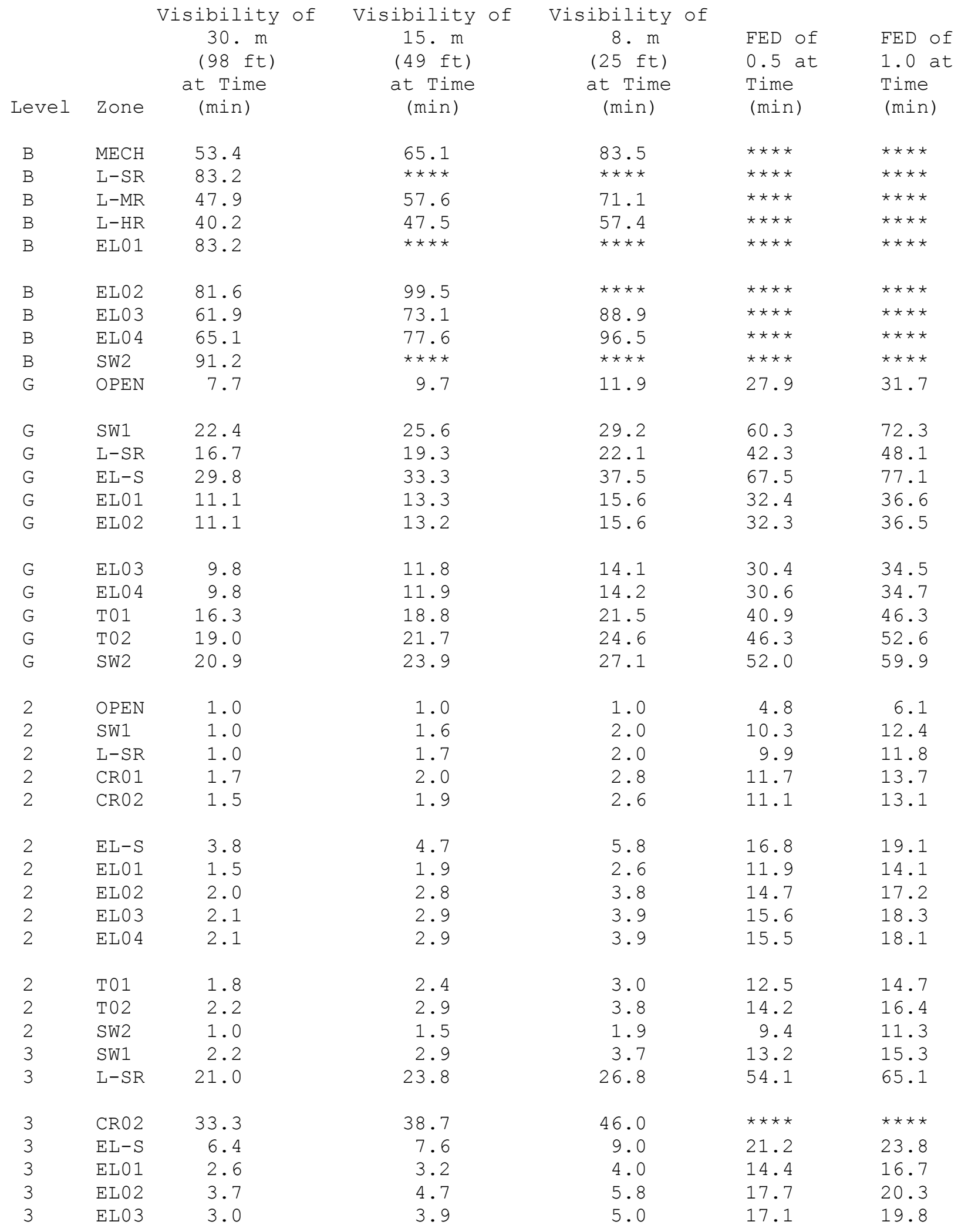


Table 15. Continued.

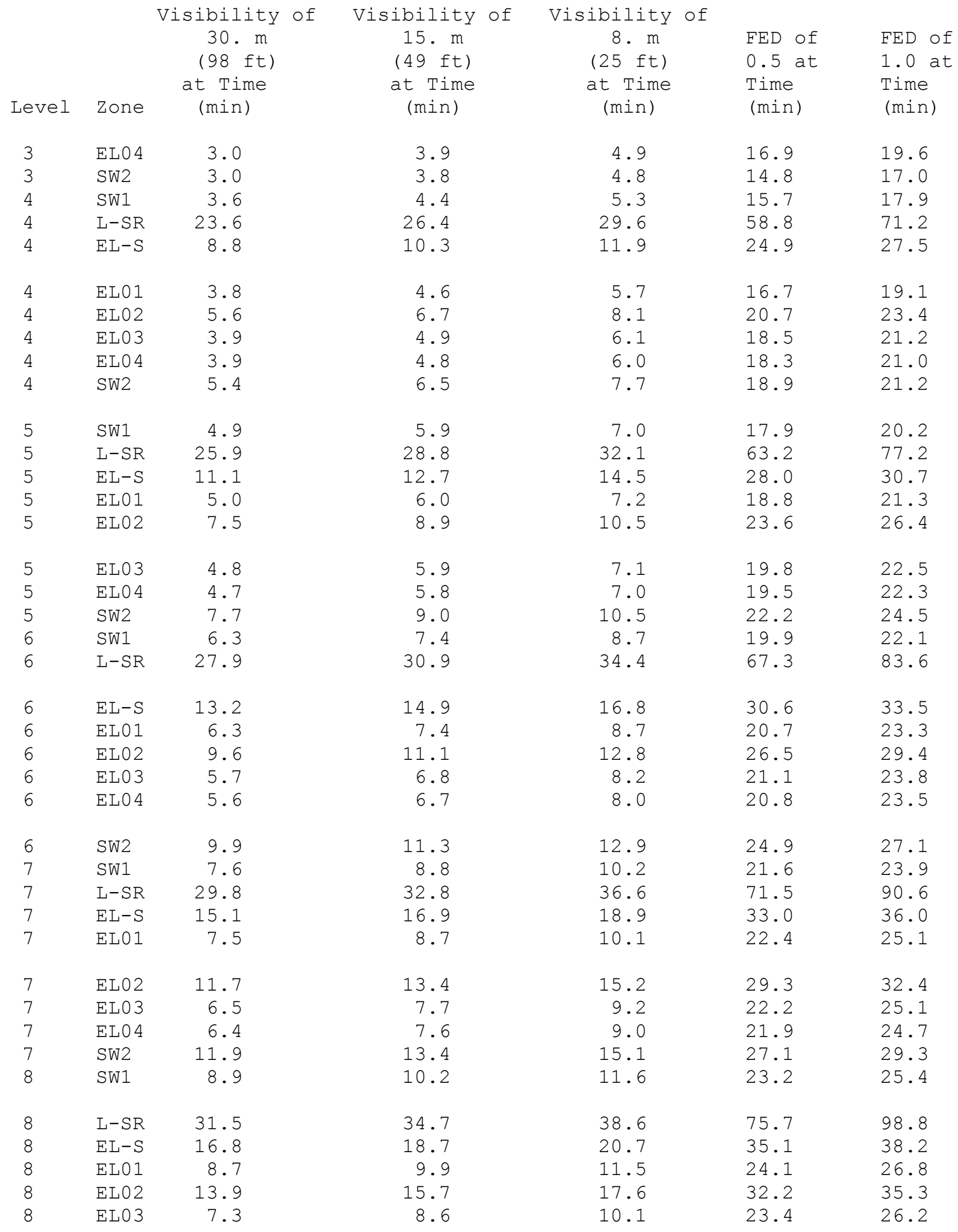


Table 15. Continued.

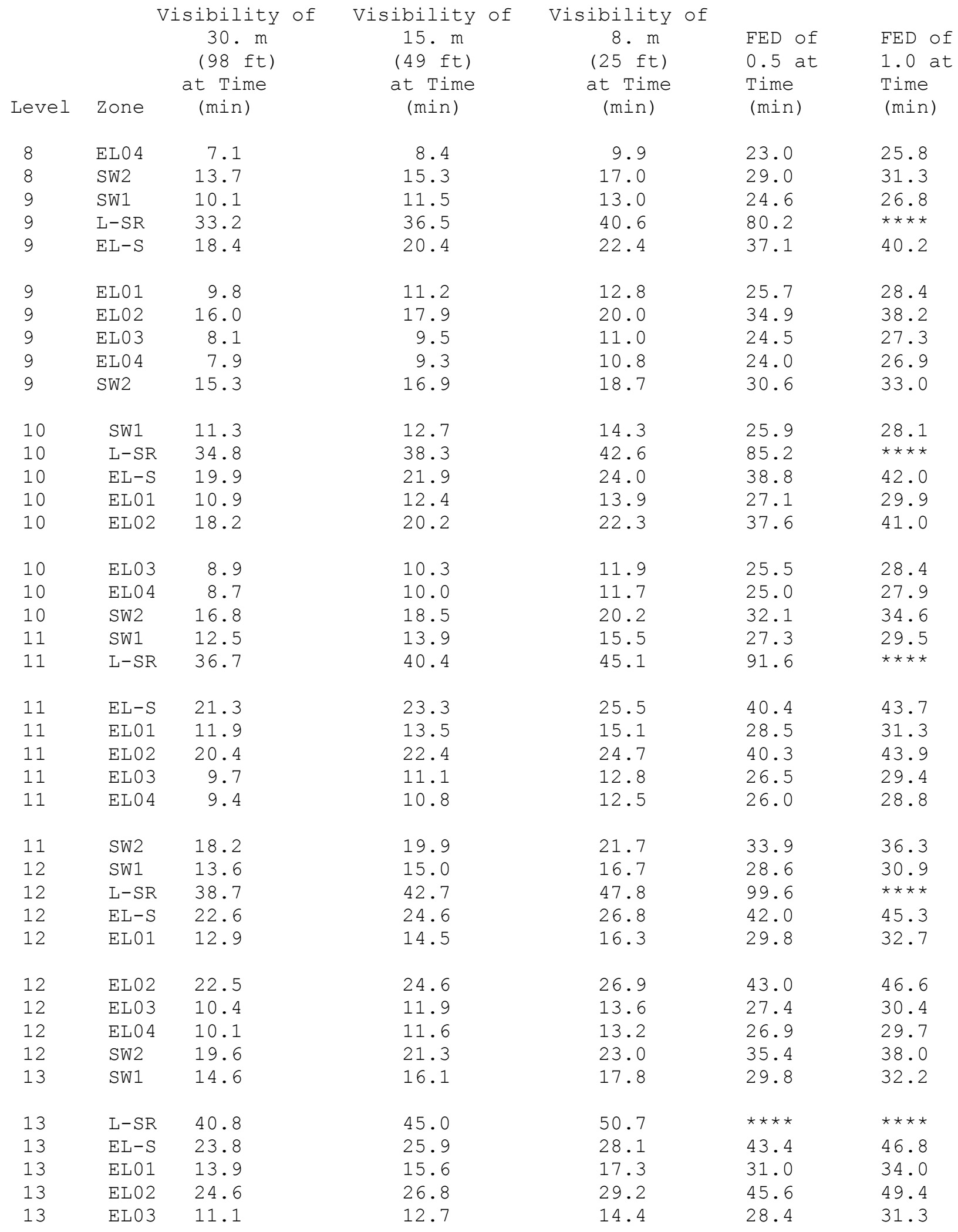


Table 15. Continued.

\begin{tabular}{|c|c|c|c|c|c|c|}
\hline Level & Zone & $\begin{array}{l}\text { sibility of } \\
30 . \mathrm{m} \\
(98 \mathrm{ft}) \\
\text { at Time } \\
\text { (min) }\end{array}$ & $\begin{array}{c}\text { Visibility of } \\
15 . \mathrm{m} \\
(49 \mathrm{ft}) \\
\text { at Time } \\
\text { (min) }\end{array}$ & $\begin{array}{c}\text { Visibility of } \\
8 . \mathrm{m} \\
(25 \mathrm{ft}) \\
\text { at Time } \\
\text { (min) }\end{array}$ & $\begin{array}{l}\text { FED of } \\
0.5 \text { at } \\
\text { Time } \\
\text { (min) }\end{array}$ & $\begin{array}{l}\text { FED of } \\
1.0 \text { at } \\
\text { Time } \\
\text { (min) }\end{array}$ \\
\hline 13 & ELO 4 & 10.8 & 12.3 & 14.0 & 27.7 & 30.6 \\
\hline 13 & sw2 & 20.8 & 22.6 & 24.4 & 36.9 & 39.6 \\
\hline 14 & SW1 & 15.6 & 17.1 & 18.8 & 31.0 & 33.3 \\
\hline 14 & $L-S R$ & 40.7 & 44.6 & 49.6 & 96.0 & 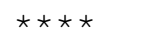 \\
\hline 14 & $\mathrm{EL}-\mathrm{S}$ & 24.9 & 27.0 & 29.2 & 44.7 & 48.1 \\
\hline 14 & EL01 & 15.5 & 17.2 & 19.1 & 33.4 & 36.4 \\
\hline 14 & ELO2 & 28.2 & 30.6 & 33.2 & 51.2 & 55.5 \\
\hline 14 & EL03 & 11.8 & 13.4 & 15.2 & 29.2 & 32.2 \\
\hline 14 & ELO 4 & 11.5 & 12.9 & 14.7 & 28.5 & 31.5 \\
\hline 14 & SW2 & 21.9 & 23.7 & 25.5 & 38.3 & 41.0 \\
\hline 15 & $\mathrm{MECH}$ & 40.4 & 43.8 & 48.0 & 80.1 & 92.5 \\
\hline 15 & SW1 & 16.4 & 18.0 & 19.7 & 31.9 & 34.3 \\
\hline 15 & $L-S R$ & 36.4 & 39.1 & 42.0 & 63.0 & 68.4 \\
\hline 15 & CR01 & 54.2 & 59.5 & 65.9 & 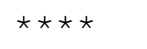 & $\star \star \star \star \star$ \\
\hline 15 & $E L-S$ & 25.8 & 27.9 & 30.2 & 45.7 & 49.2 \\
\hline 15 & EL01 & 16.2 & 17.9 & 19.9 & 34.3 & 37.4 \\
\hline 15 & EL02 & 29.6 & 32.1 & 34.8 & 53.1 & 57.6 \\
\hline 15 & ELO3 & 12.5 & 14.1 & 15.9 & 30.1 & 33.1 \\
\hline 15 & ELO 4 & 12.0 & 13.6 & 15.4 & 29.3 & 32.2 \\
\hline 15 & T01 & 38.1 & 41.3 & 45.0 & 75.7 & 87.5 \\
\hline 15 & T02 & 39.1 & 42.3 & 45.9 & 71.9 & 79.7 \\
\hline 15 & SW2 & 22.9 & 24.7 & 26.6 & 39.4 & 42.1 \\
\hline 16 & OPEN & 41.3 & 44.8 & 48.9 & 80.7 & 92.7 \\
\hline 16 & SW1 & 17.3 & 18.9 & 20.7 & 32.9 & 35.4 \\
\hline 16 & $L-S R$ & 37.1 & 39.8 & 42.7 & 63.2 & 68.5 \\
\hline 16 & CR01 & 55.1 & 60.4 & 66.7 & 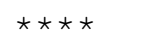 & 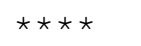 \\
\hline 16 & $\mathrm{EL}-\mathrm{S}$ & 26.8 & 28.9 & 31.2 & 46.8 & 50.3 \\
\hline 16 & EL01 & 16.9 & 18.7 & 20.6 & 35.1 & 38.3 \\
\hline 16 & EL02 & 30.9 & 33.4 & 36.1 & 54.7 & 59.4 \\
\hline 16 & EL03 & 13.1 & 14.8 & 16.6 & 30.8 & 33.9 \\
\hline 16 & ELO 4 & 12.7 & 14.3 & 16.0 & 30.0 & 33.0 \\
\hline 16 & T01 & 41.6 & 45.2 & 49.6 & 84.7 & 99.3 \\
\hline 16 & T02 & 40.0 & 43.1 & 46.7 & 72.3 & 79.8 \\
\hline 16 & SW2 & 23.9 & 25.7 & 27.6 & 40.5 & 43.3 \\
\hline 17 & OPEN & 42.5 & 46.0 & 50.2 & 82.1 & 94.2 \\
\hline 17 & SW1 & 18.2 & 19.9 & 21.6 & 34.0 & 36.4 \\
\hline 17 & $L-S R$ & 38.1 & 40.8 & 43.8 & 64.2 & 69.4 \\
\hline 17 & CR01 & 56.5 & 61.7 & 68.1 & 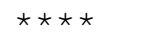 & 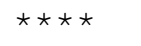 \\
\hline 17 & $E L-S$ & 27.8 & 29.9 & 32.2 & 47.9 & 51.4 \\
\hline 17 & EL01 & 17.5 & 19.3 & 21.3 & 35.9 & 39.1 \\
\hline
\end{tabular}


Table 15. Continued.

\begin{tabular}{|c|c|c|c|c|c|c|}
\hline Level & Zone & $\begin{array}{l}\text { sibility of } \\
30 . \mathrm{m} \\
(98 \mathrm{ft}) \\
\text { at Time } \\
\text { (min) }\end{array}$ & $\begin{array}{c}\text { Visibility of } \\
15 . \mathrm{m} \\
(49 \mathrm{ft}) \\
\text { at Time } \\
\text { (min) }\end{array}$ & $\begin{array}{c}\text { Visibility of } \\
8 . \mathrm{m} \\
(25 \mathrm{ft}) \\
\text { at Time } \\
\text { (min) }\end{array}$ & $\begin{array}{l}\text { FED of } \\
0.5 \text { at } \\
\text { Time } \\
\text { (min) }\end{array}$ & $\begin{array}{l}\text { FED of } \\
1.0 \text { at } \\
\text { Time } \\
\text { (min) }\end{array}$ \\
\hline 17 & ELO2 & 32.0 & 34.6 & 37.4 & 56.2 & 61.0 \\
\hline 17 & ELO3 & 13.8 & 15.4 & 17.3 & 31.6 & 34.7 \\
\hline 17 & ELO 4 & 13.3 & 14.9 & 16.7 & 30.7 & 33.7 \\
\hline 17 & T01 & 42.8 & 46.4 & 50.9 & 86.2 & 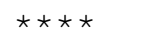 \\
\hline 17 & T02 & 41.1 & 44.2 & 47.8 & 73.3 & 80.8 \\
\hline 17 & SW2 & 25.0 & 26.8 & 28.6 & 41.7 & 44.5 \\
\hline 18 & OPEN & 43.7 & 47.3 & 51.5 & 83.6 & 95.7 \\
\hline 18 & SW1 & 19.2 & 20.8 & 22.6 & 35.0 & 37.5 \\
\hline 18 & $L-S R$ & 39.1 & 41.9 & 44.8 & 65.3 & 70.5 \\
\hline 18 & CR01 & 57.8 & 63.1 & 69.5 & $\star \star \star \star \star$ & $\star \star \star \star \star$ \\
\hline 18 & $E L-S$ & 28.8 & 30.9 & 33.2 & 49.0 & 52.5 \\
\hline 18 & EL01 & 18.1 & 19.9 & 21.9 & 36.6 & 39.8 \\
\hline 18 & EL02 & 33.1 & 35.7 & 38.5 & 57.6 & 62.5 \\
\hline 18 & ELO3 & 14.4 & 16.0 & 17.9 & 32.4 & 35.5 \\
\hline 18 & ELO 4 & 13.8 & 15.5 & 17.3 & 31.4 & 34.5 \\
\hline 18 & T01 & 44.0 & 47.7 & 52.2 & 87.8 & $\star \star \star \star \star$ \\
\hline 18 & T02 & 42.2 & 45.4 & 49.0 & 74.5 & 81.9 \\
\hline 18 & SW2 & 26.0 & 27.8 & 29.7 & 42.9 & 45.7 \\
\hline 19 & OPEN & 45.0 & 48.6 & 52.9 & 85.1 & 97.3 \\
\hline 19 & SW1 & 20.1 & 21.8 & 23.6 & 36.1 & 38.7 \\
\hline 19 & $L-S R$ & 40.2 & 42.9 & 45.9 & 66.3 & 71.5 \\
\hline 19 & CR01 & 59.2 & 64.5 & 71.0 & 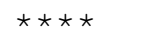 & 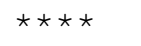 \\
\hline 19 & $E L-S$ & 29.8 & 31.9 & 34.2 & 50.1 & 53.6 \\
\hline 19 & EL01 & 18.7 & 20.5 & 22.5 & 37.3 & 40.5 \\
\hline 19 & EL02 & 34.1 & 36.7 & 39.6 & 58.9 & 63.9 \\
\hline 19 & EL03 & 15.0 & 16.7 & 18.6 & 33.1 & 36.2 \\
\hline 19 & ELO 4 & 14.4 & 16.1 & 17.9 & 32.1 & 35.2 \\
\hline 19 & T01 & 45.3 & 49.0 & 53.6 & 89.4 & 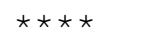 \\
\hline 19 & T02 & 43.4 & 46.6 & 50.2 & 75.7 & 83.1 \\
\hline 19 & SW2 & 27.1 & 28.9 & 30.8 & 44.1 & 47.0 \\
\hline 20 & OPEN & 46.3 & 49.9 & 54.3 & 86.7 & 99.0 \\
\hline 20 & SW1 & 21.1 & 22.8 & 24.7 & 37.3 & 39.8 \\
\hline 20 & $L-S R$ & 41.4 & 44.1 & 47.1 & 67.5 & 72.7 \\
\hline 20 & CR01 & 60.6 & 66.0 & 72.6 & 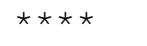 & 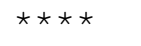 \\
\hline 20 & $E L-S$ & 30.8 & 32.9 & 35.3 & 51.2 & 54.8 \\
\hline 20 & EL01 & 19.2 & 21.0 & 23.1 & 37.9 & 41.2 \\
\hline 20 & EL02 & 35.1 & 37.7 & 40.6 & 60.1 & 65.2 \\
\hline 20 & EL03 & 15.6 & 17.3 & 19.3 & 33.8 & 37.0 \\
\hline 20 & ELO 4 & 15.0 & 16.7 & 18.6 & 32.8 & 35.9 \\
\hline 20 & T01 & 46.6 & 50.4 & 55.1 & 91.1 & 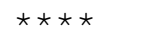 \\
\hline
\end{tabular}


Table 15. Continued.

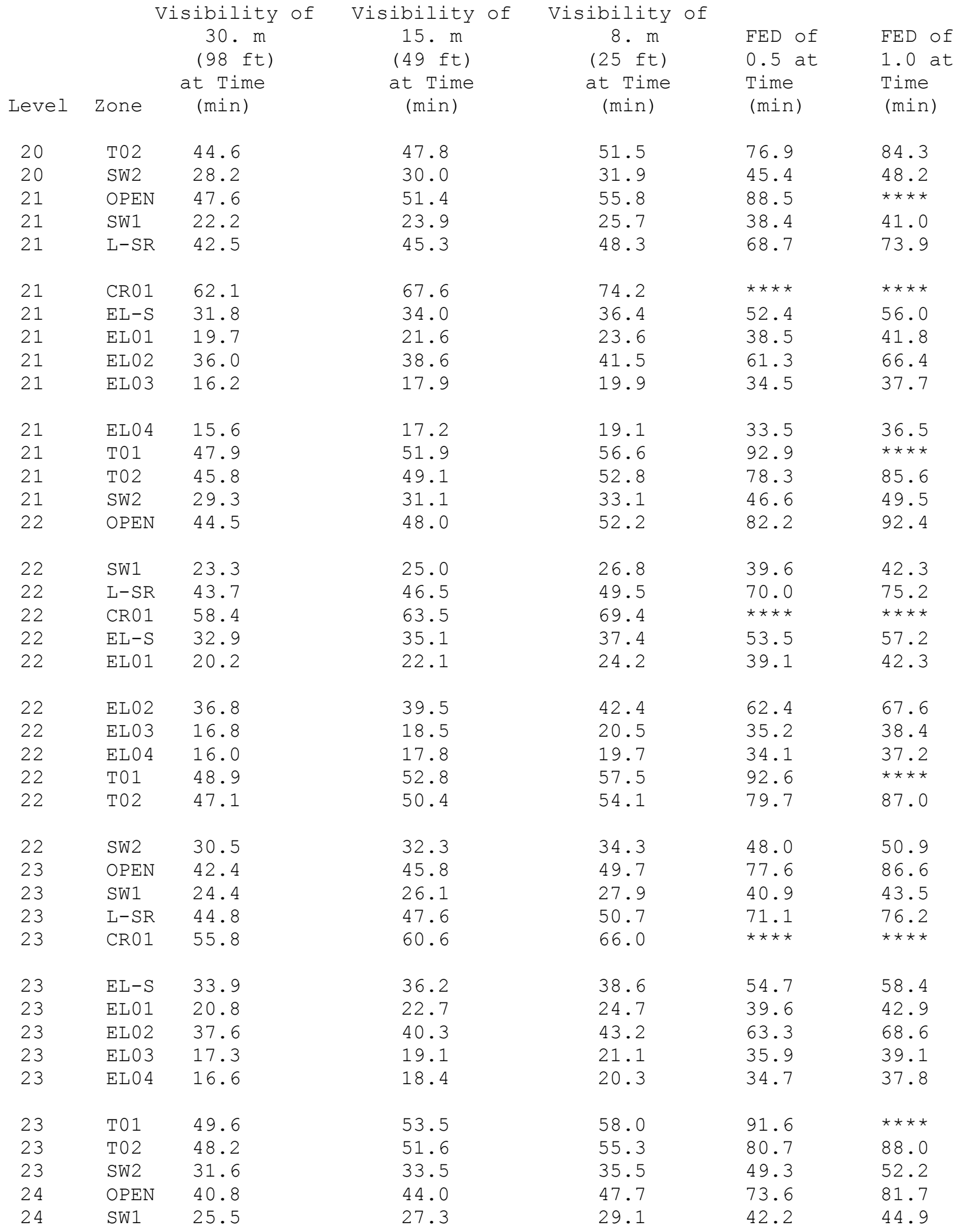


Table 15. Continued.

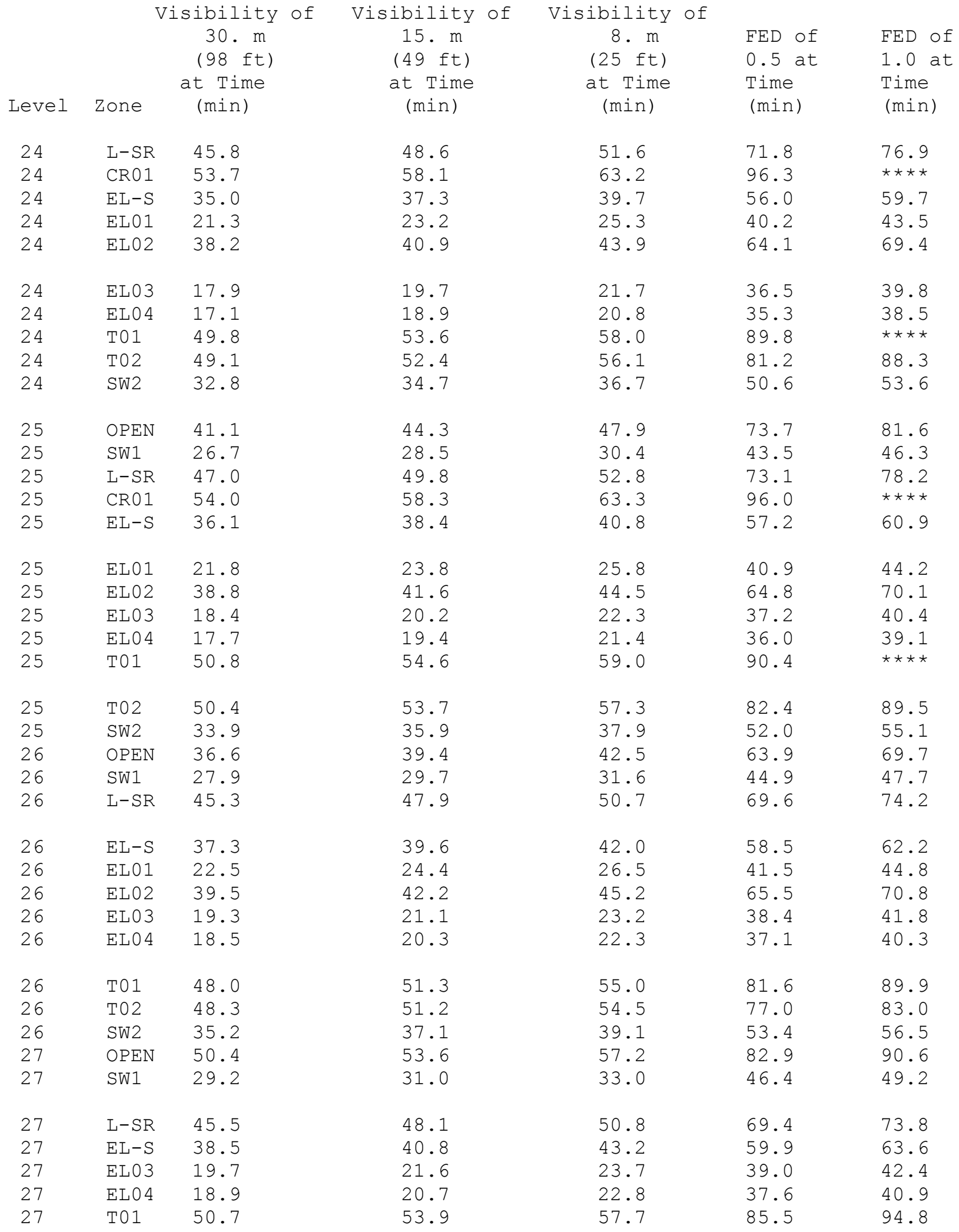


Table 15. Continued.

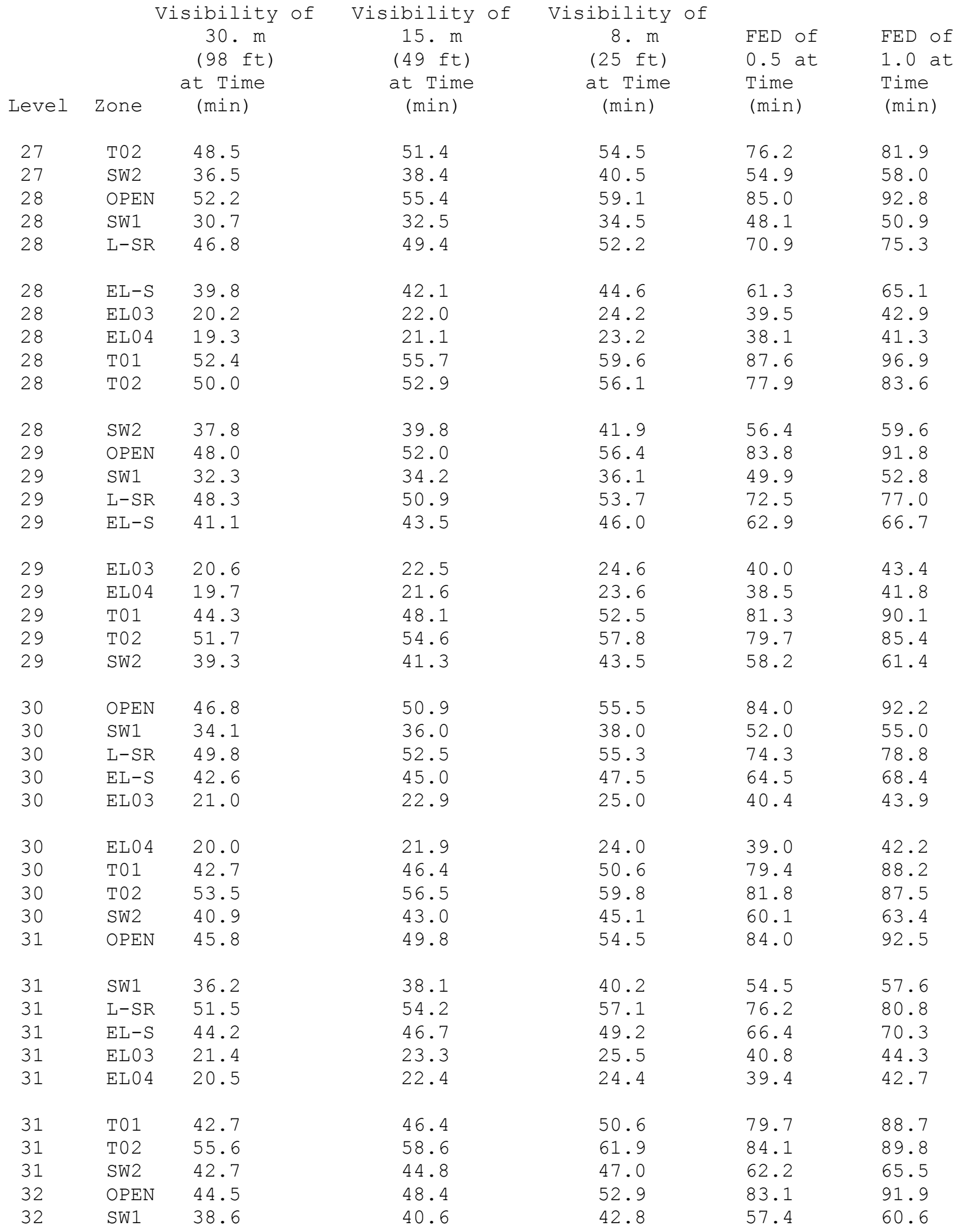


Table 15. Continued.

\begin{tabular}{|c|c|c|c|c|c|c|}
\hline Level & Zone & $\begin{array}{l}\text { sibility of } \\
30 . \mathrm{m} \\
(98 \mathrm{ft}) \\
\text { at Time } \\
\text { (min) }\end{array}$ & $\begin{array}{c}\text { Visibility of } \\
15 . \mathrm{m} \\
(49 \mathrm{ft}) \\
\text { at Time } \\
\text { (min) }\end{array}$ & $\begin{array}{c}\text { Visibility of } \\
8 . \mathrm{m} \\
(25 \mathrm{ft}) \\
\text { at Time } \\
\text { (min) }\end{array}$ & $\begin{array}{l}\text { FED of } \\
0.5 \text { at } \\
\text { Time } \\
\text { (min) }\end{array}$ & $\begin{array}{l}\text { FED of } \\
1.0 \text { at } \\
\text { Time } \\
\text { (min) }\end{array}$ \\
\hline 32 & $L-S R$ & 53.4 & 56.1 & 59.0 & 78.3 & 82.9 \\
\hline 32 & $E L-S$ & 46.0 & 48.5 & 51.0 & 68.4 & 72.4 \\
\hline 32 & EL03 & 21.8 & 23.7 & 25.8 & 41.3 & 44.7 \\
\hline 32 & ELO 4 & 20.9 & 22.8 & 24.8 & 39.8 & 43.1 \\
\hline 32 & T01 & 42.3 & 45.9 & 50.0 & 79.2 & 88.2 \\
\hline 32 & T02 & 57.9 & 61.0 & 64.4 & 86.6 & 92.4 \\
\hline 32 & SW2 & 44.7 & 46.8 & 49.0 & 64.5 & 68.0 \\
\hline 33 & OPEN & 43.8 & 47.5 & 51.8 & 82.1 & 91.3 \\
\hline 33 & SW1 & 41.6 & 43.7 & 45.9 & 61.1 & 64.4 \\
\hline 33 & $L-S R$ & 55.4 & 58.2 & 61.2 & 80.7 & 85.4 \\
\hline 33 & $E L-S$ & 48.0 & 50.5 & 53.1 & 70.7 & 74.8 \\
\hline 33 & ELO3 & 22.2 & 24.1 & 26.3 & 41.7 & 45.2 \\
\hline 33 & ELO 4 & 21.3 & 23.2 & 25.2 & 40.3 & 43.6 \\
\hline 33 & T01 & 41.9 & 45.5 & 49.5 & 78.3 & 87.4 \\
\hline 33 & T02 & 60.5 & 63.7 & 67.1 & 89.6 & 95.4 \\
\hline 33 & SW2 & 46.9 & 49.1 & 51.4 & 67.2 & 70.7 \\
\hline 34 & OPEN & 43.3 & 46.9 & 51.1 & 81.2 & 90.6 \\
\hline 34 & SW1 & 45.5 & 47.7 & 50.0 & 66.0 & 69.5 \\
\hline 34 & $L-S R$ & 57.8 & 60.6 & 63.6 & 83.4 & 88.1 \\
\hline 34 & $E L-S$ & 50.2 & 52.8 & 55.5 & 73.3 & 77.4 \\
\hline 34 & EL03 & 22.6 & 24.6 & 26.7 & 42.2 & 45.6 \\
\hline 34 & ELO 4 & 21.7 & 23.6 & 25.7 & 40.7 & 44.1 \\
\hline 34 & T01 & 41.7 & 45.1 & 49.0 & 77.4 & 86.5 \\
\hline 34 & T02 & 63.5 & 66.8 & 70.3 & 93.0 & 98.9 \\
\hline 34 & SW2 & 49.5 & 51.7 & 54.1 & 70.2 & 73.9 \\
\hline 35 & OPEN & 42.6 & 46.1 & 50.0 & 79.1 & 88.5 \\
\hline 35 & SW1 & 51.3 & 53.7 & 56.2 & 73.6 & 77.6 \\
\hline 35 & $L-S R$ & 60.4 & 63.3 & 66.4 & 86.5 & 91.3 \\
\hline 35 & $E L-S$ & 52.8 & 55.4 & 58.1 & 76.3 & 80.5 \\
\hline 35 & EL03 & 23.0 & 24.9 & 27.1 & 42.6 & 46.1 \\
\hline 35 & ELO 4 & 22.1 & 24.0 & 26.1 & 41.2 & 44.5 \\
\hline 35 & T01 & 41.2 & 44.5 & 48.2 & 75.6 & 84.4 \\
\hline 35 & T02 & 66.9 & 70.3 & 73.9 & 97.0 & 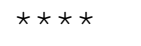 \\
\hline 35 & SW2 & 52.5 & 54.8 & 57.2 & 73.9 & 77.6 \\
\hline 36 & $\mathrm{MECH}$ & 75.2 & 79.1 & 83.5 & 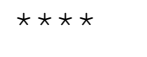 & 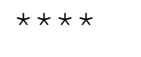 \\
\hline 36 & ELME & 79.3 & 83.6 & 88.3 & 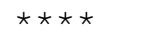 & 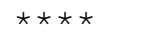 \\
\hline 36 & $E L-S$ & 55.8 & 58.4 & 61.3 & 79.9 & 84.2 \\
\hline 36 & EL03 & 23.0 & 25.0 & 27.1 & 42.6 & 46.1 \\
\hline 36 & ELO 4 & 22.1 & 24.0 & 26.1 & 41.2 & 44.5 \\
\hline 36 & SW2 & 56.1 & 58.5 & 61.0 & 78.4 & 82.3 \\
\hline
\end{tabular}


Table 15. Continued.

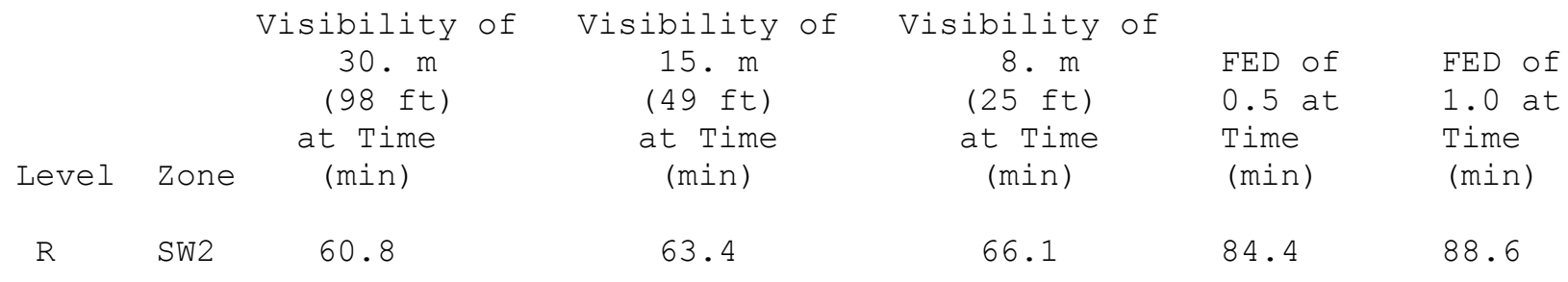


Table 16. Results of Tenability Analysis for Scenario 16.

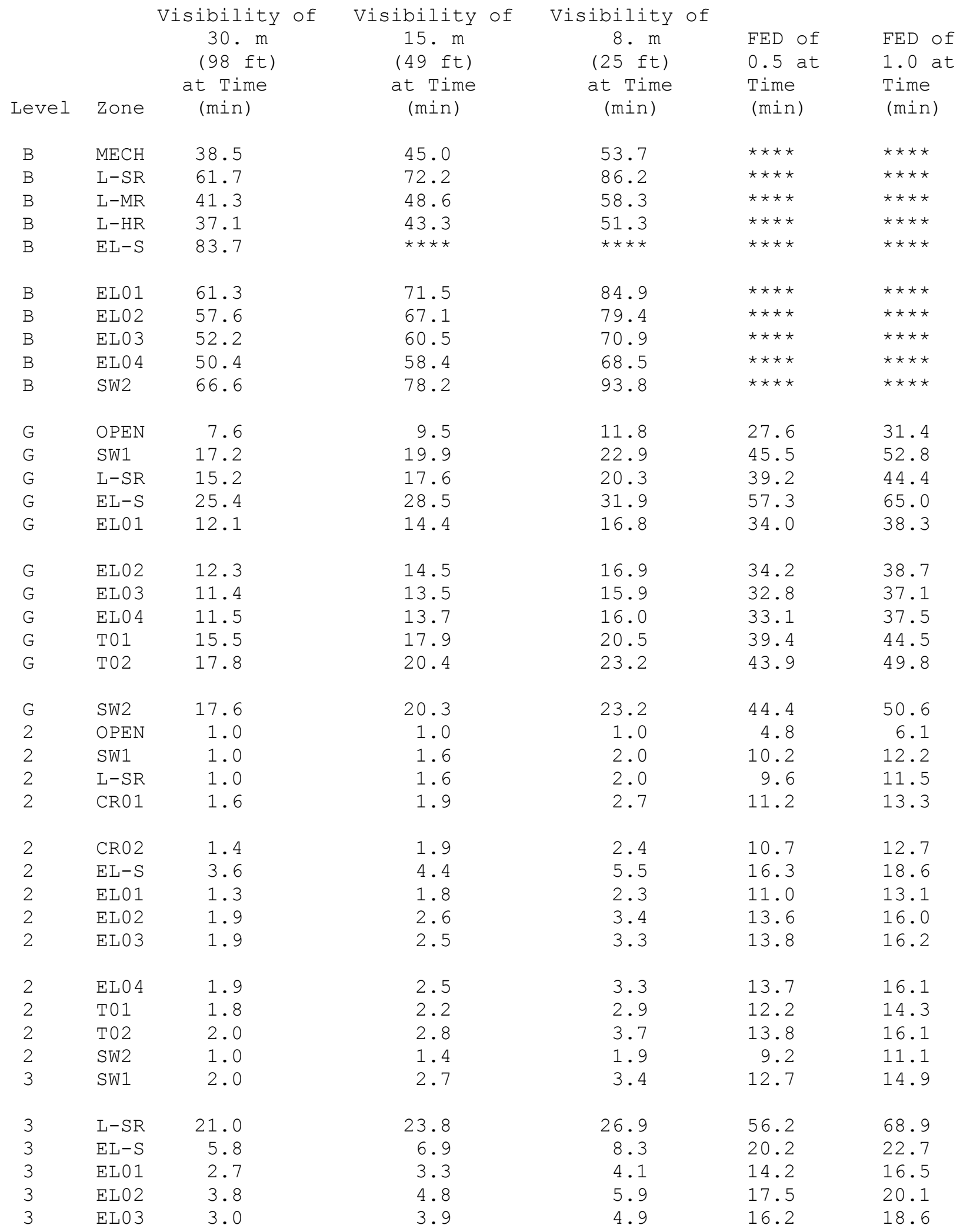


Table 16. Continued.

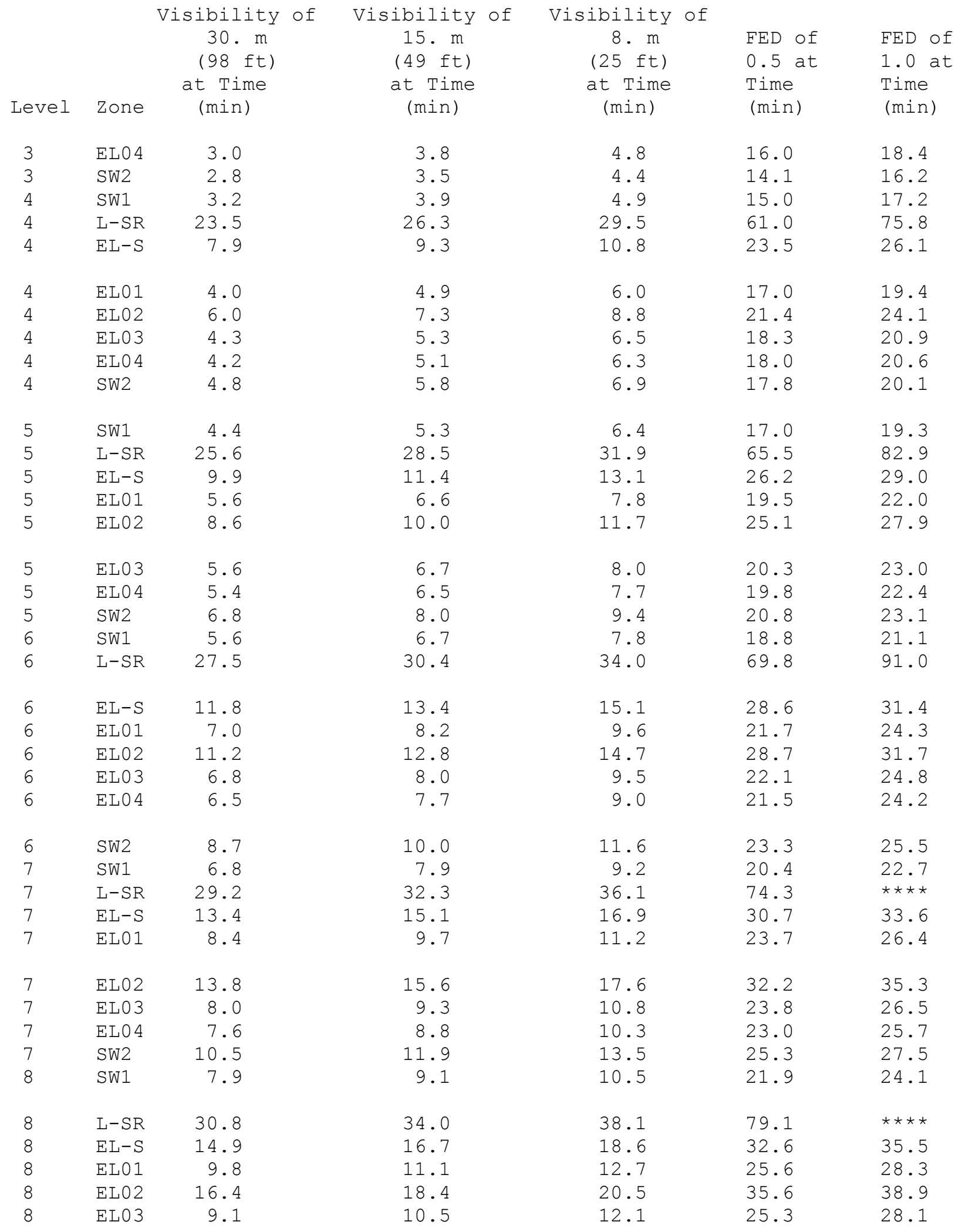


Table 16. Continued.

\begin{tabular}{|c|c|c|c|c|c|c|}
\hline Level & Zone & $\begin{array}{l}\text { sibility of } \\
30 . \mathrm{m} \\
(98 \mathrm{ft}) \\
\text { at Time } \\
\text { (min) }\end{array}$ & $\begin{array}{c}\text { Visibility of } \\
15 . \mathrm{m} \\
(49 \mathrm{ft}) \\
\text { at Time } \\
\text { (min) }\end{array}$ & $\begin{array}{c}\text { Visibility of } \\
8 . \mathrm{m} \\
(25 \mathrm{ft}) \\
\text { at Time } \\
\text { (min) }\end{array}$ & $\begin{array}{l}\text { FED of } \\
0.5 \text { at } \\
\text { Time } \\
\text { (min) }\end{array}$ & $\begin{array}{l}\text { FED of } \\
1.0 \text { at } \\
\text { Time } \\
\text { (min) }\end{array}$ \\
\hline 8 & ELO 4 & 8.6 & 9.9 & 11.5 & 24.4 & 27.1 \\
\hline 8 & SW2 & 12.0 & 13.6 & 15.2 & 27.1 & 29.3 \\
\hline 9 & SW1 & 9.0 & 10.3 & 11.7 & 23.2 & 25.4 \\
\hline 9 & $L-S R$ & 32.4 & 35.8 & 40.1 & 84.6 & 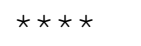 \\
\hline 9 & $E L-S$ & 16.4 & 18.2 & 20.1 & 34.3 & 37.3 \\
\hline 9 & EL01 & 11.0 & 12.5 & 14.1 & 27.3 & 30.1 \\
\hline 9 & EL02 & 19.0 & 21.0 & 23.3 & 38.9 & 42.4 \\
\hline 9 & EL03 & 10.2 & 11.7 & 13.3 & 26.7 & 29.6 \\
\hline 9 & ELO 4 & 9.6 & 11.0 & 12.6 & 25.7 & 28.4 \\
\hline 9 & SW2 & 13.6 & 15.1 & 16.8 & 28.6 & 30.9 \\
\hline 10 & SW1 & 10.0 & 11.4 & 12.8 & 24.4 & 26.6 \\
\hline 10 & $L-S R$ & 33.9 & 37.5 & 42.2 & 91.4 & 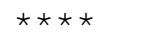 \\
\hline 10 & $E L-S$ & 17.7 & 19.5 & 21.6 & 35.9 & 39.0 \\
\hline 10 & EL01 & 12.2 & 13.8 & 15.5 & 28.9 & 31.7 \\
\hline 10 & EL02 & 21.6 & 23.7 & 26.0 & 42.1 & 45.8 \\
\hline 10 & EL03 & 11.2 & 12.8 & 14.5 & 28.1 & 31.0 \\
\hline 10 & EL04 & 10.6 & 12.0 & 13.6 & 26.9 & 29.7 \\
\hline 10 & SW2 & 14.9 & 16.5 & 18.2 & 30.0 & 32.3 \\
\hline 11 & SW1 & 11.0 & 12.4 & 13.9 & 25.6 & 27.9 \\
\hline 11 & $\mathrm{~L}-\mathrm{SR}$ & 35.9 & 39.8 & 44.9 & 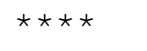 & 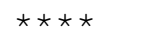 \\
\hline 11 & $E L-S$ & 18.9 & 20.8 & 22.8 & 37.3 & 40.5 \\
\hline 11 & EL01 & 13.4 & 15.0 & 16.7 & 30.3 & 33.2 \\
\hline 11 & ELO2 & 24.0 & 26.3 & 28.7 & 45.3 & 49.1 \\
\hline 11 & EL03 & 12.2 & 13.8 & 15.6 & 29.4 & 32.3 \\
\hline 11 & EL0 4 & 11.4 & 12.9 & 14.6 & 28.0 & 30.8 \\
\hline 11 & SW2 & 16.2 & 17.8 & 19.5 & 31.5 & 33.9 \\
\hline 12 & SW1 & 12.0 & 13.4 & 15.0 & 26.8 & 29.1 \\
\hline 12 & $L-S R$ & 38.0 & 42.2 & 47.9 & 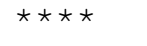 & 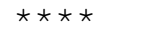 \\
\hline 12 & $E L-S$ & 20.0 & 21.9 & 24.0 & 38.7 & 41.9 \\
\hline 12 & EL01 & 14.5 & 16.1 & 17.9 & 31.7 & 34.7 \\
\hline 12 & EL02 & 26.5 & 28.8 & 31.3 & 48.4 & 52.3 \\
\hline 12 & EL03 & 13.1 & 14.8 & 16.6 & 30.6 & 33.5 \\
\hline 12 & EL0 4 & 12.3 & 13.8 & 15.6 & 29.1 & 31.9 \\
\hline 12 & SW2 & 17.4 & 19.0 & 20.8 & 32.9 & 35.4 \\
\hline 13 & SW1 & 12.9 & 14.4 & 16.0 & 28.0 & 30.3 \\
\hline 13 & $L-S R$ & 40.4 & 45.0 & 51.6 & 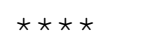 & 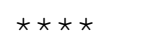 \\
\hline 13 & $E L-S$ & 21.1 & 23.0 & 25.2 & 40.0 & 43.2 \\
\hline 13 & EL01 & 15.5 & 17.2 & 19.0 & 33.0 & 36.0 \\
\hline 13 & EL02 & 28.9 & 31.3 & 33.9 & 51.4 & 55.5 \\
\hline 13 & EL03 & 14.0 & 15.7 & 17.6 & 31.7 & 34.7 \\
\hline
\end{tabular}


Table 16. Continued.

\begin{tabular}{|c|c|c|c|c|c|c|}
\hline Level & Zone & $\begin{array}{l}\text { sibility of } \\
30 . \mathrm{m} \\
(98 \mathrm{ft}) \\
\text { at Time } \\
\text { (min) }\end{array}$ & $\begin{array}{c}\text { Visibility of } \\
15 . \mathrm{m} \\
(49 \mathrm{ft}) \\
\text { at Time } \\
\text { (min) }\end{array}$ & $\begin{array}{c}\text { Visibility of } \\
8 . \mathrm{m} \\
(25 \mathrm{ft}) \\
\text { at Time } \\
\text { (min) }\end{array}$ & $\begin{array}{l}\text { FED of } \\
0.5 \text { at } \\
\text { Time } \\
\text { (min) }\end{array}$ & $\begin{array}{l}\text { FED of } \\
1.0 \text { at } \\
\text { Time } \\
\text { (min) }\end{array}$ \\
\hline 13 & ELO 4 & 13.0 & 14.7 & 16.4 & 30.1 & 33.0 \\
\hline 13 & sw2 & 18.5 & 20.2 & 21.9 & 34.2 & 36.8 \\
\hline 14 & SW1 & 13.8 & 15.3 & 16.9 & 29.0 & 31.3 \\
\hline 14 & $L-S R$ & 39.6 & 43.6 & 49.0 & 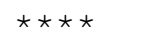 & 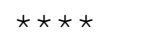 \\
\hline 14 & $\mathrm{EL}-\mathrm{S}$ & 22.1 & 24.0 & 26.2 & 41.1 & 44.4 \\
\hline 14 & EL01 & 16.7 & 18.4 & 20.3 & 34.6 & 37.6 \\
\hline 14 & ELO2 & 31.8 & 34.4 & 37.0 & 55.5 & 59.9 \\
\hline 14 & EL03 & 14.9 & 16.6 & 18.5 & 32.8 & 35.8 \\
\hline 14 & ELO 4 & 13.8 & 15.5 & 17.3 & 31.0 & 33.9 \\
\hline 14 & SW2 & 19.6 & 21.2 & 23.0 & 35.4 & 38.0 \\
\hline 15 & $\mathrm{MECH}$ & 54.4 & 63.5 & 79.3 & 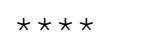 & 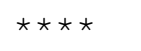 \\
\hline 15 & SW1 & 14.6 & 16.0 & 17.7 & 29.9 & 32.2 \\
\hline 15 & $L-S R$ & 38.9 & 42.6 & 47.1 & 85.9 & 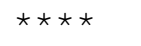 \\
\hline 15 & CR01 & 76.8 & 92.6 & $\star \star \star \star$ & $\star \star \star \star \star$ & 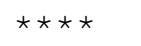 \\
\hline 15 & $E L-S$ & 22.9 & 24.9 & 27.1 & 42.1 & 45.4 \\
\hline 15 & EL01 & 17.6 & 19.4 & 21.3 & 35.7 & 38.8 \\
\hline 15 & EL02 & 33.9 & 36.5 & 39.3 & 58.3 & 62.9 \\
\hline 15 & ELO3 & 15.7 & 17.5 & 19.4 & 33.7 & 36.9 \\
\hline 15 & ELO 4 & 14.6 & 16.2 & 18.0 & 31.9 & 34.8 \\
\hline 15 & T01 & 35.9 & 39.0 & 42.7 & 74.2 & 87.3 \\
\hline 15 & T02 & 45.7 & 51.2 & 58.8 & $\star \star \star \star \star$ & $\star \star \star \star \star$ \\
\hline 15 & SW2 & 20.5 & 22.2 & 23.9 & 36.5 & 39.1 \\
\hline 16 & OPEN & 41.6 & 45.4 & 50.1 & 87.4 & 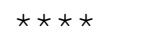 \\
\hline 16 & SW1 & 15.4 & 16.9 & 18.6 & 30.7 & 33.2 \\
\hline 16 & $L-S R$ & 39.8 & 43.3 & 47.6 & 79.8 & 91.2 \\
\hline 16 & CR01 & 55.2 & 61.0 & 68.2 & 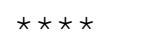 & 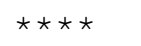 \\
\hline 16 & $\mathrm{EL}-\mathrm{S}$ & 23.8 & 25.8 & 27.9 & 43.0 & 46.3 \\
\hline 16 & EL01 & 18.4 & 20.2 & 22.2 & 36.7 & 39.9 \\
\hline 16 & EL02 & 35.8 & 38.4 & 41.3 & 60.7 & 65.5 \\
\hline 16 & EL03 & 16.5 & 18.3 & 20.2 & 34.7 & 37.8 \\
\hline 16 & ELO 4 & 15.3 & 16.9 & 18.8 & 32.7 & 35.7 \\
\hline 16 & T01 & 40.7 & 44.5 & 49.3 & 88.7 & 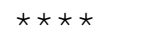 \\
\hline 16 & T02 & 41.1 & 44.8 & 49.4 & 84.1 & 97.8 \\
\hline 16 & SW2 & 21.4 & 23.0 & 24.9 & 37.5 & 40.1 \\
\hline 17 & OPEN & 41.7 & 45.4 & 49.9 & 84.9 & 99.3 \\
\hline 17 & SW1 & 16.1 & 17.7 & 19.4 & 31.6 & 34.1 \\
\hline 17 & $L-S R$ & 36.5 & 39.3 & 42.2 & 63.2 & 68.7 \\
\hline 17 & CR01 & 55.0 & 60.5 & 67.2 & 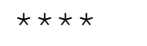 & 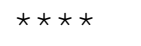 \\
\hline 17 & $E L-S$ & 24.6 & 26.7 & 28.8 & 44.0 & 47.3 \\
\hline 17 & EL01 & 19.2 & 21.0 & 23.0 & 37.7 & 40.9 \\
\hline
\end{tabular}


Table 16. Continued.

\begin{tabular}{|c|c|c|c|c|c|c|}
\hline Level & Zone & $\begin{array}{l}\text { sibility of } \\
30 . \mathrm{m} \\
(98 \mathrm{ft}) \\
\text { at Time } \\
\text { (min) }\end{array}$ & $\begin{array}{c}\text { Visibility of } \\
15 . \mathrm{m} \\
(49 \mathrm{ft}) \\
\text { at Time } \\
\text { (min) }\end{array}$ & $\begin{array}{c}\text { Visibility of } \\
8 . \mathrm{m} \\
(25 \mathrm{ft}) \\
\text { at Time } \\
\text { (min) }\end{array}$ & $\begin{array}{l}\text { FED of } \\
0.5 \text { at } \\
\text { Time } \\
\text { (min) }\end{array}$ & $\begin{array}{l}\text { FED of } \\
1.0 \text { at } \\
\text { Time } \\
\text { (min) }\end{array}$ \\
\hline 17 & ELO2 & 37.4 & 40.1 & 43.0 & 62.8 & 67.8 \\
\hline 17 & ELO3 & 17.3 & 19.0 & 21.0 & 35.6 & 38.8 \\
\hline 17 & ELO 4 & 15.9 & 17.7 & 19.5 & 33.5 & 36.5 \\
\hline 17 & T01 & 41.2 & 45.0 & 49.7 & 87.6 & 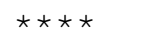 \\
\hline 17 & T02 & 40.0 & 43.2 & 46.9 & 73.6 & 81.7 \\
\hline 17 & SW2 & 22.3 & 24.0 & 25.8 & 38.5 & 41.1 \\
\hline 18 & OPEN & 42.0 & 45.6 & 49.9 & 83.3 & 96.4 \\
\hline 18 & SW1 & 17.0 & 18.6 & 20.3 & 32.6 & 35.0 \\
\hline 18 & $L-S R$ & 36.6 & 39.2 & 42.1 & 62.0 & 67.2 \\
\hline 18 & CR01 & 55.1 & 60.3 & 66.8 & $\star \star \star \star$ & $\star \star \star \star$ \\
\hline 18 & $E L-S$ & 25.5 & 27.5 & 29.7 & 44.9 & 48.2 \\
\hline 18 & EL01 & 20.0 & 21.8 & 23.9 & 38.6 & 41.8 \\
\hline 18 & EL02 & 38.8 & 41.6 & 44.6 & 64.8 & 69.9 \\
\hline 18 & ELO3 & 18.0 & 19.8 & 21.8 & 36.5 & 39.7 \\
\hline 18 & ELO 4 & 16.6 & 18.3 & 20.2 & 34.3 & 37.3 \\
\hline 18 & T01 & 41.8 & 45.5 & 50.0 & 86.7 & $\star \star \star \star \star$ \\
\hline 18 & T02 & 40.0 & 43.1 & 46.7 & 71.9 & 79.4 \\
\hline 18 & SW2 & 23.2 & 24.9 & 26.8 & 39.5 & 42.2 \\
\hline 19 & OPEN & 42.4 & 45.9 & 50.1 & 82.3 & 94.5 \\
\hline 19 & SW1 & 17.8 & 19.4 & 21.1 & 33.5 & 36.0 \\
\hline 19 & $L-S R$ & 37.0 & 39.6 & 42.4 & 61.9 & 66.8 \\
\hline 19 & CR01 & 55.3 & 60.4 & 66.6 & 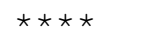 & 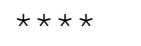 \\
\hline 19 & $E L-S$ & 26.3 & 28.4 & 30.6 & 45.8 & 49.2 \\
\hline 19 & EL01 & 20.7 & 22.6 & 24.7 & 39.5 & 42.7 \\
\hline 19 & EL02 & 40.1 & 42.9 & 46.0 & 66.6 & 71.9 \\
\hline 19 & EL03 & 18.8 & 20.6 & 22.6 & 37.4 & 40.6 \\
\hline 19 & ELO 4 & 17.3 & 19.0 & 20.9 & 35.1 & 38.1 \\
\hline 19 & T01 & 42.4 & 46.0 & 50.5 & 86.0 & 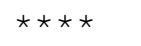 \\
\hline 19 & T02 & 40.4 & 43.4 & 46.8 & 71.3 & 78.3 \\
\hline 19 & SW2 & 24.1 & 25.9 & 27.7 & 40.6 & 43.3 \\
\hline 20 & OPEN & 43.0 & 46.4 & 50.5 & 81.8 & 93.3 \\
\hline 20 & SW1 & 18.7 & 20.3 & 22.0 & 34.5 & 37.0 \\
\hline 20 & $L-S R$ & 37.7 & 40.3 & 43.0 & 62.2 & 67.0 \\
\hline 20 & CR01 & 55.8 & 60.8 & 66.8 & 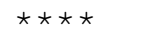 & 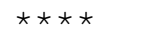 \\
\hline 20 & $E L-S$ & 27.2 & 29.3 & 31.5 & 46.8 & 50.2 \\
\hline 20 & EL01 & 21.4 & 23.3 & 25.4 & 40.3 & 43.5 \\
\hline 20 & EL02 & 41.4 & 44.2 & 47.3 & 68.2 & 73.6 \\
\hline 20 & EL03 & 19.5 & 21.3 & 23.4 & 38.2 & 41.5 \\
\hline 20 & ELO 4 & 17.9 & 19.7 & 21.6 & 35.8 & 38.8 \\
\hline 20 & T01 & 43.0 & 46.6 & 51.0 & 85.7 & 99.8 \\
\hline
\end{tabular}


Table 16. Continued.

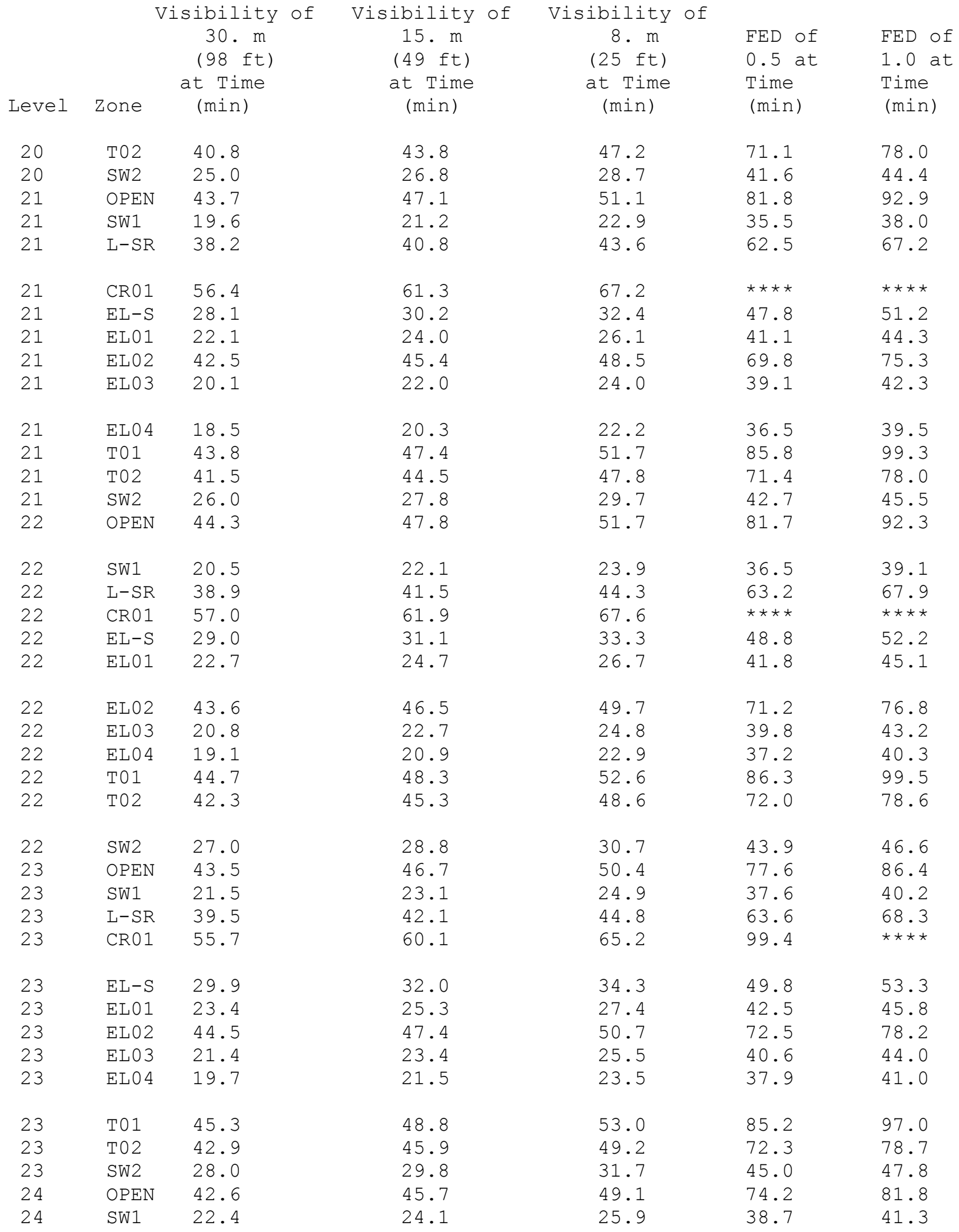


Table 16. Continued.

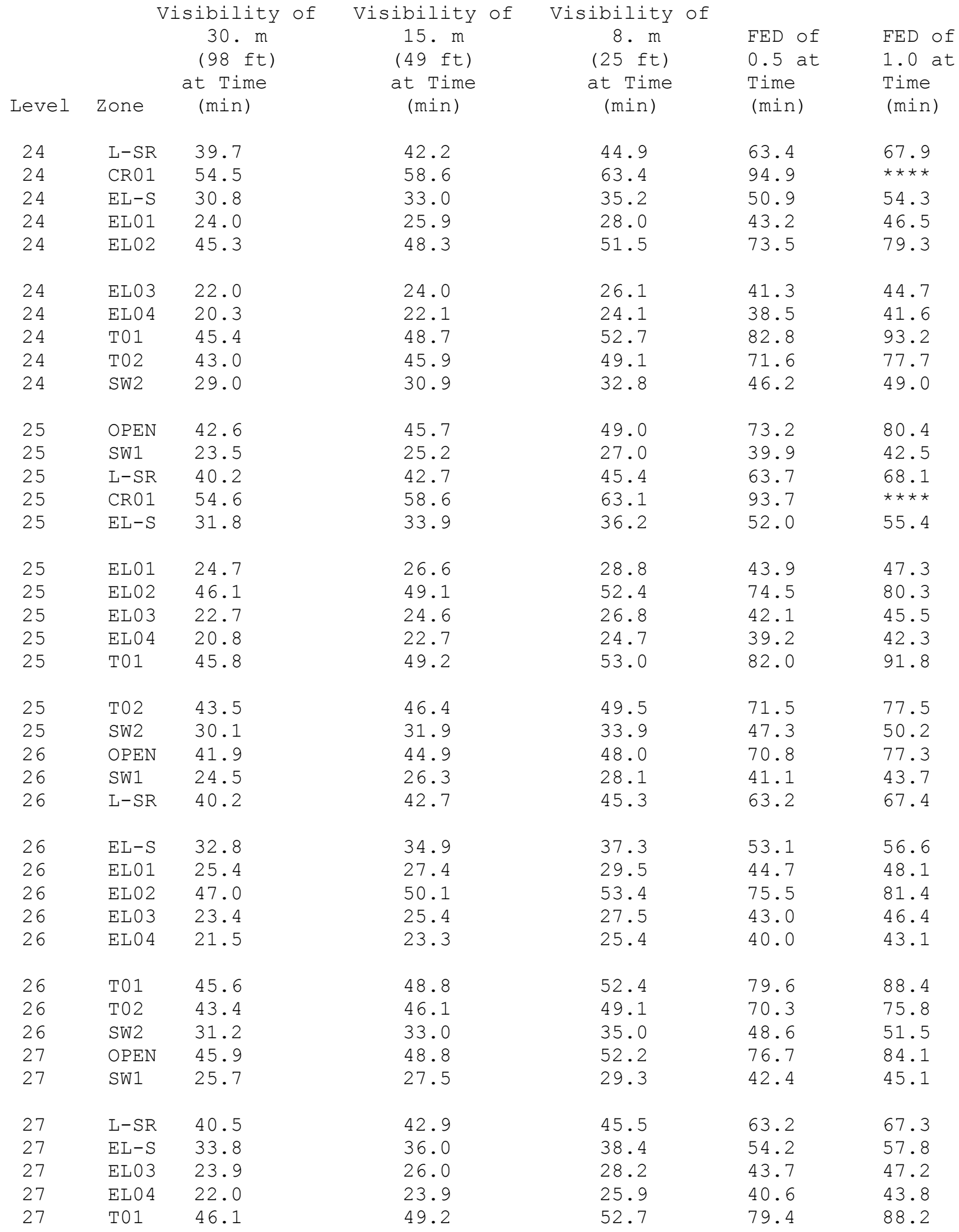


Table 16. Continued.

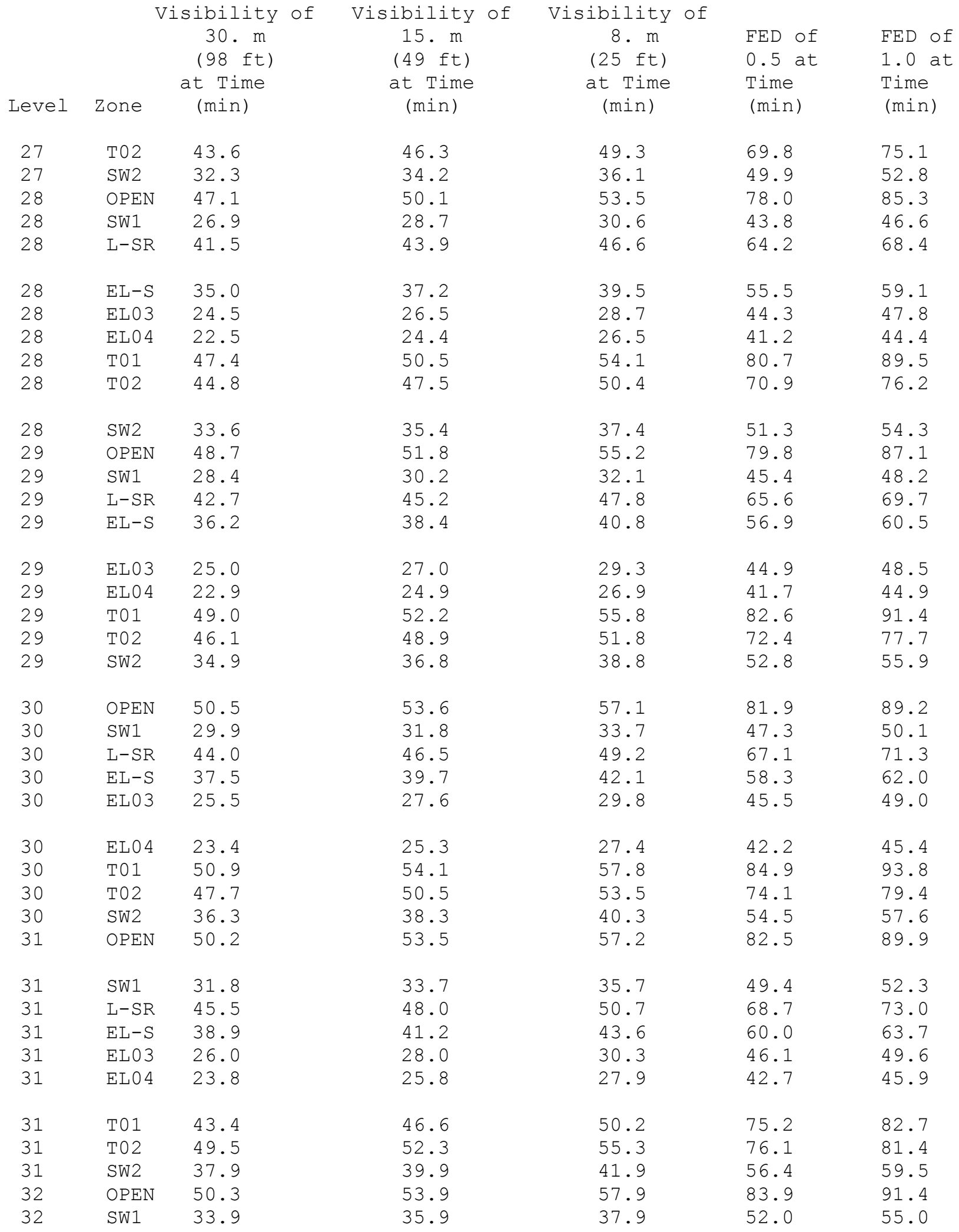


Table 16. Continued.

\begin{tabular}{|c|c|c|c|c|c|c|}
\hline Level & Zone & $\begin{array}{l}\text { sibility of } \\
30 . \mathrm{m} \\
(98 \mathrm{ft}) \\
\text { at Time } \\
\text { (min) }\end{array}$ & $\begin{array}{c}\text { Visibility of } \\
15 . \mathrm{m} \\
(49 \mathrm{ft}) \\
\text { at Time } \\
\text { (min) }\end{array}$ & $\begin{array}{c}\text { Visibility of } \\
8 . \mathrm{m} \\
(25 \mathrm{ft}) \\
\text { at Time } \\
\text { (min) }\end{array}$ & $\begin{array}{l}\text { FED of } \\
0.5 \text { at } \\
\text { Time } \\
\text { (min) }\end{array}$ & $\begin{array}{l}\text { FED of } \\
1.0 \text { at } \\
\text { Time } \\
\text { (min) }\end{array}$ \\
\hline 32 & $L-S R$ & 47.1 & 49.7 & 52.4 & 70.6 & 74.9 \\
\hline 32 & $E L-S$ & 40.5 & 42.8 & 45.3 & 61.8 & 65.5 \\
\hline 32 & EL03 & 26.5 & 28.6 & 30.8 & 46.6 & 50.2 \\
\hline 32 & ELO 4 & 24.3 & 26.2 & 28.3 & 43.2 & 46.4 \\
\hline 32 & T01 & 41.9 & 45.0 & 48.4 & 72.6 & 79.6 \\
\hline 32 & T02 & 51.5 & 54.3 & 57.4 & 78.3 & 83.6 \\
\hline 32 & SW2 & 39.7 & 41.7 & 43.8 & 58.5 & 61.7 \\
\hline 33 & OPEN & 50.8 & 54.7 & 58.9 & 86.0 & 93.7 \\
\hline 33 & SW1 & 36.6 & 38.6 & 40.7 & 55.2 & 58.3 \\
\hline 33 & $L-S R$ & 48.9 & 51.5 & 54.3 & 72.7 & 77.0 \\
\hline 33 & $E L-S$ & 42.3 & 44.6 & 47.1 & 63.8 & 67.6 \\
\hline 33 & ELO3 & 26.9 & 29.0 & 31.3 & 47.1 & 50.7 \\
\hline 33 & ELO 4 & 24.7 & 26.7 & 28.8 & 43.7 & 46.9 \\
\hline 33 & T01 & 41.7 & 44.8 & 48.1 & 72.0 & 78.9 \\
\hline 33 & T02 & 53.7 & 56.6 & 59.8 & 80.9 & 86.2 \\
\hline 33 & SW2 & 41.7 & 43.8 & 45.9 & 60.9 & 64.2 \\
\hline 34 & OPEN & 50.8 & 54.8 & 59.3 & 87.8 & 95.9 \\
\hline 34 & SW1 & 40.0 & 42.1 & 44.3 & 59.4 & 62.8 \\
\hline 34 & $L-S R$ & 51.0 & 53.6 & 56.5 & 75.1 & 79.5 \\
\hline 34 & $E L-S$ & 44.3 & 46.7 & 49.2 & 66.2 & 70.0 \\
\hline 34 & EL03 & 27.4 & 29.5 & 31.7 & 47.6 & 51.2 \\
\hline 34 & ELO 4 & 25.1 & 27.1 & 29.2 & 44.2 & 47.4 \\
\hline 34 & T01 & 42.0 & 45.0 & 48.4 & 72.3 & 79.3 \\
\hline 34 & T02 & 56.4 & 59.3 & 62.6 & 83.9 & 89.3 \\
\hline 34 & SW2 & 44.1 & 46.2 & 48.4 & 63.7 & 67.1 \\
\hline 35 & OPEN & 51.5 & 55.6 & 60.4 & 91.0 & 99.9 \\
\hline 35 & SW1 & 45.2 & 47.5 & 49.8 & 66.2 & 69.9 \\
\hline 35 & $L-S R$ & 53.4 & 56.1 & 58.9 & 77.8 & 82.3 \\
\hline 35 & $E L-S$ & 46.6 & 49.0 & 51.6 & 68.9 & 72.8 \\
\hline 35 & EL03 & 27.8 & 29.9 & 32.2 & 48.1 & 51.7 \\
\hline 35 & ELO 4 & 25.6 & 27.6 & 29.7 & 44.7 & 47.9 \\
\hline 35 & T01 & 42.5 & 45.5 & 48.9 & 73.0 & 80.2 \\
\hline 35 & T02 & 59.4 & 62.5 & 65.8 & 87.5 & 93.1 \\
\hline 35 & SW2 & 46.9 & 49.0 & 51.3 & 67.1 & 70.6 \\
\hline 36 & $\mathrm{MECH}$ & 67.9 & 71.5 & 75.4 & 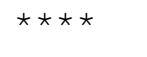 & 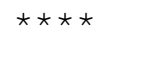 \\
\hline 36 & ELME & 71.4 & 75.3 & 79.7 & 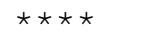 & 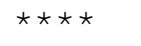 \\
\hline 36 & $E L-S$ & 49.4 & 51.9 & 54.5 & 72.2 & 76.2 \\
\hline 36 & EL03 & 27.9 & 29.9 & 32.2 & 48.1 & 51.7 \\
\hline 36 & ELO 4 & 25.7 & 27.6 & 29.7 & 44.7 & 48.0 \\
\hline 36 & SW2 & 50.3 & 52.6 & 55.0 & 71.4 & 75.1 \\
\hline
\end{tabular}


Table 16. Continued.

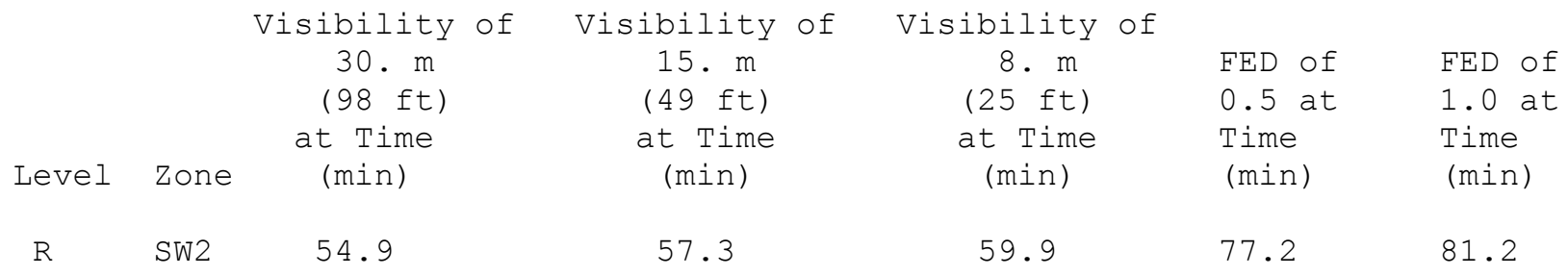


Table 17. Results of Tenability Analysis for Scenario 17.

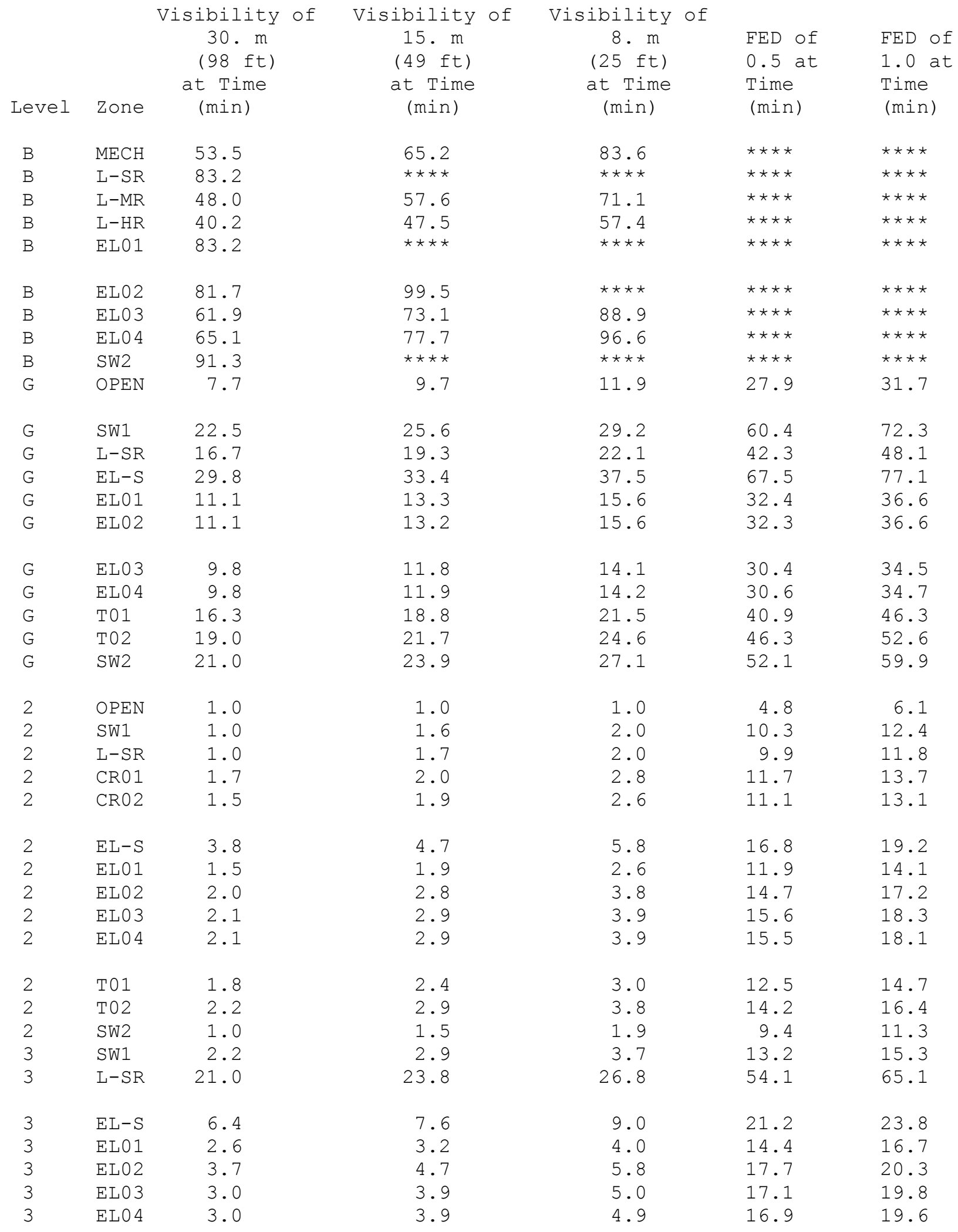


Table 17. Continued.

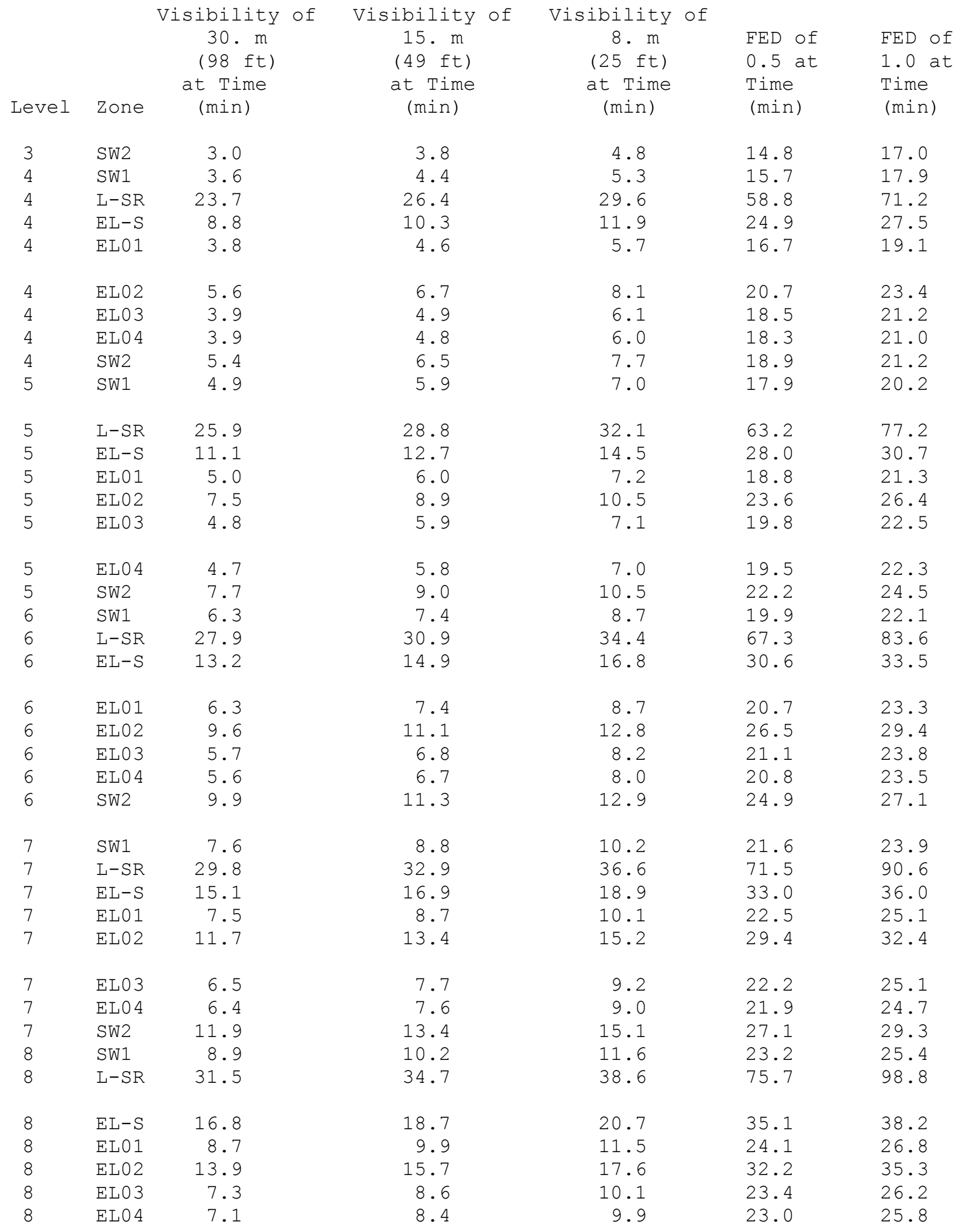


Table 17. Continued.

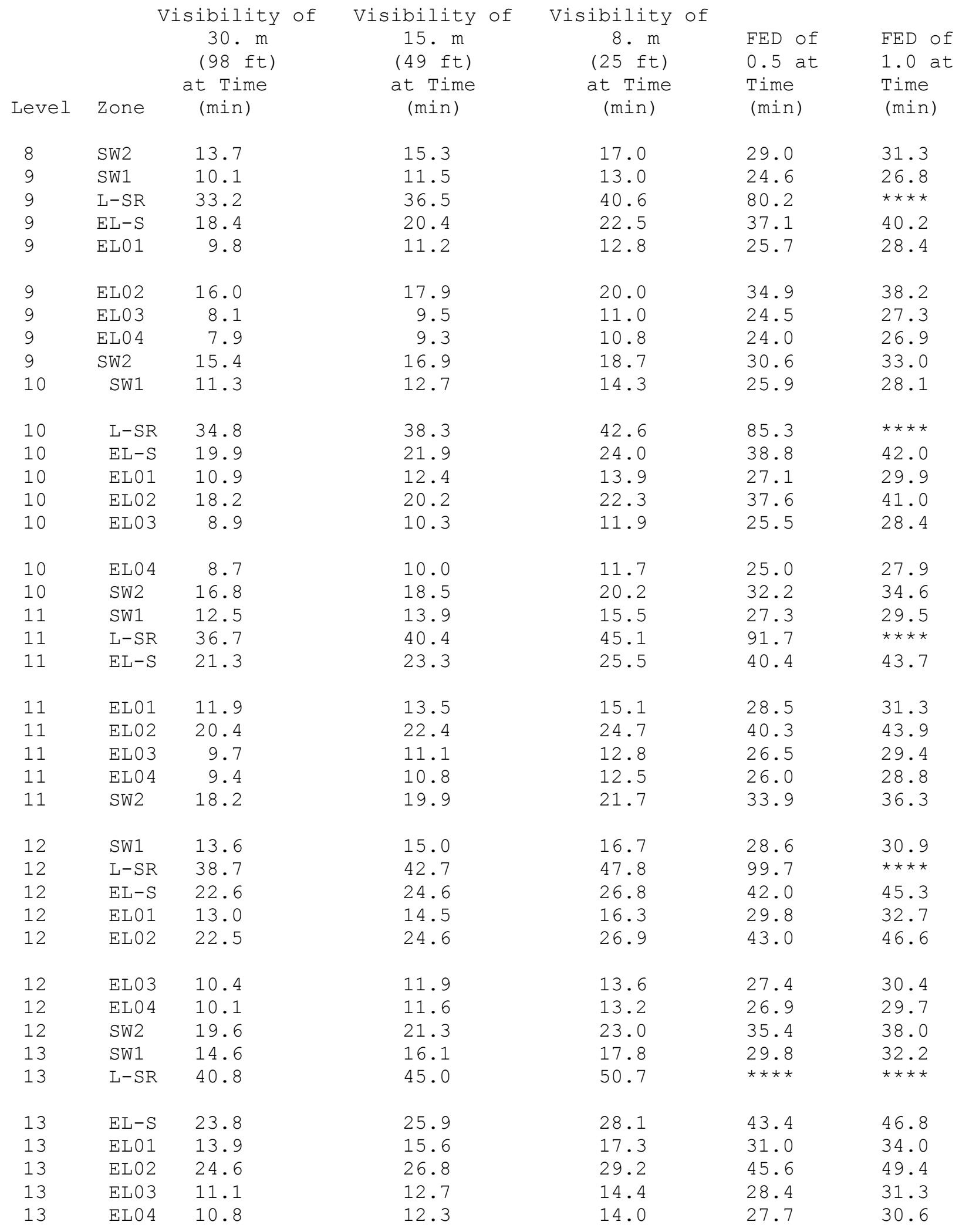


Table 17. Continued.

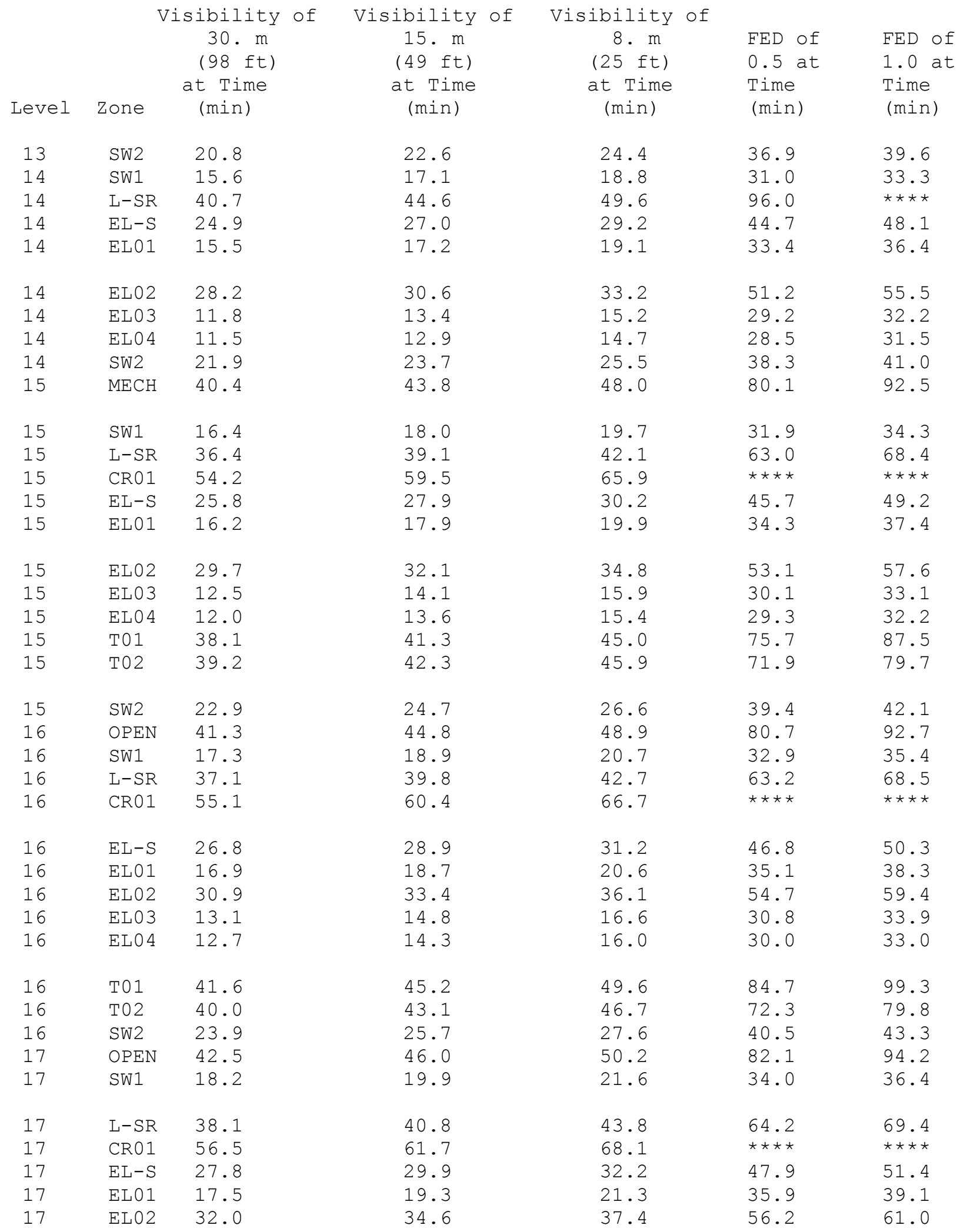


Table 17. Continued.

\begin{tabular}{|c|c|c|c|c|c|c|}
\hline Level & Zone & $\begin{array}{l}\text { sibility of } \\
30 . \mathrm{m} \\
(98 \mathrm{ft}) \\
\text { at Time } \\
\text { (min) }\end{array}$ & $\begin{array}{c}\text { Visibility of } \\
15 . \mathrm{m} \\
(49 \mathrm{ft}) \\
\text { at Time } \\
\text { (min) }\end{array}$ & $\begin{array}{c}\text { Visibility of } \\
8 . \mathrm{m} \\
(25 \mathrm{ft}) \\
\text { at Time } \\
\text { (min) }\end{array}$ & $\begin{array}{l}\text { FED of } \\
0.5 \text { at } \\
\text { Time } \\
\text { (min) }\end{array}$ & $\begin{array}{l}\text { FED of } \\
1.0 \text { at } \\
\text { Time } \\
\text { (min) }\end{array}$ \\
\hline 17 & ELO3 & 13.8 & 15.4 & 17.3 & 31.6 & 34.7 \\
\hline 17 & ELO 4 & 13.3 & 14.9 & 16.7 & 30.7 & 33.7 \\
\hline 17 & T01 & 42.8 & 46.4 & 50.9 & 86.2 & $\star \star \star \star$ \\
\hline 17 & T02 & 41.1 & 44.2 & 47.8 & 73.3 & 80.8 \\
\hline 17 & SW2 & 25.0 & 26.8 & 28.6 & 41.7 & 44.5 \\
\hline 18 & OPEN & 43.7 & 47.3 & 51.5 & 83.6 & 95.7 \\
\hline 18 & SW1 & 19.2 & 20.8 & 22.6 & 35.0 & 37.5 \\
\hline 18 & $L-S R$ & 39.1 & 41.9 & 44.8 & 65.3 & 70.5 \\
\hline 18 & CR01 & 57.8 & 63.1 & 69.6 & 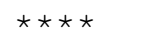 & $\star \star \star \star \star$ \\
\hline 18 & $E L-S$ & 28.8 & 30.9 & 33.2 & 49.0 & 52.5 \\
\hline 18 & EL01 & 18.1 & 19.9 & 21.9 & 36.6 & 39.8 \\
\hline 18 & ELO2 & 33.1 & 35.7 & 38.5 & 57.6 & 62.5 \\
\hline 18 & EL03 & 14.4 & 16.0 & 17.9 & 32.4 & 35.5 \\
\hline 18 & ELO 4 & 13.8 & 15.5 & 17.3 & 31.4 & 34.5 \\
\hline 18 & T01 & 44.0 & 47.7 & 52.2 & 87.8 & 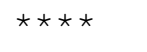 \\
\hline 18 & T02 & 42.2 & 45.4 & 49.0 & 74.5 & 81.9 \\
\hline 18 & SW2 & 26.0 & 27.8 & 29.7 & 42.9 & 45.7 \\
\hline 19 & OPEN & 45.0 & 48.6 & 52.9 & 85.1 & 97.3 \\
\hline 19 & SW1 & 20.1 & 21.8 & 23.6 & 36.1 & 38.7 \\
\hline 19 & $L-S R$ & 40.2 & 43.0 & 45.9 & 66.4 & 71.5 \\
\hline 19 & CR01 & 59.2 & 64.5 & 71.0 & $\star \star \star \star \star$ & 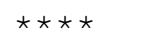 \\
\hline 19 & $E L-S$ & 29.8 & 31.9 & 34.2 & 50.1 & 53.6 \\
\hline 19 & EL01 & 18.7 & 20.5 & 22.5 & 37.3 & 40.5 \\
\hline 19 & EL02 & 34.1 & 36.8 & 39.6 & 58.9 & 63.9 \\
\hline 19 & EL03 & 15.0 & 16.7 & 18.6 & 33.1 & 36.2 \\
\hline 19 & ELO 4 & 14.4 & 16.1 & 17.9 & 32.1 & 35.2 \\
\hline 19 & T01 & 45.3 & 49.0 & 53.6 & 89.4 & 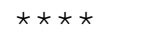 \\
\hline 19 & T02 & 43.4 & 46.6 & 50.2 & 75.7 & 83.1 \\
\hline 19 & SW2 & 27.1 & 28.9 & 30.8 & 44.1 & 47.0 \\
\hline 20 & OPEN & 46.3 & 49.9 & 54.3 & 86.7 & 99.0 \\
\hline 20 & SW1 & 21.2 & 22.8 & 24.7 & 37.3 & 39.8 \\
\hline 20 & $L-S R$ & 41.4 & 44.1 & 47.1 & 67.5 & 72.7 \\
\hline 20 & CR01 & 60.6 & 66.0 & 72.6 & 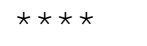 & 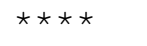 \\
\hline 20 & $E L-S$ & 30.8 & 32.9 & 35.3 & 51.2 & 54.8 \\
\hline 20 & EL01 & 19.2 & 21.0 & 23.1 & 37.9 & 41.2 \\
\hline 20 & EL02 & 35.1 & 37.7 & 40.6 & 60.2 & 65.2 \\
\hline 20 & EL03 & 15.6 & 17.3 & 19.3 & 33.8 & 37.0 \\
\hline 20 & ELO 4 & 15.0 & 16.7 & 18.6 & 32.8 & 35.9 \\
\hline 20 & T01 & 46.6 & 50.4 & 55.1 & 91.1 & 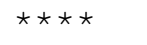 \\
\hline 20 & T02 & 44.6 & 47.8 & 51.5 & 76.9 & 84.3 \\
\hline
\end{tabular}


Table 17. Continued.

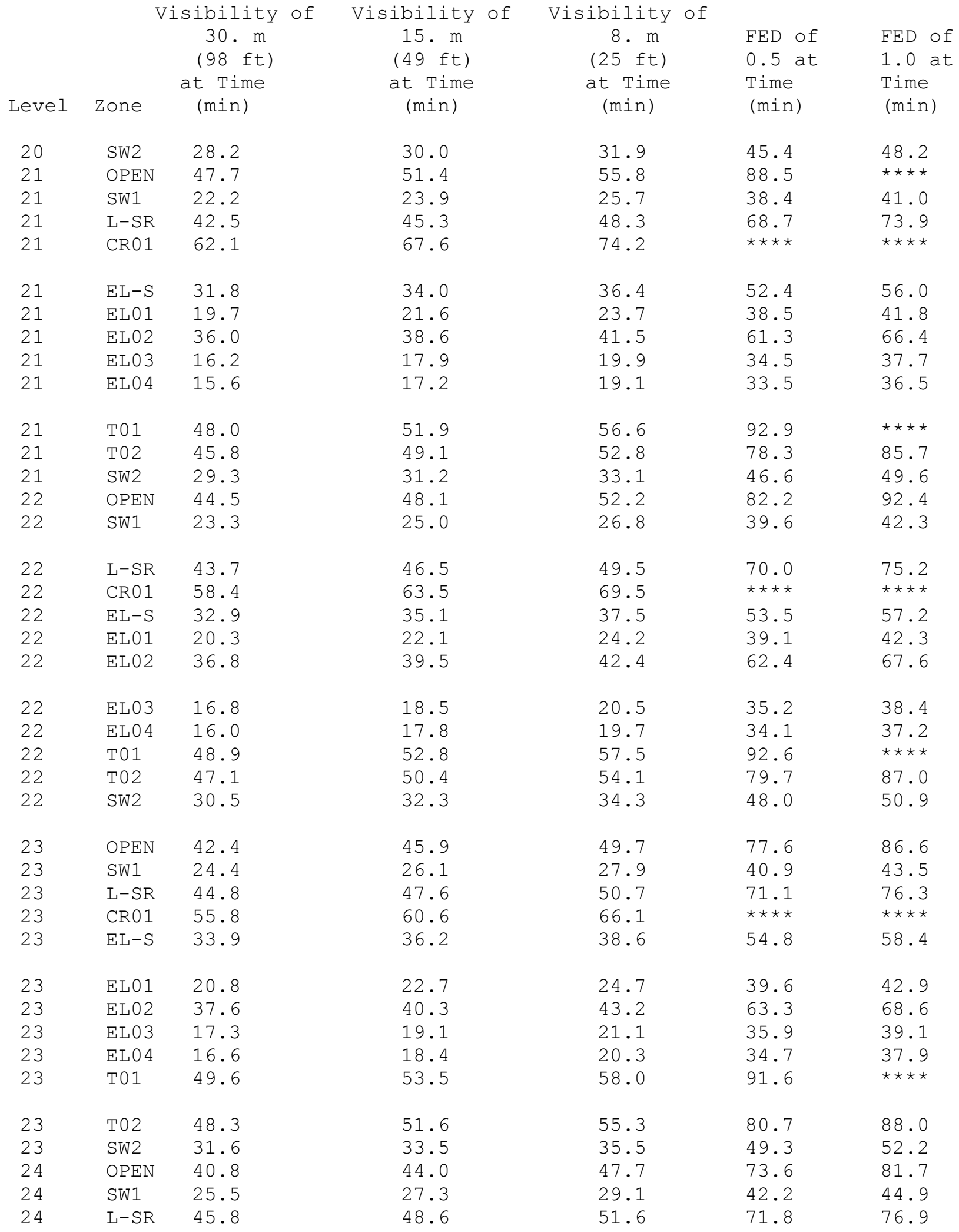


Table 17. Continued.

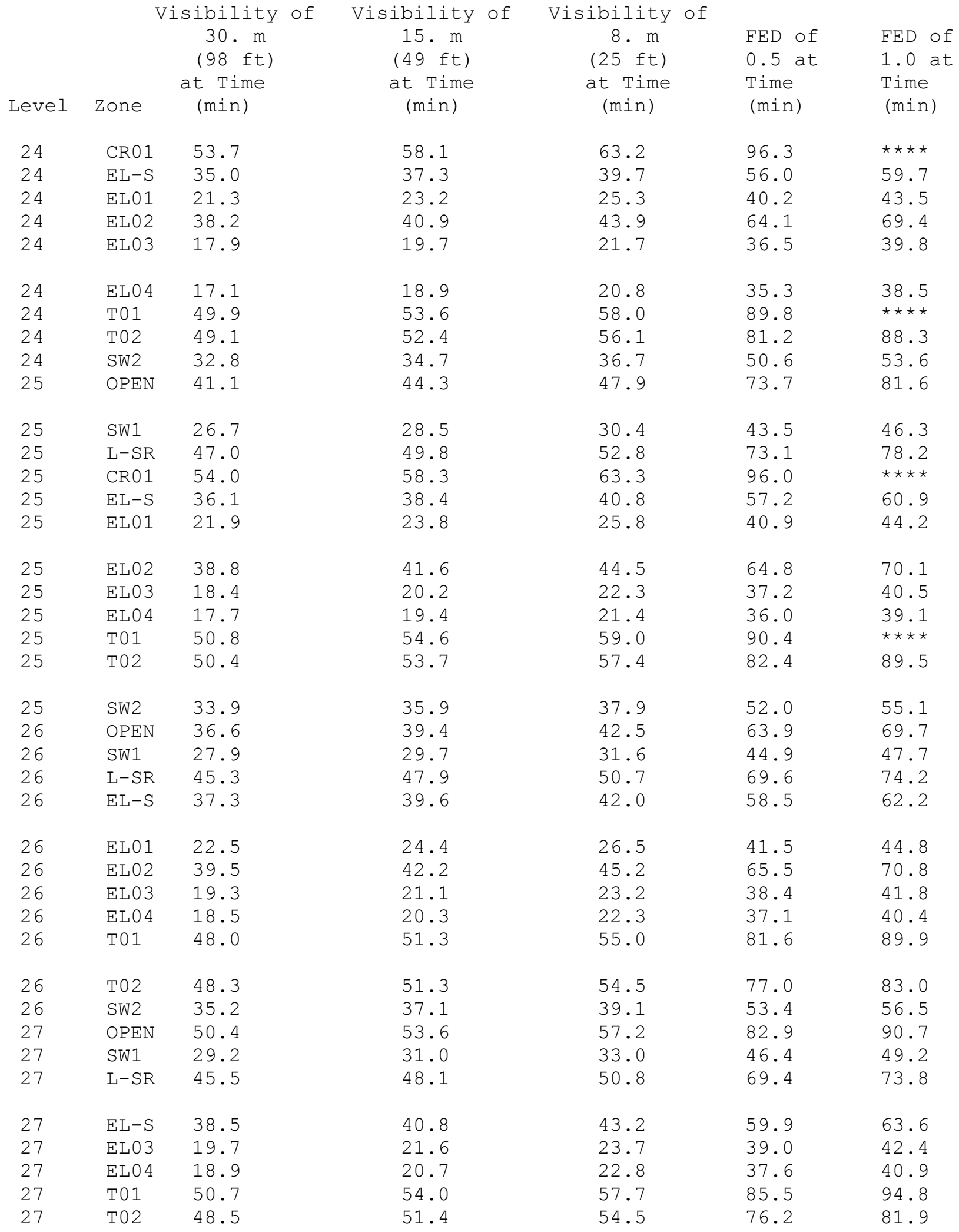


Table 17. Continued.

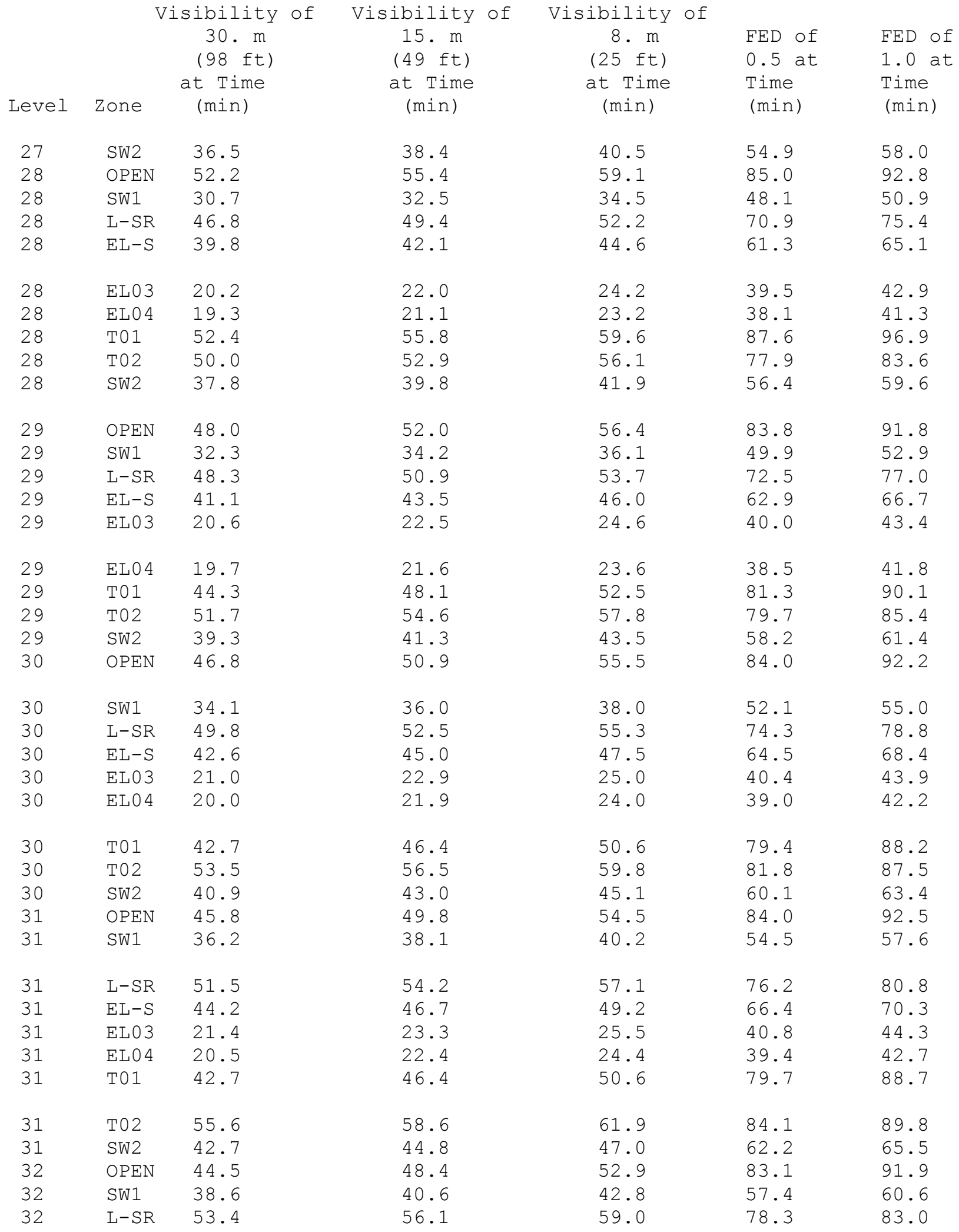


Table 17. Continued.

\begin{tabular}{|c|c|c|c|c|c|c|}
\hline Level & Zone & $\begin{array}{l}\text { sibility of } \\
30 . \mathrm{m} \\
(98 \mathrm{ft}) \\
\text { at Time } \\
\text { (min) }\end{array}$ & $\begin{array}{c}\text { Visibility of } \\
15 . \mathrm{m} \\
(49 \mathrm{ft}) \\
\text { at Time } \\
\text { (min) }\end{array}$ & $\begin{array}{c}\text { Visibility of } \\
8 . \mathrm{m} \\
(25 \mathrm{ft}) \\
\text { at Time } \\
\text { (min) }\end{array}$ & $\begin{array}{l}\text { FED of } \\
0.5 \text { at } \\
\text { Time } \\
\text { (min) }\end{array}$ & $\begin{array}{l}\text { FED of } \\
1.0 \text { at } \\
\text { Time } \\
\text { (min) }\end{array}$ \\
\hline 32 & $E L-S$ & 46.0 & 48.5 & 51.0 & 68.4 & 72.4 \\
\hline 32 & ELO3 & 21.8 & 23.7 & 25.9 & 41.3 & 44.7 \\
\hline 32 & ELO 4 & 20.9 & 22.8 & 24.8 & 39.8 & 43.1 \\
\hline 32 & T01 & 42.3 & 45.9 & 50.0 & 79.2 & 88.2 \\
\hline 32 & T02 & 57.9 & 61.0 & 64.4 & 86.6 & 92.4 \\
\hline 32 & SW2 & 44.7 & 46.8 & 49.0 & 64.5 & 68.0 \\
\hline 33 & OPEN & 43.8 & 47.5 & 51.8 & 82.1 & 91.3 \\
\hline 33 & SW1 & 41.6 & 43.7 & 45.9 & 61.1 & 64.4 \\
\hline 33 & $L-S R$ & 55.4 & 58.2 & 61.2 & 80.7 & 85.4 \\
\hline 33 & $E L-S$ & 48.0 & 50.5 & 53.1 & 70.7 & 74.8 \\
\hline 33 & EL03 & 22.2 & 24.1 & 26.3 & 41.7 & 45.2 \\
\hline 33 & ELO 4 & 21.3 & 23.2 & 25.2 & 40.3 & 43.6 \\
\hline 33 & T01 & 41.9 & 45.5 & 49.5 & 78.3 & 87.4 \\
\hline 33 & T02 & 60.5 & 63.7 & 67.1 & 89.6 & 95.4 \\
\hline 33 & SW2 & 46.9 & 49.1 & 51.4 & 67.2 & 70.7 \\
\hline 34 & OPEN & 43.3 & 46.9 & 51.1 & 81.2 & 90.6 \\
\hline 34 & SW1 & 45.5 & 47.7 & 50.0 & 66.0 & 69.5 \\
\hline 34 & $L-S R$ & 57.8 & 60.6 & 63.6 & 83.4 & 88.2 \\
\hline 34 & $E L-S$ & 50.2 & 52.8 & 55.5 & 73.3 & 77.4 \\
\hline 34 & EL03 & 22.6 & 24.6 & 26.7 & 42.2 & 45.6 \\
\hline 34 & ELO 4 & 21.7 & 23.6 & 25.7 & 40.7 & 44.1 \\
\hline 34 & T01 & 41.7 & 45.1 & 49.0 & 77.4 & 86.5 \\
\hline 34 & T02 & 63.5 & 66.8 & 70.3 & 93.0 & 98.9 \\
\hline 34 & SW2 & 49.5 & 51.7 & 54.1 & 70.2 & 73.9 \\
\hline 35 & OPEN & 42.6 & 46.1 & 50.0 & 79.1 & 88.5 \\
\hline 35 & SW1 & 51.3 & 53.7 & 56.2 & 73.6 & 77.6 \\
\hline 35 & $L-S R$ & 60.4 & 63.3 & 66.4 & 86.5 & 91.3 \\
\hline 35 & $E L-S$ & 52.8 & 55.4 & 58.1 & 76.3 & 80.5 \\
\hline 35 & EL03 & 23.0 & 24.9 & 27.1 & 42.6 & 46.1 \\
\hline 35 & ELO 4 & 22.1 & 24.0 & 26.1 & 41.2 & 44.5 \\
\hline 35 & T01 & 41.2 & 44.5 & 48.2 & 75.6 & 84.4 \\
\hline 35 & T02 & 66.9 & 70.3 & 73.9 & 97.0 & 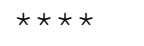 \\
\hline 35 & SW2 & 52.5 & 54.8 & 57.2 & 73.9 & 77.6 \\
\hline 36 & $\mathrm{MECH}$ & 75.2 & 79.2 & 83.5 & 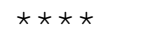 & 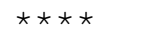 \\
\hline 36 & ELME & 79.3 & 83.6 & 88.3 & 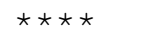 & $\star \star \star \star \star$ \\
\hline 36 & $\mathrm{EL}-\mathrm{S}$ & 55.8 & 58.4 & 61.3 & 79.9 & 84.2 \\
\hline 36 & EL03 & 23.0 & 25.0 & 27.1 & 42.6 & 46.1 \\
\hline 36 & ELO 4 & 22.1 & 24.0 & 26.1 & 41.2 & 44.5 \\
\hline 36 & SW2 & 56.1 & 58.5 & 61.1 & 78.4 & 82.3 \\
\hline $\mathrm{R}$ & SW2 & 60.8 & 63.4 & 66.1 & 84.4 & 88.6 \\
\hline
\end{tabular}


Table 17. Continued.

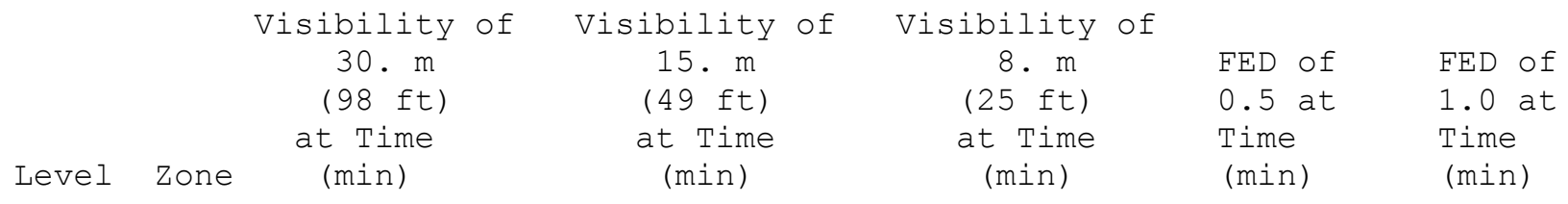


Table 18. Results of Tenability Analysis for Scenario 18.

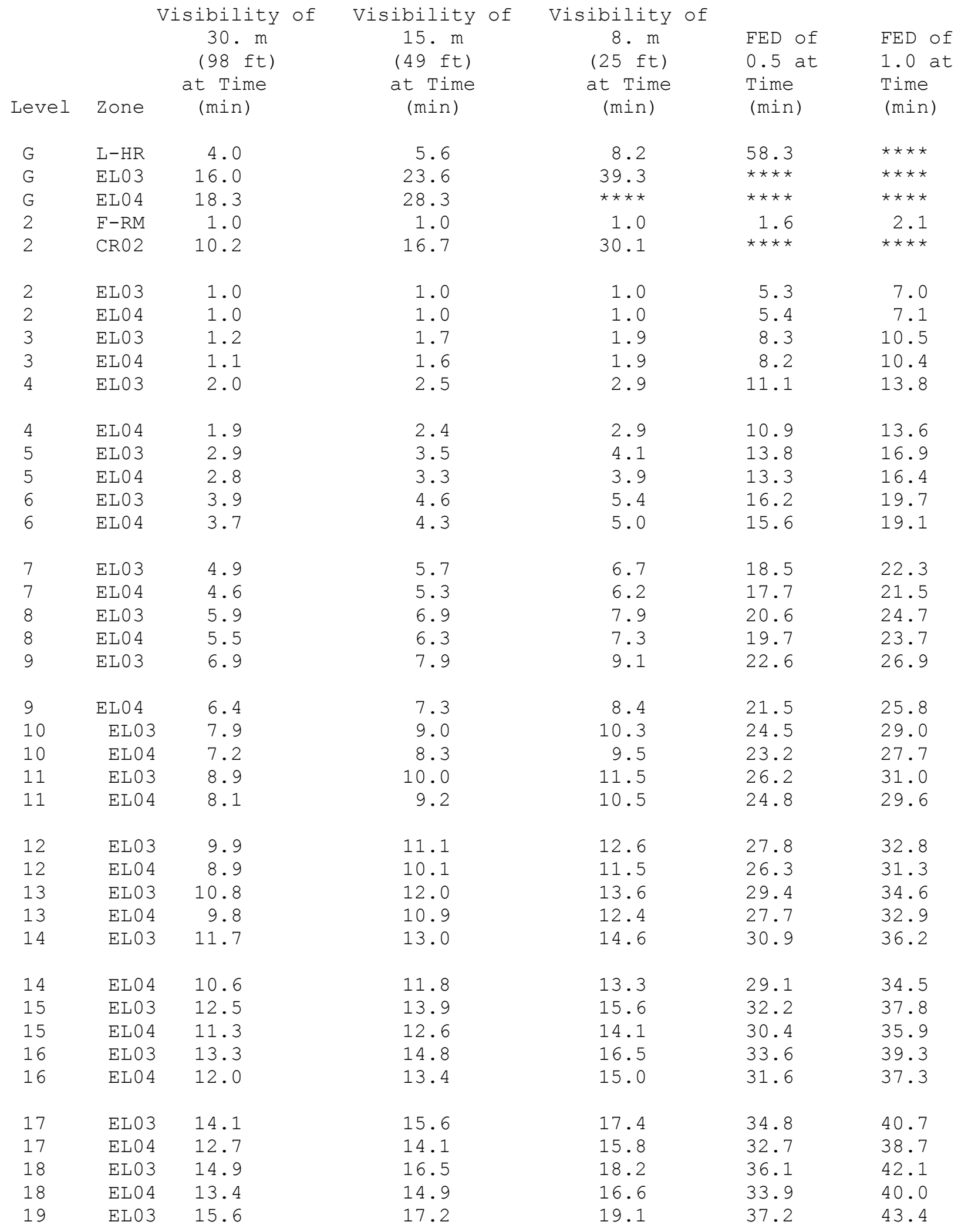


Table 18. Continued.

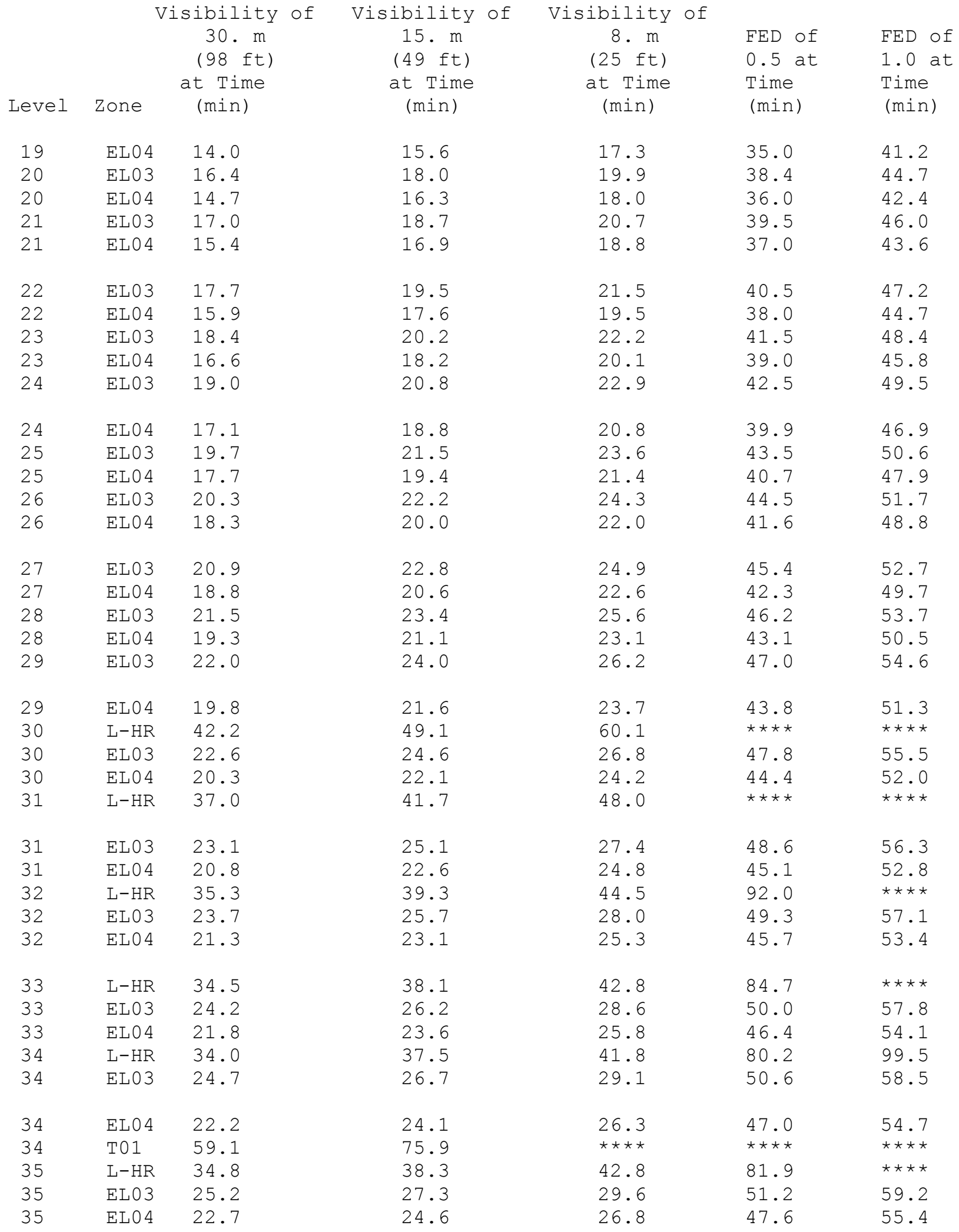


Table 18. Continued.

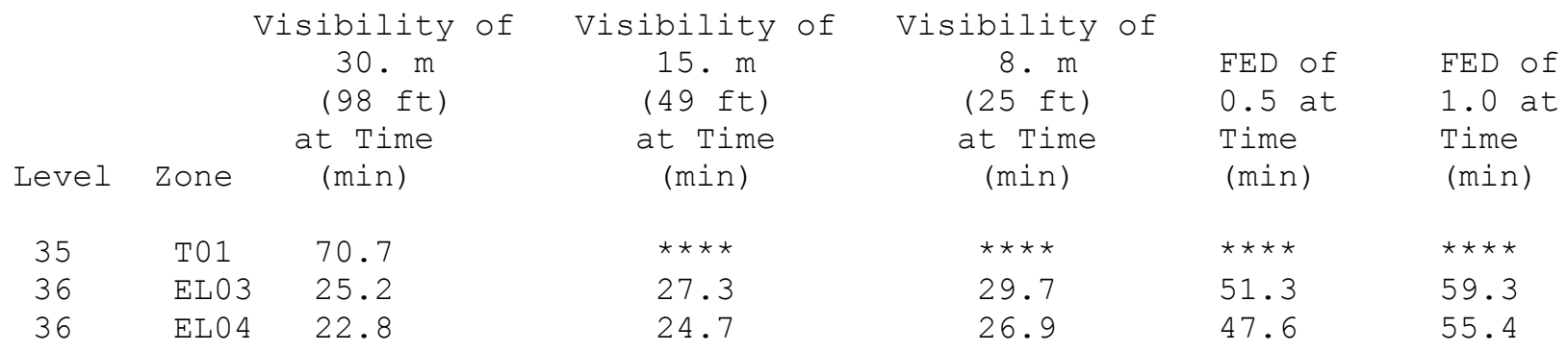


Table 19. Results of Tenability Analysis for Scenario 19.

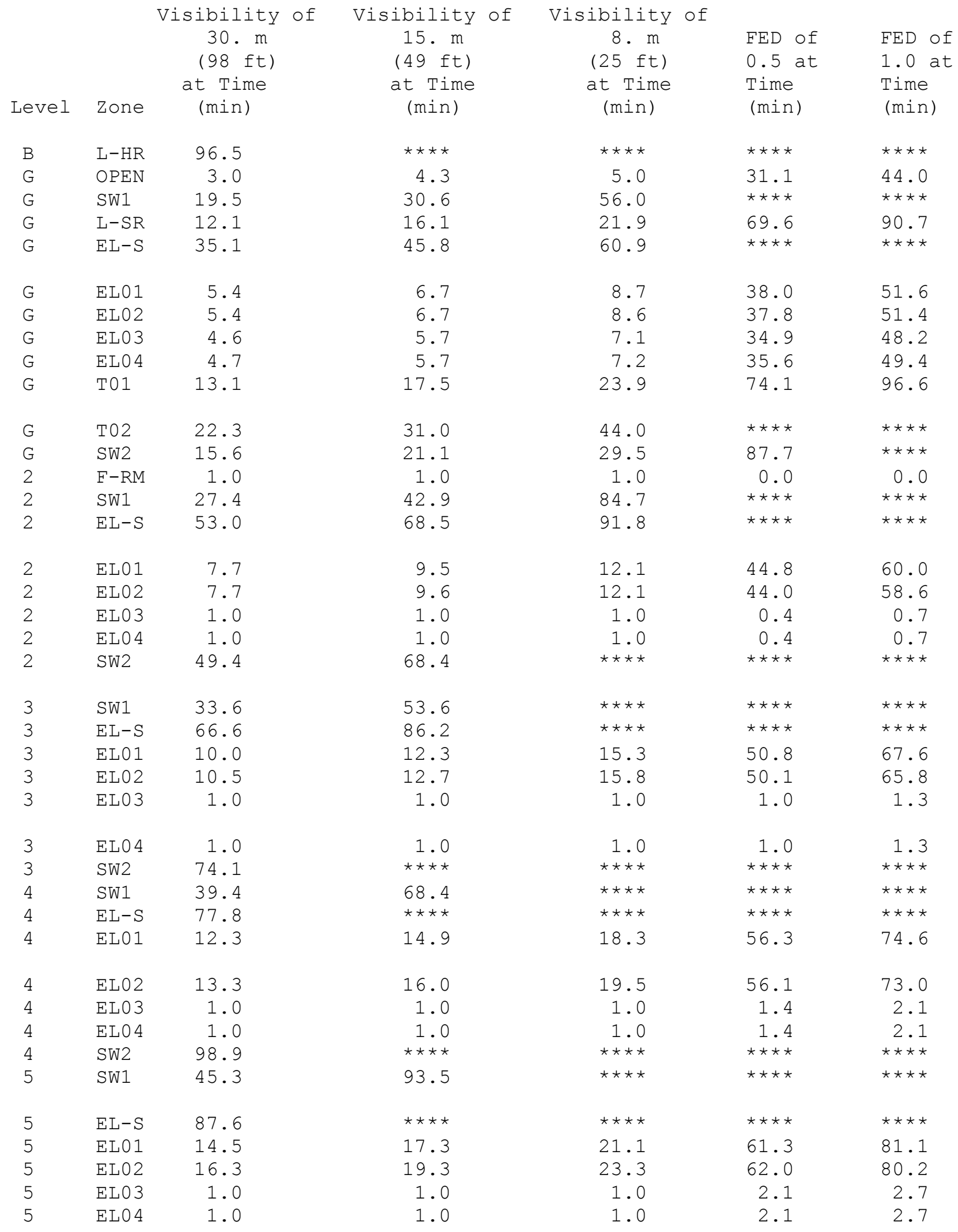


Table 19. Continued.

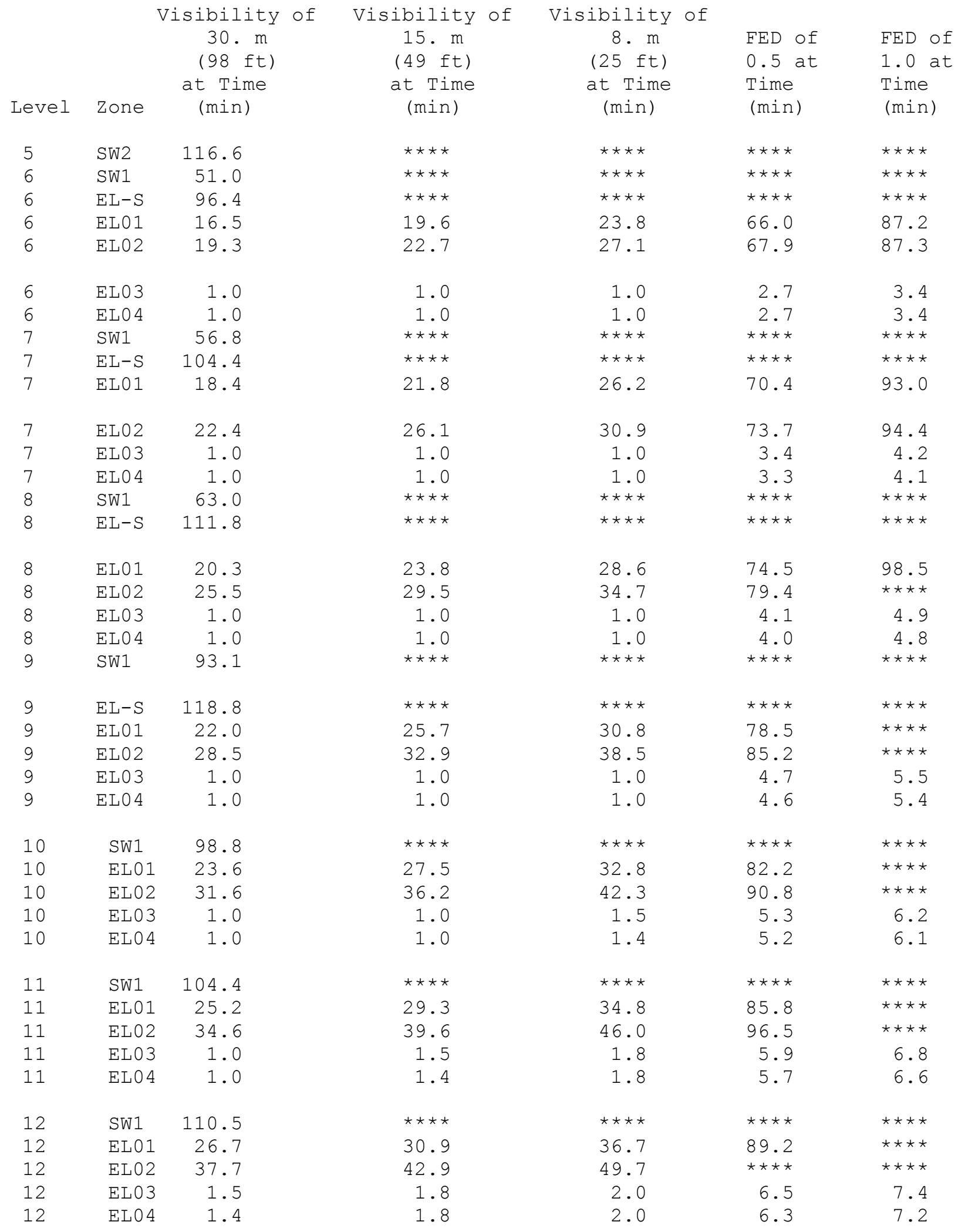


Table 19. Continued.

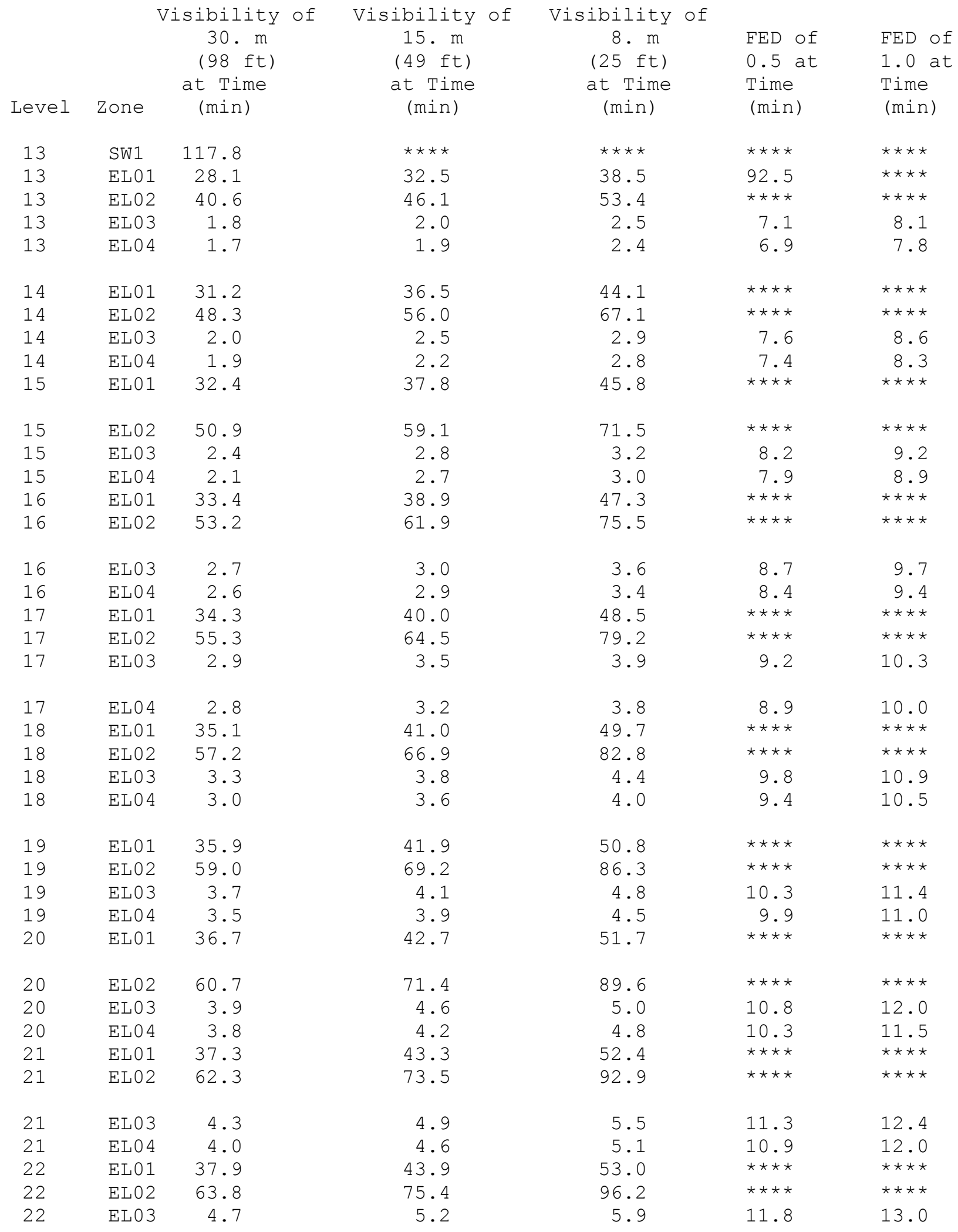


Table 19. Continued.

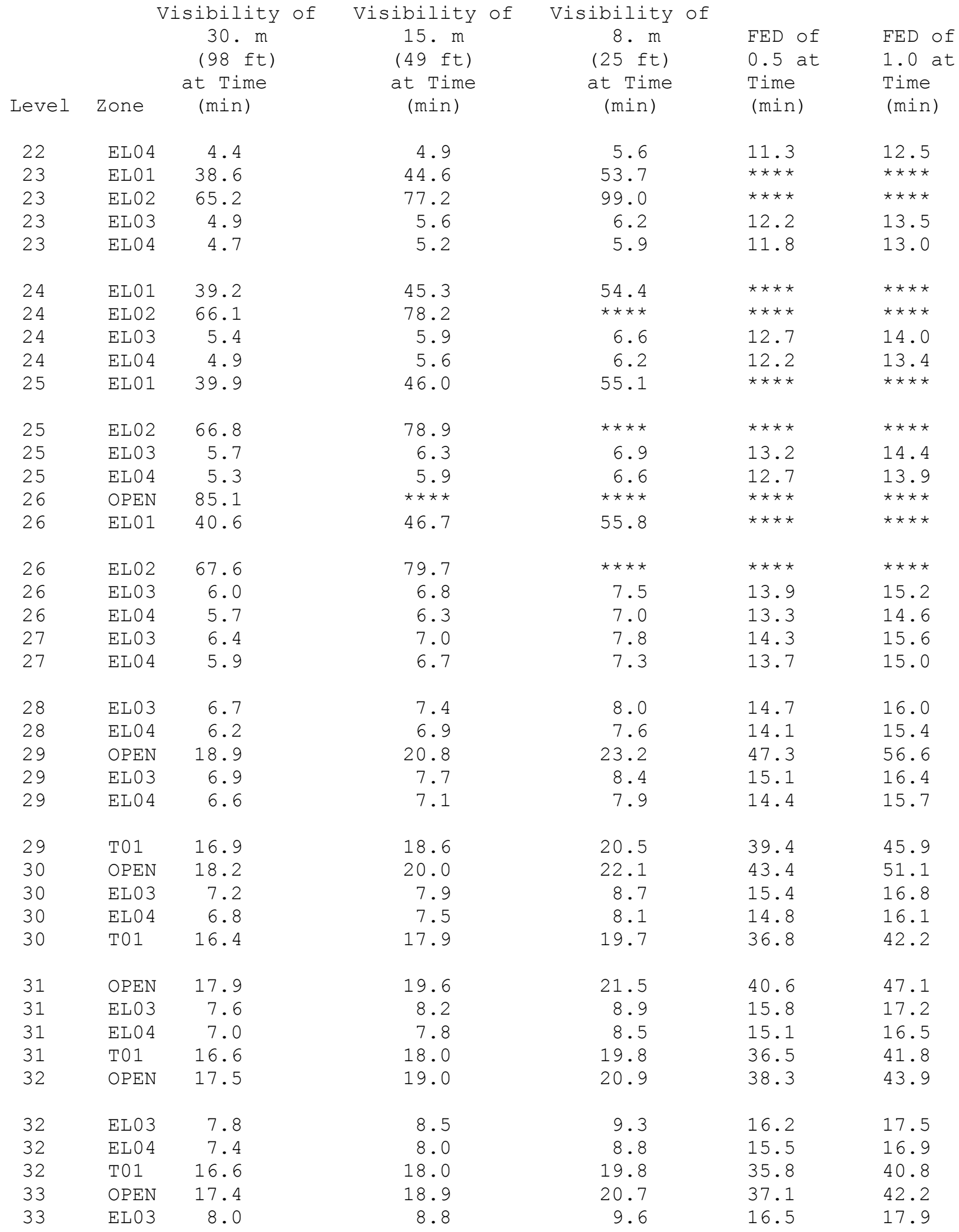


Table 19. Continued.

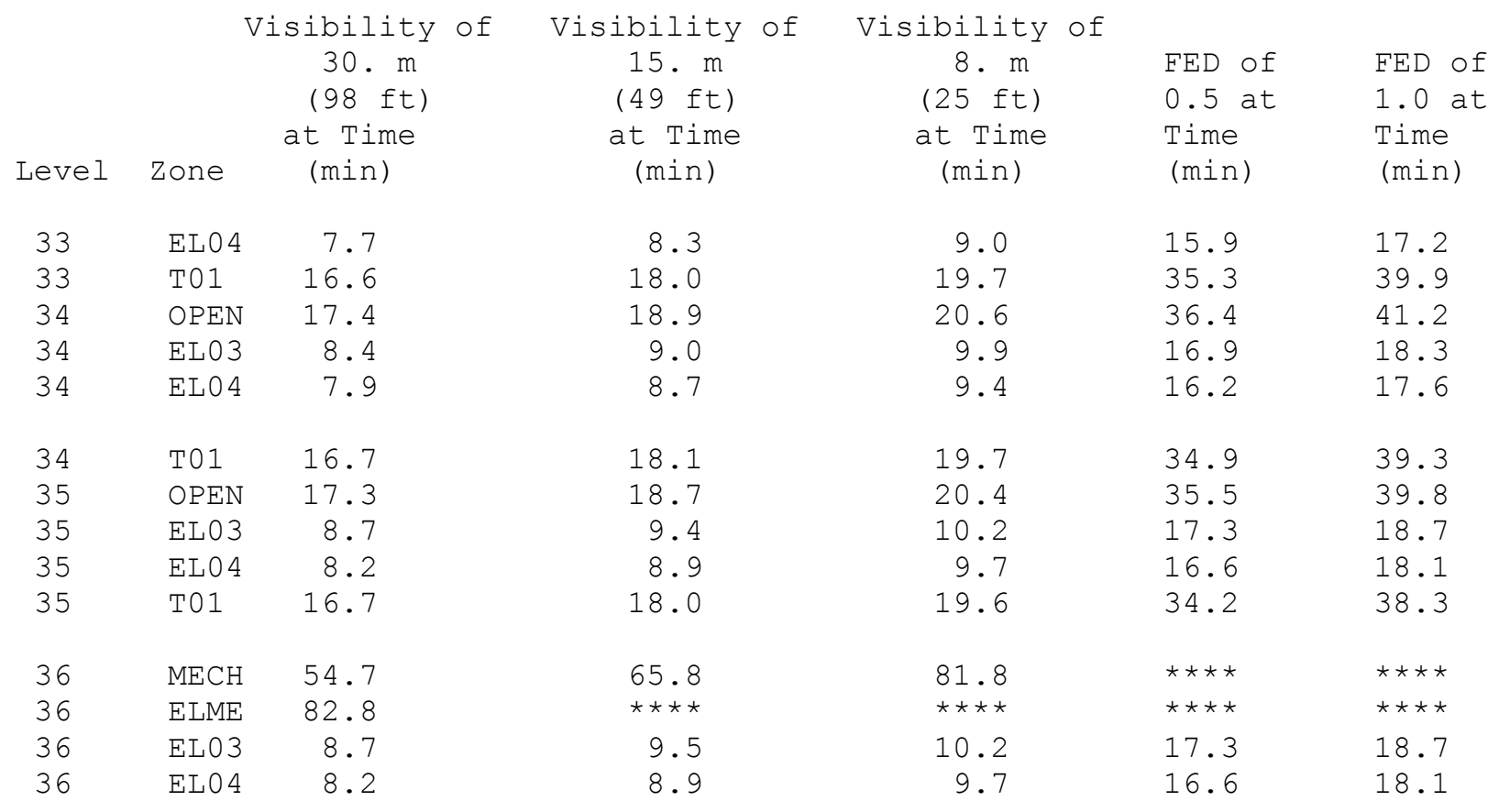


Table 20. Results of Tenability Analysis for Scenario 20.

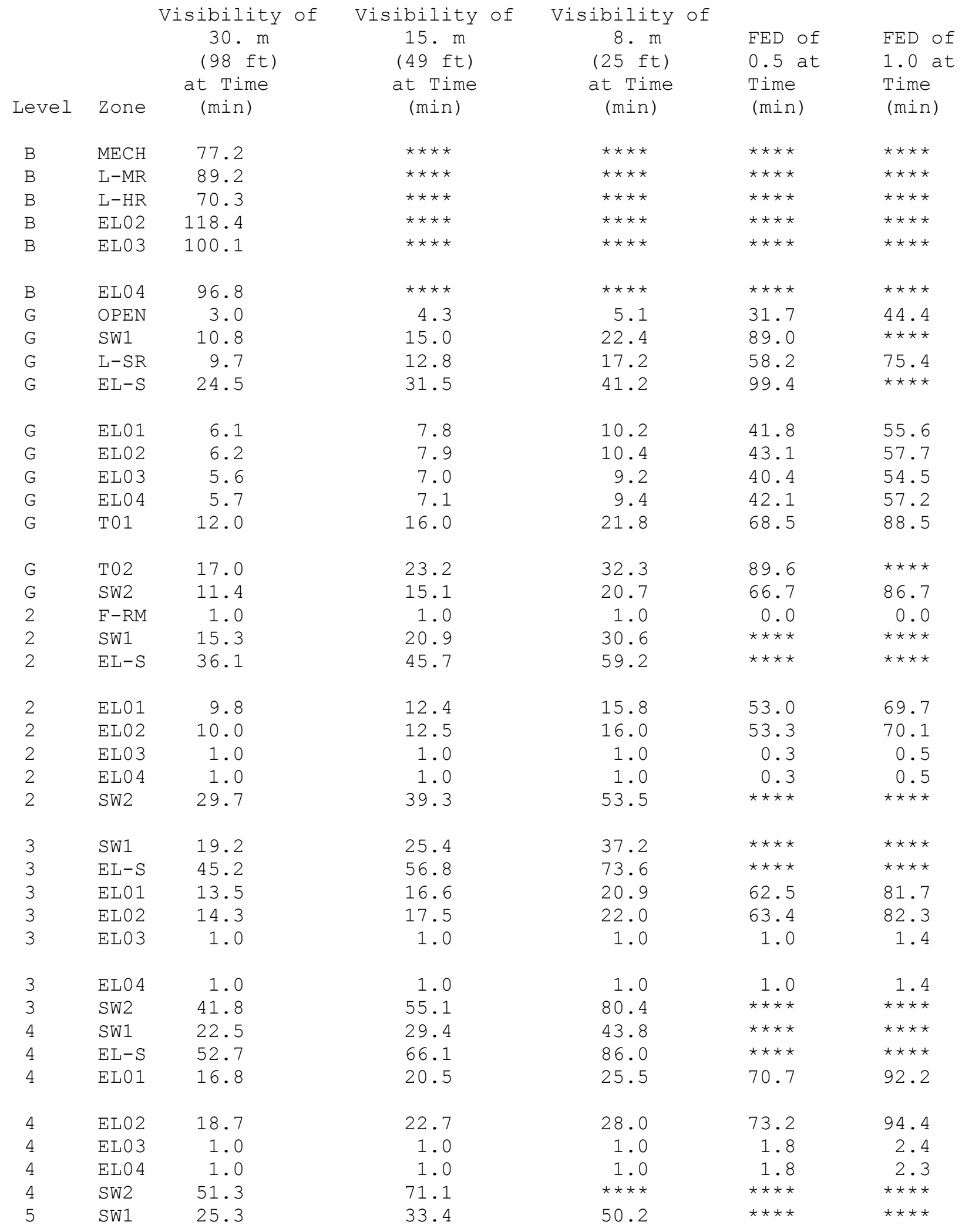


Table 20. Continued.

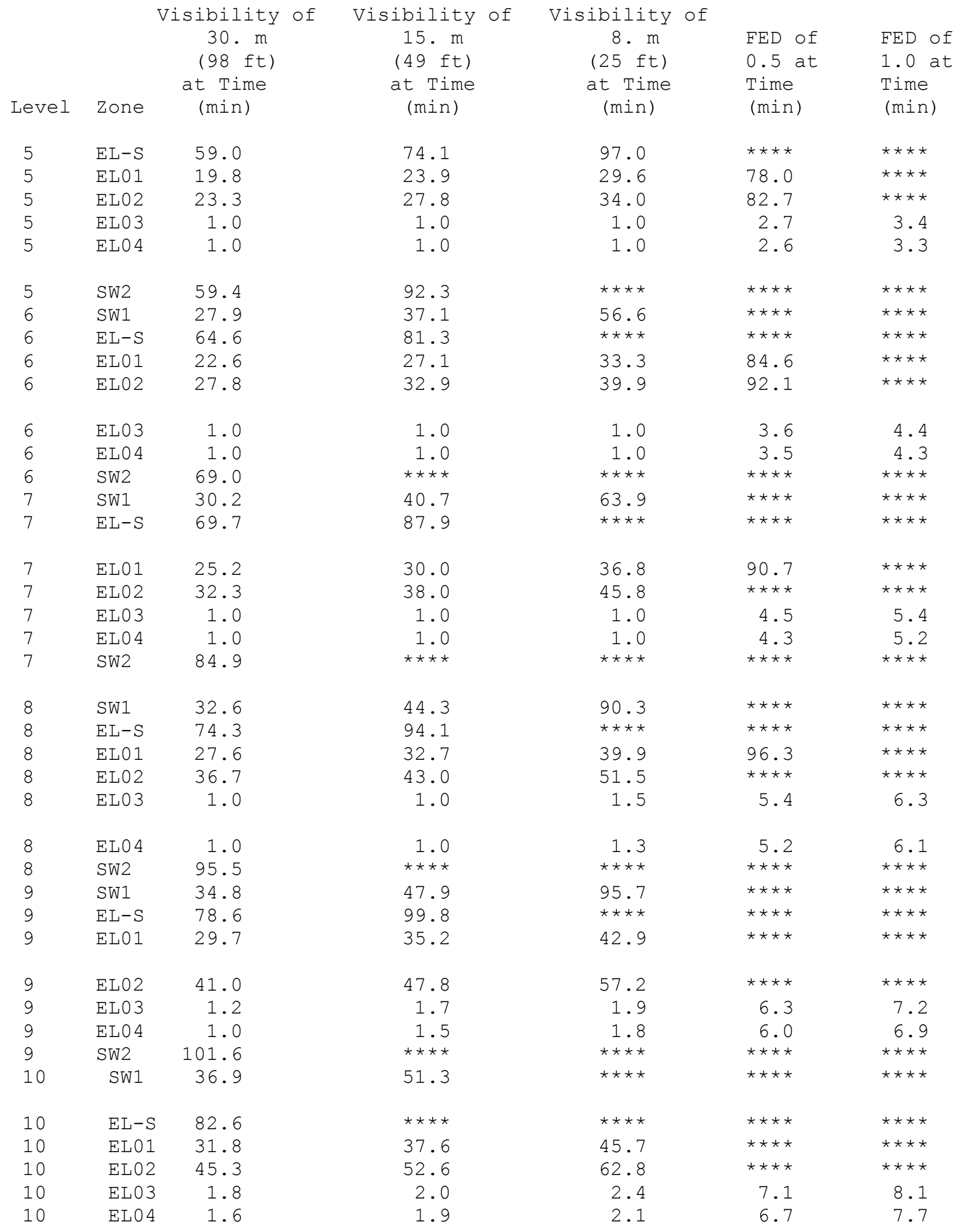


Table 20. Continued.

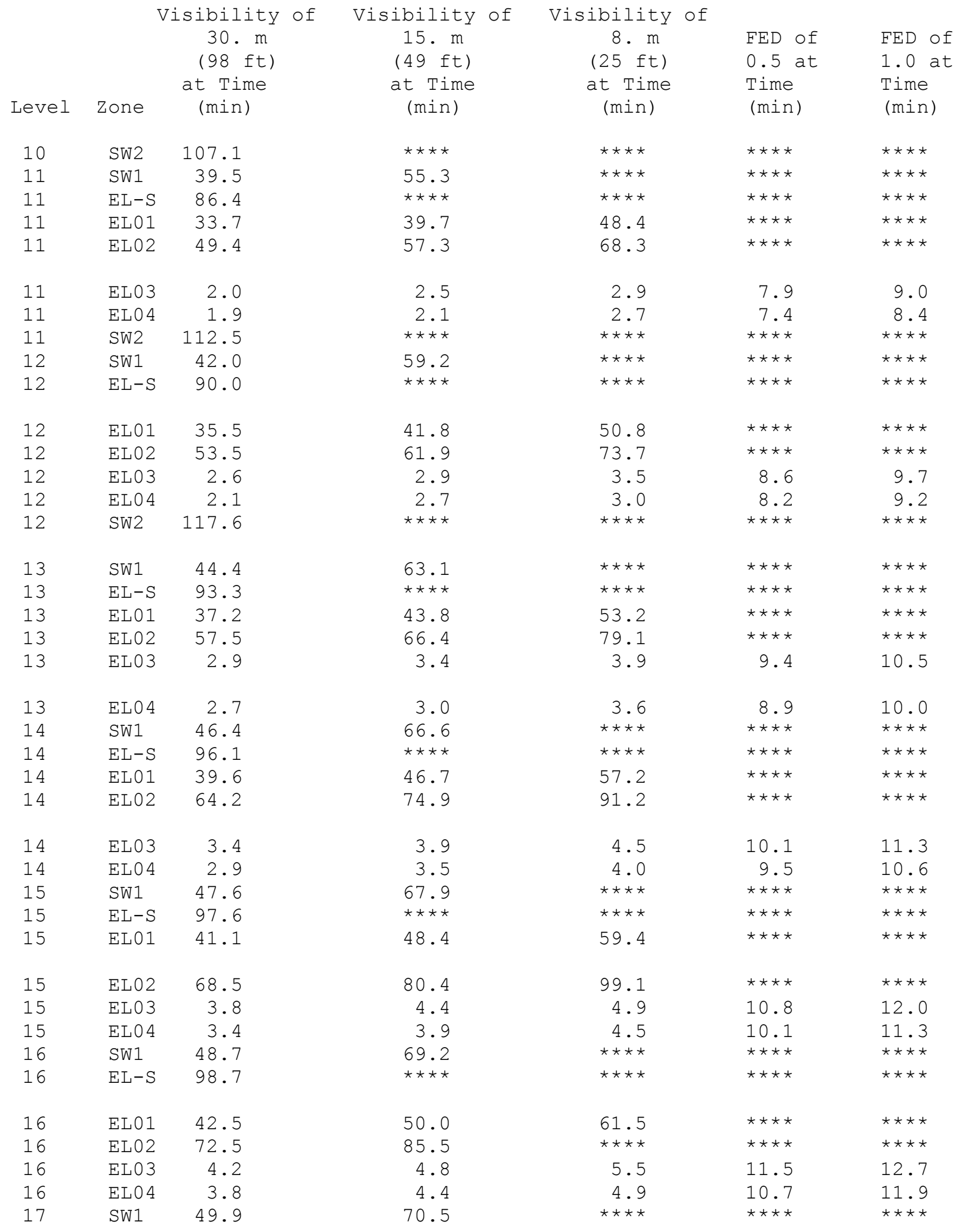


Table 20. Continued.

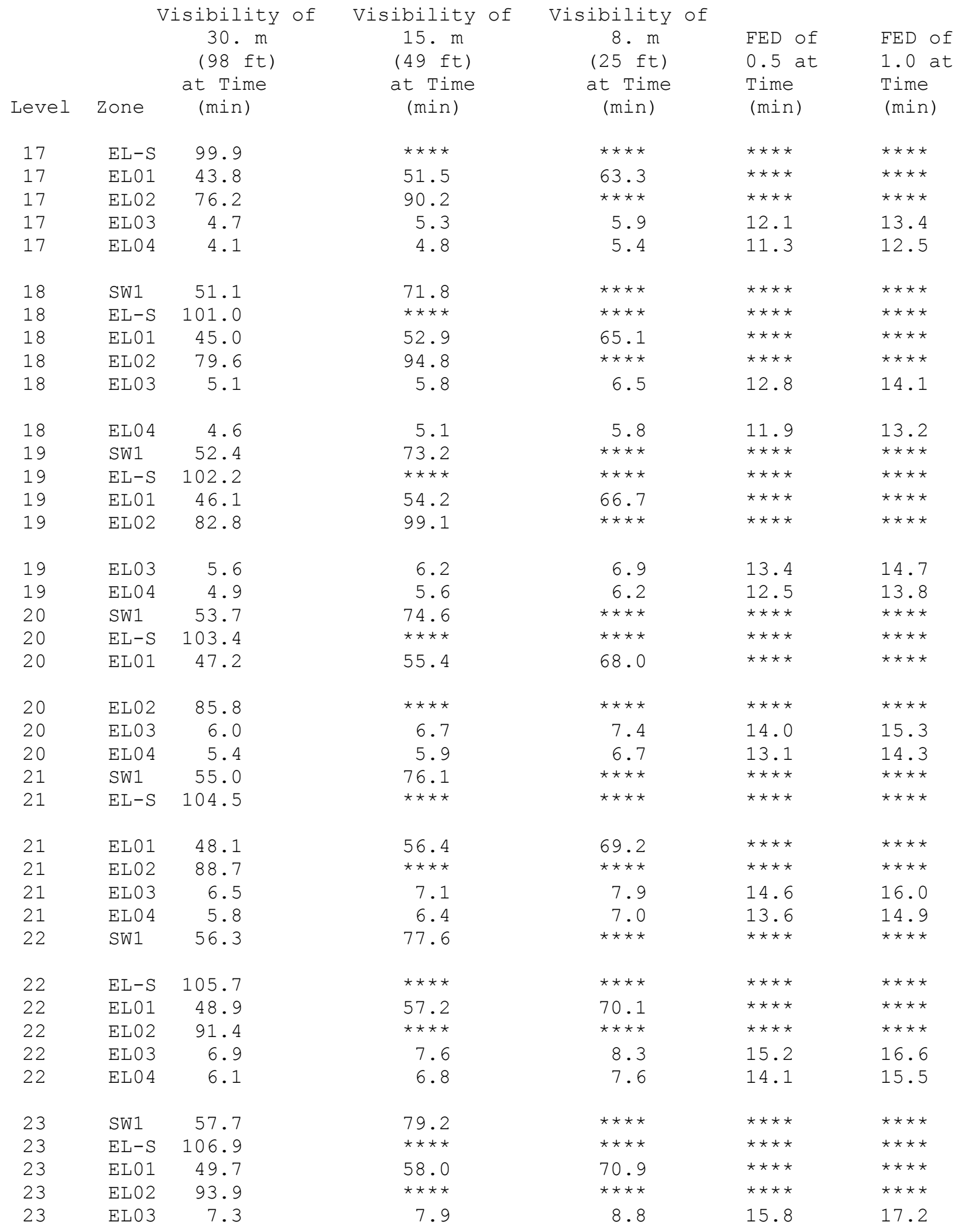


Table 20. Continued.

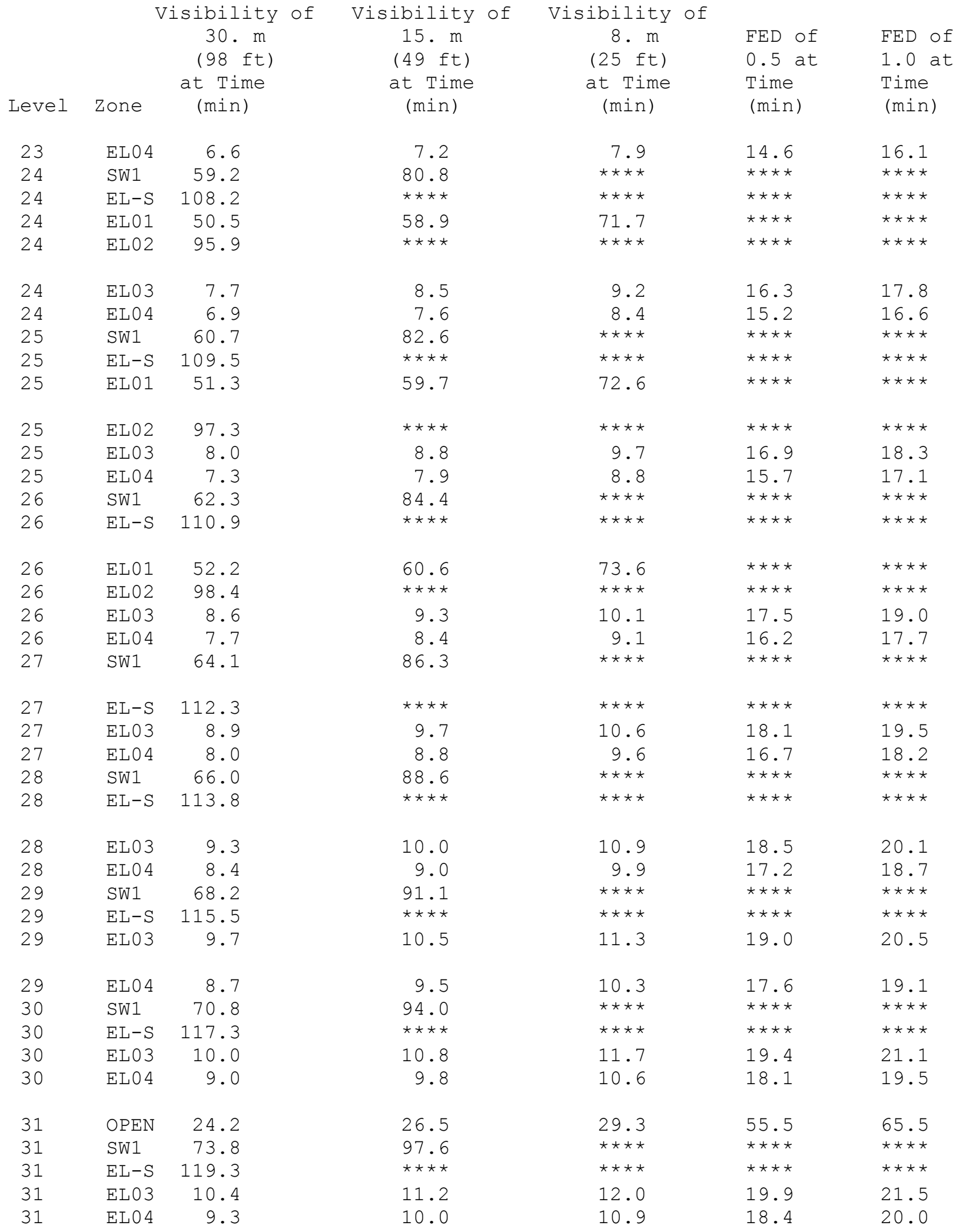


Table 20. Continued.

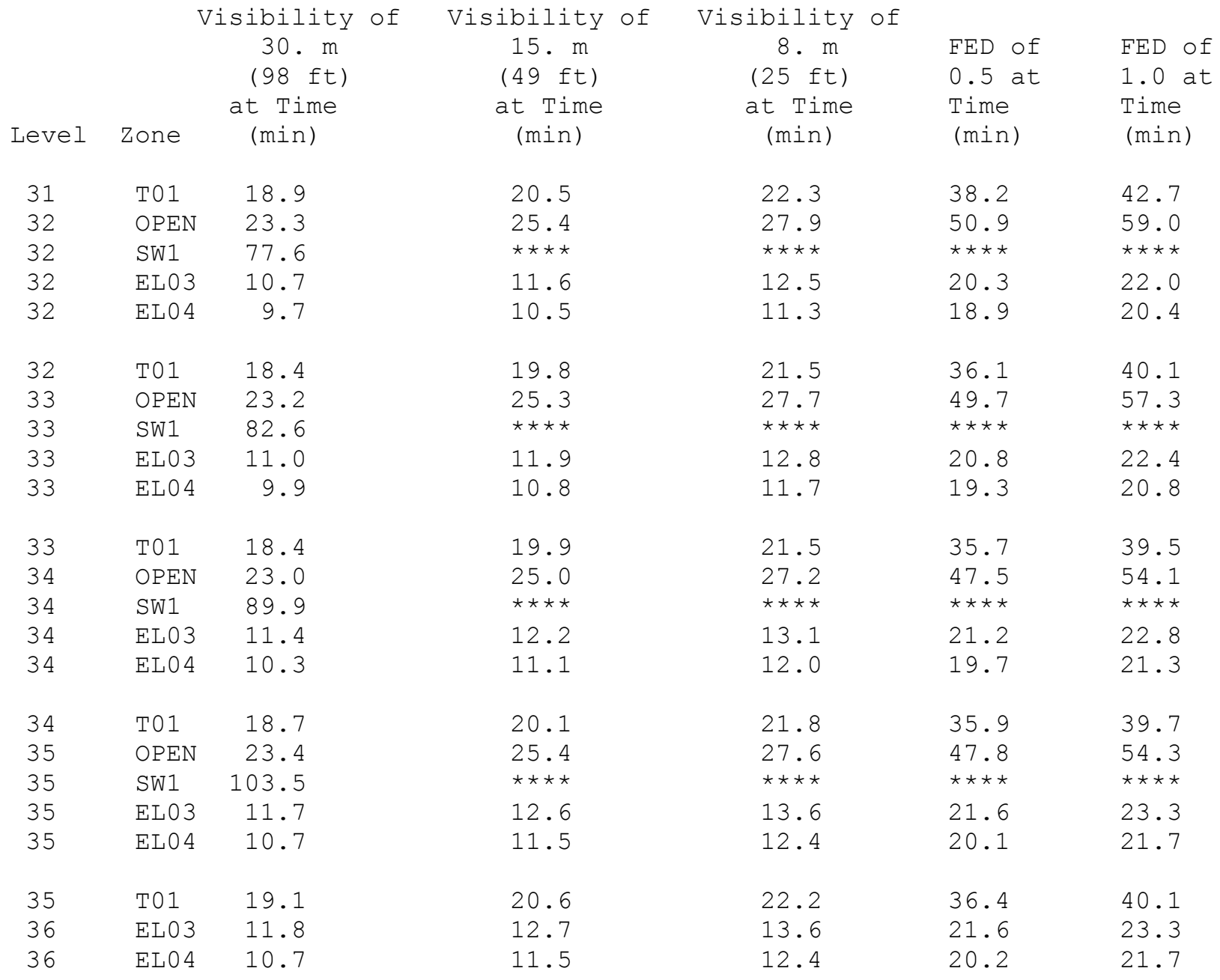


Table 21. Results of Tenability Analysis for Scenario 21.

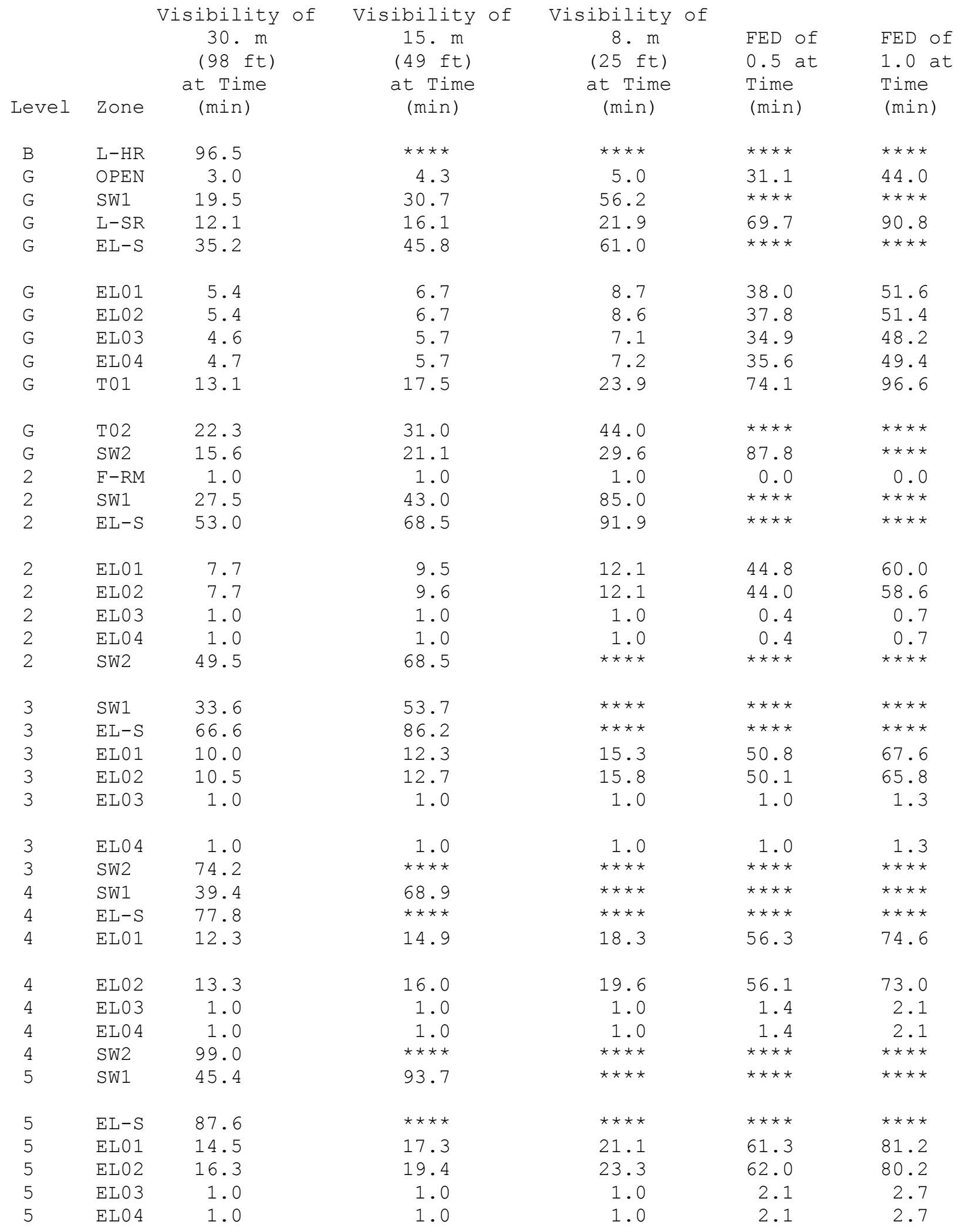


Table 21. Continued.

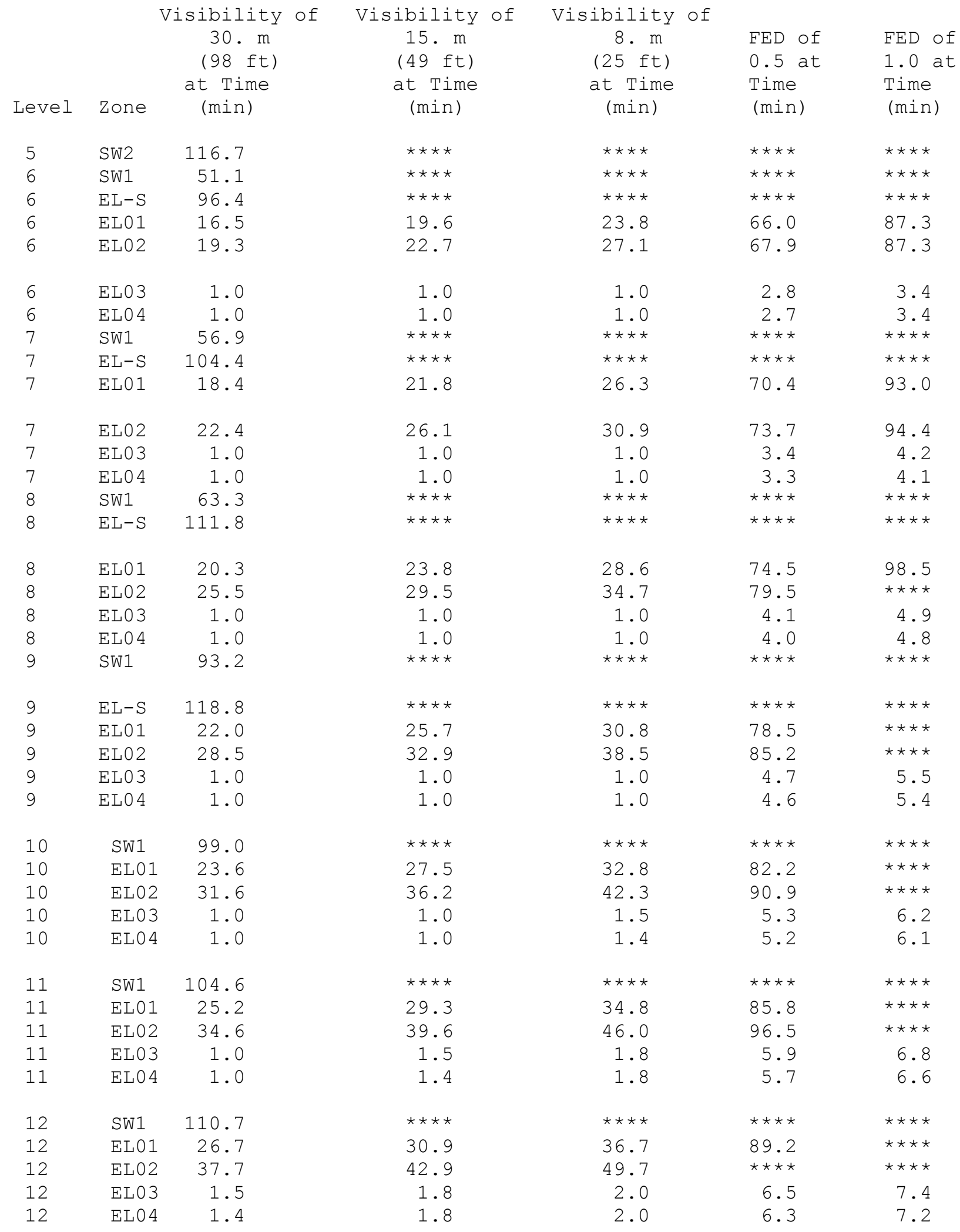


Table 21. Continued.

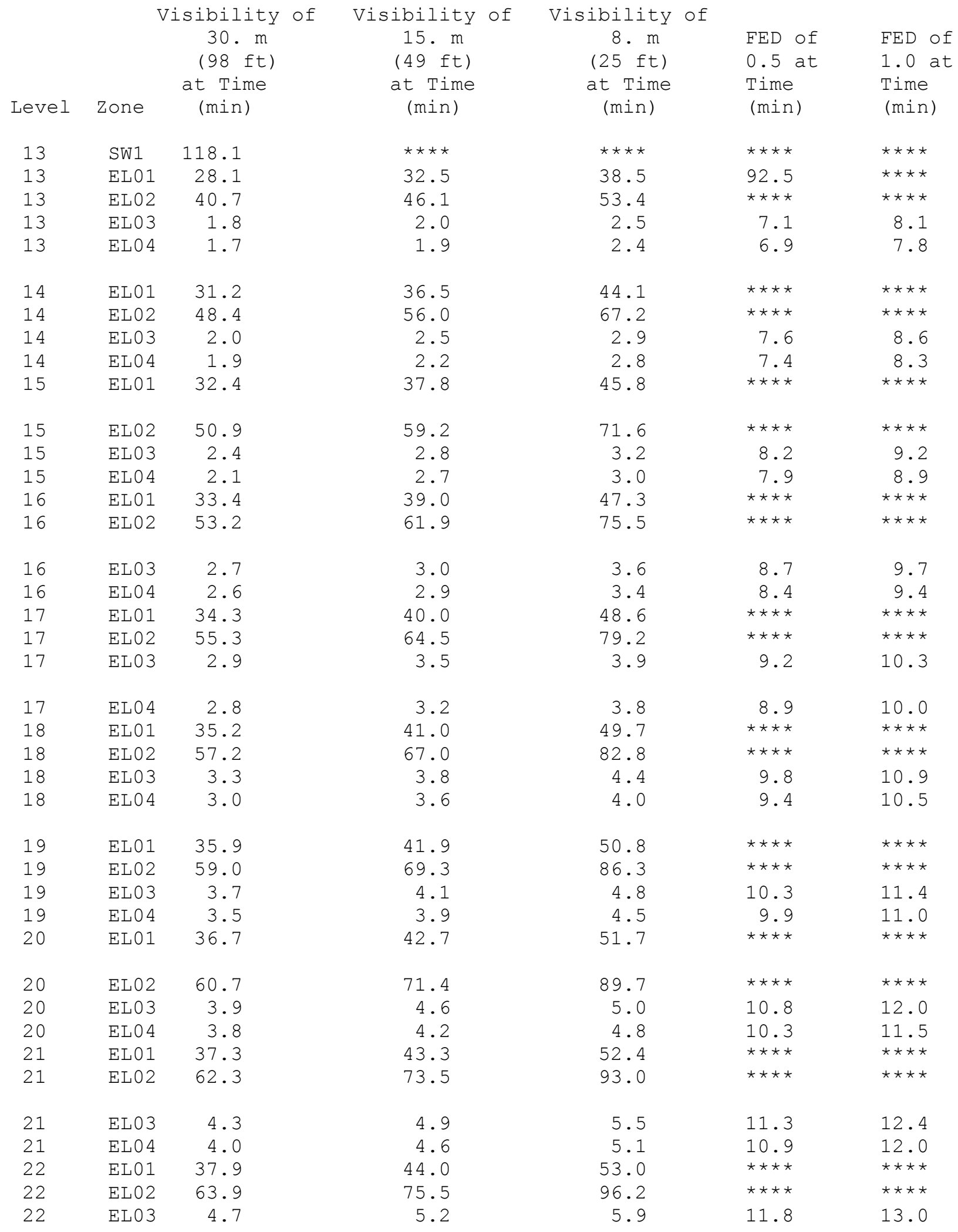


Table 21. Continued.

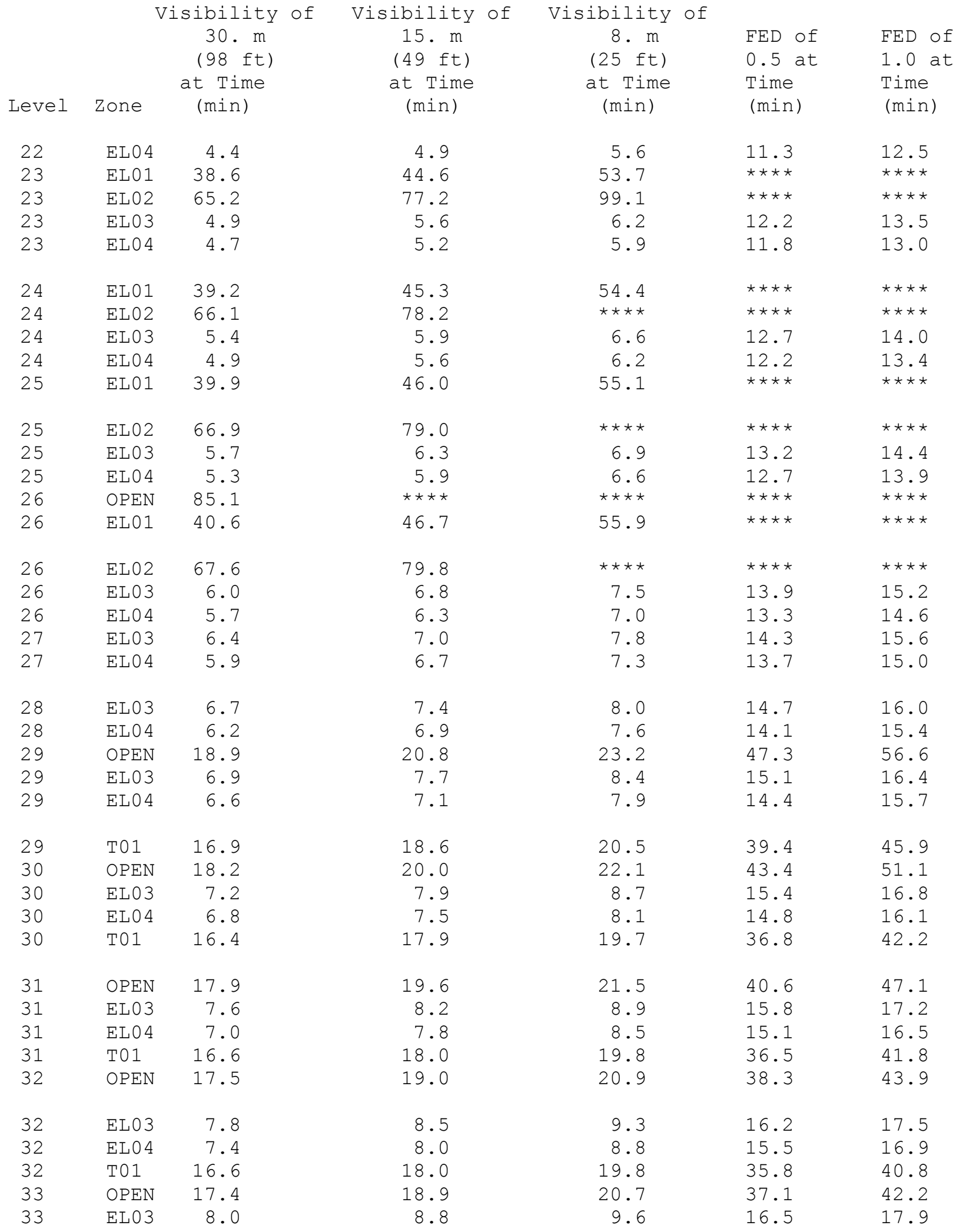


Table 21. Continued.

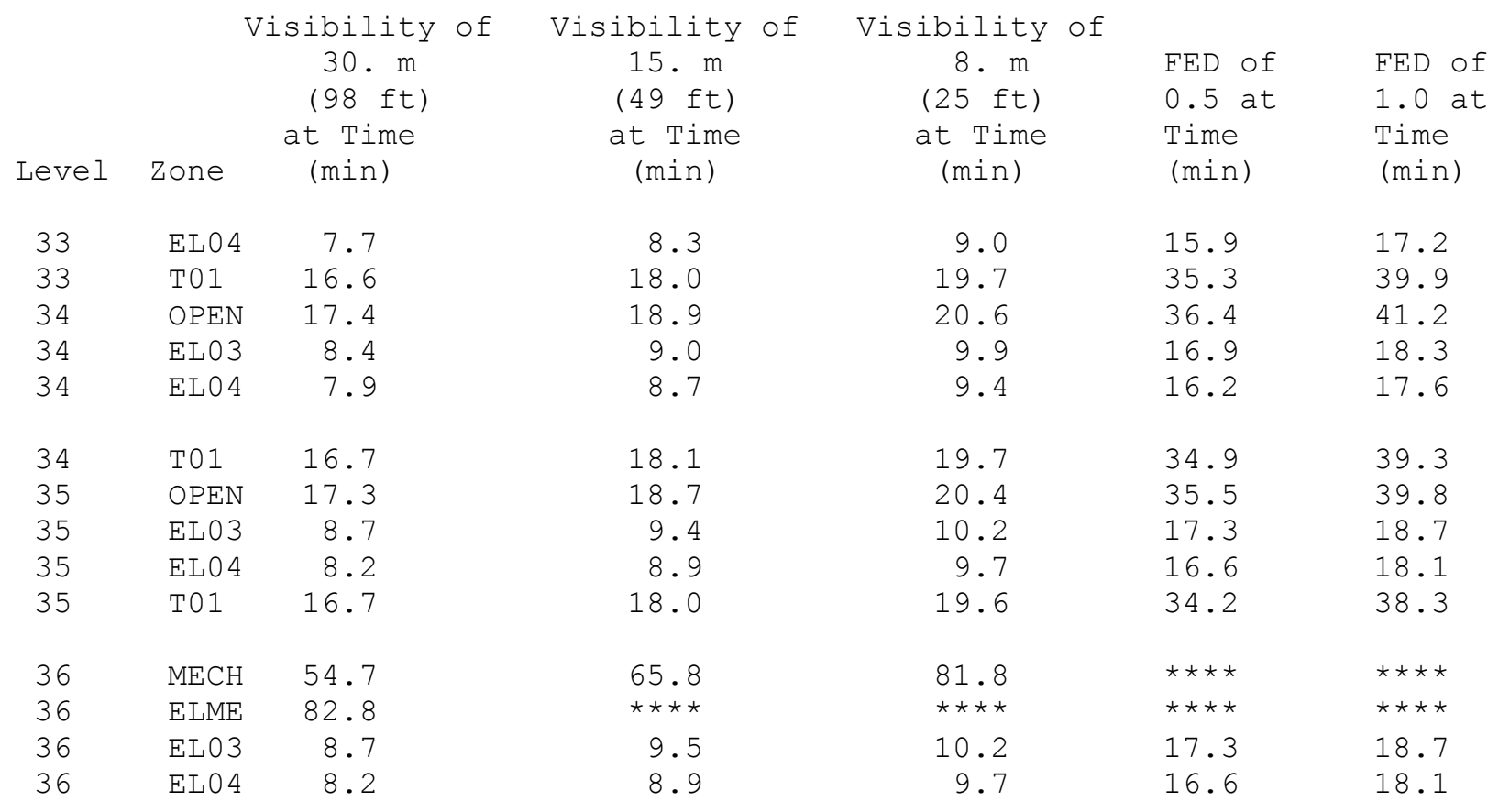


Table 22. Results of Tenability Analysis for Scenario 22.

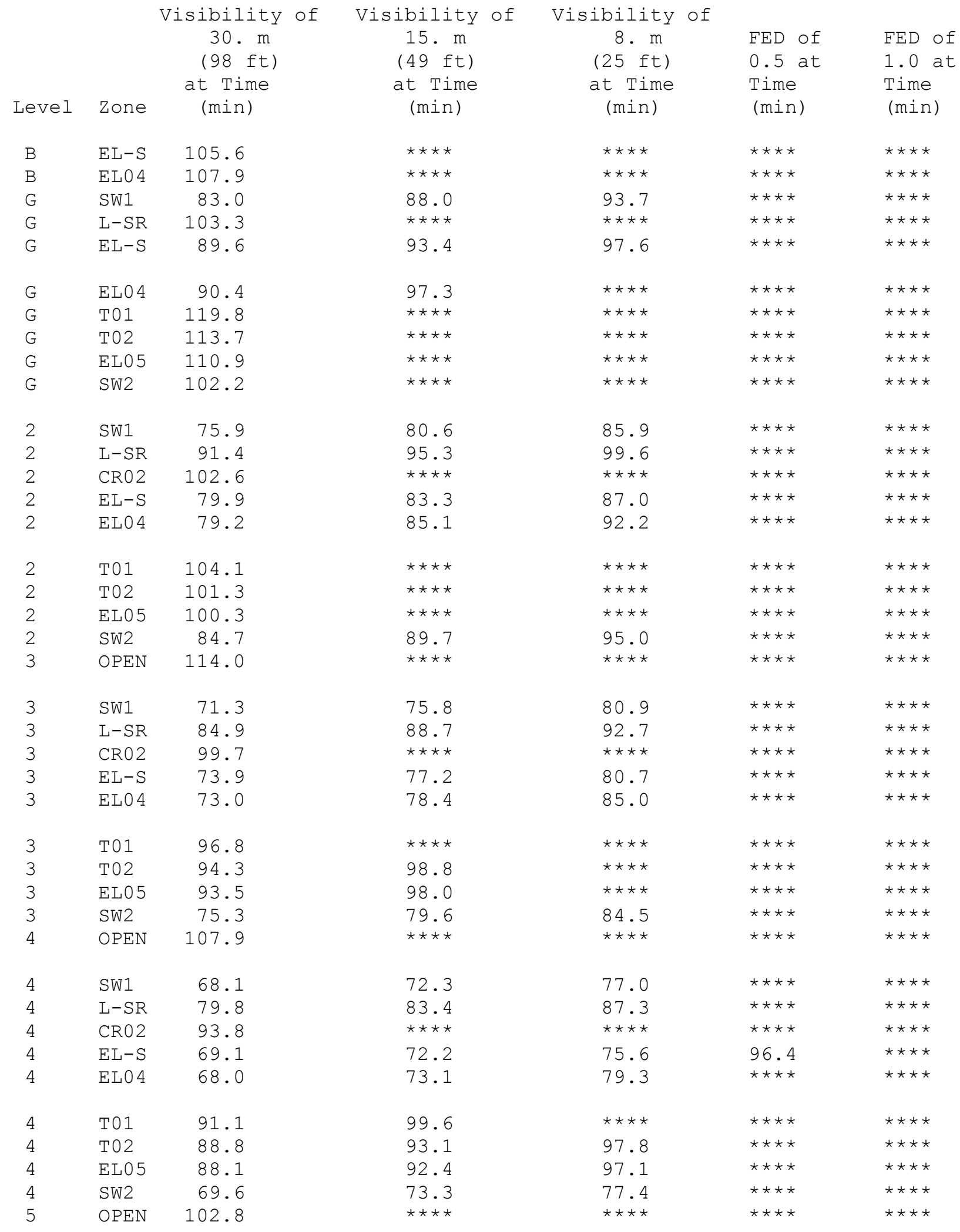


Table 22. Continued.

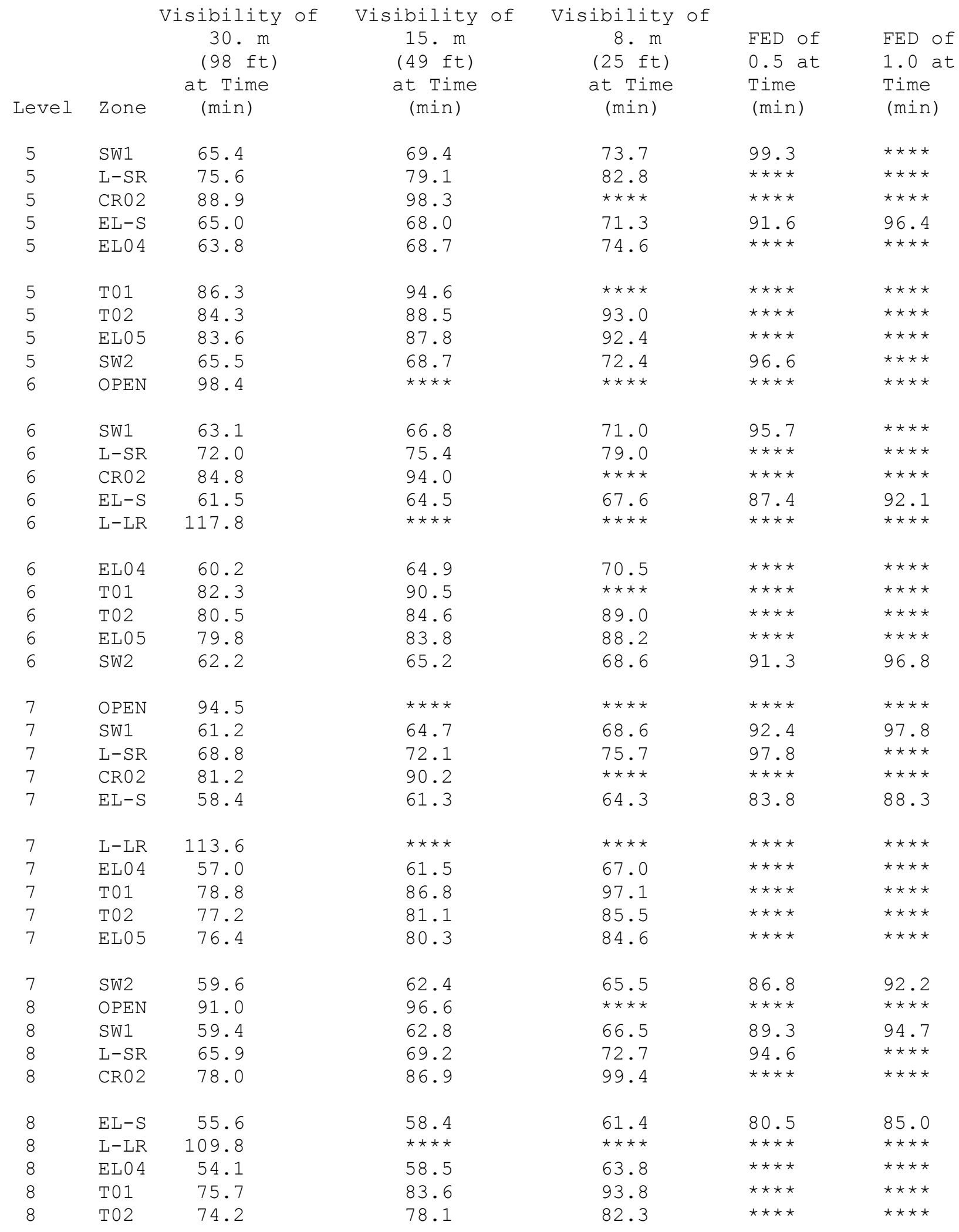


Table 22. Continued.

\begin{tabular}{|c|c|c|c|c|c|c|}
\hline Level & Zone & $\begin{array}{l}\text { isibility of } \\
30 \cdot \mathrm{m} \\
(98 \mathrm{ft}) \\
\text { at Time } \\
\text { (min) }\end{array}$ & $\begin{array}{c}\text { Visibility of } \\
15 \cdot \mathrm{m} \\
(49 \mathrm{ft}) \\
\text { at Time } \\
\text { (min) }\end{array}$ & $\begin{array}{c}\text { Visibility of } \\
8 . \mathrm{m} \\
(25 \mathrm{ft}) \\
\text { at Time } \\
\text { (min) }\end{array}$ & $\begin{array}{l}\text { FED of } \\
0.5 \text { at } \\
\text { Time } \\
\text { (min) }\end{array}$ & $\begin{array}{l}\text { FED of } \\
1.0 \text { at } \\
\text { Time } \\
(\text { min) }\end{array}$ \\
\hline 8 & EL0 5 & 73.3 & 77.2 & 81.4 & $\star \star \star \star$ & $\star \star \star \star$ \\
\hline 8 & EL0 6 & 119.9 & 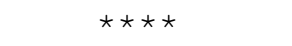 & $\star \star \star \star \star$ & 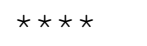 & 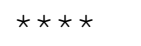 \\
\hline 8 & SW2 & 57.3 & 60.0 & 62.9 & 83.2 & 88.1 \\
\hline 9 & OPEN & 87.9 & 93.5 & 99.3 & 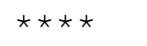 & 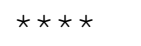 \\
\hline 9 & SW1 & 57.8 & 61.1 & 64.6 & 86.5 & 91.8 \\
\hline 9 & $L-S R$ & 63.4 & 66.6 & 70.0 & 91.7 & 97.0 \\
\hline 9 & $\mathrm{CR} 02$ & 75.1 & 83.9 & 96.3 & 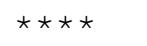 & 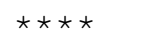 \\
\hline 9 & $E L-S$ & 53.0 & 55.8 & 58.7 & 77.6 & 81.9 \\
\hline 9 & $L-L R$ & 106.3 & 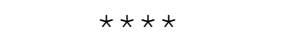 & $\star \star \star \star \star$ & 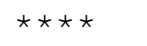 & $\star \star \star \star \star$ \\
\hline 9 & EL0 4 & 51.5 & 55.8 & 60.9 & $\star \star \star \star \star$ & $\star \star \star \star$ \\
\hline 9 & T01 & 72.9 & 80.7 & 90.9 & 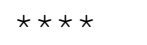 & 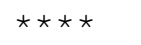 \\
\hline 9 & T02 & 71.6 & 75.4 & 79.5 & $\star \star \star \star \star$ & $\star \star \star \star \star$ \\
\hline 9 & EL0 5 & 70.6 & 74.4 & 78.5 & 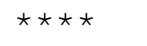 & 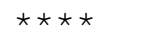 \\
\hline 9 & EL0 6 & 116.4 & $\star \star \star \star \star$ & $\star \star \star \star \star$ & $\star \star \star \star \star$ & $\star \star \star \star \star$ \\
\hline 9 & SW2 & 55.1 & 57.8 & 60.7 & 80.1 & 84.7 \\
\hline 10 & OPEN & 85.2 & 90.6 & 96.3 & 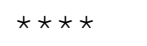 & $\star \star \star \star \star$ \\
\hline 10 & SW1 & 56.3 & 59.5 & 62.9 & 84.1 & 89.1 \\
\hline 10 & $L-S R$ & 61.0 & 64.2 & 67.6 & 89.0 & 94.3 \\
\hline 10 & $\mathrm{CRO} 2$ & 72.5 & 81.2 & 93.6 & 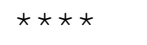 & 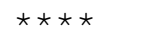 \\
\hline 10 & $E L-S$ & 50.7 & 53.4 & 56.3 & 74.9 & 79.2 \\
\hline 10 & $L-L R$ & 103.2 & 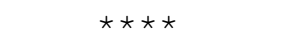 & 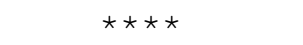 & $\star \star \star \star \star$ & $\star \star \star \star \star$ \\
\hline 10 & ELO 4 & 49.1 & 53.3 & 58.3 & 99.3 & 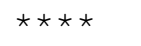 \\
\hline 10 & T01 & 70.4 & 78.1 & 88.2 & $\star \star \star \star$ & $\star \star \star \star$ \\
\hline 10 & T02 & 69.1 & 72.9 & 77.0 & $\star \star \star \star$ & $\star \star \star \star$ \\
\hline 10 & EL0 5 & 68.0 & 71.8 & 75.9 & 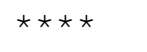 & 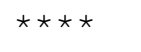 \\
\hline 10 & EL0 6 & 113.1 & $\star \star \star \star \star$ & 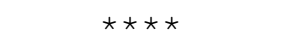 & $\star \star \star \star *$ & $\star \star \star \star *$ \\
\hline 10 & SW2 & 53.2 & 55.9 & 58.7 & 77.4 & 81.8 \\
\hline 11 & OPEN & 82.9 & 87.9 & 93.6 & 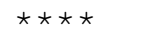 & 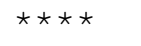 \\
\hline 11 & SW1 & 54.9 & 58.1 & 61.5 & 81.9 & 86.6 \\
\hline 11 & $L-S R$ & 58.9 & 62.0 & 65.3 & 86.6 & 91.8 \\
\hline 11 & CR02 & 70.1 & 78.8 & 91.1 & 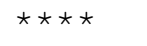 & 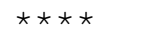 \\
\hline 11 & $E L-S$ & 48.5 & 51.2 & 54.0 & 72.3 & 76.6 \\
\hline 11 & $L-L R$ & 100.4 & 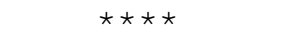 & $\star \star \star \star ~$ & 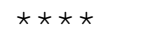 & 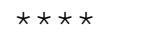 \\
\hline 11 & ELO 4 & 47.0 & 51.0 & 55.9 & 96.5 & 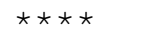 \\
\hline 11 & T01 & 68.0 & 75.7 & 85.8 & 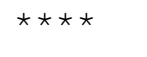 & $\star \star \star \star$ \\
\hline 11 & T02 & 66.9 & 70.6 & 74.7 & 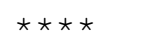 & 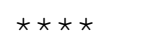 \\
\hline 11 & EL0 5 & 65.7 & 69.4 & 73.4 & 98.6 & 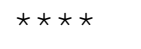 \\
\hline 11 & EL0 6 & 110.2 & 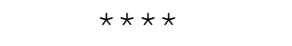 & $\star \star \star \star \star ~$ & 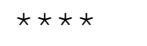 & 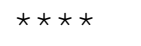 \\
\hline 11 & SW2 & 51.4 & 54.0 & 56.9 & 75.1 & 79.2 \\
\hline 12 & OPEN & 80.5 & 85.5 & 91.1 & 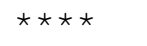 & 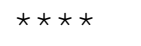 \\
\hline
\end{tabular}


Table 22. Continued.

\begin{tabular}{|c|c|c|c|c|c|c|}
\hline Level & Zone & $\begin{array}{l}\text { isibility of } \\
30 \cdot \mathrm{m} \\
(98 \mathrm{ft}) \\
\text { at Time } \\
\text { (min) }\end{array}$ & $\begin{array}{c}\text { Visibility of } \\
15 . \mathrm{m} \\
(49 \mathrm{ft}) \\
\text { at Time } \\
\text { (min) }\end{array}$ & $\begin{array}{c}\text { Visibility of } \\
8 . \mathrm{m} \\
(25 \mathrm{ft}) \\
\text { at Time } \\
\text { (min) }\end{array}$ & $\begin{array}{l}\text { FED of } \\
0.5 \text { at } \\
\text { Time } \\
\text { (min) }\end{array}$ & $\begin{array}{l}\text { FED of } \\
1.0 \text { at } \\
\text { Time } \\
\text { (min) }\end{array}$ \\
\hline 12 & SW1 & 52.9 & 56.0 & 59.3 & 79.5 & 84.2 \\
\hline 12 & $L-S R$ & 56.9 & 59.9 & 63.3 & 84.4 & 89.6 \\
\hline 12 & CR02 & 67.9 & 76.5 & 88.8 & 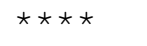 & 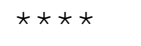 \\
\hline 12 & $E L-S$ & 46.5 & 49.1 & 51.9 & 70.0 & 74.2 \\
\hline 12 & $L-L R$ & 97.7 & $\star \star \star \star$ & $\star \star \star \star$ & $\star \star \star \star$ & $\star \star \star \star$ \\
\hline 12 & ELO 4 & 44.9 & 48.9 & 53.7 & 94.0 & 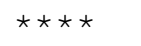 \\
\hline 12 & T01 & 65.8 & 73.5 & 83.6 & 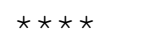 & 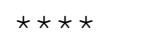 \\
\hline 12 & T02 & 64.9 & 68.6 & 72.6 & 97.8 & 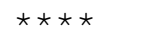 \\
\hline 12 & EL0 5 & 63.5 & 67.2 & 71.1 & 96.1 & $\star \star \star \star \star$ \\
\hline 12 & EL0 6 & 107.5 & $\star \star \star \star$ & $\star \star \star \star ~$ & $\star \star \star \star \star$ & $\star \star \star \star$ \\
\hline 12 & sw2 & 49.0 & 51.6 & 54.4 & 72.4 & 76.4 \\
\hline 13 & OPEN & 78.3 & 83.3 & 88.8 & 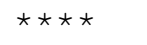 & 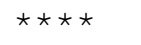 \\
\hline 13 & SW1 & 50.9 & 54.0 & 57.3 & 77.2 & 81.8 \\
\hline 13 & $L-S R$ & 55.1 & 58.1 & 61.4 & 82.5 & 87.6 \\
\hline 13 & $\mathrm{CRO} 2$ & 65.9 & 74.5 & 86.8 & $\star \star \star \star$ & 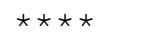 \\
\hline 13 & $E L-S$ & 44.6 & 47.1 & 49.9 & 67.8 & 72.0 \\
\hline 13 & $L-L R$ & 95.3 & 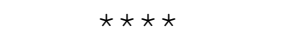 & 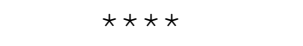 & 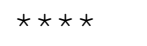 & $\star \star \star \star *$ \\
\hline 13 & ELO 4 & 43.0 & 46.9 & 51.6 & 91.6 & 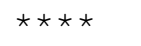 \\
\hline 13 & T01 & 63.9 & 71.5 & 81.6 & $\star \star \star \star$ & $\star \star \star \star$ \\
\hline 13 & T02 & 63.0 & 66.7 & 70.7 & 95.9 & 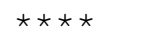 \\
\hline 13 & EL0 5 & 61.5 & 65.0 & 68.9 & 93.8 & 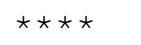 \\
\hline 13 & EL0 6 & 105.1 & 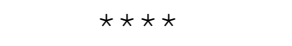 & 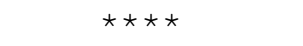 & 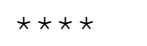 & 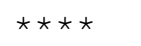 \\
\hline 13 & SW2 & 46.8 & 49.4 & 52.1 & 69.8 & 73.8 \\
\hline 14 & OPEN & 76.6 & 81.6 & 87.3 & $\star \star \star \star$ & $\star \star \star \star$ \\
\hline 14 & SW1 & 49.1 & 52.1 & 55.3 & 75.0 & 79.6 \\
\hline 14 & $L-S R$ & 53.6 & 56.6 & 59.9 & 81.0 & 86.2 \\
\hline 14 & CR02 & 64.2 & 72.8 & 85.2 & 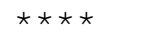 & 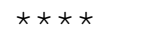 \\
\hline 14 & $E L-S$ & 42.8 & 45.3 & 48.0 & 65.8 & 69.8 \\
\hline 14 & $L-L R$ & 93.5 & 99.7 & 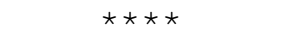 & 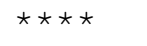 & $\star \star \star \star ~$ \\
\hline 14 & ELO 4 & 41.3 & 45.1 & 49.6 & 89.4 & 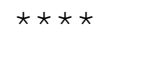 \\
\hline 14 & T01 & 62.2 & 69.8 & 80.2 & 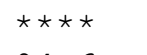 & 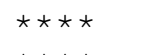 \\
\hline 14 & T02 & 61.5 & 65.2 & 69.2 & 94.6 & 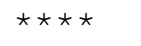 \\
\hline 14 & EL0 5 & 59.5 & 63.1 & 66.9 & 91.6 & 98.3 \\
\hline 14 & EL0 6 & 103.0 & 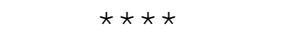 & 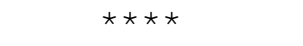 & 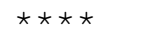 & $\star \star \star \star ~$ \\
\hline 14 & SW2 & 44.7 & 47.2 & 49.9 & 67.4 & 71.3 \\
\hline 15 & $\mathrm{MECH}$ & 77.3 & 82.7 & 88.9 & 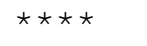 & 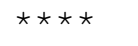 \\
\hline 15 & SW1 & 47.4 & 50.3 & 53.4 & 72.9 & 77.4 \\
\hline 15 & $L-S R$ & 53.8 & 56.9 & 60.3 & 82.3 & 87.8 \\
\hline 15 & CR01 & 63.2 & 72.0 & 84.9 & $\star \star \star \star$ & $\star \star \star \star$ \\
\hline 15 & $E L-S$ & 41.0 & 43.5 & 46.2 & 63.8 & 67.8 \\
\hline
\end{tabular}


Table 22. Continued.

\begin{tabular}{|c|c|c|c|c|c|c|}
\hline Level & Zone & $\begin{array}{l}\text { sibility of } \\
30 . \mathrm{m} \\
(98 \mathrm{ft}) \\
\text { at Time } \\
\text { (min) }\end{array}$ & $\begin{array}{c}\text { Visibility of } \\
15 . \mathrm{m} \\
(49 \mathrm{ft}) \\
\text { at Time } \\
\text { (min) }\end{array}$ & $\begin{array}{c}\text { Visibility of } \\
8 . \mathrm{m} \\
(25 \mathrm{ft}) \\
\text { at Time } \\
\text { (min) }\end{array}$ & $\begin{array}{l}\text { FED of } \\
0.5 \text { at } \\
\text { Time } \\
\text { (min) }\end{array}$ & $\begin{array}{l}\text { FED of } \\
1.0 \text { at } \\
\text { Time } \\
\text { (min) }\end{array}$ \\
\hline 15 & ELO 4 & 39.6 & 43.3 & 47.8 & 87.3 & $\star \star \star \star$ \\
\hline 15 & T01 & 61.1 & 69.0 & 80.1 & 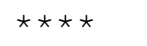 & 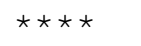 \\
\hline 15 & T02 & 62.1 & 65.9 & 70.2 & 97.1 & $\star \star \star \star$ \\
\hline 15 & SW2 & 42.7 & 45.2 & 47.8 & 65.1 & 69.0 \\
\hline 16 & OPEN & 77.0 & 82.7 & 89.2 & 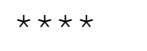 & 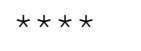 \\
\hline 16 & SW1 & 45.6 & 48.5 & 51.6 & 70.8 & 75.2 \\
\hline 16 & $L-S R$ & 53.2 & 56.4 & 59.8 & 82.2 & 88.0 \\
\hline 16 & CR01 & 61.6 & 70.5 & 83.5 & 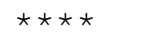 & 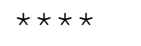 \\
\hline 16 & $E L-S$ & 39.4 & 41.8 & 44.5 & 61.9 & 65.9 \\
\hline 16 & ELO 4 & 38.0 & 41.7 & 46.0 & 85.3 & $\star \star \star \star \star$ \\
\hline 16 & T01 & 58.3 & 65.8 & 75.8 & 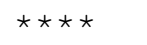 & 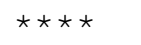 \\
\hline 16 & T02 & 61.5 & 65.5 & 69.8 & 97.4 & $\star \star \star \star *$ \\
\hline 16 & SW2 & 40.7 & 43.2 & 45.8 & 62.9 & 66.7 \\
\hline 17 & OPEN & 76.6 & 82.5 & 89.2 & 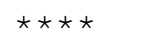 & 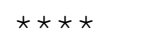 \\
\hline 17 & SW1 & 43.9 & 46.7 & 49.7 & 68.7 & 73.1 \\
\hline 17 & $L-S R$ & 52.5 & 55.7 & 59.2 & 82.1 & 88.1 \\
\hline 17 & CR01 & 60.0 & 68.9 & 81.9 & 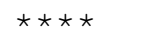 & $\star \star \star \star *$ \\
\hline 17 & $E L-S$ & 37.7 & 40.1 & 42.7 & 60.0 & 64.0 \\
\hline 17 & ELO 4 & 36.5 & 40.1 & 44.4 & 83.4 & $\star \star \star \star$ \\
\hline 17 & T01 & 56.7 & 64.2 & 74.3 & 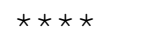 & 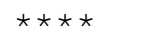 \\
\hline 17 & T02 & 61.0 & 65.0 & 69.5 & 97.9 & $\star \star \star \star \star$ \\
\hline 17 & SW2 & 38.8 & 41.2 & 43.8 & 60.7 & 64.5 \\
\hline 18 & OPEN & 76.8 & 83.0 & 90.3 & $\star \star \star \star$ & $\star \star \star \star \star$ \\
\hline 18 & SW1 & 42.2 & 45.0 & 47.9 & 66.7 & 71.0 \\
\hline 18 & $L-S R$ & 52.3 & 55.7 & 59.3 & 83.0 & 89.3 \\
\hline 18 & CR01 & 58.4 & 67.3 & 80.4 & 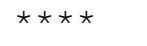 & $\star \star \star \star ~$ \\
\hline 18 & $\mathrm{EL}-\mathrm{S}$ & 36.1 & 38.5 & 41.0 & 58.2 & 62.1 \\
\hline 18 & EL0 4 & 35.0 & 38.6 & 42.8 & 81.6 & 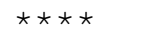 \\
\hline 18 & T01 & 55.2 & 62.7 & 72.9 & 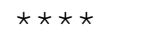 & 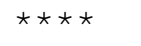 \\
\hline 18 & T02 & 61.1 & 65.3 & 70.0 & 99.8 & 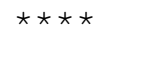 \\
\hline 18 & SW2 & 36.9 & 39.3 & 41.8 & 58.5 & 62.3 \\
\hline 19 & OPEN & 79.1 & 86.0 & 94.4 & 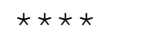 & 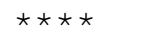 \\
\hline 19 & SW1 & 40.5 & 43.2 & 46.1 & 64.7 & 68.9 \\
\hline 19 & $L-S R$ & 54.7 & 58.4 & 62.4 & 88.8 & 96.2 \\
\hline 19 & CR01 & 56.9 & 65.8 & 78.9 & 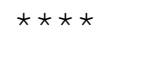 & $\star \star \star \star \star$ \\
\hline 19 & $E L-S$ & 34.5 & 36.9 & 39.4 & 56.3 & 60.2 \\
\hline 19 & ELO 4 & 33.7 & 37.1 & 41.3 & 79.9 & 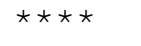 \\
\hline 19 & T01 & 53.7 & 61.2 & 71.5 & 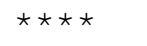 & 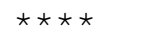 \\
\hline 19 & T02 & 64.3 & 69.1 & 74.6 & 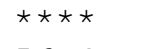 & 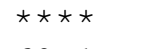 \\
\hline 19 & SW2 & 35.1 & 37.4 & 39.9 & 56.4 & 60.1 \\
\hline
\end{tabular}


Table 22. Continued.

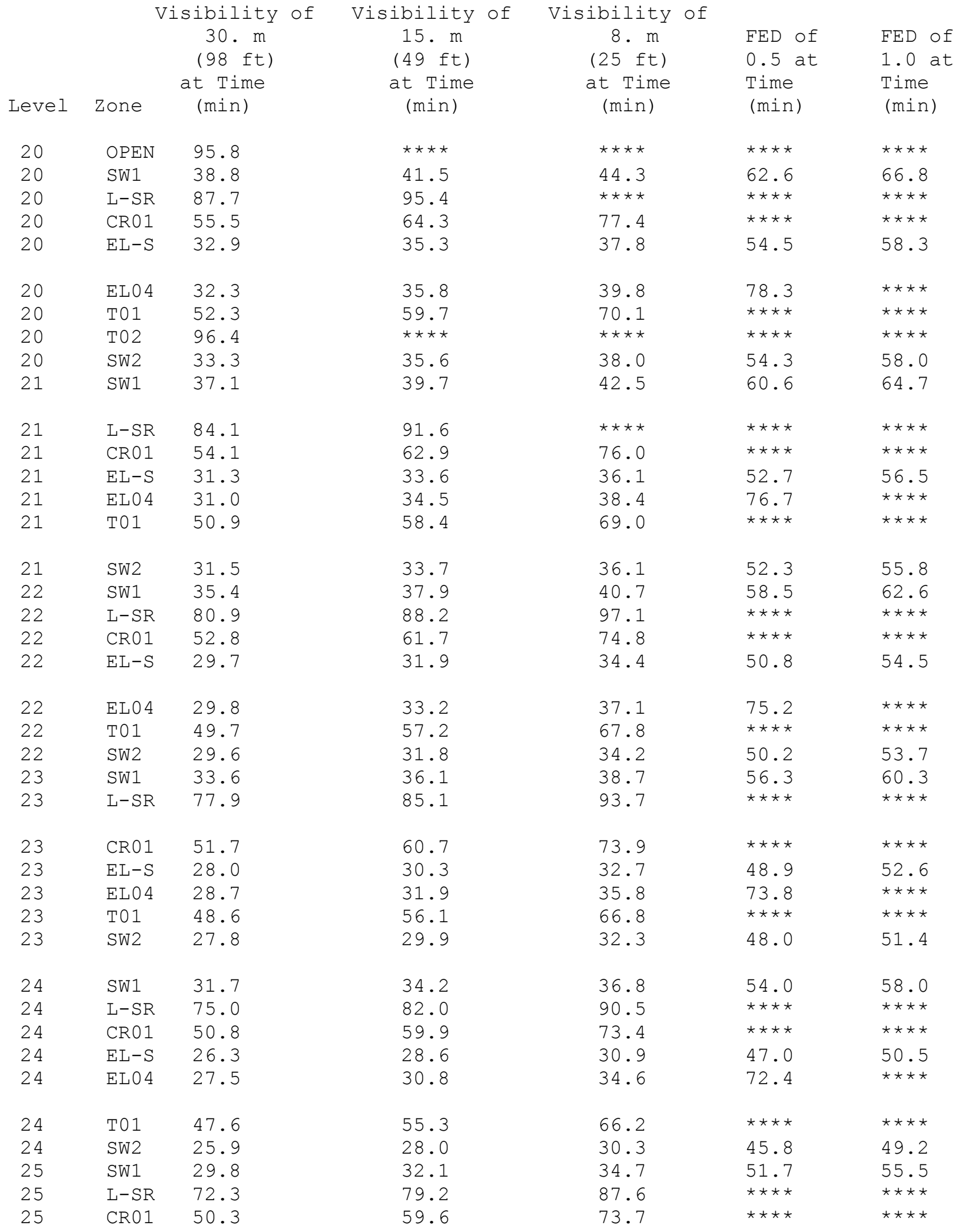


Table 22. Continued.

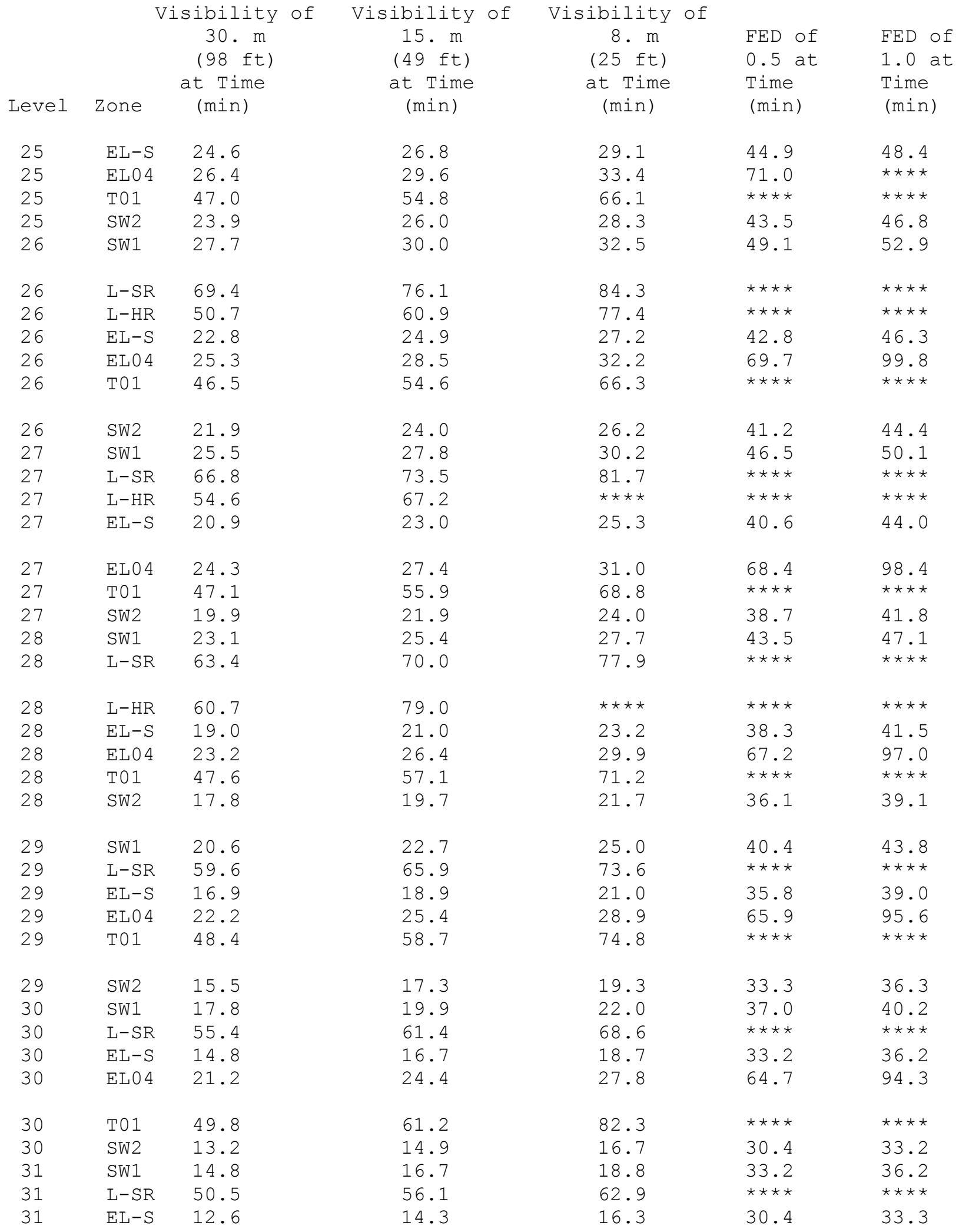


Table 22. Continued.

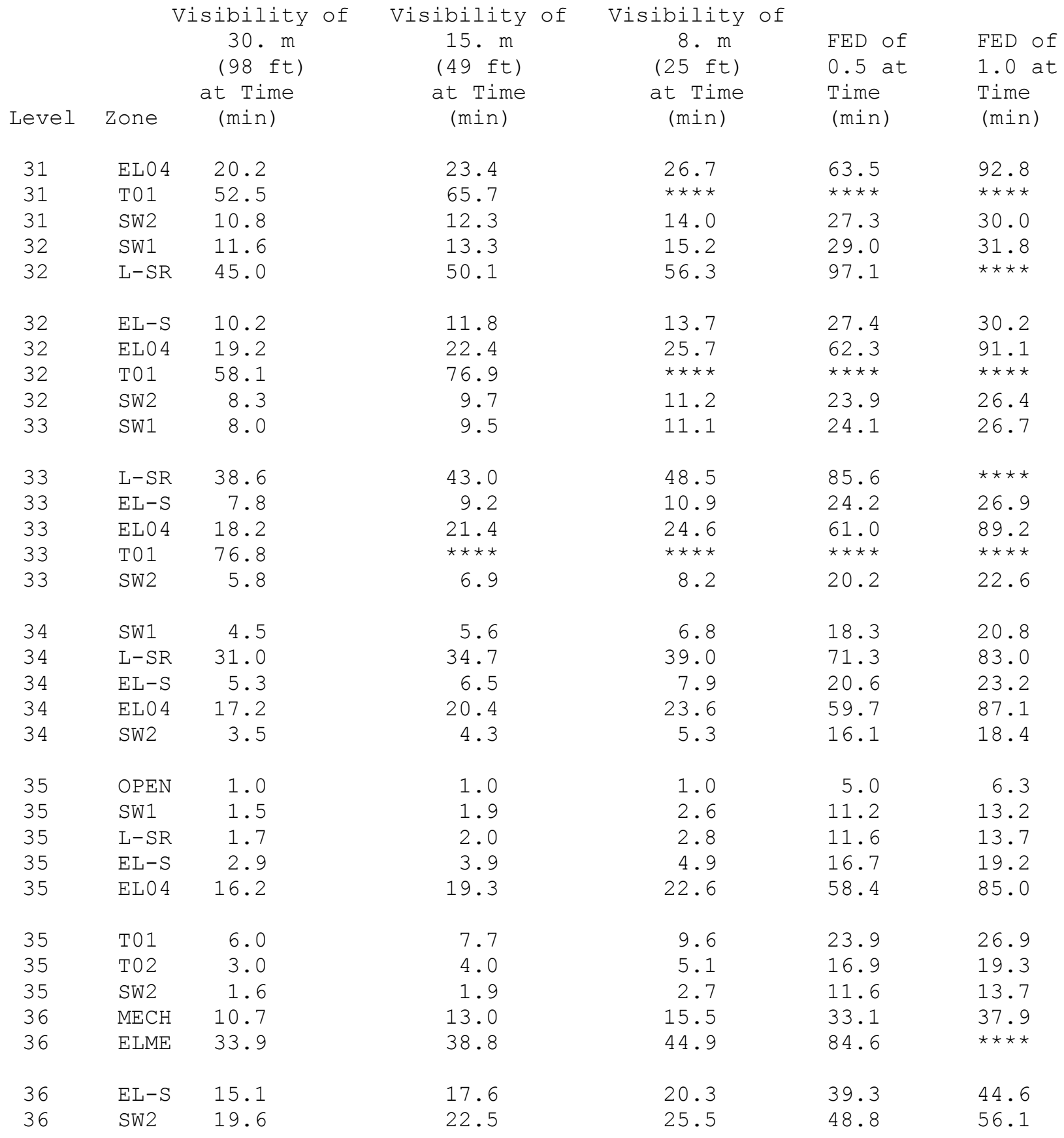


Table 23. Results of Tenability Analysis for Scenario 23.

\begin{tabular}{|c|c|c|c|c|c|c|}
\hline Level & Zone & $\begin{array}{l}\text { Libility of } \\
30 . \mathrm{m} \\
(98 \mathrm{ft}) \\
\text { at Time } \\
\text { (min) }\end{array}$ & $\begin{array}{l}15 . \mathrm{m} \\
(49 \mathrm{ft}) \\
\text { at Time } \\
\text { (min) }\end{array}$ & $\begin{array}{c}8 . \mathrm{m} \\
(25 \mathrm{ft}) \\
\text { at Time } \\
(\mathrm{min})\end{array}$ & $\begin{array}{l}\text { FED of } \\
0.5 \text { at } \\
\text { Time } \\
\text { (min) }\end{array}$ & $\begin{array}{l}\text { FED of } \\
1.0 \text { at } \\
\text { Time } \\
\text { (min) }\end{array}$ \\
\hline 35 & OPEN & 1.0 & 1.0 & 1.0 & 5.0 & 6.3 \\
\hline 36 & $\mathrm{MECH}$ & 10.5 & 12.7 & 15.2 & 32.8 & 37.6 \\
\hline 36 & ELME & 19.0 & 22.0 & 25.3 & 54.5 & 65.2 \\
\hline
\end{tabular}


Table 24. Results of Tenability Analysis for Scenario 24.

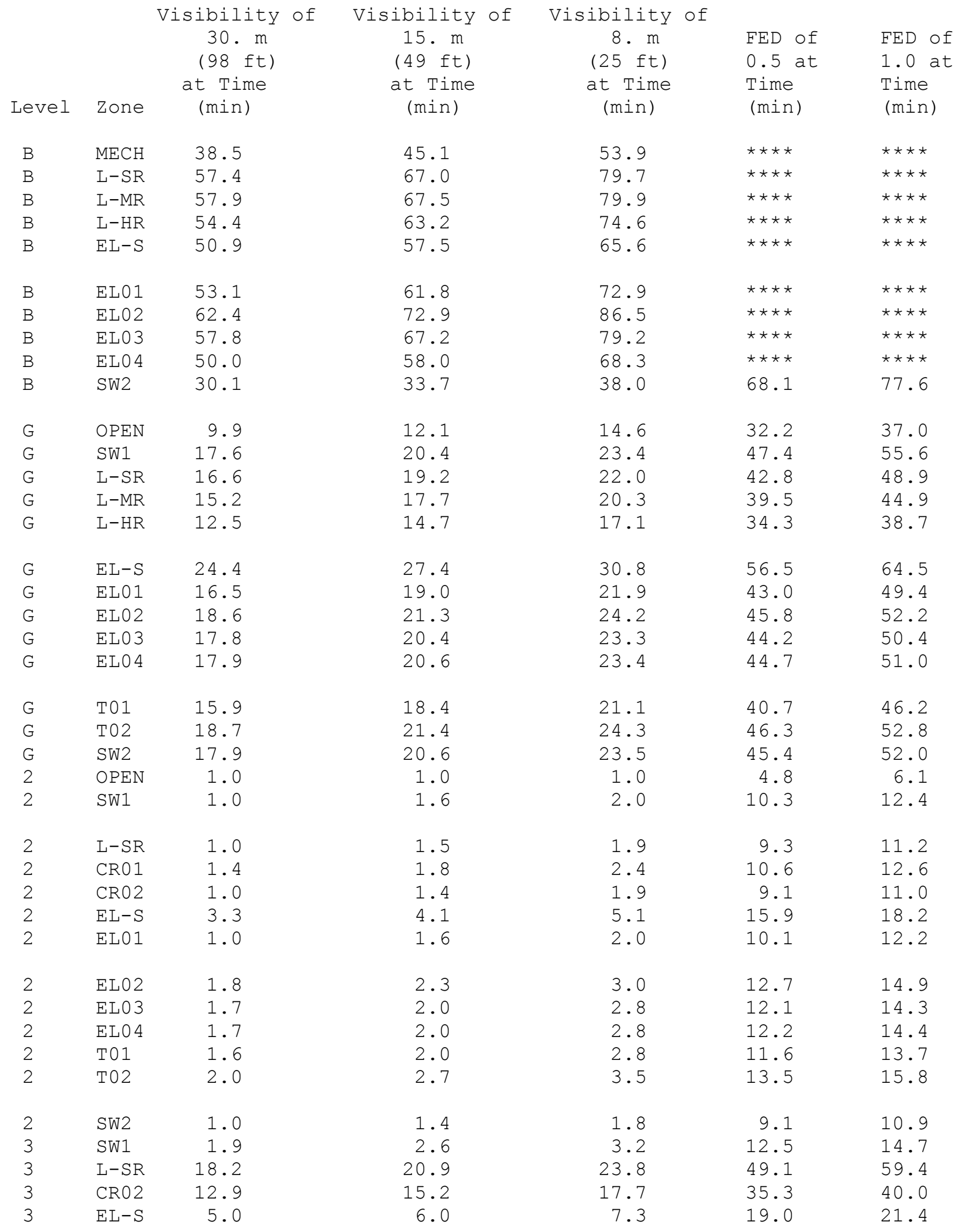


Table 24. Continued.

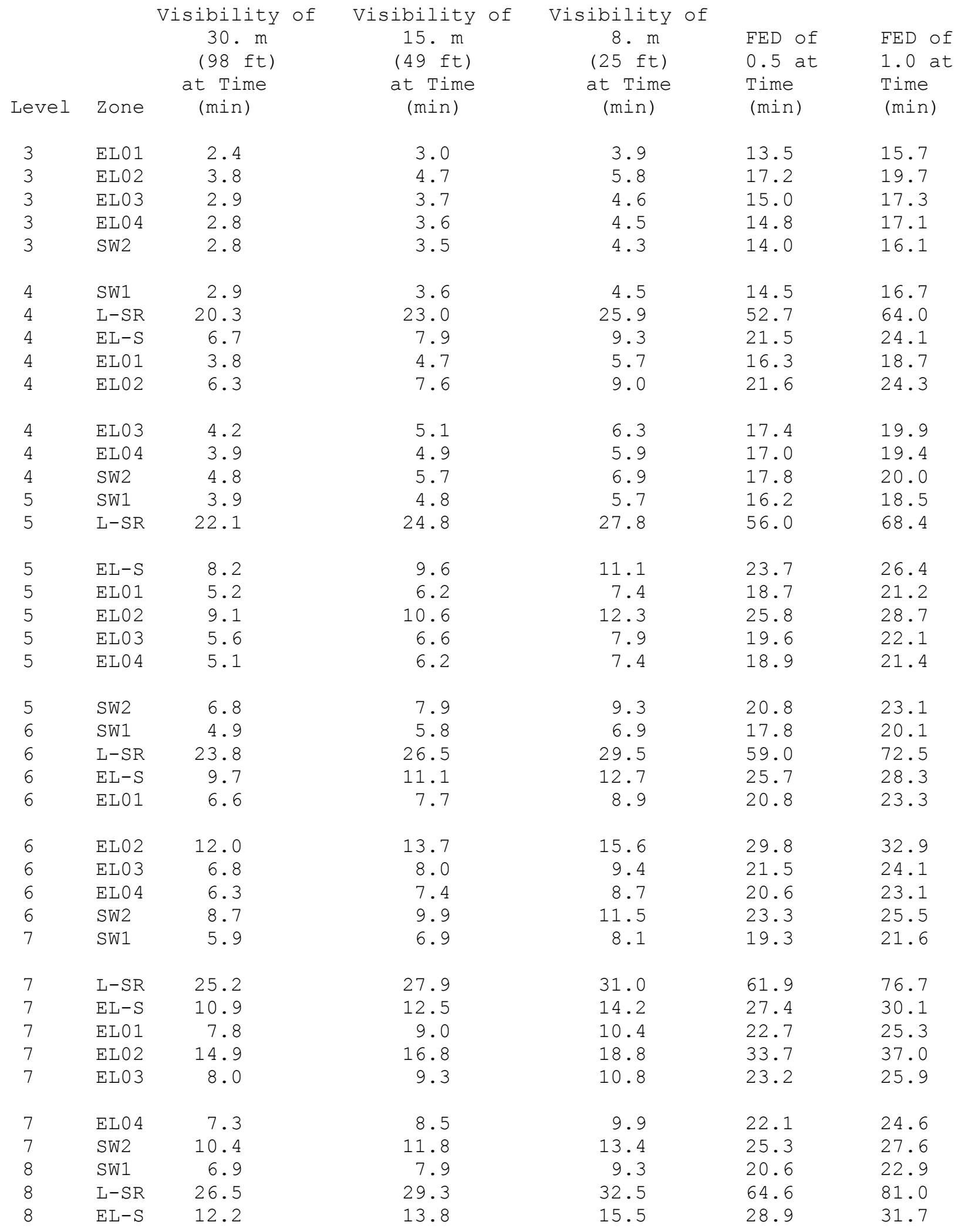


Table 24. Continued.

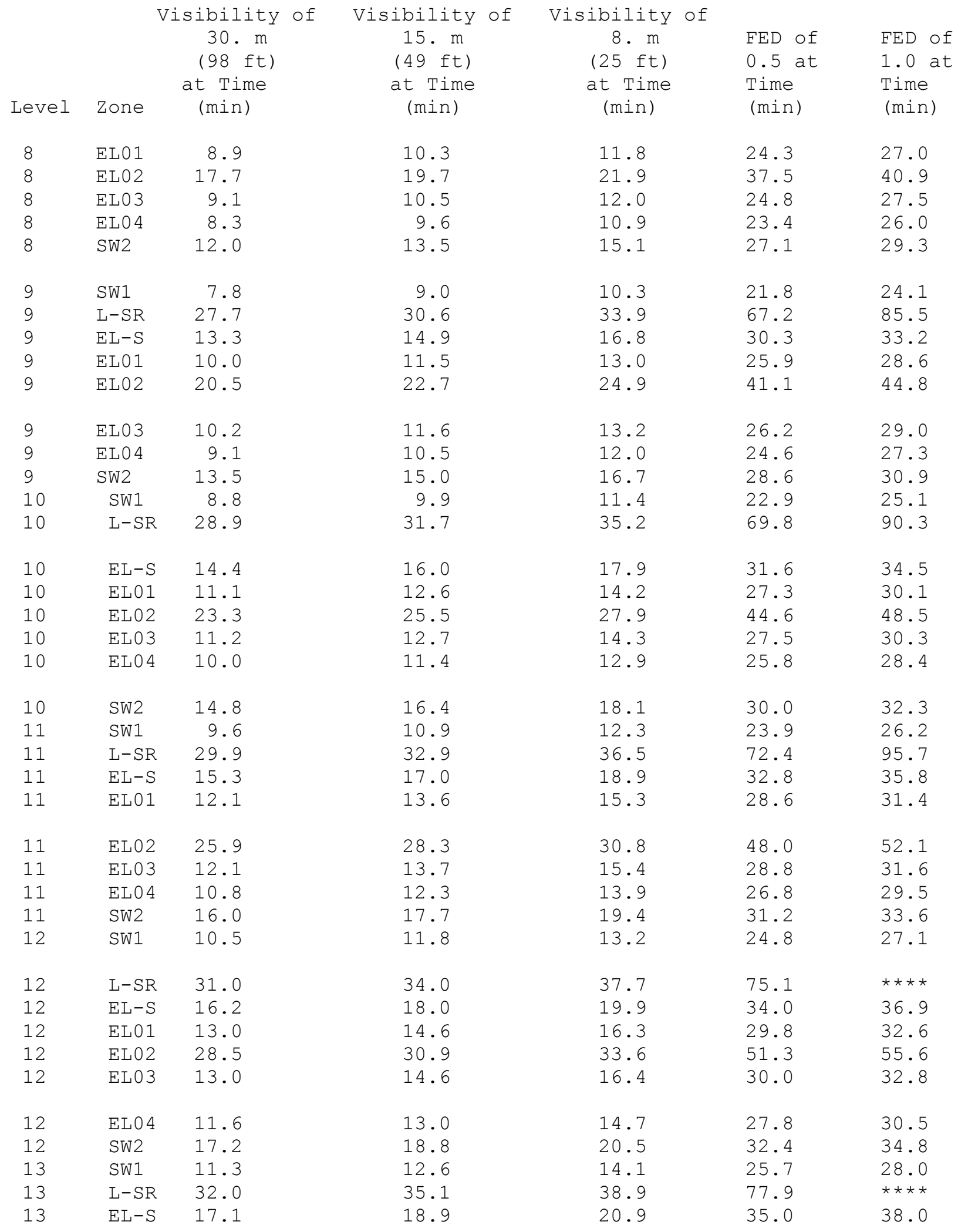


Table 24. Continued.

\begin{tabular}{|c|c|c|c|c|c|c|}
\hline Level & Zone & $\begin{array}{l}\text { sibility of } \\
30 . \mathrm{m} \\
(98 \mathrm{ft}) \\
\text { at Time } \\
\text { (min) }\end{array}$ & $\begin{array}{c}\text { Visibility of } \\
15 . \mathrm{m} \\
(49 \mathrm{ft}) \\
\text { at Time } \\
\text { (min) }\end{array}$ & $\begin{array}{c}\text { Visibility of } \\
8 . \mathrm{m} \\
(25 \mathrm{ft}) \\
\text { at Time } \\
\text { (min) }\end{array}$ & $\begin{array}{l}\text { FED of } \\
0.5 \text { at } \\
\text { Time } \\
\text { (min) }\end{array}$ & $\begin{array}{l}\text { FED of } \\
1.0 \text { at } \\
\text { Time } \\
\text { (min) }\end{array}$ \\
\hline 13 & EL01 & 13.9 & 15.5 & 17.2 & 30.9 & 33.8 \\
\hline 13 & ELO2 & 31.0 & 33.6 & 36.2 & 54.6 & 59.0 \\
\hline 13 & EL03 & 13.9 & 15.5 & 17.3 & 31.0 & 34.0 \\
\hline 13 & ELO 4 & 12.3 & 13.8 & 15.5 & 28.7 & 31.4 \\
\hline 13 & sw2 & 18.2 & 19.8 & 21.6 & 33.4 & 35.9 \\
\hline 14 & SW1 & 12.0 & 13.5 & 14.9 & 26.5 & 28.8 \\
\hline 14 & $L-S R$ & 33.0 & 36.1 & 40.1 & 80.9 & $\star \star \star \star \star$ \\
\hline 14 & $E L-S$ & 17.9 & 19.8 & 21.7 & 36.0 & 39.0 \\
\hline 14 & EL01 & 14.7 & 16.4 & 18.1 & 32.0 & 34.9 \\
\hline 14 & ELO2 & 33.5 & 36.1 & 38.9 & 57.7 & 62.3 \\
\hline 14 & EL03 & 14.7 & 16.4 & 18.2 & 32.1 & 35.0 \\
\hline 14 & ELO 4 & 13.0 & 14.6 & 16.3 & 29.5 & 32.3 \\
\hline 14 & sw2 & 19.2 & 20.8 & 22.5 & 34.4 & 37.0 \\
\hline 15 & SW1 & 12.8 & 14.2 & 15.7 & 27.3 & 29.6 \\
\hline 15 & $L-S R$ & 33.9 & 37.2 & 41.3 & 84.1 & 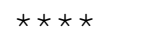 \\
\hline 15 & $E L-S$ & 18.7 & 20.6 & 22.6 & 36.9 & 40.0 \\
\hline 15 & EL01 & 15.5 & 17.2 & 19.0 & 33.0 & 35.9 \\
\hline 15 & ELO2 & 35.9 & 38.6 & 41.5 & 60.8 & 65.5 \\
\hline 15 & EL03 & 15.5 & 17.1 & 19.0 & 33.0 & 36.0 \\
\hline 15 & ELO 4 & 13.7 & 15.2 & 16.9 & 30.3 & 33.1 \\
\hline 15 & SW2 & 20.1 & 21.7 & 23.4 & 35.4 & 37.9 \\
\hline 16 & SW1 & 13.5 & 14.9 & 16.5 & 28.1 & 30.3 \\
\hline 16 & $L-S R$ & 34.9 & 38.3 & 42.5 & 87.7 & 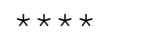 \\
\hline 16 & $E L-S$ & 19.5 & 21.3 & 23.4 & 37.8 & 40.9 \\
\hline 16 & EL01 & 16.3 & 17.9 & 19.8 & 33.9 & 36.9 \\
\hline 16 & ELO2 & 38.3 & 41.0 & 44.0 & 63.8 & 68.7 \\
\hline 16 & EL03 & 16.2 & 17.9 & 19.8 & 33.9 & 37.0 \\
\hline 16 & ELO 4 & 14.3 & 15.9 & 17.7 & 31.1 & 33.9 \\
\hline 16 & SW2 & 20.9 & 22.5 & 24.2 & 36.3 & 38.8 \\
\hline 17 & SW1 & 14.2 & 15.7 & 17.2 & 28.7 & 31.0 \\
\hline 17 & $L-S R$ & 35.9 & 39.4 & 43.8 & 92.0 & 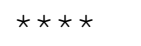 \\
\hline 17 & $E L-S$ & 20.1 & 22.0 & 24.1 & 38.6 & 41.7 \\
\hline 17 & EL01 & 17.0 & 18.7 & 20.6 & 34.8 & 37.9 \\
\hline 17 & EL02 & 40.6 & 43.4 & 46.4 & 66.7 & 71.8 \\
\hline 17 & EL03 & 16.9 & 18.7 & 20.6 & 34.8 & 37.9 \\
\hline 17 & ELO 4 & 14.9 & 16.5 & 18.3 & 31.8 & 34.7 \\
\hline 17 & SW2 & 21.7 & 23.3 & 24.9 & 37.1 & 39.7 \\
\hline 18 & SW1 & 14.9 & 16.3 & 17.9 & 29.4 & 31.7 \\
\hline 18 & $L-S R$ & 36.9 & 40.5 & 45.2 & 97.2 & 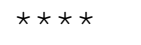 \\
\hline 18 & $E L-S$ & 20.8 & 22.7 & 24.8 & 39.4 & 42.5 \\
\hline
\end{tabular}


Table 24. Continued.

\begin{tabular}{|c|c|c|c|c|c|c|}
\hline Level & Zone & $\begin{array}{l}\text { sibility of } \\
30 . \mathrm{m} \\
(98 \mathrm{ft}) \\
\text { at Time } \\
\text { (min) }\end{array}$ & $\begin{array}{c}\text { Visibility of } \\
15 . \mathrm{m} \\
(49 \mathrm{ft}) \\
\text { at Time } \\
\text { (min) }\end{array}$ & $\begin{array}{c}\text { Visibility of } \\
8 . \mathrm{m} \\
(25 \mathrm{ft}) \\
\text { at Time } \\
\text { (min) }\end{array}$ & $\begin{array}{l}\text { FED of } \\
0.5 \text { at } \\
\text { Time } \\
\text { (min) }\end{array}$ & $\begin{array}{l}\text { FED of } \\
1.0 \text { at } \\
\text { Time } \\
\text { (min) }\end{array}$ \\
\hline 18 & EL01 & 17.7 & 19.5 & 21.4 & 35.6 & 38.7 \\
\hline 18 & ELO2 & 42.9 & 45.7 & 48.8 & 69.5 & 74.8 \\
\hline 18 & EL03 & 17.6 & 19.4 & 21.3 & 35.6 & 38.7 \\
\hline 18 & ELO 4 & 15.5 & 17.1 & 18.9 & 32.5 & 35.4 \\
\hline 18 & sw2 & 22.4 & 24.0 & 25.7 & 37.9 & 40.5 \\
\hline 19 & SW1 & 15.5 & 16.9 & 18.6 & 30.1 & 32.4 \\
\hline 19 & $L-S R$ & 38.0 & 41.8 & 46.7 & 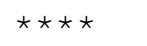 & $\star \star \star \star \star$ \\
\hline 19 & $E L-S$ & 21.5 & 23.4 & 25.5 & 40.2 & 43.3 \\
\hline 19 & EL01 & 18.4 & 20.1 & 22.0 & 36.5 & 39.6 \\
\hline 19 & ELO2 & 45.1 & 48.0 & 51.2 & 72.3 & 77.7 \\
\hline 19 & EL03 & 18.2 & 20.0 & 22.0 & 36.4 & 39.5 \\
\hline 19 & ELO 4 & 16.0 & 17.7 & 19.5 & 33.2 & 36.1 \\
\hline 19 & sw2 & 23.1 & 24.7 & 26.3 & 38.6 & 41.3 \\
\hline 20 & SW1 & 16.1 & 17.6 & 19.2 & 30.6 & 33.0 \\
\hline 20 & $L-S R$ & 39.3 & 43.2 & 48.5 & $\star \star \star \star$ & 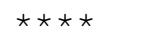 \\
\hline 20 & $E L-S$ & 22.1 & 24.0 & 26.1 & 40.9 & 44.1 \\
\hline 20 & EL01 & 19.0 & 20.8 & 22.8 & 37.3 & 40.4 \\
\hline 20 & ELO2 & 47.3 & 50.3 & 53.6 & 75.1 & 80.6 \\
\hline 20 & EL03 & 18.8 & 20.7 & 22.7 & 37.2 & 40.3 \\
\hline 20 & ELO 4 & 16.6 & 18.2 & 20.1 & 33.8 & 36.7 \\
\hline 20 & SW2 & 23.8 & 25.3 & 27.0 & 39.3 & 42.0 \\
\hline 21 & SW1 & 16.8 & 18.2 & 19.8 & 31.4 & 33.8 \\
\hline 21 & $L-S R$ & 41.0 & 45.2 & 51.2 & $\star \star \star \star$ & 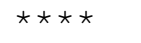 \\
\hline 21 & $E L-S$ & 22.7 & 24.7 & 26.8 & 41.6 & 44.8 \\
\hline 21 & EL01 & 19.6 & 21.4 & 23.4 & 38.0 & 41.2 \\
\hline 21 & EL02 & 49.4 & 52.5 & 55.8 & 77.8 & 83.4 \\
\hline 21 & EL03 & 19.5 & 21.3 & 23.3 & 37.9 & 41.1 \\
\hline 21 & EL0 4 & 17.0 & 18.8 & 20.6 & 34.4 & 37.3 \\
\hline 21 & SW2 & 24.5 & 26.0 & 27.8 & 40.2 & 42.9 \\
\hline 22 & SW1 & 17.4 & 18.9 & 20.5 & 32.1 & 34.5 \\
\hline 22 & $L-S R$ & 43.3 & 48.1 & 55.2 & 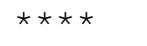 & 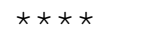 \\
\hline 22 & $E L-S$ & 23.3 & 25.2 & 27.4 & 42.2 & 45.5 \\
\hline 22 & EL01 & 20.2 & 22.0 & 24.0 & 38.7 & 41.9 \\
\hline 22 & EL02 & 51.5 & 54.7 & 58.1 & 80.4 & 86.2 \\
\hline 22 & EL03 & 20.0 & 21.9 & 23.9 & 38.6 & 41.8 \\
\hline 22 & ELO 4 & 17.6 & 19.3 & 21.1 & 35.0 & 37.9 \\
\hline 22 & SW2 & 25.2 & 26.8 & 28.5 & 41.1 & 43.8 \\
\hline 23 & SW1 & 17.9 & 19.5 & 21.1 & 32.8 & 35.2 \\
\hline 23 & $L-S R$ & 48.1 & 54.9 & 66.4 & 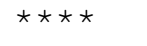 & 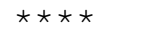 \\
\hline 23 & $E L-S$ & 23.8 & 25.8 & 27.9 & 42.9 & 46.2 \\
\hline
\end{tabular}


Table 24. Continued.

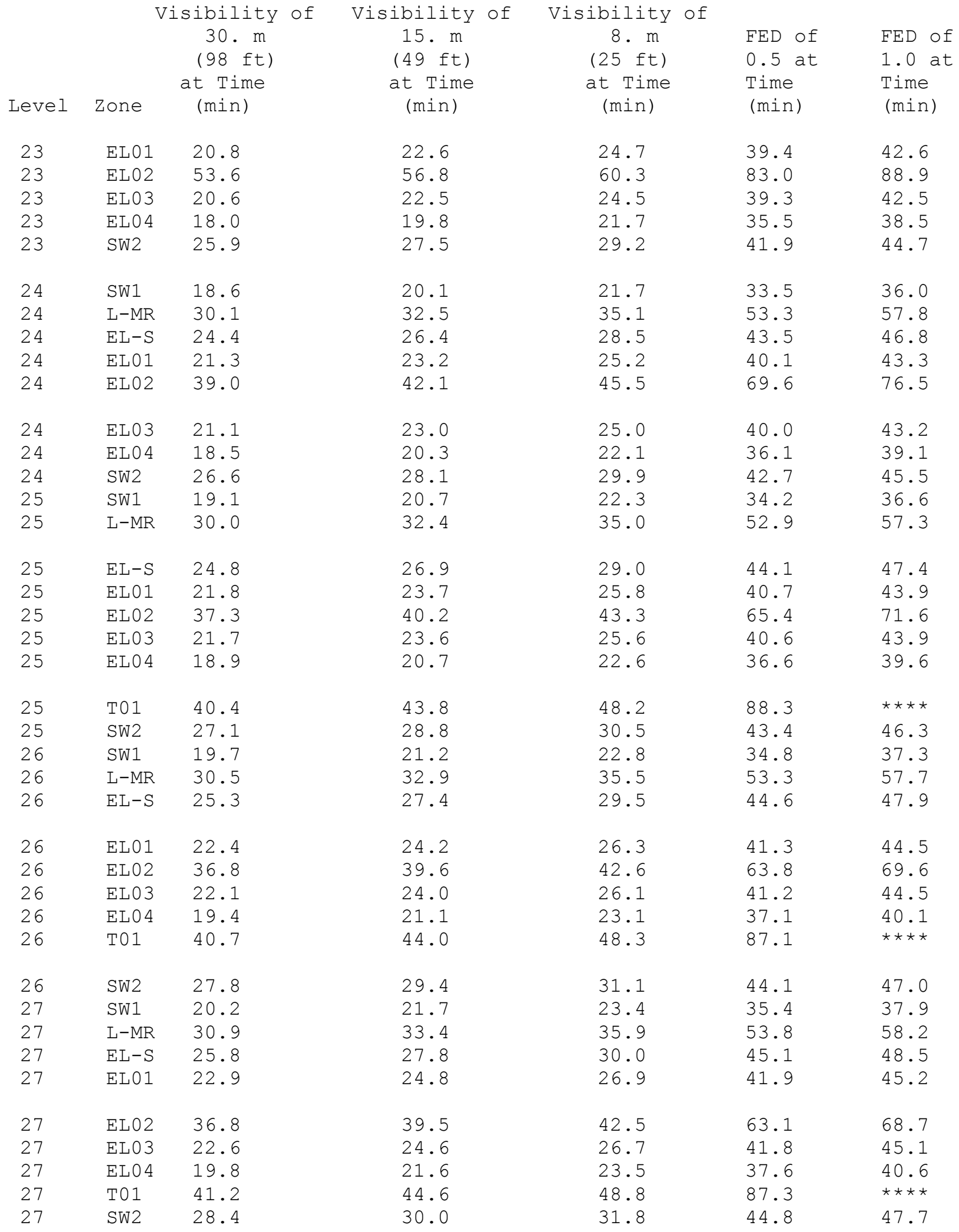


Table 24. Continued.

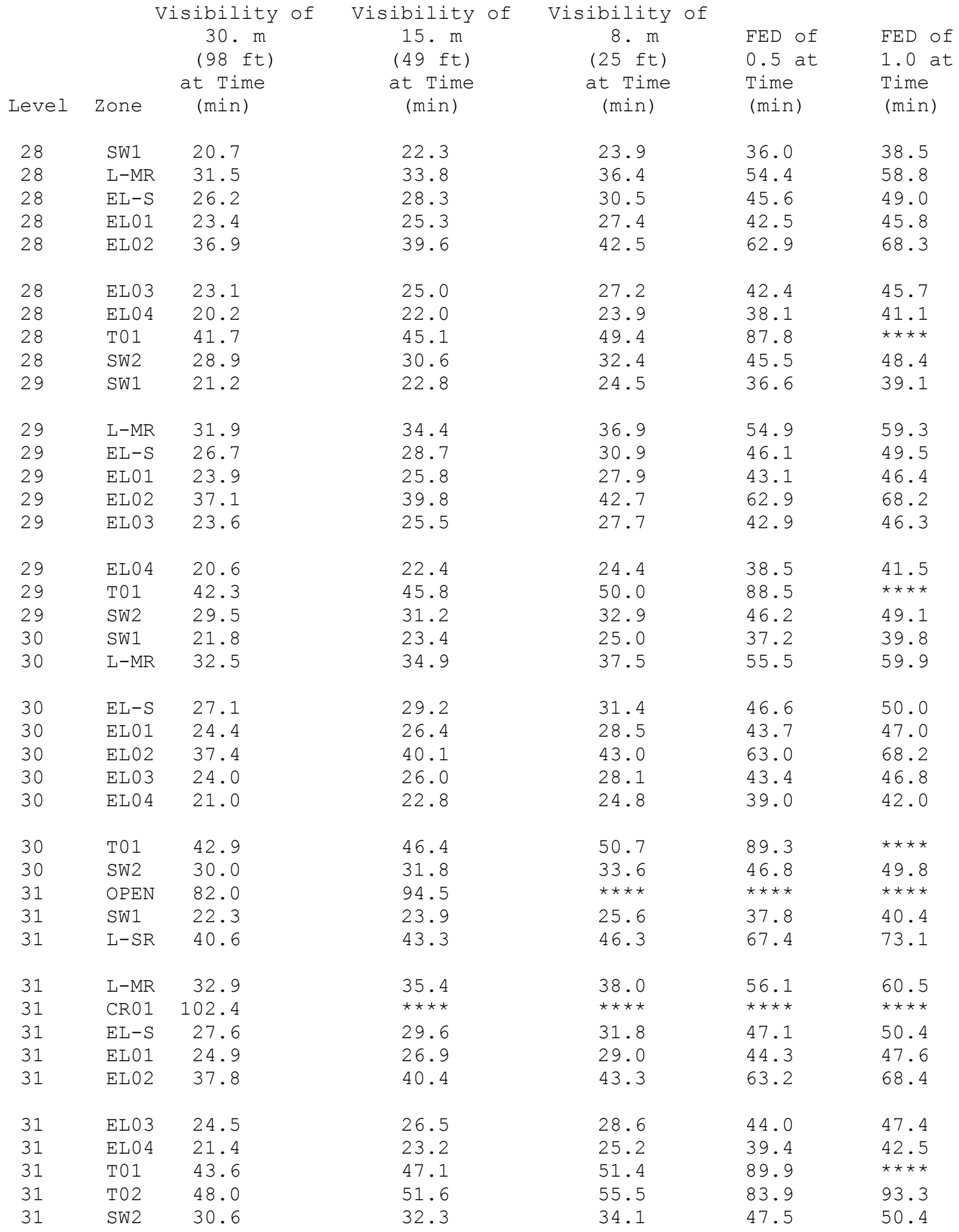


Table 24. Continued.

\begin{tabular}{|c|c|c|c|c|c|c|}
\hline Level & Zone & $\begin{array}{l}\text { sibility of } \\
30 . \mathrm{m} \\
(98 \mathrm{ft}) \\
\text { at Time } \\
\text { (min) }\end{array}$ & $\begin{array}{c}\text { Visibility of } \\
15 . \mathrm{m} \\
(49 \mathrm{ft}) \\
\text { at Time } \\
\text { (min) }\end{array}$ & $\begin{array}{c}\text { Visibility of } \\
8 . \mathrm{m} \\
(25 \mathrm{ft}) \\
\text { at Time } \\
\text { (min) }\end{array}$ & $\begin{array}{l}\text { FED of } \\
0.5 \text { at } \\
\text { Time } \\
\text { (min) }\end{array}$ & $\begin{array}{l}\text { FED of } \\
1.0 \text { at } \\
\text { Time } \\
\text { (min) }\end{array}$ \\
\hline 32 & OPEN & 64.6 & 71.0 & 79.7 & $\star \star \star \star$ & $\star \star \star \star$ \\
\hline 32 & SW1 & 22.8 & 24.4 & 26.1 & 38.4 & 41.0 \\
\hline 32 & $L-S R$ & 39.1 & 41.7 & 44.6 & 64.2 & 69.4 \\
\hline 32 & $\mathrm{~L}-\mathrm{MR}$ & 33.5 & 35.9 & 38.5 & 56.6 & 61.1 \\
\hline 32 & CR01 & 79.8 & 88.7 & $\star \star \star \star$ & $\star \star \star \star$ & $\star \star \star \star$ \\
\hline 32 & $E L-S$ & 28.0 & 30.0 & 32.2 & 47.5 & 50.9 \\
\hline 32 & EL01 & 25.5 & 27.4 & 29.6 & 44.9 & 48.2 \\
\hline 32 & ELO2 & 38.1 & 40.8 & 43.7 & 63.5 & 68.6 \\
\hline 32 & ELO3 & 24.9 & 26.9 & 29.0 & 44.5 & 47.9 \\
\hline 32 & ELO 4 & 21.8 & 23.6 & 25.6 & 39.8 & 42.9 \\
\hline 32 & T01 & 44.3 & 47.8 & 52.2 & 90.6 & 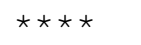 \\
\hline 32 & T02 & 46.0 & 49.2 & 52.8 & 78.4 & 86.2 \\
\hline 32 & SW2 & 31.2 & 32.9 & 34.7 & 48.1 & 51.1 \\
\hline 33 & OPEN & 59.9 & 65.0 & 71.3 & $\star \star \star \star \star$ & $\star \star \star \star \star$ \\
\hline 33 & SW1 & 23.3 & 24.9 & 26.7 & 39.0 & 41.6 \\
\hline 33 & $L-S R$ & 38.3 & 40.9 & 43.6 & 62.5 & 67.3 \\
\hline 33 & $\mathrm{~L}-\mathrm{MR}$ & 33.9 & 36.4 & 39.0 & 57.1 & 61.6 \\
\hline 33 & CR01 & 73.4 & 80.2 & 89.1 & 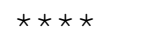 & 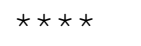 \\
\hline 33 & $E L-S$ & 28.4 & 30.5 & 32.7 & 48.0 & 51.4 \\
\hline 33 & EL01 & 25.9 & 27.9 & 30.1 & 45.5 & 48.9 \\
\hline 33 & ELO2 & 38.5 & 41.1 & 44.0 & 63.8 & 68.9 \\
\hline 33 & EL03 & 25.3 & 27.3 & 29.5 & 45.0 & 48.4 \\
\hline 33 & ELO 4 & 22.1 & 23.9 & 25.9 & 40.2 & 43.3 \\
\hline 33 & T01 & 75.7 & 83.0 & 92.6 & $\star \star \star \star$ & $\star \star \star \star \star$ \\
\hline 33 & T02 & 45.0 & 48.1 & 51.5 & 75.5 & 82.7 \\
\hline 33 & SW2 & 31.7 & 33.4 & 35.3 & 48.7 & 51.7 \\
\hline 34 & OPEN & 58.7 & 63.3 & 68.9 & 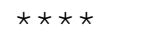 & 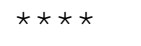 \\
\hline 34 & SW1 & 23.8 & 25.5 & 27.2 & 39.6 & 42.2 \\
\hline 34 & $L-S R$ & 38.0 & 40.6 & 43.2 & 61.8 & 66.4 \\
\hline 34 & $\mathrm{~L}-\mathrm{MR}$ & 34.4 & 36.9 & 39.5 & 57.7 & 62.1 \\
\hline 34 & CR01 & 71.5 & 77.8 & 85.6 & 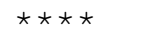 & 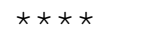 \\
\hline 34 & $E L-S$ & 28.8 & 30.9 & 33.1 & 48.5 & 51.9 \\
\hline 34 & EL01 & 26.5 & 28.5 & 30.7 & 46.1 & 49.5 \\
\hline 34 & EL02 & 38.9 & 41.5 & 44.4 & 64.1 & 69.2 \\
\hline 34 & EL03 & 25.7 & 27.8 & 29.9 & 45.5 & 49.0 \\
\hline 34 & ELO 4 & 22.5 & 24.3 & 26.3 & 40.7 & 43.8 \\
\hline 34 & T01 & 73.7 & 80.3 & 88.8 & 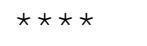 & 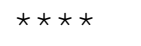 \\
\hline 34 & T02 & 44.6 & 47.6 & 50.8 & 74.1 & 80.8 \\
\hline 34 & SW2 & 32.2 & 34.0 & 35.8 & 49.4 & 52.4 \\
\hline 35 & OPEN & 58.1 & 62.5 & 67.8 & 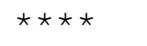 & 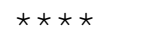 \\
\hline
\end{tabular}


Table 24. Continued.

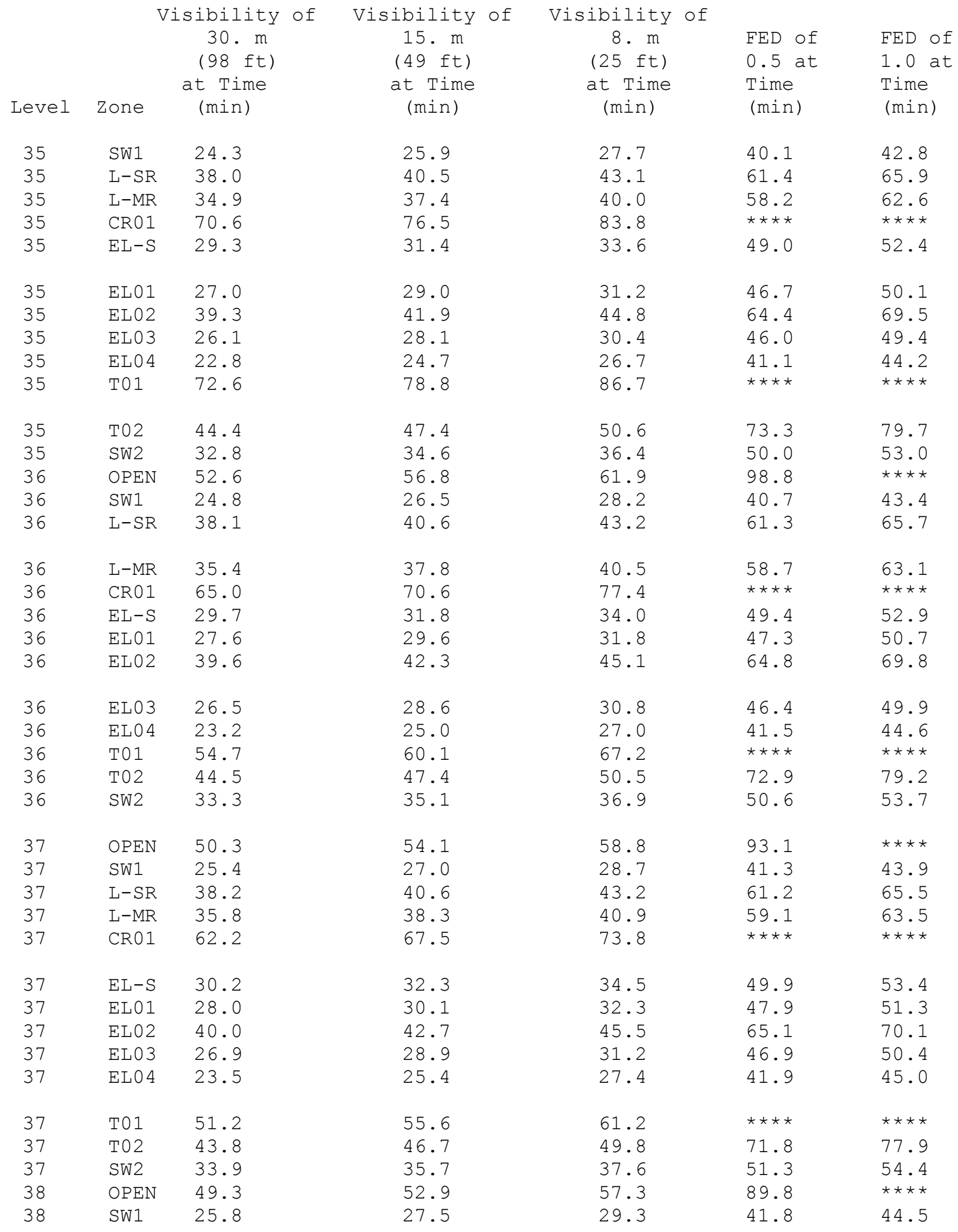


Table 24. Continued.

\begin{tabular}{|c|c|c|c|c|c|c|}
\hline Level & Zone & $\begin{array}{l}\text { sibility of } \\
30 . \mathrm{m} \\
(98 \mathrm{ft}) \\
\text { at Time } \\
\text { (min) }\end{array}$ & $\begin{array}{c}\text { Visibility of } \\
15 . \mathrm{m} \\
(49 \mathrm{ft}) \\
\text { at Time } \\
\text { (min) }\end{array}$ & $\begin{array}{c}\text { Visibility of } \\
8 . \mathrm{m} \\
(25 \mathrm{ft}) \\
\text { at Time } \\
\text { (min) }\end{array}$ & $\begin{array}{l}\text { FED of } \\
0.5 \text { at } \\
\text { Time } \\
\text { (min) }\end{array}$ & $\begin{array}{l}\text { FED of } \\
1.0 \text { at } \\
\text { Time } \\
\text { (min) }\end{array}$ \\
\hline 38 & $L-S R$ & 38.3 & 40.7 & 43.3 & 61.1 & 65.4 \\
\hline 38 & $\mathrm{~L}-\mathrm{MR}$ & 36.3 & 38.7 & 41.4 & 59.5 & 63.9 \\
\hline 38 & CR01 & 61.0 & 65.9 & 71.9 & 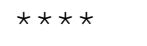 & 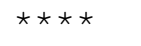 \\
\hline 38 & $E L-S$ & 30.7 & 32.8 & 35.0 & 50.4 & 53.9 \\
\hline 38 & EL01 & 28.6 & 30.6 & 32.8 & 48.5 & 52.0 \\
\hline 38 & ELO2 & 40.4 & 43.0 & 45.9 & 65.4 & 70.4 \\
\hline 38 & ELO3 & 27.3 & 29.3 & 31.6 & 47.3 & 50.9 \\
\hline 38 & ELO 4 & 23.8 & 25.7 & 27.8 & 42.2 & 45.4 \\
\hline 38 & T01 & 49.9 & 53.9 & 58.8 & 97.7 & 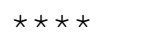 \\
\hline 38 & T02 & 43.6 & 46.4 & 49.5 & 71.1 & 77.1 \\
\hline 38 & sw2 & 34.5 & 36.2 & 38.1 & 52.0 & 55.0 \\
\hline 39 & OPEN & 48.8 & 52.3 & 56.4 & 87.4 & 98.6 \\
\hline 39 & SW1 & 26.4 & 28.0 & 29.8 & 42.4 & 45.1 \\
\hline 39 & $L-S R$ & 38.4 & 40.8 & 43.4 & 61.0 & 65.3 \\
\hline 39 & $\mathrm{~L}-\mathrm{MR}$ & 36.6 & 39.1 & 41.7 & 59.8 & 64.2 \\
\hline 39 & CR01 & 60.3 & 65.1 & 70.8 & 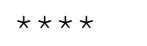 & $\star \star \star \star \star$ \\
\hline 39 & $E L-S$ & 31.1 & 33.2 & 35.5 & 51.0 & 54.4 \\
\hline 39 & EL01 & 29.1 & 31.2 & 33.4 & 49.1 & 52.6 \\
\hline 39 & EL02 & 40.7 & 43.4 & 46.2 & 65.8 & 70.8 \\
\hline 39 & EL03 & 27.7 & 29.7 & 31.9 & 47.7 & 51.3 \\
\hline 39 & ELO 4 & 24.2 & 26.0 & 28.1 & 42.6 & 45.8 \\
\hline 39 & T01 & 49.2 & 53.0 & 57.6 & 93.9 & 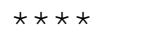 \\
\hline 39 & T02 & 43.6 & 46.3 & 49.3 & 70.6 & 76.4 \\
\hline 39 & SW2 & 35.0 & 36.8 & 38.7 & 52.6 & 55.7 \\
\hline 40 & OPEN & 48.5 & 51.9 & 55.8 & 85.6 & 96.0 \\
\hline 40 & SW1 & 26.9 & 28.6 & 30.4 & 43.0 & 45.7 \\
\hline 40 & $L-S R$ & 38.6 & 40.9 & 43.5 & 61.0 & 65.2 \\
\hline 40 & $\mathrm{~L}-\mathrm{MR}$ & 36.9 & 39.4 & 42.0 & 60.0 & 64.3 \\
\hline 40 & CR01 & 60.0 & 64.6 & 70.1 & 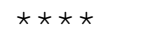 & 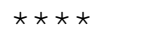 \\
\hline 40 & $E L-S$ & 31.6 & 33.7 & 36.0 & 51.5 & 55.0 \\
\hline 40 & EL01 & 29.7 & 31.7 & 33.9 & 49.7 & 53.2 \\
\hline 40 & EL02 & 41.1 & 43.7 & 46.6 & 66.1 & 71.0 \\
\hline 40 & EL03 & 28.0 & 30.1 & 32.3 & 48.2 & 51.7 \\
\hline 40 & ELO 4 & 24.5 & 26.4 & 28.4 & 43.0 & 46.2 \\
\hline 40 & T01 & 48.9 & 52.4 & 56.8 & 91.1 & $\star \star \star \star \star$ \\
\hline 40 & T02 & 43.5 & 46.3 & 49.2 & 70.2 & 75.9 \\
\hline 40 & SW2 & 35.6 & 37.4 & 39.3 & 53.3 & 56.4 \\
\hline 41 & OPEN & 48.3 & 51.6 & 55.4 & 84.2 & 94.0 \\
\hline 41 & SW1 & 27.5 & 29.1 & 30.9 & 43.6 & 46.4 \\
\hline 41 & $L-S R$ & 38.7 & 41.1 & 43.7 & 61.1 & 65.2 \\
\hline
\end{tabular}


Table 24. Continued.

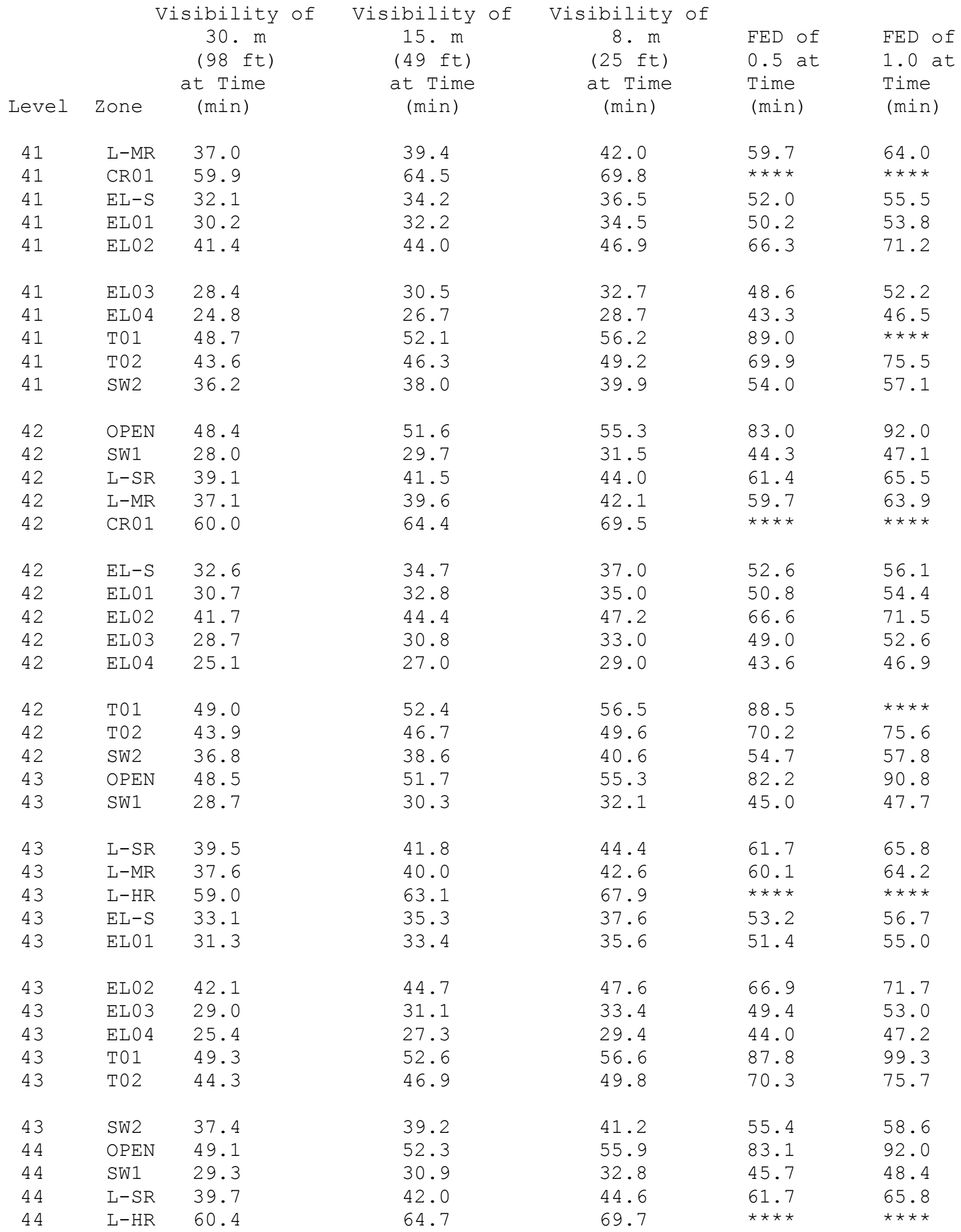


Table 24. Continued.

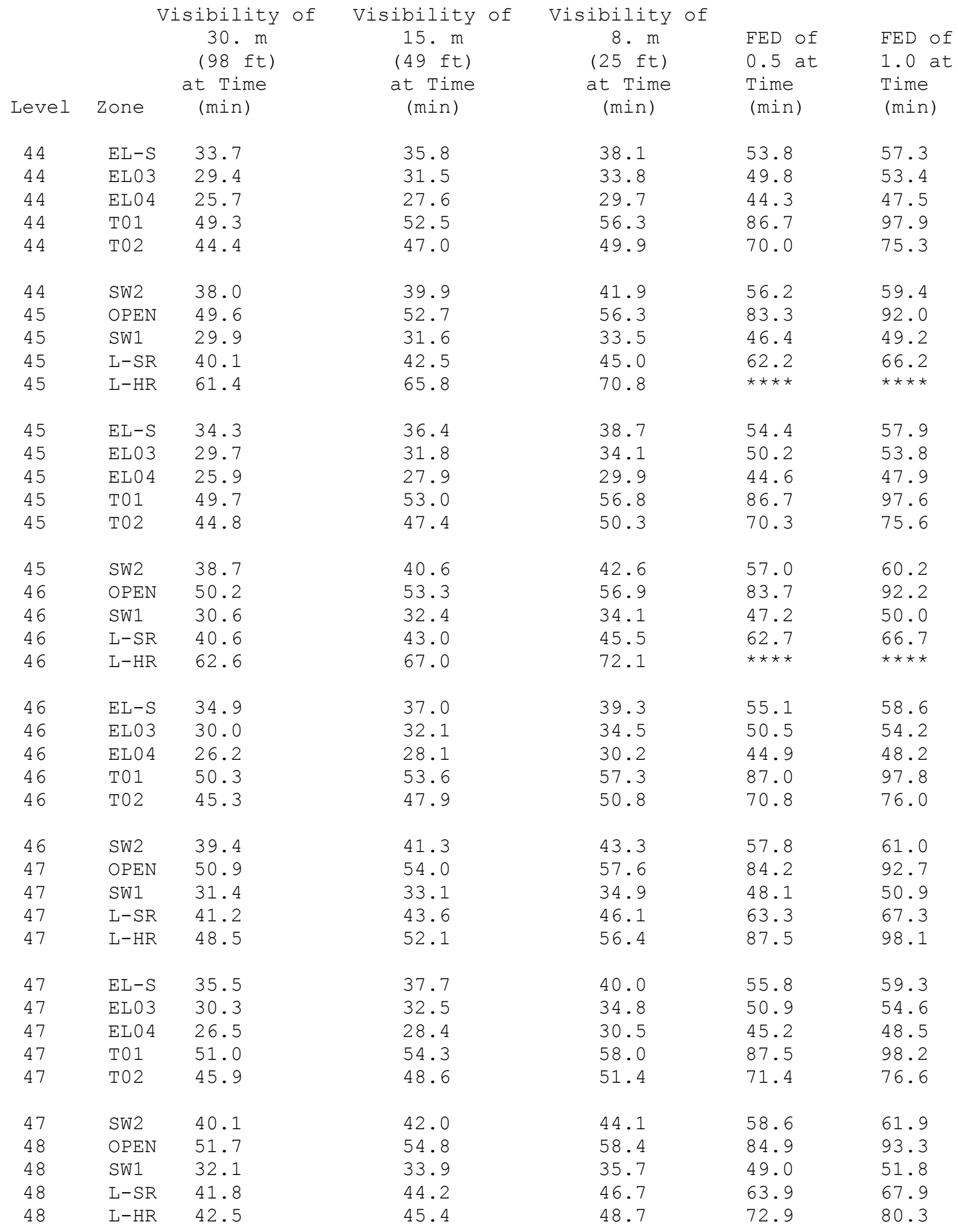


Table 24. Continued.

\begin{tabular}{|c|c|c|c|c|c|c|}
\hline Level & Zone & $\begin{array}{l}\text { sibility of } \\
30 . \mathrm{m} \\
(98 \mathrm{ft}) \\
\text { at Time } \\
\text { (min) }\end{array}$ & $\begin{array}{c}\text { Visibility of } \\
15 . \mathrm{m} \\
(49 \mathrm{ft}) \\
\text { at Time } \\
\text { (min) }\end{array}$ & $\begin{array}{c}\text { Visibility of } \\
8 . \mathrm{m} \\
(25 \mathrm{ft}) \\
\text { at Time } \\
\text { (min) }\end{array}$ & $\begin{array}{l}\text { FED of } \\
0.5 \text { at } \\
\text { Time } \\
\text { (min) }\end{array}$ & $\begin{array}{l}\text { FED of } \\
1.0 \text { at } \\
\text { Time } \\
\text { (min) }\end{array}$ \\
\hline 48 & $E L-S$ & 36.2 & 38.4 & 40.7 & 56.5 & 60.1 \\
\hline 48 & ELO3 & 30.6 & 32.8 & 35.1 & 51.3 & 54.9 \\
\hline 48 & ELO 4 & 26.7 & 28.7 & 30.8 & 45.5 & 48.8 \\
\hline 48 & T01 & 51.8 & 55.1 & 58.8 & 88.2 & 98.8 \\
\hline 48 & T02 & 46.6 & 49.2 & 52.1 & 72.0 & 77.2 \\
\hline 48 & SW2 & 40.8 & 42.8 & 44.9 & 59.6 & 62.9 \\
\hline 49 & OPEN & 52.6 & 55.7 & 59.3 & 85.7 & 94.1 \\
\hline 49 & SW1 & 33.0 & 34.8 & 36.6 & 49.9 & 52.8 \\
\hline 49 & $L-S R$ & 42.5 & 44.8 & 47.4 & 64.6 & 68.6 \\
\hline 49 & $\mathrm{~L}-\mathrm{HR}$ & 40.7 & 43.4 & 46.5 & 68.5 & 74.9 \\
\hline 49 & $E L-S$ & 36.9 & 39.1 & 41.4 & 57.3 & 60.9 \\
\hline 49 & ELO3 & 30.9 & 33.1 & 35.4 & 51.6 & 55.3 \\
\hline 49 & ELO 4 & 27.0 & 28.9 & 31.0 & 45.8 & 49.1 \\
\hline 49 & T01 & 52.7 & 56.0 & 59.8 & 89.1 & 99.6 \\
\hline 49 & T02 & 47.3 & 49.9 & 52.8 & 72.8 & 77.9 \\
\hline 49 & SW2 & 41.7 & 43.7 & 45.7 & 60.5 & 63.9 \\
\hline 50 & OPEN & 53.5 & 56.7 & 60.3 & 86.7 & 95.0 \\
\hline 50 & SW1 & 33.9 & 35.7 & 37.6 & 51.0 & 54.0 \\
\hline 50 & $L-S R$ & 43.2 & 45.6 & 48.1 & 65.4 & 69.4 \\
\hline 50 & $\mathrm{~L}-\mathrm{HR}$ & 39.7 & 42.4 & 45.3 & 66.2 & 72.0 \\
\hline 50 & $E L-S$ & 37.7 & 39.8 & 42.2 & 58.1 & 61.7 \\
\hline 50 & EL03 & 31.2 & 33.4 & 35.7 & 51.9 & 55.6 \\
\hline 50 & ELO 4 & 27.2 & 29.2 & 31.3 & 46.1 & 49.4 \\
\hline 50 & T01 & 53.8 & 57.0 & 60.8 & 90.1 & $\star \star \star \star \star$ \\
\hline 50 & T02 & 48.1 & 50.7 & 53.6 & 73.6 & 78.7 \\
\hline 50 & SW2 & 42.5 & 44.6 & 46.7 & 61.6 & 65.0 \\
\hline 51 & OPEN & 54.6 & 57.8 & 61.4 & 87.8 & 96.1 \\
\hline 51 & SW1 & 35.0 & 36.8 & 38.7 & 52.2 & 55.2 \\
\hline 51 & $L-S R$ & 44.0 & 46.4 & 48.9 & 66.3 & 70.3 \\
\hline 51 & $\mathrm{~L}-\mathrm{HR}$ & 39.1 & 41.7 & 44.5 & 64.7 & 70.2 \\
\hline 51 & $E L-S$ & 38.5 & 40.7 & 43.0 & 59.1 & 62.6 \\
\hline 51 & EL03 & 31.5 & 33.7 & 36.0 & 52.2 & 56.0 \\
\hline 51 & ELO 4 & 27.5 & 29.5 & 31.6 & 46.4 & 49.6 \\
\hline 51 & T01 & 54.9 & 58.2 & 62.0 & 91.4 & 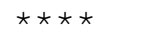 \\
\hline 51 & T02 & 48.9 & 51.6 & 54.5 & 74.5 & 79.7 \\
\hline 51 & SW2 & 43.5 & 45.5 & 47.7 & 62.7 & 66.1 \\
\hline 52 & OPEN & 55.9 & 59.1 & 62.8 & 89.2 & 97.4 \\
\hline 52 & SW1 & 36.1 & 37.9 & 39.9 & 53.5 & 56.5 \\
\hline 52 & $L-S R$ & 44.9 & 47.3 & 49.8 & 67.2 & 71.3 \\
\hline 52 & $\mathrm{~L}-\mathrm{HR}$ & 38.7 & 41.3 & 44.0 & 63.6 & 68.9 \\
\hline
\end{tabular}


Table 24. Continued.

\begin{tabular}{|c|c|c|c|c|c|c|}
\hline Level & Zone & $\begin{array}{l}\text { sibility of } \\
30 . \mathrm{m} \\
(98 \mathrm{ft}) \\
\text { at Time } \\
\text { (min) }\end{array}$ & $\begin{array}{c}\text { Visibility of } \\
15 . \mathrm{m} \\
(49 \mathrm{ft}) \\
\text { at Time } \\
\text { (min) }\end{array}$ & $\begin{array}{c}\text { Visibility of } \\
8 . \mathrm{m} \\
(25 \mathrm{ft}) \\
\text { at Time } \\
\text { (min) }\end{array}$ & $\begin{array}{l}\text { FED of } \\
0.5 \text { at } \\
\text { Time } \\
\text { (min) }\end{array}$ & $\begin{array}{l}\text { FED of } \\
1.0 \text { at } \\
\text { Time } \\
\text { (min) }\end{array}$ \\
\hline 52 & $E L-S$ & 39.4 & 41.6 & 43.9 & 60.0 & 63.6 \\
\hline 52 & ELO3 & 31.8 & 33.9 & 36.3 & 52.6 & 56.3 \\
\hline 52 & ELO 4 & 27.8 & 29.7 & 31.8 & 46.6 & 49.9 \\
\hline 52 & T01 & 56.2 & 59.6 & 63.4 & 92.9 & 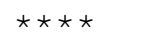 \\
\hline 52 & T02 & 49.9 & 52.6 & 55.5 & 75.6 & 80.7 \\
\hline 52 & SW2 & 44.5 & 46.5 & 48.7 & 64.0 & 67.4 \\
\hline 53 & OPEN & 57.4 & 60.6 & 64.3 & 90.8 & 99.0 \\
\hline 53 & SW1 & 37.5 & 39.3 & 41.2 & 55.1 & 58.1 \\
\hline 53 & $L-S R$ & 45.8 & 48.3 & 50.8 & 68.3 & 72.4 \\
\hline 53 & $\mathrm{~L}-\mathrm{HR}$ & 38.4 & 40.9 & 43.6 & 62.8 & 67.9 \\
\hline 53 & $E L-S$ & 40.3 & 42.6 & 44.9 & 61.1 & 64.8 \\
\hline 53 & ELO3 & 32.0 & 34.2 & 36.6 & 52.9 & 56.6 \\
\hline 53 & ELO 4 & 28.0 & 29.9 & 32.1 & 46.9 & 50.2 \\
\hline 53 & T01 & 57.8 & 61.1 & 65.1 & 94.7 & $\star \star \star \star \star$ \\
\hline 53 & T02 & 51.0 & 53.7 & 56.6 & 76.7 & 81.9 \\
\hline 53 & SW2 & 45.6 & 47.7 & 49.9 & 65.3 & 68.8 \\
\hline 54 & OPEN & 58.4 & 61.7 & 65.5 & 92.1 & 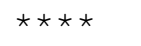 \\
\hline 54 & SW1 & 38.9 & 40.8 & 42.8 & 56.9 & 60.0 \\
\hline 54 & $L-S R$ & 46.9 & 49.4 & 51.9 & 69.5 & 73.6 \\
\hline 54 & $\mathrm{~L}-\mathrm{HR}$ & 38.1 & 40.6 & 43.2 & 62.0 & 66.8 \\
\hline 54 & $E L-S$ & 41.4 & 43.7 & 46.0 & 62.3 & 66.0 \\
\hline 54 & EL03 & 32.3 & 34.5 & 36.8 & 53.2 & 56.9 \\
\hline 54 & ELO 4 & 28.3 & 30.2 & 32.3 & 47.2 & 50.5 \\
\hline 54 & T01 & 47.5 & 50.7 & 54.4 & 80.4 & 88.4 \\
\hline 54 & T02 & 52.2 & 54.9 & 57.9 & 78.1 & 83.3 \\
\hline 54 & SW2 & 46.8 & 48.9 & 51.2 & 66.8 & 70.3 \\
\hline 55 & OPEN & 59.2 & 62.7 & 66.7 & 93.4 & 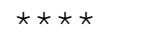 \\
\hline 55 & SW1 & 40.8 & 42.7 & 44.7 & 59.0 & 62.2 \\
\hline 55 & $L-S R$ & 48.1 & 50.6 & 53.2 & 70.9 & 75.0 \\
\hline 55 & $\mathrm{~L}-\mathrm{HR}$ & 38.1 & 40.6 & 43.2 & 61.8 & 66.6 \\
\hline 55 & $E L-S$ & 42.6 & 44.9 & 47.3 & 63.6 & 67.3 \\
\hline 55 & EL03 & 32.6 & 34.8 & 37.1 & 53.4 & 57.2 \\
\hline 55 & ELO 4 & 28.5 & 30.5 & 32.6 & 47.5 & 50.8 \\
\hline 55 & T01 & 44.7 & 47.7 & 51.0 & 74.9 & 82.0 \\
\hline 55 & T02 & 53.6 & 56.3 & 59.3 & 79.6 & 84.8 \\
\hline 55 & SW2 & 48.1 & 50.3 & 52.6 & 68.5 & 72.1 \\
\hline 56 & OPEN & 60.1 & 63.9 & 68.1 & 95.3 & 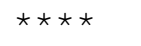 \\
\hline 56 & SW1 & 43.0 & 44.9 & 47.0 & 61.7 & 65.1 \\
\hline 56 & $L-S R$ & 49.5 & 51.9 & 54.6 & 72.4 & 76.6 \\
\hline 56 & $\mathrm{~L}-\mathrm{HR}$ & 38.2 & 40.7 & 43.3 & 61.8 & 66.6 \\
\hline
\end{tabular}


Table 24. Continued.

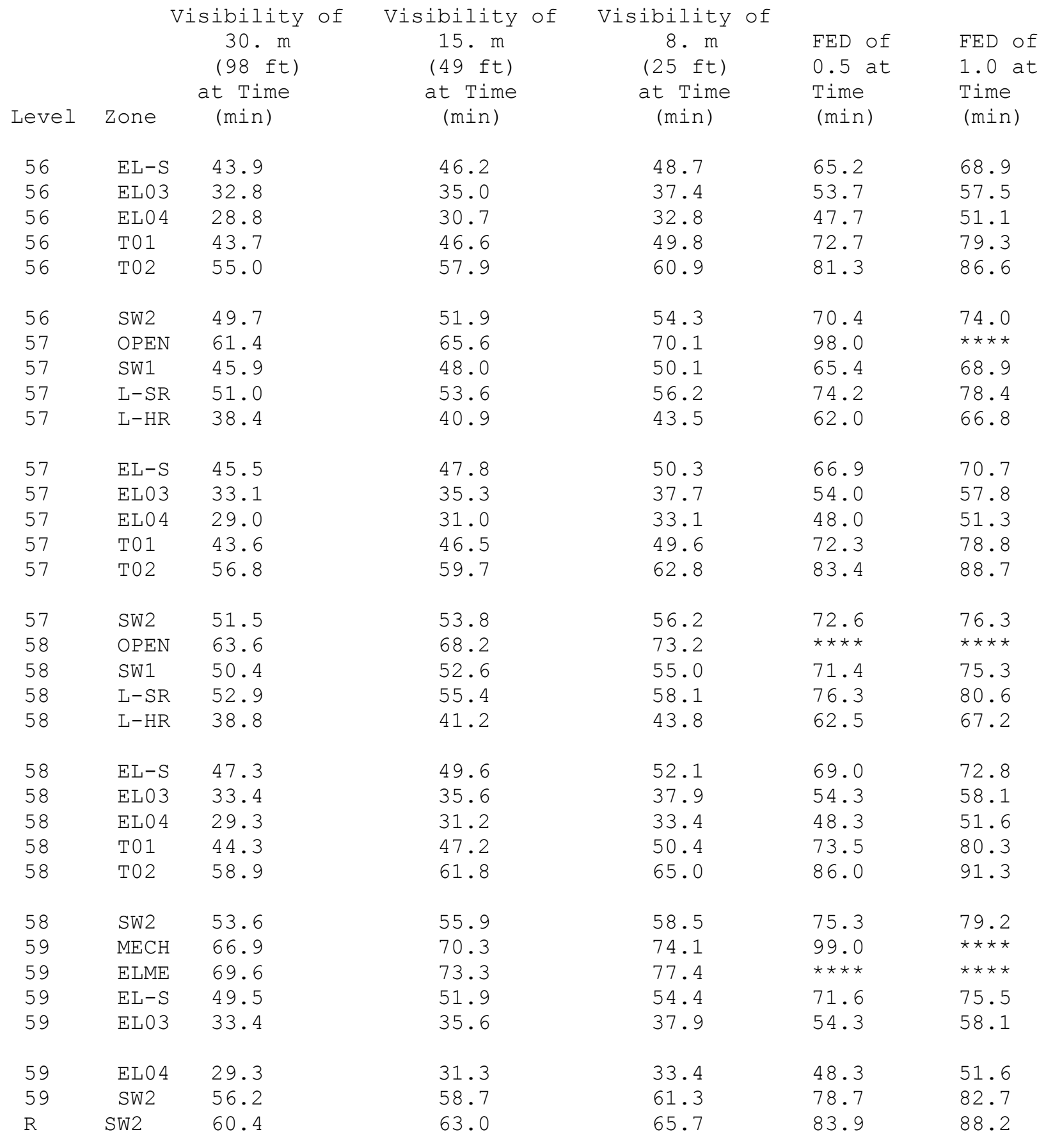


Table 25. Results of Tenability Analysis for Scenario 25.

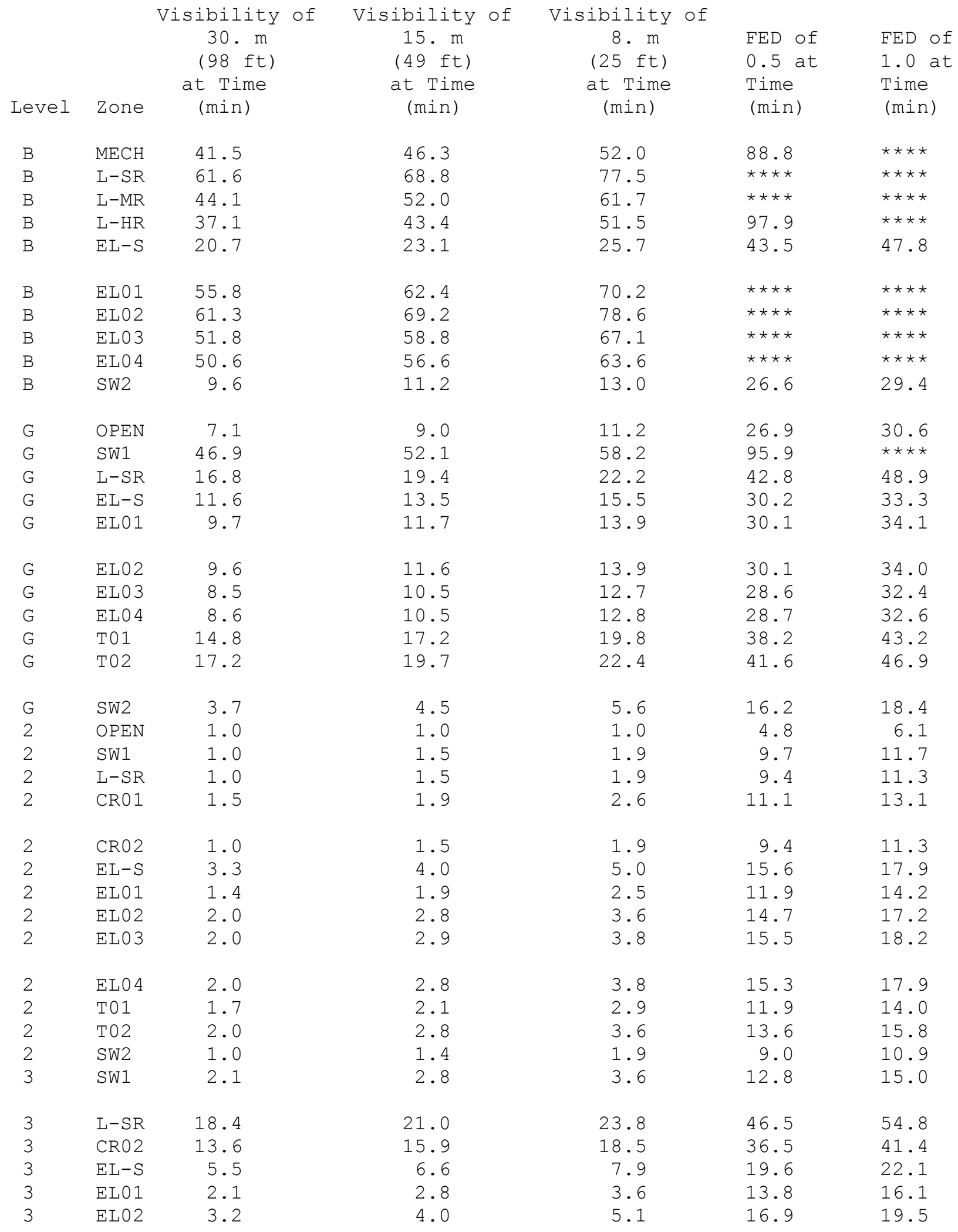


Table 25. Continued.

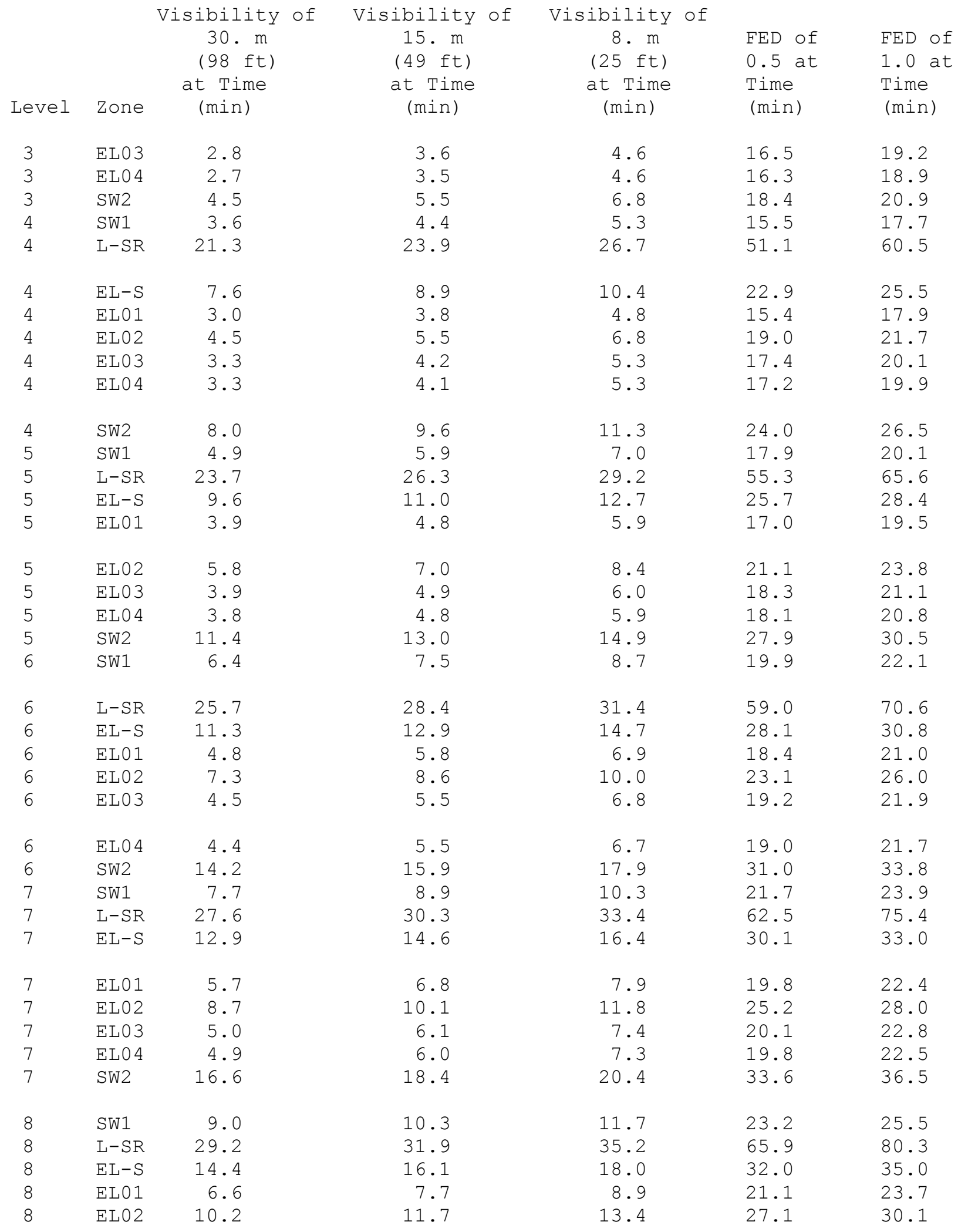


Table 25. Continued.

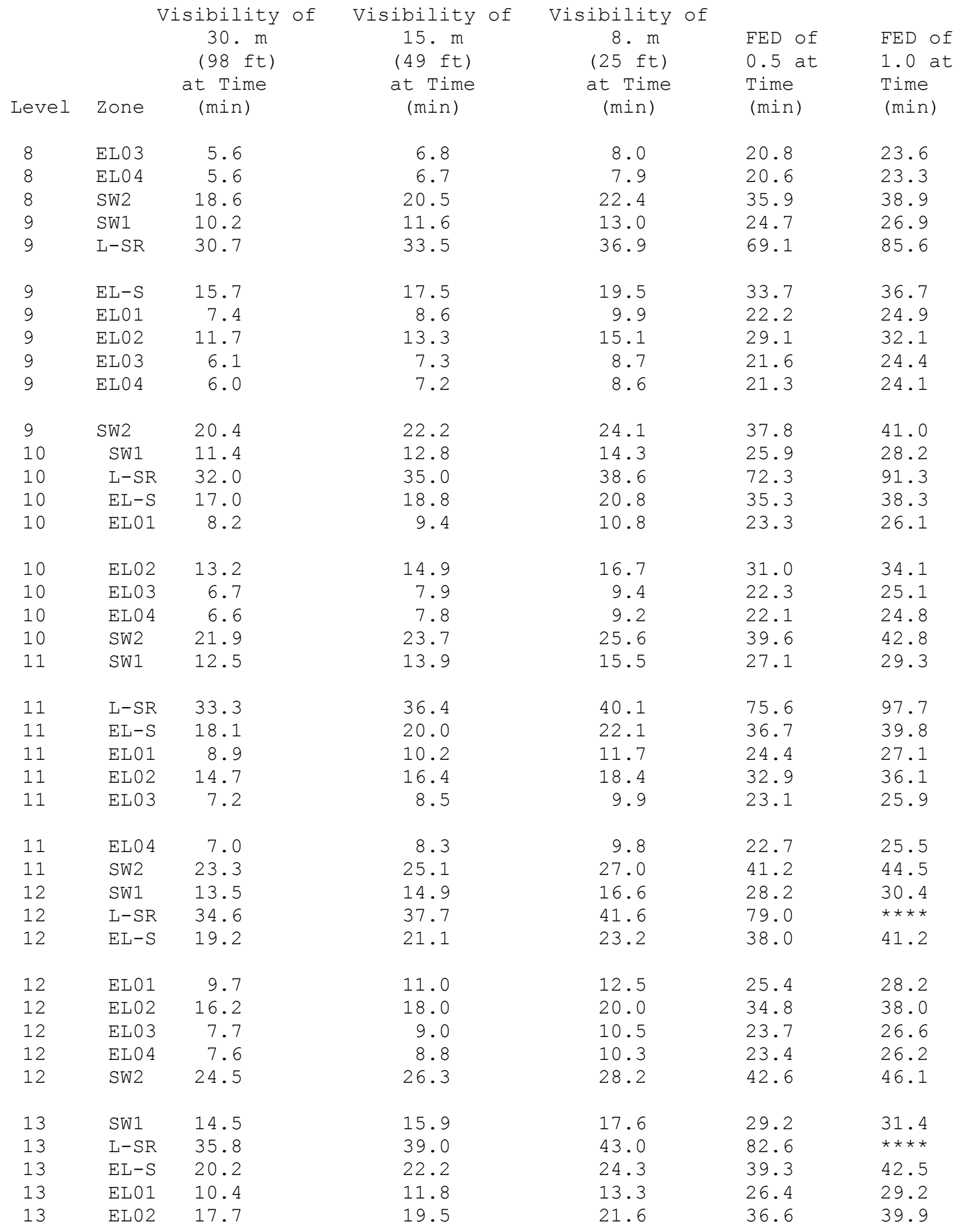


Table 25. Continued.

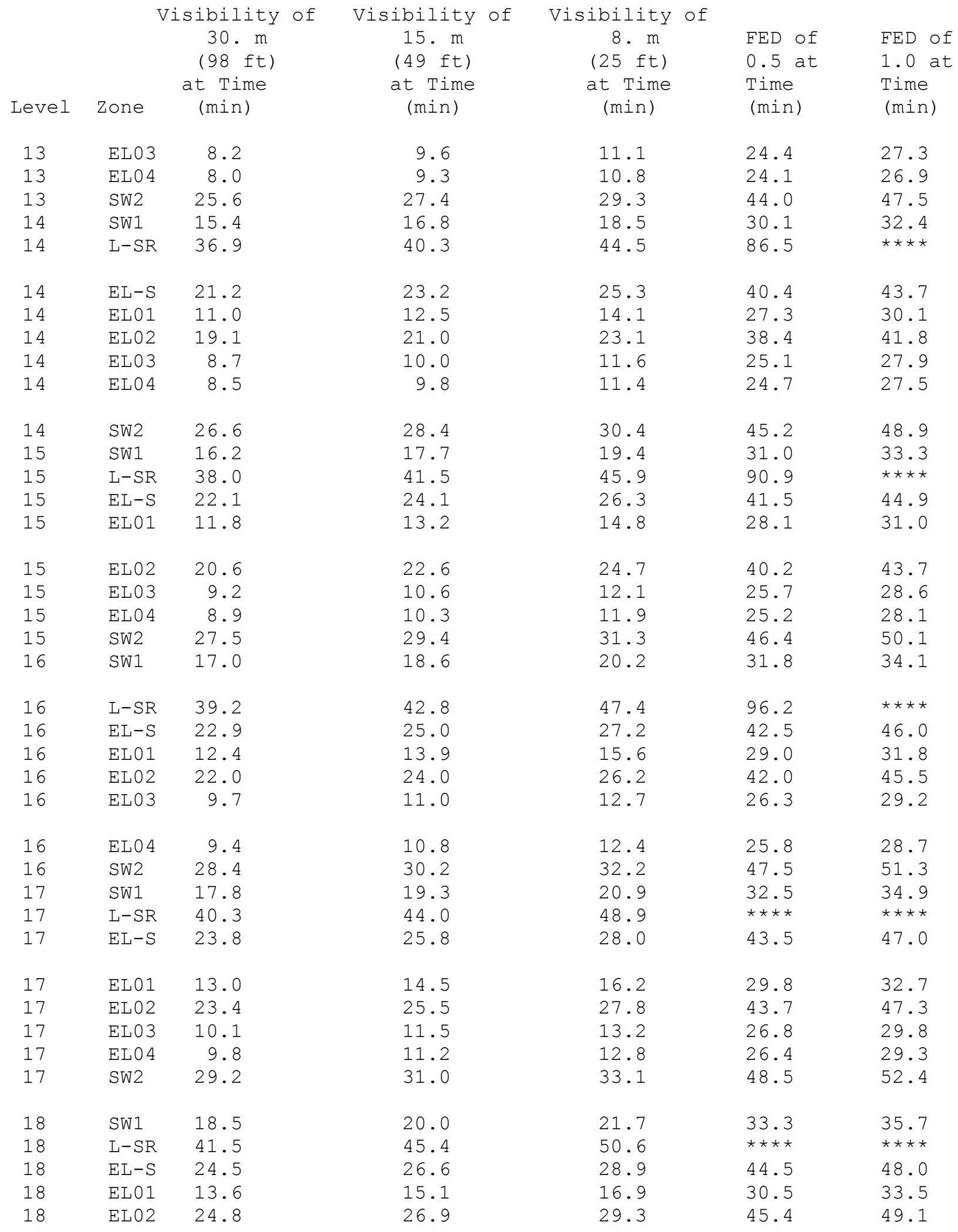


Table 25. Continued.

\begin{tabular}{|c|c|c|c|c|c|c|}
\hline Level & Zone & $\begin{array}{l}\text { sibility of } \\
30 . \mathrm{m} \\
(98 \mathrm{ft}) \\
\text { at Time } \\
\text { (min) }\end{array}$ & $\begin{array}{c}\text { Visibility of } \\
15 . \mathrm{m} \\
(49 \mathrm{ft}) \\
\text { at Time } \\
\text { (min) }\end{array}$ & $\begin{array}{c}\text { Visibility of } \\
8 . \mathrm{m} \\
(25 \mathrm{ft}) \\
\text { at Time } \\
\text { (min) }\end{array}$ & $\begin{array}{l}\text { FED of } \\
0.5 \text { at } \\
\text { Time } \\
\text { (min) }\end{array}$ & $\begin{array}{l}\text { FED of } \\
1.0 \text { at } \\
\text { Time } \\
\text { (min) }\end{array}$ \\
\hline 18 & ELO3 & 10.6 & 12.0 & 13.7 & 27.4 & 30.4 \\
\hline 18 & ELO 4 & 10.2 & 11.7 & 13.3 & 26.9 & 29.8 \\
\hline 18 & sw2 & 29.9 & 31.8 & 33.9 & 49.5 & 53.5 \\
\hline 19 & SW1 & 19.2 & 20.7 & 22.3 & 34.0 & 36.4 \\
\hline 19 & $L-S R$ & 42.8 & 46.9 & 52.5 & 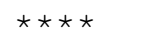 & 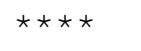 \\
\hline 19 & $E L-S$ & 25.3 & 27.4 & 29.6 & 45.3 & 48.9 \\
\hline 19 & EL01 & 14.2 & 15.8 & 17.5 & 31.3 & 34.2 \\
\hline 19 & EL02 & 26.2 & 28.4 & 30.7 & 47.1 & 50.9 \\
\hline 19 & ELO3 & 10.9 & 12.5 & 14.1 & 28.0 & 30.9 \\
\hline 19 & ELO 4 & 10.6 & 12.1 & 13.8 & 27.4 & 30.4 \\
\hline 19 & sw2 & 30.7 & 32.6 & 34.7 & 50.4 & 54.4 \\
\hline 20 & SW1 & 19.8 & 21.4 & 22.9 & 34.6 & 37.1 \\
\hline 20 & $L-S R$ & 44.3 & 48.7 & 54.7 & 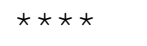 & 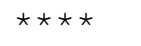 \\
\hline 20 & $E L-S$ & 25.9 & 28.1 & 30.4 & 46.2 & 49.8 \\
\hline 20 & EL01 & 14.8 & 16.4 & 18.1 & 32.0 & 35.0 \\
\hline 20 & ELO2 & 27.6 & 29.8 & 32.2 & 48.8 & 52.6 \\
\hline 20 & EL03 & 11.4 & 12.9 & 14.6 & 28.5 & 31.5 \\
\hline 20 & ELO 4 & 11.0 & 12.5 & 14.2 & 28.0 & 30.9 \\
\hline 20 & SW2 & 31.3 & 33.3 & 35.4 & 51.3 & 55.4 \\
\hline 21 & SW1 & 20.5 & 22.0 & 23.7 & 35.5 & 38.0 \\
\hline 21 & $L-S R$ & 46.3 & 51.2 & 58.2 & 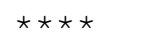 & 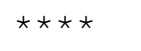 \\
\hline 21 & $E L-S$ & 26.6 & 28.8 & 31.1 & 47.0 & 50.6 \\
\hline 21 & EL01 & 15.3 & 16.9 & 18.7 & 32.7 & 35.7 \\
\hline 21 & EL02 & 28.9 & 31.2 & 33.6 & 50.4 & 54.4 \\
\hline 21 & EL03 & 11.8 & 13.3 & 15.0 & 29.0 & 32.0 \\
\hline 21 & ELO 4 & 11.4 & 12.9 & 14.6 & 28.4 & 31.4 \\
\hline 21 & SW2 & 32.2 & 34.1 & 36.2 & 52.4 & 56.6 \\
\hline 22 & SW1 & 21.1 & 22.7 & 24.3 & 36.3 & 38.8 \\
\hline 22 & $L-S R$ & 49.5 & 55.4 & 64.4 & 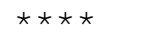 & 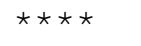 \\
\hline 22 & $E L-S$ & 27.3 & 29.5 & 31.8 & 47.8 & 51.4 \\
\hline 22 & EL01 & 15.8 & 17.5 & 19.3 & 33.3 & 36.3 \\
\hline 22 & EL02 & 30.3 & 32.6 & 35.0 & 52.1 & 56.1 \\
\hline 22 & EL03 & 12.2 & 13.7 & 15.5 & 29.5 & 32.5 \\
\hline 22 & ELO 4 & 11.8 & 13.3 & 15.0 & 28.9 & 31.9 \\
\hline 22 & SW2 & 32.9 & 34.9 & 37.1 & 53.5 & 57.7 \\
\hline 23 & SW1 & 21.8 & 23.4 & 25.0 & 37.0 & 39.6 \\
\hline 23 & $E L-S$ & 27.9 & 30.1 & 32.4 & 48.5 & 52.2 \\
\hline 23 & EL01 & 16.4 & 18.0 & 19.9 & 34.0 & 37.0 \\
\hline 23 & EL02 & 31.6 & 33.9 & 36.5 & 53.7 & 57.7 \\
\hline 23 & EL03 & 12.6 & 14.1 & 15.9 & 30.0 & 33.1 \\
\hline
\end{tabular}


Table 25. Continued.

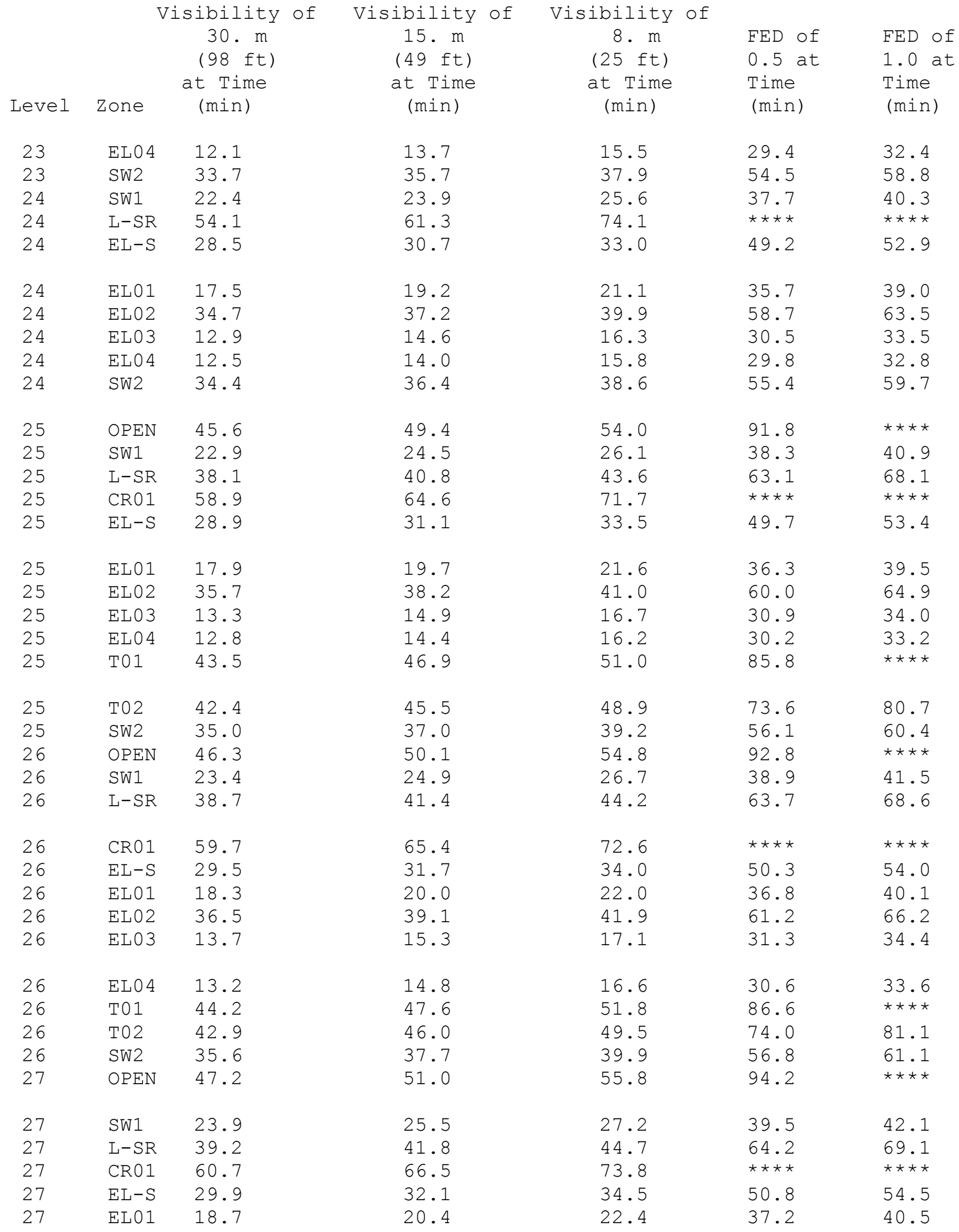


Table 25. Continued.

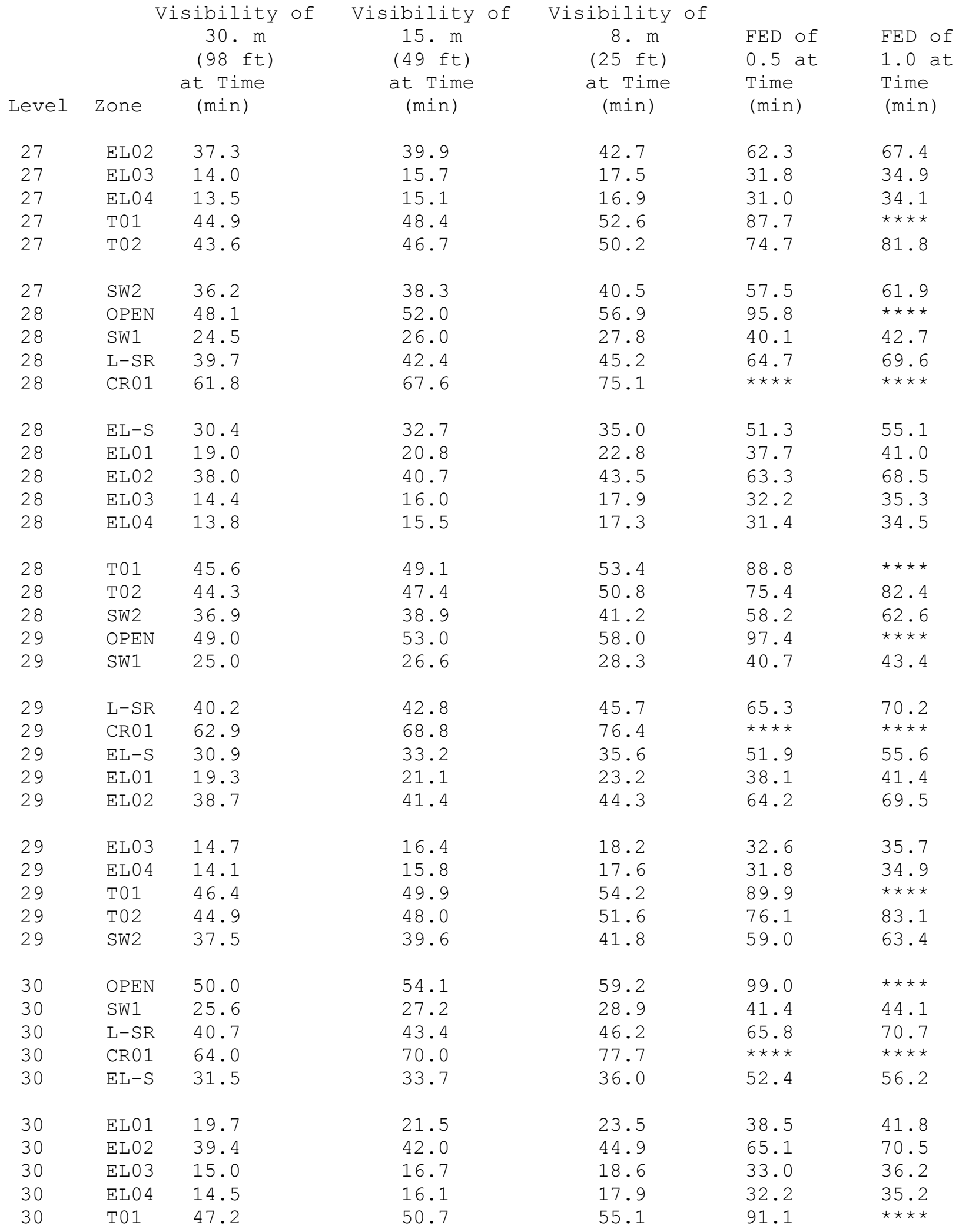


Table 25. Continued.

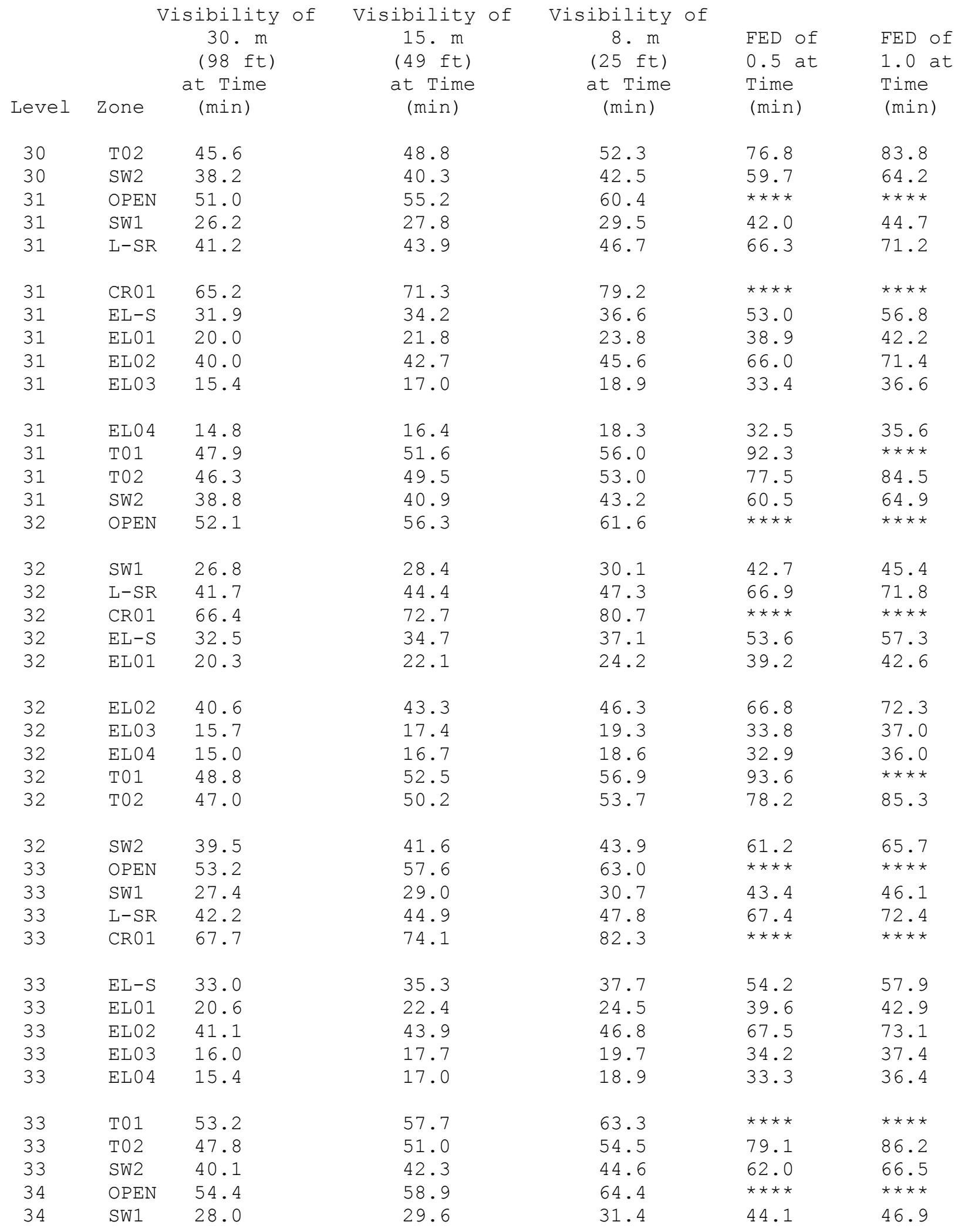


Table 25. Continued.

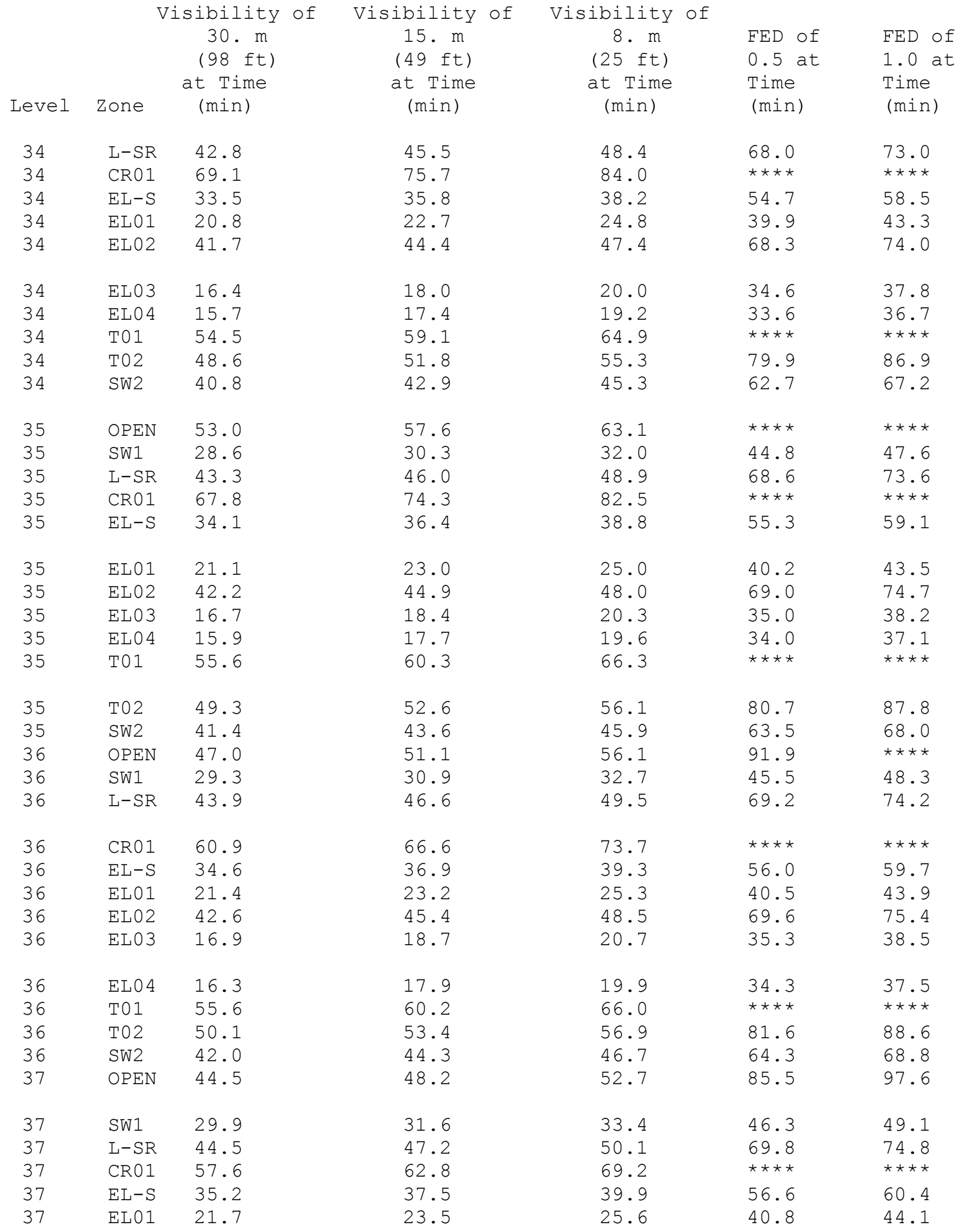


Table 25. Continued.

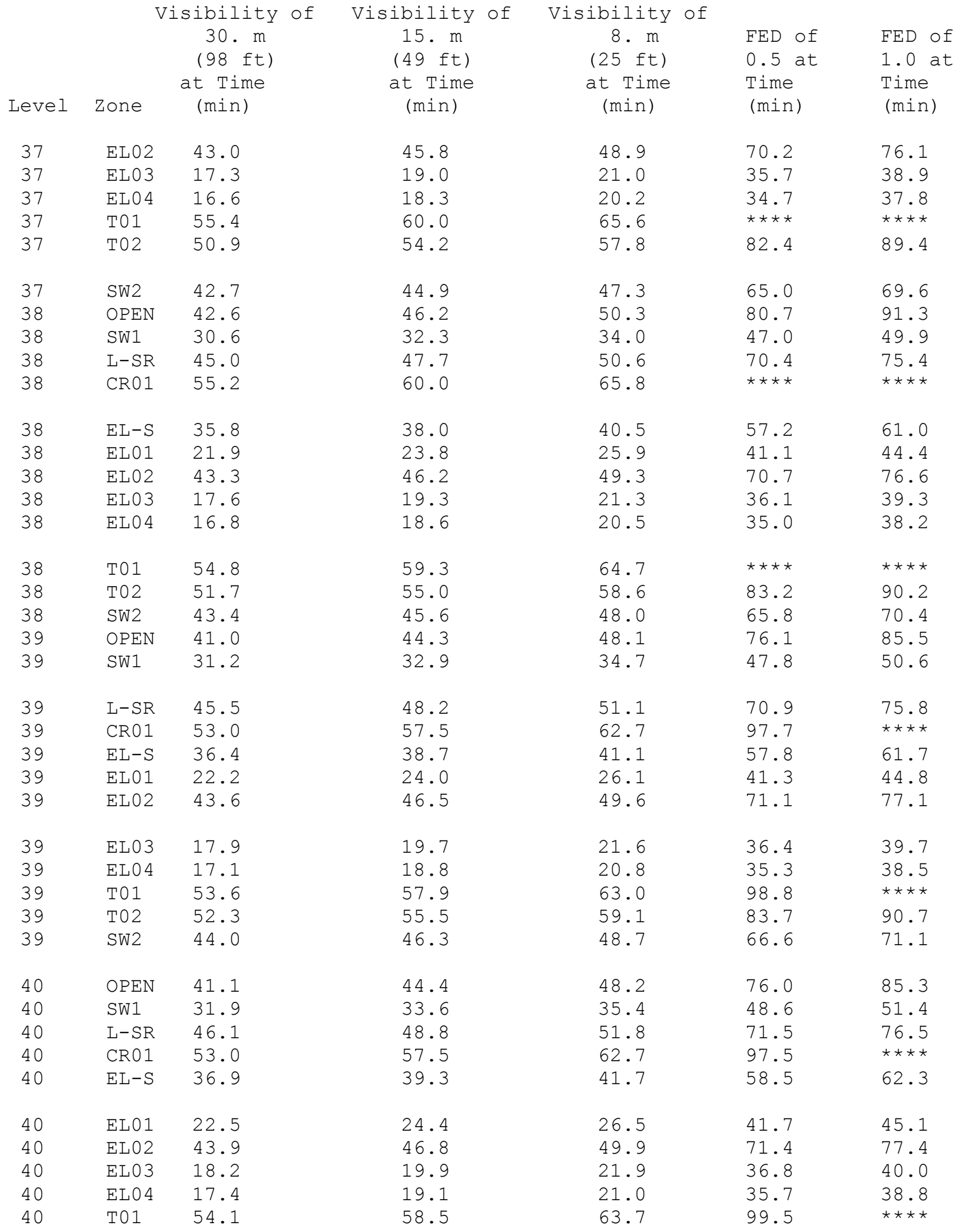


Table 25. Continued.

\begin{tabular}{|c|c|c|c|c|c|c|}
\hline Level & Zone & $\begin{array}{l}\text { sibility of } \\
30 . \mathrm{m} \\
(98 \mathrm{ft}) \\
\text { at Time } \\
\text { (min) }\end{array}$ & $\begin{array}{c}\text { Visibility of } \\
15 . \mathrm{m} \\
(49 \mathrm{ft}) \\
\text { at Time } \\
\text { (min) }\end{array}$ & $\begin{array}{c}\text { Visibility of } \\
8 . \mathrm{m} \\
(25 \mathrm{ft}) \\
\text { at Time } \\
\text { (min) }\end{array}$ & $\begin{array}{l}\text { FED of } \\
0.5 \text { at } \\
\text { Time } \\
\text { (min) }\end{array}$ & $\begin{array}{l}\text { FED of } \\
1.0 \text { at } \\
\text { Time } \\
\text { (min) }\end{array}$ \\
\hline 40 & T02 & 53.2 & 56.5 & 60.2 & 84.7 & 91.7 \\
\hline 40 & SW2 & 44.7 & 46.9 & 49.4 & 67.3 & 71.9 \\
\hline 41 & OPEN & 41.4 & 44.7 & 48.4 & 76.3 & 85.6 \\
\hline 41 & SW1 & 32.6 & 34.3 & 36.1 & 49.4 & 52.3 \\
\hline 41 & $L-S R$ & 46.7 & 49.5 & 52.4 & 72.2 & 77.2 \\
\hline 41 & CR01 & 53.3 & 57.7 & 63.0 & 97.8 & 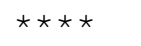 \\
\hline 41 & $E L-S$ & 37.6 & 39.9 & 42.3 & 59.1 & 63.0 \\
\hline 41 & EL01 & 22.8 & 24.7 & 26.8 & 42.0 & 45.4 \\
\hline 41 & ELO2 & 44.3 & 47.1 & 50.3 & 71.8 & 77.8 \\
\hline 41 & EL03 & 18.5 & 20.2 & 22.2 & 37.1 & 40.4 \\
\hline 41 & ELO 4 & 17.7 & 19.4 & 21.4 & 36.0 & 39.2 \\
\hline 41 & T01 & 54.8 & 59.3 & 64.6 & 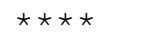 & 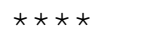 \\
\hline 41 & T02 & 53.9 & 57.2 & 60.8 & 85.4 & 92.4 \\
\hline 41 & SW2 & 45.3 & 47.6 & 50.1 & 68.1 & 72.7 \\
\hline 42 & OPEN & 41.3 & 44.6 & 48.3 & 75.7 & 84.8 \\
\hline 42 & SW1 & 33.3 & 35.0 & 36.9 & 50.2 & 53.1 \\
\hline 42 & $L-S R$ & 47.3 & 50.0 & 53.0 & 72.8 & 77.8 \\
\hline 42 & CR01 & 53.1 & 57.5 & 62.6 & 96.9 & $\star \star \star \star *$ \\
\hline 42 & $E L-S$ & 38.2 & 40.5 & 43.0 & 59.8 & 63.7 \\
\hline 42 & EL01 & 23.0 & 25.0 & 27.1 & 42.3 & 45.7 \\
\hline 42 & ELO2 & 44.6 & 47.5 & 50.6 & 72.2 & 78.2 \\
\hline 42 & EL03 & 18.7 & 20.6 & 22.6 & 37.4 & 40.7 \\
\hline 42 & ELO 4 & 17.9 & 19.7 & 21.7 & 36.3 & 39.5 \\
\hline 42 & T01 & 54.9 & 59.5 & 64.9 & $\star \star \star \star$ & $\star \star \star \star \star$ \\
\hline 42 & T02 & 54.5 & 57.8 & 61.4 & 86.0 & 92.9 \\
\hline 42 & SW2 & 45.9 & 48.3 & 50.8 & 68.9 & 73.5 \\
\hline 43 & OPEN & 35.7 & 38.5 & 41.5 & 62.7 & 68.6 \\
\hline 43 & SW1 & 34.0 & 35.8 & 37.6 & 51.0 & 53.9 \\
\hline 43 & $L-S R$ & 46.0 & 48.6 & 51.4 & 70.3 & 74.9 \\
\hline 43 & $E L-S$ & 38.8 & 41.1 & 43.6 & 60.5 & 64.4 \\
\hline 43 & EL01 & 23.4 & 25.3 & 27.4 & 42.7 & 46.1 \\
\hline 43 & EL02 & 45.0 & 47.8 & 51.0 & 72.5 & 78.5 \\
\hline 43 & EL03 & 19.3 & 21.2 & 23.2 & 38.3 & 41.7 \\
\hline 43 & ELO 4 & 18.5 & 20.3 & 22.3 & 37.2 & 40.4 \\
\hline 43 & T01 & 48.9 & 52.4 & 56.3 & 83.6 & 92.3 \\
\hline 43 & T02 & 51.2 & 54.2 & 57.5 & 80.0 & 86.1 \\
\hline 43 & SW2 & 46.6 & 49.0 & 51.5 & 69.7 & 74.3 \\
\hline 44 & OPEN & 55.1 & 58.6 & 62.6 & 92.0 & 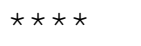 \\
\hline 44 & SW1 & 34.8 & 36.5 & 38.4 & 51.8 & 54.8 \\
\hline 44 & $L-S R$ & 45.8 & 48.4 & 51.2 & 69.8 & 74.2 \\
\hline
\end{tabular}


Table 25. Continued.

\begin{tabular}{|c|c|c|c|c|c|c|}
\hline Level & Zone & $\begin{array}{l}\text { sibility of } \\
30 . \mathrm{m} \\
(98 \mathrm{ft}) \\
\text { at Time } \\
\text { (min) }\end{array}$ & $\begin{array}{c}\text { Visibility of } \\
15 . \mathrm{m} \\
(49 \mathrm{ft}) \\
\text { at Time } \\
\text { (min) }\end{array}$ & $\begin{array}{c}\text { Visibility of } \\
8 . \mathrm{m} \\
(25 \mathrm{ft}) \\
\text { at Time } \\
\text { (min) }\end{array}$ & $\begin{array}{l}\text { FED of } \\
0.5 \text { at } \\
\text { Time } \\
\text { (min) }\end{array}$ & $\begin{array}{l}\text { FED of } \\
1.0 \text { at } \\
\text { Time } \\
\text { (min) }\end{array}$ \\
\hline 44 & $E L-S$ & 39.5 & 41.8 & 44.3 & 61.2 & 65.1 \\
\hline 44 & ELO3 & 19.6 & 21.4 & 23.5 & 38.6 & 42.1 \\
\hline 44 & ELO 4 & 18.7 & 20.5 & 22.6 & 37.4 & 40.7 \\
\hline 44 & T01 & 55.5 & 58.9 & 62.9 & 93.7 & 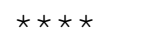 \\
\hline 44 & T02 & 50.8 & 53.7 & 56.8 & 78.6 & 84.4 \\
\hline 44 & SW2 & 47.3 & 49.7 & 52.2 & 70.5 & 75.1 \\
\hline 45 & OPEN & 56.5 & 60.0 & 64.0 & 93.7 & $\star \star \star \star \star$ \\
\hline 45 & SW1 & 35.6 & 37.3 & 39.2 & 52.7 & 55.7 \\
\hline 45 & $L-S R$ & 46.5 & 49.1 & 51.9 & 70.5 & 75.0 \\
\hline 45 & $E L-S$ & 40.1 & 42.5 & 45.0 & 62.0 & 65.9 \\
\hline 45 & EL03 & 19.8 & 21.7 & 23.7 & 38.9 & 42.3 \\
\hline 45 & ELO 4 & 18.9 & 20.8 & 22.8 & 37.7 & 41.0 \\
\hline 45 & T01 & 56.4 & 59.9 & 63.9 & 94.9 & 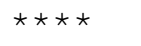 \\
\hline 45 & T02 & 51.6 & 54.5 & 57.6 & 79.4 & 85.2 \\
\hline 45 & SW2 & 48.0 & 50.4 & 53.0 & 71.3 & 75.9 \\
\hline 46 & OPEN & 55.3 & 59.2 & 63.6 & 93.6 & $\star \star \star \star \star$ \\
\hline 46 & SW1 & 36.4 & 38.2 & 40.0 & 53.7 & 56.7 \\
\hline 46 & $L-S R$ & 47.3 & 49.9 & 52.7 & 71.3 & 75.8 \\
\hline 46 & $E L-S$ & 40.9 & 43.2 & 45.8 & 62.8 & 66.7 \\
\hline 46 & EL03 & 20.0 & 21.9 & 23.9 & 39.2 & 42.6 \\
\hline 46 & ELO 4 & 19.1 & 20.9 & 23.0 & 37.9 & 41.2 \\
\hline 46 & T01 & 56.1 & 59.8 & 64.1 & 95.3 & 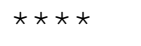 \\
\hline 46 & T02 & 52.4 & 55.3 & 58.5 & 80.3 & 86.1 \\
\hline 46 & SW2 & 48.7 & 51.2 & 53.8 & 72.2 & 76.8 \\
\hline 47 & OPEN & 48.0 & 52.6 & 57.8 & 89.2 & 99.5 \\
\hline 47 & SW1 & 37.3 & 39.1 & 41.0 & 54.7 & 57.8 \\
\hline 47 & $L-S R$ & 48.0 & 50.7 & 53.5 & 72.2 & 76.7 \\
\hline 47 & $E L-S$ & 41.7 & 44.0 & 46.6 & 63.6 & 67.6 \\
\hline 47 & EL03 & 20.3 & 22.1 & 24.2 & 39.4 & 42.9 \\
\hline 47 & ELO 4 & 19.4 & 21.2 & 23.2 & 38.2 & 41.4 \\
\hline 47 & T01 & 45.2 & 49.4 & 54.3 & 86.1 & 96.6 \\
\hline 47 & T02 & 53.2 & 56.2 & 59.4 & 81.3 & 87.1 \\
\hline 47 & SW2 & 49.5 & 52.0 & 54.6 & 73.1 & 77.8 \\
\hline 48 & OPEN & 46.0 & 50.4 & 55.5 & 87.5 & 97.7 \\
\hline 48 & SW1 & 38.3 & 40.1 & 42.0 & 55.9 & 58.9 \\
\hline 48 & $L-S R$ & 48.9 & 51.5 & 54.3 & 73.1 & 77.6 \\
\hline 48 & $E L-S$ & 42.5 & 44.8 & 47.4 & 64.5 & 68.5 \\
\hline 48 & EL03 & 20.5 & 22.4 & 24.4 & 39.7 & 43.1 \\
\hline 48 & ELO 4 & 19.6 & 21.4 & 23.4 & 38.4 & 41.7 \\
\hline 48 & T01 & 43.3 & 47.2 & 51.8 & 83.2 & 93.4 \\
\hline
\end{tabular}


Table 25. Continued.

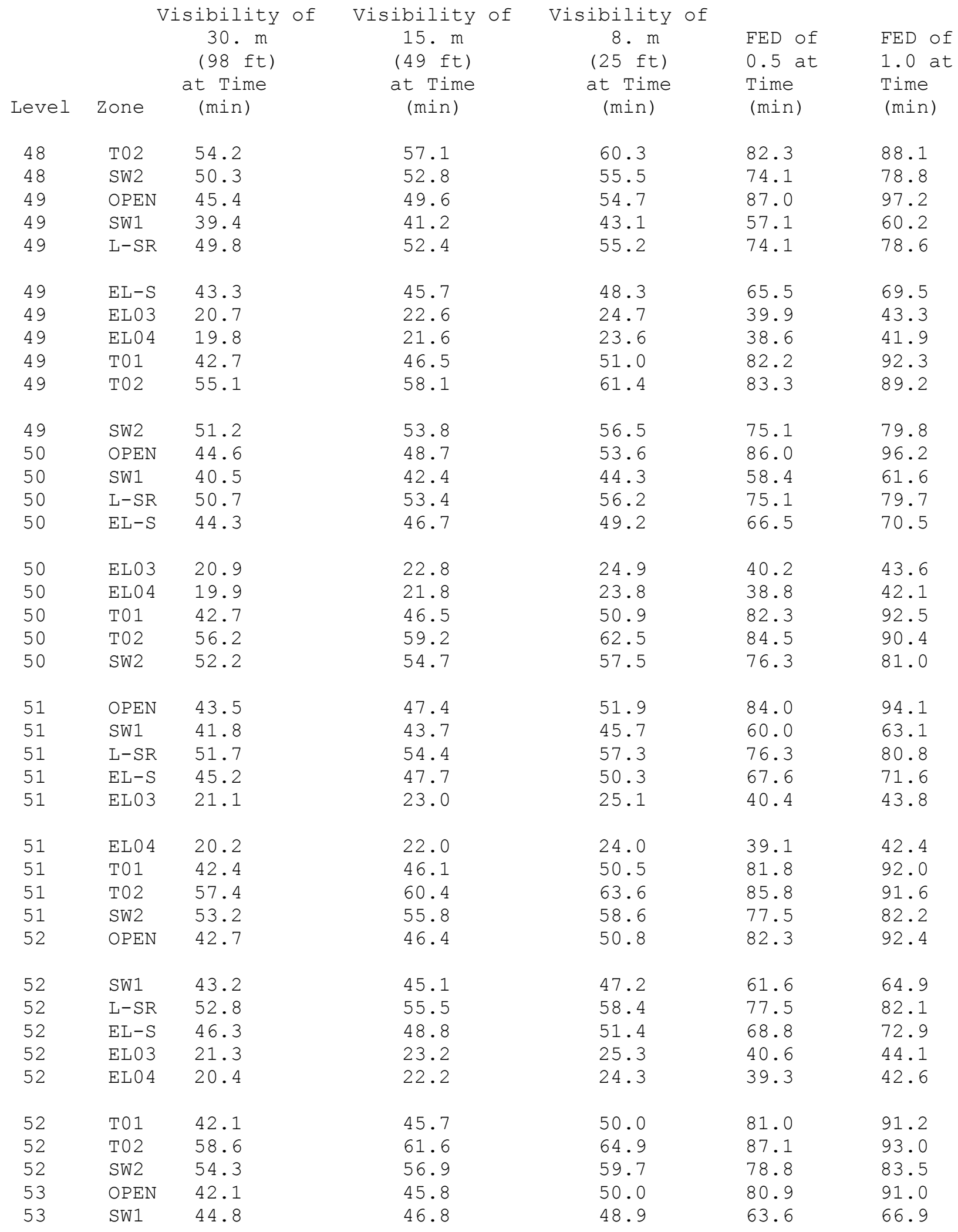


Table 25. Continued.

\begin{tabular}{|c|c|c|c|c|c|c|}
\hline Level & Zone & $\begin{array}{l}\text { sibility of } \\
30 . \mathrm{m} \\
(98 \mathrm{ft}) \\
\text { at Time } \\
\text { (min) }\end{array}$ & $\begin{array}{c}\text { Visibility of } \\
15 . \mathrm{m} \\
(49 \mathrm{ft}) \\
\text { at Time } \\
\text { (min) }\end{array}$ & $\begin{array}{c}\text { Visibility of } \\
8 . \mathrm{m} \\
(25 \mathrm{ft}) \\
\text { at Time } \\
\text { (min) }\end{array}$ & $\begin{array}{l}\text { FED of } \\
0.5 \text { at } \\
\text { Time } \\
\text { (min) }\end{array}$ & $\begin{array}{l}\text { FED of } \\
1.0 \text { at } \\
\text { Time } \\
\text { (min) }\end{array}$ \\
\hline 53 & $L-S R$ & 54.0 & 56.7 & 59.6 & 78.8 & 83.4 \\
\hline 53 & $E L-S$ & 47.5 & 49.9 & 52.6 & 70.1 & 74.2 \\
\hline 53 & EL03 & 21.5 & 23.4 & 25.5 & 40.8 & 44.3 \\
\hline 53 & ELO 4 & 20.6 & 22.5 & 24.5 & 39.5 & 42.9 \\
\hline 53 & T01 & 41.8 & 45.4 & 49.5 & 80.2 & 90.3 \\
\hline 53 & T02 & 59.9 & 63.0 & 66.3 & 88.6 & 94.5 \\
\hline 53 & SW2 & 55.5 & 58.1 & 61.0 & 80.2 & 85.0 \\
\hline 54 & OPEN & 41.7 & 45.3 & 49.4 & 79.8 & 89.8 \\
\hline 54 & SW1 & 46.7 & 48.7 & 50.8 & 65.8 & 69.2 \\
\hline 54 & $L-S R$ & 55.3 & 58.0 & 61.0 & 80.3 & 84.9 \\
\hline 54 & $E L-S$ & 48.8 & 51.2 & 53.9 & 71.5 & 75.7 \\
\hline 54 & ELO3 & 21.7 & 23.7 & 25.7 & 41.1 & 44.5 \\
\hline 54 & ELO 4 & 20.8 & 22.7 & 24.7 & 39.8 & 43.1 \\
\hline 54 & T01 & 41.5 & 45.0 & 49.1 & 79.4 & 89.5 \\
\hline 54 & T02 & 61.4 & 64.5 & 67.9 & 90.3 & 96.2 \\
\hline 54 & SW2 & 56.8 & 59.5 & 62.4 & 81.8 & 86.6 \\
\hline 55 & OPEN & 41.4 & 44.9 & 48.9 & 78.8 & 88.7 \\
\hline 55 & SW1 & 48.9 & 51.0 & 53.1 & 68.5 & 72.0 \\
\hline 55 & $L-S R$ & 56.8 & 59.5 & 62.5 & 81.9 & 86.6 \\
\hline 55 & $E L-S$ & 50.2 & 52.7 & 55.3 & 73.2 & 77.3 \\
\hline 55 & EL03 & 21.9 & 23.9 & 25.9 & 41.3 & 44.7 \\
\hline 55 & ELO 4 & 21.0 & 22.9 & 24.9 & 40.0 & 43.3 \\
\hline 55 & T01 & 41.3 & 44.8 & 48.8 & 78.7 & 88.7 \\
\hline 55 & T02 & 63.0 & 66.2 & 69.6 & 92.2 & 98.1 \\
\hline 55 & SW2 & 58.3 & 61.0 & 64.0 & 83.5 & 88.4 \\
\hline 56 & OPEN & 41.2 & 44.6 & 48.6 & 77.9 & 87.7 \\
\hline 56 & SW1 & 51.7 & 53.8 & 56.0 & 71.9 & 75.5 \\
\hline 56 & $L-S R$ & 58.4 & 61.2 & 64.1 & 83.7 & 88.5 \\
\hline 56 & $E L-S$ & 51.7 & 54.3 & 57.0 & 74.9 & 79.1 \\
\hline 56 & EL03 & 22.2 & 24.1 & 26.2 & 41.5 & 45.0 \\
\hline 56 & ELO 4 & 21.2 & 23.1 & 25.2 & 40.2 & 43.6 \\
\hline 56 & T01 & 41.2 & 44.6 & 48.6 & 78.0 & 88.0 \\
\hline 56 & T02 & 64.9 & 68.0 & 71.5 & 94.3 & 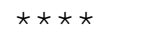 \\
\hline 56 & SW2 & 60.0 & 62.8 & 65.7 & 85.5 & 90.4 \\
\hline 57 & OPEN & 41.0 & 44.4 & 48.3 & 77.1 & 86.8 \\
\hline 57 & SW1 & 55.2 & 57.5 & 59.9 & 76.5 & 80.3 \\
\hline 57 & $L-S R$ & 60.2 & 63.0 & 66.0 & 85.8 & 90.6 \\
\hline 57 & $E L-S$ & 53.5 & 56.1 & 58.8 & 77.0 & 81.2 \\
\hline 57 & EL03 & 22.4 & 24.3 & 26.4 & 41.8 & 45.2 \\
\hline 57 & ELO 4 & 21.5 & 23.3 & 25.4 & 40.5 & 43.8 \\
\hline
\end{tabular}


Table 25. Continued.

\begin{tabular}{|c|c|c|c|c|c|c|}
\hline Level & Zone & $\begin{array}{l}\text { sibility of } \\
30 . \mathrm{m} \\
(98 \mathrm{ft}) \\
\text { at Time } \\
\text { (min) }\end{array}$ & $\begin{array}{c}\text { Visibility of } \\
15 . \mathrm{m} \\
(49 \mathrm{ft}) \\
\text { at Time } \\
\text { (min) }\end{array}$ & $\begin{array}{c}\text { Visibility of } \\
8 . \mathrm{m} \\
(25 \mathrm{ft}) \\
\text { at Time } \\
\text { (min) }\end{array}$ & $\begin{array}{l}\text { FED of } \\
0.5 \text { at } \\
\text { Time } \\
\text { (min) }\end{array}$ & $\begin{array}{l}\text { FED of } \\
1.0 \text { at } \\
\text { Time } \\
\text { (min) }\end{array}$ \\
\hline 57 & T01 & 41.0 & 44.4 & 48.3 & 77.3 & 87.1 \\
\hline 57 & T02 & 66.9 & 70.2 & 73.7 & 96.7 & 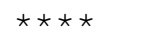 \\
\hline 57 & SW2 & 61.9 & 64.7 & 67.8 & 87.8 & 92.8 \\
\hline 58 & OPEN & 40.5 & 43.8 & 47.5 & 75.4 & 84.7 \\
\hline 58 & SW1 & 60.7 & 63.1 & 65.7 & 83.7 & 88.0 \\
\hline 58 & $L-S R$ & 62.3 & 65.2 & 68.2 & 88.2 & 93.1 \\
\hline 58 & $E L-S$ & 55.6 & 58.2 & 61.0 & 79.4 & 83.7 \\
\hline 58 & EL03 & 22.6 & 24.5 & 26.6 & 42.0 & 45.5 \\
\hline 58 & EL0 4 & 21.7 & 23.6 & 25.7 & 40.7 & 44.1 \\
\hline 58 & T01 & 40.6 & 43.9 & 47.7 & 75.8 & 85.2 \\
\hline 58 & T02 & 69.3 & 72.6 & 76.2 & 99.6 & 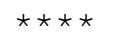 \\
\hline 58 & SW2 & 64.1 & 67.0 & 70.1 & 90.5 & 95.6 \\
\hline 59 & $\mathrm{MECH}$ & 76.8 & 80.9 & 85.4 & 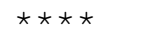 & 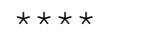 \\
\hline 59 & ELME & 80.4 & 84.7 & 89.5 & 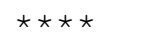 & 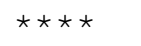 \\
\hline 59 & $E L-S$ & 58.0 & 60.7 & 63.6 & 82.3 & 86.7 \\
\hline 59 & EL03 & 22.6 & 24.6 & 26.7 & 42.0 & 45.5 \\
\hline 59 & EL0 4 & 21.7 & 23.6 & 25.7 & 40.8 & 44.1 \\
\hline 59 & SW2 & 66.9 & 69.8 & 73.0 & 93.8 & 99.0 \\
\hline $\mathrm{R}$ & SW2 & 71.4 & 74.6 & 77.9 & 99.5 & 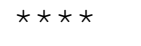 \\
\hline
\end{tabular}


Table 26. Results of Tenability Analysis for Scenario 26.

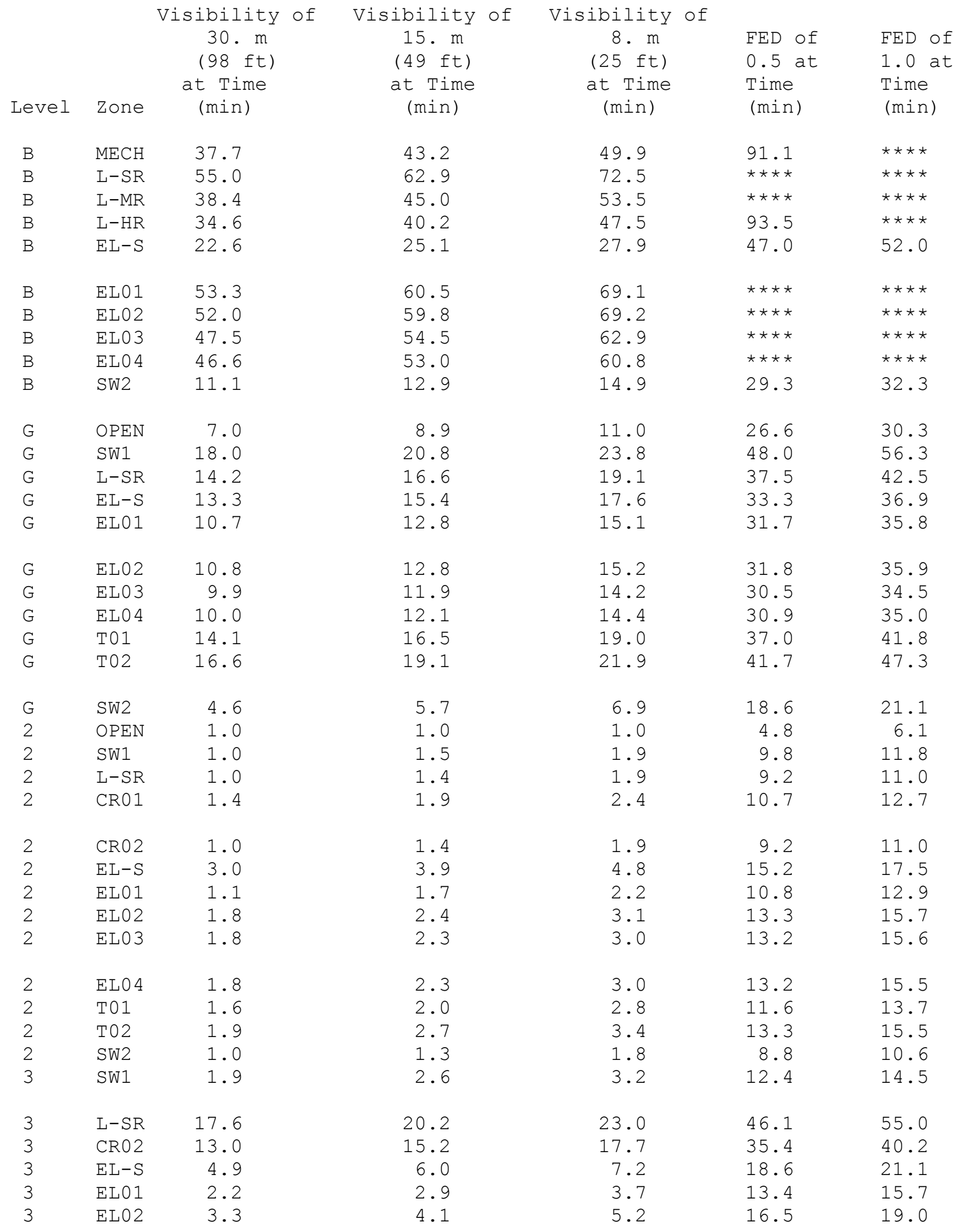


Table 26. Continued.

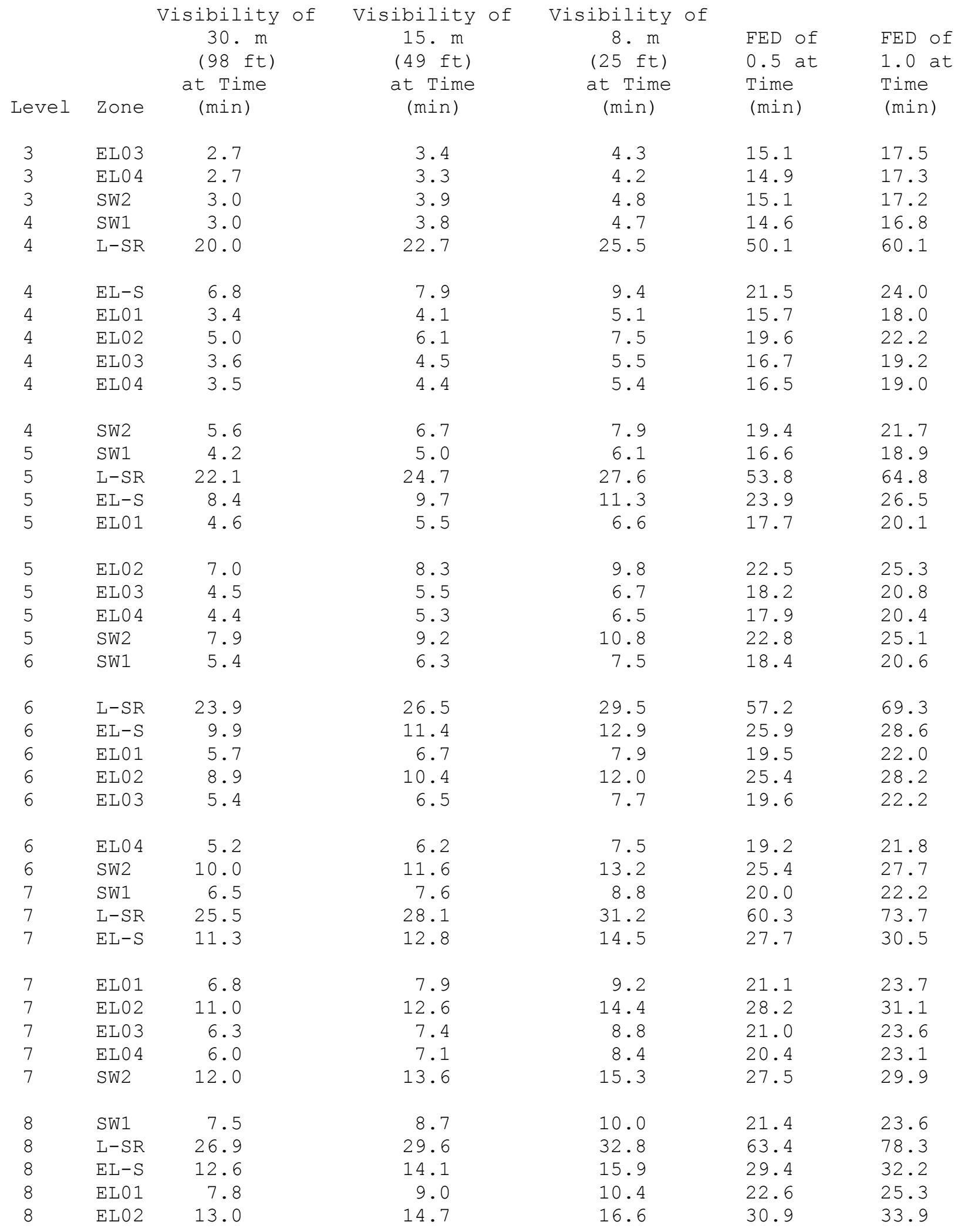


Table 26. Continued.

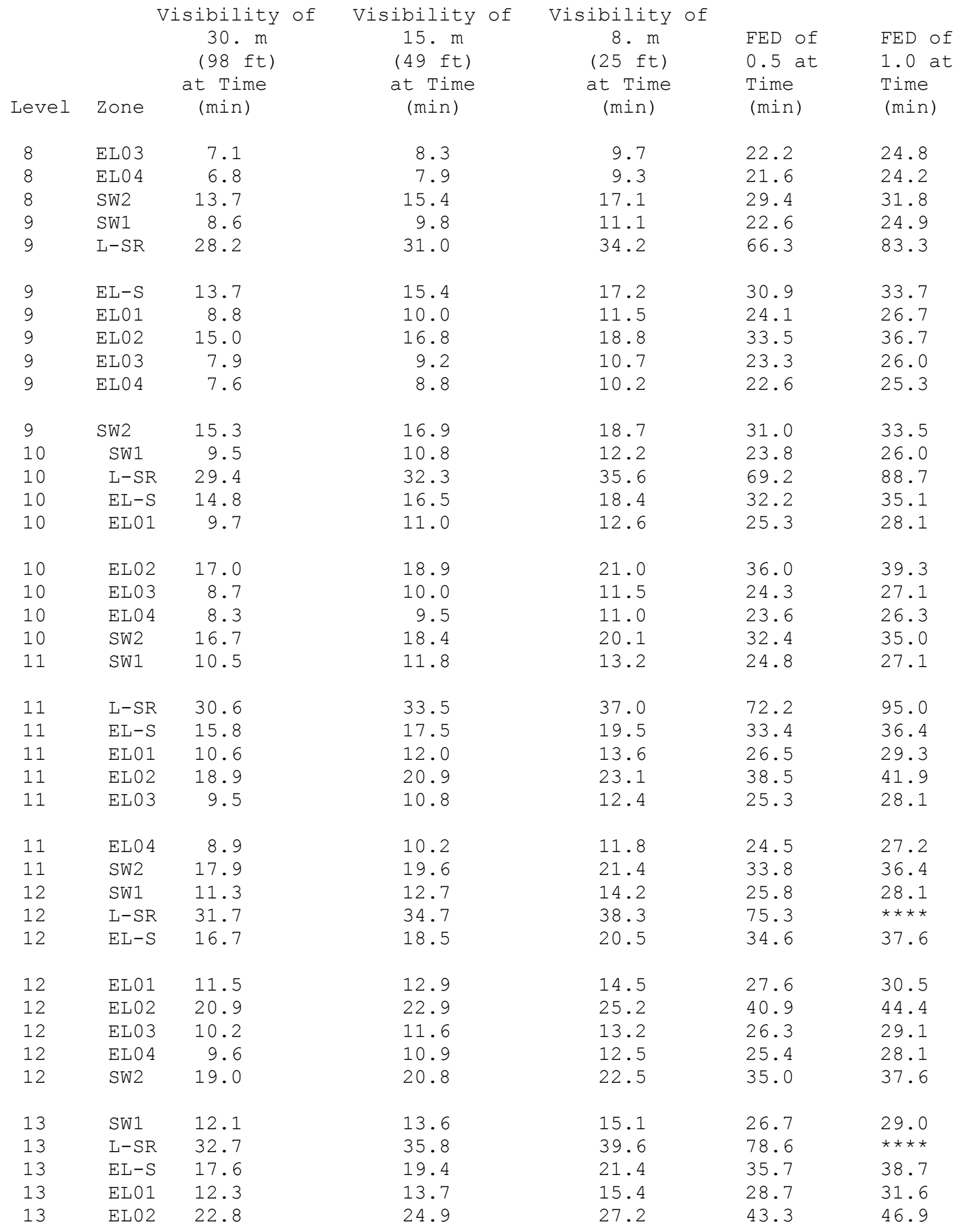


Table 26. Continued.

\begin{tabular}{|c|c|c|c|c|c|c|}
\hline Level & Zone & $\begin{array}{l}\text { sibility of } \\
30 . \mathrm{m} \\
(98 \mathrm{ft}) \\
\text { at Time } \\
\text { (min) }\end{array}$ & $\begin{array}{c}\text { Visibility of } \\
15 . \mathrm{m} \\
(49 \mathrm{ft}) \\
\text { at Time } \\
\text { (min) }\end{array}$ & $\begin{array}{c}\text { Visibility of } \\
8 . \mathrm{m} \\
(25 \mathrm{ft}) \\
\text { at Time } \\
\text { (min) }\end{array}$ & $\begin{array}{l}\text { FED of } \\
0.5 \text { at } \\
\text { Time } \\
\text { (min) }\end{array}$ & $\begin{array}{l}\text { FED of } \\
1.0 \text { at } \\
\text { Time } \\
\text { (min) }\end{array}$ \\
\hline 13 & ELO3 & 10.9 & 12.3 & 13.9 & 27.2 & 30.1 \\
\hline 13 & ELO 4 & 10.2 & 11.6 & 13.2 & 26.2 & 29.0 \\
\hline 13 & sw2 & 20.1 & 21.8 & 23.5 & 36.1 & 38.8 \\
\hline 14 & SW1 & 12.9 & 14.4 & 15.9 & 27.5 & 29.8 \\
\hline 14 & $\mathrm{~L}-\mathrm{SR}$ & 33.7 & 36.9 & 40.8 & 82.1 & 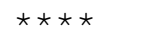 \\
\hline 14 & $E L-S$ & 18.4 & 20.3 & 22.3 & 36.7 & 39.8 \\
\hline 14 & EL01 & 13.0 & 14.6 & 16.2 & 29.7 & 32.6 \\
\hline 14 & EL02 & 24.6 & 26.8 & 29.1 & 45.5 & 49.3 \\
\hline 14 & ELO3 & 11.5 & 13.0 & 14.7 & 28.1 & 30.9 \\
\hline 14 & ELO 4 & 10.8 & 12.2 & 13.8 & 27.0 & 29.8 \\
\hline 14 & sw2 & 21.0 & 22.7 & 24.5 & 37.1 & 39.9 \\
\hline 15 & SW1 & 13.7 & 15.1 & 16.7 & 28.3 & 30.6 \\
\hline 15 & $L-S R$ & 34.7 & 38.0 & 42.1 & 86.2 & 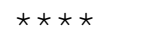 \\
\hline 15 & $E L-S$ & 19.2 & 21.1 & 23.1 & 37.6 & 40.8 \\
\hline 15 & EL01 & 13.8 & 15.3 & 17.0 & 30.7 & 33.6 \\
\hline 15 & ELO2 & 26.4 & 28.6 & 31.0 & 47.8 & 51.7 \\
\hline 15 & EL03 & 12.1 & 13.7 & 15.4 & 28.9 & 31.8 \\
\hline 15 & ELO 4 & 11.4 & 12.8 & 14.5 & 27.7 & 30.5 \\
\hline 15 & sw2 & 21.9 & 23.6 & 25.3 & 38.1 & 40.9 \\
\hline 16 & SW1 & 14.4 & 15.9 & 17.5 & 29.1 & 31.3 \\
\hline 16 & $L-S R$ & 35.7 & 39.1 & 43.4 & 90.9 & $\star \star \star \star \star$ \\
\hline 16 & $E L-S$ & 19.9 & 21.9 & 23.9 & 38.5 & 41.7 \\
\hline 16 & EL01 & 14.5 & 16.0 & 17.8 & 31.6 & 34.5 \\
\hline 16 & EL02 & 28.1 & 30.5 & 32.9 & 50.0 & 54.0 \\
\hline 16 & EL03 & 12.8 & 14.3 & 16.0 & 29.7 & 32.6 \\
\hline 16 & ELO 4 & 11.9 & 13.4 & 15.1 & 28.4 & 31.2 \\
\hline 16 & SW2 & 22.7 & 24.4 & 26.1 & 39.0 & 41.8 \\
\hline 17 & SW1 & 15.1 & 16.6 & 18.1 & 29.7 & 32.1 \\
\hline 17 & $L-S R$ & 36.8 & 40.3 & 44.8 & 96.9 & 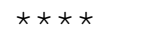 \\
\hline 17 & $E L-S$ & 20.7 & 22.6 & 24.7 & 39.4 & 42.6 \\
\hline 17 & EL01 & 15.1 & 16.8 & 18.6 & 32.4 & 35.4 \\
\hline 17 & EL02 & 29.9 & 32.2 & 34.8 & 52.1 & 56.2 \\
\hline 17 & EL03 & 13.4 & 14.9 & 16.7 & 30.4 & 33.3 \\
\hline 17 & ELO 4 & 12.5 & 14.0 & 15.7 & 29.1 & 32.0 \\
\hline 17 & SW2 & 23.5 & 25.1 & 26.8 & 39.8 & 42.7 \\
\hline 18 & SW1 & 15.8 & 17.2 & 18.8 & 30.4 & 32.7 \\
\hline 18 & $L-S R$ & 37.8 & 41.5 & 46.3 & 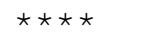 & 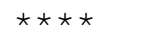 \\
\hline 18 & $E L-S$ & 21.4 & 23.3 & 25.4 & 40.2 & 43.4 \\
\hline 18 & EL01 & 15.8 & 17.5 & 19.3 & 33.2 & 36.3 \\
\hline 18 & EL02 & 31.6 & 33.9 & 36.5 & 54.2 & 58.4 \\
\hline
\end{tabular}


Table 26. Continued.

\begin{tabular}{|c|c|c|c|c|c|c|}
\hline Level & Zone & $\begin{array}{l}\text { sibility of } \\
30 . \mathrm{m} \\
(98 \mathrm{ft}) \\
\text { at Time } \\
\text { (min) }\end{array}$ & $\begin{array}{c}\text { Visibility of } \\
15 . \mathrm{m} \\
(49 \mathrm{ft}) \\
\text { at Time } \\
\text { (min) }\end{array}$ & $\begin{array}{c}\text { Visibility of } \\
8 . \mathrm{m} \\
(25 \mathrm{ft}) \\
\text { at Time } \\
\text { (min) }\end{array}$ & $\begin{array}{l}\text { FED of } \\
0.5 \text { at } \\
\text { Time } \\
\text { (min) }\end{array}$ & $\begin{array}{l}\text { FED of } \\
1.0 \text { at } \\
\text { Time } \\
\text { (min) }\end{array}$ \\
\hline 18 & ELO3 & 13.9 & 15.5 & 17.3 & 31.1 & 34.1 \\
\hline 18 & ELO 4 & 13.0 & 14.5 & 16.2 & 29.7 & 32.6 \\
\hline 18 & sw2 & 24.1 & 25.8 & 27.6 & 40.6 & 43.5 \\
\hline 19 & SW1 & 16.4 & 17.9 & 19.5 & 31.0 & 33.4 \\
\hline 19 & $L-S R$ & 39.0 & 42.8 & 48.0 & 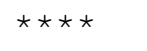 & 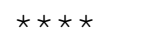 \\
\hline 19 & $E L-S$ & 22.0 & 23.9 & 26.1 & 41.0 & 44.2 \\
\hline 19 & EL01 & 16.5 & 18.1 & 19.9 & 34.0 & 37.1 \\
\hline 19 & EL02 & 33.2 & 35.7 & 38.3 & 56.2 & 60.5 \\
\hline 19 & ELO3 & 14.5 & 16.0 & 17.9 & 31.8 & 34.8 \\
\hline 19 & ELO 4 & 13.5 & 15.0 & 16.8 & 30.4 & 33.2 \\
\hline 19 & sw2 & 24.8 & 26.5 & 28.2 & 41.3 & 44.3 \\
\hline 20 & SW1 & 16.9 & 18.5 & 20.1 & 31.6 & 34.0 \\
\hline 20 & $L-S R$ & 40.3 & 44.4 & 50.0 & 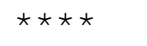 & 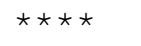 \\
\hline 20 & $E L-S$ & 22.6 & 24.6 & 26.7 & 41.7 & 45.0 \\
\hline 20 & EL01 & 17.0 & 18.7 & 20.6 & 34.8 & 37.9 \\
\hline 20 & ELO2 & 34.8 & 37.3 & 40.0 & 58.2 & 62.6 \\
\hline 20 & EL03 & 15.0 & 16.6 & 18.5 & 32.5 & 35.5 \\
\hline 20 & ELO 4 & 13.9 & 15.6 & 17.3 & 31.0 & 33.9 \\
\hline 20 & SW2 & 25.4 & 27.0 & 28.8 & 42.1 & 45.1 \\
\hline 21 & SW1 & 17.6 & 19.1 & 20.7 & 32.4 & 34.8 \\
\hline 21 & $L-S R$ & 42.2 & 46.7 & 53.2 & $\star \star \star \star \star$ & $\star \star \star \star \star$ \\
\hline 21 & $E L-S$ & 23.2 & 25.2 & 27.4 & 42.4 & 45.7 \\
\hline 21 & EL01 & 17.6 & 19.4 & 21.2 & 35.5 & 38.6 \\
\hline 21 & EL02 & 36.4 & 38.9 & 41.7 & 60.2 & 64.7 \\
\hline 21 & EL03 & 15.5 & 17.1 & 19.0 & 33.1 & 36.2 \\
\hline 21 & ELO 4 & 14.4 & 16.0 & 17.8 & 31.5 & 34.4 \\
\hline 21 & SW2 & 26.1 & 27.8 & 29.6 & 43.0 & 46.0 \\
\hline 22 & SW1 & 18.1 & 19.7 & 21.3 & 33.1 & 35.5 \\
\hline 22 & $L-S R$ & 44.9 & 50.4 & 58.8 & 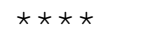 & 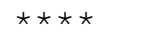 \\
\hline 22 & $E L-S$ & 23.8 & 25.8 & 27.9 & 43.1 & 46.4 \\
\hline 22 & EL01 & 18.2 & 19.9 & 21.8 & 36.2 & 39.3 \\
\hline 22 & EL02 & 37.9 & 40.6 & 43.3 & 62.1 & 66.7 \\
\hline 22 & EL03 & 16.0 & 17.7 & 19.6 & 33.7 & 36.8 \\
\hline 22 & ELO 4 & 14.9 & 16.5 & 18.3 & 32.1 & 35.0 \\
\hline 22 & SW2 & 26.8 & 28.5 & 30.2 & 43.8 & 47.0 \\
\hline 23 & SW1 & 18.7 & 20.3 & 21.9 & 33.7 & 36.2 \\
\hline 23 & $L-S R$ & 56.3 & 70.5 & 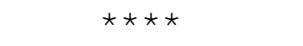 & 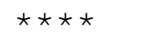 & 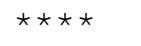 \\
\hline 23 & $E L-S$ & 24.3 & 26.4 & 28.5 & 43.7 & 47.1 \\
\hline 23 & EL01 & 18.7 & 20.5 & 22.4 & 36.9 & 40.0 \\
\hline 23 & EL02 & 39.5 & 42.1 & 44.9 & 64.0 & 68.7 \\
\hline
\end{tabular}


Table 26. Continued.

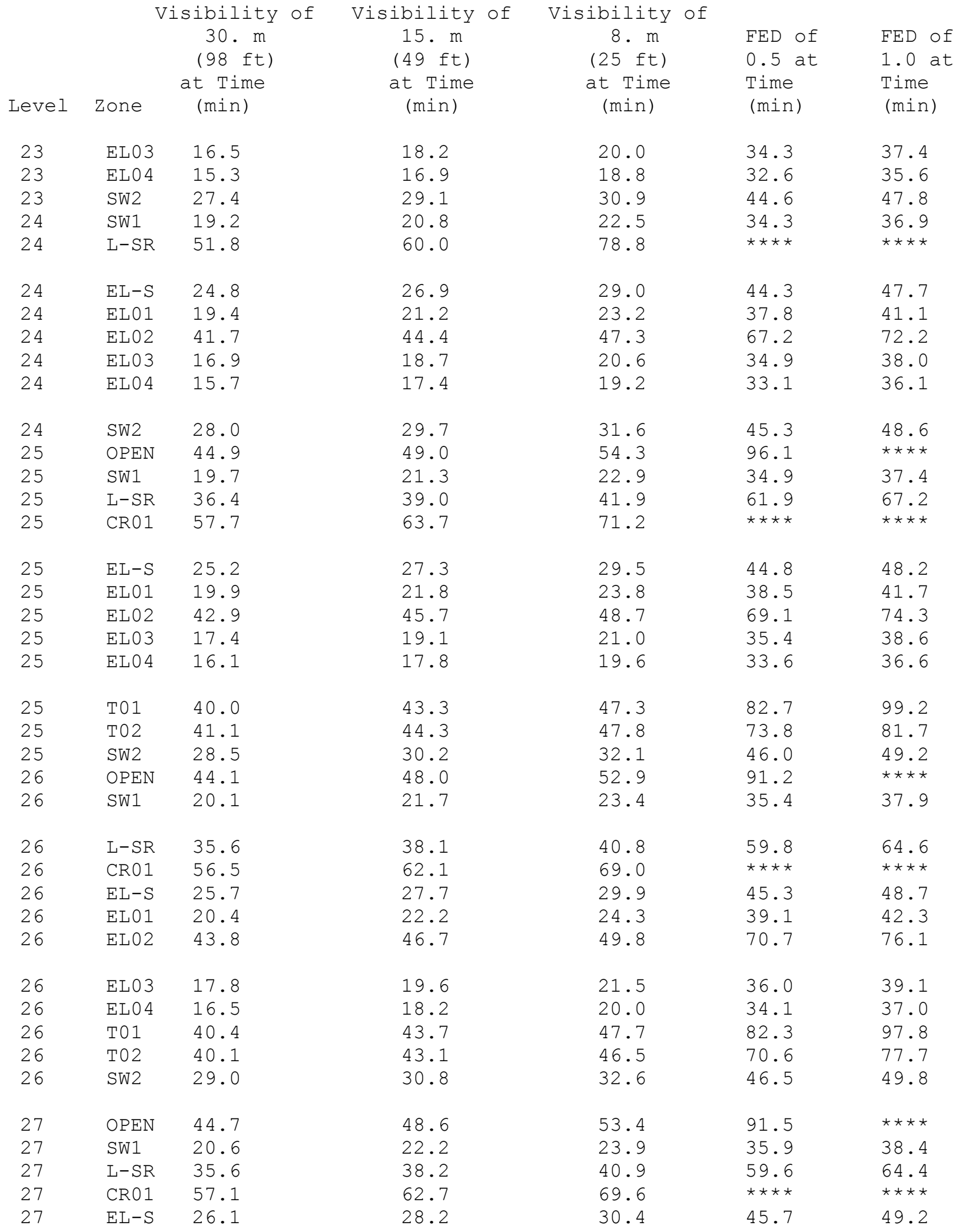


Table 26. Continued.

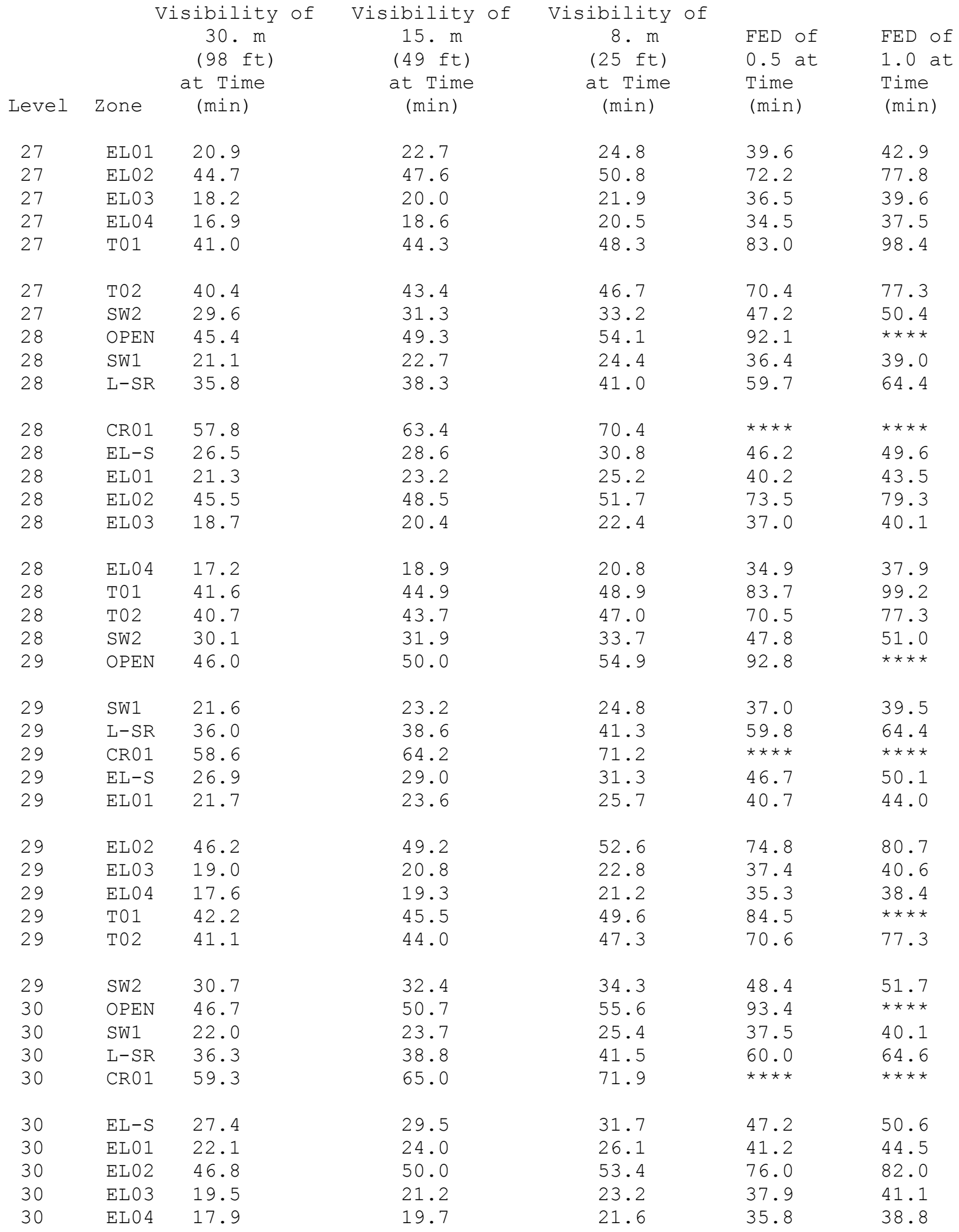


Table 26. Continued.

\begin{tabular}{|c|c|c|c|c|c|c|}
\hline Level & Zone & $\begin{array}{l}\text { sibility of } \\
30 . \mathrm{m} \\
(98 \mathrm{ft}) \\
\text { at Time } \\
\text { (min) }\end{array}$ & $\begin{array}{c}\text { Visibility of } \\
15 . \mathrm{m} \\
(49 \mathrm{ft}) \\
\text { at Time } \\
\text { (min) }\end{array}$ & $\begin{array}{c}\text { Visibility of } \\
8 . \mathrm{m} \\
(25 \mathrm{ft}) \\
\text { at Time } \\
\text { (min) }\end{array}$ & $\begin{array}{l}\text { FED of } \\
0.5 \text { at } \\
\text { Time } \\
\text { (min) }\end{array}$ & $\begin{array}{l}\text { FED of } \\
1.0 \text { at } \\
\text { Time } \\
\text { (min) }\end{array}$ \\
\hline 30 & T01 & 42.8 & 46.2 & 50.3 & 85.3 & $\star \star \star \star$ \\
\hline 30 & T02 & 41.5 & 44.4 & 47.7 & 70.8 & 77.4 \\
\hline 30 & SW2 & 31.2 & 33.0 & 34.9 & 49.1 & 52.3 \\
\hline 31 & OPEN & 47.4 & 51.3 & 56.3 & 94.0 & $\star \star \star \star \star$ \\
\hline 31 & SW1 & 22.6 & 24.2 & 25.9 & 38.1 & 40.7 \\
\hline 31 & $L-S R$ & 36.6 & 39.1 & 41.8 & 60.2 & 64.8 \\
\hline 31 & CR01 & 60.0 & 65.7 & 72.7 & 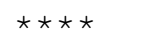 & 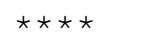 \\
\hline 31 & $E L-S$ & 27.8 & 29.9 & 32.2 & 47.6 & 51.1 \\
\hline 31 & EL01 & 22.5 & 24.4 & 26.5 & 41.6 & 45.0 \\
\hline 31 & ELO2 & 47.5 & 50.7 & 54.2 & 77.1 & 83.2 \\
\hline 31 & EL03 & 19.8 & 21.7 & 23.6 & 38.4 & 41.6 \\
\hline 31 & ELO 4 & 18.3 & 20.0 & 21.9 & 36.2 & 39.2 \\
\hline 31 & T01 & 43.4 & 46.8 & 50.9 & 86.1 & 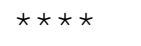 \\
\hline 31 & T02 & 41.9 & 44.8 & 48.0 & 71.0 & 77.6 \\
\hline 31 & SW2 & 31.8 & 33.6 & 35.5 & 49.7 & 53.0 \\
\hline 32 & OPEN & 48.0 & 52.0 & 57.0 & 94.5 & $\star \star \star \star \star$ \\
\hline 32 & SW1 & 23.1 & 24.7 & 26.4 & 38.7 & 41.3 \\
\hline 32 & $L-S R$ & 36.9 & 39.4 & 42.1 & 60.5 & 65.0 \\
\hline 32 & CR01 & 60.8 & 66.4 & 73.4 & $\star \star \star \star$ & $\star \star \star \star$ \\
\hline 32 & $E L-S$ & 28.3 & 30.4 & 32.6 & 48.1 & 51.6 \\
\hline 32 & EL01 & 22.9 & 24.8 & 26.9 & 42.1 & 45.4 \\
\hline 32 & EL02 & 48.1 & 51.3 & 54.9 & 78.1 & 84.4 \\
\hline 32 & EL03 & 20.2 & 22.0 & 24.0 & 38.8 & 42.1 \\
\hline 32 & ELO 4 & 18.7 & 20.4 & 22.3 & 36.6 & 39.6 \\
\hline 32 & T01 & 44.1 & 47.5 & 51.7 & 87.0 & 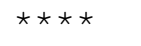 \\
\hline 32 & T02 & 42.3 & 45.2 & 48.5 & 71.3 & 77.8 \\
\hline 32 & SW2 & 32.4 & 34.1 & 36.0 & 50.3 & 53.7 \\
\hline 33 & OPEN & 48.6 & 52.6 & 57.6 & 94.9 & 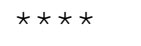 \\
\hline 33 & SW1 & 23.6 & 25.2 & 26.9 & 39.2 & 41.9 \\
\hline 33 & $L-S R$ & 37.3 & 39.8 & 42.4 & 60.7 & 65.3 \\
\hline 33 & CR01 & 61.4 & 67.1 & 74.1 & 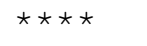 & 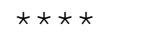 \\
\hline 33 & $E L-S$ & 28.8 & 30.8 & 33.1 & 48.6 & 52.1 \\
\hline 33 & EL01 & 23.2 & 25.2 & 27.3 & 42.5 & 45.9 \\
\hline 33 & EL02 & 48.7 & 51.9 & 55.6 & 79.1 & 85.4 \\
\hline 33 & EL03 & 20.6 & 22.4 & 24.4 & 39.3 & 42.5 \\
\hline 33 & ELO 4 & 19.0 & 20.8 & 22.7 & 37.0 & 40.1 \\
\hline 33 & T01 & 48.7 & 52.9 & 58.4 & 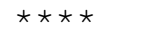 & 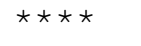 \\
\hline 33 & T02 & 42.8 & 45.7 & 48.9 & 71.7 & 78.1 \\
\hline 33 & SW2 & 32.9 & 34.7 & 36.7 & 51.0 & 54.4 \\
\hline 34 & OPEN & 49.4 & 53.4 & 58.4 & 95.7 & 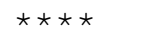 \\
\hline
\end{tabular}


Table 26. Continued.

\begin{tabular}{|c|c|c|c|c|c|c|}
\hline Level & Zone & $\begin{array}{l}\text { sibility of } \\
30 . \mathrm{m} \\
(98 \mathrm{ft}) \\
\text { at Time } \\
\text { (min) }\end{array}$ & $\begin{array}{c}\text { Visibility of } \\
15 . \mathrm{m} \\
(49 \mathrm{ft}) \\
\text { at Time } \\
\text { (min) }\end{array}$ & $\begin{array}{c}\text { Visibility of } \\
8 . \mathrm{m} \\
(25 \mathrm{ft}) \\
\text { at Time } \\
\text { (min) }\end{array}$ & $\begin{array}{l}\text { FED of } \\
0.5 \text { at } \\
\text { Time } \\
\text { (min) }\end{array}$ & $\begin{array}{l}\text { FED of } \\
1.0 \text { at } \\
\text { Time } \\
\text { (min) }\end{array}$ \\
\hline 34 & SW1 & 24.1 & 25.8 & 27.5 & 39.8 & 42.5 \\
\hline 34 & $L-S R$ & 37.6 & 40.1 & 42.8 & 61.1 & 65.6 \\
\hline 34 & CR01 & 62.3 & 67.9 & 74.9 & $\star \star \star \star$ & $\star \star \star \star$ \\
\hline 34 & $E L-S$ & 29.2 & 31.3 & 33.6 & 49.1 & 52.6 \\
\hline 34 & EL01 & 23.6 & 25.5 & 27.6 & 42.9 & 46.3 \\
\hline 34 & ELO2 & 49.3 & 52.6 & 56.2 & 80.0 & 86.5 \\
\hline 34 & ELO3 & 20.9 & 22.8 & 24.8 & 39.7 & 43.0 \\
\hline 34 & ELO 4 & 19.3 & 21.1 & 23.0 & 37.4 & 40.4 \\
\hline 34 & T01 & 49.4 & 53.8 & 59.3 & 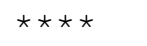 & 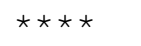 \\
\hline 34 & T02 & 43.3 & 46.2 & 49.4 & 72.1 & 78.5 \\
\hline 34 & sw2 & 33.5 & 35.3 & 37.3 & 51.7 & 55.1 \\
\hline 35 & OPEN & 50.3 & 54.4 & 59.4 & 96.9 & $\star \star \star \star *$ \\
\hline 35 & SW1 & 24.7 & 26.3 & 28.0 & 40.4 & 43.1 \\
\hline 35 & $L-S R$ & 38.0 & 40.5 & 43.2 & 61.5 & 66.0 \\
\hline 35 & $\mathrm{CR} 01$ & 63.3 & 69.0 & 76.1 & $\star \star \star \star$ & 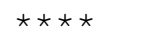 \\
\hline 35 & $E L-S$ & 29.7 & 31.8 & 34.0 & 49.6 & 53.1 \\
\hline 35 & EL01 & 23.9 & 25.9 & 28.0 & 43.3 & 46.7 \\
\hline 35 & ELO2 & 49.8 & 53.2 & 56.8 & 80.8 & 87.4 \\
\hline 35 & EL03 & 21.3 & 23.1 & 25.2 & 40.2 & 43.4 \\
\hline 35 & ELO 4 & 19.7 & 21.4 & 23.4 & 37.8 & 40.8 \\
\hline 35 & T01 & 50.4 & 54.8 & 60.4 & $\star \star \star \star \star$ & $\star \star \star \star \star$ \\
\hline 35 & T02 & 43.8 & 46.7 & 49.9 & 72.6 & 78.9 \\
\hline 35 & SW2 & 34.0 & 35.9 & 37.9 & 52.4 & 55.7 \\
\hline 36 & OPEN & 49.2 & 53.1 & 57.8 & 92.4 & $\star \star \star \star \star$ \\
\hline 36 & SW1 & 25.2 & 26.8 & 28.6 & 41.1 & 43.7 \\
\hline 36 & $L-S R$ & 38.5 & 41.0 & 43.7 & 62.0 & 66.5 \\
\hline 36 & CR01 & 61.7 & 67.1 & 73.6 & 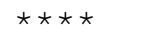 & 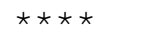 \\
\hline 36 & $E L-S$ & 30.1 & 32.3 & 34.5 & 50.2 & 53.6 \\
\hline 36 & EL01 & 24.2 & 26.2 & 28.3 & 43.6 & 47.0 \\
\hline 36 & ELO 2 & 50.3 & 53.7 & 57.4 & 81.6 & 88.3 \\
\hline 36 & EL03 & 21.7 & 23.5 & 25.6 & 40.6 & 43.9 \\
\hline 36 & ELO 4 & 19.9 & 21.8 & 23.7 & 38.1 & 41.2 \\
\hline 36 & T01 & 51.4 & 55.8 & 61.5 & 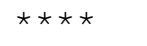 & 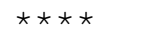 \\
\hline 36 & T02 & 44.5 & 47.4 & 50.6 & 73.2 & 79.6 \\
\hline 36 & SW2 & 34.7 & 36.5 & 38.5 & 53.1 & 56.4 \\
\hline 37 & OPEN & 47.5 & 51.1 & 55.4 & 87.1 & 98.5 \\
\hline 37 & SW1 & 25.8 & 27.4 & 29.1 & 41.7 & 44.3 \\
\hline 37 & $L-S R$ & 38.9 & 41.4 & 44.0 & 62.4 & 66.8 \\
\hline 37 & CR01 & 59.5 & 64.4 & 70.3 & 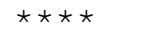 & 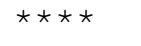 \\
\hline 37 & $E L-S$ & 30.6 & 32.8 & 35.0 & 50.7 & 54.2 \\
\hline
\end{tabular}


Table 26. Continued.

\begin{tabular}{|c|c|c|c|c|c|c|}
\hline Level & Zone & $\begin{array}{l}\text { sibility of } \\
30 . \mathrm{m} \\
(98 \mathrm{ft}) \\
\text { at Time } \\
\text { (min) }\end{array}$ & $\begin{array}{c}\text { Visibility of } \\
15 . \mathrm{m} \\
(49 \mathrm{ft}) \\
\text { at Time } \\
\text { (min) }\end{array}$ & $\begin{array}{c}\text { Visibility of } \\
8 . \mathrm{m} \\
(25 \mathrm{ft}) \\
\text { at Time } \\
\text { (min) }\end{array}$ & $\begin{array}{l}\text { FED of } \\
0.5 \text { at } \\
\text { Time } \\
\text { (min) }\end{array}$ & $\begin{array}{l}\text { FED of } \\
1.0 \text { at } \\
\text { Time } \\
\text { (min) }\end{array}$ \\
\hline 37 & EL01 & 24.6 & 26.5 & 28.6 & 44.0 & 47.4 \\
\hline 37 & ELO2 & 50.6 & 54.0 & 57.8 & 82.3 & 89.1 \\
\hline 37 & EL03 & 22.0 & 23.9 & 25.9 & 41.0 & 44.3 \\
\hline 37 & ELO 4 & 20.3 & 22.1 & 24.0 & 38.5 & 41.6 \\
\hline 37 & T01 & 51.6 & 56.0 & 61.5 & 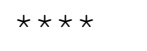 & 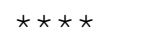 \\
\hline 37 & T02 & 44.9 & 47.8 & 51.0 & 73.6 & 79.9 \\
\hline 37 & SW2 & 35.2 & 37.1 & 39.1 & 53.7 & 57.2 \\
\hline 38 & OPEN & 46.2 & 49.7 & 53.7 & 83.2 & 93.4 \\
\hline 38 & SW1 & 26.3 & 28.0 & 29.7 & 42.3 & 45.0 \\
\hline 38 & $L-S R$ & 39.2 & 41.7 & 44.4 & 62.6 & 67.1 \\
\hline 38 & CR01 & 57.8 & 62.4 & 67.9 & 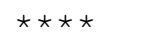 & 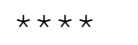 \\
\hline 38 & $E L-S$ & 31.1 & 33.3 & 35.5 & 51.2 & 54.7 \\
\hline 38 & EL01 & 24.9 & 26.8 & 28.9 & 44.3 & 47.7 \\
\hline 38 & ELO2 & 50.8 & 54.3 & 58.1 & 82.8 & 89.7 \\
\hline 38 & EL03 & 22.3 & 24.2 & 26.3 & 41.4 & 44.7 \\
\hline 38 & ELO 4 & 20.6 & 22.4 & 24.4 & 38.9 & 42.0 \\
\hline 38 & T01 & 51.4 & 55.5 & 60.6 & 98.3 & $\star \star \star \star$ \\
\hline 38 & T02 & 45.1 & 48.0 & 51.2 & 73.6 & 79.9 \\
\hline 38 & SW2 & 35.8 & 37.7 & 39.7 & 54.4 & 57.9 \\
\hline 39 & OPEN & 44.9 & 48.2 & 52.0 & 79.5 & 88.6 \\
\hline 39 & SW1 & 26.9 & 28.6 & 30.3 & 43.0 & 45.6 \\
\hline 39 & $L-S R$ & 39.5 & 41.9 & 44.6 & 62.7 & 67.1 \\
\hline 39 & CR01 & 56.3 & 60.6 & 65.6 & 99.5 & 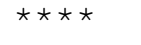 \\
\hline 39 & $E L-S$ & 31.6 & 33.8 & 36.0 & 51.8 & 55.3 \\
\hline 39 & EL01 & 25.2 & 27.2 & 29.3 & 44.7 & 48.1 \\
\hline 39 & EL02 & 50.9 & 54.4 & 58.3 & 83.2 & 90.2 \\
\hline 39 & EL03 & 22.7 & 24.6 & 26.7 & 41.8 & 45.1 \\
\hline 39 & ELO 4 & 20.9 & 22.7 & 24.7 & 39.2 & 42.3 \\
\hline 39 & T01 & 50.5 & 54.4 & 59.0 & 94.0 & 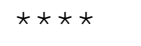 \\
\hline 39 & T02 & 45.0 & 47.9 & 51.1 & 73.2 & 79.3 \\
\hline 39 & SW2 & 36.4 & 38.3 & 40.4 & 55.2 & 58.6 \\
\hline 40 & $\mathrm{MECH}$ & 44.3 & 47.5 & 51.0 & 77.3 & 85.8 \\
\hline 40 & SW1 & 27.5 & 29.1 & 30.9 & 43.6 & 46.3 \\
\hline 40 & $L-S R$ & 39.7 & 42.2 & 44.8 & 62.8 & 67.2 \\
\hline 40 & CR01 & 55.5 & 59.6 & 64.4 & 96.9 & $\star \star \star \star \star$ \\
\hline 40 & $\mathrm{EL}-\mathrm{S}$ & 32.1 & 34.3 & 36.6 & 52.3 & 55.9 \\
\hline 40 & EL01 & 25.6 & 27.5 & 29.7 & 45.0 & 48.5 \\
\hline 40 & EL02 & 51.1 & 54.6 & 58.5 & 83.6 & 90.6 \\
\hline 40 & EL03 & 23.0 & 24.9 & 27.0 & 42.2 & 45.5 \\
\hline 40 & ELO 4 & 21.2 & 23.0 & 25.0 & 39.6 & 42.7 \\
\hline
\end{tabular}


Table 26. Continued.

\begin{tabular}{|c|c|c|c|c|c|c|}
\hline Level & Zone & $\begin{array}{l}\text { sibility of } \\
30 . \mathrm{m} \\
(98 \mathrm{ft}) \\
\text { at Time } \\
\text { (min) }\end{array}$ & $\begin{array}{c}\text { Visibility of } \\
15 . \mathrm{m} \\
(49 \mathrm{ft}) \\
\text { at Time } \\
\text { (min) }\end{array}$ & $\begin{array}{c}\text { Visibility of } \\
8 . \mathrm{m} \\
(25 \mathrm{ft}) \\
\text { at Time } \\
\text { (min) }\end{array}$ & $\begin{array}{l}\text { FED of } \\
0.5 \text { at } \\
\text { Time } \\
\text { (min) }\end{array}$ & $\begin{array}{l}\text { FED of } \\
1.0 \text { at } \\
\text { Time } \\
\text { (min) }\end{array}$ \\
\hline 40 & T01 & 50.1 & 53.8 & 58.1 & 91.2 & $\star \star \star \star \star$ \\
\hline 40 & T02 & 45.1 & 47.9 & 51.0 & 72.9 & 78.9 \\
\hline 40 & SW2 & 37.0 & 38.9 & 41.0 & 55.9 & 59.3 \\
\hline 41 & OPEN & 44.4 & 47.6 & 51.1 & 77.1 & 85.4 \\
\hline 41 & SW1 & 28.0 & 29.8 & 31.5 & 44.3 & 47.0 \\
\hline 41 & $L-S R$ & 40.1 & 42.6 & 45.2 & 63.2 & 67.6 \\
\hline 41 & CR01 & 55.6 & 59.7 & 64.5 & 96.6 & $\star \star \star \star \star$ \\
\hline 41 & $E L-S$ & 32.7 & 34.8 & 37.1 & 52.9 & 56.4 \\
\hline 41 & EL01 & 25.9 & 27.9 & 30.0 & 45.4 & 48.9 \\
\hline 41 & ELO2 & 51.4 & 54.9 & 58.8 & 84.0 & 91.1 \\
\hline 41 & EL03 & 23.3 & 25.2 & 27.4 & 42.5 & 46.0 \\
\hline 41 & ELO 4 & 21.5 & 23.3 & 25.3 & 39.9 & 43.1 \\
\hline 41 & T01 & 50.5 & 54.1 & 58.4 & 91.0 & 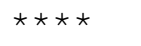 \\
\hline 41 & T02 & 45.5 & 48.4 & 51.5 & 73.3 & 79.2 \\
\hline 41 & SW2 & 37.6 & 39.6 & 41.6 & 56.6 & 60.1 \\
\hline 42 & OPEN & 44.7 & 47.9 & 51.4 & 77.3 & 85.4 \\
\hline 42 & SW1 & 28.7 & 30.4 & 32.1 & 45.0 & 47.7 \\
\hline 42 & $L-S R$ & 40.6 & 43.1 & 45.7 & 63.7 & 68.1 \\
\hline 42 & CR01 & 55.9 & 60.0 & 64.8 & 96.7 & $\star \star \star \star$ \\
\hline 42 & $E L-S$ & 33.2 & 35.4 & 37.7 & 53.5 & 57.1 \\
\hline 42 & EL01 & 26.3 & 28.2 & 30.4 & 45.8 & 49.3 \\
\hline 42 & EL02 & 51.9 & 55.4 & 59.3 & 84.5 & 91.6 \\
\hline 42 & ELO3 & 23.6 & 25.6 & 27.7 & 42.9 & 46.3 \\
\hline 42 & ELO 4 & 21.8 & 23.6 & 25.6 & 40.2 & 43.4 \\
\hline 42 & T01 & 51.0 & 54.7 & 59.0 & 91.3 & 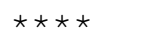 \\
\hline 42 & T02 & 46.0 & 48.9 & 52.0 & 73.7 & 79.6 \\
\hline 42 & SW2 & 38.2 & 40.2 & 42.3 & 57.3 & 60.8 \\
\hline 43 & OPEN & 42.9 & 45.9 & 49.2 & 72.8 & 79.8 \\
\hline 43 & SW1 & 29.3 & 31.0 & 32.8 & 45.7 & 48.4 \\
\hline 43 & $L-S R$ & 40.2 & 42.7 & 45.3 & 62.9 & 67.0 \\
\hline 43 & $E L-S$ & 33.8 & 35.9 & 38.2 & 54.1 & 57.7 \\
\hline 43 & EL01 & 26.7 & 28.6 & 30.8 & 46.2 & 49.7 \\
\hline 43 & EL02 & 52.4 & 55.9 & 59.8 & 85.0 & 92.1 \\
\hline 43 & EL03 & 24.0 & 26.0 & 28.1 & 43.5 & 46.9 \\
\hline 43 & ELO 4 & 22.1 & 24.0 & 26.0 & 40.7 & 43.9 \\
\hline 43 & T01 & 49.3 & 52.6 & 56.4 & 85.6 & 95.6 \\
\hline 43 & T02 & 45.1 & 47.9 & 50.8 & 71.7 & 77.2 \\
\hline 43 & SW2 & 38.9 & 40.8 & 42.9 & 58.1 & 61.6 \\
\hline 44 & OPEN & 49.5 & 52.6 & 56.2 & 83.6 & 92.6 \\
\hline 44 & SW1 & 29.9 & 31.7 & 33.5 & 46.4 & 49.2 \\
\hline
\end{tabular}


Table 26. Continued.

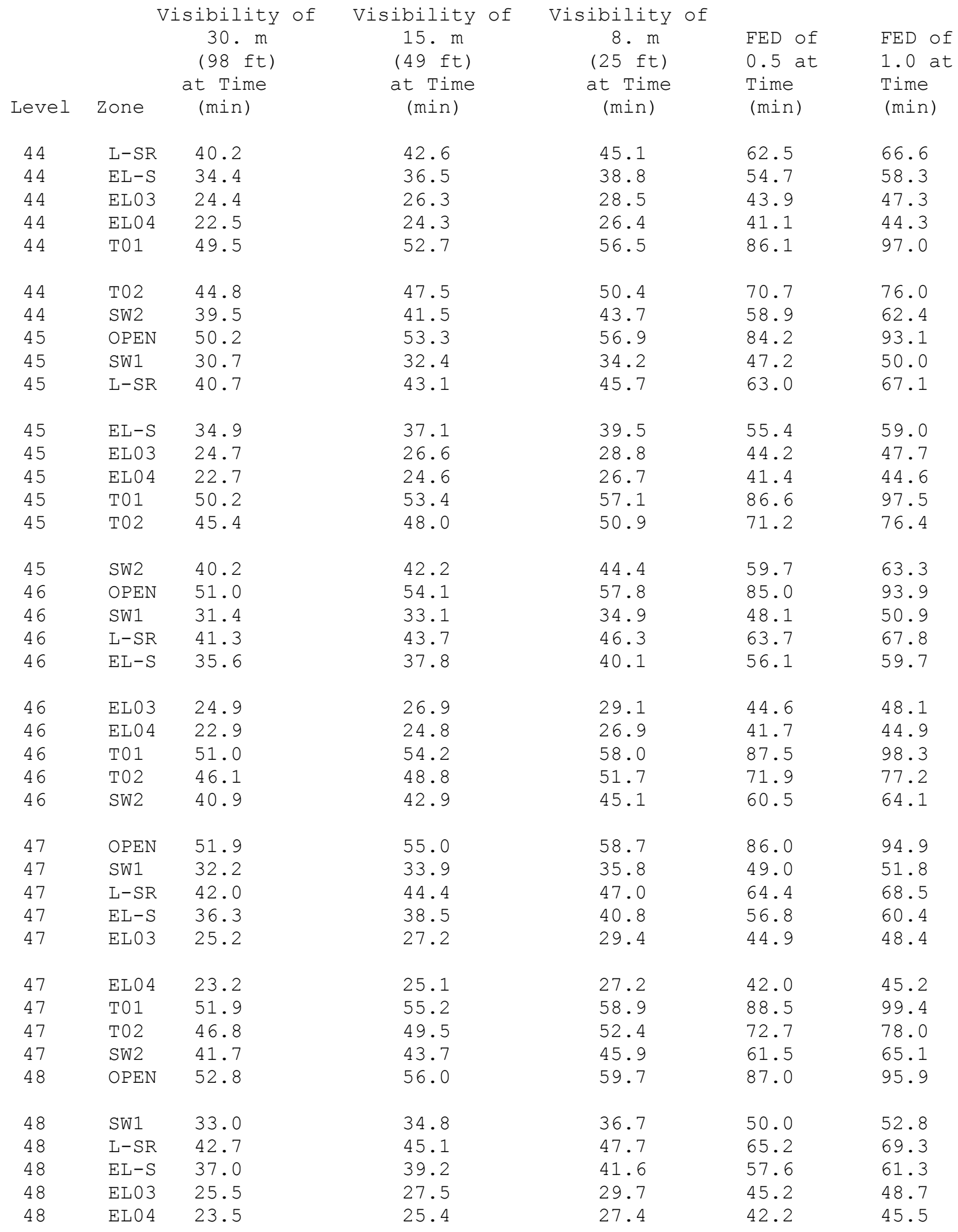


Table 26. Continued.

\begin{tabular}{|c|c|c|c|c|c|c|}
\hline Level & Zone & $\begin{array}{l}\text { sibility of } \\
30 . \mathrm{m} \\
(98 \mathrm{ft}) \\
\text { at Time } \\
\text { (min) }\end{array}$ & $\begin{array}{c}\text { Visibility of } \\
15 . \mathrm{m} \\
(49 \mathrm{ft}) \\
\text { at Time } \\
\text { (min) }\end{array}$ & $\begin{array}{c}\text { Visibility of } \\
8 . \mathrm{m} \\
(25 \mathrm{ft}) \\
\text { at Time } \\
\text { (min) }\end{array}$ & $\begin{array}{l}\text { FED of } \\
0.5 \text { at } \\
\text { Time } \\
\text { (min) }\end{array}$ & $\begin{array}{l}\text { FED of } \\
1.0 \text { at } \\
\text { Time } \\
\text { (min) }\end{array}$ \\
\hline 48 & T01 & 52.9 & 56.2 & 60.0 & 89.7 & $\star \star \star \star$ \\
\hline 48 & T02 & 47.6 & 50.3 & 53.2 & 73.5 & 78.8 \\
\hline 48 & SW2 & 42.5 & 44.6 & 46.8 & 62.4 & 66.1 \\
\hline 49 & OPEN & 52.0 & 55.4 & 59.3 & 86.7 & 95.6 \\
\hline 49 & SW1 & 34.0 & 35.8 & 37.6 & 51.0 & 53.9 \\
\hline 49 & $L-S R$ & 43.5 & 45.9 & 48.5 & 66.1 & 70.2 \\
\hline 49 & $E L-S$ & 37.7 & 39.9 & 42.3 & 58.5 & 62.1 \\
\hline 49 & EL03 & 25.7 & 27.7 & 29.9 & 45.5 & 49.0 \\
\hline 49 & ELO 4 & 23.7 & 25.6 & 27.7 & 42.5 & 45.7 \\
\hline 49 & T01 & 46.6 & 50.0 & 53.9 & 81.8 & 91.0 \\
\hline 49 & T02 & 48.5 & 51.2 & 54.1 & 74.5 & 79.8 \\
\hline 49 & SW2 & 43.3 & 45.5 & 47.7 & 63.5 & 67.1 \\
\hline 50 & OPEN & 50.5 & 54.1 & 58.2 & 85.9 & 94.6 \\
\hline 50 & SW1 & 35.0 & 36.8 & 38.7 & 52.2 & 55.2 \\
\hline 50 & $L-S R$ & 44.3 & 46.8 & 49.4 & 67.0 & 71.1 \\
\hline 50 & $E L-S$ & 38.6 & 40.8 & 43.1 & 59.4 & 63.0 \\
\hline 50 & EL03 & 26.0 & 28.0 & 30.2 & 45.8 & 49.3 \\
\hline 50 & EL0 4 & 23.9 & 25.8 & 27.9 & 42.7 & 46.0 \\
\hline 50 & T01 & 43.0 & 46.2 & 49.8 & 75.6 & 83.6 \\
\hline 50 & T02 & 49.4 & 52.1 & 55.0 & 75.5 & 80.8 \\
\hline 50 & SW2 & 44.2 & 46.4 & 48.7 & 64.6 & 68.3 \\
\hline 51 & OPEN & 49.8 & 53.6 & 57.7 & 85.7 & 94.4 \\
\hline 51 & SW1 & 36.1 & 37.9 & 39.9 & 53.5 & 56.5 \\
\hline 51 & $L-S R$ & 45.2 & 47.7 & 50.3 & 68.0 & 72.1 \\
\hline 51 & $E L-S$ & 39.4 & 41.7 & 44.0 & 60.3 & 64.0 \\
\hline 51 & EL03 & 26.2 & 28.3 & 30.5 & 46.1 & 49.6 \\
\hline 51 & EL0 4 & 24.1 & 26.0 & 28.1 & 43.0 & 46.3 \\
\hline 51 & T01 & 41.8 & 44.9 & 48.4 & 73.2 & 80.8 \\
\hline 51 & T02 & 50.4 & 53.1 & 56.1 & 76.6 & 81.9 \\
\hline 51 & SW2 & 45.2 & 47.4 & 49.7 & 65.8 & 69.5 \\
\hline 52 & OPEN & 49.6 & 53.4 & 57.7 & 86.0 & 94.8 \\
\hline 52 & SW1 & 37.4 & 39.2 & 41.2 & 55.0 & 58.0 \\
\hline 52 & $L-S R$ & 46.1 & 48.6 & 51.3 & 69.0 & 73.2 \\
\hline 52 & $E L-S$ & 40.4 & 42.6 & 45.0 & 61.4 & 65.1 \\
\hline 52 & EL03 & 26.5 & 28.5 & 30.7 & 46.3 & 49.9 \\
\hline 52 & EL0 4 & 24.4 & 26.3 & 28.4 & 43.2 & 46.5 \\
\hline 52 & T01 & 41.4 & 44.4 & 47.8 & 72.1 & 79.5 \\
\hline 52 & T02 & 51.4 & 54.2 & 57.2 & 77.7 & 83.1 \\
\hline 52 & SW2 & 46.3 & 48.5 & 50.8 & 67.1 & 70.8 \\
\hline 53 & OPEN & 49.6 & 53.5 & 57.9 & 86.8 & 95.6 \\
\hline
\end{tabular}


Table 26. Continued.

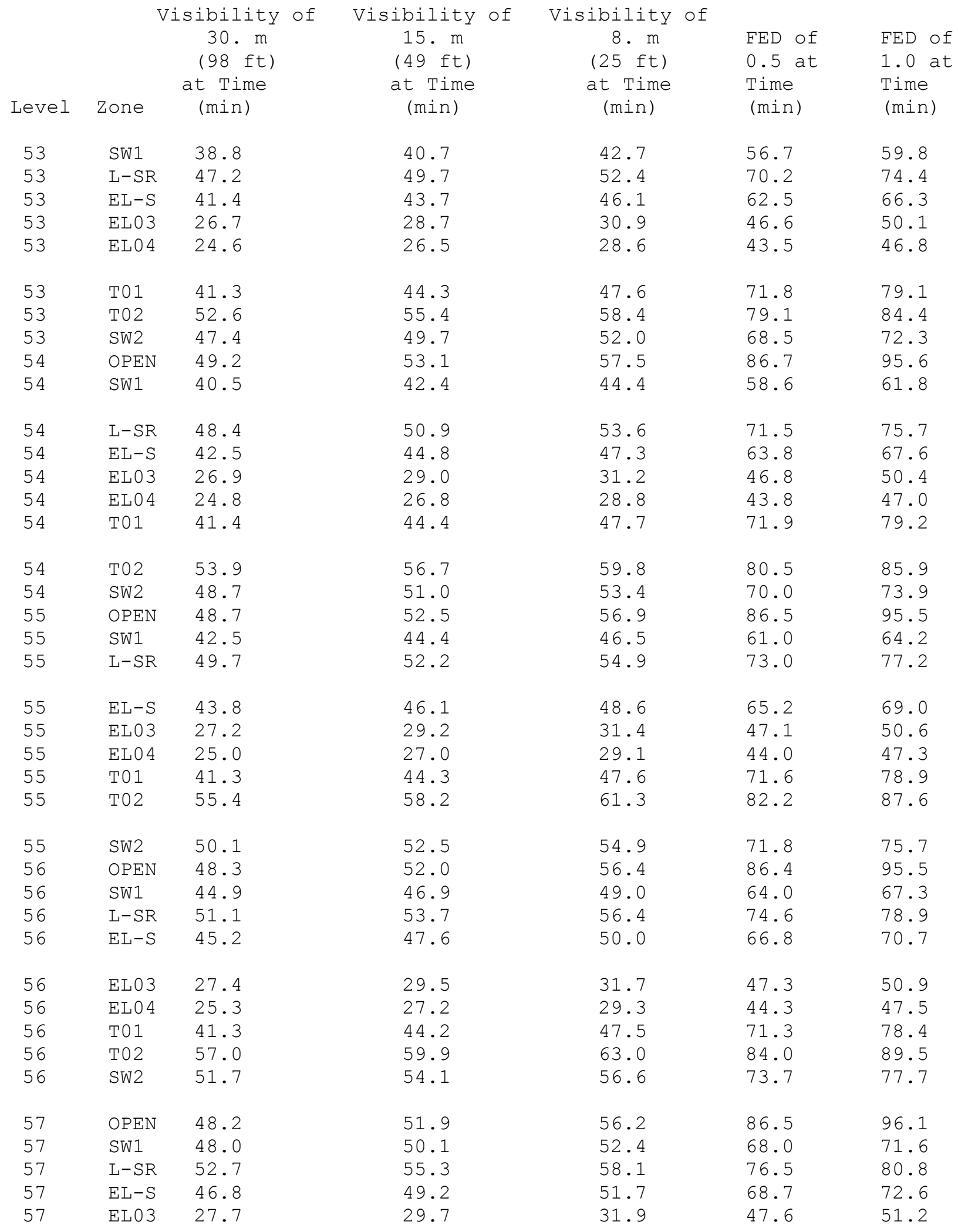


Table 26. Continued.

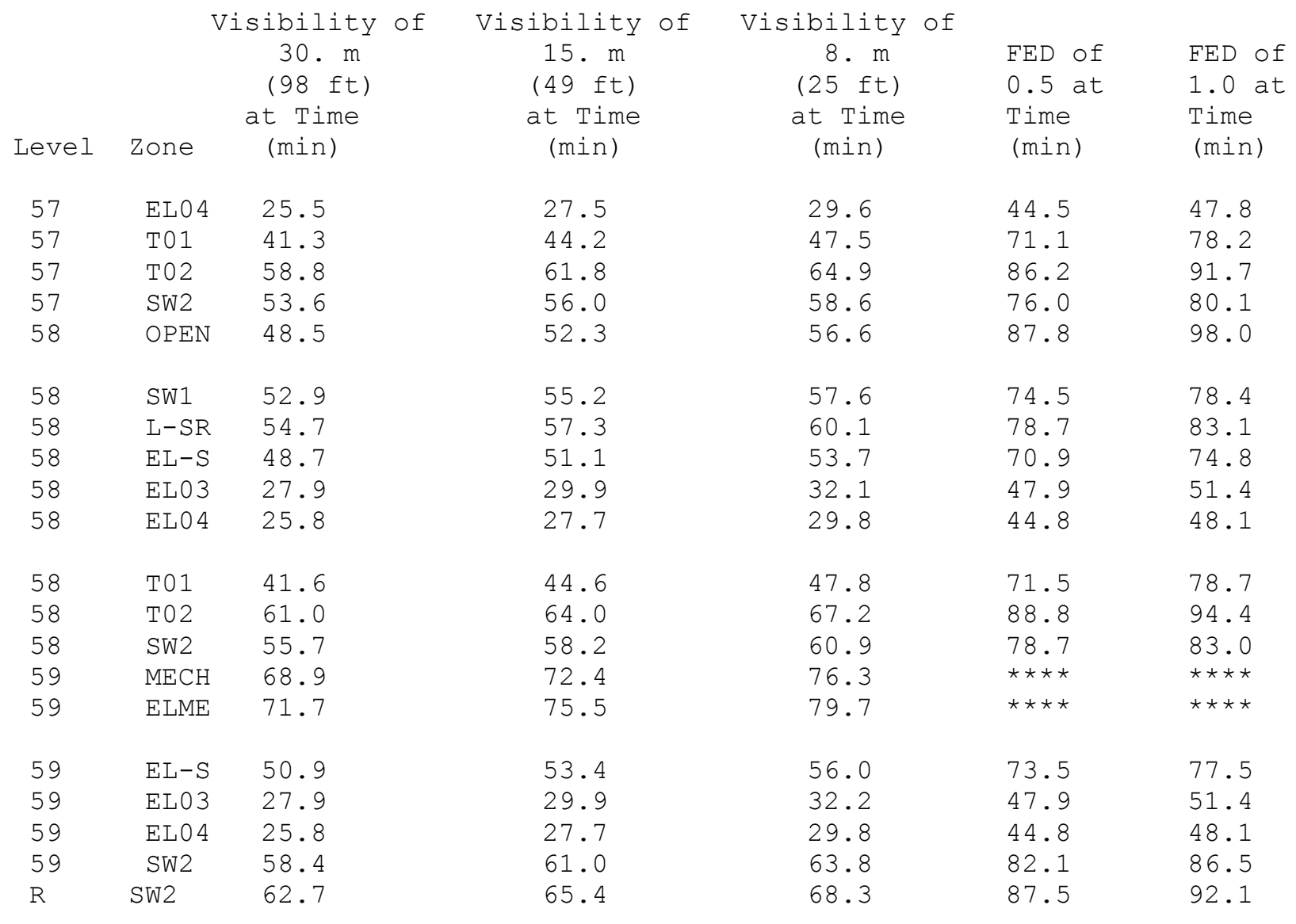


Table 27. Results of Tenability Analysis for Scenario 27.

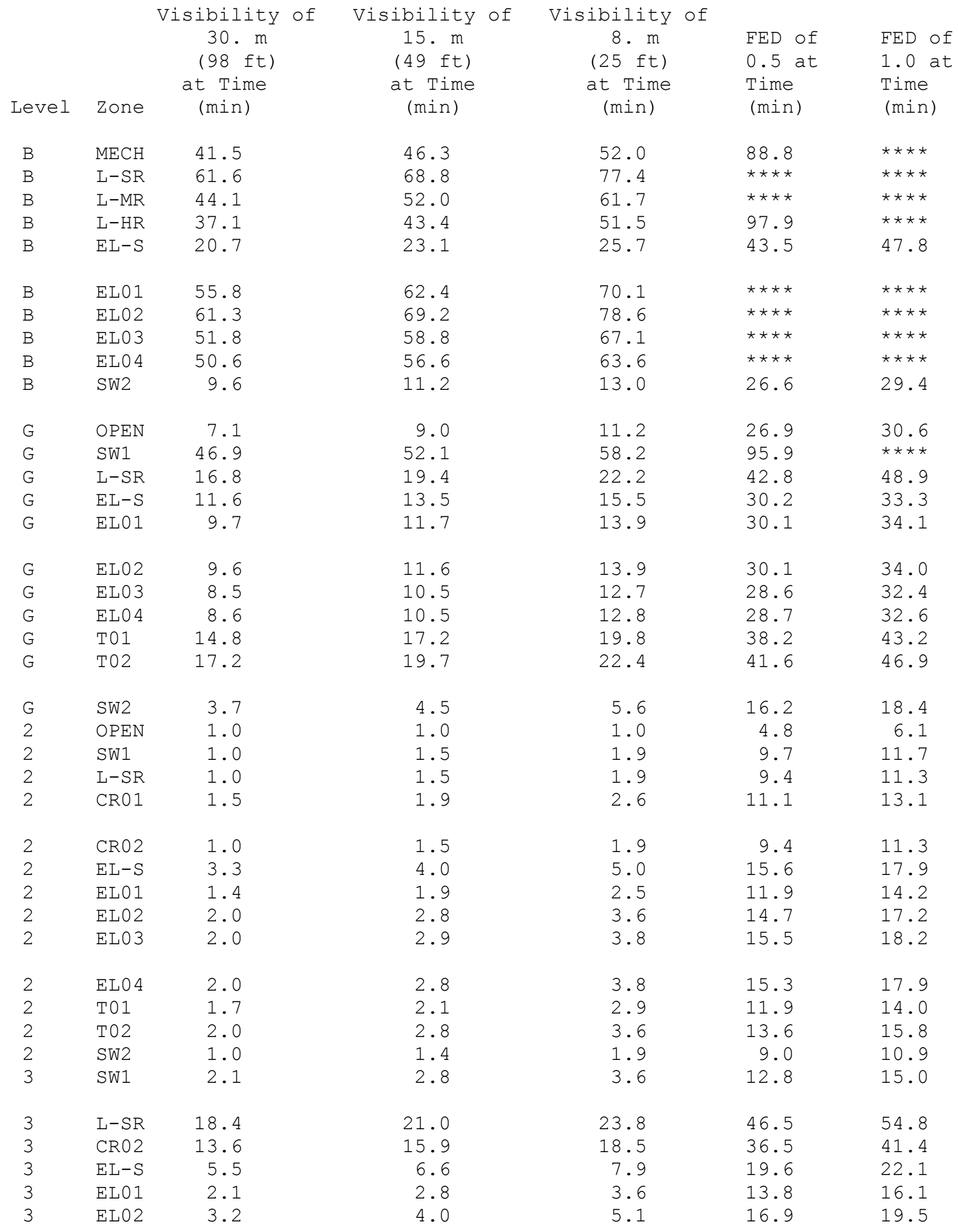


Table 27. Continued.

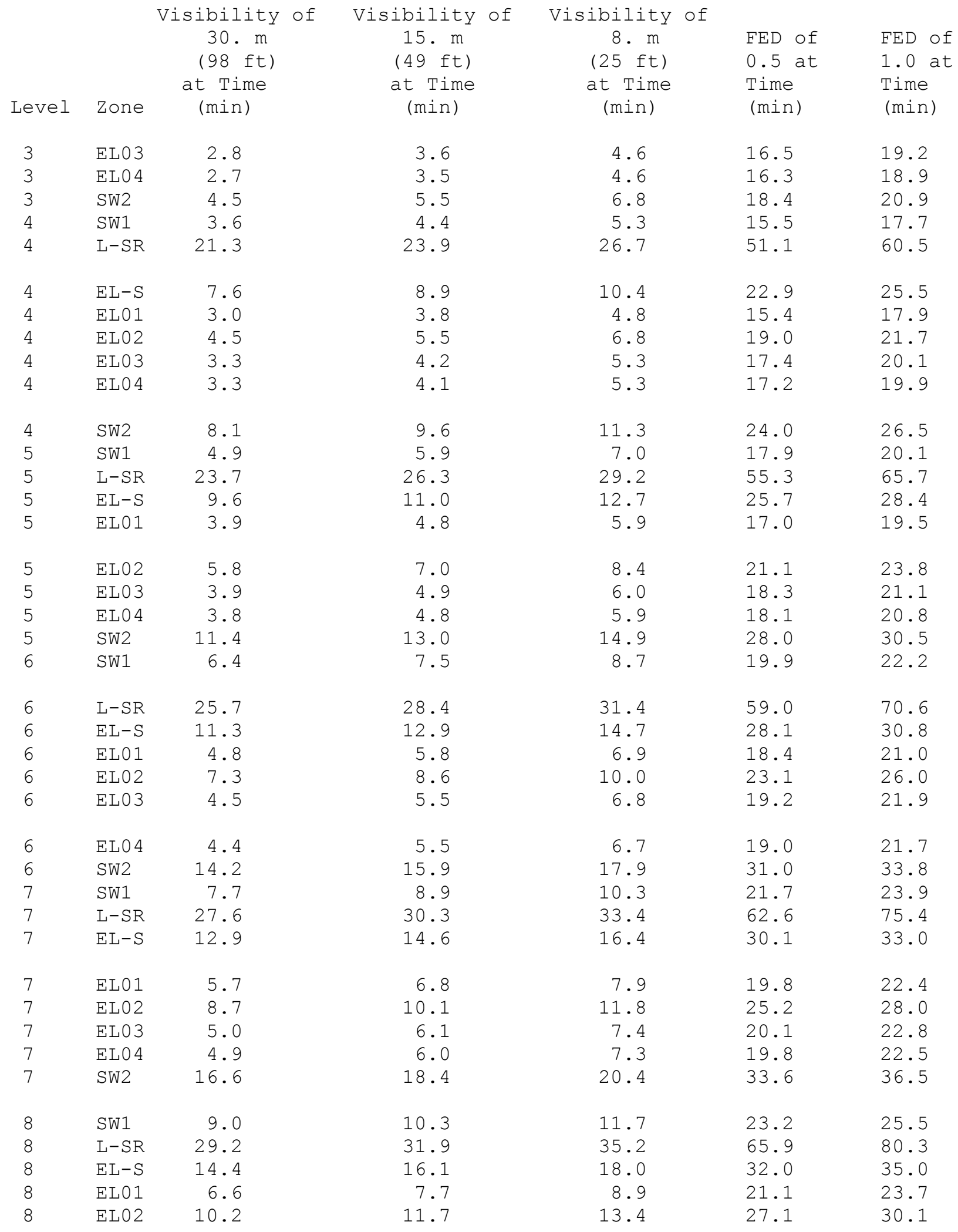


Table 27. Continued.

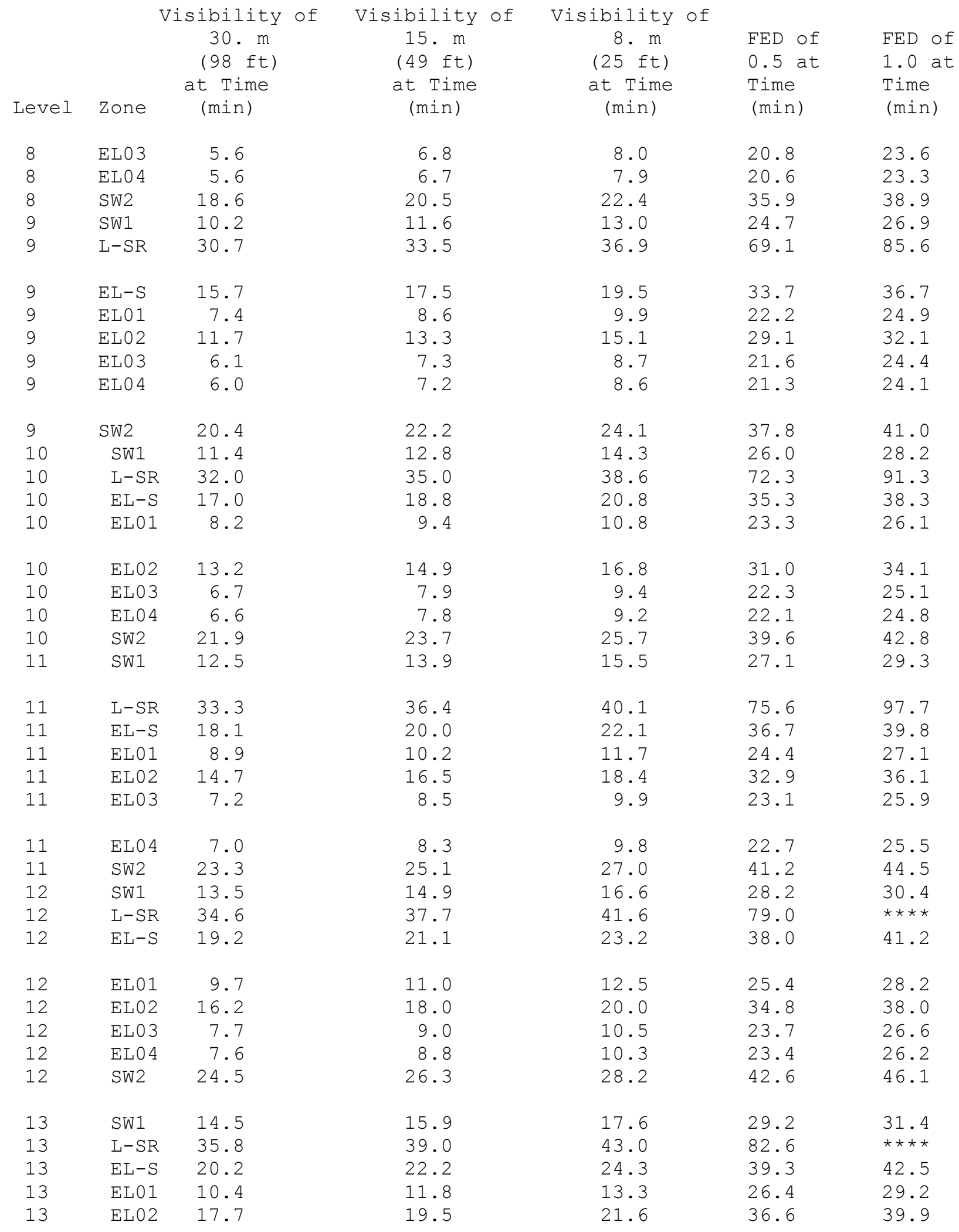


Table 27. Continued.

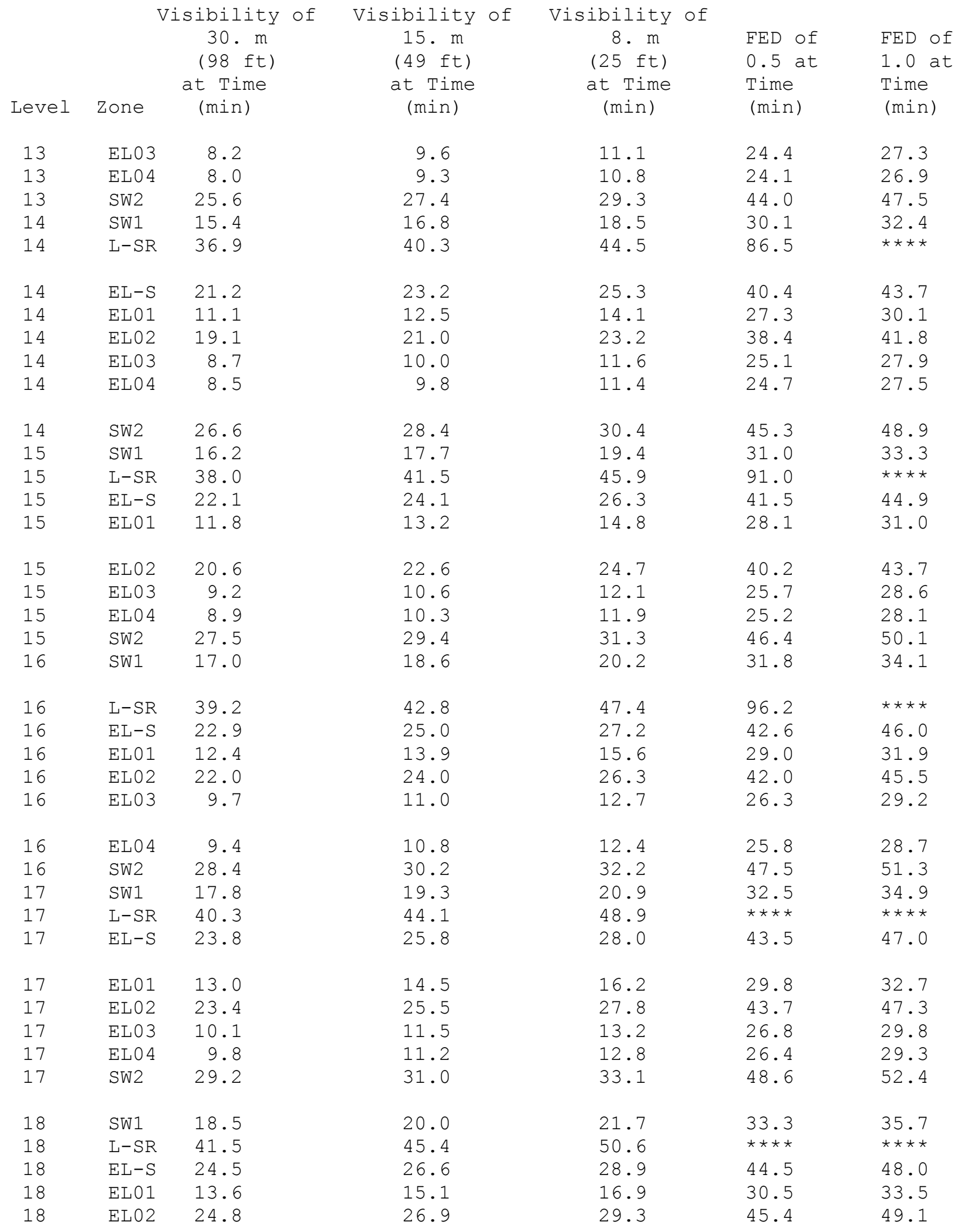


Table 27. Continued.

\begin{tabular}{|c|c|c|c|c|c|c|}
\hline Level & Zone & $\begin{array}{l}\text { sibility of } \\
30 . \mathrm{m} \\
(98 \mathrm{ft}) \\
\text { at Time } \\
\text { (min) }\end{array}$ & $\begin{array}{c}\text { Visibility of } \\
15 . \mathrm{m} \\
(49 \mathrm{ft}) \\
\text { at Time } \\
\text { (min) }\end{array}$ & $\begin{array}{c}\text { Visibility of } \\
8 . \mathrm{m} \\
(25 \mathrm{ft}) \\
\text { at Time } \\
\text { (min) }\end{array}$ & $\begin{array}{l}\text { FED of } \\
0.5 \text { at } \\
\text { Time } \\
\text { (min) }\end{array}$ & $\begin{array}{l}\text { FED of } \\
1.0 \text { at } \\
\text { Time } \\
\text { (min) }\end{array}$ \\
\hline 18 & ELO3 & 10.6 & 12.0 & 13.7 & 27.4 & 30.4 \\
\hline 18 & ELO 4 & 10.2 & 11.7 & 13.3 & 26.9 & 29.8 \\
\hline 18 & sw2 & 29.9 & 31.8 & 33.9 & 49.5 & 53.5 \\
\hline 19 & SW1 & 19.2 & 20.7 & 22.3 & 34.0 & 36.4 \\
\hline 19 & $L-S R$ & 42.8 & 46.9 & 52.5 & 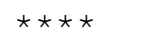 & 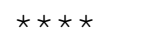 \\
\hline 19 & $E L-S$ & 25.3 & 27.4 & 29.7 & 45.4 & 48.9 \\
\hline 19 & EL01 & 14.2 & 15.8 & 17.5 & 31.3 & 34.2 \\
\hline 19 & EL02 & 26.2 & 28.4 & 30.7 & 47.1 & 50.9 \\
\hline 19 & ELO3 & 10.9 & 12.5 & 14.1 & 28.0 & 30.9 \\
\hline 19 & ELO 4 & 10.7 & 12.1 & 13.8 & 27.4 & 30.4 \\
\hline 19 & sw2 & 30.7 & 32.6 & 34.7 & 50.5 & 54.5 \\
\hline 20 & SW1 & 19.8 & 21.4 & 22.9 & 34.6 & 37.1 \\
\hline 20 & $L-S R$ & 44.3 & 48.7 & 54.8 & 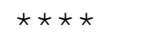 & 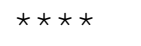 \\
\hline 20 & $E L-S$ & 25.9 & 28.1 & 30.4 & 46.2 & 49.8 \\
\hline 20 & EL01 & 14.8 & 16.4 & 18.1 & 32.0 & 35.0 \\
\hline 20 & ELO2 & 27.6 & 29.8 & 32.2 & 48.8 & 52.6 \\
\hline 20 & EL03 & 11.4 & 12.9 & 14.6 & 28.5 & 31.5 \\
\hline 20 & ELO 4 & 11.0 & 12.5 & 14.2 & 28.0 & 30.9 \\
\hline 20 & SW2 & 31.4 & 33.3 & 35.4 & 51.3 & 55.4 \\
\hline 21 & SW1 & 20.5 & 22.0 & 23.7 & 35.5 & 38.0 \\
\hline 21 & $L-S R$ & 46.4 & 51.2 & 58.2 & $\star \star \star \star \star$ & $\star \star \star \star \star$ \\
\hline 21 & $E L-S$ & 26.7 & 28.8 & 31.1 & 47.0 & 50.6 \\
\hline 21 & EL01 & 15.3 & 16.9 & 18.7 & 32.7 & 35.7 \\
\hline 21 & EL02 & 28.9 & 31.2 & 33.6 & 50.4 & 54.4 \\
\hline 21 & EL03 & 11.8 & 13.3 & 15.0 & 29.0 & 32.0 \\
\hline 21 & ELO 4 & 11.4 & 12.9 & 14.6 & 28.4 & 31.4 \\
\hline 21 & SW2 & 32.2 & 34.1 & 36.2 & 52.4 & 56.6 \\
\hline 22 & SW1 & 21.1 & 22.7 & 24.3 & 36.3 & 38.8 \\
\hline 22 & $L-S R$ & 49.5 & 55.4 & 64.4 & 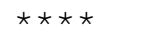 & 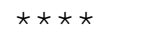 \\
\hline 22 & $E L-S$ & 27.3 & 29.5 & 31.8 & 47.8 & 51.4 \\
\hline 22 & EL01 & 15.8 & 17.5 & 19.3 & 33.3 & 36.4 \\
\hline 22 & EL02 & 30.3 & 32.6 & 35.0 & 52.1 & 56.1 \\
\hline 22 & EL03 & 12.2 & 13.7 & 15.5 & 29.5 & 32.5 \\
\hline 22 & ELO 4 & 11.8 & 13.3 & 15.0 & 28.9 & 31.9 \\
\hline 22 & SW2 & 32.9 & 34.9 & 37.1 & 53.5 & 57.7 \\
\hline 23 & SW1 & 21.8 & 23.4 & 25.0 & 37.0 & 39.6 \\
\hline 23 & $E L-S$ & 27.9 & 30.1 & 32.4 & 48.5 & 52.2 \\
\hline 23 & EL01 & 16.4 & 18.0 & 19.9 & 34.0 & 37.0 \\
\hline 23 & EL02 & 31.6 & 33.9 & 36.5 & 53.7 & 57.8 \\
\hline 23 & EL03 & 12.6 & 14.1 & 15.9 & 30.0 & 33.1 \\
\hline
\end{tabular}


Table 27. Continued.

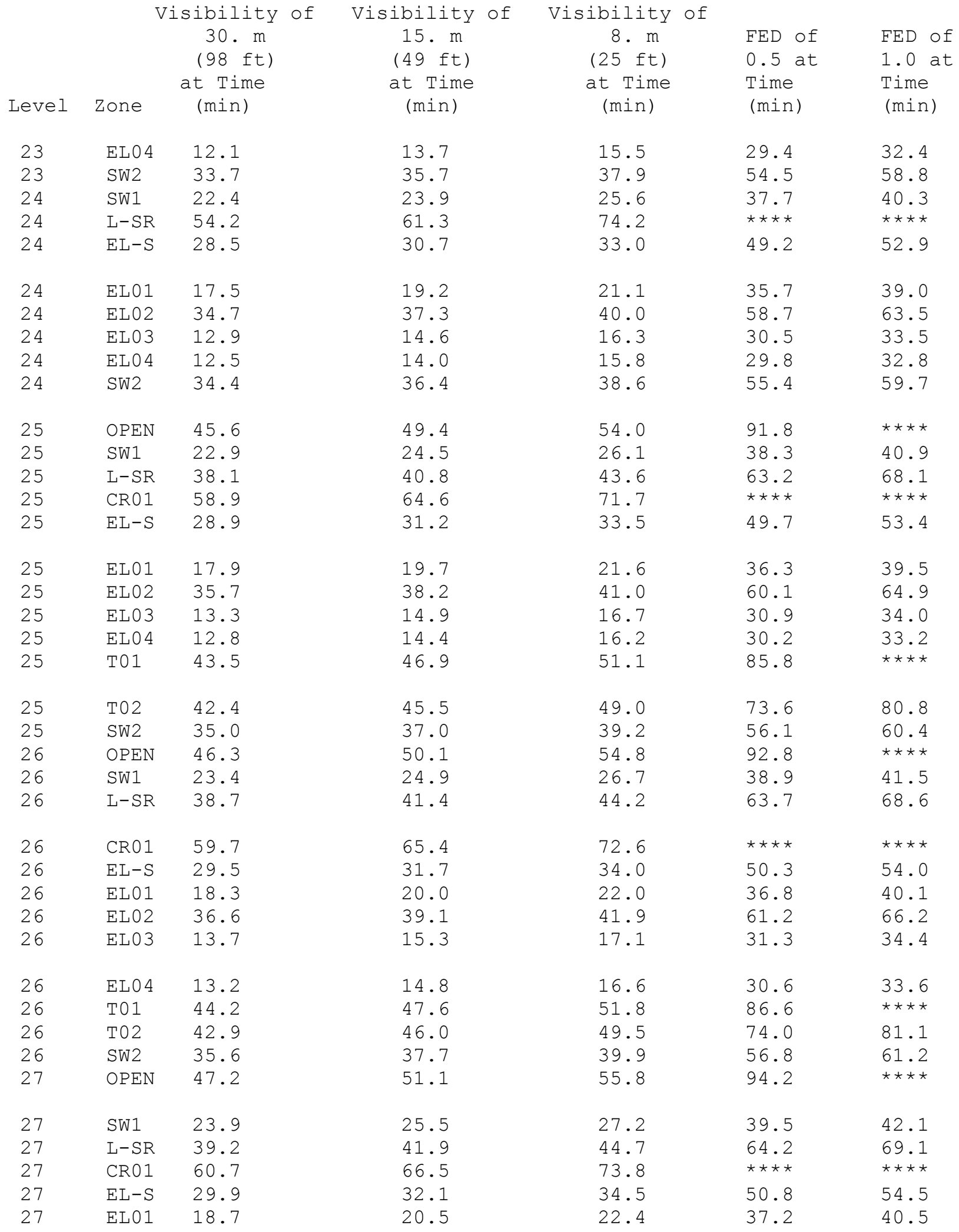


Table 27. Continued.

\begin{tabular}{|c|c|c|c|c|c|c|}
\hline Level & Zone & $\begin{array}{l}\text { sibility of } \\
30 \cdot \mathrm{m} \\
(98 \mathrm{ft}) \\
\text { at Time } \\
\text { (min) }\end{array}$ & $\begin{array}{c}\text { Visibility of } \\
15 \cdot \mathrm{m} \\
(49 \mathrm{ft}) \\
\text { at Time } \\
\text { (min) }\end{array}$ & $\begin{array}{c}\text { Visibility of } \\
8 . \mathrm{m} \\
(25 \mathrm{ft}) \\
\text { at Time } \\
\text { (min) }\end{array}$ & $\begin{array}{l}\text { FED of } \\
0.5 \text { at } \\
\text { Time } \\
(\mathrm{min})\end{array}$ & $\begin{array}{l}\text { FED of } \\
1.0 \text { at } \\
\text { Time } \\
\text { (min) }\end{array}$ \\
\hline 27 & ELO2 & 37.3 & 39.9 & 42.8 & 62.3 & 67.4 \\
\hline 27 & EL03 & 14.0 & 15.7 & 17.5 & 31.8 & 34.9 \\
\hline 27 & ELO 4 & 13.5 & 15.1 & 16.9 & 31.0 & 34.1 \\
\hline 27 & T01 & 44.9 & 48.4 & 52.6 & 87.7 & 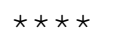 \\
\hline 27 & T02 & 43.6 & 46.7 & 50.2 & 74.7 & 81.8 \\
\hline 27 & SW2 & 36.2 & 38.3 & 40.5 & 57.5 & 61.9 \\
\hline 28 & OPEN & 48.1 & 52.0 & 56.9 & 95.8 & $\star \star \star \star \star$ \\
\hline 28 & SW1 & 24.5 & 26.0 & 27.8 & 40.1 & 42.8 \\
\hline 28 & $L-S R$ & 39.7 & 42.4 & 45.2 & 64.7 & 69.6 \\
\hline 28 & CR01 & 61.8 & 67.7 & 75.1 & $\star \star \star \star *$ & $\star \star \star \star *$ \\
\hline 28 & $E L-S$ & 30.5 & 32.7 & 35.0 & 51.4 & 55.1 \\
\hline 28 & EL01 & 19.0 & 20.8 & 22.8 & 37.7 & 41.0 \\
\hline 28 & ELO2 & 38.0 & 40.7 & 43.5 & 63.3 & 68.5 \\
\hline 28 & EL03 & 14.4 & 16.0 & 17.9 & 32.2 & 35.3 \\
\hline 28 & ELO 4 & 13.8 & 15.5 & 17.3 & 31.4 & 34.5 \\
\hline 28 & T01 & 45.6 & 49.1 & 53.4 & 88.8 & $\star \star \star \star \star$ \\
\hline 28 & T02 & 44.3 & 47.4 & 50.9 & 75.4 & 82.4 \\
\hline 28 & SW2 & 36.9 & 38.9 & 41.2 & 58.2 & 62.6 \\
\hline 29 & OPEN & 49.0 & 53.0 & 58.0 & 97.4 & $\star \star \star \star \star$ \\
\hline 29 & SW1 & 25.0 & 26.6 & 28.3 & 40.7 & 43.4 \\
\hline 29 & $L-S R$ & 40.2 & 42.8 & 45.7 & 65.3 & 70.2 \\
\hline 29 & CR01 & 62.9 & 68.8 & 76.4 & 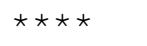 & $\star \star \star \star \star$ \\
\hline 29 & $E L-S$ & 30.9 & 33.2 & 35.6 & 51.9 & 55.6 \\
\hline 29 & EL01 & 19.3 & 21.1 & 23.2 & 38.1 & 41.4 \\
\hline 29 & EL02 & 38.7 & 41.4 & 44.3 & 64.2 & 69.5 \\
\hline 29 & ELO3 & 14.7 & 16.4 & 18.2 & 32.6 & 35.7 \\
\hline 29 & ELO 4 & 14.1 & 15.8 & 17.6 & 31.8 & 34.9 \\
\hline 29 & T01 & 46.4 & 49.9 & 54.2 & 89.9 & 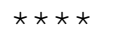 \\
\hline 29 & T02 & 44.9 & 48.0 & 51.6 & 76.1 & 83.1 \\
\hline 29 & SW2 & 37.5 & 39.6 & 41.9 & 59.0 & 63.4 \\
\hline 30 & OPEN & 50.0 & 54.1 & 59.2 & 99.0 & 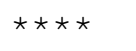 \\
\hline 30 & SW1 & 25.6 & 27.2 & 28.9 & 41.4 & 44.1 \\
\hline 30 & $L-S R$ & 40.7 & 43.4 & 46.2 & 65.8 & 70.7 \\
\hline 30 & CR01 & 64.0 & 70.1 & 77.8 & 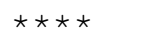 & 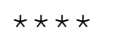 \\
\hline 30 & $E L-S$ & 31.5 & 33.7 & 36.0 & 52.5 & 56.2 \\
\hline 30 & EL01 & 19.7 & 21.5 & 23.5 & 38.5 & 41.8 \\
\hline 30 & ELO2 & 39.4 & 42.1 & 45.0 & 65.1 & 70.5 \\
\hline 30 & EL03 & 15.0 & 16.7 & 18.6 & 33.0 & 36.2 \\
\hline 30 & ELO 4 & 14.5 & 16.1 & 17.9 & 32.2 & 35.2 \\
\hline 30 & T01 & 47.2 & 50.7 & 55.1 & 91.1 & $\star \star \star \star \star ~$ \\
\hline
\end{tabular}


Table 27. Continued.

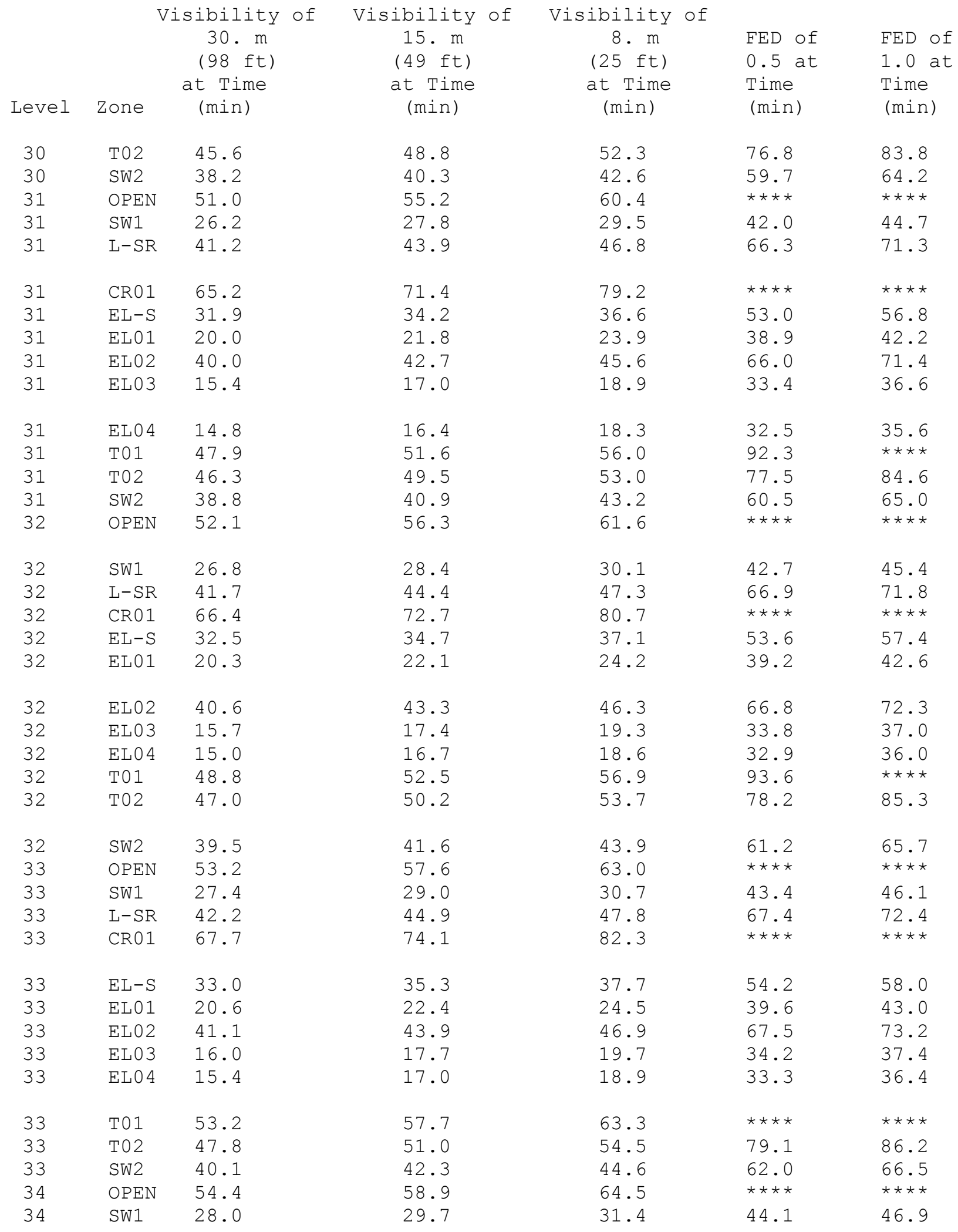


Table 27. Continued.

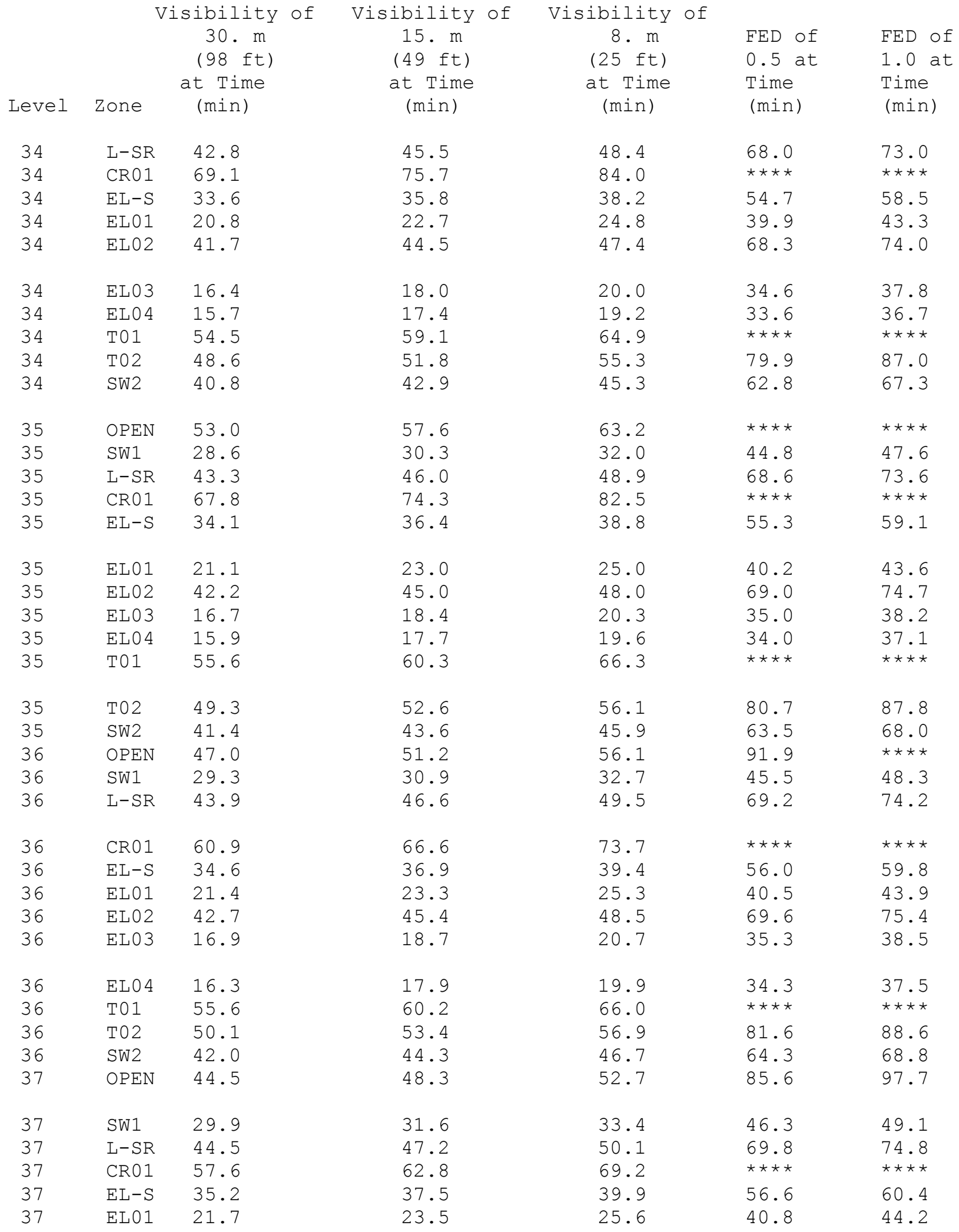


Table 27. Continued.

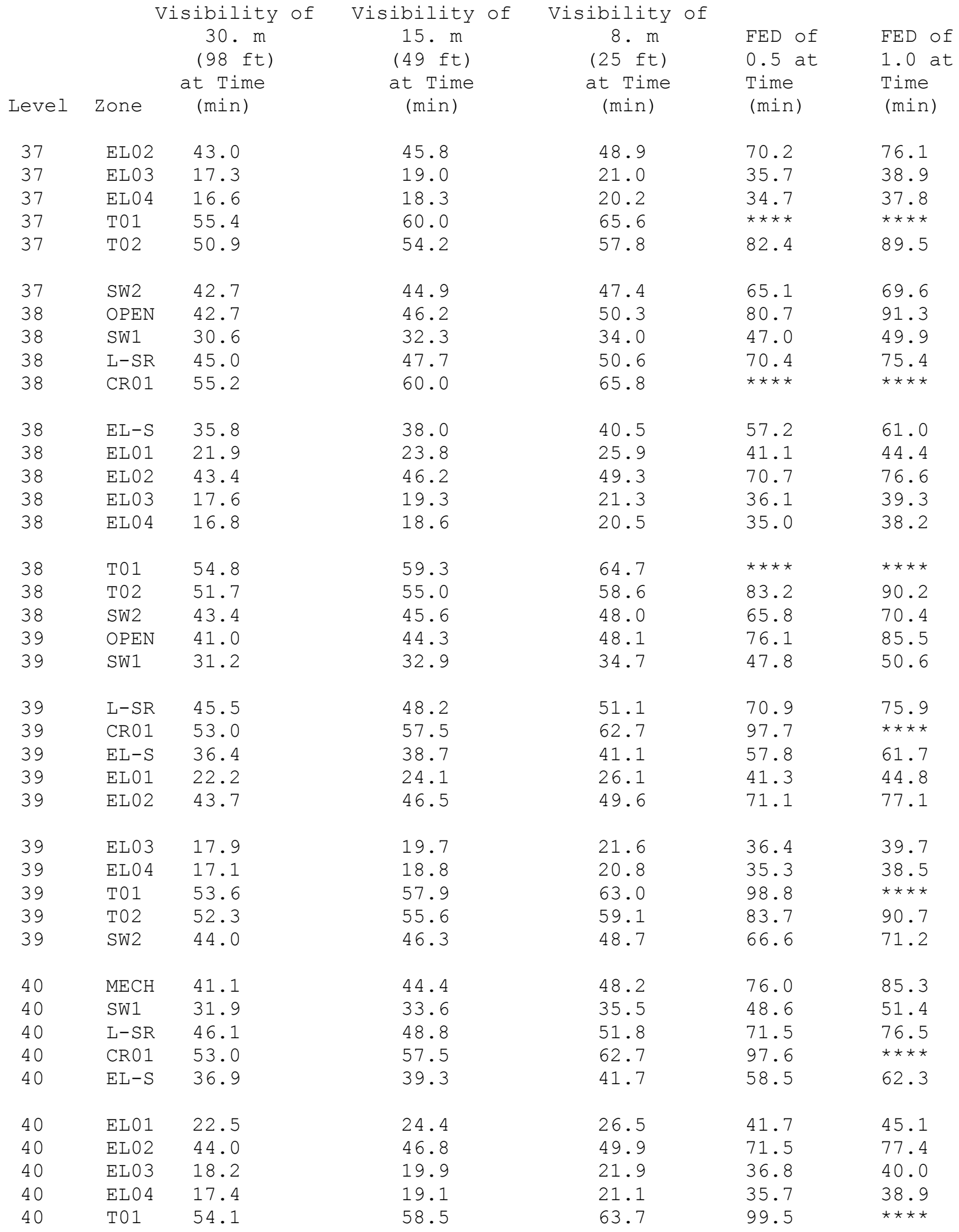


Table 27. Continued.

\begin{tabular}{|c|c|c|c|c|c|c|}
\hline Level & Zone & $\begin{array}{l}\text { sibility of } \\
\text { 30. m } \\
\text { (98 ft) } \\
\text { at Time } \\
\text { (min) }\end{array}$ & $\begin{array}{c}\text { Visibility of } \\
15 . \mathrm{m} \\
(49 \mathrm{ft}) \\
\text { at Time } \\
\text { (min) }\end{array}$ & $\begin{array}{c}\text { Visibility of } \\
8 . \mathrm{m} \\
(25 \mathrm{ft}) \\
\text { at Time } \\
\text { (min) }\end{array}$ & $\begin{array}{l}\text { FED of } \\
0.5 \text { at } \\
\text { Time } \\
(\mathrm{min})\end{array}$ & $\begin{array}{l}\text { FED of } \\
1.0 \text { at } \\
\text { Time } \\
\text { (min) }\end{array}$ \\
\hline 40 & T02 & 53.3 & 56.6 & 60.2 & 84.7 & 91.7 \\
\hline 40 & SW2 & 44.7 & 46.9 & 49.4 & 67.4 & 71.9 \\
\hline 41 & OPEN & 41.4 & 44.7 & 48.4 & 76.3 & 85.6 \\
\hline 41 & SW1 & 32.6 & 34.3 & 36.1 & 49.4 & 52.3 \\
\hline 41 & $\mathrm{~L}-\mathrm{SR}$ & 46.7 & 49.5 & 52.4 & 72.2 & 77.2 \\
\hline 41 & CR01 & 53.3 & 57.7 & 63.0 & 97.8 & 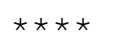 \\
\hline 41 & $E L-S$ & 37.6 & 39.9 & 42.4 & 59.1 & 63.0 \\
\hline 41 & EL01 & 22.8 & 24.7 & 26.8 & 42.0 & 45.4 \\
\hline 41 & ELO2 & 44.3 & 47.2 & 50.3 & 71.8 & 77.8 \\
\hline 41 & EL03 & 18.5 & 20.2 & 22.2 & 37.1 & 40.4 \\
\hline 41 & ELO 4 & 17.7 & 19.4 & 21.4 & 36.0 & 39.2 \\
\hline 41 & T01 & 54.8 & 59.3 & 64.6 & 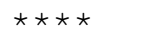 & $\star \star \star \star \star$ \\
\hline 41 & T02 & 53.9 & 57.2 & 60.8 & 85.4 & 92.4 \\
\hline 41 & SW2 & 45.3 & 47.6 & 50.1 & 68.1 & 72.7 \\
\hline 42 & OPEN & 41.3 & 44.6 & 48.3 & 75.7 & 84.8 \\
\hline 42 & SW1 & 33.3 & 35.0 & 36.9 & 50.2 & 53.1 \\
\hline 42 & $L-S R$ & 47.3 & 50.0 & 53.0 & 72.8 & 77.8 \\
\hline 42 & CR01 & 53.1 & 57.5 & 62.6 & 96.9 & $\star \star \star \star \star$ \\
\hline 42 & $E L-S$ & 38.2 & 40.5 & 43.0 & 59.8 & 63.7 \\
\hline 42 & EL01 & 23.0 & 25.0 & 27.1 & 42.3 & 45.7 \\
\hline 42 & ELO2 & 44.6 & 47.5 & 50.6 & 72.2 & 78.2 \\
\hline 42 & ELO3 & 18.7 & 20.6 & 22.6 & 37.4 & 40.7 \\
\hline 42 & ELO 4 & 17.9 & 19.7 & 21.7 & 36.3 & 39.5 \\
\hline 42 & T01 & 54.9 & 59.5 & 64.9 & 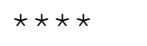 & $\star \star \star \star \star$ \\
\hline 42 & T02 & 54.5 & 57.8 & 61.4 & 86.0 & 92.9 \\
\hline 42 & SW2 & 45.9 & 48.3 & 50.8 & 68.9 & 73.5 \\
\hline 43 & OPEN & 35.7 & 38.5 & 41.5 & 62.7 & 68.6 \\
\hline 43 & SW1 & 34.0 & 35.8 & 37.6 & 51.0 & 53.9 \\
\hline 43 & $\mathrm{~L}-\mathrm{SR}$ & 46.0 & 48.6 & 51.4 & 70.3 & 74.9 \\
\hline 43 & $E L-S$ & 38.8 & 41.1 & 43.6 & 60.5 & 64.4 \\
\hline 43 & EL01 & 23.4 & 25.3 & 27.4 & 42.7 & 46.1 \\
\hline 43 & ELO2 & 45.0 & 47.9 & 51.0 & 72.6 & 78.6 \\
\hline 43 & EL03 & 19.3 & 21.2 & 23.2 & 38.4 & 41.7 \\
\hline 43 & ELO 4 & 18.5 & 20.3 & 22.3 & 37.2 & 40.4 \\
\hline 43 & T01 & 48.9 & 52.4 & 56.3 & 83.6 & 92.3 \\
\hline 43 & T02 & 51.2 & 54.2 & 57.5 & 80.0 & 86.1 \\
\hline 43 & SW2 & 46.6 & 49.0 & 51.5 & 69.7 & 74.3 \\
\hline 44 & OPEN & 55.1 & 58.6 & 62.6 & 92.0 & $\star \star \star \star \star ~$ \\
\hline 44 & SW1 & 34.8 & 36.5 & 38.4 & 51.8 & 54.8 \\
\hline 44 & $L-S R$ & 45.8 & 48.4 & 51.2 & 69.8 & 74.2 \\
\hline
\end{tabular}


Table 27. Continued.

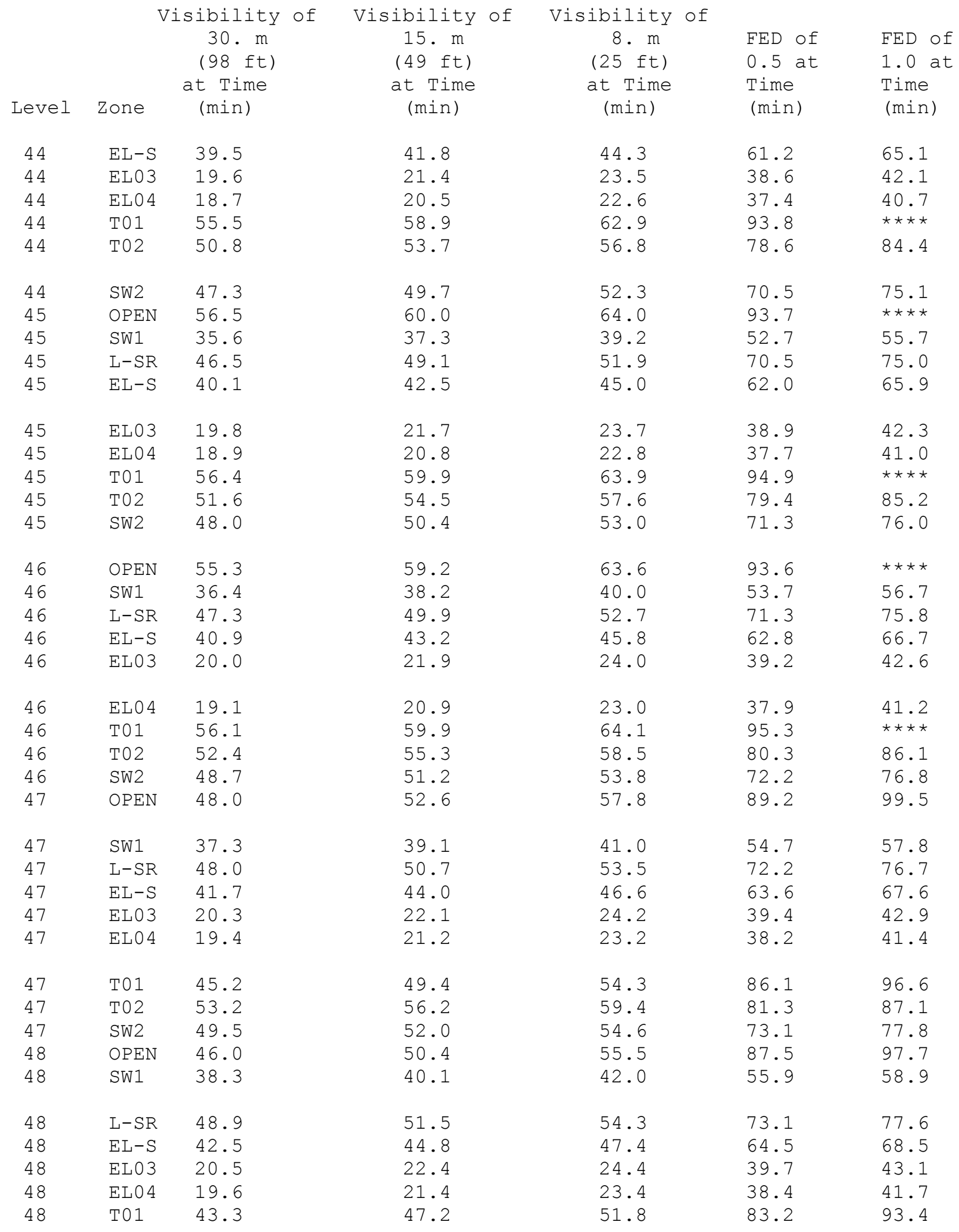


Table 27. Continued.

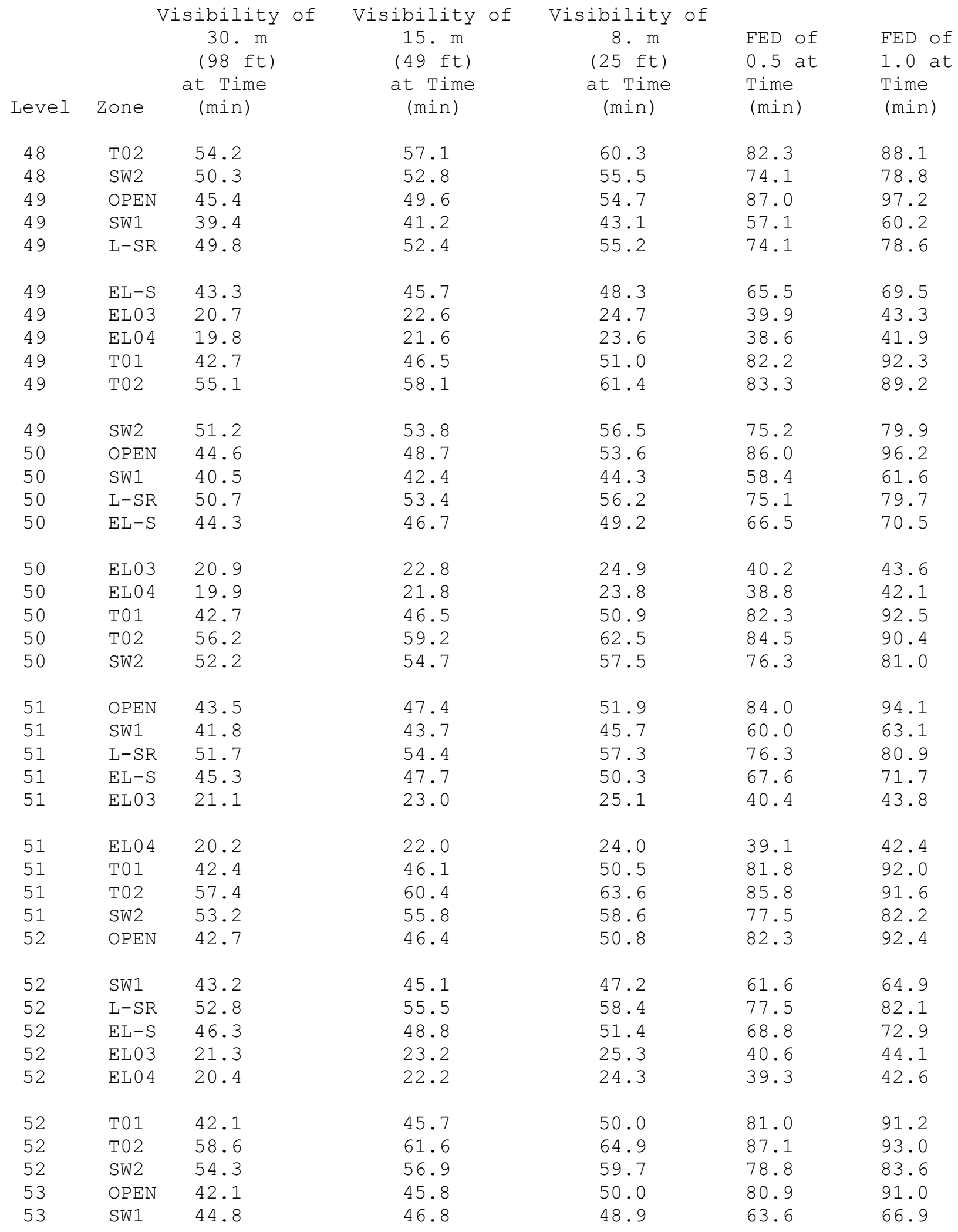


Table 27. Continued.

\begin{tabular}{|c|c|c|c|c|c|c|}
\hline Level & Zone & $\begin{array}{l}\text { sibility of } \\
30 . \mathrm{m} \\
(98 \mathrm{ft}) \\
\text { at Time } \\
\text { (min) }\end{array}$ & $\begin{array}{c}\text { Visibility of } \\
15 . \mathrm{m} \\
(49 \mathrm{ft}) \\
\text { at Time } \\
\text { (min) }\end{array}$ & $\begin{array}{c}\text { Visibility of } \\
8 . \mathrm{m} \\
(25 \mathrm{ft}) \\
\text { at Time } \\
\text { (min) }\end{array}$ & $\begin{array}{l}\text { FED of } \\
0.5 \text { at } \\
\text { Time } \\
\text { (min) }\end{array}$ & $\begin{array}{l}\text { FED of } \\
1.0 \text { at } \\
\text { Time } \\
\text { (min) }\end{array}$ \\
\hline 53 & $L-S R$ & 54.0 & 56.7 & 59.6 & 78.8 & 83.4 \\
\hline 53 & $E L-S$ & 47.5 & 49.9 & 52.6 & 70.1 & 74.2 \\
\hline 53 & EL03 & 21.5 & 23.4 & 25.5 & 40.8 & 44.3 \\
\hline 53 & ELO 4 & 20.6 & 22.5 & 24.5 & 39.5 & 42.9 \\
\hline 53 & T01 & 41.8 & 45.4 & 49.5 & 80.2 & 90.3 \\
\hline 53 & T02 & 59.9 & 63.0 & 66.3 & 88.6 & 94.5 \\
\hline 53 & SW2 & 55.5 & 58.2 & 61.0 & 80.2 & 85.0 \\
\hline 54 & OPEN & 41.7 & 45.3 & 49.4 & 79.8 & 89.8 \\
\hline 54 & SW1 & 46.7 & 48.7 & 50.8 & 65.8 & 69.2 \\
\hline 54 & $L-S R$ & 55.3 & 58.0 & 61.0 & 80.3 & 85.0 \\
\hline 54 & $E L-S$ & 48.8 & 51.2 & 53.9 & 71.6 & 75.7 \\
\hline 54 & ELO3 & 21.7 & 23.7 & 25.7 & 41.1 & 44.5 \\
\hline 54 & ELO 4 & 20.8 & 22.7 & 24.7 & 39.8 & 43.1 \\
\hline 54 & T01 & 41.5 & 45.0 & 49.1 & 79.4 & 89.5 \\
\hline 54 & T02 & 61.4 & 64.5 & 67.9 & 90.3 & 96.2 \\
\hline 54 & SW2 & 56.8 & 59.5 & 62.4 & 81.8 & 86.6 \\
\hline 55 & OPEN & 41.4 & 44.9 & 48.9 & 78.8 & 88.7 \\
\hline 55 & SW1 & 48.9 & 51.0 & 53.1 & 68.5 & 72.0 \\
\hline 55 & $L-S R$ & 56.8 & 59.5 & 62.5 & 81.9 & 86.6 \\
\hline 55 & $E L-S$ & 50.2 & 52.7 & 55.4 & 73.2 & 77.3 \\
\hline 55 & EL03 & 21.9 & 23.9 & 25.9 & 41.3 & 44.7 \\
\hline 55 & ELO 4 & 21.0 & 22.9 & 24.9 & 40.0 & 43.3 \\
\hline 55 & T01 & 41.3 & 44.8 & 48.8 & 78.7 & 88.7 \\
\hline 55 & T02 & 63.0 & 66.2 & 69.6 & 92.2 & 98.1 \\
\hline 55 & SW2 & 58.3 & 61.0 & 64.0 & 83.5 & 88.4 \\
\hline 56 & OPEN & 41.2 & 44.6 & 48.6 & 77.9 & 87.7 \\
\hline 56 & SW1 & 51.7 & 53.8 & 56.0 & 71.9 & 75.5 \\
\hline 56 & $L-S R$ & 58.4 & 61.2 & 64.1 & 83.7 & 88.5 \\
\hline 56 & $E L-S$ & 51.7 & 54.3 & 57.0 & 75.0 & 79.1 \\
\hline 56 & EL03 & 22.2 & 24.1 & 26.2 & 41.5 & 45.0 \\
\hline 56 & ELO 4 & 21.2 & 23.1 & 25.2 & 40.2 & 43.6 \\
\hline 56 & T01 & 41.2 & 44.6 & 48.6 & 78.0 & 88.0 \\
\hline 56 & T02 & 64.9 & 68.0 & 71.5 & 94.3 & 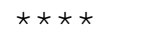 \\
\hline 56 & SW2 & 60.0 & 62.8 & 65.7 & 85.5 & 90.4 \\
\hline 57 & OPEN & 41.0 & 44.4 & 48.3 & 77.1 & 86.8 \\
\hline 57 & SW1 & 55.3 & 57.5 & 59.9 & 76.5 & 80.3 \\
\hline 57 & $L-S R$ & 60.2 & 63.0 & 66.1 & 85.8 & 90.6 \\
\hline 57 & $E L-S$ & 53.5 & 56.1 & 58.8 & 77.0 & 81.2 \\
\hline 57 & EL03 & 22.4 & 24.3 & 26.4 & 41.8 & 45.2 \\
\hline 57 & ELO 4 & 21.5 & 23.3 & 25.4 & 40.5 & 43.8 \\
\hline
\end{tabular}


Table 27. Continued.

\begin{tabular}{|c|c|c|c|c|c|c|}
\hline Level & Zone & $\begin{array}{l}\text { sibility of } \\
30 . \mathrm{m} \\
(98 \mathrm{ft}) \\
\text { at Time } \\
\text { (min) }\end{array}$ & $\begin{array}{c}\text { Visibility of } \\
15 . \mathrm{m} \\
(49 \mathrm{ft}) \\
\text { at Time } \\
\text { (min) }\end{array}$ & $\begin{array}{c}\text { Visibility of } \\
8 . \mathrm{m} \\
(25 \mathrm{ft}) \\
\text { at Time } \\
\text { (min) }\end{array}$ & $\begin{array}{l}\text { FED of } \\
0.5 \text { at } \\
\text { Time } \\
\text { (min) }\end{array}$ & $\begin{array}{l}\text { FED of } \\
1.0 \text { at } \\
\text { Time } \\
\text { (min) }\end{array}$ \\
\hline 57 & T01 & 41.0 & 44.4 & 48.3 & 77.3 & 87.2 \\
\hline 57 & T02 & 66.9 & 70.2 & 73.7 & 96.7 & 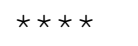 \\
\hline 57 & SW2 & 61.9 & 64.7 & 67.8 & 87.8 & 92.8 \\
\hline 58 & OPEN & 40.5 & 43.8 & 47.6 & 75.4 & 84.7 \\
\hline 58 & SW1 & 60.7 & 63.1 & 65.7 & 83.7 & 88.0 \\
\hline 58 & $L-S R$ & 62.3 & 65.2 & 68.3 & 88.2 & 93.1 \\
\hline 58 & $\mathrm{EL}-\mathrm{S}$ & 55.6 & 58.2 & 61.0 & 79.4 & 83.7 \\
\hline 58 & ELO3 & 22.6 & 24.5 & 26.6 & 42.0 & 45.5 \\
\hline 58 & ELO 4 & 21.7 & 23.6 & 25.7 & 40.7 & 44.1 \\
\hline 58 & T01 & 40.6 & 43.9 & 47.7 & 75.8 & 85.2 \\
\hline 58 & T02 & 69.3 & 72.6 & 76.2 & 99.6 & 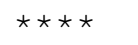 \\
\hline 58 & SW2 & 64.1 & 67.0 & 70.1 & 90.5 & 95.6 \\
\hline 59 & $\mathrm{MECH}$ & 76.8 & 80.9 & 85.4 & 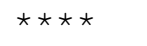 & 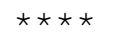 \\
\hline 59 & ELME & 80.4 & 84.7 & 89.5 & $\star \star \star \star \star$ & $\star \star \star \star \star$ \\
\hline 59 & $E L-S$ & 58.0 & 60.7 & 63.6 & 82.3 & 86.7 \\
\hline 59 & ELO3 & 22.6 & 24.6 & 26.7 & 42.0 & 45.5 \\
\hline 59 & ELO 4 & 21.7 & 23.6 & 25.7 & 40.8 & 44.1 \\
\hline 59 & SW2 & 66.9 & 69.8 & 73.0 & 93.8 & 99.0 \\
\hline $\mathrm{R}$ & SW2 & 71.4 & 74.6 & 77.9 & 99.5 & 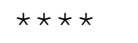 \\
\hline
\end{tabular}


Appendix G

\section{The Basis for Egress Provisions in U.S. Building Codes}




\title{
The Basis for Egress Provisions in U.S. Building Codes
}

\author{
Richard W. Bukowski, P.E., FSFPE and Erica Kuligowski \\ NIST Building and Fire Research Laboratory \\ Gaithersburg, Maryland 20899 USA
}

\begin{abstract}
Some of the earliest public safety-from-fire regulations in the US are requirements for egress stairs adopted by New York City in $1860^{1}$. One of the first model regulations promulgated by the National Fire Protection Association (NFPA) was the 1927 Building Exits Code, predecessor of the Life Safety Code. Thus the need to move occupants out of harms' way in building fires has long been central to fire safety regulations.

The need to move occupants to a safe place was underscored in numerous historical fire disasters. Locked exits contributed to the high number of fatalities (150) in the 1911 Triangle Shirtwaist Factory fire and exit doors that opened inwards blocked by crowds was cited in the 492 fatalities of the Cocoanut Grove fire $(1942)^{2}$. Incidents like these resulted in public outcry for stronger code provisions but even today egress problems leading to high numbers of deaths persist. The 100 fatalities at the Station Club in Rhode Island in 2003 provide the most recent example. Since the Rhode Island fire, NFPA and other code authorities are reviewing current requirements for level of safety, especially for assembly spaces.
\end{abstract}

These current prescriptive codes used for building design contain a list of egress specifications depending upon certain aspects of the building, such as the type of occupancy, the configuration of the space, the presence of sprinklers, and the type of construction of the building. These code specifications aid the designer in providing a certain level of life safety for their building, but little effort has been put into quantifying this level of life safety in terms of egress times.

This paper attempts to describe the prescriptive design process for specific types of buildings. Secondly, by applying some assumptions to the egress specifications listed in the codes, an estimate of resulting egress times for maximum occupant loads were performed for specific occupancies. The egress times were obtained using multiple calculation methods and include estimates of pre-movement time, time to exit the occupied room, and time spent to travel one flight of stairs. Lastly, additional egress issues, such as merging flows and the use of elevators for occupant egress, are discussed.

\section{History of Egress Provisions in Regulations}

Some of the earliest public safety-from-fire regulations in the US are requirements for egress stairs adopted by New York City in $1860^{1}$. One of the first model regulations promulgated by the National Fire Protection Association (NFPA) was the 1927 Building Exits Code, predecessor of the Life Safety Code. Thus the need to move occupants out of harms' way in building fires has long been central to fire safety regulations.

The need to move occupants to a safe place was underscored in numerous historical fire disasters. Locked exits contributed to the high number of fatalities (150) in the 1911 Triangle Shirtwaist Factory fire and exit doors that opened inwards blocked by crowds was cited in the 492 fatalities of the Cocoanut Grove fire $(1942)^{2}$. Incidents like these resulted in public outcry for stronger code provisions but even today egress problems leading to high number of deaths persist. The 100 fatalities at the Station Club in Rhode Island in 2003 provide the most recent example.

\section{Basic Principles of Egress Safety}

The basic concept of occupant egress implemented in building regulations involves the provision of a properly designed means of egress that is continuous and unobstructed from any point in the building to the outside. Proper design includes the width of the spaces and doors, direction of door swing, lighting and marking, protection from the fire and its effects, and geometry of stairs or ramps, among others. Limits on travel distances 
to reach a means of egress and on common paths of travel, dead ends, and the provision of alternate means of egress if the primary path is blocked by fire are also basic concepts of egress design.

The means of egress described in building regulation consists of three parts. The exit access is the corridor, aisle, balcony, gallery, room, porch, or portion of a roof over which an occupant must travel to reach the exit. The exit is a door leading to the outside or through a protected passageway to the outside, a smokeproof tower, protected stairway, exit passageway, enclosed ramp, escalator, or moving walkway within a building. The exit discharge is the door to the outside, although some regulations allow not more than half the exits to discharge onto a floor with an unobstructed path to the outside, and is protected by sprinklers and a 2-hr separation from floors below.

It must further be possible for all the occupants using the exit discharge to reach a safe place away from the building. Thus if exits discharge to a yard or alley these must lead to a safe place and have the capacity to carry all occupants and to protect them from the effects of the fire as they move away from the building. In Japanese building regulations ${ }^{3}$ the means of egress includes the entire path to a safe place of sufficient capacity to accommodate the entire population of all buildings intended to evacuate to that place. Thus Japanese cities are dotted with parks that serve as gathering places for occupants of multiple buildings. Those parks utilize perimeter trees intended to protect people in the park from thermal radiation from fires in surrounding buildings from which they evacuated.

\section{Designing an Egress System}

The objective of the egress system design is to allow the unimpeded evacuation of the building population without exposure to fire or smoke. Prescriptive building regulations address this by specifying a population density (people per unit floor area) for each building use group, called the occupant load factor. When multiplied by the floor area, the occupant load is obtained on which the egress system design is based (unless there is reason to believe that the actual load will be greater or the owner desires a greater allowance).

The means of egress is then designed to accommodate that occupant load by specifying an egress width per occupant served. Values are specified for stairs and for other egress components, sprinklered and unsprinklered, and with special values for type-H (high hazard) and type-I (institutional) building uses to allow for higher egress speeds (high hazard) and greater number of wheelchairs or evacuation in patient beds (institutional), respectively.

The width of the egress system at each floor is sized to accommodate the number of occupants on that floor only. There is an additional requirement that the egress system width cannot become narrower in the direction of egress travel and beyond any convergence of two or more egress systems from different directions, the capacity cannot be less than the sum of the capacities. These requirements are intended to account for the 
accumulation of flows from multiple floors.

For very tall buildings, it was recognized that the accumulating flow from a large number of floors would result in congestion in the stairways and a reduction of flow speeds. Widening the stairway to increase the capacity has a serious economic impact that could make tall buildings impractical. Thus the concept of phased evacuation was developed where occupants are evacuated from the (3) floors closest to the fire first, while others wait their turn. Such systems require a voice communication system to manage the process by voice messages from a fire command center staffed by the fire service, and (e.g., in New York City) fire wardens on each floor directing the flow.

\section{Egress System Performance}

Egress systems designed in accordance with these rules are considered to allow all building occupants to get to a safe place, "in time." Unfortunately, "in time" is not quantified. In the last 20 years, the engineering concept of Available Safe Egress Time (or ASET) vs. Required Safe Egress Time (RSET) has become popular. ASET is defined as the time available for safe egress before conditions within a space or building become untenable ${ }^{4}$. RSET is defined as the time required for the occupants in a structure to evacuate without harm. Time available is normally estimated by fire modeling and the application of tenability limits for human tolerance to fire effects. Time required is estimated by traffic flow calculations for speed of people movement through the egress system.

With use, the ASET/RSET methodologies became more refined. The time required calculations began to include other, significant components such as pre-movement times and behavioral rules to account for many situations where people do not immediately evacuate. Human factors research documented large variability in movement speeds ${ }^{4}$ and toxicology research showed large differences in individual tolerance to smoke depending on age and pre-existing physiological conditions. Recently questions have been raised about sub-lethal effects ${ }^{5}$ that are difficult to estimate and unethical to measure, further clouding the picture.

Because of the large variability in movement speeds, it is possible for individual designs to pass or fail by selection of a characteristic speed or by the application of an appropriately large factor of safety. A safety factor of $2^{4}$ is generally recommended in the fire protection engineering literature ${ }^{6}$. Thus it would be of value to establish a benchmark for what might be considered adequate escape time. The prescriptive regulatory system for egress system design implies such a benchmark value as follows.

\section{Prescriptive Egress Specifications}

Traditional building codes specify the design of egress systems by first estimating the number of occupants in an area to be evacuated, second determining the (combined) width of the exit system needed for that number of occupants, and third dividing that width among the number of exits needed to achieve the travel distance limits.

In current building codes, design occupant densities (called loads) range from $46.5 \mathrm{~m}^{2}$ 
$\left(500 \mathrm{ft}^{2}\right)\left(\right.$ gross $^{13}$ - the area within the confining perimeter walls of the building) per occupant (aircraft hangers, warehouses) to $0.46 \mathrm{~m}^{2}\left(5 \mathrm{ft}^{2}\right)\left(\right.$ net ${ }^{13}-$ the actual occupied space only) per occupant (assembly, standing space). Common values are $9.3 \mathrm{~m}^{2}(100$ $\left.\mathrm{ft}^{2}\right)$ (gross) per occupant (business, industrial) or $18.6 \mathrm{~m}^{2}\left(200 \mathrm{ft}^{2}\right)$ (gross) per occupant (residential). By multiplying these loads by the floor area, the number of people to be evacuated is obtained.

With the exception of hazardous and health care occupancies, both the $\mathrm{IBC}^{7}$ (without sprinkler protection) and NFPA $5000^{8}$ (sprinklered or not) specify the same egress system width of $7.6 \mathrm{~mm}(0.3 \mathrm{in})$ per occupant in exit stairways and $5 \mathrm{~mm}(0.2 \mathrm{in})$ per occupant elsewhere. The IBC reduces egress capacity where sprinklered to $5 \mathrm{~mm}(0.2$ in) per occupant in stairs and $3.8 \mathrm{~mm}(0.15 \mathrm{in})$ elsewhere. The egress capacity of the exit system is the smallest capacity of any component. For example, a $0.86 \mathrm{~m}$ (34 in) (clear width) door leading into a $1.1 \mathrm{~m}$ (44 in) (clear) stair have capacities of $170(0.86 \mathrm{~m} / 5 \mathrm{~mm})$ and $147(1.1 \mathrm{~m} / 7.6 \mathrm{~mm})$ respectively. Thus the exit capacity is the smaller of the two, or 147 . The minimum number of exits specified in both model codes is two for populations up to 500 , three from 501 to 1000 , and four if over 1000 .

Finally, building codes specify maximum travel distances to an exit by occupancy. The

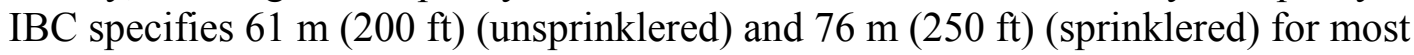

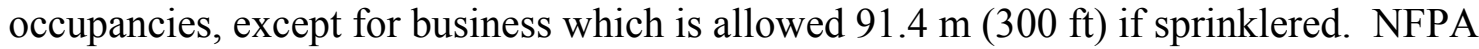
5000 specifies travel distances without sprinklers of $30.5 \mathrm{~m}(100 \mathrm{ft})$ (hotels, apartments, mercantile), $45.7 \mathrm{~m}$ (150 ft) (health care, educational) or $61 \mathrm{~m}$ (200 ft) (business, industrial, assembly). When fully sprinklered, these increase to $61 \mathrm{~m}$ (200 ft) (hotel, apartments, educational), $76 \mathrm{~m}$ (250 ft) (mercantile, industrial, assembly) and $91.4 \mathrm{~m}$ (300 ft) (business). While most buildings will require two or more exits, the travel distance requirement only applies to the distance from any point to the closest (single) exit. The distance to any other exit(s) is unregulated.

An unforeseen problem may exist involving travel distances of the occupants to the "main entrance" of assembly occupancies. For assembly occupancies, there exists a requirement that the "main entrance" of the building must be designed for half of the egress capacity. The travel distance requirement, however, applies only to the closest (single) exit from any point of occupancy in the building. The question that arises is whether or not a specific travel distance should be required for the "main entrance" of the building, especially since the exit is designed for use by half of the building population.

For example, an assembly space with $650 \mathrm{~m}^{2}\left(7,000 \mathrm{ft}^{2}\right)$ (net) will contain a design occupant load of 1000 people. The code requires 3 exits and sprinklers, which results in a travel distance limit of $76 \mathrm{~m}(250 \mathrm{ft})$. The "main entrance" is designed for half of the population (500 occupants), and the two other exits of the building include a larger exit designed for 400 occupants and a smaller exit designed for 100 occupants. If the smallest exit is $76 \mathrm{~m}(250 \mathrm{ft})$ away from the furthest occupied space in the building, the travel distance requirement for the building is met. The other two exits, the larger exit and the "main entrance" are not required to meet any travel distance requirements. In this example, $90 \%$ of the required egress capacity can be in exits that require excessively long 
travel distances to reach.

\section{Benchmarking the Intent of the Codes}

By applying some assumptions to the specifications previously listed, it is possible to estimate the resulting egress times for maximum occupant loads by occupancy. In each case the occupant load can be estimated by assuming a square compartment with exits in opposite corners so that the diagonal dimension is the maximum travel distance. This establishes an area that, when multiplied by the occupant load, gives the number of occupants to be evacuated.

Egress times are generally taken to be the time between notification of the occupants of the need to evacuate (initiation of the fire alarm system) and the time the occupants get into the stairway or a protected stairway access (this is not the normal exit access corridor but rather an extension of the stairway meeting the same fire and smoke protection requirements).

The time required to evacuate these occupants is the pre-movement time plus the time required to move the (maximum) travel distance plus the time required to pass through the door. Table $\mathrm{A}^{9}$ presents estimates of pre-movement times for various occupancies and type of warning system. Also, other references provide alternatives for premovement times, which were obtained from fire drills, experiments, and post-fire analysis $^{10,11,12}$.

Walking speeds on horizontal surfaces vary with density and fall within the range of 1.19 $\mathrm{m} / \mathrm{s}(235 \mathrm{ft} / \mathrm{min})$ at 0.54 people $/ \mathrm{m}^{2}\left(0.05\right.$ people $\left./ \mathrm{ft}^{2}\right)$ to $0.63 \mathrm{~m} / \mathrm{s}(125 \mathrm{ft} / \mathrm{min})$ at 2.17 people $/ \mathrm{m}^{2}\left(0.2 \text { people } / \mathrm{ft}^{2}\right)^{4}$. While walking speeds vary with exposure to smoke, it is reasonable to assume that codes would be based on no smoke exposure due to the limited data on this interaction. Travel speeds and flow rates are typically restricted by flow through doorways. The maximum rate of flow through doors is given in the literature as 1.3 persons/s-m of effective width (24 people/min- $\mathrm{ft})^{4}$. 
Table A - Estimated Delay Time to Start Evacuation

\begin{tabular}{|l|l|l|l|}
\hline Occupancy Type & $\begin{array}{l}\text { W1 } \\
\text { (min) }\end{array}$ & $\begin{array}{l}\text { W2 } \\
\text { (min) }\end{array}$ & $\begin{array}{l}\text { W3 } \\
\text { (min) }\end{array}$ \\
\hline $\begin{array}{l}\text { Offices, commercial and industrial buildings, schools, colleges, } \\
\text { and universities (Occupants awake and familiar with the building, } \\
\text { the alarm system, and evacuation procedure) }\end{array}$ & $<1$ & 3 & $>4$ \\
\hline $\begin{array}{l}\text { Shops, museums, leisure-sport centers, and } \\
\text { other assembly buildings (Occupants awake but may be } \\
\text { unfamiliar with building, alarm system, evacuation procedure) }\end{array}$ & $<2$ & 3 & $>6$ \\
\hline $\begin{array}{l}\text { Dormitories, residential mid- and high-rise (Occupants may be } \\
\text { asleep but are predominantly familiar with the building, alarm } \\
\text { system, evacuation procedure) }\end{array}$ & $<2$ & 4 & $>5$ \\
\hline $\begin{array}{l}\text { Hotels and boarding houses (Occupants may be asleep and } \\
\text { unfamiliar with building, alarm system, evacuation procedure) }\end{array}$ & $<2$ & 4 & $>6$ \\
\hline $\begin{array}{l}\text { Hospitals, nursing homes, and other institutional (A significant } \\
\text { number of occupants may require assistance) }\end{array}$ & $<3$ & 5 & $>8$ \\
\hline
\end{tabular}

W1: live directives using voice communication system from a control room with closed-circuit television facility or live directives in conjunction with well-trained, uniformed staff that can be seen and heard by all occupants in the space.

W2: nondirective voice messages (pre-recorded) and/or informative warning visual display with trained staff. W3: warning system using fire alarm signal and staff with no relevant training

The building codes specify that egress doors cannot be less than $0.8 \mathrm{~m}$ (32 in) (clear) nor more than $1.2 \mathrm{~m}$ (48 in) (clear) in width (per leaf). Door capacities range from 160 persons for a $0.8 \mathrm{~m}$ door to 240 persons for a $1.2 \mathrm{~m}$ door with a differential of 10 people per $51 \mathrm{~mm}(2 \mathrm{in})$ of width.

Egress stairs cannot be less than $1.1 \mathrm{~m}$ (44 in) in width with no maximum. Design capacities for stairs range from 147 people for a $1.1 \mathrm{~m}$ (44 in) stair to 220 people for a $1.67 \mathrm{~m}$ (66 in) stair with a differential of 13 people per $102 \mathrm{~mm}$ (4 in) of width.

\section{Horizontal Movement}

Tables B1 and B2 show estimates of the worst-case egress times for each occupancy type; assembly without fixed seating, business, and residential (open space). Each egress time is the combination of the travel time to the stairwell door and the time for all of the occupants to go through the door into the stairwell. Prescriptive codes consider the occupant to reach safety as soon as they enter the stairwell. In the tables, egress times are separated first into occupancy type, and then second into whether or not the occupancy is sprinklered ( $\mathrm{S}$ refers to sprinklered spaces and $\mathrm{N}$ refers to nonsprinklered (or unsprinklered) spaces in each table). Both designations ultimately affect the travel distances and number of occupants in a space, as shown in the table.

For each occupancy type, a square room is configured so that the diagonal dimension is equivalent to the travel distance. Then, the dimensions of the compartment are used to calculate the number of occupants in the space according to the Life Safety Code ${ }^{13}$ (Table 7.3.1.2). The "travel time" is used to represent the longest possible distance traveled by 
an occupant to reach the stairway door. As shown in Figure 1, this longest distance with

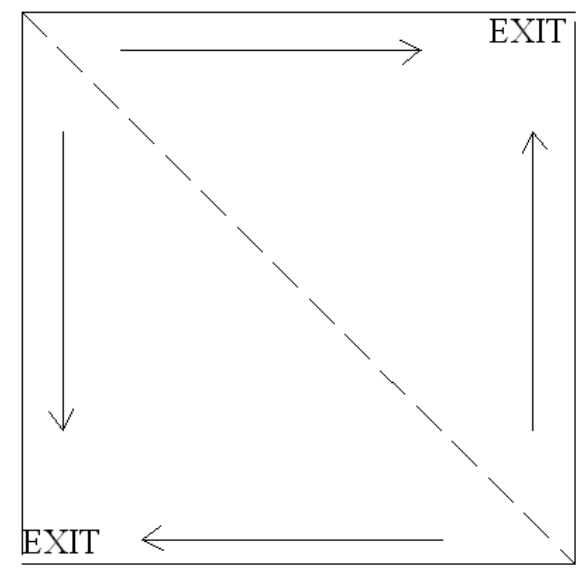

Figure 1: Square compartment all exits available is the distance along the side of the compartment (shown by the arrows in the figure). This provides a conservative estimate of travel time for that space. The speeds used to calculate travel time for each occupancy reflect the actual density of the space and were obtained from Pauls' density correlations in the SFPE handbook ${ }^{14}$.

The next calculation in Table B1, specifically, shows the time for all of the distributed occupants to travel through their designated door. Each occupancy has a different number of exit doors depending upon the number of occupants in the space. The "through door" time is calculated by dividing the number of occupants through the door by the calculated flow (maximum specific flow $x$ effective door width) in persons/minute. The door calculation takes into account that occupants will maintain a boundary layer of $150 \mathrm{~mm}$ (6 in) from each side of the doorway.

Table B1 - Estimates of worst-case egress times using SFPE Handbook values

\begin{tabular}{|l|c|c|c|c|c|c|}
\hline \multirow{2}{*}{} & \multicolumn{2}{|c|}{ Assembly } & \multicolumn{2}{c|}{ Business } & \multicolumn{2}{c|}{ Residential } \\
\cline { 2 - 7 } & $\mathrm{S}^{\mathrm{b}}$ & $\mathrm{NS}^{\mathrm{c}}$ & $\mathrm{S}$ & $\mathrm{NS}$ & $\mathrm{S}$ & $\mathrm{NS}$ \\
\hline $\begin{array}{l}\text { Travel distance } \\
\text { (diagonal dimension- }\end{array}$ & $\begin{array}{c}76 \\
\text { Fig. 1) in meters (ft) }\end{array}$ & $\begin{array}{c}61 \\
(250)\end{array}$ & $\begin{array}{c}91.4 \\
(300)\end{array}$ & $\begin{array}{c}61 \\
(200)\end{array}$ & $\begin{array}{c}61^{\mathrm{a}} \\
(200)\end{array}$ & $\begin{array}{c}30.5^{\mathrm{a}} \\
(100)\end{array}$ \\
\hline $\begin{array}{l}\text { Compartment side } \\
\text { dimensions in m (ft) }\end{array}$ & $\begin{array}{c}54.3 \\
(178)\end{array}$ & $\begin{array}{c}43.6 \\
(143)\end{array}$ & $\begin{array}{c}65.2 \\
(214)\end{array}$ & $\begin{array}{c}43.6 \\
(143)\end{array}$ & $\begin{array}{c}43.6 \\
(143)\end{array}$ & $\begin{array}{c}21.6 \\
(71)\end{array}$ \\
\hline $\begin{array}{l}\text { Occupant \# } \\
\text { (load x area) }\end{array}$ & 6336 & 4090 & 458 & 205 & 102 & 25 \\
\hline Travel time (s) & 85 & 69 & 55 & 37 & 37 & 18 \\
\hline $\begin{array}{l}\text { Exit doors, \# x width } \\
\text { in m (people per set } \\
\text { of doors) }\end{array}$ & $\begin{array}{c}14 \times 2.4 \\
(452)\end{array}$ & $\begin{array}{c}9 \times 2.4 \\
(455)\end{array}$ & $\begin{array}{c}2 \times 1.17 \\
(229)\end{array}$ & $\begin{array}{c}2 \times 0.8 \\
(103)\end{array}$ & $\begin{array}{c}2 \times 0.8 \\
(51)\end{array}$ & $\begin{array}{c}2 \times 0.8 \\
(13)\end{array}$ \\
\hline Through door (s) & \multicolumn{7}{|c|}{162} & \multicolumn{7}{|c|}{163} & 202 & 155 & 77 & 20 \\
\hline $\begin{array}{l}\text { a Travel distance shown is from the door to any individual living unit to the exit. } \\
\text { Additional travel time would be required for travel within the living unit. } \\
\text { b Refers to a Sprinklered space; }{ }^{\mathrm{c}} \text { Refers to a Nonsprinklered space }\end{array}$ \\
\hline
\end{tabular}

For Table B2, as a variation to the calculations made in Table B1, it is assumed that the doors act as turnstiles. From video tapes of egress through doors taken by Fruin ${ }^{15}$, it can be seen that each exiting person places his/her hand on the door before leaving the building. Nelson ${ }^{16}$ speculates that this behavior limits the flow through each door to about 50 to 60 persons per minute. This applies to the full range of door widths from 0.8 $\mathrm{m}$ (32 in) to $1.2 \mathrm{~m}$ (48 in). For the assembly space, a $2.4 \mathrm{~m}$ (96 in) door represents a twoleaf set of $1.2 \mathrm{~m}$ (48 in) wide doors, which would indicate a flow of 100 to 120 persons 
per minute. For all calculations in Table B2, a midrange value of 55 persons per minute per door was used to achieve times through the door. For example, in the assembly space, 452 people will pass through a two-leaf set of $1.2 \mathrm{~m}$ (48 in) doors, which corresponds to a flow of 110 people per minute. For sprinklered assembly spaces, the result is 247 seconds to flow 452 people through the $2-1.2 \mathrm{~m}$ (48 in) doors.

Table B2 - Estimates of worst-case egress times using Nelson and Fruin turnstile values (each door allows 55 persons/minute)

\begin{tabular}{|c|c|c|c|c|c|c|}
\hline & \multicolumn{2}{|c|}{ Assembly } & \multicolumn{2}{|c|}{ Business } & \multicolumn{2}{|c|}{ Residential } \\
\hline & $\mathrm{S}^{\mathrm{b}}$ & $\mathrm{NS}^{\mathrm{c}}$ & $\mathrm{S}$ & NS & $\mathrm{S}$ & NS \\
\hline $\begin{array}{l}\text { Travel distance in } \\
\text { meters }(\mathrm{ft})\end{array}$ & $\begin{array}{c}76 \\
(250)\end{array}$ & $\begin{array}{c}61 \\
(200)\end{array}$ & $\begin{array}{l}91.4 \\
(300)\end{array}$ & $\begin{array}{c}61 \\
(200)\end{array}$ & $\begin{array}{l}61^{\mathrm{a}} \\
(200)\end{array}$ & $\begin{array}{l}30.5^{\mathrm{a}} \\
(100)\end{array}$ \\
\hline $\begin{array}{l}\text { Compartment side } \\
\text { dimensions in } \mathrm{m}(\mathrm{ft})\end{array}$ & $\begin{array}{c}54.3 \\
(178)\end{array}$ & $\begin{array}{c}43.6 \\
(143)\end{array}$ & $\begin{array}{c}65.2 \\
(214)\end{array}$ & $\begin{array}{c}43.6 \\
(143)\end{array}$ & $\begin{array}{c}43.6 \\
(143)\end{array}$ & $\begin{array}{l}21.6 \\
(71)\end{array}$ \\
\hline $\begin{array}{l}\text { Occupant \# } \\
\text { (load x area) }\end{array}$ & 6336 & 4090 & 458 & 205 & 102 & 25 \\
\hline Travel time (s) & 85 & 69 & 55 & 37 & 37 & 18 \\
\hline $\begin{array}{l}\text { Exit doors, \# x width } \\
\text { in } m \text { (people per set } \\
\text { of doors) }\end{array}$ & $\begin{array}{c}14 \times 2.4 \\
(452)\end{array}$ & $\begin{array}{l}9 \times 2.4 \\
(455)\end{array}$ & $\begin{array}{c}2 \times 1.17 \\
(229)\end{array}$ & $\begin{array}{l}2 \times 0.8 \\
(103)\end{array}$ & $\begin{array}{c}2 \times 0.8 \\
(51)\end{array}$ & $\begin{array}{c}2 \times 0.8 \\
(13)\end{array}$ \\
\hline Through door (s) & 247 & 248 & 250 & 112 & 56 & 14 \\
\hline
\end{tabular}

By using the turnstile approach in Table B2, it can be seen that the flows become restricted in the larger density spaces. This causes a longer time through the door. Again, as with the calculations made in Table B1, these can be considered as conservative estimates of egress times for movement without the presence of fire effects.

\section{Assumptions lead to alternative approach to calculate egress times}

There are three assumptions made to calculate the horizontal travel time and time through the door shown in Tables B1 and B2. It should be understood that these calculations are approximations of general situations and certain assumptions needed to be made to complete the calculations for each case. The first assumption involves an even distribution of occupants to the doors leading to the stairwells.

The second and third assumptions correspond to the addition of the "travel time" and the "through door" time to achieve the evacuation time for each room. There is an assumption made that "travel time" and "through door" time do not overlap. In the case where a queue forms after some period of time during the evacuation, the addition of these two values (travel and through door time) produces an evacuation time that is overly conservative. While the most remote occupant travels to the doorway, other occupants closer to the door leave the room. At some point, the remote occupant reaches a queue, meaning that they have not walked the entire travel distance. Once they reach the queue, the "through door" calculation dominates the evacuation time. Also, not all 
occupants are part of the queue, as was assumed in the "through door" calculation, since some leave while others join the queue.

The third assumption made is that "travel" and "through door" times both have values that are nonzero. This is not always the case. For lower density spaces, such as the residential unsprinklered, if a queue never forms, the evacuation time should equal the "travel" time of the most remote occupant in the space. For the very high density spaces, such as the assembly spaces, a queue forms immediately. In the case of assembly spaces, the evacuation time is equivalent to the "through door" time only.

Because of the previous assumptions made about the addition of travel time and time through the door, several evacuation simulations were run using the Simulex ${ }^{*}$ model $^{17}$ to correct these assumptions. The purpose of these evacuation simulations was to note how long occupants travel to the door unimpeded before a queue would form at the door, at which time the "through door" egress time dominates the total egress time from the room.

Each occupancy (sprinklered and unsprinklered) was drawn using TurboCAD and imported into Simulex. The room for each occupancy was equipped with exits at opposing corners (except for the Assembly spaces which had doors all around the space) separated by the maximum travel distance along the diagonal. Simulex allows the user to input a travel speed and body size for each occupant in the simulation. For each run, all occupants moved at $1.2 \mathrm{~m} / \mathrm{s}(235 \mathrm{ft} / \mathrm{min})$ unimpeded and contained the "median" adult body size (average of men and women). The occupants were spaced evenly throughout the room and moved immediately with the start of the simulation. The model, Simulex, was used only to track the unimpeded movement of the occupants from their starting position to the doorway. Overall, these Simulex runs were used to obtain the amount of time that occupants walked through the door before a queue formed. The results were as follows:

Table C - Simulated time before a queue developed at the doors

\begin{tabular}{|l|c|c|c|c|c|c|}
\hline & \multicolumn{2}{|c|}{ Assembly } & \multicolumn{2}{c|}{ Business } & \multicolumn{2}{c|}{ Residential } \\
\cline { 2 - 7 } & $\mathrm{S}$ & $\mathrm{NS}$ & $\mathrm{S}$ & $\mathrm{NS}$ & $\mathrm{S}$ & $\mathrm{NS}$ \\
\hline Time (s) before queue at door & $\approx 0$ & $\approx 0$ & 12 & 12 & 16 & $\infty$ \\
\hline
\end{tabular}

A time of 0 seconds corresponds to a queue developing almost instantaneously in the assembly spaces. This was expected due to the fact that the assembly spaces were packed at an allowable density of $0.46 \mathrm{~m}^{2} /$ person $\left(5 \mathrm{ft}^{2} /\right.$ person $)$. On the other hand, the unsprinklered residential space never formed a queue at the door, which is described as an infinite time in Table $C$. This was also expected due to the size of the space and the low number of occupants that needed to evacuate. For the business (sprinklered and unsprinklered) spaces and the sprinklered residential space, there was a recognized time

\footnotetext{
${ }^{*}$ Certain commercial entities, equipment, or materials may be identified in this document in order to describe an experimental procedure or concept adequately. Such identification is not intended to imply recommendation or endorsement by the National Institute of Standards and Technology, nor is it intended to imply that the entities, materials, or equipment are necessarily the best available for the purpose.
} 
before queuing began, and for the rest of the evacuation, the time through the door dominated. This shows that for these occupancies in this example, the evacuation time is a mix of the travel time and the time through the door. The appropriate evacuation time can be calculated, given the information in Table $\mathrm{C}$.

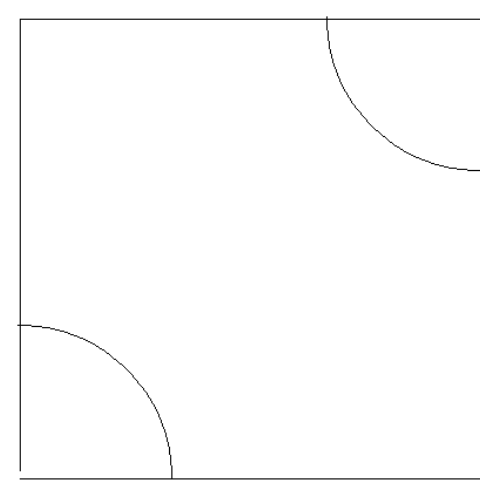

Figure 2: Arc display of occupants who leave the room before queuing occurs

Since Table $\mathrm{C}$ displays the time before queuing begins for the three occupancies (Business Sprinklered, Business Unsprinklered, and Residential Sprinklered), the number of people that pass through the door in that amount of time can be calculated. The time before the queue forms and the speed of the occupants at the specific density is known, and from this information, the distance that the occupants traveled to evacuate before a queue formed can be calculated. As shown in Figure 2, an arc is drawn in front of each doorway, with the radius consisting of the distance traveled by the occupants before queuing. Essentially, this arc is drawn to show the position of the occupants that left before queuing began. By solving for the area of the arc, the number of occupants residing in this arc space (using the density of the space) can be found and used as the number of occupants evacuating during the pre-queuing time. These occupants are then subtracted out from the population. Lastly, the time for the rest of the occupants to move through the door is calculated using two different methods; the effective width method and the turnstile method. These values are shown in Table B3.

Table B3 - Estimates of egress times without overlapping travel time and time through the doorway.

\begin{tabular}{|c|c|c|c|c|c|c|}
\hline & \multicolumn{2}{|c|}{ Assembly } & \multicolumn{2}{|c|}{ Business } & \multicolumn{2}{|c|}{ Residential } \\
\hline & $\mathrm{S}$ & NS & $\mathrm{S}$ & NS & $\mathrm{S}$ & NS \\
\hline Travel distance in meters $(\mathrm{ft})$ & $\begin{array}{c}76 \\
(250)\end{array}$ & $\begin{array}{c}61 \\
(200)\end{array}$ & $\begin{array}{c}91.4 \\
(300)\end{array}$ & $\begin{array}{c}61 \\
(200)\end{array}$ & $\begin{array}{c}61 \\
(200)\end{array}$ & $\begin{array}{c}30.5 \\
(100)\end{array}$ \\
\hline $\begin{array}{l}\text { Compartment side dimensions in } \mathrm{m} \\
\text { (ft) }\end{array}$ & $\begin{array}{c}54.3 \\
(178)\end{array}$ & $\begin{array}{c}43.6 \\
(143)\end{array}$ & $\begin{array}{c}65.2 \\
(214)\end{array}$ & $\begin{array}{c}43.6 \\
(143)\end{array}$ & $\begin{array}{c}43.6 \\
(143)\end{array}$ & $\begin{array}{l}21.6 \\
(71)\end{array}$ \\
\hline Occupant \# (load x area) & 6336 & 4090 & 458 & 205 & 102 & 25 \\
\hline Time (s) before queue at door & 0 & 0 & 12 & 12 & 16 & $\infty(18)$ \\
\hline $\begin{array}{l}\text { \# of occupants evacuating during } \\
\text { pre-queue per door } \\
\text { (\# of occupants left at time of queue) }\end{array}$ & $\begin{array}{c}0 \\
(452)\end{array}$ & $\begin{array}{c}0 \\
(455)\end{array}$ & $\begin{array}{c}17 \\
(212)\end{array}$ & $\begin{array}{c}17 \\
(86)\end{array}$ & $\begin{array}{l}15 \\
(36)\end{array}$ & $\begin{array}{l}13 \\
(0)\end{array}$ \\
\hline $\begin{array}{l}\text { Through door (s) for queuing } \\
\text { occupants - effective width method }\end{array}$ & 162 & 163 & 188 & 129 & 54 & $18^{\mathrm{a}}$ \\
\hline $\begin{array}{l}\text { Through door (s) for queuing } \\
\text { occupants - turnstile method }\end{array}$ & 247 & 248 & 231 & 94 & 39 & $18^{\mathrm{a}}$ \\
\hline
\end{tabular}


For all occupancies, except for the residential unsprinklered, horizontal travel time was not explicitly included in the egress times from each space. This is because the egress times are dominated by the time through the door, as shown in the Simulex runs of each occupancy (except for residential unsprinklered). Because of this, the total egress time for the space is calculated by adding the "time before queue at door" and the "through door" time (depending upon the calculation method preferred).

\section{Overall}

If a more conservative evacuation time is preferred, it is recommended to add the travel time to the door and the time through the door for the business occupancy (sprinklered and unsprinklered) and the sprinklered residential occupancy.

\section{$\underline{\text { Stairs }}$}

While prescriptive codes generally designate occupants as safe when they enter the protected egress stair, evacuation often requires that the occupants travel down stairs to the level of exit discharge. From the literature, the maximum flow rate in a (7/11) egress stair is estimated to be 1 person/s-m (18.5 people/min-ft) of effective width. Thus typical/maximum flow rates for $1.1 \mathrm{~m}$ (44 in) to $1.67 \mathrm{~m}$ (66 in) egress stairs range from 49 to 83 people per min. This does not include the effect of congestion in the stairs that results from accumulating flows from several floors accessing the stairs.

Table D shows the time for travel on the stairs from one floor to another (including one landing in between flights). The times were obtained by assuming that the calculated flow (people/min) from one section of the building is equal to the calculated flow on the next section, except for the unsprinklered residential. For the unsprinklered residential occupancy, since no queue has formed at the door, unimpeded speed was used to calculate movement on the staircase. For all other occupancies, the occupants travel from the doorway into the stairwell with the same calculated flow, but different widths, and therefore, different specific flows. It is assumed that they travel from the room at a specific flow of 1.3 people/m-s (24 people/ft-min). The Life Safety code specifies 7.6 $\mathrm{mm} /$ person $(0.3 \mathrm{in} /$ person $)$ of stair width, which was used to calculate the appropriate stair width for each occupancy, sprinklered or unsprinklered. By solving for the specific flow for the staircase, the appropriate travel speed can be obtained from the SFPE handbook ${ }^{4}$ in order to calculate the travel times for the section of stair. Stair travel distance was estimated by first, multiplying the vertical distance of the floor by the diagonal travel distance conversion factor found in Nelson's chapter of the SFPE Handbook, Table 3-14.3 ${ }^{4}$, and second, adding travel distance of the 2 landings. The calculated range of times for stair travel from one floor to another (assuming a $3.7 \mathrm{~m} \mathrm{(12}$ $\mathrm{ft}$ ) ceiling height - slab to slab and (7/11) stairs) was 12-25 seconds, depending upon the occupancy and method of calculation. 
Table D - Travel times on Stairs

\begin{tabular}{|l|c|c|c|c|c|c|}
\hline & \multicolumn{2}{|c|}{ Assembly } & \multicolumn{2}{c|}{ Business } & \multicolumn{2}{c|}{ Residential } \\
\cline { 2 - 7 } & $\mathrm{S}$ & $\mathrm{NS}$ & $\mathrm{S}$ & $\mathrm{NS}$ & $\mathrm{S}$ & $\mathrm{NS}$ \\
\hline Travel distance in room (m) & 76 & 61 & 91.4 & 61 & 61 & 30.5 \\
\hline People per door/stair & 452 & 455 & 229 & 103 & 51 & 13 \\
\hline Stair width (m) & 3.4 & 3.47 & 1.7 & 1.1 & 1.1 & 1.1 \\
\hline Travel dist on Stairs (m) & 20.5 & 20.5 & 13.7 & 11.2 & 11.2 & 11.2 \\
\hline $\begin{array}{l}\text { Time on each flight (s) - } \\
\text { effective width method }\end{array}$ & 25 & 25 & 16 & 13 & 13 & 12 \\
\hline $\begin{array}{l}\text { Time on each flight (s) - } \\
\text { turnstile method }\end{array}$ & 22 & 22 & 15 & 18 & 18 & 12 \\
\hline
\end{tabular}

Due to the number of occupants evacuating the three occupancies, especially in the case of the assembly space, the stairwells used in Table D are quite wide. The Life Safety Code specifies that handrails need to be placed $1.5 \mathrm{~m}$ (60 in) apart in order to provide support for occupants descending wider staircases. This handrail specification affects both the sprinklered and unsprinklered assembly spaces and the sprinklered business space. The calculations provided in Table D account for boundary layers (150 mm (6 in)) around the walls of the staircase, but not the handrails placed in the middle of the stair. Boundary layers from walls are used in evacuation calculations to account for lateral body sway in the stair 9 . For this estimation of stair time, it is assumed that the occupants will allow their bodies to get within millimeters of the handrail, negating the need for additional boundary layers around handrails. It is possible that the presence of handrails in the center of a staircase can negatively affect the flow of occupants during egress, but there lacks a sufficient amount of data on this topic to include such in the estimation.

Thus the benchmark egress times on the initial floor implied in current building codes range from approximately 5.5 minutes (sprinklered assembly) to $0.3 \mathrm{~min}$ (unsprinklered residential), depending upon the method of calculation used and the type of occupancy. When added to the alarm time for the initial notification of the occupants (generally on the order of one minute from sustained ignition of the first item), estimated premovement times (Table A) and descent times (per floor times number of floors, Table D) as appropriate, these can be used to benchmark egress system performance for systems designed by calculation.

\section{Congestion and Merging Flows on Stairs}

Merging flows occur when occupants from a floor and the stairwell above enter the stairwell section simultaneously during downward flow. This can also occur during upward flow if occupants are traveling from basement levels of the building. In a highrise building, congestion points occur at each entrance into the stairway from all floors of the building.

During merging flows, it is likely for researchers to witness the phenomenon of deference behavior. Deference behavior describes how occupants from the floors above yield to the 
occupants entering the stairwell from their floor. This behavior is often seen on airplanes where the rows leave before the passengers already waiting in the plane aisle.

Merging flows and congestion frequently occur in high-rise buildings during full or total evacuation of the structure. Currently all US model building codes (International Building Code and NFPA5000) design tall buildings, particularly door and stair widths, based on a partial or phased evacuation plan for the building. The code specifies that the width of the stairs depends on the number of occupants on a particular floor, irrespective of building zones or the entire building population. This would result in congestion in high-rise buildings if the entire population evacuates simultaneously. Since 9/11, New York City has imposed a requirement for an evacuation drill (the entire population evacuating to the street) annually. It is reported that occupants of surrounding buildings seeing the evacuation themselves, then evacuate their buildings. Situations like this result in the opinion that the process for evacuation of tall buildings needs to be rethought.

\section{Elevators}

Currently there are no building codes that permit elevators to be used as a means of occupant egress, and ASME A $17.1^{18}$ requires signs at all elevators warning that they shall not be used in fires. NFPA 5000 permits protected elevators as a secondary means of egress for air traffic control towers and the City of Las Vegas accepted elevators as a primary means of occupant egress from Stratosphere Tower based on a performancebased design $^{19}$.

US codes require accessible elevators as part of a means of egress that may be used by the fire service to evacuate people with disabilities. These elevators must comply with the emergency operation requirements of ASME A17.1 (Phase II emergency operation by the fire service), be provided with emergency power, be accessible from an area of refuge or a horizontal exit (unless the building is fully sprinklered), and operate in a smoke protected hoistway. Phase II operation involves the use of an elevator by a firefighter for fire service access or for rescue of people with disabilities performed under manual control (with the use of a special key).

According to a survey ${ }^{20}$ by the International Organization for Standardization technical committee on elevators (ISO TC178), there are twelve countries that require firefighter lifts, generally in buildings that exceed $30 \mathrm{~m}(98 \mathrm{ft})$ in height. Standards for firefighter lifts generally describe a firefighting shaft consisting of protected elevators, enclosed lobbies on each floor and an associated stairway, all of which have at least 1-hr fire resistance and smoke protection. Firefighters use the elevator to move their people and equipment to two floors below the fire, from which point they advance up the stairs, which contain a standpipe and provide a protected path for retreat. These firefighter lifts can be used to provide evacuation assistance for occupants with disabilities after suppression activities are underway.

NIST studies have shown that the use of protected elevators to supplement stairs for occupant egress (not just for people with disabilities) can result in a significant reduction 
in total egress times, especially for taller buildings ${ }^{21}$. Given the observation that occupants may resist certain evacuation approaches, such as phased evacuation, protected elevators is clearly the most promising to address the problem without incurring huge penalties in decreased leasable space.

\section{Conclusions}

Based on the preceding analysis, the longest egress times expected in buildings designed in accordance with current (prescriptive) U.S. codes would occur in larger, assembly occupancies without fixed seating (the so-called festival seating) having the maximum occupant densities. Benchmark egress times would be approximately 4 minutes premovement, 5 minutes to get into the stairs, and $0.5(25 / 60 \mathrm{~s})$ minutes per floor to get to the level of exit discharge.

In an office (business occupancy) egress times might be 3 minutes pre-movement, 5 minutes to get into the stairs, and 0.3 minutes per floor to get to the level of exit discharge. In residential occupancies egress times might be 4 minutes pre-movement (but with much higher variability since there is likely additional delays to assist family members, obtain pets and valuables, etc.), 2 minutes to get into the stairs, and 0.3 minutes per floor to get to the level of exit discharge. These times attempt to account for queuing entering the stairs but do not include delays due to congestion within stairs that would be expected to increase with building height.

These times represent estimates of the egress performance implied by egress system designs prescribed in current U.S. model building codes. These should not be taken as requirements nor even as the performance intended by the code developers, since this is the first attempt to quantify what might be expected from means of egress complying with the minimum requirements of the codes. The intent of this paper is simply to provide benchmarks that can be compared against performance-based egress analyses. 


\section{References}

${ }^{1} 1984$ Fire Almanac, NFPA Quincy, MA 02269.

${ }^{2}$ Reily, E., “Third Code Revolution: A Brief History of US Building Codes," Sprinkler Age, 10, 7, July 1991.

${ }^{3}$ Building Standard Law of Japan, Official Translation by the Architectural Institute of Japan, Tokyo.

${ }^{4}$ Nelson, H.E. and Mowrer, F.W. (2002), "Section 3, Chapter 14 Emergency Movement," The SFPE

Handbook of Fire Protection Engineering, $3^{\text {rd }}$ Edition, National Fire Protection Association, Quincy, MA.

${ }^{5}$ Gann, R.G., Averill, J.D., Johnsoon, E.L., Nyden, M.R., \& Peacock, R.D., "Smoke Component Yields from Room-scale Fire Tests," National Institute of Standards and Technology, NIST TN 1453, 159 pp., April 2003.

${ }^{6}$ Bukowski, R. W., "Predicting the Fire Performance of Buildings: Establishing Appropriate Calculation Methods for Regulatory Applications," Proc AsiaFlam '95, International Conference on Fire Science and Engineering, March 15-16, 1995, Kowloon Hong Kong, pp 9-18.

${ }^{7}$ International Building Code, 2003 edition, International Code Council, Inc., Falls Church, VA 22041.

${ }^{8}$ Building Construction and Safety Code (NFPA 5000-2003), National Fire Protection Assn., Quincy, MA 02269.

9 Proulx, G. (2002), "Movement of People: The Evacuation Timing, Section 3 Chapter 13," The SFPE Handbook of Fire Protection Engineering $3^{\text {rd }}$ ed., P.J. DiNenno ed., NFPA, Quincy, MA.

${ }^{10}$ Fahy, R.F. \& Proulx, G., "Toward Creating a Database on Delay Times to Start Evacuation and Walking Speeds for Use in Evacuation Modeling," Proceedings of the Second International Symposium on Human Behaviour in Fire, Boston, Mass., USA (2001).

${ }^{11}$ Brennan, P. "Timing Human Response in Real Fires," Proceedings of the Fifth International Symposium on Fire Safety Science, Melbourne, Australia (1997).

${ }^{12}$ Shields, T.J., Boyce, K.E., and Silcock, G.W.H., "Towards the Characterization of Large Retail Stores," Proceedings of the First International Symposium on Human Behaviour in Fire, Belfast, UK (1998).

${ }^{13}$ Life Safety Code (NFPA 101-2003), National Fire Protection Assn., Quincy, MA 02269.

${ }^{14}$ Pauls, J. (1995), "Movement of People, Section 1 Chapter 15," The SFPE Handbook of Fire Protection Engineering $2^{\text {nd }}$ Edition, P.J. DiNenno, ed., NFPA, Quincy, MA.

${ }^{15}$ Fruin, J.J., Pedestrian Planning and Design, Revised Edition, Elevator World, Inc., Mobile, AL, Fruin, J.J., ed, 211 p., 1987.

${ }^{16}$ Nelson, H.E. (1990), “FPETOOL User's Guide,” NISTIR 4439, National Institute of Standards and Technology, Gaithersburg, MD.

${ }^{17}$ IES, "Simulex: Evacuation Modeling Software," Integrated Environmental Solutions, Inc., March, 2001.

${ }^{18}$ Safety Code for Elevators and Escalators ASME A17.1 2000, American Society of Mechanical Engineers, New York, NY.

${ }^{19}$ Bukowski, R.W., "Protected Elevators for Egress and Access During Fires in Tall Buildings," Proc of the CIB-CTBUH Conf on Tall Buildings, 20-23 October 2003, Kuala Lumpur Mayalasia.

${ }^{20}$ Comparison of Worldwide Lift (Elevator) Safety Standards - Firefighters Lifts (Elevators), ISO/TR 16765:2002(E), ISO, Geneva, Switzerland.

${ }^{21}$ Klote, J.H., Alvord, D.M., Levin, B.M., and Groner, N.E. (1992), "Feasibility and Design Considerations of Emergency Evacuation by Elevators," NISTIR 4870, National Institute of Standards and Technology, Gaithersburg, MD. 
Appendix $\mathrm{H}$

Is There a Need to Enclose Elevator Lobbies in Tall Buildings? 


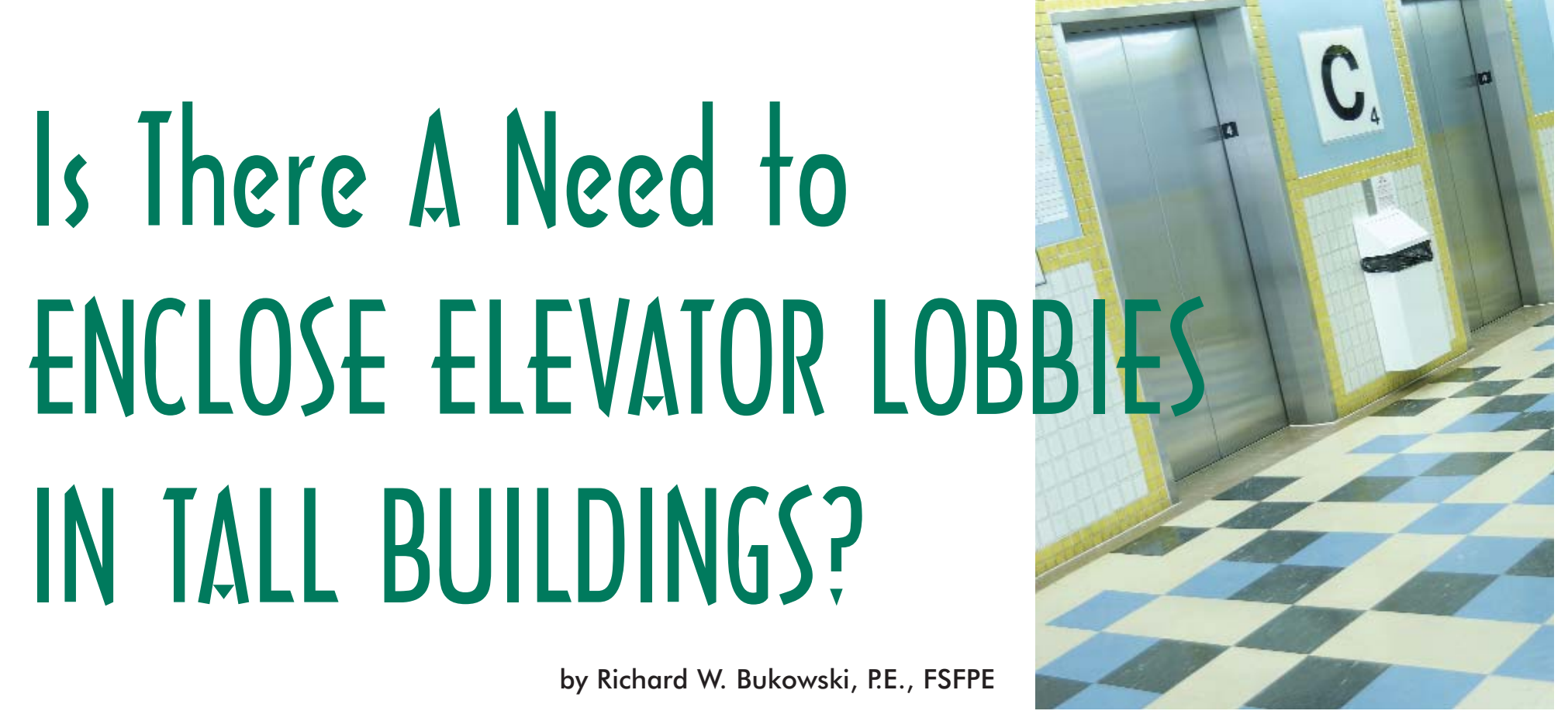

everal proposals have been submitted in recent years to model building code organizations to require enclosure of elevator lobbies in order to restrict the movement of smoke to other parts of buildings via hoistways. A significant development in this area occurred recently when the National Institute of Standards and Technology (NIST) - which was already involved with a consortium of industry representatives, codes and standards developers, and other interested parties in a study of the protection of elevators for occupant evacuation and fire service access 1 - was asked by the U.S. General Services Administration (GSA) to research the conditions under which enclosed elevator lobbies were called for. This article will provide an overview of the progress made to date on this line of research.

\section{Background}

Vertical shafts in tall buildings are subject to something called "stack effect," which describes an induction of airflow resulting from differences in temperature between the inside and outside of the shaft. When the outside temperature is colder, the induced flow is upward (normal stack effect); when the outside temperature is warmer, the flow is downward (reverse stack effect). While firestopping is effective in limiting the upward spread of flames through vertical openings and shafts, smoke is far harder to stop because even small leakages can allow it to pass. This has led to the use of smoke management systems which employ pressure differences to block smoke flow even through small cracks ${ }^{2}$.

There are several examples of fires in which smoke spread in shafts has been implicated in deaths on upper floors, with perhaps the most infamous being the November 21, 1980, conflagration at the MGM Grand in Las Vegas. Although the flames were confined to the casino area on the first floor of the structure, 61 of the 85 casualties occurred on upper (above the 20th) floors due to smoke spread up elevator hoistways and seismic joints between the building core and wings. ${ }^{3}$

It is not surprising that such tragedies are frequently cited as substantiation for proposals to enclose elevator lobbies. However, the potential for smoke flow in hoistways is a function not only of leakage of the elevator doors but also of the strength of the stack flow, fire temperature (buoyancy flows) and the height of the shaft. Each of these factors was taken into account in NIST's analysis of the potential flows under varying conditions in order to identify those situations where significant shaft flows might be expected.

\section{Shaft Flow Analysis}

NIST contracted with John H. Klote, Inc.- which is a well known for its expertise in the fields of both smoke management and elevators - for the analysis. Klote's report contains the details of the scenarios examined and the results obtained for each ${ }^{4}$ and was summarized in a paper presented at the 2004 ASME Workshop on Use of Elevators in Fires and Other Emergencies. ${ }^{5}$

\section{Scenarios Studied}

A number of primary variables were identified for study, including building size and configuration (five types), extent of fire (three types), lobby enclosure (two conditions), weather (winter or summer), and two alternate methods of preventing smoke flow in the shaft. This resulted in the 27 scenarios shown in Table 1, which were then evaluated using a combination of numerical models and NIST's Consolidated Model of Fire Growth and Smoke Transport (CFAST) ${ }^{6}$ and CONTAM multizone airflow and contamination transport analysis software programs. ${ }^{7}$ 
Table 1. Scenarios Examined.

\begin{tabular}{|c|c|c|c|c|c|c|}
\hline SCENARIO & BUILDING' & $\begin{array}{c}\text { FIRE } \\
\text { TYPE }^{2}\end{array}$ & $\begin{array}{c}\text { FIRE } \\
\text { FLOOR }^{3}\end{array}$ & $\begin{array}{c}\text { ENCLOSED } \\
\text { ELEV. LOBBY }\end{array}$ & WEATHER ${ }^{4}$ & $\begin{array}{c}\text { ALTERNATIVE } \\
\text { METHODS }^{5}\end{array}$ \\
\hline 1 & $A$ & $\mathrm{SP}$ & 2 & $\mathrm{Y}$ & W-NW & none \\
\hline 2 & $A$ & FDR & 2 & $Y$ & W-NW & none \\
\hline 3 & $A$ & FDF & 2 & $\mathrm{Y}$ & W-NW & none \\
\hline 4 & A & FDF & 2 & $\mathrm{~N}$ & W-NW & none \\
\hline 5 & $B$ & FDF & 2 & $\mathrm{Y}$ & W-NW & none \\
\hline 6 & B & FDF & 2 & $\mathrm{~N}$ & W-NW & none \\
\hline 7 & $B$ & FDF & 2 & $\mathrm{~N}$ & W-NW & TB \\
\hline 8 & $\mathrm{~B}$ & FDF & 2 & $\mathrm{~N}$ & W-NW & JPC \\
\hline 9 & $\mathrm{C}$ & FDF & 2 & $Y$ & W-NW & none \\
\hline 10 & C & FDF & 2 & $\mathrm{~N}$ & W-NW & none \\
\hline 11 & C & FDF & 2 & $\mathrm{~N}$ & W-W & none \\
\hline 12 & C & FDF & 2 & $\mathrm{~N}$ & W-NW & TB \\
\hline 13 & $\mathrm{C}$ & FDF & 2 & $\mathrm{~N}$ & W-NW & JPC \\
\hline 14 & $\mathrm{D}$ & FDF & 2 & $Y$ & W-NW & none \\
\hline 15 & D & FDF & 2 & $\mathrm{~N}$ & W-NW & none \\
\hline 16 & $\mathrm{D}$ & FDF & 2 & $\mathrm{~N}$ & W-NW & TB \\
\hline 17 & D & FDF & 2 & $\mathrm{~N}$ & W-NW & JPC \\
\hline 18 & $\mathrm{D}$ & FDR & 2 & $Y$ & W-NW & none \\
\hline 19 & $D$ & FDR & 2 & $\mathrm{~N}$ & W-NW & none \\
\hline 20 & $\mathrm{D}$ & FDR & 2 & $\mathrm{~N}$ & W-NW & TB \\
\hline 21 & $\mathrm{D}$ & FDR & 2 & $\mathrm{~N}$ & W-NW & JPC \\
\hline 22 & D & FDF & 36 & $Y$ & S-NW & none \\
\hline 23 & D & FDF & 36 & $\mathrm{~N}$ & S-NW & none \\
\hline 24 & $E$ & FDF & 2 & $Y$ & W-NW & none \\
\hline 25 & $E$ & FDF & 2 & $\mathrm{~N}$ & W-NW & none \\
\hline 26 & $E$ & FDF & 2 & $\mathrm{~N}$ & W-NW & TB \\
\hline 27 & $E$ & FDF & 2 & $\mathrm{~N}$ & W-NW & JPC \\
\hline $\begin{array}{l}\text { 1. See Table } 2 . \\
\text { 2. SP is a sprin } \\
\text { 3. FDR fires are } \\
\text { 4. W-NW for wi }\end{array}$ & $\begin{array}{l}\text { d fire, FDR is } \\
\text { with no wind, }\end{array}$ & develop & $\begin{array}{l}\text { fire, FDF } \\
\text { or indicate }\end{array}$ & $\begin{array}{l}\text { Ily developed floor } \\
=\text { fires are located } \\
\text { or winter with winc }\end{array}$ & open floor plan & ace on that floor. \\
\hline
\end{tabular}

\section{Building Characteristics}

The buildings considered were all office use and were assumed to have typical floor heights of 4.0 meters (13.1 feet) except for the ground floors, which were assumed to have heights of 6.0 meters (19.7 feet). Total building heights ranged from 6 to 58 floors. The number of elevators and their arrangements were typical for the building's sizes and configurations-see Table 2. The buildings were based on several actual GSA office buildings previously studied. ${ }^{8}$

Table 2. Building Characteristics.

\begin{tabular}{|cccc|}
\hline BUILDING & $\begin{array}{c}\text { NUMBER } \\
\text { OF STORIES* }\end{array}$ & \multicolumn{1}{c|}{$\begin{array}{c}\text { PASSENGER } \\
\text { ELEVATORS }\end{array}$} & $\begin{array}{c}\text { SERVICE } \\
\text { ELEVATOR }\end{array}$ \\
\hline A & 6 & 1 bank of 3 elevators & None \\
B & 13 & 1 bank of 6 elevators & None \\
C & 16 & 1 bank of 6 elevators & None \\
D & 35 & $\begin{array}{l}\text { 3 banks of 6 elevators: } \\
\text { low, medium \& high rise }\end{array}$ & 2 \\
E & 58 & $\begin{array}{l}\text { 3 banks of 8 elevators: } \\
\text { low, medium \& high rise }\end{array}$ & 2 \\
\hline
\end{tabular}

* Does not include mechanical penthouse.

\section{Flow Paths}

Buildings are surprisingly leaky, and these leaks are characterized in the smoke management literature. ${ }^{9}$ Leakages occur through construction cracks and around doors, especially elevator doors. Values typical of reasonably tight construction were assumed for this study and are displayed in Table 3. Hoistway vents required by the building codes and increased leakage due to warpage of some doors by the heat of the fire are included. ${ }^{10}$ 
Table 3. Flow Coefficients and Equivalent Leakage Areas for Building Flow Paths.

\begin{tabular}{|c|c|c|c|c|c|}
\hline COMPONENT & $\begin{array}{l}\text { PATH } \\
\text { TYPE }^{1}\end{array}$ & $\begin{array}{c}\text { PATH } \\
\text { IDENTIFIER }^{2}\end{array}$ & $\begin{array}{c}\text { FLOW } \\
\text { COEFFICIENT }^{3}\end{array}$ & \multicolumn{2}{|c|}{$\begin{array}{c}\text { AREA } \\
\mathbf{m}^{2} / \mathbf{m}^{2}\left(\mathbf{f t}^{2} / \mathbf{f t}^{2}\right)\end{array}$} \\
\hline Exterior wall & 0 & W-EXT & 0.65 & \multicolumn{2}{|c|}{0.00017} \\
\hline Exterior wall below grade ${ }^{5}$ & $\mathrm{O}$ & W-UG & 0.65 & \multicolumn{2}{|c|}{0.000085} \\
\hline Interior wall & $\mathrm{O}$ & W-INT & 0.65 & \multicolumn{2}{|c|}{0.00011} \\
\hline Elevator wall & $\mathrm{O}$ & W-EL & 0.65 & \multicolumn{2}{|c|}{0.00084} \\
\hline Floor & $\mathrm{O}$ & FLOOR & 0.65 & \multicolumn{2}{|c|}{0.000052} \\
\hline Roof $^{5}$ & $\mathrm{O}$ & ROOF & 0.65 & \multicolumn{2}{|c|}{0.000026} \\
\hline Closed doors & & & & $\mathrm{m}^{2}$ & $\mathrm{ft}^{2}$ \\
\hline Single door & $\mathrm{T}$ & DR-SI & 0.65 & 0.016 & 0.17 \\
\hline Double door & $\mathrm{T}$ & DR-DO & 0.65 & 0.027 & 0.29 \\
\hline Elevator doors ${ }^{6}$ & $\mathrm{~T}$ & DR-EL42 & 0.65 & 0.047 & 0.50 \\
\hline Large elevator doors ${ }^{7}$ & $\mathrm{~T}$ & DR-EL48 & 0.65 & 0.049 & 0.53 \\
\hline Warped single door & $\mathrm{T}$ & DR-SI-W & 0.65 & 0.043 & 0.46 \\
\hline Warped double door & $\mathrm{T}$ & DR-DO-W & 0.65 & 0.070 & 0.75 \\
\hline \multicolumn{6}{|l|}{ Open doors } \\
\hline Single door & $\mathrm{T}$ & DR-SI-O & 0.35 & 1.95 & 21 \\
\hline Double door & $\mathrm{T}$ & DR-DO-O & 0.35 & 3.90 & 42 \\
\hline \multicolumn{6}{|l|}{ Shaft equivalent area ${ }^{8}$} \\
\hline Stairwell & 0 & STAIR & 0.60 & 2.3 & 25 \\
\hline 3-car passenger elevator & $\mathrm{O}$ & EL-P3 & 0.60 & 230 & 2500 \\
\hline 4-car passenger elevator & $\mathrm{O}$ & EL-P4 & 0.06 & 360 & 3900 \\
\hline 2-car service elevator & $\mathrm{O}$ & EL-S2 & 0.60 & 160 & 1700 \\
\hline \multicolumn{6}{|l|}{ Open elevator vent ${ }^{9}$} \\
\hline 3-Car passenger elevator & $\mathrm{O}$ & EL-P3V & 0.32 & 0.70 & 7.5 \\
\hline 4-Car passenger elevator & $\mathrm{O}$ & EL-P4V & 0.32 & 1.05 & 11.3 \\
\hline 2-Car service elevator & $\mathrm{O}$ & EL-S2V & 0.32 & 0.52 & 5.6 \\
\hline Roll down barriers & $\mathrm{T}$ & ROLL & 0.65 & 0.011 & 0.12 \\
\hline \multicolumn{6}{|l|}{ Shafts with cars in place } \\
\hline 3-car passenger elevator & $\mathrm{O}$ & EL-P3C & 0.65 & 6.5 & 70 \\
\hline 4-car passenger elevator & $\mathrm{O}$ & EL-P4C & 0.65 & 9.1 & 98 \\
\hline
\end{tabular}

1. O indicates an orifice path for which flow is in one direction, $T$ indicates a two-directional flow path. The two-directional flow is used for doors, and the leakage is uniformly distributed over the height of the door.

2. The path identifiers are used with CONTAMW for data input.

3. The flow coefficient is defined as $m \mathrm{~A}^{-1}(2 \rho \Delta p)^{-1 / 2}$ where $m$ is the mass flow through the path, $\rho$ is the density of gas flowing in the path, and $p$ is the pressure difference across the path.

4. Areas for walls and floors are listed as area of flow path per unit of area of wall or of floor as appropriate.

5. Due to lack of experimental data, the flow areas of the exterior wall below grade and the roof were estimated at half that of the exterior wall and floor, respectively.

6. This elevator door is $1.07 \mathrm{~m}(3.5 \mathrm{ft})$ wide. It is used for all passenger elevators in this study except for that in Building $\mathrm{E}$.

7. This elevator door is $1.22 \mathrm{~m}(4.0 \mathrm{ft})$ wide. It is used for the passenger elevators in Building $E$ and the service elevators.

8. Shaft equivalent areas are used to calculate the pressure losses due to friction in shafts. For more information, see chapter 6 of Klote and Milke (2002).

9. Vent area was calculated at $3.5 \%$ of the shaft area but not less than $0.28 \mathrm{~m}^{2}\left(3 \mathrm{ft}^{2}\right)$.

\section{Weather}

Because stack effect is driven by the difference between inside and outside temperatures, typical environmental conditions needed to be taken into account. The following representative conditions were used in the calculations.

- winter outdoor temperature: $-16^{\circ} \mathrm{C}\left(3^{\circ} \mathrm{F}\right)$

- summer outdoor temperature: $35^{\circ} \mathrm{C}\left(95^{\circ} \mathrm{F}\right)$

- wind speed: 11 meters per second (25 miles per hour)

\section{Interior Temperature}

Interior temperatures in buildings are normally maintained in a narrow range around $23^{\circ} \mathrm{C}\left(73^{\circ} \mathrm{F}\right)$, so that was the value used in the calculations.

\section{Limiting the Spread of Smoke in Shafts}

The spread of smoke in shafts can be limited by sealing leakages and/or by producing pressure differences that result in airflows in the desired direction. The recognition that many leakages are hidden or difficult to seal leads to the use of active smoke management techniques, particularly for egress stairways, but there are some other techniques that might be effective in reducing leakages into elevator hoistways to low levels. 
Landing doors for both passenger and freight elevators are known to be particularly leaky because they open laterally by a mechanism carried on the elevator cars. Gaps, the provision of safety mechanisms to prevent the doors from closing on passengers, and the tendency of sliding doors to jam when subjected to pressure differences all tend to exacerbate the leakage problem. As a result, solutions to reduce smoke leakage into hoistways generally involve the provision of an enclosed lobby (creating an air lock with an entry door capable of far better sealing against infiltration) or by a roll-down barrier that covers the normal elevator door. Both of these approaches were evaluated.

Suggestions have been made that hoistways themselves could be blocked during a fire by an extendable or inflatable barrier, mounted either within them or on the bottoms of the cars, that would be deployed when needed. This approach has many limitations (e.g., interference by the elevator cables unless the car is above the barrier), but it was decided to examine the potential for positioning a car near the neutral plane to partially block the hoistway and reduce the flow in the shaft. If found to be effective, this could be done for no additional cost beyond programming elevator controllers appropriately. Therefore, the study also evaluated the "judicious" positioning of elevator cars near the neutral plane to limit shaft flow.

Another new technology is a type of elevator door seal that is intended to be tight enough to restrict smoke leakage into hoistways. These type of seals are currently being tested in Japan (where they originate) and the U.S. In the past, however, similar seals were found to be problematic because they required adjustments to door closing forces that increased the hazard of passengers becoming struck. It remains to be seen if the newer seals will perform better.

\section{Methodology}

Fires on a lower floor during winter and on an upper floor in summer were examined to determine the quantity of smoke that might spread to the upper or lower floors, respectively, by means of the hoistways (heat is not a significant hazard long distances from a fire source because temperatures rapidly diminish to near ambient level through entrainment and heat losses to the surroundings). It was assumed that all exterior and interior stairway doors were closed. Windows to the exterior were also assumed to be closed except for in the case of a fully developed floor fire, the intense heat of which can break the glass.

The hazards of smoke obscuration and toxic potency were assessed using engineering criteria frequently employed in building performance analysis. ${ }^{11}$ A fire (heat release rate) curve representative of the scenario being considered was first chosen - see Figure 1 for the heat release rates selected. Then the CFAST fire model was used to determine the burning rate as affected by the geometry and ventilation, resulting in the production over time of energy, smoke particulates and combustion gasses. Consumption of oxygen and its effect on burning rate and combustion chemistry was also computed.

The energy and mass produced moves through the building by buoyancy and building flows, including stack effect. These were calculated by the model CONTAM, resulting in estimates of temperature, smoke density and gas concentrations over time in spaces remote from the fire. The exposure of evacuating occupants would change as they moved from space to space, but the analysis used the more conservative approach of evaluating the exposure of stationary occupants in order to take into account those with disabilities or otherwise unable to escape.

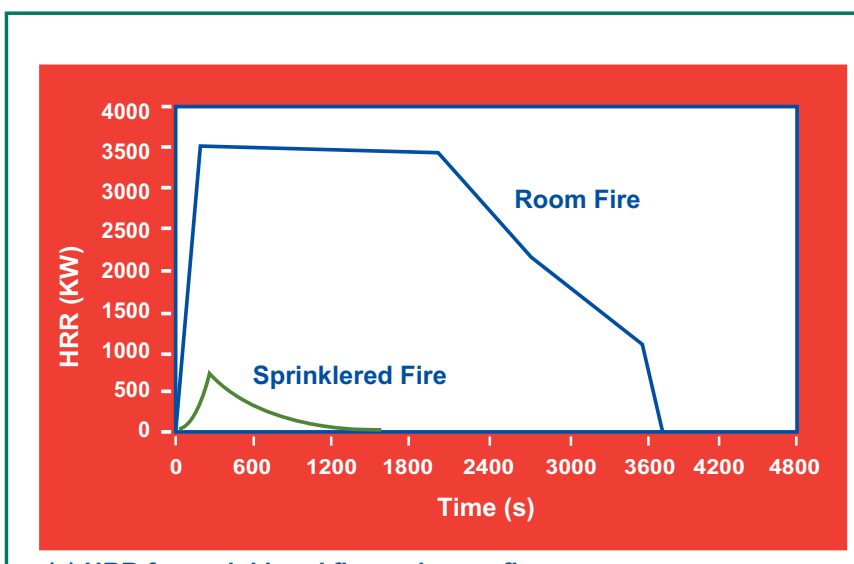

(a) HRR for sprinklered fire and room fire.

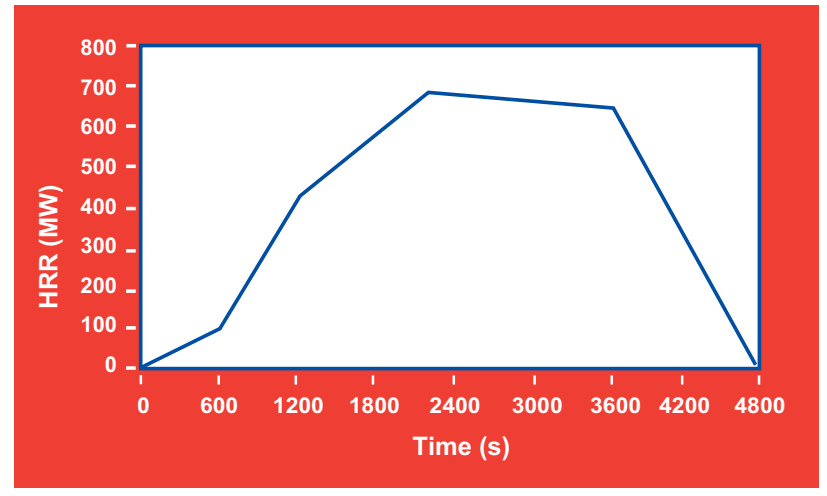

(b) HRR for floor fire.

Figure 1. Heat release rates.

\section{Results}

As expected, sprinklered fires were not shown to represent a significant hazard to occupants because the sprinklers activated and extinguished the fires before they could release significant energy or mass. Little or no smoke or gasses entered the hoistways, and none reached remote locations in any building regardless of height or other conditions examined.

(continued) 


\section{Elevator Lobbies in Tall Buildings (continued)}

Fully developed room fires (flashovers) released significant energy and mass, and strong fire-induced flows drove those products to the hoistways. Enclosed lobbies prevented any substantial portion of that mass or energy from entering the hoistways, but the absence of a lobby resulted in untenable conditions in terms of reduced visibility and toxicity on the upper floors of the tallest building, which had the greatest stack effect.

Where the fire spread to the entire floor, enclosed lobbies continued to provide some protection, allowing sufficient smoke to exceed visibility limits at remote locations in all of the buildings but limiting toxicity to less than the limiting value for the time studied. In addition, times at which visibility limits were exceeded occurred significantly later when lobbies were present. The increases in time to untenable visibility increased by 50 percent to 200 percent for lobbies enclosed by normal construction and by 0 percent to 20 percent with the use of roll down barriers due to their greater leakage characteristics (temporary barriers with better leakage characteristics would be expected to perform better). Without lobbies, tenability conditions for both visibility and toxicity were exceeded at locations remote from the fire in all buildings regardless of height.

The "judicious" positioning of elevator cars had no effect on smoke flow in the hoistways because the leakage area around cars is quite large.

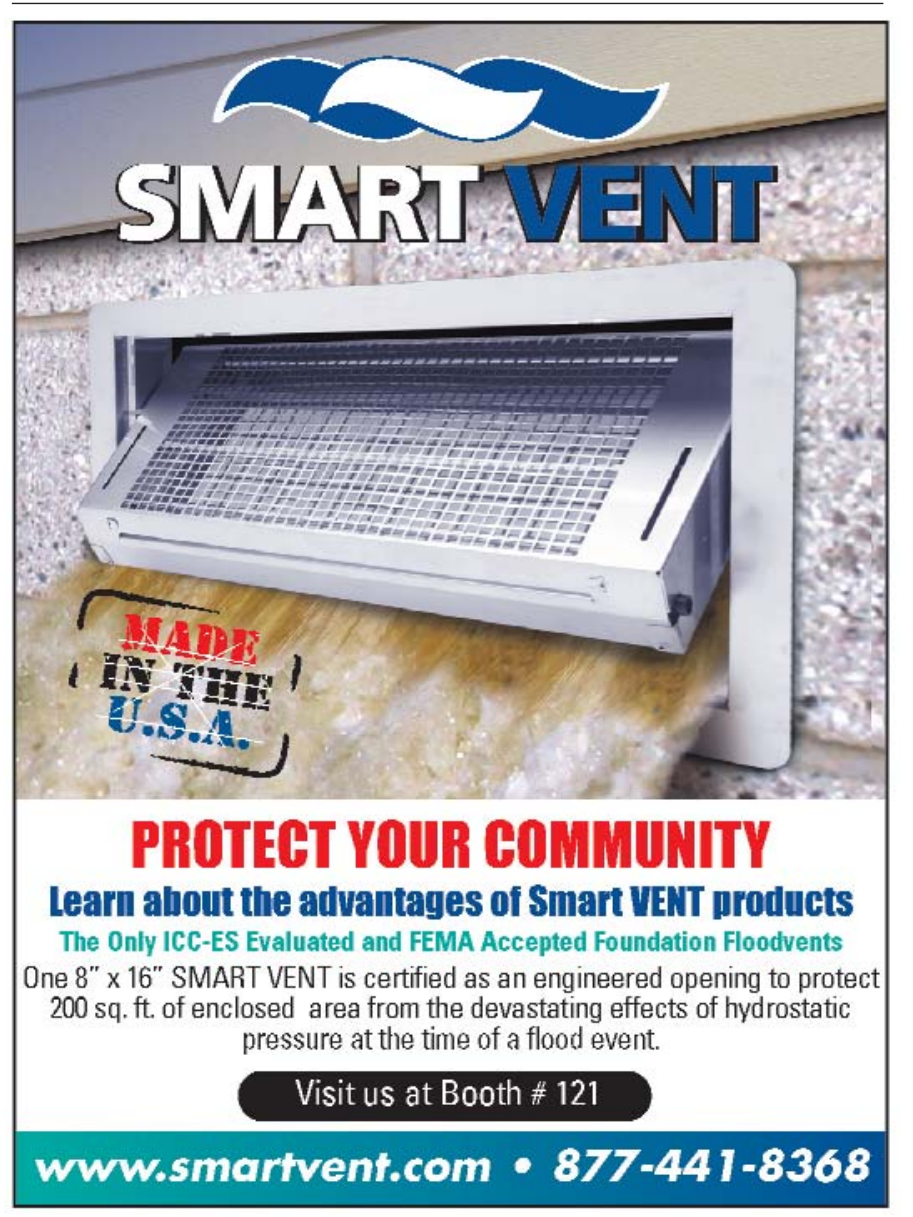

\section{Discussion}

It may therefore be concluded from the study results that enclosed elevator lobbies are not necessary in buildings with operational fire sprinkler systems. From a risk management perspective, this means that the need for enclosed elevator lobbies depends on the probability that a sprinkler system will not work (operational reliability) and the consequences (expected losses) of such a failure.

\section{Sprinkler System Reliability}

Data on in-service failures of wet pipe sprinkler systems in U.S. Department of Energy (DOE) facilities show operational reliabilities of 99.2 percent, ${ }^{12}$ but these systems are subject to testing and maintenance programs more rigorous than those typically performed on commercial systems. Studies of commercial sprinkler systems installed per industry standards indicate an operational reliability of about 95 percent, ${ }^{13}$ so the decision whether or not to incorporate enclosed lobbies might be based on a 5-percent probability of sprinkler system failure unless a maintenance program comparable to the DOE's is in place.

Statistics indicate that most sprinkler system failures are due to impaired water supplies such as closed valves, blocked pipes, impaired sources, etc., which tend to affect sections of or the entire system. As such, system reliability can be increased by active monitoring of water supplies and controls. The general consensus is that problems with individual sprinkler heads are rare. However, it may well be asserted that current data do not accurately reflect the upsurge in the use of quick-response heads, and the fact that several models of these have been involved in recent recalls underscores the need to update field reliability data for light hazard systems commonly used in business and residential occupancies.

\section{Consequences of Failure}

Minimal stack effect was produced in shafts - including hoistways - in low-rise buildings (less than 7 stories or 75feet high), so the spread of smoke and fire gasses to upper floors may be considered to be of no great concern even when there are no operational sprinklers. While smoke from fully developed floor fires exceeded tenability limits in lowrise buildings without elevator lobbies, this occurred long after such buildings would be expected to be fully evacuated. A risk manager might therefore conclude that enclosed lobbies are not needed in low-rise buildings, particularly when sprinklered.

In taller buildings, which experience greater stack effect and require more time for occupant egress, untenable conditions are reached much sooner if lobbies are not provided and if sprinkler system failure allows a fire to grow to room 
flashover or full floor involvement. A risk manager may therefore decide to provide enclosed elevator lobbies in high-rise buildings even when sprinklered unless the sprinklers can be shown to have operational reliabilities similar to that achieved by DOE systems. Elevator lobbies should be of 2-hour fire-resistance rated construction (1-hour rated in fully sprinklered buildings) and have direct access to an egress stair.

Richard W. Bukowski, P.E., FSFPE, is a Senior Engineer and Coordinator of Standards and Codes for the National Institute of Standards and Technology Building and Fire Research Laboratory, chairs several committees and task groups for the National Fire Protection Association (NFPA), is Coordinator of the International Council on Building Standards and Documentation (CIB) Working Commission 14: Fire, and is active in the work of CIB TG50: Tall Buildings. He is also the U.S. representative to ISO TAG8, which advises the International Organization for Standardization (ISO) Technical Management Board and provides oversight to all ISO Technical Committees working in the building and fire areas, and served on the committee that developed the International Code Council Performance Code $^{\mathrm{Tm}}$ for Buildings and Facilities and on NFPA's Standards Council.

Bukowski is a Fellow of the Society of Fire Protection Engineers and a licensed Professional Engineer in the States of Illinois and Maryland. His professional awards include being was named 1997 Automatic Fire Alarm Association Person of the Year and 2003 Commerce Department Federal Engineer of the Year by the National Society of Professional Engineers.

\section{References}

1. Bukowski, R.W., "Protected Elevators for Egress and Access During Fires in Tall Buildings, Strategies for Performance in the Aftermath of the World Trade Center." Proceedings of the International CIB-CTBUH Conference on Tall Buildings. CIB Publication No. 290. F. Shafii, R. Bukowski and R. Klemencic (Eds.). pp 187-192, 2003.

2. NFPA 92, Recommended Practice for Smoke Control Systems. National Fire Protection Association.

3. Best, R. and D.P. Demers, "Investigation Report on the MGM Grand Hotel Fire-Las Vegas, Nevada, November 21, 1980," Fire Journal 76(1), pp 19-37, January 1982.

4. Klote, J.H., "Hazards Due to Smoke Migration through Elevator Shafts," NIST GCR04-864-I, Volume 1: Analysis and Discussion, and NIST GCR04-864-II Volume 2: Results of Tenability Calculations. National Institute of Standards and Technology, 2004.

5. Klote, J.H., "Analysis of the Consequences of Smoke Migration through Elevator Shafts," Workshop on Use of Elevators in Fires and Other Emergencies, Conference

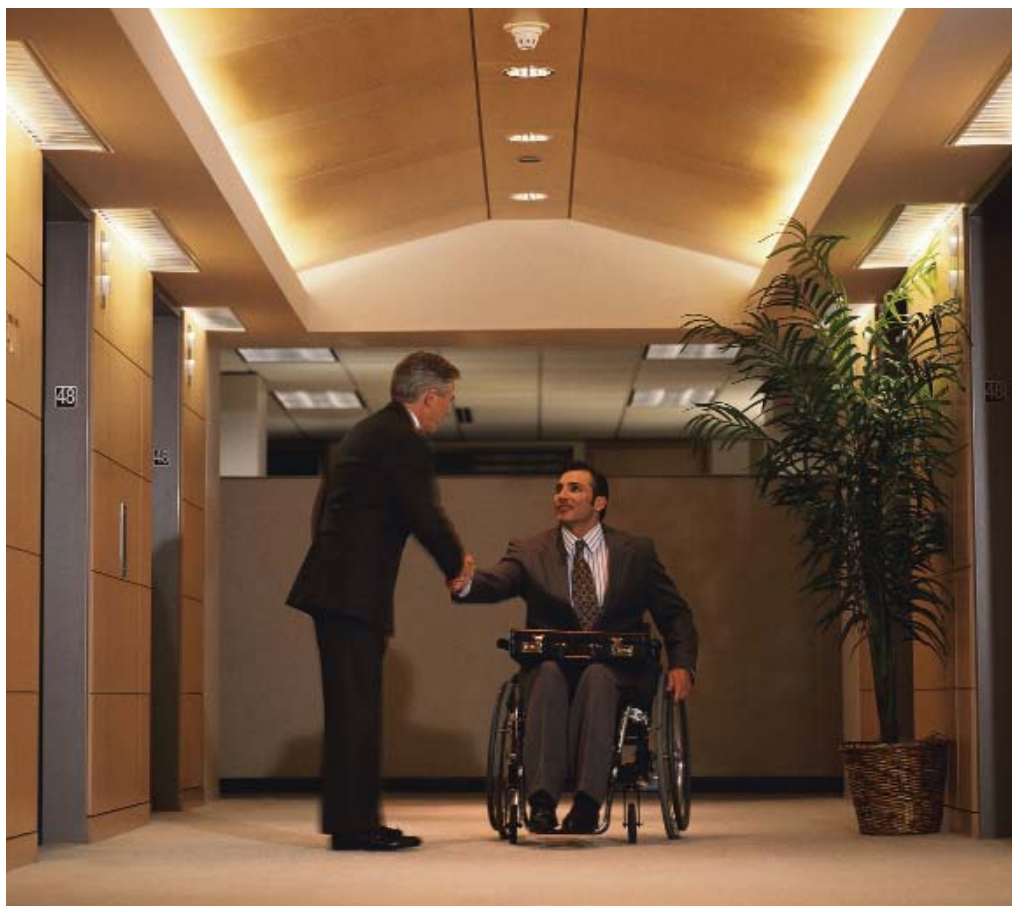

Proceedings. Co-sponsors: ASME International, the National Institute of Standards and Tech-nology, the International Code Council, the National Fire Protection Association, the U.S. Architectural and Transportation Barriers Compliance Board, and the International Association of Fire Fighters.

6. Peacock, R.D., et al., NIST Technical Note 1299, CFAST, the Consolidated Model of Fire Growth and Smoke Transport. National Institute of Standards and Technology, 1993.

7. Dols, W.S. and G.N. Walton, NISTIR 6921, CONTAMW 2.0 User Manual. National Institute of Standards and Technology, 2002.

8. Klote, J.H., et al., NISTIR 4770, Staging Areas for Persons with Mobility Limitations. National Institute of Standards and Technology, 1992.

9. Klote, J.H. and J.A. Milke, Principles of Smoke Management. Amercan Society of Heating, Refrigerating and AirConditioning Engineers, 2002.

10. VanGeyn, M, National Fire Door Fire Test Project Technical Report 6285, Positive Pressure Furnace Fire Tests. Fire Protection Research Foundation, 1994.

11. Purser, D.A., "Toxicity Assessment of Combustion Products," SFPE Handbook of Fire Protection Engineering. Third Edition. P.J. DiNenno (Ed.). National Fire Protection Association, 2002.

12. Bukowski, R.W., E.K. Budnick and C.F. Schemel, "Estimates of the Operational Reliability of Fire Protection Systems," International Conference on Fire Research and Engineering, Third Proceedings, pp 87-98. Cosponsors: the Building and Fire Research Laboratory, the National Institute of Standards and Technology, and the Society of Fire Protection Engineers.

13. Maybee, W.W., "Sprinkler Performance Update, 1952-1986," Sprinkler Quarterly, pp 49-51, Spring 1987. 


\section{Appendix I}

\section{Protected Elevators and the Disabled}




\section{Protected Elevators and the Disabled}

Richard W. Bukowski, P.E., FSFPE

NIST, Building and Fire Research Laboratory

Gaithersburg, Maryland 20899 USA

It was 1989 and I was giving a talk to local federal agencies on the newly-released HAZARD I software and its promise for performance-based design for fire safety. After the talk several attendees came up to talk to me, including a gentleman in an electric wheelchair. He told me that he worked on the $10^{\text {th }}$ floor of a nearby, high-rise office building and that when he first came to work there the safety officer did not really know what to do with him. He was instructed that in case of a fire evacuation, he was to go to the stairway. If there was someone there to open the door (he was quadriplegic and could not grip nor turn the knob) he should proceed onto the top landing. Otherwise he should wait at the stairway door for assistance. He told me that it was clear to him that they wanted to know where to go to collect the body.

It was just the next year, 1990, when the Americans with Disabilities Act (ADA) was passed to provide equal access to public buildings for all Americans. The objective of the ADA regulations was to permit people with disabilities access to the places where we live, work, and play with little thought of how they would get out in case of emergency. Fifteen years later we are still addressing this important issue.

The purpose of this article is to present the issues that need to be addressed in the development of elevators that can be used in fires to safely evacuate occupants, particularly those with limited mobility that affects their ability to use stairs.

\section{Accessibility}

The ADA accessibility requirements are intended to result in public buildings that can be accessed and used by people with a range of limitations including vision, hearing, and mobility. The guidelines provide for signs that include Braille markings, strobe lights and other visible warnings, and doors with powered openers that are wide enough for wheelchairs. Smaller changes in elevation require ramps or platform lifts that eliminate barriers to wheelchair users.

Building codes contain special provisions for an accessible means of egress that either leads out of the building (including through a horizontal exit) or to an area of refuge, which may be served by an accessible elevator. Elevators are the primary means of routine ingress and egress for all occupants in most buildings and under most conditions, except during fires. Elevators are posted with signs warning that they are

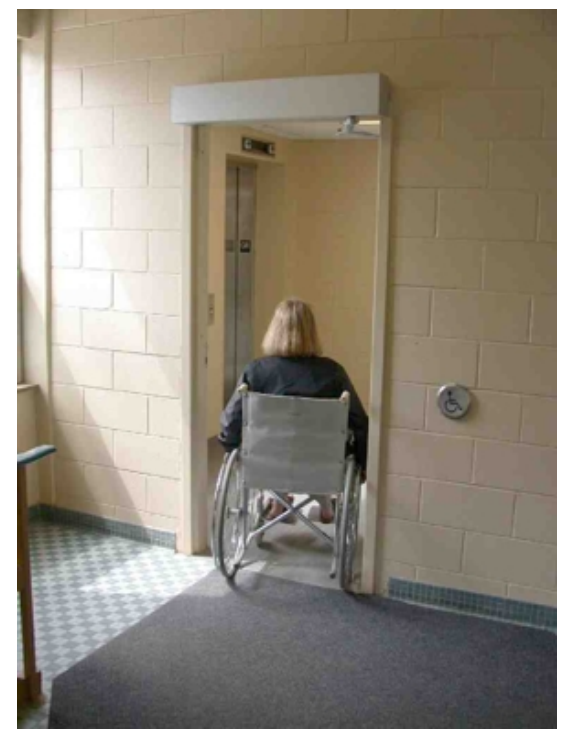

Accessible elevators are required by the Building Codes and ADA requirements 
not to be used during a fire. Occupants and firefighters are relegated to stairways that may have only the capacity to carry the occupants from a few floors at a time, without the counterflow of firefighters trying to move up carrying equipment. And what about those people with disabilities (including both disabilities as defined by the ADA and those occupants who needed assistance to exit long distances) who now represent $6 \%$ to $10 \%$ of the occupant load?

\section{Elevator Safety}

While lifts for goods have been in use for thousands of years it is only since the development in 1854 of the automatic safety brake by Elisha Graves Otis that the passenger elevator became a reality. Often cited as the safest mode of human transportation, millions of people ride elevators daily without incident. This laudable safety record has been achieved through the pervasive safety culture of the elevator industry and the committees who write the safety codes that govern the design, installation, operation, maintenance, and inspection of passenger elevators. In the U.S., this is the American Society of Mechanical Engineers (ASME) A17.1

Committee.

The issue addressed by Otis' brake was a failure of the lifting rope causing the car to fall. Doors or gates on the landing opening and car prevented people from falling out or getting their body parts caught between the car and shaft wall. Additional improvements in safety and reliability over the years have led to the admirable safety performance of modern elevators.

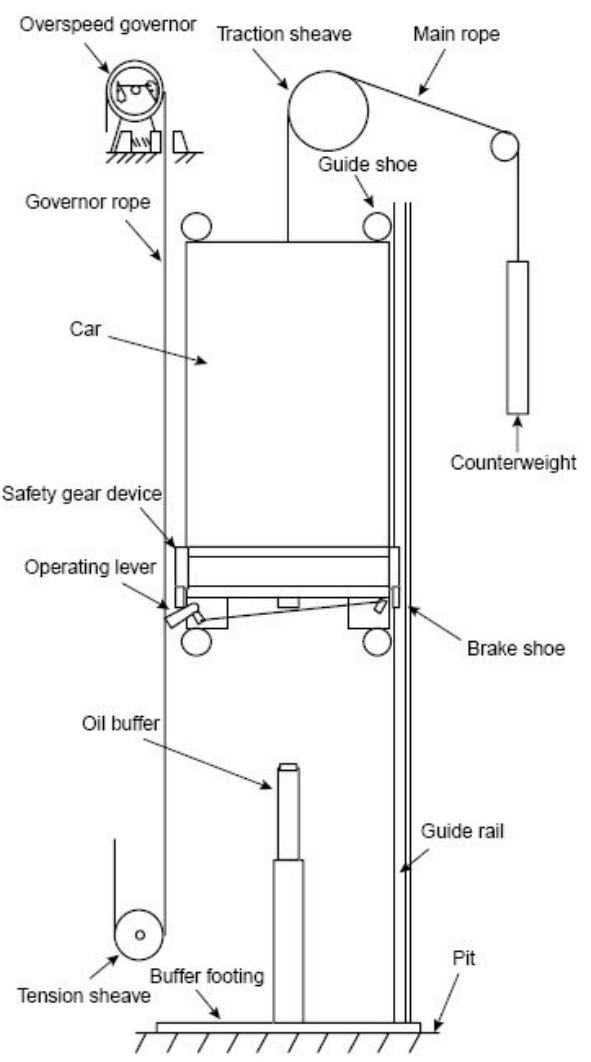

A fundamental industry assumption is that entrapment in an elevator is a fail-safe condition and a special system has been implemented to ensure that trapped passengers can be extracted quickly and safely. Every elevator is equipped

\section{Safety brakes located under the car are triggered by an overspeed governor in the machine room (drawing courtesy Mitsubishi)} with a telephone to summon help, and every elevator maintenance contractor has technicians on call 24/7 to respond. Even in major incidents such as the 2003 blackout in the Northeast U.S. and Canada, hundreds of entrapment calls were cleared in only a few hours. The acceptance of temporary entrapment leads to the common arrangement that, if the many safety controls on an elevator sense something is going wrong, the elevator controller shuts the system down. In recent times it has been recognized that there are two conditions where entrapment is not a safe condition - during an earthquake or during a fire. 


\section{Door Restrictors}

A more recent safety device required on passenger elevators is called a door restrictor. These are devices that restrict the ability of a passenger to force open the car door unless the floor of the car is within at least $75 \mathrm{~mm}$ but not more than $450 \mathrm{~mm}$ ( 3 in to $18 \mathrm{in}$ ) above or below the level of the landing. Passengers have been known to force open the doors and fall down the hoistway if the car became stuck or even to "joyride" on the top of the car, especially since the roof hatch began to be locked from the inside. These door restrictors have been successful at eliminating many injuries and deaths (according to decreases in reports of deaths and injuries from falling down shafts all of which occur in elevators not retrofit with door restrictors), but became an issue in the WTC Towers on September 11, 2001. There were several cases of occupants entrapped in cars that were not close enough to the landing to release the restrictor. The industry is now studying ways of releasing restrictors in an emergency that would not lose their safety function in other circumstances.

\section{Elevators and Earthquakes}

The vertical and lateral motions associated with a seismic event can affect the operational safety of an elevator. In an earthquake it is possible for the elevator or its counterweight (for traction elevators) to be jarred out of their guide rails. The most dangerous result is where the car runs into the counterweight. Thus the elevator code requires that all elevators located in Seismic Zone 2 or greater are designed with greater clearances, retainer brackets where the car and counterweight attach to the rails and with seismic switches set to activate at an acceleration of $0.15 \mathrm{~g}$. Activation of the switch causes the car to stop, and move in the direction away from the counterweight to the next available landing where the doors open and the car is locked out of service until the system is manually reset. This can only be done from the machine room by an elevator technician after determining that the system can operate safely [ASME 2004].

\section{Elevators and Fires}

Beyond the direct impacts on the safe operation of the elevator, there are several interactions between the elevator system and the building during a fire. One is the hoistway as a vertical shaft spreading smoke through the building. Most landing doors open horizontally and are far leakier than other types of doors. The shaft itself is subject to what is known as stack effect, which is a vertical airflow resulting from differences in indoor to outdoor temperatures and the height of the shaft. This shaft flow draws air into or out of the shaft through the landing doors depending on the position of the landing relative to the neutral plane and the direction of the shaft flow. [Klote and Milke 1992]

Stack effect flows are driven by differences in indoor and outdoor temperatures with upward flows in winter (outdoors colder than indoors) and downward in summer (outdoors warmer than indoors). The greater the difference, the greater the flow; therefore stack effect is larger in more extreme climates and for taller shafts. Even without a fire, stack effect flows can cause problems in tall buildings, resulting in strong flows and noise at landing doors near the top and bottom of the shaft. These flows can cause jamming of landing doors and may require seasonal door adjustments by elevator technicians. During a fire, stack effect flows can carry smoke and fire gases to remote 
parts of the building. For example, in the MGM Grand [Fire Journal 1981] and DuPont Plaza [Klem 1987] fires which both occurred near the ground floor level, there were fatalities on upper floors due only to smoke carried up elevator shafts by stack effect flows.

It is important to note that both examples occurred in unsprinklered (at least in the area of the fire) buildings. A recent analytical study by the author [Bukowski 2005] showed that stack effect flows sufficient to create safety problems on upper floors would not be likely in fully sprinklered buildings (with working sprinkler systems) or in buildings not tall enough (less than 75 feet under less than extreme weather conditions) to produce strong shaft flows. In some mission critical applications it might be appropriate to provide for the small likelihood of a failure of the sprinkler system. [Bukowski 2005]

\section{Elevators and Water}

Water from fire sprinklers or hose streams can result in safety problems for elevators during fires. Water can enter the hoistway and cause electrical shorts in safety controls causing them to fail. Water on the drum of the elevator machine can cause the car to slip although the safety brake would stop a car from overspeed or falling down the shaft.

To address this situation, elevators protected by sprinklers in the hoistway or machine room are equipped with a shunt breaker to deenergize main power before a sprinkler activates. Connected to a heat detector that would activate before the sprinkler, the shunt breaker activation removes power and stops the elevator, but can result in entrapment. The shunt breaker will not protect the system from water from sprinklers or hose streams at landings leaking into the hoistway.

Firefighters Emergency Operation

In the mid-1970's the elevator industry developed firefighters emergency operation to improve the safety of the system during fires. Smoke detectors are installed in the elevator lobby within $6.4 \mathrm{~m}(21 \mathrm{ft})$ of any landing door on each floor. The smoke detectors protect the elevator system by detecting any encroachment of the fire and triggering Phase I recall. Here the elevator cars are sent immediately to the designated landing which is generally the level of exit discharge. There the elevators stop, the doors open, and the elevators are locked out of service. If a fire is detected on the designated landing, the cars are sent to an alternate floor.
FIRE OPERATION

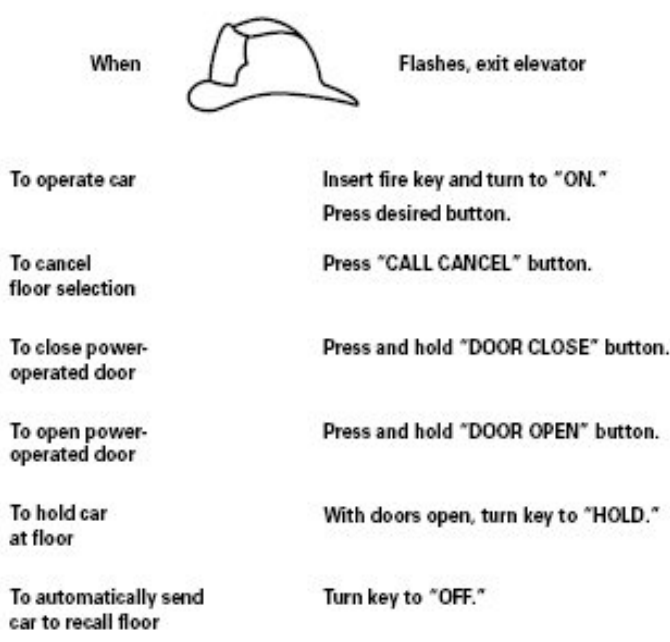

A fire operation instruction panel is required in every elevator fitted for this service (courtesy ASME)

Upon their arrival, firefighters are able to place individual cars back into manual service by use of a firefighters key, in what is called Phase II operation. While operating in this 
mode, a light on the car control panel marked with the symbol of a firefighters hat is illuminated. In this mode, the controls in the car operate in a special manner designed to protect the firefighter operating the car. For example, the car will move to a selected floor but the doors will not open. Depressing the door open button opens the doors but only as long as the button is depressed. Thus, if smoke enters the car and the firefighter reacts by jumping back, the door will close.

Additional smoke detectors installed at the top of the hoistway and in the machine room monitor the system integrity. If activated, the firefighters hat light in the car begins to flash warning the operator that the system may become erratic and to move to a safe location.

It is generally accepted by the experts that as long as the system is operating in normal service (before Phase I activates) the elevators are safe to use, even if there is a fire in the building. Such a fire would need to be sufficiently remote from the elevator lobby so as to not have activated a lobby smoke detector triggering Phase I recall.

\section{Elevator Assisted Egress}

In the wake of the September 11, 2001 attacks on the World Trade Center Towers, the concept of protected elevators for occupant egress and for fire service access from tall buildings received new interest. The primary issues are the need for more rapid egress from very tall buildings and additional capacity to support simultaneous evacuation of occupants who were now reluctant to await a phased evacuation. Since even minimal additional egress capacity by stairs has a very large cost penalty in lost leasable space, use of the elevators that are already present is a logical approach. But arguably the most important issue is to provide for self-evacuation of people with disabilities and those for whom evacuation down long stairways presents significant difficulties.

\section{3 and 2001 WTC Evacuations}

In the 1993 bombing at the World Trade Center, it was found that many more occupants experienced difficulties than just those with traditional disabilities. People with temporary disabilities such as broken legs, people with asthma, pregnancy, or obesity all reported difficulties in mobility or stamina that limited their own evacuation abilities and that of others behind them in the stairways.

Recently Bukowski and Kuligowski [Bukowski and Kuligowski 2004] benchmarked evacuation times for egress systems designed in accordance with modern building codes. They found for office occupancies that it requires about 5 minutes to empty a floor and $1 / 2$ to 1 minute per floor to egress down stairs without delays for queuing, congestion, or resting (total evacuation times would further need to include pre-evacuation times). Based on this benchmark, the World Trade towers would have required 1 to 2 hours (without congestion delays). Observed evacuation time in the 1993 bombing and total evacuation time in 2001 estimated for a full occupant load of 25,000 by state-of-the-art egress models that included queuing and congestion was about double the best case times or about 4 hours. [Fahy and Proulx, 2002] 
One crucial observation from 2001 involves the evacuation of 2 World Trade Center (South Tower) in the 16 minutes between the aircraft strike on the North Tower and the strike on the South Tower. Having seen what happened to the North Tower, many of the occupants in the South Tower decided to evacuate. Since their building was undamaged many used their normal procedure of elevators. NIST estimated that about 3000 people evacuated from above the (eventual) aircraft strike zone using the stairs or elevators [Averill 2005]. After the South Tower was hit NIST estimated that only 18 additional occupants escaped from above the impact region.

\section{Protected Elevators}

NIST has been working on the development of protected (also called hardened or Phase III) elevators in cooperation with the elevator industry, fire alarm industry, and key codes and standards organizations in the hope of developing the needed technology and code provisions to put these into practice. This work is making slow but steady progress and should be ready for demonstration in a year or two.

Early work focused on the issues discussed previously including water sensitivity and protection of the elevator system from the fire. Enclosed and (real time) monitored lobbies would provide a protected space for occupants to await the elevator as well as an additional layer of passive protection for the hoistway. Information displays and communication to the fire command station would provide reassurance to those waiting, and direct access to a stair would provide a second way out for those capable of using it. It is expected that people with disabilities would be given priority access to the elevator cars. [Bukowski 2003]

An important benchmark of elevator evacuation performance can be seen in the typical design objective for elevator systems. The number, capacity, and speed of elevators are typically designed to move $15 \%$ of the total occupant load of the building in 5 minutes. This means that a typical system utilizing an efficient evacuation protocol (e.g., ignoring hall and car calls and operating in a shuttle mode between a 3-floor fire zone and the level of exit discharge) would be capable of evacuating the entire occupant load of 3 floors of a 20 story building or 6 floors of a 40 story building in 5 minutes.

\section{Layers of Protection}

In order to protect the elevator system from compromise by the fire and provide a protected space in which to wait, protected elevator systems would incorporate enclosed lobbies on each floor above the level of exit discharge and would be found in fully sprinklered buildings. In a 1993 report done for GSA, Klote et al [Klote 1993] found that separate staging areas were not needed in fully sprinklered buildings since the entire building remains tenable as long as the sprinkler system is operational and the fire is not shielded from the sprinkler. The addition of protected lobbies adds an additional layer of protection, not only for the elevator, but also for occupants awaiting the arrival of the elevator. This is particularly important for occupants who cannot use the stairs and who need to be protected in place until they can egress using the elevators or be assisted by others. 


\section{Hoistway pressurization}

Another function of the lobby is to prevent smoke from exposing people waiting for the elevator as well as to prevent smoke from entering the hoistway. While the lobby enclosure can be made smoke tight, the door will be opened repeatedly as occupants enter, so a pressurization system would be needed. Based on prior NIST work, it is important to minimize pressure differences across the landing door that might lead to jamming [Klote 1982]. Thus, a system where the hoistway is pressurized and a positive pressure of the lobby (with respect to the rest of the floor) is produced by leakage through the landing door, will provide the desired result. Pressurization of the order of $12 \mathrm{~Pa}$ (0.05 inches of water) is a reasonable design value [Klote and Milke 1992].

\section{Real-Time Monitoring}

An important layer of protection is the ability of the fire service to monitor the conditions within the lobbies, hoistway and machine room in real time to ensure that there are no threats to people or systems. These monitoring functions will be carried out by the fire alarm system and displayed in the fire command station on a special fire service display. These displays comply with National Fire Protection Association (NFPA) and National Electrical Manufacturers Association (NEMA) standards so that they are consistent in form and operation across all equipment manufacturers. All conditions and

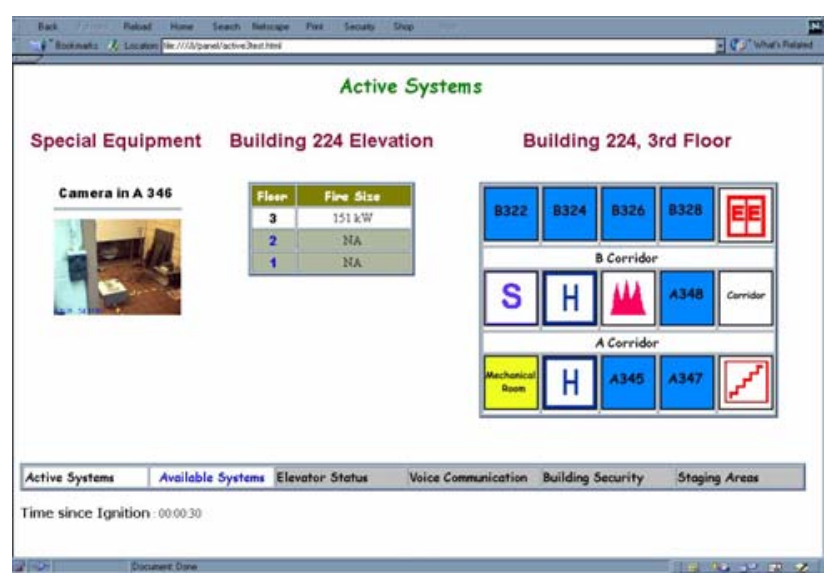

Conditions in lobbies and status of elevators can be displayed in real time in the building fire command station functionality critical to the safe and reliable operation of the system are monitored.

\section{Information systems}

Crucial to the safety and peace of mind of occupants using the system is the provision of real time information on the system status. Displays in the lobbies will show waiting occupants that the elevators are in service and how long they will need to wait to be served. People who are capable of using the stairs will be free to do so if they feel the wait is too long, either taking the stairs to a lower level to reenter and await an elevator, or all the way to the street. Should it be necessary to take the elevators out of service, the lobby display would indicate that those capable should use the stairs and others could communicate directly with the fire command station to request assistance.

\section{Evacuation mode}

Elevators are the most efficient at moving people in "shuttle mode" where the times associated with deceleration, loading, and acceleration are minimized. Thus it has been proposed to establish an evacuation mode of operation that will optimize system performance. 
In general, evacuation mode would be triggered on a general alarm in the building. All elevators would be captured and returned to the level of exit discharge to unload any passengers. An automatic message in the elevators would explain that there is an emergency reported in the building and the elevators are being put into service to assist in evacuation. Signs on the discharge level would warn people not to enter. One (predesignated) car would be held for fire service access and the rest would go into evacuation service; moving to the first priority floor group (fire floor, one above and one below). Destination buttons in the car (Car calls) would be disabled and the buttons that summon the elevator to a floor (hall calls) would register where occupants are awaiting the elevator for egress but would not direct service.

Once the first priority group of floors is evacuated, the system would serve additional floor groups in a logical order until all occupants have been evacuated. If Phase I recall is activated at any time in the process, evacuation mode would end, but cars could be put into Phase II service if the fire service considers it safe to do so.

\section{Mobility Impaired Occupants}

The evacuations of the World Trade Center towers in 1993 and in 2001 provided some common lessons regarding egress of people with impaired mobility. First, there are more people who have difficulty in moving long distances down stairs in very tall buildings than those who usually come to mind. People with temporary disabilities (broken legs/sprains using canes or crutches, pregnant, or those injured in the initiating event), asthmatic or other respiratory conditions, obese or other conditions that limit stamina, all have been observed to require extra time and frequent rest stops. In the WTC evacuation $6 \%$ of the survivors reported having some pre-existing condition that limited their mobility. If you add to that, people injured by the initiating event or just after beginning to evacuate the number could be higher. Even women in high heels and men in new dress shoes were reported to have caused backups in stairs by moving more slowly [Averill 2005]. While $6 \%$ is not unreasonable for traditional disabilities, designing for a disabled population of $10 \%$ would be conservative for many buildings.

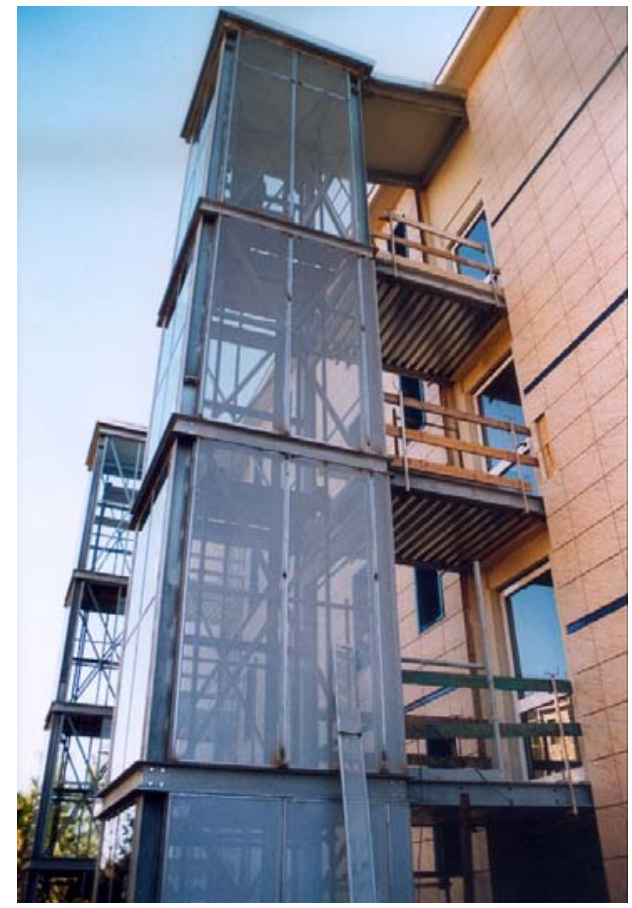

This smokeproof elevator is installed at an Italian residential facility for mobility impaired people to provide access and egress. The glass hoistway enclosure permits the fire service to determine if the elevator is in use. (courtesy CNR)

In some buildings such as residences for the elderly, the proportion could be considerably higher. A recent paper [Sekizawa 2004] mentions a fire in Japan where $80 \%$ of the elderly occupants were unable to evacuate down the stairs and used the elevators successfully. 
In the September 11, 2001 evacuation, first responders moving down stairs in WTC 1 after the collapse of WTC 2 found 40 to 60 mobility impaired occupants on the $12^{\text {th }}$ floor where they had been moved. About 20 of these occupants were being assisted down the stairs just prior to the collapse of WTC 1. It is unclear how many of these or the 20 to 40 others who had been staged on the $12^{\text {th }}$ floor perished [Picciotto 2002].

\section{Conclusions}

Protected elevators that can provide for unassisted egress of occupants with disabilities can result in significant reductions in total evacuation times for tall buildings and more efficient flows in stairs by people capable of using them. Considering the optimum flow rates down stairs of 30 seconds per floor without congestion or the need to stop and rest, elevators designed to move $15 \%$ of the occupant load in 5 minutes could evacuate 60 floors (including wait times) in the same time it takes for occupants to descend 60 floors, or 30 minutes.

By reducing stair flow impediments through the use of elevators for up to half the population it should be possible to totally evacuate buildings of any height in the order of 30 minutes. Those using the elevators would include all people with disabilities and those highest in the building, while the stairs would be used by the most physically capable from the lower floors. This approach is used by the 88-story Petronas Towers in Kuala Lumpur, Malaysia where a total evacuation time in a drill was reported to be 32 minutes, utilizing a combination of stairs and elevators. [Arliff 2003]

\section{References}

Arliff, A., Review of Evacuation Procedures for the Petronas Twin Towers, Proc CIBCTBUH Conference on Tall Buildings, Kuala Lumpur Malaysia 2003.

ASME, Safety Code for Elevators and Escalators, ASME A17.1-2004 Section 84.10.1.3, ASME New York, NY 2004.

Averill, J., et al, Federal Building and Fire Safety Investigation of the World Trade Center Disaster: Occupant Behavior, Egress, and Emergency Communications, NCSTAR 1-7, NIST Gaithersburg, MD 208992005.

Bukowski, R.W., Is There a Need to Enclose Elevator Lobbies in Tall Buildings, Building Safety Journal, Vol III, No. 4, ICC Whittier, CA, August 2005.

Bukowski, R.W., Protected Elevators for Egress and Access During Fires in Tall Buildings, Proc CIB-CTBUH Conference on Tall Buildings, Kuala Lumpur Malaysia 2003.

Bukowski, R.W. and Kuligowski, E.D., The Basis for Egress Provisions in U.S. Building Codes, Proc InterFlam 2004, Interscience Communications, London, 2004. Fire Journal, Fire at the MGM Grand, NFPA Fire Journal, Vol. 75, No. 2, 33-36, March 1981.

Klem, T., 97 Die in Arson Fire at DuPont Plaza Hotel, Fire Journal, Vol. 81, No. 3, 7477, 79,+, May/June 1987.

Klote, J. H., Elevators as a Means of Fire Escape. American Society of Heating Refrigerating and Air Conditioning Engineers Transactions, Vol. 89, No. 2, 1-16, 1983. NBSIR 82-2507; 37 p. May 1982. 
Klote, J.H., Nelson, H.E., Deal, S., and Levin, B.M., Staging Areas for Persons with Mobility Limitations, NISTIR 4770, Nat Inst Stand Tech, 18p, Jan 1993.

Klote, J.H. and Milke, J.A., Design of Smoke Management Systems, ASHRAE 1992.

Fahy, R. and Proulx, G., A Comparison of the 1993 and 2001 Evacuations of the World Trade Center, Proc Fire Risk and Hazard Assessment Research Application Symposium, Fire Prot. Res. Foundation, Quincy, MA July 24-26, 2002.

Picciotto, R., Last Man Down, Berkley Publishing, NY, NY 2002

Sekizawa, A., Nakahama, S., Notake, H., Ebihara, M., and Ikehata, Y., Study on Feasibility of Evacuation Using Elevators in High-Rise Buildings, Proc ASME Workshop on Emergency Use of Elevators, Atlanta GA March 2-4 2004. 
Appendix $\mathbf{J}$

Elevator Controls 


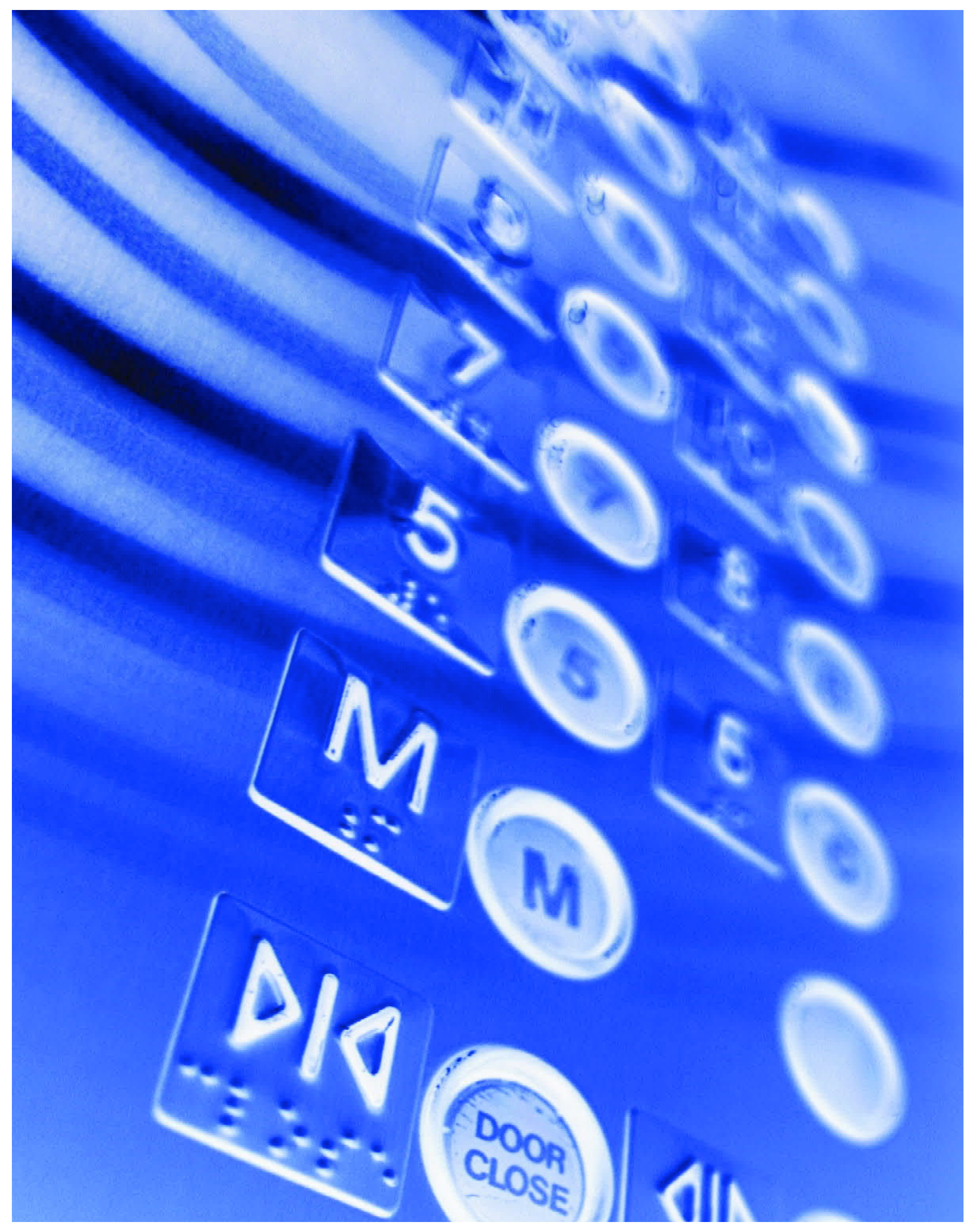


It is important that all parties, from rescue personnel to building designers understand the intent of the fire service operation provisions of ASME A17.1, Safety Code for Elevators and Escalators.

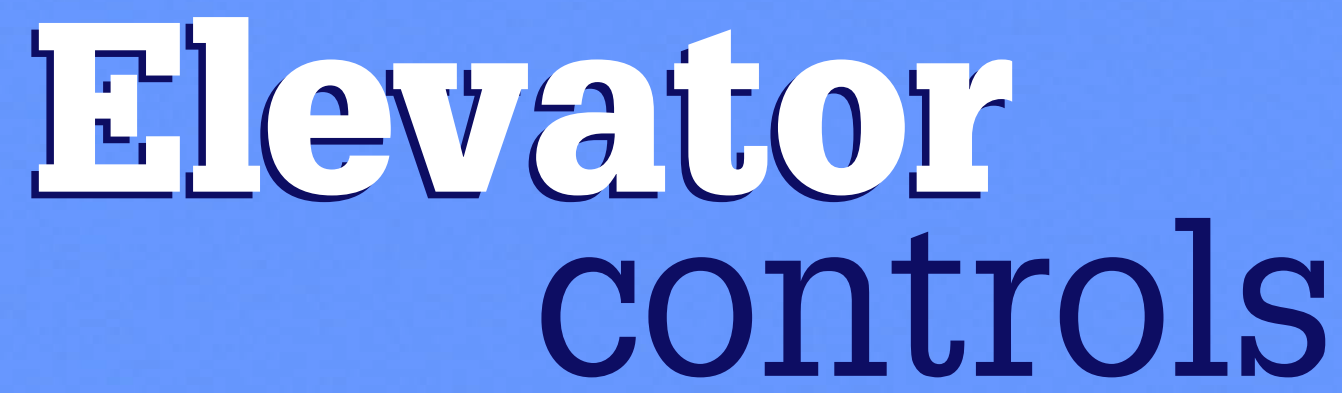

THE DEVELOPMENT OF THE PASSENGER ELEVATOR is tied directly to the emergence of tall buildings. While various types of freight lifts were found in warehouses and factories before the advent of the highrise, these were considered too dangerous to move people.

In 1854, however, Elisha Graves Otis demonstrated an automatic safety brake that changed the landscape. Within a few years, his steam elevators had eliminated one of the major limits to building height.

By Richard Bukowski, P.E.

Russell Fleming, P.E.

Jeffrey Tubbs, P.E.

Christopher Marrion, P.E.

Jill Dirksen

Chris Duke

Debbie Prince

Lee F. Richardson

Lieutenant Dave Beste, and

Dottie Stanlaske 
But, while elevators proved to be one of the safest forms of transportation, there were instances where people were killed while using elevators during building fires. Heat sometimes activated call buttons bringing cars to the fire floor where smoke prevented the doors from closing (light beams are in modern day elevators to detect people in the doorway) and water in the shaft sometimes shorted out electrical safety devices or may have caused failure of braking systems. Thus, the use of elevators for occupant egress or fire department access was discouraged.

\section{In 1973 , the elevator industry developed a system that recalls elevators and takes them out of service if smoke is detected in the lobbies, machine room, or hoistway.}

In 1973, the elevator industry developed a system that recalls elevators and takes them out of service if smoke is detected in the lobbies, machine room, or hoistway. Mandated in the American Society of Mechanical Engineers (ASME) A17.1, Safety Code for Elevators and Escalators, ${ }^{1}$ for all automatic passenger elevators, this system involves two distinct phases of emergency operation.

In Phase I, the detection of smoke or heat causes the elevators to be recalled to the ground floor, unless this is where smoke was detected. The doors open, and the elevators are locked out of service. Responding fire fighters may use the elevators under manual control of a fire fighter in the car using a special fire fighter key in what is called Phase-II operation.

While Phase II operation is used to evacuate people with mobility impairments, some fire department standard operating procedures for high-rise fire fighting rely on stairs for access, staging, and operations. ASME A17.4, Guide for Emergency Personnel, ${ }^{2}$ contains detailed instructions for fire fighters' service operation.

In the 1980s, the United Kingdom developed BS5588 part $5^{3}$, a standard for fire fighter lifts. It describes a fire-fighting shaft consisting of an elevator, protected lobbies on

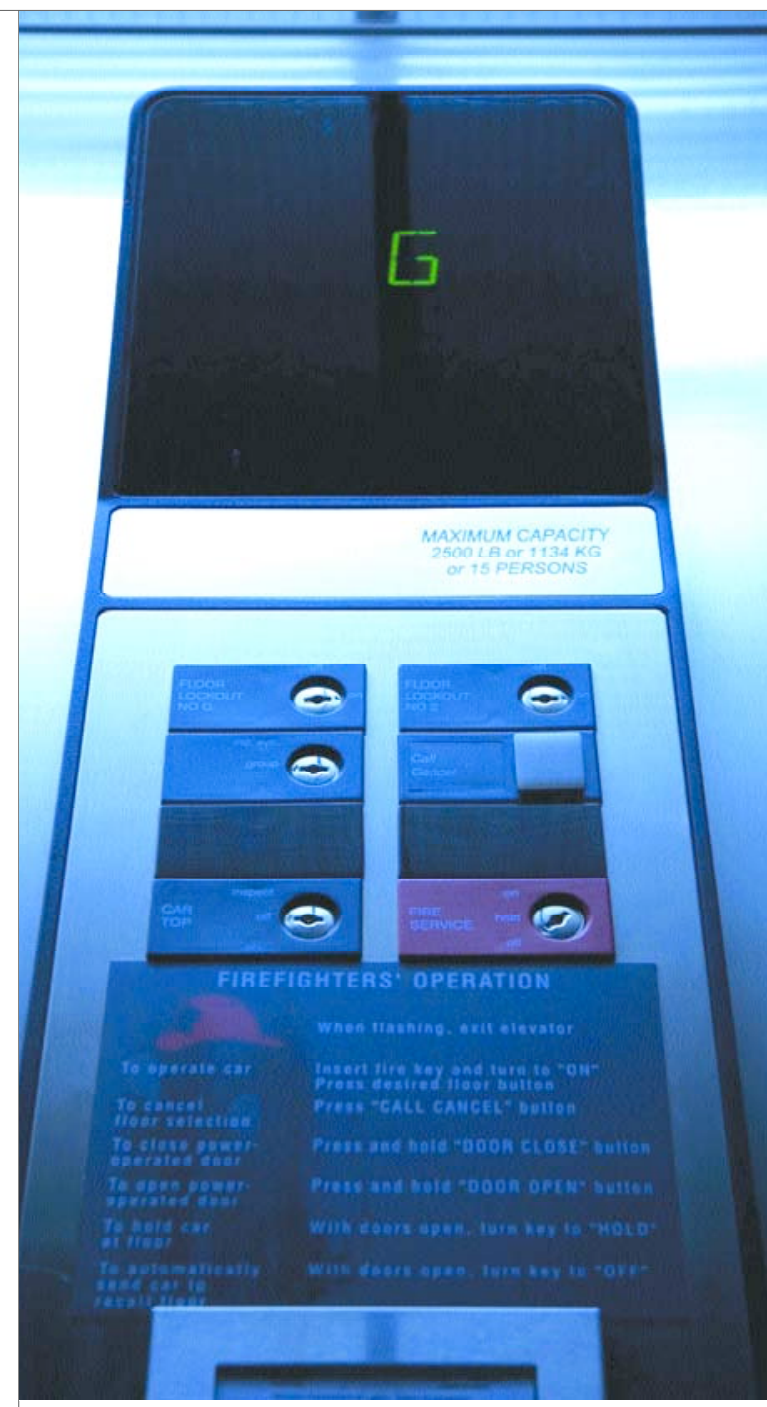

each floor with direct access to one of the required stairs, and standpipes, all enclosed in fire resistant construction. According to a survey $^{4}$ by the International Organization for Standardization (ISO) committee responsible for ISO/TC178 elevator standards, this system is used in a few countries, generally former British colonies, for buildings greater than 18 meters (60 feet). Recently, BS5588 part 5 has been adopted as CEN Standard EN 81-73 for use throughout the European Union.

Also in the 1980s, the Federal Aviation Administration (FAA) was interested in providing a secondary means of egress from air traffic control towers. Because a control tower's footprint is so small, it is not possible to provide two remote stairs, but any tower of significant height has an elevator and stairs. The FAA contacted the National Institute of Standards and Technology (NIST), and a cooperative project launched with the elevator 
industry, coordinated through the National Elevator Industry Institute, resulted in changes in the 1997 edition of NFPA $101^{\circledR}$, Life Safety Code ${ }^{\mathbb{E} 5}$, that were subsequently incorporated into NFPA $5000^{\circledR}$, Building and Construction Safety Code ${ }^{\circledR}$. In addition to the technical requirements for the equipment and components, NFPA criteria also limits the number of occupants in the tower and requires periodic drills.

While requirements exist for elevators for emergency use by fire fighters and people with mobility impairments, there are currently no codes or standards for egress elevators for use by building occupants. There are, however, egress elevators accepted under performancebased design provisions based on engineering analysis. An example of where such elevators can be found is the Stratosphere Tower in Las Vegas, Nevada.

Atop the 800-foot (250-meter) Stratosphere Tower is an 11-story building, known as the Pod. The Pod has an emergency staircase that is considered impractical for use in emergency conditions. Thus the four double-deck elevators designed for emergency use. One is reserved for the fire department, and the others are used under manual control to evacuate all occupants from the two lower floors of the Pod, which were designed as areas of refuge. Occupancy of the tower is limited to the number of people that can be evacuated by the elevators in one hour. ${ }^{6}$

\section{New demands for protected elevators}

The attacks on the World Trade Center on September 11, 2001, showed that access by fire fighters to incidents on upper floors of tall buildings was problematic. Fire fighters in their protective clothing and carrying the normal gear for high-rise firefighting that includes hose packs and forced entry tools require about 2 minutes per floor to ascend stairs. Once they arrive at the fire scene, they are likely to require rest before they can begin suppression operations. Logistics is also an issue, especially re-supplying oxygen tanks that have a practical capacity of 15 minutes to $20 \mathrm{~min}$ utes, depending on the level of exertion.

Clearly, using elevators to move people and equipment to a staging area, which is normally two floors below the fire floor, is the only reasonable approach. Although many in the fire service did not trust the safety of elevators during a fire incident, some departments began to cautiously incorporate elevator access into their high-rise firefighting procedures after $9 / 11$, requiring inspection of the hoistway for signs of smoke and sometimes stationing a fire fighter in the machine room.

In the summer of 2003, NIST approached the ASME A17 committee with a proposal to explore the development of protected elevators for fire service access and for occupant egress in collaboration with the A17 code committee, elevator industry, and fire service. These groups agreed and organized a workshop to explore issues and barriers. A call for papers resulted in a range of speakers, most of whom supported the concept. Breakout groups identified many issues and some ideas on features that should be incorporated into any such system.

Based on these results, the ASME A17 committee established two task groups under the Emergency Operations Committee to develop recommendations for fire-service access elevators and for occupant egress elevators.

A key finding from the workshop was that the incorporation of fire fighters emergency service operation in the 1980s resulted in systems that could continue to operate safely during a fire and would safely take the elevators out of service before there was any risk of entrapment from an effect of the fire. However, many fire departments would manually initiate recall of the elevators on their arrival to control access and to ensure that there were no trapped occupants. While this practice would not materially affect fire service access, it would affect the use of the elevators for occupant egress.

The ASME A17 task groups followed a formal hazard analysis using an ISO standard for risk assessment without the step of assigning probabilities. While tedious, this process is thorough and results in a detailed record of the conditions the committee considered and the mitigation of all hazards identified.

\section{Protecting elevators}

The ASME A17 task groups largely addressed the safety issues associated with fire service access elevators by adding real-time monitoring of critical systems from the fire command station that the building codes already required as the incident command location for high-rise buildings. This allows the fire service to monitor the safety and functionality of the systems and to warn fire fighters by radio if 
the safety of the elevator is in doubt. The task groups also identified other improvements that would make it less likely that the fire or firefighting operations might cause the systems to fail, including better protecting the power to the system, monitoring the internal temperature of the controller, and protecting some critical components in the hoistway from water damage. Finally, the groups provided arrangements to facilitate self-rescue in case of entrapment.

Far more complicated are the arrangements and protocols needed to evacuate occupants by elevator. Unlike the fire service, elevator occupants are not trained or equipped to deal with emergencies. The only thing that can be assumed is familiarity with the normal use of the elevators, as these are the primary means of daily ingress and egress. Thus, while some degree of proactive management of the evacuation by the fire service is provided, the use of elevators for evacuation must be as close to "normal" as possible, with some allowance for guidance by informational messages.

\section{The current ASME A.17 requirements for fire fighter emergency operation are considered effective in maintain- ing safe operation, even during a fire.}

The task groups' concept of occupant egress elevators included protecting the entire bank of cars to take advantage of the system's full handling capacity. This is an elevator industry term describing the design of the system for normal operation where the number, size, and speed of the cars, number of floors served, and occupant load are all considered to achieve a specific service objective.

The elevators in an office building are designed with a handling capacity of 8 percent to 10 percent (downpeak 5), meaning that 8 percent to 10 percent of the entire population of the building can be collected from various floors and transported to the ground floor in five minutes. Apartment buildings are typically designed for a handling capacity of 4 percent to 5 percent (downpeak 5), and some high-end offices, such as the new WTC 7 owned by Silverstein Properties in New York City, are being designed for 12.5 percent, meaning shorter waits for an elevator at 5 p.m. The handling capacity calculation is standardized throughout the elevator industry and is discussed in design manuals such as the Vertical Transportation Handbook. ${ }^{7}$

The current ASME A17 requirements for fire fighter emergency operation are considered effective in maintaining safe operation, even during a fire. If the elevators are to be used for occupant egress, it is important to keep them in service for as long as possible. This led the task groups to observe that enclosed and protected lobbies are needed on every floor, not only to provide a protected space for occupants to wait, but also to protect the elevator lobby from smoke or fire exposure that will initiate elevator recall. Previous work by NIST showed that elevator-landing doors are particularly susceptible to jamming with relatively small pressure differences across them. However, a system in which the hoistway is pressurized and the lobby has a positive pressure with respect to the rest of the building by leakage can provide smoke protection for the hoistway and lobby without causing problems with the landing doors.

Provision of real-time environmental monitoring of the lobbies and two-way communication with the fire command station would also be specified. Dynamic signs, which the fire alarm industry calls textural notification appliances, would be provided in each lobby to give information to waiting occupants. In most modern systems, the elevator controller's dispatch software can provide realtime estimates of the time before an elevator car arrives at that floor, and this will be specified as part of the system.

\section{Evacuation protocol}

To provide the needed efficiencies in quickly moving occupants, a new operational protocol is being developed and recommended. Since elevators are most efficient when the number of starts and stops is minimized, the elevators would operate in a shuttle mode in the evacuation protocol. The cars would not respond to car calls-that is, floor buttons in the car-and hall calls, or call buttons in the lobby, would only register that there are occupants waiting there. First priority would be given to collecting occupants on the fire floor, one floor above, and two floors below, and taking them 
to the main lobby. Note that the initial evacuation zone extends two floors below the fire so that the lobby normally used by the fire fighters for staging would be unoccupied by the time they arrive.

Once the fire zone was empty, the elevator evacuation would proceed from the highest floors downward. People on lower floors would be told the length of wait for an elevator and they might choose to start down the exit stair that would be accessible from the lobby. If any of these occupants needed to rest, they could enter a lobby and do so, or wait for an elevator.

By taking advantage of all the handling capacity of the system, it is unnecessary to restrict access to the evacuation elevators to just people with limited mobility. Since the lower floors would be the last to be served, there is incentive for most occupants on those floors to egress by the stairs. By starting with the upper floors, the occupants who require the longest egress times by stairs would be evacuated first, dramatically lowering the total egress time for even the tallest buildings.

Many of the features described here are already being implemented in tall buildings outside the United States. For example, the Petronas Towers in Kuala Lumpur reports that incorporating elevators into the egress plan has resulted in total evacuation times in both towers of about 20 minutes. Taipei 101, which is currently the tallest building in the world at 101 occupied stories, reports a total evacuation time for the tower and the very large podium area at the base of just under one hour.

\section{Addressing user needs}

The fire service must be confident that an elevator is safe and reliable and that they can escape or be rescued quickly by their colleagues if they become entrapped. The fire service has the opportunity to train with the elevator systems and, when the practice becomes more common, they will have an opportunity to use them during real fires. Monitoring critical systems at the fire command station in real time makes them confident that incident command can relay warnings by radio if needed and will know quickly if an entrapment occurs.

Occupant egress elevators provide a different set of challenges. Using them for emergency egress should be as close to using them for normal egress as possible, and a steady stream of information is needed. This can be addressed primarily by incorporating dynamic signage, operated from the fire alarm system, in each elevator lobby to provide a high level of reliability. Again, monitoring critical systems in real-time and having two-way communication capabilities would supplement information transfer and increase reliability.

The occupant egress elevator further addresses the needs of people with various disabilities by providing a means of egress they can use with all other building occupants without outside assistance. By protecting all the elevators, the normal design capacity of the system would be sufficient for use by everyone, with the backup of the fire service access elevators to help those who need it after suppression operations have begun. If additional capacity were needed, the fire service could press any occupant egress elevators into service under manual control.

Recognizing the potential benefits of protected elevators in federal buildings and elsewhere, the U.S. General Services Administration (GSA) is providing funding that supplements NIST's investment in these activities and has agreed to incorporate such systems in a future federal building as a demonstration of the technology. NIST welcomes the opportunity to work with GSA to advance technologies beneficial to government workers and to the public.

\section{Fire sprinklers and elevators}

Rules relating to sprinkler installation in elevator shafts and machinery rooms have long been a source of conflict, but there have been significant efforts to coordinate the requirements of NFPA 13, Installation of Sprinkler Systems, with those of ASME A17, Safety Code for Elevators and Escalators.

The most notable took place following the February 1991 Symposium on Elevators and Fire, jointly sponsored by ASME, NFPA, and the Council of American Building Officials. The organizations established a code coordination committee that met in late 1991 and 1992 and reached several key points of agreement:

\section{Summary of requirements}

1. Sprinklers in Elevator Pits: It was agreed that sprinklers in elevator pits are a good idea because this is a likely location of fire due to the accumulation of debris. Although the accumula- 


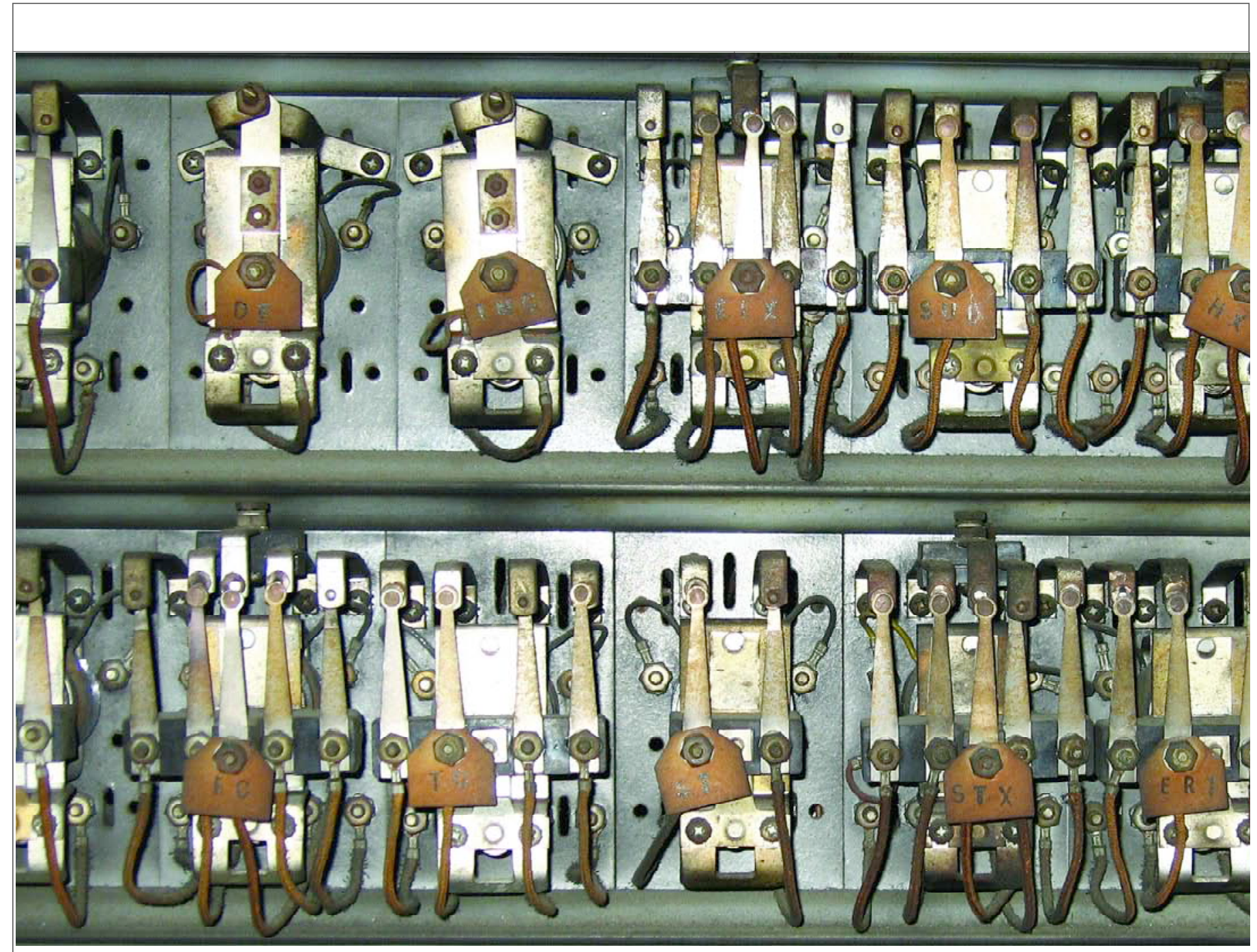

tion of water in the pit is a potential concern, this concern can take place regardless of whether sprinkler protection is provided.

2. Sprinklers in Hoistways: It was agreed that sprinklers are not necessary at the tops of hoistways if the hoistway is noncombustible and the elevator car is constructed in accordance with the flame spread and smoke development requirements of ASME A17.1.

3. Sprinklers in Machine Rooms: It was agreed that sprinklers may not be necessary in an elevator machine room if it is located at the top of a building and contains nothing other than elevator equipment. It was further agreed that concern over water discharge and power-disconnect requirements can be addressed by requiring means to automatically disconnect the main line power supply to the affected elevator upon or prior to the application of water.

These points of agreement were largely adopted into the 1994 edition of NFPA 13 through a major rewrite of Section 4.5.5. The
NFPA 13 requirements have changed very little since that time. Now contained in Section 8.14.5 of the 2002 edition of NFPA 13, the rules make specific accommodations for elevators.

Pit sprinklers: Sidewall sprinklers are to be placed within 2 feet (61 centimeters) of the floor of an elevator pit, without regard to the normal distances required below a ceiling. The NFPA 13 Annex suggests placing the sidewall sprinklers near the side of the pit below the elevator doors and taking care to avoid interference with the elevator toe guard. The pit sprinklers can be omitted for enclosed, noncombustible shafts that do not contain combustible hydraulic fluids. Since sprinklers at the base of the shaft are not expected to discharge onto operating components of the elevator, they can be connected directly to the building sprinkler system with no special valving or delay mechanism.

Hoistway sprinklers: Upright or pendent sprinklers are required at the tops of elevator hoistways, except noncombustible hoistways 
for passenger elevators with car enclosure materials meeting ASME A17.1.

Machine room sprinklers: The standard has no special rules for elevator machine rooms, except to require that machine room, sprinklers and sprinklers at the tops of hoist$w$ ays be of ordinary or intermediate temperature rating. In other words, high temperature rated sprinklers that would be delayed in operation are not permitted. Sprinkler protection of elevator machine rooms is expected as part of a complete sprinkler system since these spaces are not specifically excluded from the need for sprinklers.

An Annex section in NFPA 13 discusses the ASME A17.1 requirement that power to the elevators be shut down upon or before the application of water in elevator machine rooms or hoistways, and suggests this can be accomplished by a sufficiently sensitive detection system or by using devices that effect power shutdown immediately upon sprinkler activation, such as a waterflow switch with no time delay.

The NFPA Committee on Automatic Sprinklers is now completing work on the next, 2007, edition of NFPA 13. One of the proposals accepted in this cycle allows the option of sidewall sprinklers at the top of hoistways rather than upright or pendent sprinklers. A proposal that would have required the hoistway sprinklers to be part of a preaction system was rejected on the basis that there are other ways to meet the ASME A17.1 requirements. Another proposal would have eliminated sprinklers from the elevator machine room under certain conditions of smoke detection, signage prohibiting storage, and control of combustible contents, as now permitted in the Commonwealth of Massachusetts. The Technical Committee rejected this proposal on the basis that "buildings are to be fully sprinklered which includes these types of spaces. Storage can occur in these types of spaces regardless of signage." The Committee is aware that reliance on housekeeping practices has historically been an inadequate substitute for complete sprinkler protection.

In the view of the fire sprinkler community, the current rules represent a reasonable approach to elevator protection. Unfortunately, continued lack of consistency in the application and enforcement of these rules can create problems that go beyond the lack of protection. Disagreements among multiple authorities having jurisdiction for an elevator installation have led in some instances to lastminute changes in protection, with consequences of improper valving, inadequate protection against freezing, or other problems.

At the least, it is necessary that elevator protection issues be discussed at the project planning stage. Ideally, those discussions will lead to recognition that sprinkler protection in accordance with NFPA 13 is reasonable and proper.

\section{Elevator smoke control}

Deadly fires, such as the 1980 MGM Grand Hotel and Casino fire ${ }^{8}$ and the 1988 First Interstate Building fire, ${ }^{9}$ have shown that unprotected elevators can provide a significant path for vertical smoke movement from fires through building.

Several factors, including the lack of sprinkler protection on the fire floor, elevator doors that did not provide an effective smoke barrier, as well as the combined effects of the natural buoyancy of hot smoke and the stack effect, resulted in smoke spread through the elevator hoistways to upper levels. A properly designed smoke management system could have helped to mitigate smoke movement through the elevator shafts in these high-rise buildings.

Designers have several alternatives when designing smoke management systems for elevator shafts ${ }^{10}$, including pressurize the elevator hoistway; pressurize the elevator lobby; and exhausting the fire floor, which creates a positive pressure in the elevator hoistway relative to the fire floor.

\section{Passive systems}

These methods can be used individually or in combination.

Pressurize Histway: Some jurisdictions require hoistway pressurization when elevator lobbies are not provided. In general, dedicated supply fans are used to pressurize hoistways to a minimum pressure 0.05 inches $(0.13$ centimeters) of water column. Since the elevator machine room in cable elevators is open to the hoistway through the cable sleeves, these rooms can be pressurized along with the shaft.

Elevator doors are typically not tight-fitting and tend to be a major source of leakage in the shaft, as do vents. Doors and vents, as well as other sources of leakage, must be accounted for in the design.

In addition, the piston effect may need to be considered if elevators are expected to be used by responders or others during as fire event. 
Pressurize Elevator Lobby: If an elevator lobby is provided, this lobby can be pressurized along with the elevator shaft. A second design goal for these types of system is that the opening force for the elevator lobby doors cannot exceed 30 pounds (13.6 kilograms) at the latch side when it is operating and the pressure should not interfere with the opening or closing of the elevator doors. This approach typically allows smaller fans, since the leakage air is lower, but a duct system is necessary to distribute air to the various floors.

Exhaust Fire Floor: Exhausting the fire floor has a similar effect as pressurizing the hoistway or lobby; however, these systems tend to be larger, more costly and more complicated than elevator pressurization systems. The goal of this approach is to limit smoke to the fire floor.

Passive Systems: Smoke tight elevator hoistways and/or lobbies can be an effective means of limiting smoke movement. If protected lobbies are not provided, doors on hold-open devices or deployable smoke barriers can be installed across the elevator doors to maintain an effective smoke barrier. Given the effectiveness of quick-response sprinklers, the requirement for smoke-tight separations is a constant topic of debate.

\section{Design considerations}

When designing smoke management systems for elevators, as well as other areas, it is helpful to understand the stack effect, a phenomenon that occurs when there are temperature differences between the air outside the elevator shaft and the air in the rest of the building. Where the air outside the shaft is cooler than the air inside it, buoyancy causes the hot interior air to flow toward the top of an elevator shaft, while air from the lower areas of the building or outside the building enters the shaft towards the bottom to replace the hot air. This causes a general upward flow that can help push smoke into the shaft. When the temperature difference is reversed, the opposite flow results.

Other design considerations include the piston effects, wind effects, and normal HVAC effects that need to be taken into consideration. As elevators travel up within the shaft, air from within the top of the shaft is pressurized and air in the bottom of the shaft is de-pressurized. Pressures are reversed when elevators are moving down. Wind velocity may also influence the design, as the wind will increase pressure on the side being impacted by the wind and decrease pressure on the downstream side of the building. Normal HVAC is typically shutdown during emergency operation. Klote $^{11}$ describes methods for accounting for the piston effect and wind velocity.

Consideration should be also be given to providing automatic sprinklers when designing these systems, as the 0.05 inches of water column assumes that a large fire would not occur within the space. Additionally, emergency power is necessary for required life safety systems.

Although the design of smoke management systems presents challenges, smoke management techniques can increase the level of elevator safety in high-rise buildings. With the recent discussions about the use of elevators for evacuation, it is perhaps even more critical to consider smoke management solutions for elevators now than ever before.

\section{Elevator sump pumps}

Elevator sump pits are intended to keep water away from the equipment at the bottom of an elevator shaft if the hoistway fire suppression system is activated. Just allow the water to drain into the elevator sump pit, and the equipment stays dry and functional. It's as simple as that. Or is it?

Anyone designing an elevator sump pump system must consider not only removing discharged sprinkler water, but also preventing any oil that has leaked from the elevator's hydraulic lift from entering the sewer system. If the hydraulic system works properly, it generally releases only a small amount of oil. If the system fails, however, a sizable volume could be lost. This oil, combined with the volume of water discharged by one sprinkler, provides a design challenge for the engineer.

In an effort to keep oil from leaking into their sewer systems, some states are trying require the design and installation of large sum pits below elevator shaft floors from which water may be pumped out and disposed of later. Unfortunately, a blanket requirement mandating that a sump pit contain a pump is not necessarily the right way to design the system.

Section 2.2.2.5 of the 2000 edition of ASME A17.1 requires all elevator pits with Firefighters' Emergency Operations (FEO) to have a drain or sump pump. ASME A17.1 also requires a connection to the emergency power supply and protection of circuits to ensure that 
accidental grounding or short-circuiting does not occur after an emergency has begun.

Instead of a sump pump, an oil separator or some other device can be used to remove oil from the elevator shaft, thus preventing discharge into the sanitary sewer. However, an oversized oil separator is a maintenance issue, and an undersized oil separator will not remove oil effectively.

Replacing the oil separator with a system called an "oil minder" could help resolve the issue. The oil minder concept relies on the fact that oil floats on water. As water is pumped from the bottom of the pit and the water level falls, the oil minder's sensing device detects the oil and shuts off the pump, thus allowing the water out and keeping the oil in.

This controversy has been a long time in the making, but a blanket requirement to provide an elevator sump pump creates more design issues than it solves.

\section{Pros and cons of elevator door restrictors}

When entering an elevator, most passengers do not realize they have agreed to be securely locked in that elevator cab until the car reaches its destination. Should the elevator lose power before reaching its destination, all methods of self-evacuation are mechanically prohibited. This applies equally to emergency personnel and the public.

Door restrictors, which ASME A17.1 requires on passenger elevators, are mechanical devices designed to prevent a passenger from opening the elevator car or hoistway doors more than 4 inches (10.2 centimeters) when the elevator car is outside the "unlocking zone." ASME defines the unlocking zone as "a zone extending from the landing floor level to a point not less than 75 millimeters (3 inches) or more than 450 millimeters (18 inches) above and below the landing."

The requirement for door restrictors was implemented to prevent passengers from falling into an open hoistway underneath the elevator platform while trying to evacuate from an elevator that is stuck between floors.

Is this a real concern? Unfortunately, it is.

Picture yourself in an elevator that has stopped 5 feet (1.5 meters) above the landing. If you could open the elevator car door, you would have access to the hoistway door interlock, which is typically easy to open from this position. Once you opened the standard hoistway door, you would discover that you now

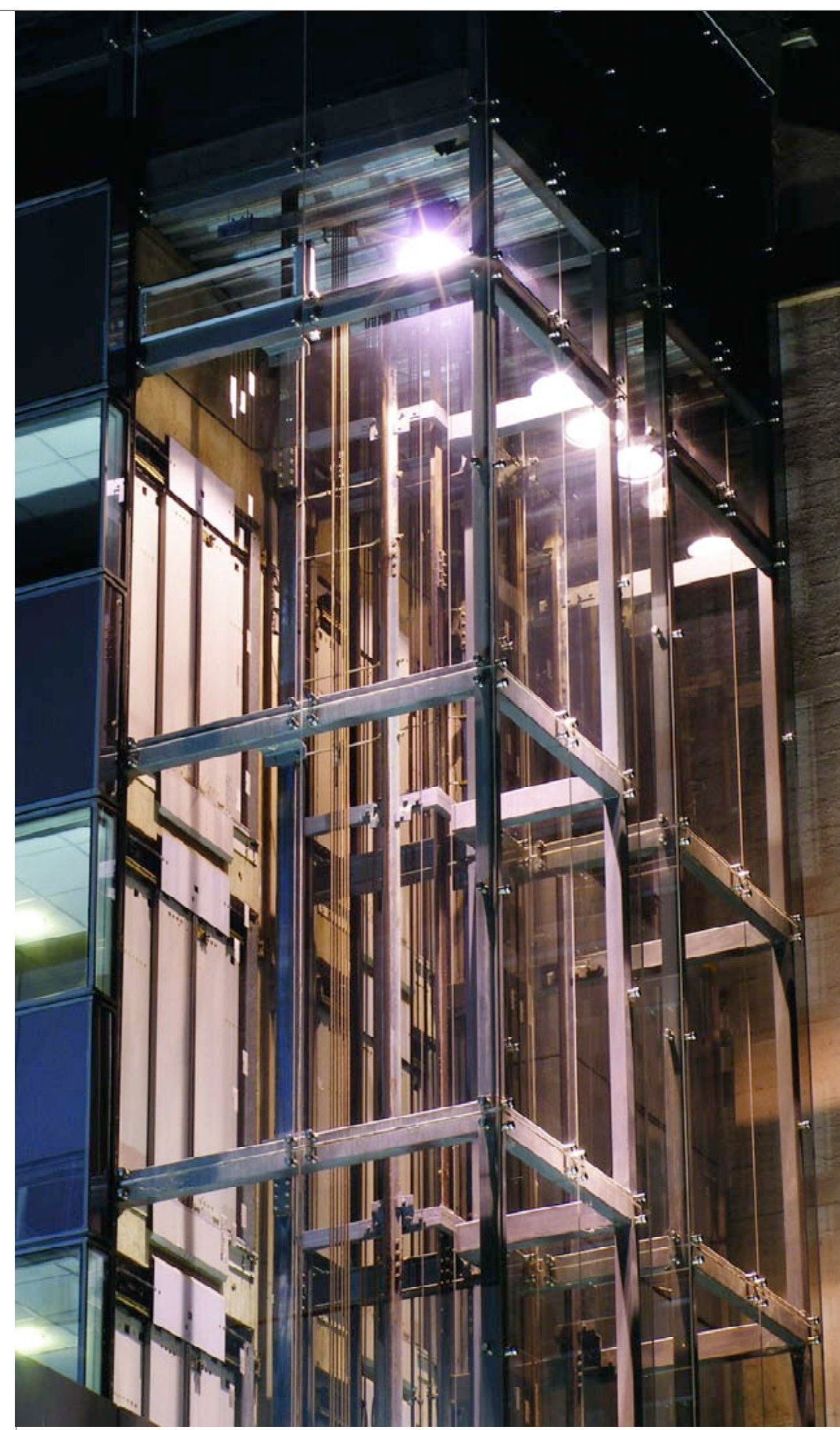

had access to an opening 2 feet (0.6 meters) high from which you could try to exit the elevator. What you wouldn't be able to see is the unprotected space underneath the platform and platform guard. If you were to lower yourself backward from the elevator, your feet would tend to push into the hoistway. If you were to jump forward, you would risk falling backward into the hoistway.

So why not lock passengers in the elevator? Imagine being trapped inside an elevator that 


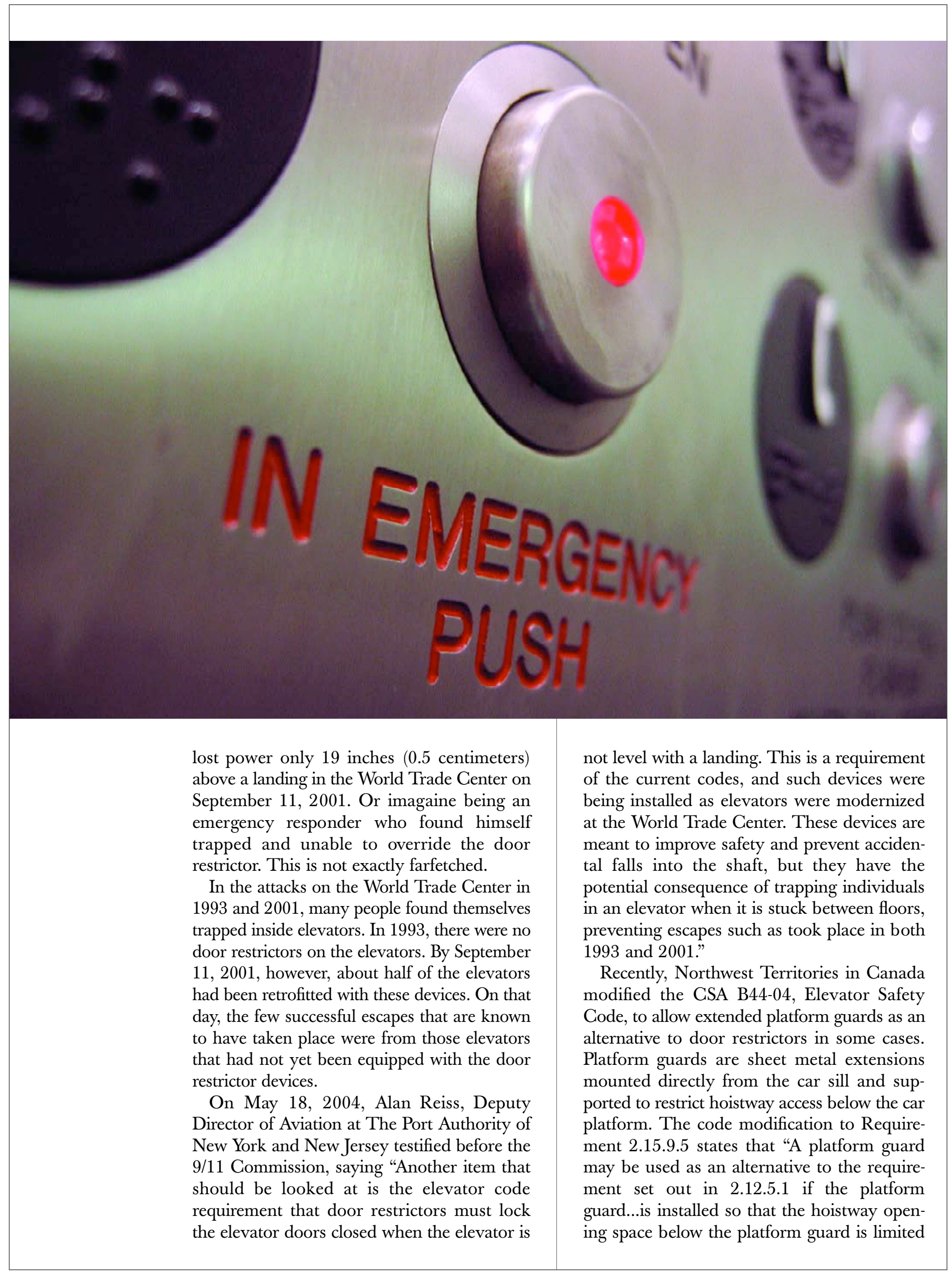


to not more than 250 milimeters (9.8 inches) between the floor and the bottom of the platform guard, regardless of the location of the elevator car when it is stopped."

While this alternative certainly prevents falling into the hoistway and allows for selfevacuation if necessary, the pit depth on many existing elevators is insufficient to accommodate this extended guard length. In addition, the platform guard does not prevent injuries during the unassisted evacuation of an elevator that has stopped significantly above or below the landing, other than the falling scenario described above.

So if power is lost while traveling in an elevator, how likely is it that you will be prevented from getting out of the elevator? In a building with the typical 10-foot (3-meter) floor-to-floor height and a maximum unlocking zone of 18 inches ( 45.7 centimeters) above and below the floor, the elevator car doors will be mechanically restricted during 70 percent of the hoistway travel. The probability increases to 95 percent where the minimum unlocking zone of 3 inches (7.6 centimeters) above and below the floor is employed.

In any case, there is a significant potential of being locked in the elevator should there be a loss of power. This is a fact of which most passengers, including the public and emergency responders, are probably unaware.

\section{Emergency operation overview}

ASME A17.1, Safety Code for Elevators and Escalators, includes special provisions for elevator operation during fire emergencies. These are identified as Phase I Emergency Recall Operation and Phase II Emergency In-Car Operation.

Phase I Emergency Recall Operation is used to take elevators out of normal service. This prevents building occupants from going to the fire floor and also makes the elevators available for use by firefighters. Recall operation can be activated manually by firefighters from the key-operated "FIRE RECALL" switch located at the designated level. Manual activation causes the elevator(s) to return nonstop to the designated level.

Recall operation can also be activated automatically by the fire alarm system in response to the actuation of specific fire alarm initiating devices. These initiating devices are those required at each elevator lobby, elevator machine room, and elevator hoistway when sprinklers are installed in those hoistways.
The use of smoke detectors is required unless environmental conditions require the use of another type of automatic initiating device such as a heat detector. Automatic activation of recall operation causes the elevator to return nonstop to either the "designated level" or the "alternate level" as determined by the building configuration and the location of the first of these initiating devices to actuate. The designated level is typically the level where firefighters would normally arrive. The alternate level is used when the first initiating device to actuate is located at the designated level, either in the lobby or in the machine room if it is located at the designated level. Note that only these specific fire alarm initiating devices can activate recall operation. Fire alarm signals from devices in other building locations do not result in elevator recall.

Each elevator car is equipped with a special visual signal (fire hat) that will illuminate when Phase I Emergency Recall Operation is activated manually or automatically. This visual signal remains activated until elevator operation is restored to automatic operation.

Once Phase I Emergency Recall Operation has been activated and elevator cars have returned to the appropriate level, Phase II Emergency In-Car Operation can be activated. Phase II operation is activated manually by firefighters from the key-operated "FIRE OPERATION" switch located in each elevator car. Once activated fire fighters have control of the elevator.

There is a potential that operation of the elevator could be adversely affected during a fire event. To help warn firefighters of this potential, the special visual signal (fire hat) used to indicate that activation of Phase I Emergency Recall Operation is caused to illuminate intermittently (flashing instead of steady illumination). The trigger for this intermittent illumination is when Phase I Emergency Recall Operation is activated automatically by a fire alarm initiating device located in elevator machine room or hoistway, since a fire in these locations could impact the operation of the elevator. It should be noted that when the visual signal is flashing, Phase II Emergency In-Car Operation is still permitted and fire fighters are allowed to continue using the elevator at there own discretion based on their knowledge of the fire conditions.

ASME A17.1 also includes special provisions for automatic elevator shutdown when elevator equipment is located where the appli- 
cation of water from automatic fire sprinklers could cause unsafe elevator operation. The use of heat detectors located in proximity to the sprinkler heads is one means used to achieve elevator shutdown. Heat detector operation causes the main line power to the elevator to be automatically disconnected. This is typically referred to as "shunt trip" due to the name of the mechanism used to operate the main line power circuit breaker. When elevator shutdown occurs the elevator will stop in place due to the failsafe operation of the elevator braking mechanism.

Because of the potential of entrapment associated with shunt trip operation, revisions processed for the 2006 edition of ASME A17.1 will require the heat detectors used for shunt trip to initiate Phase I Emergency Recall Operation and delay the removal of power and the release of water to allow the completion of recall. Note that if the elevators are already operating on Phase II Emergency In-Car Operation, the recall operation will not occur, but shutdown and water release will still be delayed. If the elevator is on Phase II operation, the delay will allow the car to go to the next selected floor. Once the car has stopped at the floor all registered calls are canceled and shunt trip will activate. As a warning to fire fighters of the impending elevator shutdown, the heat detectors used for this operation will also cause the special visual signal (fire hat) to illuminate intermittently. Note that in the case of impending elevator shutdown, once the elevator car has stopped at a landing, it will remain at the landing and car calls will not register. While the new shunt trip provisions should greatly minimize the risk of entrapment, it should be recognized that complete elimination of this risk may not be possible.

\section{Elevators and the fire service}

Although elevators normally operate flawlessly, they can fail. Their safe operation should not be taken for granted.

In many jurisdictions, building owners test Firefighters' Emergency Operation (FEO) monthly in accordance with Section 8.6.10.1 of the 2004 edition of ASME A17.1. And authorities having jurisdiction over elevator licensing requirements should also test FEO regularly. In addition, those jurisdictions that have adopted NFPA 1, Uniform Fire Code", should also be testing and assuring at each elevator has an FEO. Since fire fighters cannot be certain when FEO was last tested or the quality of the inspection, however, they should confirm that the elevator is operating properly before using it during a fire.

An elevator's FEO consists of a Phase I and a Phase II.

Phase I is activated by the Phase I key switch or by a fire alarm initiating device (FAID). The FAIDs that initiate Phase I recall are located at each floor the elevator serves, typically in the elevator lobby; in the elevator machine room; and in the elevator hoistway, when required. When Phase I is activated, the elevator ceases normal operation, illuminates the fire fighter helmet pictograph, and returns the elevator non-stop to the designated level or, if the FAID initiating Phase I is on the designated level, to an alternate landing. This keeps the public from taking an elevator to the fire floor and renders the car call buttons, corridor call buttons, and automatic door reopening devices inoperative.

Once recalled, the elevator will not operate until it is reset or the Phase II switch located in the elevator is placed in the "on" position.

Upon arrival at a fire, fire fighters should confirm that all elevators have recalled to the designated or alternate recall floor. This can normally be done from the fire control room. If the elevators have not been recalled, they should be recalled manually using the Phase I key switch in the fire control room. If an elevator does not manually recall, fire fighters must search for it to confirm that no one is trapped inside or above the fire floor.

When a fire occurs at the elevator's designated recall landing, the elevators may automatically recall to an alternate floor. Once at the alternate floor, the elevator can still be recalled manually to the designated landing by activating the Phase I key switch in the elevator lobby or, when applicable, by activating both the Phase I key switch in the elevator lobby and the key switch in the fire control room. The Phase I key switch in the elevator lobby should only be activated when fire fighters know that the designated level is safe.

Before using the elevator, fire crews should check the hoistway for fire, water, or smoke and make sure the helmet pictograph is not flashing. In newer elevators, the flashing pictograph indicates that the elevator may malfunction and possibly trap the fire fighters in the elevator. After checking the hoistway and pictograph, the Phase II key switch must 
be placed in the "on" position.

Before traveling to an upper floor, fire fighters must test the "door open" and "door close" buttons to confirm that they operate properly. Both buttons require constant pressure in Phase II operation and must be depressed until the door is completely closed or opened. If the button is released before the doors are fully closed or open, they will automatically reverse direction.

Once the doors have been tested, a floor can be registered. While traveling to the selected floor, fire fighters should depress the "call cancel" button to ensure that all car calls cancel and the elevator stops at or before the next available landing. Before leaving the elevator, fire fighters should test the "hold" position of the Phase II key switch to confirm it is operating properly.

ASME A17.1 requires all equipment necessary for the operation of Phase II to be located in the main car-operating panel behind a locked cover, labeled "Firefighters' Operation," that can be opened with the fire service key. ASME A17.1 also requires a "run/stop" switch behind the cover that will cancel all registered calls and cut power to the elevator when placed in the "stop" position.

\section{Training}

To prevent injuries and deaths, every fire department should develop, implement, and strictly enforce of standard operating procedures that specifically address elevator use during fires. Every fire fighter and fire inspector should be trained to operate FEO, including Phase I and Phase II, emergency power activation, and fire fighter self-rescue.

Fire fighters, fire inspectors, and building owners must become familiar with the codes specific to elevator FEO. They must be diligent about testing and inspecting its operation and take time to research and implement an elevator-training program. Not only will this increase the reliability of the elevators, but it might save the life of a fire fighter.

\section{Emergency operation on an elevator}

In the event of a fire, the Firefighters' Emergency Operation (FEO) on an elevator may prove invaluable in controlling the fire and safely evacuating the building.

Since 1973, ASME A17.1 Safety Code for Elevators and Escalators, ${ }^{12,13}$ has required that elevators travelling 25 feet (7.2 meters) or more be equipped with a feature that, when initiated, will return the elevator to the main floor or another designated floor of the building. This feature is commonly referred to as Phase I Emergency Recall Operation and can be started with a key-switch or by a fire alarm initiating device.

Beginning in 1981, ASME A17.1 further required all automatic elevators with Phase I Emergency Recall Operation to be equipped with a feature that allows fire fighters or other authorized personnel to operate the elevator during an emergency from within the car. This feature is commonly referred to as Phase II Emergency In-Car Operation.

\section{One of the most reliable methods of ensuring that elevator equipment will function correctly is to verify that it has been properly maintained and inspected}

One of the most reliable methods of ensuring that elevator equipment will function correctly is to verify that it has been properly maintained and inspected. ASME A17.1 requires that the Phase I Recall of all elevators with FEO be tested monthly using the lobby key switch and that the Phase II Emergency Operation be tested a minimum of a one-floor run. Deficiencies found during the monthly testing procedure must be corrected.

A record of the test results, usually in the form of a test log located in the elevator machine room, must be made available to elevator personnel and the authority having jurisdiction. A sample monthly fire service test log may be downloaded without charge at www.naesai.org.

Many elevator inspection agencies train fire service personnel how to use the Phase I and Phase II Emergency Recall Operation. If such training is not available, however, fire fighters can follow some basic instructions to ensure that the Phase I and Phase II features are operating properly:

To recall the elevators, fire fighters should insert the key into the designated level key- 
operated switch, turn the switch to the "on" position, and remove the key. All elevators should return to the designated level and park with the doors open. Then the fire fighters should enter the elevator and push a car button to ensure that the elevator will not leave the floor.

Once this has been verified, the emergency responders can initiate Phase II by inserting the key in the key-switch, turning the switch to the "on" position, and verifying that the key can be removed when the switch is in that position. The responder can then press the desired floor button. If more than one floor button is pressed, the elevator will travel to the first available floor and all other floor calls will be cancelled.

To cancel the floor selection, the responder can press the "Call Cancel" button. The elevator will go to the next available floor, and the doors will stay closed until the next step has been initiated.

Once the car has arrived at the floor, the fire fighter should press and hold the "door open" button to open the car door. If the button is released before the doors fully open, the doors will close. This allows the doors to close immediately if there is a fire or smoke at that floor.

To hold the car at the floor once the doors have opened, fire fighters can turn the key in the car to the "hold" position and remove the key. This will ensure that the car will stay at the landing until Phase II is initiated again or the in-car switch has been turned to the "off" position.

To close the elevator door, fire fighters can press and hold the "door close" button. If the button is released before the doors are fully closed, the doors will reopen.

Finally, to return the car to the recall floorturn the Phase II key to the "off" position. The car doors will close automatically, and the elevator will return to the recall floor.

\section{Endnotes}

1. Safety Code for Elevators and Escalators, ASME A17.1-2000, American Society of Mechanical Engineers, New York, 2000.

2. Guide for Emergency Personnel, ASME A17.41999, ibid

3. Fire Precautions in the Design, Construction, and Use of Buildings, BS 5588 Part 5 1991, Code of Practice for Firefighting Lifts and Stairs, British Standards Institution, London.

4. Comparison of Worldwide Lift (elevator) Safety Standards - Fire fighters Lifts (eleva- tors), ISO/TR 16765:2002(E), International Organization for Standardization, Geneva, Switzerland, 2002.

5. NFPA $101^{\circledR}$, Life Safety Code ${ }^{\circledR}, 2000$, National Fire Protection Association, Quincy, MA.

6. Quiter, J. R. Application of Performance Based Concepts at the Stratosphere Tower, Las Vegas, Nevada. Rolf Jensen and Associates, Inc., Deerfield, IL. Fire Risk and Hazard Assessment Symposium. Research and Practice: Bridging the Gap. Proceedings. National Fire Protection Research Foundation. June 26-28, 1996, San Francisco, CA, 118-126 pp, 1996.

7. Vertical Transportation Handbook, George R. Strakosch, Editor, John Wiley \& Sons, Inc., New York, New York, 1999.

8. Best, R. and Demers, D., Investigation Report on the MGM Grand Hotel Fire, Las Vegas, Nevada. Revised Report, Jan 1982. NFPA, Quincy, MA, 1982.

9. Isner, M. and Klem. T., Fire Investigation Report: World Trade Center Explosion and Fire, New York, New York, February 26. NFPA, Quincy, MA, 1993.

10. NFPA, Recommended Practice for Smoke-Control Systems, (NFPA 92A), National Fire Protection Association, Quincy, MA, 2006.

11. Klote, J., Principles of Smoke Management (NFPA 92B), American Society of Heating, Refrigeration, and Air-Conditioning Engineers, Atlanta, GA, 2002.

12. ASME A17.1-2004 Safety Code for Elevators and Escalators: Section 2.27-Emergency Operation and Signaling Devices

13. ASME A17.2-2004 Guide for Inspection of Elevators, Escalators, and Moving Walks.

\section{About the authors}

RICHARD W. BUKOWSKI P.E., FSFPE is Standards and Codes Coordinator for the Building and Fire Research Laboratory of the National Institute of Standards and Technology and Senior Engineer in the Integrated Performance Assessment Group. Mr. Bukowski is very active within the U.S. and international standards communities. He is a member of the Standards Council of the National Fire Protection Association, which is the body that administers the NFPA's standards development process and issues all NFPA documents. Mr. Bukowski is Coordinator of the International Council on Building Standards and Documentation (CIB), Working Commission 14: Fire, and is active in the work of CIB TG37: Performance-based Building Regulatory Systems and CIB TG50: Tall Build- 
ings. He was appointed by ANSI as U.S representative to ISO TAG8, which advises the ISO Technical Management Board and provides oversight to all ISO Technical Committees working in the building and fire areas. He is a member of the NFPA, member of the Research Section, Building Fire Safety Systems Section, and Education Section, a Fellow of the Society of Fire Protection Engineers, and is a licensed Professional Engineer in the states of Illinois and Maryland.

RUSSELL P. FLEMING, P.E. is the executive vice-president for the National Fire Sprinkler Association and a member of several NFPA technical committees including the NFPA 13 technical committee. He is also a regular columnist for the NFPA Journa ${ }^{\circledR}$ and a former member of the NFPA Board of Directors.

JEFFREY TUBBS, P.E. is an Associate Principal and staff group leader of their Westborough, MA office. Jeff has a broad range of experience with unique projects; he has focused upon providing innovative, pragmatic solutions in the context of both prescriptive and performance codes throughout the U.S. and internationally. Jeff holds positions on various fire and life safety committees, including secretary of ASHRAE TC5.6: Control of Fire and Smoke, and member of the NFPA smoke Management committee (Responsible for NFPA 92A, 92B and 204) and the Assembly Occupancy Committee, and an alternate member on ICC's Code Technology Committee. Jeff led Arup's efforts to assist the NIST's National Construction Safety Team investigation of the February 20, 2002 fire at the West Warwick Station Nightclub with egress issues.

CHRISTOPHER MARRION, P.E. is an Associate Principal with Arup in their New York City office, where he leads the N.Y. Arup Fire group. Chris has worked for various fire engineering consulting firms in the United States, United Kingdom, Hong Kong, and Europe for the last 15 years. He has been involved with various committees in the fire industry, including SFPE/NISTNational R\&D Roadmap for Fire Safety Design And Retrofit of Structures Workshop-Steering Committee; New York City Department of Buildings-New NYC Bldg Code Committees for Egress and Fire Protection Systems; SFPE Performance-Based Design Committee-Steering Committee; SFPE Design Basis Fires Committee-Chair; ICC/SFPE Enforcer's Guide to Performance Based Design Review; and NFPA 72, Appendix B-Engineering Guide for Automatic Fire Detection-Chair. Chris was also a member of the FEMA/ASCE Building Performance Assessment Team for the World Trade Center assessment.

CHRIS DUKE is the owner CNY Elevator Consultants in Syracuse, New York. He is a member of the A17.1 Repair, Renovation, and Replacement Committee and the A17.1 Existing Installations Committee.

DEBBIE PRINCE is a Code Specialist employed with Motion Control Engineering, Inc. since March 1987; she's a member of A17 Electrical and Emergency Operations committees.

JILL DIRKSEN is the Managing and Technical Director for the American Society of Plumbing Engineers. Prior to her employment with the association, she worked at Albert Kahn Associates in Detroit, Michigan. She has held many board positions on local ASPE chapter level and serves as Co-Chairman on the ASPE standard committee for Hot Water Temperature and Control.

LEE F. RICHARDSON is a senior electrical engineer at NFPA where he is responsible for several standards, which include NFPA $72^{\circledR}$, National Fire Alarm Code ${ }^{\circledR}$. He is also the co-editor of the National Fire Alarm Handbook and a member of the ASME A17.1 Emergency Operations Committee. He is also a frequent contributor to the NFPA Journal.

DAVE BESTE is a Lieutenant at the Bellevue, Washington, Fire Department and a former Elevator Constructor. $\mathrm{He}$ is a member of the ASME A17.1 Emergency Operations Committee, an affiliate member of the International Association of Fire Chief's (IAFC) Fire and Life Safety Section, and has developed and instructs Elevator Safety and Rescue for Fire Fighters.

DOTTIE STANLASKE is the Executive Director for NAESA International (National Association of Elevator Safety Authorities). In her role of Executive Director, Ms. Stanlaske represents NAESA at various national and international codes and standards, and industry association meetings,including the ASME A17 Elevator and Escalator Safety Code Committees, and the International Standards Organization, ISO Technical Committee 178. She is a veteran of the elevator industry having held positions of increasing responsibility in labor, supervision and management for Beckwith and Otis Elevator companies. She is also a former elevator inspector for various states including Massachusetts and Washington. 


\section{Appendix K}

\section{Emergency Egress Strategies for Buildings}




\title{
Emergency Egress Strategies for Buildings
}

\author{
Richard W. Bukowski, P.E., FSFPE \\ NIST Building and Fire Research Laboratory \\ Gaithersburg, Maryland 20899 USA
}

\section{INTRODUCTION}

The primary strategy for the safety of building occupants in emergencies (especially fires) is by facilitating their relocation to a safe place. In other than a few institutional occupancies (health care and detentional) this generally involves the use of stairs as part of a protected means of egress (MOE) for vertical evacuation. For tall buildings with large populations, providing sufficient stair capacity for simultaneous egress has been considered impractical by code making organizations, so the strategy of phased evacuation has been employed. To this point in time, little attention has been paid to the special needs of people with disabilities and other (permanent or temporary) physical limitations in moving on stairs.

In the aftermath of September 11, 2001 new attention is being paid to many issues, especially emergency egress from tall buildings. A number of experts have called for a fundamental rethinking of egress strategies including all of the possible components that might be employed. In September 2006 a workshop was organized in Atlanta by CIB W14:Fire and TG50:Tall Buildings, with one of the discussion topics devoted to this issue. This paper is intended to continue that discussion.

\section{PERFORMANCE METRICS FOR EGRESS}

In performance design, the usual performance metric for egress systems is that of timed egress analysis. Here a range of calculation methods from simple hand calculations to sophisticated computer simulations that may include behavioral rules of human interaction are used to estimate the Required Safe Egress Time (or RSET). Fire models or calculational methods estimate the time available before escaping occupants are exposed to untenable conditions, Available Safe Egress Time (ASET) and as long as RSET is less than ASET, safety is assumed to be achieved.

A problem is that the design parameter for means of egress in regulation is that of capacity. MOE components are rated by the number of people (total) per unit width. Thus there is no direct connection between regulatory design requirements and the critical performance metric of egress time. A detailed discussion of the basis for egress systems design in regulation can be found in Bukowski and Kuligowski ${ }^{1}$.

\section{COMPONENTS OF A MEANS OF EGRESS}

A MOE consists of an exit access (normally a common use corridor leading to the exit), the exit itself (normally a stair), and an exit discharge (normally a door to the outside or into a protected corridor leading to the outside). Egress stairs may incorporate 
areas of rescue assistance which are part of enlarged landings providing space for people (especially with disabilities) to move out of the flow to rest or await assistance. Egress stairs may also incorporate transfer corridors that are used to shift the vertical alignment of the stair horizontally, to go around equipment or to maintain minimum required stair separation at floors where the building floor area changes.

This separation into a horizontal travel component on the originating floor, a vertical component to travel from the originating floor to the level of exit discharge (or other safe location), and a horizontal component to travel to the building perimeter would be common to any egress system. Further, the horizontal components are unlikely to be of a length that an occupant would require more than a few minutes to traverse, so any improvements to them would be unlikely to provide any significant impact on overall performance of the MOE, although their reliability might be improved.

\section{STAIRS}

Stairs are the primary means of vertical travel during fire emergencies and are generally effective and reliable, but with several significant shortcomings. Most building regulations require at least two independent stairs so that a single event cannot block access to both. This independence comes from the location of the stairs remote from each other. In some locations scissor stairs (two, intertwined stairs in a common shaft) are popular since they minimize the building space required. The disadvantage is that they are not remote and can both be easily compromised by openings in the separating partition. However, when counted as a single stair they provide additional stair capacity in a better configuration than a single, wider stair since there is better access to handrails as people descend.

Another shortcoming of stairs in high rise buildings is that standard firefighting procedures involve the designation of one of the stairs as the attack stair, in which the fire hose is extended to permit its advance onto the fire floor. Once the hose is extended in the stair and charged with water it is nearly impossible for occupants to pass from above. Further, once the door to the fire floor is opened to advance the hose, smoke may enter the stair and contaminate the floors above. Thus it may be necessary to delay firefighting until all occupants clear the stair above the fire floor.

This was observed in the fire in the 52-story Boston Prudential Center on January 2, $1986^{2}$. The fire began on the $14^{\text {th }}$ floor while the floor was undergoing a tenant fitout with an estimated 1500 occupants in the building. The $14^{\text {th }}$ floor door to stairway B failed early in the fire, permitting smoke and fire to make this stair untenable above the $12^{\text {th }}$ floor. This left only stair A for both occupant egress and fire attack. The fire department could not begin to attack the fire until evacuation was complete - about one hour. The fire severity was somewhat limited by the fact that the fire floor was unfinished and the fuel consisted primarily of stored construction materials. If the fire floor door to stair A had also failed, any remaining occupants above the fire would have been trapped. 
A conservative estimate of the time needed for most occupants to descend undamaged and smoke-free egress stairs is about one floor per minute ${ }^{\mathrm{a}}$. But a growing proportion of the population has difficulty in traveling on stairs and a small number of people cannot use any stairs without assistance. In general, the number of people who have difficulty with stairs increases with building height. These people include those with obvious mobility impairments (wheelchair, walker, and crutch users) but increasingly include people with respiratory or cardiac conditions, obesity, and those with temporary conditions ranging from pregnancy to sprains.

Today there are buildings under construction and planned where stairs are impractical for anyone in the upper reaches of a building 250 to 350 floors in height. For stairs used as a means of egress in fires, the record has been very good but not without incident. The most frequent problem is contamination of a stair by smoke due to a door not closed or to (usually pre-existing) breaches in the stair enclosure. Stair enclosures compromised by the initiating event (as was the case at the World Trade Center in both the 1993 and 2001 attacks) are rare, but stair enclosures are only required by regulation to exhibit fire resistance, with no requirements for structural integrity nor impact resistance. Such requirements are only now being considered in response to NIST's WTC recommendations ${ }^{3}$. For example, New York City has adopted a building code requirement ${ }^{4}$ for egress stair enclosures to comply with level 2 performance for impact resistance under ASTM C $1629^{5}$.

As mentioned above, any stairs represent significant challenges for some people with disabilities. With some conditions, a person's wheelchair provides critical life support and the person may not survive for long if separated from it. Such chairs are usually quite heavy and difficult for even several people to carry down stairs. Evacuation chairs that can be used to convey many wheelchair users or others with mobility limitations down stairs cannot accommodate these life support devices. These evacuation chairs or even just the physical support of another can allow some people with disabilities to traverse some stairs, but this requires people willing to assist, is fatiguing if the distance traversed is long, and can slow the flow of people in the stair. All these shortcomings need to be considered when determining RSET.

The most detailed studies of flow on stairs were performed by Templar in $1975^{6}$ and influenced the regulatory requirements still in place today. Although Templar found that the current $1100 \mathrm{~mm}$ (44 in) minimum stair was "adequate," a $1400 \mathrm{~mm}$ (56 in) stair was "preferable." Recently Pauls ${ }^{7}$ has challenged the applicability of these to modern society due to the increased trend to obesity and lower stamina. Larger people need more stair width to maintain the same flow, move more slowly, and are capable of traversing fewer flights of stairs before resting. Pauls' hypothesis is supported by recent studies of drills ${ }^{8}$ and fire evacuations ${ }^{9}$ showing travel speeds down stairs decreasing to a quarter of what was observed in Templar's work. Since the costs to the owner in lost rent over the life of

\footnotetext{
${ }^{a}$ Reported flow rates down stairs are often in the range of (20 to 30) seconds per floor but can slow as building height increases. Rates of 50 seconds per floor were reported in the 2001 World Trade Center evacuation. Ambiguity of cues, debris in the stairs, or the presence of impaired occupants can slow flows even further. Thus a rule of thumb estimate of one minute per floor is reasonable.
} 
the building for space used by wider stairs can be very high, even significant construction costs of alternate approaches to these problems may be cost effective.

Recently, proposals have been submitted to both US model building code organizations to increase the minimum width of required egress stairs from $1100 \mathrm{~mm}$ (44 in) to 1400 $\mathrm{mm}$ (56 in) where the stair serves a cumulative occupant load of more than 2000 people $^{10}$. The US General Services Administration estimated that the cost of construction of this wider stair is increased by about $21 \%$, and that the cost in lost rental of the space occupied by the wider stair is $\$ 250000$ to $\$ 500000$ per year for a 50 story (2 stairway) office building, depending on geographic location ${ }^{11}$.

\section{CORE ARRANGEMENT}

Most tall buildings are designed with a core area which contains the elevators, stairs, and shafts in which the utilities run vertically through the building. The core usually serves as the building's spine and often plays a significant role in the structural system. Because the core is most often infrastructure and common use space it is less likely to generate revenue for the owner. The designers spend a great effort to "optimize" the core design, meaning to make it as small as possible, maximizing the revenue producing space on each floor.

The exit access is generally arranged just outside and surrounding the core, with the stairway doors facing outward and cross corridors providing access to elevator lobbies. This exposes the exit access to the exterior of the building, protected only by any partitions that may provide for separation of spaces. In its new 7 World Trade Center ${ }^{12}$, the architects (SOM) moved the exit access to the center of the core such that the (reinforced concrete) core protects the access corridor and creates a refuge area on each floor. While this makes the core larger the protected space can shelter the floor occupants from external, natural and man-made hazards with direct access to the stairs and elevators. The cost-benefit of such arrangements needs to be examined.

An aspect of egress system design associated with the arrangement of the core is remoteness. Buildings are required to have at least two, independent exits, separated by a minimum distance; usually not less than one third of the diagonal dimension of the space served. Remoteness is intended to ensure that no single incident can block access to both stairs. Some regulations permit the separation distance to be measured along a walking path between exits, which can allow exits to be adjacent but separated by a perpendicular wall of at least half the required dimension in length. If the initiating event compromises this wall, the remoteness is defeated.

\section{OCCUPANT EGRESS ELEVATORS}

Elevators are the normal means of vertical transport in any building taller than a few stories. However during fires, the safety of elevators can be affected by the fire itself and by water from sprinklers and fire hoses, so the policy worldwide is not to use 
elevators during fires. Elevators are also taken out of service during earthquakes when the lateral acceleration exceeds a level that might compromise further safe operation.

In the 1980's the elevator industry developed Firefighters Emergency Operation (FEO) that is now required in building regulations worldwide. In FEO, detection of smoke in the elevator lobby on any floor or in the machine room results in the elevators being immediately recalled to the designated landing (generally the level of exit discharge) and taken out of service. The responding fire brigade can use a special key to re-activate individual cars to be driven manually by a firefighter. In this mode, hall calls are ignored and the in-car controls operate somewhat differently to provide enhanced safety. Most regulations permit the fire brigade to use elevators being driven by a firefighter to be used to assist people with disabilities in evacuation.

While there are currently no regulations that generally permit occupant egress elevators there are a growing number of systems being approved worldwide under performancebased or alternate solutions provisions. Much of this recent acceptance is associated with an intensive effort in the US by NIST, the American Society of Mechanical Engineers (ASME) and the elevator industry to develop requirements for occupant egress elevators, as documented in a number of publications ${ }^{13}, 14,15$.

The prospect of using the elevators for occupant egress in fires is being enthusiastically embraced by building owners, designers, and regulators for several reasons. First, it permits the location of assembly occupancies (bars, restaurants, and observation decks) on upper floors of tall buildings without the building-code-mandated penalty of larger stairs running the full height of the building to accommodate the occupant load. This is premium space based on the views available from the top. An example is 30 St. Mary Axe in London, which incorporates a bar and restaurant on the top floor and protected elevators running between the assembly space and street level. Second, egress elevators directly address the needs of people with disabilities for self-evacuation. Developers of high-rise condominiums for the elderly see egress elevators as a significant marketing advantage. An example is Petronas Properties in Kuala Lumpur and Marriott Corp. in the US, both of whom are developing high rise condominium properties marketed to older residents. Third, integrating egress elevators into the evacuation procedures of very tall buildings has a very significant impact on total egress times. An example is Taipei 101 where the total evacuation time was reduced from 2 hours to 57 minutes when elevators were incorporated into the evacuation $\operatorname{plan}^{16}$.

\section{FIRE SERVICE ACCESS ELEVATORS}

While fire service access elevators are not a part of the means of egress they do have a significant impact on occupant egress in tall buildings. For any building of sufficient height that egress has not completed before the fire service begins to move into position to begin operations, there is a conflict between occupants leaving and firefighters entering resulting from counterflow in the stairs. NIST studies of the WTC evacuation and of drills in federal buildings indicate that counterflow has little effect on occupant evacuation but significant impact on fire service access, delaying the start of operations 
and separating firefighting teams. Transferring fire service access to protected elevators eliminates counterflow along with numerous additional advantages to operational efficiency ${ }^{17}$.

It should be noted that the use of fire service access elevators does not eliminate the issue of the fire department taking over an attack stairway which is then blocked for occupant use from above by the charged hose. This would still occur because the fire attack would still be made from the stair - however the impact is greatly lessened if the occupants are using elevators for egress or if there are additional stairs.

\section{ELEVATOR EGRESS STRATEGIES}

When incorporating elevators into fire evacuation it is important to exploit their strengths while protecting their weaknesses. The typical design metric for elevators in a modern high rise commercial building is to provide sufficient car capacity and speed to be capable of moving $10 \%$ of the total population of the building in 5 minutes during peak times at the start and end of the work day. Thus, any high rise building is able to move its entire population by elevators in one hour or less with the elevators provided for normal use.

Elevators are most efficient when operating in shuttle mode (avoiding time needed for accelerating and decelerating smoothly). Further, it makes sense to use the elevators to move those with the longest distance to go, first. Occupants of lower floors (without disabilities) have a choice to use the stairs. Another consideration is that it is unlikely that any large building will initiate a complete evacuation on an automatic alarm due to the potential for significant business disruption without cause. But there is recent experience with occupants of large buildings initiating a full scale evacuation on their own if they suspect something is wrong in their building. This and other issues are being studied in a survey of high rise building occupants attitudes regarding building evacuation $^{18}$.

Thus, an elevator evacuation protocol is likely to begin with an initial alarm summoning the fire department and taking the designated fire service elevator out of service to await fire department arrival at the designated landing. The remaining elevators will go into evacuation mode where they collect occupants of the fire zone (fire floor and two floors above and below) to shuttle them to the level of exit discharge. The elevators would then wait at the designated level for a decision by the incident commander for partial or complete evacuation or for a return to normal service. Waiting at the designated level prevents arriving people from taking the elevators to upper floors during the fire.

A decision for total evacuation would initiate a second phase of the evacuation protocol where the elevators would collect occupants from the highest floors first, shuttling them to the level of exit discharge and returning for another load, working their way down from the top. Hall calls would register people awaiting pickup but would not alter the sequence. People with disabilities would not be given any priority since all occupants are accommodated equally in this system. 
Enclosed lobbies on every floor would provide a protected space in which to wait and serve to protect the hoistway from smoke/fire (delaying the initiation of Phase I recall) and from water intrusion from sprinklers or hose streams. Real time signs in every lobby would report system status in real time including how long before cars would arrive to evacuate that floor. The signs at the level of exit discharge would warn not to enter as the elevators are in evacuation mode. Conditions in the lobbies and machine room would be monitored in real time from the incident command. Once staging is completed, the fire service elevator can be used to pick up the injured or stragglers. All of this can be accomplished with commercially available systems.

\section{REFUGE FLOORS}

In several Asian countries (China, Singapore) tall buildings must be provided with refuge floors every 20 to 25 floors. These are usually mechanical floors (no normally occupied space) with at least $50 \%$ of the floor area configured as an area of refuge (2-hr separations to equipment spaces, no fuel load, space to hold all occupants of the floors between refuge floors at $0.3 \mathrm{~m}^{2}$ or $3 \mathrm{ft}^{2}$ per person). They are required to be open on two opposite sides so that smoke will not accumulate. Refuge floors provide a protected space for occupants to rest or to await assistance, or to cross between stairways ${ }^{19}$.

Requirements for refuge floors are relatively new and are currently found in only a few buildings. No real evacuations have occurred but there is some experience from drills that indicates there may be a problem when people reach a refuge floor and decide to wait there rather than continuing the evacuation ${ }^{20}$. Occupants accumulate on the refuge floor such that additional arriving occupants cannot enter. This may be an artifact of a drill where the occupants know they are not in danger and that they will be returning to their floor after the drill. Also, a study using cfd models showed the open sides could permit smoke to enter from an external fire plume originating on a lower floor ${ }^{21}$. Recent revisions require drencher systems on the open sides.

The World Financial Center currently under construction in Shanghai incorporates refuge floors and also utilizes two observation elevators running on the outside of the super columns on diagonal corners of the building. These elevators were originally designed to provide express service only to the observation deck on the top floor. These observation elevators were modified to stop at each of the refuge floors to be used for occupant egress in fires. Thus the furthest an occupant would need to travel in the stairs is 25 floors (13 floors if procedures were to suggest using the closest refuge floor even if it was above your position). Occupants not capable of using the stairs to reach a refuge floor would be picked up by a firefighter driving an interior elevator under FEO.

\section{ACTIVE EVACUATION MANAGEMENT}

Increasingly, experts are saying that occupant evacuation proceeding during fire department operations should be actively managed, since those operations can result in risks to occupants due to changing conditions. This was seen in the Cook County office 
building fire ${ }^{22}$ and others where suppression operations make the attack stairway untenable above the fire floor. Such active management involves monitoring in real time to identify conditions that require a modification to the evacuation, and a means to communicate instructions.

Monitoring would likely involve the installation of video cameras in the stairways (one proposal submitted to the ICC in the US is for cameras every five floors). Some concerns have been raised about the workload of monitoring all these cameras. With modern security cameras and software it is unnecessary for a person to monitor the images. The software monitors the image and, as long as there are people moving down the stairs the image is in background. Should there be no people or no movement for a preset time the image is brought forward for the operator. This would allow rapid identification of blockages without undue distraction. These cameras can also identify smoke in the stair which would require redirection of occupants through the voice communication systems already present under current codes.

\section{COMMUNICATION SYSTEMS FOR EGRESS MANAGEMENT}

Since the early $20^{\text {th }}$ Century fire alarm systems have been provided in buildings to notify occupants of the need to evacuate. Once the alarm was sounded there was no further need for communication since the action was simply to leave the building as quickly as possible. This changed in the mid-1980's when phased evacuation was introduced for tall buildings where the egress system could not support simultaneous evacuation. It was felt that where occupants were asked to wait for their turn to evacuate, it is necessary to provide a means of making pre-recorded and live, voice messages until the evacuation was complete. This communication was carried out from a fire command center specifically arranged for the fire department to conduct incident command.

New York City adopted Local Law 5-1973 which required voice communication systems for new, high rise (defined as exceeding 100 feet or $30.5 \mathrm{~m}$ in height) office buildings and extended this requirement to new mercantile and all high rise hotel occupancies through Local Law 16-1984. In the U.S., the National Fire Protection Association's Technical Committee on Protective Signaling Systems developed NFPA 72F (High Rise Voice Communication Systems, which was published in 1988 and then incorporated as a chapter in the consolidated National Fire Alarm Code, NFPA 72 (1993 and subsequent).

Total evacuation of tall buildings has been a rare event, but as society becomes more risk averse we may find that it occurs more frequently. Also, fire is not the only condition that might trigger a total evacuation. Severe weather, chemical spills, earthquakes, major water leaks, workplace violence, and large-scale power outages are only some of the conditions that have led to building evacuations. In some cases the emergency action is to shelter within the building, which may involve some relocation. The complexity of getting occupants to take the desired action makes an even stronger case for communication systems and proactive evacuation management. 
Human factors research clearly shows that people will generally make the right decisions when provided with the (clear and unambiguous) information upon which to base those decisions $^{23}$. Events such as the 1993 and 2001 World Trade Center evacuations as well as evacuations and drills carried out in other tall buildings show the range of things that can go wrong when evacuating large number of people. These all demonstrate the need to actively manage evacuations, including monitoring the process to identify problems, and communications systems to give directions that resolve these problems.

Today, emergency communication systems are common, even in smaller buildings. These initially provide to specific areas (individual floors or fire zones, stairs, and elevators) or to the entire building, pre-recorded or digitally generated voice instructions initially, and the ability for the incident commander to issue live instructions during the incident. Current discussions include the provision of cameras in refuge areas and stairs to provide the incident commander the ability to monitor the evacuation process and to quickly identify problems. To reduce monitoring workload these would be arranged to only display their image if the system detected no people or people not moving in the stairs, or if a call were placed from the location to the command center. Dynamic signs are being discussed to provide textural information in real time. These could display the time before elevators arrive at a given floor as part of an elevator evacuation system, or to give directions at key points in the egress system on which direction to go. Such dynamic signs have been installed in the new WTC 7 building on the transfer floor, within the egress stairs to instruct occupants on which street exits to use. These signs can display any messages entered from either the fire command or security center of the building.

Another experimental information system developed by the US General Services Administration is a text pager that is issued to any hearing impaired occupant and available to hearing impaired visitors at the security desk. This system can display messages and instructions in real time during any incident and vibrates to get the user's attention. The only problems noted in technology studies is getting people to carry them and recovering units issued to visitors.

\section{PERFORMANCE GOALS FOR EGRESS SYSTEMS}

In its recommendations for changes to codes, standards, and practices resulting from the WTC collapse investigation, NIST recommends that buildings be designed for "timely, complete evacuation." The point is not that total, simultaneous evacuation will become the norm or will even be common; but it is reasonable to expect that every building will need to be completely evacuated a small number of times over its lifetime. In the recommendations, timely is not defined. Recent experience with the use of elevators for occupant egress in very tall buildings indicates that it is possible to evacuate the entire population of any building of any height within one hour, without any changes to the number, size, or speed of the elevators that would be present if they were not used for evacuation. Thus, the goal of being able to evacuate a building in one hour or less is achievable as an RSET. 
In modeling of occupant egress it is recommended that a safety factor of 2 by applied when dealing with the uncertainties of human behavior ${ }^{24}$. In keeping with this conservative approach it is reasonable to double the time available and to require a minimum of $2 \mathrm{~h}$ of ASET (available safe egress time) and this is a common requirement today for the fire resistance of the primary structural frame in sprinklered high rise buildings. The result should represent a reasonable and conservative performance goal for complete evacuation (including people with disabilities) within one hour. In addition this permits people with disabilities to self-evacuate with every one else and without the need for assistance or special devices.

\section{CONCLUSIONS}

From this discussion it appears obvious that protected elevators will become a primary means of vertical travel in tall buildings. Assuming regulatory agreement with the performance goal of total evacuation in one hour or less, occupant egress elevators would be required in buildings taller than about 50 stories and fire service access elevators in buildings taller than (6 to 9) stories. At the estimated one floor per minute rate, buildings of up to 50 stories can be evacuated in one hour or less using stairs alone. Most fire departments report a preference to use elevators to access fires above the sixth floor. Discussion and consensus is needed on the role of stairs, refuge floors, communication systems, and procedures for egress, relocation, or protection in place in the range of incidents that may be encountered in any building. In some cases, formal threat assessment may be needed to identify scenarios that need to be considered.

Where protected elevators are provided for occupant egress much of the occupant load would be carried by the elevators. Thus there may be less need for wider stairs, and the avoided costs of wider stairs should be more than adequate to cover the additional costs for protecting the elevators and adding monitoring. Owners then would be free to place assembly occupancies high in the buildings without the need for increasing stair capacity. People with disabilities would be afforded the ability to self-evacuate with all other occupants without the need for special arrangements or equipment. In an event where the incident commander decides to require simultaneous evacuation of a building, the entire population should be capable of clearing the building in an hour or less. An hour should be an achievable RSET even for very tall buildings and it should be well within the practical ability of safety designs to provide a protected environment (ASET) of two hours in which to carry out an evacuation including a conservative factor of safety of 2 for variation in human behavior and capability.

\section{REFERENCES}

\footnotetext{
${ }^{1}$ Bukowski, R.W. and Kuligowski, E.D., The Basis for Egress Provisions in U.S. Building Codes, InterFlam 2004, Edinburgh, UK, July 2004.

${ }^{2}$ Klem, T. and Kyte, G., Fire at the Prudential Building, Fire Command, 53, No. 3, 14-19, March 1986.

${ }^{3}$ NCSTAR 1 Final Report on the Collapse of the World Trade Center Towers, Chapter 9

Recommendations, Nat Inst Stand Tech, Gaithersburg, MD 208992005.

${ }^{4}$ Local Law 26-2004, Ammendments to the Building Code of New York City, New York City Department of Buildings, 2004.
} 


\footnotetext{
${ }^{5}$ Standard Classification for Abuse-Resistant Nondecorated Interior Gypsum Panel Products and FiberReinforced Cement Panels, ASTM C 1629/C 1629M-05, ASTM International, West Conshohocken, PA. ${ }^{6}$ Templar, J., The Staircase, Studies of Hazards, Falls, and Safer Design, MIT Press, Atlanta, GA 1992.

${ }^{7}$ Pauls, J., Selected Human Factors Aspects of Egress System Design, presentation at CIB TG50 and W14 Joint Symposium on Tall Buildings and Fire, September 2006, proceedings available at http://www.cibworld.nl/

${ }^{8}$ Averill, J. and Peacock, R., SFPE PED Conference proceedings (in press)

${ }^{9}$ Averill, J., Mileti, D., Peacock, R., Kuligowski, E., Groner, N., Proulx,G., Reneke, P., and Nelson, H., Occupant Behavior, Egress, and Emergency Communications, NCSTAR 1-7, NIST, Gaithersburg, MD 2005, available at http://wtc.nist.gov/

${ }^{10}$ Life Safety Code, NFPA 101-2006, Table 7.2.2.2.1.2 (B), Nat Fire Prot Assn, Quincy, MA 02269

${ }^{11}$ David Frable, GSA, private communication.

${ }^{12}$ Details of the design of 7 WTC can be viewed on the Silverstein Properties website http://silversteinproperties.com/

${ }^{13}$ Bukowski, R.W., Protected Elevators for Egress and Access During Fires in Tall Buildings, Strategies for Performance in the Aftermath of the World Trade Center. CIB-CTBUH Conference on Tall Buildings.

Proceedings. Task Group on Tall Buildings: CIB TG50. CIB Publication No. 290. October 20-23, 2003, Kuala Lumpur, Malaysia, Shafii, F.; Bukowski, R.; Klemencic, R., Editors, 187-192 pp, 2003.

${ }^{14}$ Bukowski, R. et al, Elevator Controls, NFPA Journal, Nat Fire Protect Assoc., Quincy, MA 100, No 2 , March/April 2006

${ }^{15}$ Bukowski, R., Protected Elevators and the Disabled, Fire Protection Engineering, SFPE, Bethesda, MD, Issue 28, Fall, 2005.

${ }^{16}$ Hsiung, K., Wen, W., Chien, S., and Shih, B., A Research of the Elevator Evacuation Performance for Taipei 101 Financial Center, Proc 6th International Conference on Performance-based Codes and Fire Safety Design Methods, 14-16 June 2006, SFPE Bethesda, MD 2006.

${ }^{17}$ Kuligowski, E.D. and Bukowski, R.W., Design of Occupant Egress Systems for Tall Buildings, Use of Elevators in Fires and Other Emergencies Workshop Proceedings. Co-Sponsored by American Society of Mechanical Engineers (ASME International); National Institute of Standards and Technology (NIST); International Code Council (ICC); National Fire Protection Association (NFPA); U.S. Access Board and International Association of Fire Fighters (IAFF). March 2-4, 2004, Atlanta, GA, 1-12 pp, 2004, 2004.

${ }^{18}$ Fire Protection Research Foundation Project on High Rise Occupants and Evacuation, Fire Protection Research Foundation, Quincy, MA 02269.

${ }^{19}$ Code of Practice for the Provision of Means of Escape in Case of Fire, Part II, Section 21 Refuge Floors, Hong Kong Building Authority, 1996.

${ }^{20}$ Meacham, B., Refuge Floors in Tall Buildings: The Asian Experience, presentation at CIB TG50 and W14 Joint Symposium on Tall Buildings and Fire, September 2006, proceedings available at http://www.cibworld.nl/

${ }^{21}$ Yuen, K., Lo, S., and Yeoh, G., Numerical Simulation of Wind-Smoke Effect on Designated Refuge Floor in High Rise Buildings, Proc InterFlam “99, Volume 2. June 29-July 1, 1999, Edinburgh, Scotland, Interscience Communications Ltd., London, England, 1273-1279 pp, 1999

${ }^{22}$ Proulx, G. and eid, I., Occupant Behavior and Evacuation during the Chicago Cook County Administration Building Fire, Journal of Fire Protection Engineering, SFPE Bethesda, MD, 16, No 4, 2006

${ }^{23}$ Proulx, G. and Koroluk, W., Fires Mean People Need Fast, Accurate Information, NRCC-41088, CABA Home and Building Automation Quarterly, 17-19, Summer 1997.

${ }^{24}$ Nelson, H.E. and Morwer, F. W., Emergency Movement, SFPE Handbook of Fire Protection Engineering, $3^{\text {rd }}$ ed., SFPE Bethesda, MD, 2002.
} 
Appendix L

Emergency Egress from Buildings, Part 1: History and Current Regulations for Egress Systems Design 


\title{
Emergency Egress from Buildings Part 1: History and Current Regulations for Egress Systems Design
}

\author{
Richard W. Bukowski, P.E., FSFPE \\ NIST Building and Fire Research Laboratory \\ Gaithersburg, Maryland 20899 USA
}

\section{INTRODUCTION}

For most of history buildings were short enough that stairs provided for access were sufficient for rapid egress in the event of fire. Even in single stair (mostly residential) buildings, experience showed that this stair was sufficient for fire egress as long as the fire did not expose or block access to the stair. Fire resistant apartment doors shielded the stair from most fires and exterior fire escapes provided a second egress path beginning early in the $20^{\text {th }}$ Century.

The 1854 invention of the elevator safety brake enabling the passenger elevator is credited with facilitating increases in building height and the first so-called skyscraper in Chicago in 1885 . These buildings utilized steel frames protected by masonry or tile and were dubbed "fireproof construction" providing a (possibly false) sense of security. By 1914 authorities had begun to question these arrangements as evidenced by a move to change the term "fireproof" to "fire-resistive," and description of egress provisions in regulations as "exceedingly deficient."

Model building regulations in the US started with the National Building Code published by the National Board of Fire Underwriters (NBFU) following the Great Fire of Boston (1872). Property loss claims from this fire resulted in more than 70 insurance companies being driven into bankruptcy, causing insurance interests to form the NBFU and to develop building fire safety rules aimed at reducing property losses in fires. These rules became the first model building code, called the National Building Code (NBC), and first published in 1905. The NBFU was able to tie compliance with their rules to their Municipal Grading Schedule on which insurance rates are based. Cities needed favorable rates to attract investment, so they were motivated to adopt regulations consistent with the National Building Code ${ }^{2}$. The first (1905) edition of the NBC required exit stairs to have a minimum width of 20 in $(510 \mathrm{~mm})^{*}$.

The purpose of this paper is to document current regulatory requirements for means of egress in fires, their origins and scientific basis, and the approaches used in other countries. Then the paper will present an argument for why these approaches and requirements should be re-evaluated to reflect changes both in buildings and in their occupants. Finally the paper will make some suggestions for reasonable revisions to

\footnotetext{
* This paper will cite primary dimensions in the units found in the code cited. Thus U.S. codes will show English units first and non-U.S. will show metric first. Unit conversions are approximate because the paper cites the equivalent values found in the building regulations of various countries which are normally round numbers.
} 
design practice along with a more holistic philosophy that takes better account of human behavior and is based on a more appropriate performance metric.

\section{ORIGINS OF THE 44 INCH EXIT STAIR IN THE US}

In the 1913 National Fire Protection Association (NFPA) Proceedings ${ }^{3}$, the Committee on Fireproof (later, Fire-Resistive) Construction reported a number of recommendations, including one for minimum 44-in exit stairs (unobstructed width except that handrails would be permitted to intrude not more than $3 \frac{1}{2}$ in on each side). That same year NFPA formed their Committee on Safety to Life. That committee's first activity was to conduct a comprehensive review of fire safety issues and regulatory approaches found in building codes and local regulations in several, geographically diverse cities. At the NFPA's 1914 meeting they reported that,

“... existing laws are exceedingly deficient in this very important matter of egress. A number of states report frankly that they have no real legislation upon the subject, many City Ordinances are of the most indefinite character, and in some the matter is simply left to the discretion of the fire department or other officials."

In the 1914 NFPA Proceedings, section on egress, the Safety to Life Committee cites the 1913 NFPA Annual Meeting report of the Committee on Fire-Resistive Construction in which they said was presented,

"... a splendid set of specifications for the construction of a standard building. Egress received detailed attention; -- specifications for smoke-proof towers, for stairs, for horizontal exits, and for the capacity of vertical and horizontal exits were included."

The committee also cites the 1913 laws of the New York State Department of Labor which, “... as regards fundamentals appear to agree entirely with the requirements of our Committee ...” Extracting from the referenced New York statute, they cite,

" $a$. For buildings erected in the future, a minimum of 22 inches of stair width shall be required for not to exceed 14 persons on any one floor.

b. On buildings already erected this figure is reduced to 18 inches as a minimum.

c. A 44-inch stair in new buildings permits 28 persons to be housed on each floor above the first one.

d. In arriving at this decision the idea has been that all of the persons on all floors shall be able to remain in the stair tower without any movement, a person requiring about 22 inches in width, and one person to stand on every other stair."

They further characterize the New York laws' stair geometry ( $73 / 4$ in riser height by 10 in tread) as "good", and that they recommend a minimum 44 inch wide stair for new buildings as this width is

"reported sufficient to prevent three persons from forming an arch and blocking traffic."

\section{EXIT CAPACITY}

The above explains why the US designs exits for "capacity" and why the capacity is based on the population of a single floor. The exit is sized to "store" people, motionless 
within the protected exit enclosure, such that the population of one floor will fit within one flight of the stair, with each person in a space 22 inches wide and standing on every other step.

This philosophy was recognized in the 1935 National Bureau of Standards (NBS now NIST) publication, Design and Construction of Building Exits ${ }^{4}$. Developed by the Department of Commerce Building Code Committee, this report included survey data on exit sizes and configurations drawn from eight cities chosen, "... with a view to covering places varying in size and sufficiently distributed to give a fair cross section of building construction." The survey included population counts on typical floors and compiled data on movement of people in buildings (railway terminals and schools). Studies of the flow of occupants of government buildings during fire drills were conducted and the data presented as discharge rates for stairs (as a function of width and stair geometry), ramps, and doorways.

The data were used to suggest possible approaches to calculating minimum width of exits necessary to provide for occupant safety. These included (note that the descriptive text is paraphrased from the 1935 report):

1. Capacity Method, which is based on the concept of storing occupants on the stairs within a protected stair enclosure, and allowing for the subsequent safe and orderly evacuation of the building. It recognized that travel down a long series of stairs in high buildings is exhausting even to normal persons. Objections of building owners over the loss of rentable space are noted as well as the comment by some authorities that people may not stand still in stairways, even in high buildings.

2. Flow Method, which is based on the concept that people will move down the stairs at a typical flow, assumed to be 45 persons per 22 in unit of width per minute and 60 persons per minute through doorways. It is stated that this method is usually coupled with an assumed time in which it is safe to exit the building and that this method calls for considerably less stairway width than the capacity method. However they felt that it would be limited to a few occupancies and to buildings of low to moderate height since continuous movement down stairways in high buildings cannot be expected without serious effects on some occupants.

3. Combined Method suggests the flow method for lower buildings shifting to the capacity method for taller buildings also accounting for type of construction and use. Once again they point out that tall buildings would require a disproportionate amount of space devoted to stairways as compared with useable floor area.

4. Probability Method considers only the population of the six, most densely populated floors since it is improbable that simultaneous evacuation of all floors of a large building is needed. This is the first time that phased evacuation (as currently practiced in tall buildings) is suggested.

5. Floor Area Method relates area to units of exit width needed as a function of construction type and use. Like the probability method, simultaneous evacuation of all floors is not considered but the number of floors considered varies with occupancy. 
In the end, the 1935 report suggests that the needs of the vast majority of buildings can be met with the provision of two, two-unit-width (44 in) stairs. The capacity method (occupants waiting within the exit enclosure) is appropriate for low buildings with a gradual shift to the flow method for taller buildings where people will be less comfortable waiting in the stair. For tall buildings the floor area method has some application as these are of fire resistive construction and only those near the floor of origin are initially at risk but six floors is not sufficient for larger buildings. They suggest half of the floors should be considered.

\section{EARLY THOUGHTS ON ELEVATORS AS A MEANS OF EGRESS}

Both the 1914 NFPA Proceedings ${ }^{\text {Error! Bookmark not defined. }}$ and the 1935 NBS report discuss the possible use of elevators for egress from tall buildings. In 1914 the Committee on Safety to Life expressed the opinion that, “... elevator shafts properly enclosed and with openings adequately protected have decided value from an escape standpoint, and are absolutely necessary in high buildings." They cited as "... loss of life possibilities in many modern so-called fireproof buildings ..." the common practice of unenclosed stair and elevator shafts that might permit a fire in lower stories that, "... spread with unexpected speed could result in a loss of life which would stagger the civilized world." The Committee called for enclosing elevator shafts, improving the fire resisting powers of elevator doors, ensuring the integrity of the electric current applied to elevators, and "drilling" elevator operators in emergency procedures, including that persons in the upper stories shall first be taken to the ground.

The 1935 NBS report discusses a credit for elevators against required aggregate exit width. They discount automatic elevators as unsuitable as their "...capacity and rate of speed is not great." And "... they are not subject to a single will as in the case of an elevator operator, but to demands from many tenants." While there was a suggestion in the formulae of the flow method that five elevators might be equal to a single unit of exit stair width for some construction types and use, in the end they concluded that the uncertainties were such that no direct credit be given for elevators but to recognize their availability in high buildings.

\section{EARLY REGULATORY APPROACHES IN THE US}

The 1914 report of the Committee on Safety to Life included detailed recommendations for the design and arrangement of egress stairs and fire escapes with the intent that this material would be incorporated by others into building regulations. No code or standard was produced by the Committee until the 1927 publication of the first edition of the NFPA Building Exits Code (NFPA 101-T) ${ }^{5}$ which later became the Life Safety Code.

The 1927 edition of NFPA 101-T defined stairs as Class A, B, or C. Class A stairs were the main stair of a newly-constructed Assembly occupancy, and were 44 in $(1100 \mathrm{~mm})$ wide (handrails could intrude not more than $3 \frac{1}{2}$ in $(89 \mathrm{~mm})$ on each side) with a rise of not more than 7 in $(178 \mathrm{~mm})$ and a tread of not less than $101 / 2$ in $(267 \mathrm{~mm})$. Class B stairs were for new construction of all stairs not required to be Class $\mathrm{A}$, and for existing 
construction where Class A stairs would be required if new. Class B stairs were the same width as Class A but the rise was permitted to be not more than $73 / 4$ in $(197 \mathrm{~mm})$ with a tread of not less than $9 \frac{1}{2}$ in $(241 \mathrm{~mm})$. Class $C$ stairs covered existing stairs in existing buildings and were at least 36 in $(0.9 \mathrm{~m})$ wide (not less than $32 \mathrm{in}, 0.81 \mathrm{~m}$ between handrails, but stairs less than 44 in $(1100 \mathrm{~mm})$ wide only required a handrail on one side). Occupant load on a floor dictates required capacity (total width of stairs in number of 22 in units) required in a minimum of two stairs located "as remote as practical."

The 1935 NBS report included recommended code language in an appendix that did not follow any of the five methods for calculating minimum exit widths discussed previously. They explained that tentative requirements were drawn up and compared against the results of the field studies. Eventually a consensus of the Committee was reached and was presented in the recommended code language.

The suggested code requirements largely followed the capacity method for at least two stairs of two (22 in, $550 \mathrm{~mm}$ ) units of exit width each, with the floor area method used (by means of occupancy load factors consistent with those found in current regulations) to determine aggregate width. No suggestions of maximum egress time (including no references to fire resistance times associated with construction types, building height, and use) that might facilitate the use of the flow method, and no mention of partial evacuation of tall buildings as discussed in the probability and floor area methods was made. These recommendations were consistent with those in the 1927 edition of NFPA 101-T, but this is not surprising since the Committee on Safety to Life was represented on the NBS Committee. The requirements suggested in the NBS report and NFPA 101 were adopted in the model codes and building regulations throughout the US until the mid-1980's when the 22 in $(550 \mathrm{~mm})$ unit of exit width was abandoned for assessing exit capacity in units of people per inch, but retaining the 44 in $(1100 \mathrm{~mm})$ minimum width. This method provides similar results for aggregate exit width but provides more capacity credit for fractions of the 22 in unit.

\section{SCIENTIFIC STUDIES OF FLOW RATE}

The 1935 NBS report included field surveys of discharge rates down exit stairs and through doors for various government buildings during drills and for subway and rail terminals at rush hours. The data collected were discussed by the Committee and a consensus reached that there was a clear correlation between width and flow. The committee agreed that, “... rates of 45 persons per 22-inch unit per minute for travel down stairways, and 60 persons per 22-inch unit per minute through doorways, which had been in use on the basis of earlier observations, were sufficiently confirmed to warrant their retention in connection with the requirements under development."

Almost from the start there were issues raised with the assumed flow rate on stairs of 45 persons per minute per (22 in) unit of exit width. Togawa ${ }^{6}$ in Japan conducted research in the 1940's and 50's, that showed for densities above 1 person per square meter (10 square feet) that flow rates decreased significantly. His data suggested a flow rate of 26 persons per minute per (22 in) unit of exit width. 
Pauls has published extensively on this topic and continues to be the scientific conscience of stair design in the US codes. Pauls ${ }^{7}$ and Fruin ${ }^{8}$ both discussed the concept of effective width of a stair, which is generally $0.3 \mathrm{~m}(1 \mathrm{ft})$ narrower than the actual width due to the natural tendency of people to keep a distance from walls and handrails. Fruin further spoke of the personal space (buffer) around people that increases their effective space requirement. Pauls found that for people walking on stairs their body sways from side to side and they desire sufficient space so that they do not make contact with the person beside them. Pauls work confirmed that of Togawa finding that flow rate in stairs at typical densities is about 27 persons per minute per (22 in) unit of exit width. Extensive studies in Russia also confirmed the effects of density on flow rates including the values suggested by Pauls and Togawa, as reported in a 1969 book by Predtechenskii and Milinskii ${ }^{9}$.

From the data collected by NIST in the investigation of the World Trade Center (WTC) collapse on September 11, 2001, the flow rate in the stairways can be estimated ${ }^{10}$. For WTC 1, there were approximately 7900 survivors who exited the building over the 102 minutes between the aircraft strike and the collapse. The building had three stairs, two at 44 in $(1100 \mathrm{~mm})$ and one at 56 in $(1400 \mathrm{~mm})$. Assuming the occupants used the stairs equally, there were 2630 people in each 2-unit wide stair who exited in 102 minutes, or 13 people per minute per unit of exit width. The NIST study found that the egress flow decreased by about $80 \%$ in the last 20 minutes before collapse. If one assumes the 2630 people exited in 82 minutes, the flow rate would be 16 people per minute per unit of exit width. These estimates support the argument that current flow rates may be significantly less than the rate suggested by Pauls and Togawa in the 1970's and one third the rate proposed in $1914^{\text {Error! Bookmark not defined. }}$

\section{SCIENTIFIC STUDIES OF EXIT WIDTH}

Clearly, the current 44 in $(1100 \mathrm{~mm})$ minimum exit stair width is intended to support two, 22 in queues of occupants either standing still (capacity method) or moving down the stair (or a single queue of occupants moving down and being passed by firefighters moving up, known as counterflow). The 22 in dimension for the width of a person was offered in 1914 as originating with soldiers standing in a line ${ }^{\text {Error! Bookmark not defined. }}$

Challenges to the adequacy of the 22 in dimension include the need to provide for body sway as people move down the stair (Pauls), and the need to allow for some personal space (Fruin, Predtechenskii and Milinskii). Recently, the adequacy of the basic 22 inch dimension is being questioned in light of the increasing size and weight of the typical person, especially in the US. The 22 inch dimension refers to the width of a person at the shoulders, which is assumed to be the widest part. Predtechenskii and Milinskii suggest that 4 in $(100 \mathrm{~mm})$ be added to each side to allow for a personal buffer except that for low obstructions (like handrails) the additional space is not needed since one's shoulders are at a higher level and will extend over the obstruction. 
From anthropometric data for modern Americans, the width at the hip is approaching the width at the shoulder, and it seems that this exception may no longer be valid. Thus, with the shoulder width of the $97.5^{\text {th }}$ percentile adult male reaching 20 in $(510 \mathrm{~mm})^{11}$ and allowing the 4 in on each side for handrail and personal space, the new unit of exit width should be 28 in $(700 \mathrm{~mm})$ and the minimum stair width 56 in $(1400 \mathrm{~mm})$, see Fig 1.

Arguably the most comprehensive studies of movement on stairs were

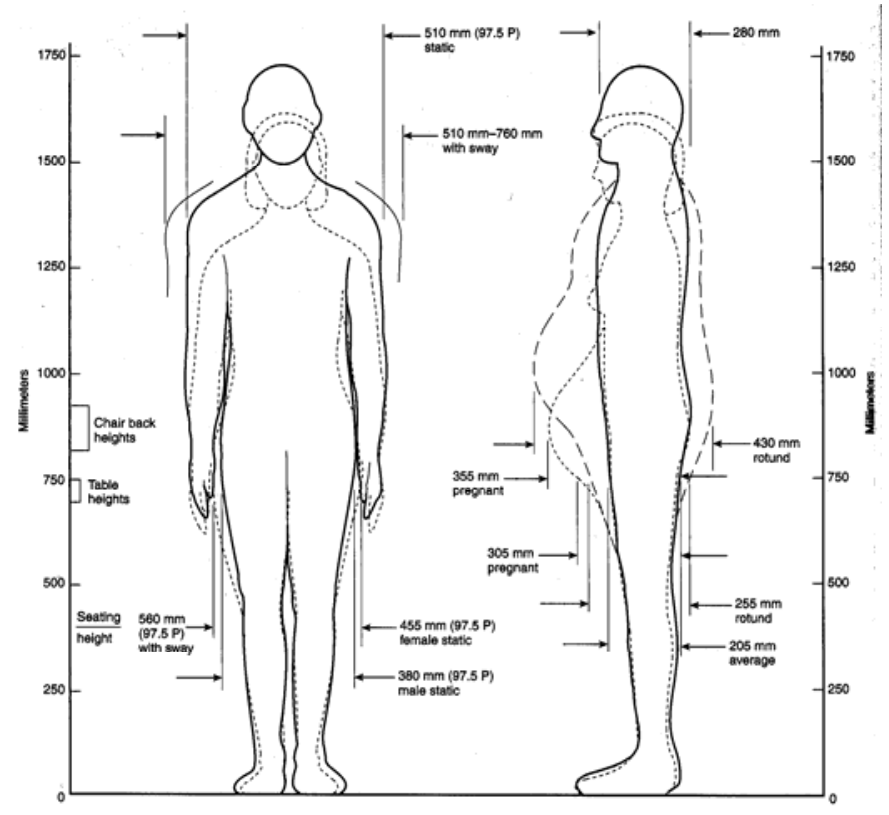
conducted by Templer, beginning with his doctoral research ${ }^{12}$ and including work at $\mathrm{NBS}^{13}$ in the 1980 's. Templer observed the movement of many

Figure 1 Anthropometric data for adults Reprinted with permission from NFPA $101 \circledR$ the Life Safety Code $₫$, copyright $\odot 2006$ National Fire Protection Association individuals up and down stairs of varying width and tread geometry, tabulating variables ranging from quantitative (speed, number of stumbles) to qualitative (perceived comfort). From this work Templer concluded that the minimum width of an egress stair should be 56 in $(1400 \mathrm{~mm})$.

\section{SCIENTIFIC STUDIES OF TREAD GEOMETRY}

One of the earliest studies of stair geometry was conducted by an architect in France named Francois Blondel ${ }^{14}$. Blondel was primarily interested in comfort rather than safety and observed that the main stairs of classic cathedrals were comfortable to use and accommodated large numbers of people attending services. He made measurements and found that the ratio of stair height to tread depth was a constant, and he related this dimension to the length of the human gait. His formula was $2 R+G=24$ in, where $R$ is the rise and $\mathrm{G}$ is the going (or run). Templer adjusted Blondel's formula for the use of the old (pre French Revolution) inch and a modern gait more like 28 in $(71 \mathrm{~cm})$ and arrived at a modern (metric) formula, $2 \mathrm{R}+\mathrm{G}=710$. The so-called $7 / 11$ stair geometry commonly required in US codes meets the relation $2 \mathrm{R}+\mathrm{G}=635$.

Templer ${ }^{15}$ summarizes a number of research studies of stair geometry and safety. Many such studies were conducted by observing people moving up or down stairs in buildings. Observations in subway or train stations at rush hours provided data for higher population densities. A few studies were conducted in laboratory settings on specially constructed stair sections where the geometries and stair angle could be varied systematically. Templer himself conducted several of these studies, including some at NBS. 
Most of the studies reviewed concluded that the measure of Total Energy Cost per Meter Rise is a useful metric for the evaluation of stair design for normal use and comfort; however stair safety is more closely related to the likelihood of missteps which is a function of how the stair relates to the human gait. In both cases the effect is different for ascent and descent, with descent being more hazardous.

When ascending a stair a person walks on the ball of the foot with less of the foot placed on the step. Shorter treads (goings) and higher risers produce fewer missteps. When descending a stair the heel and most of the foot needs to be placed on the tread. Too much of the front of the foot extending over the nosing results in rotation of the foot and a fall, or a distorted gait while trying to place more foot on the tread. Tread depths of at least 11 in $(280 \mathrm{~mm})$ are recommended to accommodate the $95^{\text {th }}$ percentile foot, but considering only gait and accident history treads (goings) of at least 9 in $(230 \mathrm{~mm})$ are required. Riser heights of 6.3 in to $7.2 \mathrm{in}(160 \mathrm{~mm}$ to $183 \mathrm{~mm})$ had the fewest missteps. Other dimensions apply to curved stairs ${ }^{16}$.

Other factors relevant to stair safety include lighting, slip resistance, single steps (most codes prohibit flights of fewer than three steps), handrails, and inability to detect the edge of the tread due to lack of contrast.

\section{REVIEW OF INTERNATIONAL CODE REQUIREMENTS FOR EGRESS STAIRS}

The building regulations summarized below are from countries that are widely disbursed and culturally different, and should be representative of any range of methods used to treat egress. Where the original code documents are published in languages other than English, the codes used were official translations published in English, so they can be presumed accurate.

Characteristics of egress stair design include the factors previously discussed as well as the minimum number of egress stairs provided, maximum travel distance to a stair, width of doors and passageways, interior finish, lighting and marking, headroom, and handrails. All of the codes examined address all of these characteristics and all are reasonably consistent in requirements. For example, all require handrails on both sides of an egress stair and a center handrail when stair width exceeds $1800 \mathrm{~mm}$ (71 in). It is interesting to note that, while all the codes require a minimum of two egress stairs from every floor, many of the codes address specific conditions in which a single stairway is permitted, and some are quite liberal in this regard. Design occupant loads are generally consistent among most building regulations in the world.

\section{United States}

In the United States model building regulations are developed by private sector, nonprofit organizations and are adopted by State and local governments with modifications that reflect local needs and practices. Two such model codes exist but the requirements of both are reasonably consistent, especially with respect to egress system design. A 
detailed review of current US building code requirements for egress system design is provided by Bukowski and Kuligowski ${ }^{17}$.

In the US codes, the minimum width for an egress stair is $1100 \mathrm{~mm}$ (44 in) except that a space served by no more than 50 people can have a $900 \mathrm{~mm}$ (36 in) stair. The capacity of a stair (number of people served per floor) is 0.3 in per person unsprinklered and 0.2 in per person sprinklered. Thus, for the $1100 \mathrm{~mm}$ (44 in) stair the capacity is 147 unsprinklered and 220 sprinklered. As an example, the design occupant load for offices specified in US building regulations is $10 \mathrm{~m}^{2}$ per person (100 $\mathrm{ft}^{2}$ per person).

\section{Australia}

In Australia the legal responsibility for regulation of buildings rests with the States and Territories. Since 1996 a national model building code, the Building Code of Australia (BCA) has been developed under a mutual agreement (and funding) by the Australian Building Codes Board, and is adopted with local modifications by the States and Territories. The local modifications are published as individual annexes in the BCA document.

The BCA $2006^{18}$ is a performance-based code that includes prescriptive requirements drawn from the predecessor code as deemed-to-satisfy requirements within the published code document. While it is common to use performance analysis to address such issues as travel distances, remoteness requirements, or fire resistance requirements for shaft enclosures, stair geometries and minimum widths generally comply with the prescriptive rules.

The minimum clear width (between handrails) of a required exit stair serving a storey or mezzanine accommodating up to 100 people is $1000 \mathrm{~mm}$ (39 in). Stairs serving a storey that accommodates more than 100 but not more than 200 must have an aggregate width of at least $1000 \mathrm{~mm}$ (39 in) plus $250 \mathrm{~mm}$ (10 in) for each 25 people (or fraction thereof) in excess of 100, and stories accommodating more than 200 must have an aggregate width of $2000 \mathrm{~mm}$ (78 in) plus $500 \mathrm{~mm}$ (20 in) for every 75 people (or fraction thereof) in excess of 200 unless the stair or ramp is steeper than 1 in 12, when the additional 500 $\mathrm{mm}$ (20 in) is for every 60 people in excess of 200. Design occupant loads are similar to the US codes. For example, for offices the design load is $10 \mathrm{~m}^{2}$ per person which is identical to the US $100 \mathrm{ft}^{2}$ per person.

Stair geometry is specified as a range for both the riser (rise) and going (tread), along with a range of the ratio of twice the riser plus the going (Blondel's formula). The values specified are a riser between $115 \mathrm{~mm}$ and $190 \mathrm{~mm}$ (4.5 in and $7.5 \mathrm{in}$ ), a going between $250 \mathrm{~mm}$ and $355 \mathrm{~mm}(10$ in and $14 \mathrm{in})$ and the ratio $(2 \mathrm{R}+\mathrm{G})$ between 510 and 700 .

\section{United Kingdom}

The UK building regulations apply to England and Wales but not in Scotland or Ireland. In 1985 UK adopted a performance-based code and converted its prescriptive rules to 
Approved Documents which represent deemed-to-satisfy rules. Approved Document B ${ }^{19}$ deals with Fire Safety.

Section 5 deals with Design for Vertical Escape for buildings other than Dwellings, with minimum stair widths for simultaneous evacuation on Table 7 and for phased evacuation in Table 8. Table 7 lists the maximum capacity (number of persons served) as a function of stair width and number of floors. Stair widths range from $1000 \mathrm{~mm}$ (39 in) to 1800 $\mathrm{mm}$ (71 in) with the provision that stairs wider than $1800 \mathrm{~mm}$ must be divided by a handrail. Thus the minimum permitted width is $1000 \mathrm{~mm}$ (39 in). For a stair of 1100 mm equivalent to the US minimum 44 in stair, 260 people can be accommodated on two floors, increasing by 40 people for each additional floor. For phased evacuation 120 people per floor can be accommodated by a $1100 \mathrm{~mm}$ (44 in) stair with an additional 10 people for each $100 \mathrm{~mm}$ (4 in) in width. Design occupant loads in Approved Document $\mathrm{B}$ are somewhat more conservative than in other codes, for example offices are $6 \mathrm{~m}^{2}(60$ $\mathrm{ft}^{2}$ ) per person.

Some insights into the development of the table appear in the supporting text in Approved Document B. Provision 4.25 presents an alternative to using Table 7 for stairs $1100 \mathrm{~mm}$ (44 in) or wider to determine number of persons served (P) for simultaneous evacuation by applying the formula $\mathrm{P}=200 \mathrm{w}+50(\mathrm{w}-0.3)(\mathrm{n}-1)$. Note 5 to this formula explains that $200 \mathrm{w}$ represents the number of persons estimated to have left the stair after 2.5 min of evacuation and the second term represents the number accommodated on the stair at that time. This implies that they are assuming a flow of 45 persons per minute per $510 \mathrm{~mm}$ (22 in) of width and a storage capacity of 50 people per (meter minus 0.3 , which may represent Fruin's boundary space) in each story of stairway. This appears to follow the 1935 NBS recommendation for a combination of the flow method and the capacity method with the assumption that the first $2.5 \mathrm{~min}$ of evacuation time is safe.

It is also interesting to note that Approved Document B suggests that buildings in excess of $30 \mathrm{~m}(100 \mathrm{ft})$ in height be designed for phased evacuation. This has somewhat different stair capacity requirements but also suggests that the capacity should be provided by the stairs remaining after any one is discounted as being used by the fire service for fire attack. Appropriate arrangements are to be worked out for specific building conditions in consultation with the fire brigade. This is in addition to a requirement that buildings in excess of $30 \mathrm{~m}(100 \mathrm{ft})$ in height be equipped with a firefighting shaft including a protected elevator dedicated to emergency response service.

\section{Spain}

Spain has a national building regulation developed by the Ministry of Housing and issued by Royal Decree. Like Australia, Spain recently adopted a performance-based building regulation that includes deemed-to-satisfy requirements within the code that are based on the traditional rules. Because Spain is a Member State of the European Union (EU) they fall under the Construction Products Directive of the EU which requires coordination of construction regulations so that the regulations do not become a barrier to free trade within the Union. 
The Spanish regulations ${ }^{20}$ (Section SI 3, table 4.2) assign evacuation capacity (number of occupants who may use the stair) of protected stairs as a function of stair width and number of floors to be traveled. For unprotected stairs they assign different values for travel upward and downward as a function of width. Stair widths ranging from $1000 \mathrm{~mm}$ (39 in) to $2400 \mathrm{~mm}(95 \mathrm{in})$ are covered, implying a minimum width of $1 \mathrm{~m}$ (39 in). A $1100 \mathrm{~mm}$ (44 in) wide stair corresponding to the US minimum, can accommodate 248 people on two floors, increasing by 36 people for each additional floor.

Occupant loads in the Spanish code are consistent with other countries; e.g., offices are $10 \mathrm{~m}^{2}\left(100 \mathrm{ft}^{2}\right)$ per person. Stair geometry is regulated in the code section on protection from falling (Section SU) where stair treads must be at least $280 \mathrm{~mm}$ (11 in) and risers $130 \mathrm{~mm}(5 \mathrm{in})$ and no more than $185 \mathrm{~mm}$ (7 in), with the tread to riser ratio of 4:1 for the entire length of the stair.

\section{Hong Kong}

The Hong Kong building regulations are prescriptive and derive from the British rules. Following the return of Hong Kong to Chinese sovereignty their designation as a Special Administrative Region (SAR) permitted them to continue using prior regulations. There is a separate document for Means of Escape in Case of Fire ${ }^{21}$ (MOE). Table 5 (unsprinklered building) and Table 6 (sprinklered building) are similar to the Spanish table, providing a discharge value (number of occupants who may use the stair) as a function of width and number of stories. Widths range from $1050 \mathrm{~mm}$ (41 in) to 1900 $\mathrm{mm}$ (75 in) in $150 \mathrm{~mm}$ (6 in) increments, and values for widths exceeding $1900 \mathrm{~mm}$ are permitted by linear extrapolation (without limit). A $1100 \mathrm{~mm}$ (44 in) wide stair corresponding to the US minimum, can accommodate 242 (unsprinklered) or 452 (sprinklered) people on two floors, increasing by 32 people for each additional floor.

Occupant loads in the Hong Kong code are only slightly greater than other countries; e.g., offices are $9 \mathrm{~m}^{2}\left(90 \mathrm{ft}^{2}\right)$ per person. Stair geometry requirements specify treads at least $225 \mathrm{~mm}$ (9 in) and risers not more than $175 \mathrm{~mm}$ (7 in).

The Hong Kong MOE includes a unique requirement for refuge floors in buildings exceeding 25 stories in height. Every 25 stories an unoccupied floor (normally a mechanical floor) must arrange at least $50 \%$ of its area as an area of refuge $(2 \mathrm{~h}$ fire separation) for occupants to rest or to cross between stairways. They are required to be open on at least two sides (with water curtains) above a safe railing height to provide natural smoke control. They must be served by a fireman's lift to facilitate rescue assistance. These requirements have also been adopted in other areas of China and in some other Asian countries.

\section{Peoples Republic of China}

Regulations for building fire safety in China are contained in the Code for Design of Building Fire Protection ${ }^{22}$ (GBJ 16-87) and published as a National Standard that is locally enforced. Section 5.3 deals with Safety Evacuation of Civil Buildings. 
The total width of stairs is specified per 100 people for buildings of specific height (in stories) and construction class (1 through 4) along with a minimum width of any stair of $1100 \mathrm{~mm}(44 \mathrm{in})$. While the definitions of the Chinese construction classes do not align completely with those specified in US codes, an approximate correlation is presented below.

Class 1 or 2 buildings (similar to US Type IA and IIIA) require a minimum aggregate width of $650 \mathrm{~mm}$ (26 in) per 100 people for 1 and 2 story buildings, $750 \mathrm{~mm}$ (30 in) per 100 people for 3 story and $1000 \mathrm{~mm}$ (39 in) per 100 people for 4 story or higher. Class 3 buildings (similar to US Type IIIB) require a minimum aggregate width of $750 \mathrm{~mm}$ (30 in) per 100 people for 1 or 2 story, $1000 \mathrm{~mm}$ (39 in) for 2 story and $1250 \mathrm{~mm}$ (49 in) for 4 story or higher. Class 4 buildings (similar to US Type IV heavy timber) require 1000 $\mathrm{mm}$ (39 in) per 100 people for 1 and 2 story buildings. Class 4 buildings are not permitted taller than 2 stories.

\section{Japan}

Japan regulates building safety through a national law that is promulgated by the national government, through the Ministry of Land, Infrastructure, and Transport (MLIT). The Building Standard Law of Japan ${ }^{23}$ (BSL) is utilized nationally without local amendment and is enforced by local officials who are empowered to determine compliance or lack thereof, but not empowered to issue variances or determination of equivalencies. These can only be determined by the MLIT. Unlike most building regulations the BSL combines building and zoning regulations.

Beginning in 2000 the Building Standard Law was revised to a performance-based structure with the prescriptive rules moved into the Building Standard Law Enforcement Order to facilitate updating and interpretation.

Chapter II, Article 23 deals with stairs which may be through stairs or escape stairs. This article establishes a minimum stair width of $1200 \mathrm{~mm}$ (47 in) with stair treads of $240 \mathrm{~mm}$ (9.5 in) or more and a rise of $200 \mathrm{~mm}(8 \mathrm{in})$ or less.

Chapter V of the BSL Enforcement Order deals with Evacuation Facilities. Article 120 addresses through stairs provided for access and egress, and article 121 requires that at least two through stairs be provided. Article 122 requires that certain through stairs be designated as escape stairs and be constructed in accordance with article 123. None of these articles address stair width or geometry. Article 124 requires that the aggregate width of escape stairs in stores (mercantile) be not less than $600 \mathrm{~mm}$ (24 in) per $100 \mathrm{~m}^{2}$ $\left(1000 \mathrm{ft}^{2}\right)$ of floor area of the largest floor served by the stair.

It does not appear that the Japanese code incorporates the concept of occupant load but rather specifies required stair capacity in terms of the floor area served, which is the equivalent of applying a uniform occupant load to all use categories in the group. The Japanese code typically groups assembly type uses, educational, mercantile, and residential uses when specifying minimum widths of stairs, doors, and corridors. 


\section{Part 2: New Thinking on Egress from Buildings}

\section{BUILDINGS ARE TALLER}

At the start of the $20^{\text {th }}$ Century the tallest building in the world (Park Row Building in Manhattan) stood just 391 feet $(119 \mathrm{~m})$. By 1913 the record height had doubled with the completion of the Woolworth Building at 792 feet $(241 \mathrm{~m})$. Record heights crossed the thousand foot mark in 1930 with the Chrysler Building (1046 feet, $319 \mathrm{~m})$ ) and went to 1250 feet $(381 \mathrm{~m})$ with completion of the Empire State Building the following year (1931). The World Trade Center (1368 ft, 417 $\mathrm{m}$ in 1971), Sears Tower (1450 ft, 442 $\mathrm{m}$ in 1974) and Petronas Towers (1486 $\mathrm{ft}, 448 \mathrm{~m}$ in 1998) ended the century with the tallest building record just short of 1500 feet $(457 \mathrm{~m})$.

The early $21^{\text {st }}$ Century has seen a rapid surge skyward, first in Asia and then in the Middle East. The height record (as of this writing) is Taipei 101 at $1671 \mathrm{ft}$ $(510 \mathrm{~m})$, but several taller buildings are under construction. The Burj Dubai Tower is estimated to top out at no less than $2624 \mathrm{ft}(800 \mathrm{~m})$ and there is said to be a building planned for elsewhere in the Middle East at $3280 \mathrm{ft}(1000 \mathrm{~m})$.

Prior to the World Trade Center Towers, nearly all the tall buildings were tapered (or stepped) for a number of reasons, ranging from reducing structural loads to not casting shadows on neighboring buildings (see Fig 2). This meant Source: Skyscraper Museum (used with permission) that the occupant load decreased on the higher floors, decreasing the cumulative load on the stairs, unless there was an assembly use at the top such as an observation deck or restaurant. Today, most of the taller buildings are uniform with height with no such decrease in the number of occupants served by the stairs. 
In tapered buildings the number or width of the egress stairs can be increased for the lower floors to accommodate the increased occupant load. However, for tall buildings of uniform cross section the cumulative occupant load can lead to congestion, and the number of stairs needed to accommodate simultaneous egress would require so much space that the building would not be economical. Here, emergency plans rely on phased evacuation; but this should theoretically include fire endurance for any building elements that might impact egress at least as long as the required egress times.

Up to and including the Empire State Building these tall buildings were typically Type 1A ( $4 \mathrm{hr}$ ) construction. Thus a reasonable limit on egress times would be $2 \mathrm{~h}$ (the $4 \mathrm{~h}$ fire resistance time with a safety factor of 2). From a flow and egress time perspective, using a conservative $1 \mathrm{~min}$ per floor descent rate would limit heights of Type 1A buildings to 100 floors. A rate of 50 floors per hour is used to allow for notification, pre-movement, and horizontal travel times as well as some rest stops in the stairs.

Beginning with the World Trade Center Towers it became common to permit Type 1B construction ( $3 \mathrm{hr}$ ). With an occupant load of 390 per floor (110 floors) and three egress stairs (6 $1 / 2$ units of total exit width) total (simultaneous) evacuation times were estimated at about four hours (including congestion, queuing, and transfer corridors), which is consistent with the egress times observed in the 1993 bombing. Applying the criterion of a total egress time of half the fire resistance time, one would want the building to withstand a fire for $8 \mathrm{~h}$ or until complete burnout of all combustibles, whichever occurs first.

\section{PEOPLE ARE BIGGER AND LESS FIT}

In the early $20^{\text {th }}$ Century the 22 in $(1.1 \mathrm{~m})$ unit of exit width was sufficient for the $95^{\text {th }}$ percentile US adult male. In the $21^{\text {st }}$ Century this is no longer the case. The American male is larger with a $95^{\text {th }}$ percentile shoulder width of 20 in $(510 \mathrm{~mm})$, which requires a 28 in unit if exit width and a 56 in $(1.4 \mathrm{~m})$ stair (applying Templer's 4 in on each side to account for body sway and personal space). Templer did

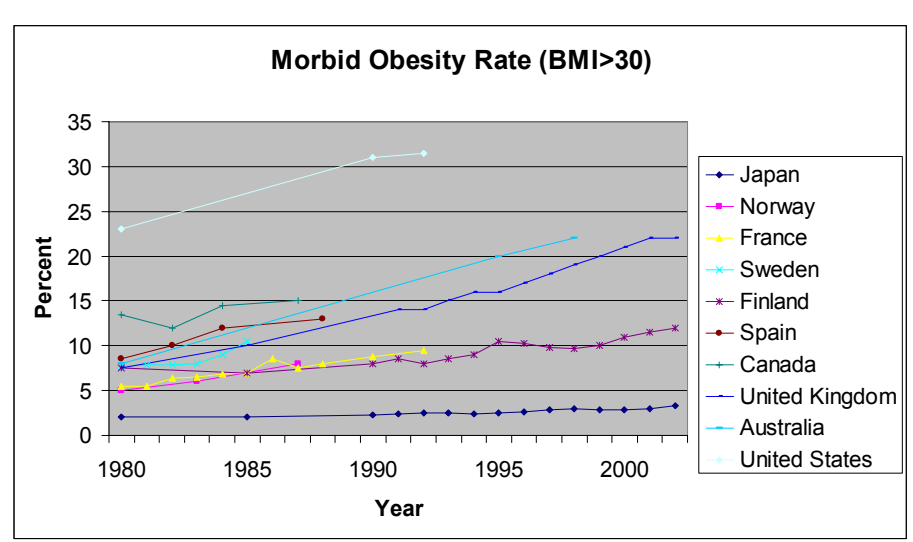

Figure 3 - Obesity rates by country

Data: International Obesity Task Force, EU Briefing paper, 2005 not allow the 4 in to a handrail since people were narrower at the waist and hip than at the shoulder, but this is no longer true.

The physical condition of the average occupant is such that the exertion of descending many flights of stairs is no longer possible without frequent rest stops and a slower pace. 
High percentile $\left(95^{\text {th }}\right)$ average weights have increased substantially in recent years (Fig 3$)$, and the number of people reporting that they need assistance due to physical conditions has also increased.

The WTC Investigation found $6 \%$ of occupants reporting the need for assistance in traveling down stairs. These increases can be attributed to the widespread adoption of modern accessibility regulations that have made it easier for people with mobility limitations to be more active in society, and to the recognition that there are many conditions not generally considered to be disabilities that can limit the ability of people to move down many flights of stairs.

\section{NEW TECHNOLOGIES}

A number of new technologies are available to address limitations of the past. One of the most promising is the ability to design and operate elevators safely and reliably during fires. Here the ability to provide reliable power, sophisticated operational protocols, and real time monitoring of critical functions, permit the use of protected elevators as a primary means of egress in fires. Further, fire departments have recognized the need for protected elevators to provide logistical support to operations in tall buildings.

Modern fire alarm systems combine reliability, flexibility, and advanced functionality that permits real time monitoring and tactical support for incident management not previously possible. With the advent of the industry standard $^{24}$ fire service interface in the U.S., it is possible for the incident command to actively manage the evacuation process for improved safety and efficiency. For example, it is possible to monitor conditions in the stairways in real time and to advise occupants to change stairs to avoid congestion, especially where crossover corridors or refuge floors are provided. Inexpensive cameras and digital image processing software make it possible to present images for action to fire service personnel only when issues arise, permitting a few personnel to monitor many locations.

Advances in photoluminescent materials now permit issues of lighting levels and contrast within stairs to be addressed without the need for complex emergency power systems(Fig 4). When fully charged by continuous ambient light these materials provide more light for longer periods and can be applied to highlight stair nosing and handrails and as path lighting in transfer hallways.

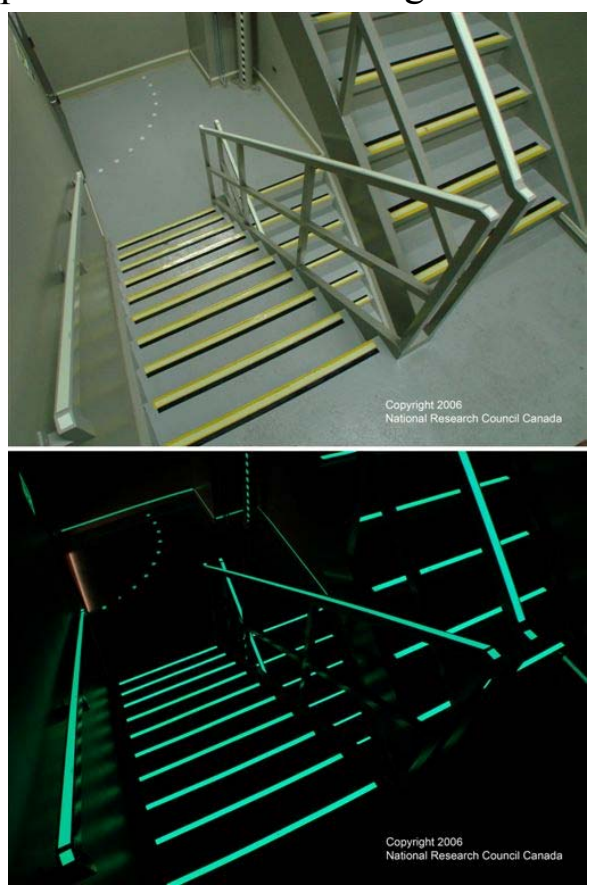

Figure 4 - Photoliminescent materials can be used to illuminate stairways

Source: NRC Canada (used with permission) 


\section{REFUGE FLOORS}

The incorporation of refuge floors in tall buildings in Asia also represents a new approach worthy of review. As discussed earlier, these are arranged every 20 to 25 floors (generally on mechanical floors) to provide a protected area for occupants to rest temporarily on their journey down the stairs and to cross over from one stair to another. Refuge floors are also intended as protected space in which people with disabilities can await rescue by the fire department (fire service elevators are generally arranged to be able to stop at the refuge floors).

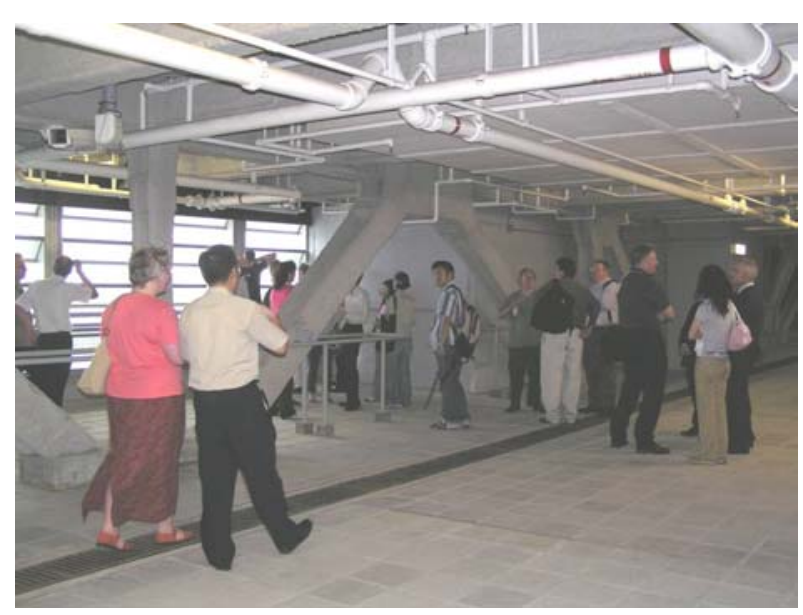

Figure 5 - Refuge floor in a Hong Kong high-rise during a fire drill Source: Arup (used with permission)

Since these requirements are fairly new there have been no emergency evacuations of buildings so equipped, but there have been evacuation drills that have shed some light on performance (Fig 5). One issue identified in drills is that many occupants decide to wait on the refuge floor for the "all clear" which fills the available space, preventing additional people to enter the floor from the stair. Without wardens or fire service personnel stationed on the floor to keep people moving, the purpose is defeated. It is not clear in a real emergency if this will be a problem since occupants may be motivated to get completely out of the building.

\section{PERFORMANCE METRICS FOR EGRESS SYSTEMS}

In the U.S., Australia and Japan, the design of egress systems are based on the population of the largest, single floor. In U.K., Spain, and China the number of floors served by the stair impacts the total number of people served by a stair of a given width. Yet in any performance analysis of an egress system in these or other countries, regulators require a timed egress analysis to estimate Required Safe Egress Time (RSET) which is compared against Available Safe Egress Time (ASET). ASET is generally determined by fire modeling to estimate conditions in the egress path that might lead to injury or death.

Clearly the appropriate performance metric is time, yet there is no regulatory performance objective nor design criterion for egress systems in terms of time in any of the codes examined. As early as 1914 the Safety to Life Committee recognized that designing egress stairs on the basis of flow (of occupants down the stair) required some "assumed time in which it is safe to exit the building" which is the ASET mentioned above.

For compliance with the life safety objective of any building regulation, it is reasonable to determine ASET as the time to reach potentially incapacitating or lethal conditions 
anywhere within the means of egress. Considering the fact that the means of egress is designed to protect people within it from exposure to fire or smoke, it is also reasonable to assume that a limiting ASET would be the time to fire-induced partial structural collapse. If burnout occurs before collapse, there is no theoretical limit to the ASET though a reasonable value may be prescribed instead. Currently, the fire resistance time of structural components and assemblies rated by a standard fire exposure in units of time has not been shown to correlate with the time to structural failure of the component, assembly, or system as a whole for an arbitrary real fire. Clearly, some factor of safety that is appropriate for the level of uncertainty is needed in order to approximate ASET by the fire resistance rating in cases where local collapse is estimated to occur before burnout.

Based on these arguments an appropriate performance objective for egress systems design may be that the time needed for total evacuation of the building be less than the required fire resistance time for the primary structural frame (i.e., the columns and other structural members including girders, beams, trusses, and spandrels having direct connections to the columns and bracing members designed to carry gravity loads). Where the fire resistance time is determined by test against a standard fire curve (i.e., ASTM E119 or ISO 834) a safety factor could be applied that is large enough to account for the variability of egress performance and the uncertainty in the fire resistance time representing the time to failure of at least one element of the primary structural frame. Where the fire resistance time is determined by engineering analysis following the Natural Fires or other similar method which accounts for the actual design level fire event, some lower safety factor could be applied since the predicted time to structural failure would be expected to be less uncertain although the egress variability would be the same. For the sake of this discussion factors of safety of 2.0 and 1.5 , respectively will be used; however, the actual values represent policy decisions that need to be established through the model code development and regulatory adoption processes.

Since high-rise buildings in any of the codes examined for this paper are required to have a primary structural frame of not less than 3-h fire resistance as determined by

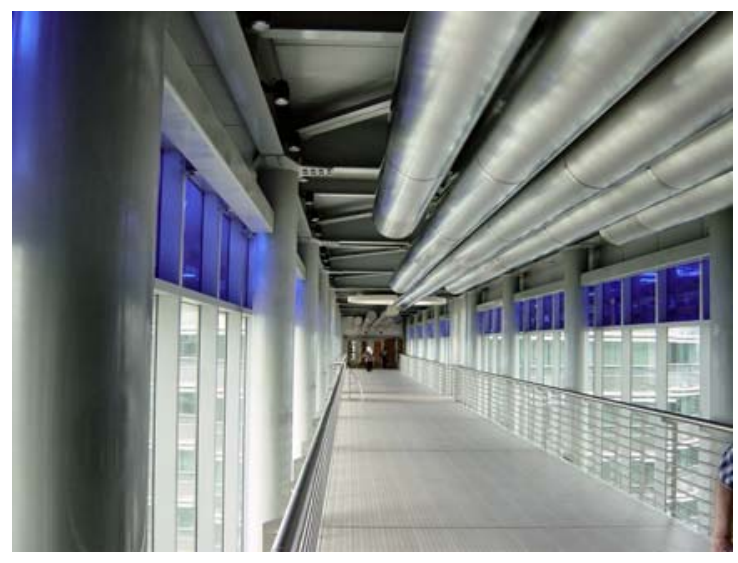

Figure 6 - Interior of skybridge connecting the Petronas Towers at mid-height Source: Bukowski (used with permission) standard test, the total evacuation time would be required to be no more than $11 / 2 \mathrm{~h}$, reflecting the safety factor of 2.0 discussed above. Recent analyses have shown that evacuation times of $1 \mathrm{~h}$ may be achievable with stairs in buildings up to about 50 stories and with a combination of protected elevators and stairs for most buildings of any height, without increasing the number or size of the stairs or elevators above current practice; this objective is clearly practicable ${ }^{25}$. 
These same arguments can be applied to the issue of a performance objective for fire department access. Since U.S. codes require provision of $30 \mathrm{~min}$ of local water supply in high rise buildings, it is reasonable to say that it should be possible for the fire department to be able to put water on a fire at any height within $30 \mathrm{~min}$. The $30 \mathrm{~min}$ local water supply requirement includes both sprinkler and standpipe flows, and in that initial $30 \mathrm{~min}$ there would be no standpipe flow, so this results in a safety factor. Using protected elevators fire departments can meet the 30 min objective for buildings of any height. Using fire department response time and a conservative estimate of 2 min per floor for ascent with equipment it is straightforward to determine the height threshold for fire service access elevators.

\section{RETHINKING EGRESS SYSTEMS DESIGN}

Some will argue that, other than some specific extreme events like the World Trade Center attacks, there have been no reported failures to evacuate even the tallest buildings. Therefore there is no reason to change what has been done for more than 100 years. There are several things wrong with this argument.

First, there have been some failures in tall building evacuations. A real evacuation of both Petronas Towers for a bomb scare in 2001 resulted in an evacuation time of several hours when the skybridge (Fig 6) jammed with occupants crossing to the opposite tower in accordance with the original evacuation plan. By incorporating elevator egress for floors above the skybridge the total time for total (simultaneous) evacuation of both towers was observed in a drill to be $20 \mathrm{~min}^{26}$. For Taipei 101 an evacuation drill conducted prior to opening showed a total evacuation time of about $2 \frac{1}{2} \mathrm{~h}$. The fire brigade reported being uncomfortable with this time. Incorporating protected elevators for egress from the upper floors reduced that time to just under one hour ${ }^{27}$.

As discussed previously, buildings have become much taller and heights continue to increase beyond the ability of anyone from the upper stories to egress down stairs. Also, these buildings are much less tapered with height compared to early skyscrapers, with larger occupant loads in the upper floors. People today are larger and less fit, and accessibility regulations have resulted in a growing fraction of occupants with mobility limitations requiring egress assistance. Increasingly, there are people in buildings who cannot be moved down

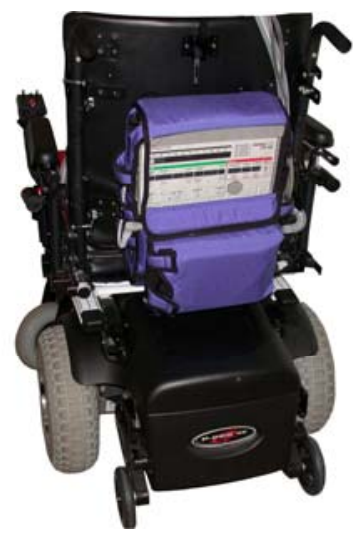

Figure 7 -Typical powered wheelchair with attached ventilator is used by people with severe disabilities such as Christopher Reeve. He could only survive away from his chair for a few minutes, and he and the chair weighed $300 \mathrm{~kg}(660 \mathrm{lb})$ (photo used with permission) stairs under any circumstances (Fig 7). Following the collapse of the WTC buildings, occupants of tall buildings are reluctant to delay egress and are not comfortable with long egress times. 


\section{STRAWMAN EGRESS SYSTEM PERFORMANCE METRICS}

Based on the prior review and discussion the following suggestions are provided to facilitate the needed rethinking of the philosophy and details of egress system design for buildings. Thresholds and performance levels are public policy decisions that need to be made in conformance with the methods in place for making regulatory decisions in an individual country. These usually require public consultation and a legislative or administrative process. The suggestions provided in the following sections include provisions that would be formatted as code requirements (in bold) followed by explanatory material.

\section{Performance Objectives}

Buildings shall be designed and arranged such that the responding fire brigade can access a fire on any floor and begin suppression operations within 30 minutes of the transmission of the original alarm, $95 \%$ of the time.

It is expected that this objective will require the provision of a fire service access elevator in buildings with occupied floors more than $30 \mathrm{~m}(100 \mathrm{ft})$ above the level of fire department access. The $95 \%$ criterion is intended to recognize that conditions may exist that prevent the objective from being met on occasion, but that most expected conditions should be considered. The $30 \mathrm{~min}$ limit is based on the U.S. requirement for local water supply for automatic suppression systems.

Buildings shall be designed and arranged such that $98 \%$ of the expected occupants are able to evacuate the building without outside assistance in a time not exceeding half of the required fire resistance time of the primary structural frame.

In the U.S. model building codes buildings taller than 4 stories are required to be Type I construction with either 3-h (Type IA) or 2-h (Type IB) fire resistance as determined in ASTM E119 for elements comprising the primary structural frame. Thus the maximum total egress time (applying a safety factor of 2.0 ) would be either $1.5 \mathrm{~h}$ or $1 \mathrm{~h}$, respectively. The $98 \%$ reflects an expectation that there may be some occupants who will require the assistance of the fire brigade for egress, but that even most occupants with disabilities can either self-evacuate or require only assistance from other occupants. It is expected that this requirement would result in occupant egress elevators in Type IA buildings taller than 80 stories and Type IB buildings taller than 50 stories.

\section{Protected Fire Service Access Elevators}

Where required, at least one elevator serving every floor shall be designated for use by the fire service in emergencies. This elevator shall be powered by normal and emergency power, with both power and control wiring protected by fire resistant construction at least equal to the fire resistance requirement applicable to the primary structural frame. Any alarm transmission to the fire brigade shall result in the designated fire service elevator being taken out of normal service and recalled to 
the designated level. The designated fire service elevator shall open on every floor into a protected lobby with direct access to a building stair containing a standpipe and any other required equipment for fire department use. The elevator equipment shall be protected from compromise by water from sprinklers or firefighting. Reliable communication with fire service personnel using the elevator and monitoring of critical functions in the fire command center shall be provided.

Fire service access is not normally considered part of the egress system design except to the extent operations within the building can have an impact on the evacuating occupants. The only code found where this is explicitly discussed is in UK Approved Document B which suggests that in tall buildings one stair may need to be discounted because it will be blocked by operations on the fire floor and one or two floors below. It should also be recognized that this "attack stair" may be compromised on any floor(s) above the fire due to smoke leakage into the stair from the fire floor when the hose is advanced onto the floor, since the standpipe is located within the stair. Only where a vestibule is provided (in the U.S. called a smokeproof tower or fire tower) would the stair itself be kept mostly smoke free. However, the evacuation assistance provided by the fire service, especially by the fire service elevator, will have a significant impact on the success of the evacuation.

\section{Protected Occupant Egress Elevators}

Where required, all elevators except any designated fire service elevator(s) shall be designed and arranged to permit their safe use for occupant evacuation. These occupant elevators shall be powered by normal and emergency power, with both power and control wiring protected by fire resistant construction at least equal to the fire resistance requirement applicable to the primary structural frame. Occupant egress elevators shall operate in a hoistway protected from the adverse effects of water and opening into a protected lobby on each floor that serves as an area of refuge while awaiting the elevator. The lobby shall be sized to accommodate $75 \%$ of the occupant load of the floor at $0.5 \mathrm{~m}^{2}\left(5 \mathrm{ft}^{2}\right)$ per person. Elevator lobbies shall have direct access to an egress stair and be provided with two-way communications to the fire command center and approved means to provide real time information to waiting occupants.

On a fire alarm the elevators shall begin evacuating occupants of the fire floor and two floors above and below the fire floor, taking them to the level of exit discharge before returning for another load until all 5 floors are evacuated. On a decision for a full building evacuation by the official in charge the elevators shall evacuate all remaining occupants from the highest floors and proceeding downwards, shuttling occupants to the level of exit discharge before returning for another load. Information systems on all floors except the level of exit discharge shall communicate to occupants the status of the system and the estimated wait time. Information systems on the level of exit discharge shall indicate that the elevators are out of service and people should not enter. 
Occupant egress elevators are by far the fastest means of evacuating a tall building. In normal service the number, size, and speed of passenger elevators in most buildings are designed to be able to move approximately $10 \%$ of the total population of the building from random floors to the level of exit discharge in $5 \mathrm{~min}$. This means that any building of any height can be totally evacuated by elevator in one hour or less without increasing the number, size, or speed of the elevators normally provided. Modern elevators utilize computerized controllers capable of sophisticated operational protocols, and the addition of real time monitoring and information systems can add the necessary reliability and guidance to users to permit their use for egress during fires. In addition, occupants use the building elevators every day for normal ingress and egress. The use of the elevators for egress in fires is not appreciably different as long as the people are provided with sufficient information to make decisions.

Considerable effort by NIST, the elevator industry, the American Society of Mechanical Engineers (ASME), and the building code organizations is being put into the development of standards and code requirements for protected elevators both for fire service access and for occupant egress. The language suggested above for both purposes is consistent with that effort but the activity needs to play out to arrive at a consensus on requirements for the elevator equipment. Similarly, proposals are being considered by the model building code organizations for the building code related parts of the systems. Again, the performance objectives above are consistent with those proposals but the process should play out to arrive at a consensus of the involved parties.

\section{Stair Width}

Where stairs are the primary means of vertical egress in fires and other emergencies such stairs shall be a minimum width of $1400 \mathrm{~mm}(56 \mathrm{in})$. Where protected elevators are provided as the primary means of vertical egress in fires and other emergencies stairs shall be a minimum width of $1100 \mathrm{~mm}$ (44 in).

Wider stairs are needed to accommodate the increased body size of occupants but this additional width is not needed where most occupants would be expected to egress by elevator. Further, any building provided with occupant egress elevators would also have fire service access elevators, eliminating the issue of counterflow except for the fire floor and one or two floors below in the attack stair.

\section{Stair Capacity}

Where stairs are the primary means of vertical egress in fires and other emergencies sufficient stair capacity shall be provided to accommodate the maximum number of building occupants on all floors except any with direct access to the outside, within the stairways. Where protected elevators are provided as the primary means of vertical egress in fires and other emergencies sufficient stair capacity shall be provided to accommodate at least half the maximum number of building occupants on all floors except any with direct access to the outside, within the stairways. Any floor containing an assembly space that results in a higher occupant load when 
provided with an area of refuge sized to accommodate $100 \%$ of the occupant load of that floor with direct access to a stair and an occupant egress elevator, shall be permitted to neglect the additional occupant load for the purpose of determining stair capacity.

While the philosophy of "storing" stationary occupants in stairs is not intended, the stairs remain a more protected space within the building. Some occupants may choose to use stairs (particularly on the lower floors) and the ability to find refuge in stairs is an important redundancy. Where occupant egress elevators are provided it is expected that most occupants will use them, but some minimum capacity for refuge is needed. Likewise, the provision of assembly occupancies (restaurants, bars, conference facilities, observation decks, ...) that result in local concentrations of additional people traditionally required additional stair capacity that continued through the building to the level of exit discharge. With occupant egress elevators most of these people will egress by elevator and it is only necessary to accommodate them temporarily while they await the elevators.

The capacity of an egress stair is defined as the number of occupants who can descend the stair in a time equal to one half the fire resistance time of the primary structural frame, at a flow rate of 47 occupants per minute per meter of stair width (26 occupants per minute per unit of exit width). (The design flow rate is a policy decision among $(81,47$, or 30$)$ occupants per minute per meter with 47 being used in this example).

The number of occupants that could be served by a stair should be based on the flow or discharge rate (Flow Method as defined in the 1935 NBS report) over 1h (Type IB) or 1 $1 / 2 \mathrm{~h}$ (Type IA). Table 1 below shows discharge rates per hour, per (22 in) unit and per meter, and for a 1100 (44 in) and 1400 (56 in) stair, based on assumed flows of 45 occ/min/unit (which has no specific scientific basis but is used in the UK Approved Document B), $26 \mathrm{occ} / \mathrm{min} /$ unit (based on the work of Togawa and Pauls), and 16 $\mathrm{occ} / \mathrm{min} / \mathrm{unit}$ (based on estimates from the NIST WTC report). If one used a flow rate of $26 \mathrm{occ} / \mathrm{min} /$ unit, a single $1100 \mathrm{~mm}$ (44 in) stair could serve 2160 people (4320 for two stairs) and a $1400 \mathrm{~mm}$ (56 in) stair could serve 2750 people (5500 for two stairs). This would be the total number of occupants served by the stair(s) on all floors except those with direct egress to the outside (who would not use the stairs). This would also be limited to 50 or 80 stories since it would take longer than $\left(1\right.$ or $\left.1 \frac{1}{2}\right)$ hours to descend from greater heights.

Table 1 - Total Number of Occupants Served by an Egress Stair Based on Flow

\begin{tabular}{|l|l|l|l|l|l|}
\hline $\begin{array}{l}\text { Flow } \\
\text { occ/min/unit }\end{array}$ & $\begin{array}{l}\text { Flow } \\
\text { occ/min/meter }\end{array}$ & $\begin{array}{l}\text { Dis Rate } \\
\text { occ/h/unit* }\end{array}$ & $\begin{array}{l}\text { Dis Rate } \\
\text { Occ/h/meter* }\end{array}$ & $\begin{array}{l}\text { Dis Rate } \\
\text { Occ/h/1.1 m* }\end{array}$ & $\begin{array}{l}\text { Dis Rate } \\
\text { Occ/h/1.4 m* }\end{array}$ \\
\hline 45 & 81 & 2700 & 4860 & 5350 & 5830 \\
\hline 26 & 47 & 1560 & 2820 & 3100 & 3380 \\
\hline 16 & 30 & 960 & 1800 & 1980 & 2160 \\
\hline
\end{tabular}

* Multiply by 1.5 for Type IA Construction where ASET is $1 \frac{1}{2} \mathrm{~h}$ 
In a system designed by the flow method it is important to ensure that the flow through doors is equal to or greater than the stair flow so that flow restrictions and congestion is avoided. This raises an interesting issue. There seems to be consensus that flow through doors is about 60 occupants per minute per door regardless of width. If a design stair flow rate of 26 occupants per minute per unit is selected, the stair flow in a 2-unit (44 in, $1100 \mathrm{~mm}$ ) stair is 52 per minute which can be accommodated by a single door. In a $2 \frac{1 / 2}{2}$ unit (56 in, $1400 \mathrm{~mm}$ ) stair the flow is 65 per minute which will theoretically result in an accumulation of 5 people per minute at the upstream side of a single door. It needs to be determined if 56 in stairs need double doors to prevent congestion, as this can be a significant cost issue in design.

\section{Stair Geometry}

Current requirements in the building codes reviewed are consistent with the research recommendations.

\section{Refuge Floors}

Horizontal transfer corridors designed as means of egress components shall be provided every 25 floors (generally on mechanical floors) to link all egress stairs and to provide the ability to safely move between stairs.

The initial experience with refuge floors indicates that the provision of a means to transfer stairways has merit but the provision of a large space to "rest" encourages delays in evacuation that may be counterproductive to safety. The protected lobby with direct access to a stair provided as part of the occupant egress elevator system can provide for rest stops if needed, but most occupants would use the elevators and not need to rest. Thus, it is recommended to not provide refuge floors but to consider a protected horizontal transfer corridor linking all stairways on the mechanical floors. The 25 floor increment is based on the Asian requirement for refuge floors but could be flexible where only stairway crossovers are provided.

\section{Evacuation Management}

Video cameras shall be installed every 5 floors in every egress stairway and in every egress elevator lobby with the images displayed in the fire command center. Image analysis software shall be employed to minimize the fire department burden for monitoring these images.

The potential for changing conditions impacting the safety and efficiency of the evacuation suggests that full building evacuations need to be actively managed. The addition of cameras in the stairs and egress elevator lobbies which can be monitored in the fire command can facilitate such management. Using available software developed for the security industry the monitoring burden in fire command can be minimized. Images from cameras in stairs would be kept in background except when no movement is detected for some time interval, indicating no people or no movement of people. Images 
from lobby cameras would be kept in background except when movement is detected, indicating there are people in the lobby needing pickup. If that floor has not yet been evacuated this information can be registered with the elevator controller. If the floor has already been evacuated the presence of stragglers would be noted to the fire department. Placement every 5 floors is considered reasonable for the purpose. More frequent is probably not necessary for active management of egress but less frequent might permit unobserved blockages.

\section{CONCLUDING REMARKS}

The increasing height of buildings coupled with changing demographics and public concerns about the safety of tall buildings have led to a call for a fundamental rethinking of egress systems. This paper provides a review of the approaches currently found in building regulations internationally, and attempts to identify the origins of these specifications including the extent to which they may be based on scientific data or consensus opinion. The case for moving to a performance metric of time is presented and a set of criteria for evaluating egress systems against safe egress time is suggested. Performance criteria based on practical objectives are suggested but these and suggested regulatory thresholds need to be vetted through the existing consensus process of model code development and regulatory adoption followed in the adopting jurisdiction. The result should be a design approach that addresses the needs of occupants and buildings of all heights with criteria based on sound engineering principles.

\section{REFERENCES}

\footnotetext{
${ }^{1}$ Proc of the $18^{\text {th }}$ Annual Meeting, National Fire Protection Association, Boston, MA 1914.

${ }^{2}$ Bukowski, R.W., Progress Toward a Performance-Based Codes System for the United States, Applications of Fire Safety Engineering. Symposium for '97 FORUM. Proceedings. FORUM for International Cooperation on Fire Research, Tianjin Fire Research Inst. and Shanghai Yatai Fire Engineering Co., Ltd. October 6-7, 1997, Tianjin, China, 97-107 pp, 1997.

${ }^{3}$ Proc of the $17^{\text {th }}$ Annual Meeting, National Fire Protection Association, Boston, MA 1913.

${ }^{4}$ Design and Construction of Building Exits, National Bureau of Standards Miscellaneous Publication M151, Washington DC, 1935.

${ }^{5}$ Building Exits Code, NFPA 101-T, National Fire Protection Association, Boston, MA, 1927.

${ }^{6}$ Togawa, K., Study on Fire Escapes Basing on the Observations of Multitude Current, in Building Research Institute of Japan, U.S./Japan Government Cooperative Program on Natural Resources (UJNR) Panel on Fire Research and Safety, Vol 2, Human Behavior, Tokyo, Japan, pp1-3, 1976.

${ }^{7}$ Pauls, J. L., Building Evacuation and Other Fire Safety Measures: Some Research Results and their Application to Building Design, Operation, and Regulation, in D.H. Carson, ed., Man-Environment Interactions: Evaluations and Applications - The State of the Art in Environmental Design Research (EDRA 5) Part 4, pp 147-168, 1974.

${ }^{8}$ Fruin, J.J., Pedestrian Planning and Design, Elevator World, Mobile, AL, 211 pp, 1987.

${ }^{9}$ Predtechenskii, V.M. and Milinskii, A.I., Planning for Foot Traffic Flow in Buildings, Translated and Published by NBS, 240 pp, 1978.

${ }^{10}$ Averill, J.D. et al, Federal Building and Fire Safety Investigation of the World Trade Center Disaster, Occupant Behavior, Egress, and Emergency Communications, NCSTAR 1-7, NIST, Gaithersburg, MD 2005.

${ }^{11}$ Life Safety Code (2006 ed), Figure A.7.3.4.1.1 (b), NFPA, Quincy MA 2006.

${ }^{12}$ Templer, J., Stair Shape and Human Movement, Ph.D. dissertation, Colombia University, 1974.

13 Templer, J., Mullet, G.M., Archea, J., and Margulis, S.T., An Analysis of the Behavior of Stair Users, NBSIR 78-1554, NBS, 1978.
} 
${ }^{14}$ Blondel, F., 1675-1683. Cours d'Architecture Enseigne dans l'Academie Royale d'Architecture, Paris.

${ }^{15}$ Templer, J., The Staircase, Studies of Hazards, Falls, and Safer Design, MIT Press, 1992.

${ }^{16}$ Fitch, J.M, Templer, J., and Corcoran, P., The Dimensions of Stairs, Scientific American, 231(4), 1974.

${ }^{17}$ Bukowski, R.W. and Kuligowski, E.D., The Basis for Egress Provisions in U.S. Building Codes, InterFlam 2004, Edinburgh, UK, July 2004.

${ }^{18}$ Building Code of Australia, 2006 ed., Australian Building Codes Board, Canberra, AU, 2006.

${ }^{19}$ Approved Document B: Fire Safety, 2006 ed., Department of Communities and Local Government, London, 2006.

${ }^{20}$ Codigo Tecnico (Building Code), Basic Document SI: Fire Safety, Ministry of Housing, Madrid, 2003.

${ }^{21}$ Code of Practice for the Provision of Means of Escape in Case of Fire, Building Authority of Hong Kong, 1996.

${ }^{22}$ Code for Design of Building Fire Protection, National Standard GBJ 16-87, People's Republic of China, Beijing 1995.

${ }^{23}$ Building Standard Law of Japan, Building Center of Japan, 2004.

${ }^{24}$ Fire Service Annunciator and Interface, NEMA SB30, Natiopnal Electrical Manufacturers Association, Rosylin, VA 2006.

${ }^{25}$ Bukowski, R.W., Emergency Egress Strategies for Buildings, Proc InterFlam 2007, Interscience Communications, London 2007.

${ }^{26}$ Arliff, A., Review of Evacuation Procedures for the Petronas Twin Towers, Strategies for Performance in the Aftermath of the World Trade Center. CIB-CTBUH Conference on Tall Buildings. Proceedings. Task Group on Tall Buildings: CIB TG50. CIB Publication No. 290. October 20-23, 2003, Kuala Lumpur, Malaysia, Shafii, F.; Bukowski, R.; Klemencic, R., Editors, 35-42 pp, 2003.

${ }^{27}$ Hsiung, K.H., Wen, W.J., Chien, S.W., and Shih, B.J., A Research of the Elevator Evacuation Performance for Taipei 101 Financial Center, Proc $6^{\text {th }}$ Int Conf on Performance-based Codes and Fire Safety Design Methods, June 14-16, 2006, Tokyo, Japan, SFPE Bethesda, MD 213-225p, 2006. 